
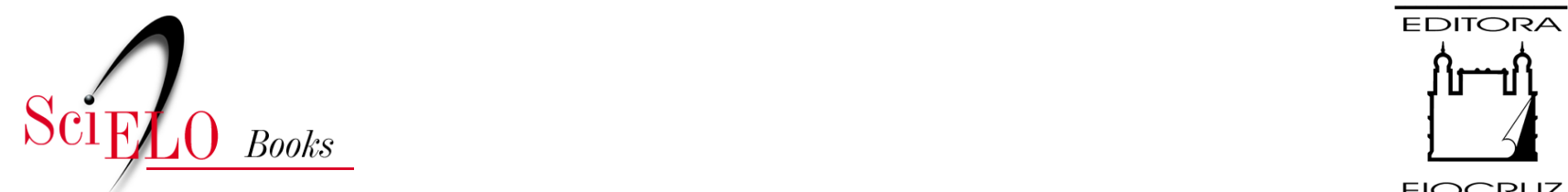

FIOCRUZ

\title{
Brasil Saúde Amanhã dimensões para o planejamento da atenção à saúde
}

\author{
José Carvalho de Noronha \\ Luciana Dias de Lima \\ Adolfo Horácio Chorny \\ Mario Roberto Dal Poz \\ Paulo Gadelha \\ (orgs.)
}

\section{SciELO Books / SciELO Livros / SciELO Libros}

NORONHA, J.C., LIMA, L.D., CHORNY, A.H., DAL POZ, M.R., and GADELHA, P., eds. Brasil Saúde Amanhã: dimensões para o planejamento da atenção à saúde [online]. Rio de Janeiro: Editora FIOCRUZ, 2017, 236 p. ISBN: 978-65-5708-090-0. https://doi.org/10.7476/9786557080900.

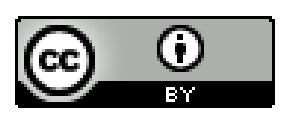

All the contents of this work, except where otherwise noted, is licensed under a Creative Commons Attribution 4.0 International license.

Todo o conteúdo deste trabalho, exceto quando houver ressalva, é publicado sob a licença Creative Commons Atribição 4.0.

Todo el contenido de esta obra, excepto donde se indique lo contrario, está bajo licencia de la licencia $\underline{\text { Creative }}$ Commons Reconocimento 4.0. 


\section{BRAS I L S A Ú DE A M A N H Ã \\ dimensões para o planejamento da atenção à saúde}




\section{FUNDAÇÃO OSWALDO CRUZ}

Presidente

Nísia Trindade Lima

Vice-Presidente de Educação, Informação e Comunicação Manoel Barral Netto

\section{EDITORA FIOCRUZ}

\section{Diretor}

Manoel Barral Netto

Editor Executivo

João Carlos Canossa Mendes

Editores Científicos

Carlos Machado de Freitas

Gilberto Hochman

Conselho Editorial

Denise Valle

José Roberto Lapa e Silva

Kenneth Rochel de Camargo Jr.

Ligia Maria Vieira da Silva

Marcos Cueto

Maria Cecília de Souza Minayo

Marilia Santini de Oliveira

Moisés Goldbaum

Rafael Linden

Ricardo Ventura Santos 
José Carvalho de Noronha Luciana Dias de Lima Adolfo Horácio Chorny Mario Roberto Dal Poz Paulo Gadelha

organizadores

\section{BRA S I L SA Ú DE A M A N H Ã \\ dimensões para o planejamento da atenção à saúde}


Copyright (C) 2017 dos autores

Todos os direitos desta edição reservados à

FUNDAÇÃO OSWALDO CRUZ / EDITORA

Revisão e copidesque

Augusta Porto Avalle

Normalização de referências

Clarissa Bravo

Capa e projeto gráfico

Carlota Rios

Produção gráfico-editorial

Phelipe Gasiglia

Catalogação na fonte

Instituto de Comunicação e Informação Científica e Tecnológica em Saúde/Fiocruz Biblioteca de Saúde Pública

B823b Brasil Saúde Amanhã: dimensões para o planejamento da atenção à saúde. / organizado por José Carvalho de Noronha et al. - Rio de Janeiro: Editora FIOCRUZ, 2017

236 p.: il.; tab.; graf.

ISBN: 978-85-7541-499-6

1. Brasil - epidemiologia. 2. Movimentação e Reposicionamento de Pacientes. 3. Hospitalização. 4. Gestão em Saúde. 5. Sistema Único de Saúde. 6. Educação Superior. 7. Recursos Humanos em Saúde. 8. Força de Trabalho. I. Noronha, José Carvalho de (Org.). II. Título.

Av. Brasil, 4036, térreo, sala 112 - Manguinhos

21040-361 - Rio de Janeiro, RJ

Tels: (21) 3882-9039 / 3882-9041

Telefax: (21) 3882-9006

e-mail: editora@fiocruz.br

http://www.fiocruz.br

Editora filiada

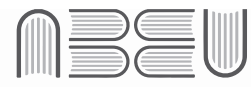

Associação Brasileira das Editoras Universitárias 


\section{AUTORES \& ORGANIZADORES}

\section{Adolfo Horácio Chorny (organizador)}

Graduado em administração de empresas; aposentado como professor titular da Fundação Oswaldo Cruz.

\section{Alcides Silva de Miranda}

Médico, doutor em saúde coletiva pelo Instituto de Saúde Coletiva da Universidade Federal da Bahia; professor associado da Universidade Federal do Rio Grande do Sul.

\section{Ana Cristina Marques Martins}

Graduada em nutrição, doutora em epidemiologia pela Escola Nacional de Saúde Pública Sergio Arouca, da Fundação Oswaldo Cruz; especialista em regulação em saúde suplementar da Agência Nacional de Saúde Suplementar.

\section{Ana Luiza d'Ávila Viana}

Economista, doutora em economia pelo Instituto de Economia da Universidade Estadual de Campinas; professora aposentada do Departamento de Medicina Preventiva da Faculdade de Medicina da Universidade de São Paulo, onde é orientadora do Programa de Pós-Graduação, coordenadora da Plataforma Região e Redes e especialista em análise de políticas públicas.

\section{Celia Regina Pierantoni}

Médica, pós-doutorado em saúde pública pelo Departamento de Medicina Preventiva da Faculdade de Medicina da Universidade de São Paulo; professora associada do Instituto de Medicina Social da Universidade do Estado do Rio de Janeiro (IMS/Uerj), diretora do Centro Colaborador da Organização Pan-Americana da Saúde/Organização Mundial da Saúde para Planejamento e Informação da Força de Trabalho em Saúde e coordenadora geral da Estação de Trabalho IMS/Uerj-ObservaRH.

\section{Claudia Risso de Araujo Lima}

Arquiteta e urbanista, doutora em saúde pública pelo Departamento de Epidemiologia da Escola Nacional de Saúde Pública Sergio Arouca, da Fundação Oswaldo Cruz (Ensp/Fiocruz); trabalha nos Cadernos de Saúde Pública da Ensp/ Fiocruz.

\section{Cristiana Leite Carvalho}

Graduada em odontologia, doutora em saúde pública pela Escola Nacional de Saúde Pública Sergio Arouca, da Fundação Oswaldo Cruz, pós-doutorado pela Johns Hopkins University (EUA); professora adjunta da Pontifícia Universidade Católica de Minas Gerais e pesquisadora da Estação de Pesquisa de Sinais de Mercado do Núcleo de Estudos em Saúde Coletiva da Faculdade de Medicina da Universidade Federal de Minas Gerais.

\section{Diego Ricardo Xavier}

Graduado em enfermagem, mestre em epidemiologia pela Escola Nacional de Saúde Pública Sergio Arouca, da Fundação Oswaldo Cruz (Fiocruz); pesquisador do Instituto de Comunicação e Informação Científica e Tecnológica em Saúde da Fiocruz. 


\section{Francisco Viacava}

Médico, mestre em medicina preventiva pela Universidade de São Paulo e em nutrição humana pela Columbia University (EUA); pesquisador do Laboratório de Informações em Saúde do Instituto de Comunicação e Informação Científica e Tecnológica em Saúde da Fundação Oswaldo Cruz.

\section{Hudson Pacifico da Silva}

Graduado em ciências econômicas, doutor em ciências pelo Departamento de Medicina Preventiva da Faculdade de Medicina da Universidade de São Paulo; pesquisador do Institut de Recherche en Santé Publique de l'Université de Montréal (Canadá).

\section{Isabela Soares Santos}

Graduada em ciências sociais, doutora em saúde pública pela Escola Nacional de Saúde Pública Sergio Arouca, da Fundação Oswaldo Cruz (Ensp/Fiocruz); pesquisadora em saúde pública do Departamento de Administração e Planejamento em Saúde da Ensp/Fiocruz, diretora executiva do Centro Brasileiro de Estudos de Saúde e coordenadora do Programa de Políticas Públicas e Modelos de Atenção e Gestão dos Serviços e Sistema de Saúde da Vice-Presidência de Pesquisa e Coleções Biológicas da Fiocruz.

\section{Jaime Gregorio Bellido}

Graduado em matemática aplicada, doutor em engenharia de produção pela Universidade Federal do Rio de Janeiro; pesquisador associado da Fundação Oswaldo Cruz.

\section{Jarbas Barbosa da Silva Jr.}

Médico, doutor em saúde coletiva pela Universidade Estadual de Campinas; diretor-presidente da Agência Nacional de Vigilância Sanitária do Ministério da Saúde.

\section{José Carvalho de Noronha (organizador)}

Médico sanitarista, doutor em saúde coletiva pela Universidade do Estado do Rio de Janeiro; médico do Laboratório de Informações em Saúde do Instituto de Comunicação e Informação Científica e Tecnológica da Fundação Oswaldo Cruz (Fiocruz), coordenador executivo da iniciativa Brasil Saúde Amanhã, da Fiocruz.

\section{Juliana Pires Machado}

Graduada em enfermagem, doutora em saúde pública pela Escola Nacional de Saúde Pública Sergio Arouca da Fundação Oswaldo Cruz; especialista em regulação da saúde suplementar, subárea epidemiologia, na Agência Nacional de Saúde Suplementar.

\section{Lucas Wan Der Maas}

Graduado em ciências sociais, mestre em ciências sociais pela Pontifícia Universidade Católica de Minas Gerais; pesquisador da Estação de Pesquisa de Sinais de Mercado/Observatório de Recursos Humanos em Saúde do Núcleo de Educação em Saúde Coletiva, da Faculdade de Medicina da Universidade Federal de Minas Gerais.

\section{Luciana Dias de Lima (organizadora)}

Médica, doutora em saúde coletiva pelo Instituto de Medicina Social da Universidade do Estado do Rio de Janeiro; pesquisadora e docente do Departamento de Administração e Planejamento em Saúde da Escola Nacional de Saúde Pública Sergio Arouca da Fundação Oswaldo Cruz.

\section{Luisa Regina Pessôa}

Arquiteta e urbanista, doutora em saúde pública pela Fundação Oswaldo Cruz (Fiocruz); pesquisadora do Centro de Referência Professor Hélio Fraga da Escola Nacional de Saúde Pública Sergio Arouca, da Fiocruz, e apoia o Programa de Políticas Públicas e Modelos de Atenção e Gestão dos Serviços e Sistema de Saúde da Vice-Presidência de Pesquisa e Coleções Biológicas da Fiocruz. 


\section{Maria Ruth dos Santos}

Graduada em farmácia-bioquímica, doutora em saúde coletiva pela Universidade do Estado do Rio de Janeiro; especialista em regulação e vigilância sanitária na Agência Nacional de Vigilância Sanitária do Ministério da Saúde.

\section{Mario Roberto Dal Poz (organizador)}

Médico, doutor em saúde pública pela Fundação Oswaldo Cruz; professor associado do Instituto de Medicina Social da Universidade do Estado do Rio de Janeiro e editor-chefe do periódico Human Resources for Health.

\section{Mônica de Avelar Figueiredo Mafra Magalhães}

Engenheira cartográfica, doutora em saúde coletiva pelo Instituto de Estudos em Saúde Coletiva da Universidade Federal do Rio de Janeiro; tecnologista em saúde pública da Fundação Oswaldo Cruz (Fiocruz) e pesquisadora do Laboratório de Informação em Saúde do Instituto de Comunicação e Informação Científica e Tecnológica em Saúde da Fiocruz.

\section{Paulo Gadelha (organizador)}

Médico, doutor em saúde pública pela Escola Nacional de Saúde Pública Sergio Arouca, da Fundação Oswaldo Cruz (Fiocruz); pesquisador titular da Fiocruz, onde é coordenador da iniciativa Brasil Saúde Amanhã.

\section{Sabado Nicolau Girardi}

Médico, residência em medicina preventiva e social pela Universidade Federal de Minas Gerais (UFMG) e saúde internacional pela Organização Pan-Americana da Saúde; coordenador da Estação de Pesquisa de Sinais de Mercado/ Observatório de Recursos Humanos em Saúde do Núcleo de Educação em Saúde Coletiva da UFMG e médico da área de gestão da Secretaria de Estado de Saúde de Minas Gerais.

\section{Thereza Christina Varella}

Graduada em enfermagem e obstetrícia, doutora em saúde coletiva pela Universidade do Estado do Rio de Janeiro (Uerj); professora adjunta da Faculdade de Enfermagem da Uerj.

\section{Vanderlei Pascoal de Matos}

Engenheiro cartográfico, mestre em ciências em engenharia cartográfica pelo Instituto Militar de Engenharia; pesquisador do Laboratório de Informação em Saúde do Instituto de Comunicação e Informação Científica e Tecnológica em Saúde, da Fundação Oswaldo Cruz.

\section{Walter Massa Ramalho}

Médico veterinário, doutor em medicina tropical pelo Núcleo de Medicina Tropical da Universidade de Brasília (UnB); docente da UnB.

\section{Wisley Velasco}

Analista de sistemas, mestre em informação e comunicação em saúde pelo Instituto de Comunicação e Informação Científica e Tecnológica, da Fundação Oswaldo Cruz; cientista de dados do ConectaSUS da Secretaria de Estado da Saúde de Goiás. 

1. Cenário Epidemiológico do Brasil em 2033: uma prospecção sobre as próximas duas décadas

Jarbas Barbosa da Silva Jr., Walter Massa Ramalho

2. Os Recursos Físicos de Saúde no Brasil: um olhar para o futuro Isabela Soares Santos, Luisa Regina Pessôa Juliana Pires Machado, Ana Cristina Marques Martins Claudia Risso de Araujo Lima

3. Polos e Fluxos de Deslocamento de Pacientes para Internação Hospitalar e Procedimentos Selecionados no Sistema Único de Saúde

Diego Ricardo Xavier, Vanderlei Pascoal de Matos

Mônica de Avelar Figueiredo Mafra Magalhães

Jaime Gregorio Bellido, Wisley Velasco, Francisco Viacava

4. Segmentos Institucionais de Gestão em Saúde: descrição, tendências e cenários prospectivos

Ana Luiza d'Ávila Viana, Alcides Silva de Miranda Hudson Pacifico da Silva

5. Estrutura Atual e Estimativas Futuras da Força de Trabalho em Medicina, Enfermagem e Odontologia no Brasil - 2000 a 2030

Sabado Nicolau Girardi, Lucas Wan Der Maas

Cristiana Leite Carvalho, Celia Regina Pierantoni

6. Projeção das Capacidades de Formação de Profissionais da Saúde Mario Roberto Dal Poz, Thereza Christina Varella Maria Ruth dos Santos 



\section{PREFÁCIO}

O projeto Saúde Amanhã, desenvolvido sob a coordenação da Fiocruz, tem fornecido ao setor e ao Sistema Único de Saúde (SUS) importantes contribuições tanto para o diagnóstico do presente como, particularmente, para delinear os desafios do futuro, por meio de estudos de projeção e análises que permitirão ao país dispor de elementos para escolher alternativas para a melhoria do sistema de saúde brasileiro. O presente da saúde no Brasil é resultado complexo da história da democracia e dos direitos sociais desde meados do século XX ao passado recente da Reforma Sanitária, da Constituição Federal, dos desdobramentos da implantação, ainda que com resistências, do SUS e da espetacular retomada da hegemonia do setor privado.

Desde o início da sua criação, o SUS desafia os interesses no interior do Estado e submete a risco permanente a consolidação da conquista constitucional. Entretanto, do cenário de disputas travadas ao longo desses anos resultam decisões que comprometem as condições requeridas para sua implementação e consolidação. No plano político, em quase três décadas de existência, o SUS sobrevive à descrença por parte da população e à baixa adesão entre representantes do campo político sendo bombardeado, sistemática e impiedosamente, pela mídia. Causa e consequência simultâneas da sua fragilidade construída conforme um ciclo vicioso e perverso no qual o crônico subfinanciamento produz baixa qualidade de serviços assistenciais e de gestão, aliado à convivência desfavorável com o setor suplementar.

Brasil Saúde Amanhã: dimensões para o planejamento da atenção à saúde tem o mérito de oferecer sólidas propostas relacionadas à regionalização e à gestão territorial do SUS, além de oferecer ferramentas e informações para aperfeiçoamento do planejamento em saúde e para a resolução de impasses presentes na conjuntura setorial em cujo cenário prevalecem interesses e conflitos que subtraem o direito universal à saúde. A estratégia do planejamento ascendente está articulada ao desafio de responder às necessidades e demandas locais e regionais em saúde que, por sua vez, precisam ser permanentemente identificadas e analisadas para incorporação ao processo de gestão nos territórios.

Apresentam-se ao leitor importantes elementos para ampliar a compreensão e alertar em relação a temas e situações emergentes associados a alguns desafios que o Brasil deverá enfrentar no futuro próximo, mas que demandam para o setor imediatas medidas e reformulações. Com base nas projeções epidemiológicas e respectivas análises de ajustes ou inovações de políticas e de gestão delineiam-se 
propostas e caminhos a serem adotados nas diferentes realidades nacionais em médio e longo prazo. Trata-se, portanto, de um conjunto de ferramentas baseadas nas pesquisas que inauguram os estudos de tendências e permitem definir o projeto para o futuro da sociedade brasileira em termos de saúde.

As desigualdades sociais e de saúde no território brasileiro requerem um esforço cada vez maior para a construção de alternativas voltadas a reduzir iniquidades e estabelecer um caminho virtuoso para a promoção de equidade. Nessa perspectiva, um Plano Nacional de Saúde deve contemplar a diversidade dessas necessidades e demandas das distintas populações que habitam os territórios nacionais ou que por suas características socioculturais e econômicas apresentem especificidades em relação à saúde. Políticas de promoção da equidade, organização de redes de atenção à saúde (RAS) e o decreto n. 7508/2011 são algumas das iniciativas convergentes para reforçar o enfoque regional na formulação de políticas e planejamento e organização dos serviços, visto que, embora insuficientes, contribuem para o aperfeiçoamento do processo de gestão orientando planos e enfatizando a gestão intergovernamental das regiões de saúde. É ainda necessário pavimentar o caminho para tornar efetiva a regionalização e a gestão regional, necessárias para a consolidação das redes de saúde nos territórios vivos, ou seja, o lugar onde a população vive, trabalha e transita e onde ocorrem os processos saúde-doença.

No capítulo "Cenário epidemiológico do Brasil em 2033: uma prospecção sobre as próximas duas décadas" não apenas se apresenta um volumoso conjunto de informações e tendências quanto ao perfil epidemiológico da população brasileira como se analisam os desafios para o setor Saúde decorrentes das transformações passíveis de ocorrerem nos próximos vinte anos. Essas mudanças nos modos de adoecer e morrer resultam dos novos padrões demográfico, econômico, industrial, social e cultural determinantes para a condição de saúde e modos de organização dos serviços para atendimento das novas demandas. As projeções indicam um predomínio das doenças crônicas não transmissíveis, com destaque importante da morbidade e mortalidade por doenças relacionadas ao grupo de neoplasias. Ações de prevenção, diagnóstico, tratamento e recuperação devem passar a ser uma preocupação do SUS e do Brasil como um todo, já que diversas iniciativas dependerão de outras políticas como, por exemplo, a redução da exposição a agrotóxicos e insumos agrícolas sabidamente relacionados à etiologia de tais doenças.

A ampliação dos anos de vida da população brasileira não apenas traz como consequência o protagonismo das doenças cardiovasculares, do diabetes e das neoplasias, mas também o crescimento expressivo das demências, em particular da doença de Alzheimer, que apresenta perspectiva de aumento em todas as regiões do Brasil, mudando fortemente o padrão epidemiológico do Nordeste brasileiro. Já na região Norte, a mudança fica por conta do diabetes mellitus e, no Sul, tomam lugar as infecções respiratórias inferiores. Esses distintos padrões refletem as desiguais condições de vida e o nível de desenvolvimento em cada uma das regiões brasileiras que, por sua vez, exigem diferentes formas de planejamento e implementação das ações e serviços.

Para o setor Saúde restam muitos desafios que exigem o fortalecimento do SUS, por meio da regulação efetiva por parte do setor privado da atenção e controle das enfermidades crônicas, garantindo cobertura do cuidado e monitoramento permanente. Para o SUS, reforça o desafio de consolidar 
redes de atenção ordenadas pela atenção básica, coordenadoras da saúde das pessoas, com papel de destaque na prevenção, atenção domiciliar e no cuidado a doenças crônicas.

Valendo-se dessas mudanças, torna-se essencial conhecer a base de recursos que o país dispõe para atendimento de sua população nos distintos territórios e a tarefa que se impõe é a de investigar a rede real de serviços e fluxos trilhados pela população em busca de cuidados de saúde, nos diferentes tipos de municípios e regiões brasileiras. Dois estudos complementares expostos em capítulos deste livro assumem essa tarefa complexa. Trata-se dos capítulos "Os recursos físicos de saúde no Brasil: um olhar para o futuro" e "Polos e fluxos de deslocamento de pacientes para internação hospitalar e procedimentos selecionados no Sistema Único de Saúde".

Tais estudos trazem elementos importantes para compreender os rumos do setor Saúde no Brasil. Recursos e infraestrutura de assistência à saúde altamente concentrados, vazios de oferta de leitos em terapia intensiva - de alto custo e elevada taxa de uso de procedimentos - e, por outro lado, a oferta de serviços privados convivendo na mesma unidade de saúde que atende pelo SUS, revelando formas de pagamento diferenciadas na mesma unidade assistencial.

No estudo sobre os fluxos se oferece um mapeamento das internações, exames diagnósticos e terapias classificados em níveis de complexidade - internação de baixa e média complexidade, serviços de apoio diagnóstico e terapêutico e internação de alta complexidade - com a intenção de evidenciar como se manifesta a demanda por atendimento nas regiões mais e menos concentradas de oferta de serviços e dessa forma verificar as distintas capacidades dos municípios no atendimento às necessidades.

Por meio dos resultados reafirmam-se as desigualdades do acesso, desvelando a enormidade de vazios nos municípios e nos territórios nacionais. O desenho dos fluxos mostra a peregrinação pela qual passa a maior parte de nossa população para ser atendida nas suas necessidades de saúde. Essa constatação tem eloquência suficiente para conduzir à urgente necessidade da reformulação espacial da oferta de saúde, cobrindo desigualdades que persistem após o insuficiente desenvolvimento de políticas específicas concentradas em regiões mais longínquas e escassas de serviços - Norte e Nordeste do país. Ampliar o acesso com integralidade do cuidado e da saúde requer robustecer outras políticas intersetoriais, permitindo ao cidadão ter acesso ao conjunto das políticas sociais que determinam as condições de vida, transporte, moradia, segurança alimentar como marco de um projeto de desenvolvimento integrado com justiça social e equidade para todo o país.

No capítulo "Segmentos institucionais de gestão em saúde: descrição, tendências e cenários prospectivos" são identificadas as pluralidades dos segmentos institucionais presentes na administração e na prestação de serviços de saúde tipificados com base na natureza jurídica: pública e estatal, pública e não estatal e privada. Desse diagnóstico de comportamento do período entre 2005 a 2013, os autores partem para a exploração das tendências e cenários futuros.

A descentralização e o empresariamento setorial ocorridos na primeira década de implantação do SUS são adotados como referência pelos autores que, baseados em dados secundários provenientes do Cadastro Nacional de Estabelecimentos de Saúde, analisam os efeitos desses dois fenômenos sobre o setor. 
Valendo-se das tendências encontradas na diminuição do peso proporcional de segmentos institucionais de gestão em saúde sob a orientação do direito público e consequente crescimento daqueles regidos pelo direito privado, os autores esboçam cenários possíveis para o futuro e analisam as respectivas consequências para o sistema de saúde brasileiro, em três perspectivas: inercial de agenciamento contratual com regulação produtiva, inovação institucional focada na universalidade integral e equidade redistributiva e a tendência à privatização subvencionada pelo poder público e regulação agenciada.

Prosseguindo na exploração dos futuros desafios setoriais, esta coletânea é perpassada pela importante e adiada questão dos recursos humanos em saúde, tanto no que diz respeito ao provimento quanto à formação da força de trabalho em saúde. Trata-se de um tema complexo não apenas no Brasil, mas que aqui, a despeito dos inúmeros diagnósticos e alertas, ainda não havia adquirido centralidade como ocorreu com o Programa Mais Médicos, que apresenta propostas de soluções para uma categoria e deixa pendente as demais profissões que integram as equipes de cuidado à saúde.

Não existem instrumentos normativos que definam as profissões da saúde e, nesse vácuo, ao regulamentar sobre as representações dos profissionais que podem ocupar assento no Conselho Nacional de Saúde (CNS), definiram-se 14 categorias ocupacionais em 1998. Desde então as instituições de saúde passaram a utilizar essa recomendação do CNS destinada a orientar sua composição e as suas equipes e definir sobre a oferta de vagas. Diversos profissionais que não foram contemplados nessa resolução do CNS demandam ser incorporados, como é o caso dos sanitaristas graduados a partir dos anos 2000 .

Em "Estrutura atual e estimativas futuras da força de trabalho em medicina, enfermagem e odontologia no Brasil - 2000 a 2030" elabora-se um cenário prospectivo do estoque de médicos, enfermeiros e cirurgiões-dentistas. Analisando as tendências, os autores assinalam a substantiva melhora da proporção de médicos no cenário produzido pelo Programa Mais Médicos, mas também indicam que ocorrerá aumento do contingente de profissionais formados em enfermagem e odontologia, restando o desafio da incorporação dessa força de trabalho de forma adequada para solucionar problemas de escassez nas regiões remotas.

Por fim, o capítulo "Projeção das capacidades de formação de profissionais da saúde" teve como objetivo analisar a formação das diversas profissões da saúde com base no panorama de crescimento da educação superior ocorrido recentemente no Brasil. Os resultados dessas mudanças determinaram o desenho das tendências, segundo as quais sobressai a concentração regional no Sudeste de todos os cursos da área da saúde e o crescimento expressivo da oferta de cursos pelo setor privado de ensino que, nessa região, representa $72 \%$ das instituições de ensino analisadas, mesmo que os resultados dos estudos de desempenho dessas escolas sejam abaixo do desejável.

O cenário requer monitoramento da qualidade dos processos de formação e das instituições que os oferecem, pois há uma forte tendência de piora no quadro o que pode resultar em arranjos institucionais de consórcios e aglomerados para atender às demandas regulatórias e do próprio mercado. Essa situação é comum ao conjunto das profissões analisadas, mas se agrava para os médicos, uma 
vez que o incremento de postos de trabalho ocasionado pelo Programa Mais Médicos teve como consequência a expansão das vagas, oferecidas por instituições privadas em sua maioria.

É, portanto, uma obra de fôlego que, ao desnudar a realidade desenhando cenários possíveis para o setor, assume seu grande potencial de contribuir para a construção do direito à saúde e impulsionar novos estudos. As pedras estão lançadas e, com base nas tendências, traçam-se os riscos e os caminhos. Cabe àqueles que dispõem do poder decidir se o Brasil parte para seu desenvolvimento como um Estado que promove direitos e bem-estar social ou se permitirá a guinada final para saciar a volúpia do mercado.

Este livro reforça que o desenvolvimento regional também resulta de investimentos realizados na saúde, não apenas pelo que gera de circulação de insumos e de emprego, mas, particularmente, porque permite atuar sobre situações de iniquidade regional e alterar as condições de vida das populações. Igualmente, alia-se à expectativa da Reforma Sanitária e da Constituição por localizar e garantir o lugar estruturante da saúde entre as políticas para um desenvolvimento pleno, justo e democrático pautado nos direitos e nas necessidades humanas, o que chancela a mobilização acadêmica, política e social pela saúde que costura cada capítulo desta coletânea. Boa leitura!

Ana Maria Costa

Professora da Escola Superior de Ciências da Saúde, diretora do Centro Brasileiro de Estudos de Saúde e coordenadora-geral da Associação Latino-Americana de Medicina Social 



\section{APRESENTAÇÃO}

\section{Planejamento Nacional, Território e Saúde}

O Sistema Único de Saúde (SUS) conforma o modelo público de ações e serviços de saúde no Brasil. Orientado por um conjunto de princípios e diretrizes válidos para todo o território nacional, parte de uma concepção ampla do direito à saúde e do papel do Estado na garantia desse direito, rompendo com o padrão de estratificação da cidadania social que modulou por mais de cinquenta anos a assistência à saúde no país.

A implantação do SUS teve início na década de 1990, após a promulgação da Lei Orgânica da Saúde (Brasil, 1990), sendo marcada por um processo de descentralização que redefiniu responsabilidades e resultou na transferência de poder decisório, da gestão de prestadores e de recursos financeiros, antes concentrados no governo federal, principalmente, para os executivos municipais. Entretanto, somente nos anos 2000, quando se observam novas orientações na condução da política nacional e a recuperação fiscal dos estados brasileiros, a regionalização adquiriu maior destaque entre as diretrizes que orientam a implementação do SUS.

Historicamente, a regionalização é uma função atribuída ao Estado e envolve a definição de recortes espaciais para fins de planejamento e gestão territorial de políticas públicas (Ribeiro, 2004). Tais preocupações se expressam na trajetória de conformação de sistemas universais de saúde em diversos países (Kuschnir \& Chorny, 2010), nos quais diferentes escalas territoriais são utilizadas para o planejamento e organização de redes de cuidados segundo níveis de complexidade da atenção, e para a gestão da prestação de ações e serviços. Nesses casos, os objetivos da regionalização estão relacionados à ampliação do acesso e à melhoria do desempenho do sistema de saúde.

No Brasil, a regionalização do SUS é um processo de enorme complexidade, condicionado por uma série de fatores (Viana \& Lima, 2011), entre eles: a desigualdade na distribuição espacial de equipamentos, insumos e tecnologias e na disponibilidade de recursos humanos e financeiros; as dificuldades de integração regional das políticas públicas e das ações do Estado nos diversos campos da atenção à saúde (assistência, vigilâncias, desenvolvimento e provisão de tecnologias e insumos, educação e gestão da força de trabalho em saúde); e a diversidade de agentes (governamentais e não governamentais, públicos e privados) que participam da gestão e prestação de serviços no território. 
Desde 2011 esse processo segue as normas estabelecidas no decreto n.7.508 (Brasil, 2011), por meio das quais se enfatiza a importância do enfoque regional na formulação de políticas e se propõe uma série de instrumentos para apoiar o planejamento, a pactuação e a gestão intergovernamental nas regiões de saúde constituídas nos estados brasileiros. Entretanto, ainda que ganhos de institucionalidade possam ser observados na implementação dos dispositivos do decreto, problemas estruturais comprometem maiores avanços e a sustentabilidade da regionalização no SUS.

Visando contribuir para a superação desses entraves, este livro reúne trabalhos desenvolvidos sobre os temas relacionados às projeções do perfil epidemiológico do país e a organização e gestão dos serviços de saúde, com o objetivo de apoiar o planejamento e a prospecção estratégica do sistema de saúde em âmbito nacional. A abordagem de prospecção estratégica adotada pela iniciativa Brasil Saúde Amanhã pretende expandir a capacidade de compreensão em relação a temas e situações emergentes fundamentais para o planejamento em saúde de médio e longo prazo (Habegger, 2010). Para tanto, integra perspectivas, procedimentos e ferramentas das pesquisas de tendências e dos estudos de futuro.

A justificativa para os enfoques dos trabalhos aqui reunidos se fundamenta em três argumentos principais. Em primeiro lugar, ressalta-se a necessidade do fortalecimento do planejamento nacional em saúde e, particularmente, da sua dimensão territorial, para identificar necessidades de intervenção, propiciar a formulação de políticas diferenciadas segundo parâmetros regionais e realizar investimentos associados a estratégias de desenvolvimento para a redução das desigualdades existentes.

Sabe-se que as dinâmicas territoriais no Brasil são variadas (Oliveira \& O 'Neill, 2013). Existem regiões caracterizadas por intensa concentração da população, de atividades econômicas e de serviços sociais, como as metropolitanas que, em 2010, concentravam cerca de $45 \%$ da população do país. Outras regiões são marcadas por rarefeita densidade demográfica e baixo dinamismo econômico, além de tendência à estagnação ou à redução em razão, principalmente, dos fluxos migratórios para cidades médias do interior e para as periferias das metrópoles e grandes centros urbanos. Há, ainda, aquelas caracterizadas por dinâmicas singulares com grande diversidade interna, como a Amazônia Legal, que alberga $60 \%$ do território nacional, e as áreas de fronteira internacional, que representam $27 \%$ do território.

A diversidade territorial brasileira - ambiental, produtiva e étnico-cultural - se traduz no esforço recente do governo federal de reordenamento do espaço geográfico para fins de planejamento e identificação de vetores estratégicos para o desenvolvimento, que inclui seis regiões: o bioma florestal amazônico; o Centro-Norte; o Centro-Oeste; o sertão semiárido nordestino; o litoral Sudeste-Sul; e o litoral norte-nordestino (IBGE, 2008).

Essas diferenciações espaciais têm implicações para a saúde em diferentes aspectos, como por exemplo: o perfil de ocorrência de agravos e doenças na população; a configuração do sistema (distribuição e tipo dos serviços, composição público-privada) e uso dos serviços de saúde; as exigências em termos das políticas de saúde e organização da atenção, e a efetividade e eficiência dos resultados alcançados pelo setor. 
As dinâmicas do território também repercutem na definição dos recortes regionais para fins de planejamento, já que é necessário um nível mínimo de aglomeração populacional e demanda para a organização da oferta de serviços públicos mais especializados e complexos. Critérios de economia de escala na distribuição de equipamentos estão relacionados tanto à otimização de recursos disponíveis quanto à qualidade do cuidado em saúde. A distância que é possível e desejável percorrer para ter acesso a determinados serviços essenciais também é um elemento central a ser considerado no planejamento territorial da atenção à saúde.

Embora iniciativas decorrentes de políticas específicas e incentivos financeiros tenham se dirigido para regiões mais carentes, não houve no período de implementação do SUS esforços sistemáticos da esfera federal para o planejamento territorial em saúde; em nível nacional, o planejamento não se restringe à coordenação de um processo "de base local e ascendente", visto que existem atributos próprios dessa função em cada esfera de governo. A fragilidade do enfoque territorial nas estratégias desenvolvidas pelo Ministério da Saúde dificulta sua adequação às múltiplas realidades brasileiras. Além disso, ainda são limitados os investimentos que buscam relacionar as necessidades das populações às condições de oferta e atendimento dos serviços, visando à adequação do modelo de atenção e à redução da iniquidade em saúde.

Nota-se que o conceito de região apresenta variações ao longo da história, tanto no âmbito acadêmico, como no que diz respeito à ação do Estado. Nesse caso, reconhece-se que o desenvolvimento de um olhar ampliado sobre o território pode ser um elemento de integração entre a política de saúde com outras políticas setoriais fundamentadas na regionalização (Duarte, Contel \& Balbim, 2013).

Em segundo lugar, destacam-se os vínculos existentes entre saúde e desenvolvimento na perspectiva territorial (Gadelha et al., 2011). Em capítulo da obra Brasil Saúde Amanhã: população, economia e gestão, Antônio Tadeu Ribeiro de Oliveira e Maria Monica Vieira Caetano O 'Neill demonstram a importância dos equipamentos e especialidades da saúde para a organização das redes urbanas, influenciando a capacidade de polarização e hierarquia das cidades.

Tomando-se como base a centralidade definida para cada município por meio da disponibilidade de um conjunto de serviços hierarquizados por níveis de complexidade, verificou-se que aproximadamente 20\% dos municípios brasileiros não têm essa característica, ou seja, que as demandas de saúde de suas populações se deslocam em direção a outros municípios para obtenção de atendimento. Somente um município, São Paulo, apresenta centralidade máxima, ao passo que 3.997 têm centralidade mínima, de modo que se pode supor que retenham uma parte ínfima de sua demanda.

Apenas 31 municípios têm centralidade nos três níveis mais complexos, o que além de indicar a existência de grandes fluxos de população para atender suas necessidades de saúde, sinaliza a existência de grandes vazios no que diz respeito à disponibilidade de serviços, forte indício da necessidade de uma reformulação espacial da oferta de saúde.

Nos estudos recentes, demonstra-se que, nos últimos dez anos, impactos regionais diferenciados podem ser atribuídos às políticas nacionais que favoreceram, especialmente, as regiões mais pobres do Norte e Nordeste do país (Araujo, 2013). Em grande parte, as políticas setoriais e as de corte 
territorial contribuíram mais para a redução das desigualdades regionais herdadas no país, se comparadas às políticas regionais explícitas. Entretanto, as cidades, como elementos-chave da dinâmica regional, não foram contempladas a contento.

A consideração da rede urbana como expressão da dimensão territorial brasileira é um importante instrumento para a formulação da política de regionalização de ações e serviços de saúde. A partir dos estudos conduzidos no âmbito desse projeto e de uma análise cuidadosa das Regiões de Influência das Cidades (IBGE, 2008), observa-se que regiões nas quais há município com maior área de influência tendem a suprir sua população em relação a serviços de assistência mais complexos. Já regiões com municípios de pouca influência e baixa capacidade de polarização apresentam dificuldades até mesmo para a oferta de serviços básicos em saúde.

Depreende-se que a saúde pode ser um elemento indicativo para as políticas de desenvolvimento regional, captando a intensidade das relações de troca que estruturam a rede de serviços e a malha urbana (Gadelha et al., 2011). Investimentos no setor possibilitariam um padrão de urbanização polinuclear, distinto do que o país experimentou no século passado, com valorização de centros urbanos estratégicos em várias regiões e estímulo a um desenvolvimento regional, nos próximos vinte anos, menos desigual e concentrado no litoral e no eixo Sudeste/Sul. Por sua vez, o direcionamento das políticas públicas para ampliação da capacidade de oferta, criação de novos polos assistenciais e melhoria das condições de acesso e da qualidade dos serviços de saúde permite atenuar situações de iniquidade regional, alterando as condições de vida das populações.

Um terceiro argumento está relacionado de modo mais específico aos desafios associados à definição de regiões para fins de planejamento, organização e gestão territorial do SUS. Diante das imensas desigualdades e diversidades subjacentes, é extremamente difícil relacionar níveis assistenciais (ou uma determinada capacidade de resposta do sistema de saúde) a um único recorte regional. A adoção de um enfoque estratégico e dinâmico no planejamento territorial pressupõe a definição de múltiplas escalas espaciais (Brandão, 2007), em razão dos diversos fatores que incidem sobre a organização do sistema de saúde.

No que tange à gestão territorial, em face da especificidade do federalismo, das relações públicoprivadas e dos novos formatos organizacionais da gestão pública no Brasil, a condução do sistema em âmbito regional sempre exigirá esforços de coordenação e regulação de agentes com poderes, lógicas de atuação e interesses distintos. A regionalização, portanto, pressupõe a constituição de regras e espaços democráticos de negociação e decisão política que permitam a construção de uma autoridade estatal no espaço regional capaz de orientar as ações dos diferentes atores na lógica dos interesses coletivos e da consolidação do SUS.

De certa forma, nesses últimos anos percebem-se tentativas de articulação dos recortes territoriais, para fins de planejamento, aos espaços de negociação e pactuação federativa da política de saúde em âmbito regional. Entretanto, nem sempre esse processo permite o fortalecimento do enfoque territorial no planejamento em saúde em razão das características do arranjo federativo brasileiro e das restrições impostas pelos limites regionais associados aos acordos intergovernamentais no SUS (atribuídos aos espaços definidos pelas Comissões Intergestores Regionais, aos Contratos Organiza- 
tivos de Ação Pública ou aos consórcios). Por sua vez, fez-se necessário considerar as repercussões dos arranjos híbridos - públicos e privados - na gestão e prestação dos serviços de saúde para a governança regional do SUS.

Na saúde, a discussão dos mecanismos gerenciais acabou se sobrepondo à questão da região em si (Balbim \& Contel, 2013; Duarte, Contel \& Balbim, 2013) ou a do próprio planejamento como função essencial do Estado. Tal debate corrobora a necessidade de desenvolver diagnósticos que permitam uma articulação mais efetiva entre território e saúde nesse processo, visando alcançar maior coerência no desenho de propostas de intervenção e gestão.

Partindo desses pressupostos, no primeiro capítulo deste livro, "Cenário epidemiológico do Brasil em 2033: uma prospecção sobre as próximas duas décadas”, Jarbas Barbosa da Silva Jr. e Walter Massa Ramalho apresentam o perfil epidemiológico da população brasileira, analisando as tendências e mudanças passíveis nos próximos vinte anos. Entende-se que o exame prospectivo da organização dos serviços de saúde passa necessariamente pelo esforço em identificar a situação de saúde à qual esses serviços devem responder.

Em um empenho que segue àquele apresentado nos textos de Barreto (Barreto, 2013) e Luna (Luna \& Silva Jr., 2013) na publicação A Saúde no Brasil em 2030: diretrizes para a prospecção estratégica do sistema de saúde brasileiro, os autores avançam na projeção das condições de morbimortalidade da população brasileira, destacando os impactos decorrentes dessas mudanças para o SUS e as estratégias e ações necessárias para enfrentar o quadro previsto.

Apoiado em metodologia prospectiva - o método Arima (sigla em inglês para autoregressive integrated moving average) -, os modelos preditivos construídos consideram as diferenças regionais e indicam a manutenção das tendências já observadas quanto a primazia das doenças crônicas não transmissíveis (DCNT), a relevância das mortes por agressões, a diminuição da morbimortalidade por doenças transmissíveis e a redução da taxa de mortalidade infantil (TMI).

Considerando a mortalidade proporcional pelos grandes grupos de causa, os autores observam que as doenças do aparelho circulatório (DAC) sofrerão redução no período até 2033, quando representarão $27,6 \%$ dos óbitos no país, mantendo ainda o primeiro lugar entre as cinco causas principais; o grupo das neoplasias, ao qual serão atribuídas duas de cada dez mortes que ocorrerão no país em 2033, passará a ocupar o segundo posto (19,8\%), ultrapassando as causas externas (12,6\%); e as afecções perinatais e as doenças infecciosas e parasitárias (DIP) também diminuirão proporcionalmente com 0,4\%, e 3,8\%, respectivamente, em relação ao total de óbitos.

Efetuaram-se projeções para 14 causas específicas mais importantes de óbito por meio das quais se demonstram variações significativas em relação a 1980 e entre as regiões do país. Os dados projetados revelam um incremento de 165,6\% na taxa de mortalidade por Alzheimer e outras demências, o maior aumento entre as 14 causas consideradas, o que posicionará esse grupo em oitavo lugar entre as causas de óbito em 2033.

As variações são bastante relevantes quando se consideram as regiões do país. Na região Norte, o primeiro lugar entre as 14 principais causas de morte será ocupado pelo diabetes mellitus, com um 
crescimento projetado de $167,1 \%$. Na região Nordeste, o maior crescimento relativo $(295,7 \%)$ será do grupo Alzheimer e outras demências, no entanto, as doenças isquêmicas do coração ocuparão o primeiro lugar, seguidas pelas doenças cerebrovasculares.

No Sudeste, crescerão as infecções respiratórias inferiores (122,3\%), primeiro lugar entre as 15 causas e Alzheimer e outras demências (175,0\%). Destaca-se que diminuirão os óbitos por agressões, a maior redução entre as 14 causas mais importantes.

Como nas demais regiões, prevê-se para a região Sul um crescimento expressivo do Alzheimer e outras demências (164\%). Mas os primeiros lugares na mortalidade serão dos grupos das doenças isquêmicas e doenças cerebrovasculares.

Na região Centro-Oeste, a principal causa de óbito será de doenças isquêmicas seguidas pelas infecções respiratórias de vias inferiores. Mantendo o padrão das demais regiões, indica-se o crescimento da mortalidade por Alzheimer e outras demências.

Quanto à taxa de mortalidade infantil, espera-se redução significativa - 6,7 por 1.000 nascidos vivos em 2033 -, decréscimo de 54,5\% em relação a 2013, ou seja, 17,8 mil óbitos infantis deixarão de ocorrer. Com isso, a taxa projetada para o Brasil será apenas 1,8 vezes maior que aquela prevista para os países desenvolvidos.

Os autores concluem as análises com recomendações e medidas que poderão impactar significativamente tanto no perfil epidemiológico quanto na organização da atenção à saúde.

Nos dois capítulos seguintes, "Os recursos físicos de saúde no Brasil: um olhar para o futuro" e "Polos e fluxos de deslocamento de pacientes para internação hospitalar e procedimentos selecionados no Sistema Único de Saúde" buscam-se identificar os recursos físicos, a oferta e os fluxos da população atendida no SUS com objetivo de determinar uma linha de base que sirva como ponto de partida para especulações futuras. Ambos os estudos se apoiaram, principalmente, em dados secundários disponíveis em bases nacionais de domínio público (Cadastro Nacional de Estabelecimentos de Saúde, Sistema de Informações Hospitalares e Sistema de Informações Ambulatoriais do SUS), submetidos aos tratamentos pertinentes para obtenção das informações necessárias.

No segundo capítulo, "Os recursos físicos de saúde no Brasil: um olhar para o futuro", Isabela Soares Santos, Luisa Regina Pessôa, Juliana Pires Machado, Ana Cristina Marques Martins e Claudia Risso de Araujo Lima apresentam o mapeamento dos recursos físicos da saúde no Brasil em dezembro de 2013. Verificaram-se a disponibilidade e distribuição territorial da capacidade hospitalar instalada, vinculada ou não ao SUS, incluindo o número de estabelecimentos, leitos (clínicos, cirúrgicos e especialidades) e estruturas para atendimento de agravos e situações específicas consideradas relevantes para a organização da assistência à saúde (como, por exemplo, trauma, cirurgia cardíaca e doença renal).

No período examinado o sistema de saúde brasileiro tinha 113.167 unidades de saúde, entre públicas, privadas sem fins lucrativos e privadas com fins lucrativos. A distribuição dos estabelecimentos difere nas regiões do país, especialmente daqueles relacionados ao cuidado ambulatorial. No Sul e Sudeste, os consultórios eram mais de $60 \%$ dos estabelecimentos registrados, ao passo que 
no Norte e Nordeste eram pouco mais de 32\%. Já os postos e centros de saúde que totalizavam 36\% dos estabelecimentos no Norte e Nordeste variavam entre 12\%, 14\% e 15\% nas regiões Sudeste, Sul e Centro-Oeste, respectivamente.

As unidades com leitos de internação estavam concentradas em 3.521 municípios, e cerca de 80\% dos estabelecimentos contavam com menos de cem leitos. Essas unidades disponibilizavam 430 mil leitos, sendo 296.131 leitos SUS (68\%) e 135.909 Não SUS (32\%). A distribuição dos leitos também se verificava de modo disperso no território. Por um lado, no Rio de Janeiro, a oferta de leitos Não SUS era superior à oferta de leitos SUS, ao passo que em Recife e Salvador a situação era inversa.

Em 1.759 municípios somente serviços vinculados ao SUS ofereciam internação e em 1.701 municípios isso ocorria em ambos os segmentos. Os leitos SUS ultrapassavam o dobro dos Não SUS em 1.537 municípios; em 163 municípios a oferta Não SUS era 36\% maior.

O mapeamento da disponibilidade desses recursos sugere a alta concentração de equipamentos em poucas unidades hospitalares e municípios brasileiros. Destaca-se a baixa oferta de leitos de unidade de terapia intensiva (UTI) em relação aos leitos existentes. Entretanto, em relação aos serviços de alta complexidade e custo, percebeu-se que a provisão de poucos itens relacionados à habilitação da oferta, segundo regulamentação específica, permitiria a configuração de polos de referência para alguns tipos de serviços em regiões selecionadas.

A oferta de recursos físicos para o sistema público e o privado em uma mesma unidade de saúde estava presente na maior parte dos municípios, o que indica a possibilidade de formas distintas tanto de financiamento como de atenção a pacientes que estão ou não cobertos pelo segmento suplementar. Esse dado reforça a preocupação com a garantia da equidade no acesso à saúde em um país desigual e com alta cobertura de plano privado de saúde (em torno de $25 \%$ da população).

O terceiro capítulo, intitulado "Polos e fluxos de deslocamento de pacientes para internação hospitalar e procedimentos selecionados no Sistema Único de Saúde”, de autoria de Diego Ricardo Xavier, Vanderlei Pascoal de Matos, Mônica Magalhães, Jaime Gregorio Belido, Wisley Velasco e Francisco Viacava, reúne o mapeamento das internações, dos exames diagnósticos e terapias e dos fluxos da população atendida no SUS, no período 2010-2012. Para isso, os autores selecionaram três grandes grupos de procedimentos diferenciados por complexidade: internação de baixa-média complexidade, serviços de apoio diagnóstico e terapêutico e internação de alta complexidade. Esses três grupos foram subdivididos de maneira que fosse possível compreender melhor: como se manifesta a demanda por atendimento considerando as situações de maior concentração e aquelas em que o cuidado é mais disperso; e também a capacidade dos municípios segundo os vários grupos de procedimentos atendidos. Nos mapas de fluxos procurou-se relacionar o destino e a origem do atendimento, além da indicação de possíveis polos e redes de atenção específicas.

Pela leitura dos resultados, depreende-se que os municípios mais populosos estavam entre os vinte primeiros que mais realizavam procedimentos (mais de 50\% do total). Embora as capitais estivessem presentes na maioria das situações, verificou-se nos casos de procedimentos de baixa complexidade que a população desses municípios era preponderante. Nos níveis mais altos de 
complexidade foi maior o percentual de atendimento a não residentes. As capitais representavam polos mais importantes, contudo, municípios de médio porte se destacaram nos procedimentos de alta complexidade.

A situação de concentração da atenção era diretamente relacionada à complexidade dos procedimentos. De modo geral, foi possível classificar os fluxos de pacientes segundo os procedimentos analisados e as distâncias percorridas da seguinte forma: na internação de baixa-média complexidade registravam-se pequenas distâncias percorridas pelos pacientes e a presença de polos intraestaduais; para os serviços de apoio diagnóstico e terapêutico e de alta complexidade os fluxos eram mais intensos e distâncias maiores, indicando a situação de polos nacionais.

Na baixa-média complexidade notou-se semelhança na rede de atenção relacionada à internação clínica e cirúrgica (incluindo pediatria, adultos e parto cesáreo). Em procedimentos cirúrgicos, os fluxos pareciam ser mais intensos em comparação aos procedimentos clínicos.

No caso das mamografias, observou-se que, além de grandes capitais, cidades de médio porte também se destacavam quanto ao maior volume de atendimentos. Nos procedimentos de quimioterapia e radioterapia a distribuição espacial era mais concentrada nas capitais do Nordeste, Sudeste e Sul do País, além de cidades no norte do estado de São Paulo. Os mapas de fluxo para esses procedimentos apresentavam maiores distâncias percorridas, sobretudo porque pacientes das regiões Norte e Centro-Oeste do país buscavam atendimento em municípios do Sul e Sudeste.

Para os procedimentos de tomografia computadorizada e ressonância magnética também se observaram polos similares de atendimento. No entanto, os procedimentos de tomografia computadorizada estavam dispersos em vários municípios do território nacional, ao passo que os exames de ressonância magnética se concentravam em um número menor de municípios. Por conta disso, as distâncias percorridas foram maiores no caso das ressonâncias magnéticas, se comparadas às tomografias.

Apenas 25 municípios realizavam transplantes de medula óssea e demais órgãos sólidos, sendo boa parte desses municípios polos para ambos os procedimentos. Os polos para atendimento em neurocirurgia e cirurgia ortopédica do quadril coincidiram em algumas regiões do país, sobretudo no Sudeste e Sul. Ressalta-se que as cirurgias ortopédicas de joelho não se concentravam nos mesmos polos que as cirurgias ortopédicas de quadril.

Os principais municípios para realização de procedimentos de angioplastia foram aqueles que se destacaram na revascularização do miocárdio como polos de atendimento. Considerando os procedimentos oncológicos em geral, destacaram-se municípios no interior do estado de São Paulo, região de Barretos, Ribeirão Preto e São José do Rio Preto, além de municípios no oeste do estado do Paraná. Nas unidades de terapia intensiva (UTI), observou-se que o volume de internações dos adultos foi superior ao das internações pediátricas, concentradas em poucos municípios do país.

Algumas tendências e direcionamentos para o futuro podem ser extraídos desses dois trabalhos. Do ponto de vista da organização dos serviços de saúde, a consideração dos municípios como pontos no território nacional sugere questionamentos quanto as suas propriedades e os fatores que expli- 
cam as relações que se estabelecem entre eles referentes aos atendimentos. É razoável supor que a população se desloca na procura de atenção à saúde desde aqueles pontos com nenhuma ou pouca disponibilidade de recursos para aqueles que contam com uma maior quantidade de equipamentos e especialidades.

Os movimentos populacionais observados na procura de atendimento às demandas e necessidades de saúde se enquadram em certos padrões de ordem geral:

- A atração exercida por um ponto (município) sobre a população de outros municípios está relacionada com a complexidade dos serviços oferecidos e a disponibilidade para atender um número de usuários maior do que aquele gerado pela própria população do município. Em outras palavras, a oferta de serviços de saúde deve ser superior à demanda local. Nesse caso, um modulador importante da demanda externa gerada pode ser representado pela imagem que esses serviços têm para a população demandante.

- A força de atração é maior, ou seja, é exercida em maior distância quando a complexidade dos serviços ofertados é mais elevada.

Ressalta-se que os fluxos populacionais em busca de serviços especializados são, na sua maioria, diferenciados, não sendo possível a formulação de uma proposição geral como explicação dessa tendência, que varia em função das demandas, dos recursos físicos e das ofertas específicas.

No quarto capítulo, intitulado "Segmentos institucionais de gestão em saúde: descrição, tendências e cenários prospectivos”, desenvolvido por Ana Luiza d`Ávila Viana, Alcides Silva de Miranda e Hudson Pacifico da Silva, procurou-se identificar os principais segmentos institucionais da administração e prestação dos serviços de saúde no Brasil - pública e estatal, pública não estatal e privada - e explorar possíveis tendências e cenários futuros derivados de sua conformação no período de 2005 a 2013.

Os autores adotaram uma perspectiva de análise que conjugasse a atuação de dois fenômenos que marcaram a implementação do sistema de saúde nas décadas de 1990 e 2000: a descentralização e o empresariamento. Buscou-se relacionar e discutir os efeitos desses dois processos na conformação de segmentos institucionais de gestão e prestação de serviços de saúde nas macrorregiões e estados brasileiros, de forma a especular sobre a evolução futura dos modelos de gestão na saúde no território nacional. O estudo também se ancorou em dados secundários obtidos do Cadastro Nacional de Estabelecimentos de Saúde.

O ensaio estabelece uma tipologia relativa às modalidades institucionais de gestão e prestação de serviços de saúde existentes no Brasil em 2013. Três setores primordiais de institucionalidades foram identificados com base na natureza jurídica dos prestadores: pública estatal, pública não estatal e privada. Com base nessa classificação inicial foram agregadas outras informações que resultaram em nove segmentos de gestão.

Observou-se que a trajetória tendencial dos segmentos institucionais de gestão em saúde no período 2005-2013 apresentou variações significativas acerca dos seguintes aspectos: quantidade de estabelecimentos, proporção de estabelecimentos com vínculo de complementaridade ao SUS, tipos de estabelecimentos, disponibilidade de leitos hospitalares para o SUS, níveis de complexidade 
assistencial, taxas de oferta por estados brasileiros, disponibilização de atividades de ensino e caracterização de vínculos empregatícios de servidores.

Em geral, houve um crescimento de 10,6\% de estabelecimentos no período. A taxa também foi positiva para cada um dos segmentos separadamente, embora o incremento não tenha sido o mesmo para todos os tipos de estabelecimentos. Quatro segmentos apresentaram taxas médias de incremento anual superior à média total: o estatal de administração indireta e direito privado (19\%); o público não estatal de direito privado (17,2\%); o estatal de administração indireta e direito público (16,6\%); e o privado com fins lucrativos (14,9\%). Por outro lado, apresentaram crescimento abaixo da média os segmentos estatal de administração direta do setor Saúde (4,5\%), estatal de administração direta de outros órgãos da administração pública $(5,4 \%)$ e privado sem fins lucrativos $(7,4 \%)$. A tendência, portanto, indica a diminuição do peso proporcional de segmentos institucionais de gestão em saúde sob a égide do direito público, e crescimento daqueles sob a égide do direito privado.

Com base no estudo, os autores sugerem três prováveis cenários para a gestão do sistema de saúde brasileiro: o pluralismo empresariado sob a égide do direito privado (tendência inercial de agenciamento contratual com regulação produtiva); o pluralismo integrado na perspectiva do direito público (tendência de inovação institucional focada na universalidade integral e equidade redistributiva); e o pluralismo mercantil sob a ótica do direito privado (tendência à privatização subvencionada pelo poder público e regulação agenciada).

Em cada cenário apontam-se as diferenças e repercussões do modelo de gestão para a estrutura segmentar (natureza estatal, pública ou privada), as formas de organização da atenção (níveis de complexidade preponderantes, mecanismos de integração entre serviços), a preponderância administrativa e jurídica dos prestadores, a relação com o SUS (próprio, suplementar ou complementar), o tipo de financiamento público predominante (direto ou por meio de subsídios), os vínculos empregatícios e as características da força de trabalho e a governança prevalente.

Para cada um deles também se verificam as capacidades de regulação estatal e controle público, elemento fundamental para a definição das tendências que orientarão o futuro do modelo de gestão da saúde no Brasil.

Nos dois últimos capítulos do livro examinam-se a dinâmica da oferta e formação de algumas das profissões da saúde. Por meio de estudos baseados em evidências, demonstra-se que a possibilidade de superação da dramática situação de saúde de uma parcela significativa da população mundial está associada à disponibilidade de uma relação mínima de força de trabalho em saúde por número de habitantes (OMS, 2007).

No Brasil, estudos do índice de escassez de médicos no país vêm induzindo políticas públicas de alocação de profissionais para superação das desigualdades na distribuição regional e microrregional. Estima-se que em torno de 7\% dos municípios brasileiros não contam com médicos residindo em seus limites, e em torno de 25\% contam com a razão de um médico para mais de 3.000 habitantes. Do ponto de vista regional, observa-se que as regiões Norte e Nordeste - com $8 \%$ e $28 \%$ da população do país - concentravam no mesmo período 4,3\% e 18,2\% dos médicos, respectivamente; ao passo que o Sudeste - com 42\% da população - concentrava 60\% dos médicos (Campos, Machado \& Girardi, 2009). 
Contudo, ações mais coordenadas entre a organização dos sistemas de saúde e as instituições de ensino superior necessitam ser implementadas para prover serviços com profissionais qualificados e em quantidade suficiente atendendo a diversidade e superando as graves desigualdades do país em relação aos indicadores de saúde. Ressalte-se ainda que não se operam serviços com uma única categoria profissional, mas ao contrário, verifica-se a exigência de um número cada vez maior de profissões para atender a complexidade do trabalho em saúde ditada pelas transformações tecnológicas e imposições do mundo contemporâneo.

Nos dois últimos capítulos investigam-se os temas relacionados à estrutura atual e à capacidade de formação da força de trabalho em saúde com o objetivo de contribuir para a prospecção estratégica de recursos humanos para atender ao sistema de saúde no Brasil. Exploram também alguns cenários nos quais os estoques futuros de profissionais são adequados de acordo com alterações nos escopos de prática.

O Conselho Nacional de Saúde (Brasil, 1998) regulamentou 14 profissões de nível superior. De 1990 a 2014, 43 categorias ocupacionais de nível médio e elementar da área da saúde foram regulamentadas pelo Ministério da Educação. Esse é o conjunto de trabalhadores que são colocados no mercado de trabalho para a produção do setor.

Em uma primeira parte, a análise dos principais aspectos históricos e conceituais das mudanças e necessidades de qualificação técnica, conhecimento especializado e oferta de formação das profissões da saúde de nível superior tem o objetivo de delinear os condicionantes, a situação atual e os cenários possíveis e prováveis das categorias de médicos, enfermeiros, farmacêuticos, dentistas e fisioterapeutas.

No quinto capítulo, "Estrutura atual e estimativas futuras da força de trabalho em medicina, enfermagem e odontologia no Brasil - 2000 a 2030", de autoria de Sabado Nicolau Girardi, Lucas Wan Der Maas, Cristiana Leite Carvalho e Celia Regina Pierantoni, o cenário prospectivo do estoque de médicos, enfermeiros e cirurgiões-dentistas foi definido utilizando uma adequação da metodologia de projeções de população conhecida como "método das componentes demográficas".

Os autores constroem cenários que resultam, para 2030, em estoques oscilando entre 543,3 e 664,7 mil profissionais médicos para o Brasil. No caso do cenário tendencial, esperar-se-ia que a atual razão de médicos por habitantes, de 1,69 médicos por cada mil habitantes em 2010, passe para 2,75 em 2030. A razão ficaria em 2,42 no cenário de crescimento zero do número de vagas; em 2,96 no cenário do Programa Mais Médicos. A composição por idade obtida no cenário tendencial indica que a atual diferença por sexo propende a cair, visto que, atualmente, o número de vestibulandos e estudantes segundo sexo tende a ser igual, com ligeira tendência de aumento entre as mulheres.

Para a enfermagem, esses cenários resultam, para 2030, em estoques flutuando de 1,499 a 2,037 milhões de enfermeiros para o Brasil. No caso do cenário tendencial, esperar-se-ia que a atual razão, de 1,59 enfermeiros por cada mil habitantes em 2010, atinja 6,68 em 2030. No cenário de crescimento zero do número de vagas a razão ficaria em torno de 7,54 e, no cenário regulatório, 9,07.

Para os cirurgiões-dentistas, de acordo com os cenários, estabelecem-se, para 2030, estoques variando entre 458,4 e 566,1 mil cirurgiões-dentistas para Brasil. No caso do cenário tendencial, 
esperar-se-ia que a atual razão entre profissionais e população, de 1,11 profissionais por cada mil habitantes em 2010, evolua para 2,25 em 2030. A razão ficaria em torno de 2,04 no cenário de crescimento zero do número de vagas e 2,52 no cenário de universalização da Política Nacional de Saúde Bucal.

No sexto capítulo, "Projeção das capacidades de formação de profissionais da saúde", de autoria de Mario Roberto Dal Poz, Thereza Christina Varella e Maria Ruth dos Santos, os autores analisam a formação das profissões da saúde, considerando-se os possíveis cenários e tendências para as próximas décadas.

No panorama da educação superior no Brasil se destaca o crescimento expressivo do ensino universitário a partir da última década do século XX, em sintonia com as mudanças introduzidas pelas Diretrizes Curriculares Nacionais. Na sequência, é traçado um paralelo entre a formação superior em saúde e a organização e funcionamento do sistema de saúde no país, com a apresentação da situação e da evolução da formação das profissões da saúde ressaltando as principais tendências quantitativas observadas desde 2000.

Observaram-se, na situação da formação superior das profissões da saúde no período de 2000 a 2012, algumas tendências gerais que permearam a maioria dos cursos da saúde (Brasil, 2014). Em primeiro lugar, tem-se uma concentração regional no Sudeste de todos os cursos da área e um expressivo crescimento dos cursos fortemente pautado pela presença de instituições privadas que detêm em média $72 \%$ do total dessa oferta. Essa mesma tendência é observada para o número de vagas, ingressantes e concluintes. Verifica-se também ao longo da década uma diminuição na taxa de ocupação das vagas, em especial no setor privado, a partir dos anos 2004 e 2005, exceção para o curso de medicina. A taxa de eficiência terminal dos cursos é baixa e vem decrescendo no período, o que pode ser atribuído ao aumento da evasão.

O Exame Nacional de Desempenho dos Estudantes (Enade) para os cursos da saúde apresenta resultados pífios para a maioria dos cursos das instituições de ensino de natureza privada e, considerando esse método de avaliação, os cursos das instituições públicas em geral se distinguem com melhores resultados.

Em razão dos diversos fatores analisados, incluindo a lei n. 12.871/2013, que institui o Programa Mais Médicos (Brasil, 2013), a expectativa é a de que o número de concluintes em medicina aumente progressivamente nas próximas duas décadas. No caso da enfermagem, há uma tendência à redução do número de vagas no setor privado, o que leva à hipótese mais provável de tendência à estabilidade, no curto e médio prazo, e a uma redução do número de concluintes de pelo menos 1\% ao ano na projeção para 2030. Para a área de odontologia há indicações de que continuará crescendo no mesmo ritmo do crescimento demográfico. O aumento em resposta à expansão acelerada do mercado de trabalho da área de farmácia deve manter-se inalterado ainda nos próximos 15 anos. No entanto, o número de concluintes de fisioterapia deve retomar o crescimento, provavelmente associado à evolução demográfica.

A tendência que se configura é de uma acentuada divisão entre poucas instituições de excelência acadêmica e tecnológica, situadas nos centros urbanos do eixo Sul e Sudeste e um grande número 
de instituições com dificuldade para atender aos padrões mínimos de exigência de qualificação para o ensino e incapazes de realizar pesquisa e extensão. Em tal cenário, se forem levados a termo os processos regulatórios baseados nos mecanismos avaliativos das instituições de ensino superior, o resultado pode ser uma reconfiguração da área, com fechamento de instituições ou novos arranjos institucionais por conglomerados e consórcios para atender às pressões do mercado.

No contexto em que se encontram as políticas públicas de saúde e de educação, a formação dos profissionais da saúde se afigura como uma das estratégias centrais para consolidar e defender os interesses da sociedade que realmente atendam às necessidades de saúde colocadas pela população usuária do SUS. Além disso, aumentam as exigências para que as instituições de ensino superior rompam com o modelo de ensino fragmentado, medicalizado, individualizado e com ênfase tecnicista, e se orientem para projetos de ensino voltados para a satisfação das necessidades sociais de saúde do país.

Em síntese, o livro oferece um conjunto diversificado de informações, todas de suma relevância para o planejamento nacional em saúde. Esperamos que ele possa contribuir para o debate acerca das mudanças, tendências e desafios para as políticas de saúde nas próximas décadas e para a proposição de alternativas que busquem o fortalecimento do sistema público de saúde no Brasil.

Os organizadores

\section{Referências}

ARAUJO, T. B. Tendências do desenvolvimento regional recente no Brasil. In: BRANDÃO, C. \& SIQUEIRA, H. (Orgs.). Pacto Federativo, Integração Nacional e Desenvolvimento Regional. São Paulo: Editora Fundação Perseu Abramo, 2013.

BALBIM, R. \& CONTEL, F. Região e regionalização: subsídios teóricos para o ordenamento territorial e o desenvolvimento brasileiro. In: BOUERI, R. \& COSTA, M. A. (Eds.). Brasil em Desenvolvimento 2013: estado, planejamento e políticas públicas. Brasília: Ipea, 2013.

BARRETO, M. L. Esboços para um cenário das condições de saúde da população brasileira 2022/2030. In: GADELHA, P.; CARVALHO, J. N. \& PEREIRA, T. R. A Saúde no Brasil em 2030: diretrizes para a prospeç̧ão estratégica do sistema de saúde brasileiro. Rio de Janeiro: Fiocruz, Ipea, Ministério da Saúde, Secretaria de Assuntos Estratégicos da Presidência da República, 2013.

BRANDÃO, C. Território \& Desenvolvimento: as múltiplas escalas entre o local e o global. São Paulo: Editora Unicamp, 2007.

BRASIL. Lei n. 8080, de 19 set. 1990. Dispõe sobre as condições para a promoção, proteção e recuperação da saúde, a organização e o funcionamento dos serviços correspondentes e dá outras providências. Lei Orgânica da Saúde. Brasília, Diário Oficial da União, 20 set. 1990.

BRASIL. Conselho Nacional de Saúde. Resolução n. 287/98, de 8 out. 1998. Disponível em: < http://conselho. saude.gov.br/resolucoes/1998/Reso287.doc>. Acesso em: 26 set. 2014.

BRASIL. Decreto n. 7.508, de 28 jun. 2011. Regulamenta a Lei n. 8.080, de 19 set. 1990, para dispor sobre a organização do Sistema Único de Saúde - SUS, o planejamento da saúde, a assistência à saúde e a articulação interfederativa, e dá outras providências. Brasília, Diário Oficial da União, 2011. 
BRASIL. Lei n. 12.871 de 22 out. 2013. Institui o Programa Mais Médicos, altera as Leis n. 8.745, de 9 dez. 1993, e n. 6.932, de 7 jul. 1981, e dá outras providências. Disponível em <www.planalto.gov.br/ccivil_03/_ato20112014/2013/Lei/L12871.htm > . Acesso em: 26 set. 2014.

BRASIL. Ministério da Educação. Instituto Nacional de Estudos e Pesquisas Educacionais Anísio Teixeira. Censos da Educação Superior, 2000-2012. Disponível em<http://portal.inep.gov.br/web/guest/censo-da-educacaosuperior>. Acesso em: 26 set. 2014.

CAMPOS, F. E.; MACHADO, M. H. \& GIRARDI, S. N. A fixação de profissionais de saúde em regiões de necessidades. Revista Divulgação em Saúde para Debate, 44: 13-24, 2009.

DUARTE, L. S.; CONTEL, F. B. \& BALBIM, R. Regionalização da saúde e ordenamento territorial: análises exploratórias de convergências. In: BOUERI, R. \& COSTA, M. A. (Eds.). Brasil em Desenvolvimento 2013: estado, planejamento e políticas públicas. Brasília: Ipea, 2013.

GADELHA, C. A. G. et al. Saúde e territorialização na perspectiva do desenvolvimento. Ciência e Saúde Coletiva, 16(6): 3.003-3.016, 2011.

HABEGGER, B. Strategic foresight in public policy: reviewing the experiences of the UK, Singapore, and the Netherlands. Futures, 42(1): 49-58, 2010.

INSTITUTO BRASILEIRO DE GEOGRAFIA E ESTATÍSTICA (IBGE). Regiões de Influência nas Cidades 2007. Rio de Janeiro: IBGE, 2008.

KUSCHNIR, R. \& CHORNY, A. H. Redes de atenção à saúde: contextualizando o debate. Ciência e Saúde Coletiva, 15(5): 2.307-2.316, 2010.

LUNA, E. J. A. \& SILVA JR., J. B. Doenças transmissíveis, endemias, epidemias e pandemias. In: GADELHA, P; CARVALHO, J. N. \& PEREIRA, T. R. A Saúde no Brasil em 2030: diretrizes para a prospecção estratégica do sistema de saúde brasileiro. Rio de Janeiro: Fiocruz, Ipea, Ministério da Saúde, Secretaria de Assuntos Estratégicos da Presidência da República, 2013.

OLIVEIRA, A. T. R. \& ONEILL, M. M. V. C. Cenário sociodemográfico em 2022/2030 e distribuição territorial da população: uso e ocupação do solo. In: GADELHA, P.; CARVALHO, J. N. \& PEREIRA, T. R. A Saúde no Brasil em 2030: diretrizes para a prospecção estratégica do sistema de saúde brasileiro. Rio de Janeiro: Fiocruz, Ipea, Ministério da Saúde, Secretaria de Assuntos Estratégicos da Presidência da República, 2013.

OLIVEIRA, A. T. R. \& ONEILL, M. M. V. C. Dinâmica demográfica e distribuição espacial da população: acesso aos serviços de saúde. In: NORONHA, J. C.; DAIN, S. \& PEREIRA, T. R. (Orgs.). Brasil Saúde Amanhã: população, economia e gestão. Rio de Janeiro: Editora Fiocruz, 2016.

ORGANIZAÇÃO MUNDIAL DA SAÚDE (OMS). Trabalhando Juntos pela Saúde: relatório mundial de saúde 2006. Brasília: Ministério da Saúde, 2007. (Série B. Textos Básicos de Saúde)

RIBEIRO, A. C. T. Regionalização: fato e ferramenta. In: LIMONAD, E.; HAESBAERT, R. \& MOREIRA, R. Brasil, Século XXI: por uma nova regionalização? Agentes, processos e escalas. São Paulo: Max Limonad, 2004.

VIANA, A. L. \& LIMA, L. D. Regionalização e Relações Federativas na Política de Saúde do Brasil. Rio de Janeiro: Contracapa, 2011. 


\section{CENÁRIO EPIDEMIOLÓGICO DO BRASIL EM 2033: UMA PROSPECÇÃO SOBRE AS PRÓXIMAS DUAS DÉCADAS}

Jarbas Barbosa da Silva Jr.

Walter Massa Ramalho

O Brasil tem experimentado rápidas e profundas transformações no seu perfil demográfico, socioeconômico e epidemiológico nas décadas recentes. Algumas dessas mudanças, como o maior intercâmbio de pessoas e produtos com consequente incremento no compartilhamento de riscos relacionados com surtos de doenças transmissíveis, integram processos que se observam em escala global. Outras, como a urbanização acelerada sem a infraestrutura adequada e o rápido envelhecimento da população, estão mais relacionadas com características de países de desenvolvimento recente que experimentaram processos sociais e econômicos semelhantes aos que têm ocorrido em nosso país. O resultado é um cenário complexo em que se observa uma superposição de problemas de saúde com distintos determinantes, formas de expressão e impactos sobre a saúde pública.

Esse quadro continuará a se desenvolver nas próximas duas décadas, com os grandes grupos de problemas de saúde que atualmente se superpõem no nosso perfil epidemiológico - as doenças transmissíveis, as doenças crônicas não transmissíveis e os acidentes e violências - evoluindo em ritmos diversos, uma vez que podem ser influenciados diferentemente tanto pelas alterações que serão produzidas nos seus determinantes como pelas inovações tecnológicas e novas estratégias que poderão ser introduzidas na sua resposta.

A evolução do cenário epidemiológico, diferentemente do demográfico que é mais previsível, pode apresentar variações importantes ao longo de um período de tempo como duas décadas, seja para as doenças transmissíveis (DT), as doenças crônicas não transmissíveis (DCNT) ou para os acidentes e violências. A emergência de uma doença transmissível que se dissemine rapidamente pode alterar de maneira importante o perfil de morbimortalidade, como ocorreu com a Aids, que só passou a ser conhecida no início da década de 1980 e, atualmente, figura em sexto lugar entre as dez causas de morte mais importantes no mundo, respondendo por 1,6 milhão de mortes, concentradas principalmente entre países de baixa renda, onde ocupa o segundo lugar (WHO, 2014d).

A introdução de novos testes diagnósticos, vacinas ou tratamentos, assim como o desenvolvimento de estratégias que utilizem de forma mais efetiva os recursos já disponíveis também podem produzir alterações importantes na morbimortalidade causada por doenças transmissíveis. Esse tipo de mudança, ainda que em ritmo mais lento, também pode ocorrer entre as doenças crônicas não transmissíveis, impulsionada pela redução na prevalência de fatores de risco importantes para o câncer e as doenças cardiovasculares, como o tabagismo, ou ainda pela ampliação do acesso ao 
diagnóstico precoce e tratamento para alguns tipos ainda muito prevalentes de câncer, como o de colo do útero, de mama e de cólon.

Como exemplo do impacto que pode ser produzido por ações apenas no interior do setor Saúde, estimava-se que o uso apropriado de exames de triagem (screening) poderia reduzir a taxa de mortalidade por câncer colorretal de 30 a 80\% entre adultos com mais de 50 anos, de 25 a $30 \%$ na mortalidade de câncer de mama entre mulheres com mais de 50 anos e de 20 a $60 \%$ na mortalidade de câncer de colo do útero entre mulheres com mais de 18 anos (Curry, Byers \& Hewitt, 2003).

As causas externas, que compreendem os acidentes e as violências, também podem apresentar mudanças profundas de tendências e características num espaço de tempo como duas décadas. Para exemplificar, em menos de uma década, entre 2002 e 2011, as motocicletas aumentaram sua participação na frota nacional de veículos, de $16,3 \%$ para $26,1 \%$, um ritmo muito maior que o crescimento das frotas de todos os outros tipos de veículos, o que tem produzido alterações na tendência da mortalidade e das hospitalizações decorrentes de acidentes de transporte terrestre (ATT) (Brasil, 2013a).

Neste capítulo se realiza um estudo exploratório sobre as mudanças no perfil epidemiológico que provavelmente ocorrerão nos próximos vinte anos no país, buscando delinear o cenário de morbimortalidade com maior probabilidade de estar vigente em 2033 e suas implicações para o Sistema Único de Saúde (SUS). Também serão discutidas as estratégias e ações requeridas ao SUS ao longo desse período para maximizar os condicionantes e determinantes que impulsionam a melhoria no nível de saúde da população e eliminar, ou atenuar, aqueles que operam no sentido de agravá-lo.

\section{Métodos}

Os dados sobre morbidade e mortalidade utilizados neste capítulo foram retirados, respectivamente, do Sistema de Informação de Agravos de Notificação (Sinan) e do Sistema de Informações sobre Mortalidade (SIM), sistemas oficiais do Ministério da Saúde.

Os dados populacionais utilizados foram obtidos da projeção realizada pelo Instituto Brasileiro de Geografia e Estatística (IBGE) para os anos de 2000 a 2033 para o Brasil (IBGE, 2008). A população anual para as regiões, entre os anos de 2030 e 2033, foi projetada utilizando-se a função auto.arima, ao passo que a função spline presente na biblioteca tseries (Trapletti \& Hornik, 2013), também do pacote estatístico R, foi utilizada para a interpolação anual da população censitária dos anos 1980, 1990 e 2000.

Os modelos preditivos foram construídos com base nos métodos Arima (sigla em inglês para autoregressive integrated moving average), por meio da função auto.arima, nos casos de valores absolutos; e exponencial, através da função ETS, para os valores de taxas. Ambas as funções estão presentes na biblioteca Forecast desenvolvida por Hyndman (2010) e implementada no pacote estatístico R (Core Team, 2013).

Os indicadores de mortalidade foram construídos com base nos dados do SIM, excluindo-se os registros nulos para sexo, idade ou município de residência. Indicadores de Mortalidade Proporcional foram construídos segundo projeções de óbitos por capítulos da Classificação Internacional de Doenças, 10ª revisão (CID-10), compatibilizada com a classificação presente na $9^{\mathrm{a}}$ revisão (CID-9). 
Coeficientes de mortalidade foram construídos com base em dados projetados dos óbitos e da população (2008). Causas específicas de óbitos foram agrupadas segundo classificação adotada pela Organização Mundial da Saúde (OMS) no projeto Carga Global de Doenças (CGD) (WHO, 2013a), para a CID-10, contando com uma série observada para o período de 1996 a 2011. Para outras análises de mortalidade por grupos de causa, utilizou-se o agrupamento proposto pela Rede Interagencial de Informações para a Saúde (Ripsa) (2008).

Com relação aos dados das taxas de mortalidade infantil (TMI) foram utilizados, para o período de 1993 a 2011, os dados consolidados pela Ripsa, que combinam cálculos diretos valendo-se dos dados de mortalidade originados do SIM e de nascidos vivos do Sistema de Informações sobre Nascidos Vivos (Sinasc) para as unidades federadas que têm esses dois sistemas com padrões adequados de cobertura e qualidade, e por cálculos indiretos, resultantes de estimativas para as unidades federadas que "apresentam cobertura do Sinasc inferior a 90\% ou que não atingem o valor de $80 \%$ de um índice composto, especialmente criado, que combina a cobertura de óbitos infantis com a regularidade do SIM" (Ripsa, 2000).

No Gráfico 1, encontra-se a representação do crescimento da população para o período 1980 até 2033, de acordo com os registros e as estimativas do IBGE dos óbitos registrados no SIM para o período de 1980 até 2011, e dos projetados para o período 2012 a 2033, com a visualização da projeção média e sua faixa de variação mínima e máxima, de acordo com o modelo utilizado.

Gráfico 1 - População, óbitos e modelo de projeção adotado no capítulo. Brasil - 1980-2033

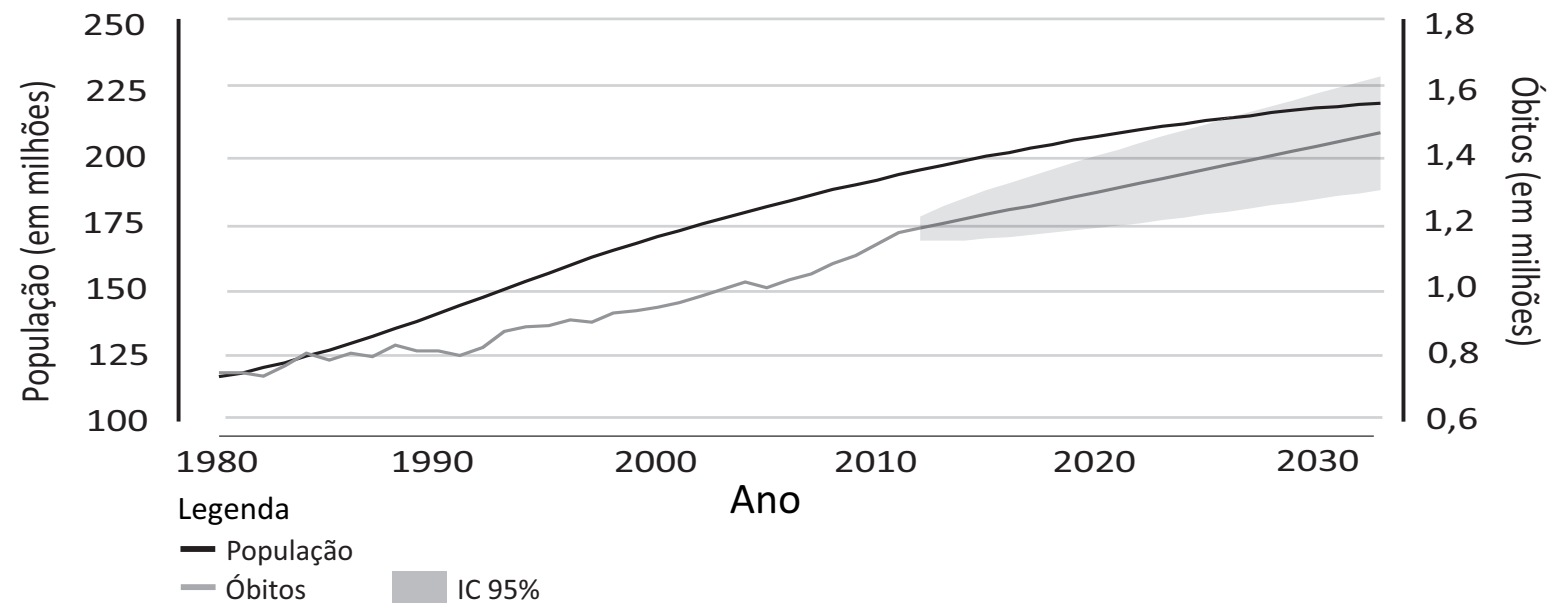

Fonte: elaborado pelos autores com dados do SIM para o período de 1980 a 2011 (Brasil, 2012c) e projeções para o período de 2012 a 2033. Estimativas populacionais construídas pelo IBGE (IBGE, 2008). 


\section{As Mudanças no Perfil de Morbimortalidade dos Brasileiros e os Desafios Futuros}

Por meio da análise da morbimortalidade projetada para o ano 2033, demonstra-se, por um lado, o aprofundamento das tendências que vêm se observando nos anos recentes, no país, com a continuidade do aumento do peso das DCNT e, particularmente, de algumas causas específicas no interior desse grupo; a redução da morbimortalidade relacionada com as doenças transmissíveis, principalmente impulsionada por aquelas para as quais se dispõe de ferramentas eficazes de prevenção e controle; a persistência de características singulares como a importância das mortes decorrentes das agressões; e o aprofundamento da redução da TMI e das desigualdades regionais apresentadas por esse indicador. Esse quadro complexo é apresentado a seguir, buscando analisar as tendências verificadas até o momento, os contextos em que elas estão ocorrendo, os determinantes que as influenciam, as diferenças regionais encontradas e as projeções para os próximos vinte anos.

\section{Mudanças no perfil das causas de mortalidade dos brasileiros}

A evolução da mortalidade proporcional dos grandes grupos de causas de óbitos para o período 1980 a 2033 sintetiza bem algumas das principais características do perfil de mortes nas décadas recentes e das modificações que deverão ocorrer. Como se trata de mortalidade proporcional, devese levar em conta, na interpretação dos dados, que as variações experimentadas por cada grupo de causa dependem não apenas do seu próprio comportamento ao longo do período, mas também do que acontece com os demais grupos. O aumento da mortalidade proporcional verificado para um determinado grupo de causa pode ser decorrente do aumento efetivo do número de mortes em relação ao total de óbitos, ou pelo fato desse grupo ter apresentado uma redução na sua taxa de mortalidade em velocidade menor que a de outros grupos, ao longo do período.

Em 2011, a mortalidade por DCNT já representa cerca de 70\% da mortalidade total do país, em consonância com o que ocorre atualmente nos países desenvolvidos e nos países do estrato elevado entre aqueles com renda média. Entretanto, apesar de nos últimos anos observar-se uma redução de cerca de $2 \%$ ao ano na mortalidade precoce em menores de 70 anos, por DCNT, ainda persiste uma proporção relativamente elevada dessa mortalidade, relacionada, em grande parte, com o diagnóstico e tratamento tardios para alguns tipos ainda muito frequentes de câncer e/ou manejo clínico e controle inadequados de condições como a diabetes e a hipertensão.

Analisando-se as modificações ocorridas para a mortalidade proporcional dos grandes grupos de causa ao longo do período, verifica-se que as doenças do aparelho circulatório (DAC) permanecem com o maior peso relativo durante todo o período, apesar de sofrerem uma redução em 2033, que proporcionará menor valor quando comparado com o de 1980. As neoplasias, que em 1980 ocupavam a terceira posição, respondendo por $10,5 \%$ do total de mortes, experimentarão um crescimento importante até 2033, ao atingir um percentual de 19,8\%, ultrapassando as causas externas, que, com $12,6 \%$, passarão a ocupar a terceira posição. As afecções perinatais constituem-se no grupo de causas com a maior redução, diminuindo sua participação relativa no conjunto dos óbitos de 9,3\%, em 1980, 
para 0,4\%, em 2033. As doenças infecciosas e parasitárias (DIP), que em 1980 ainda representavam 11,6\% do total das mortes do país, em 2033 serão responsáveis por apenas 3,8\% (Gráfico 2).

Gráfico 2 - Mortalidade proporcional por grupos de causa (Capítulos da CID), estratificado segundo os 10 grupos de maior peso para o ano de 2011. Brasil - 1980-2033

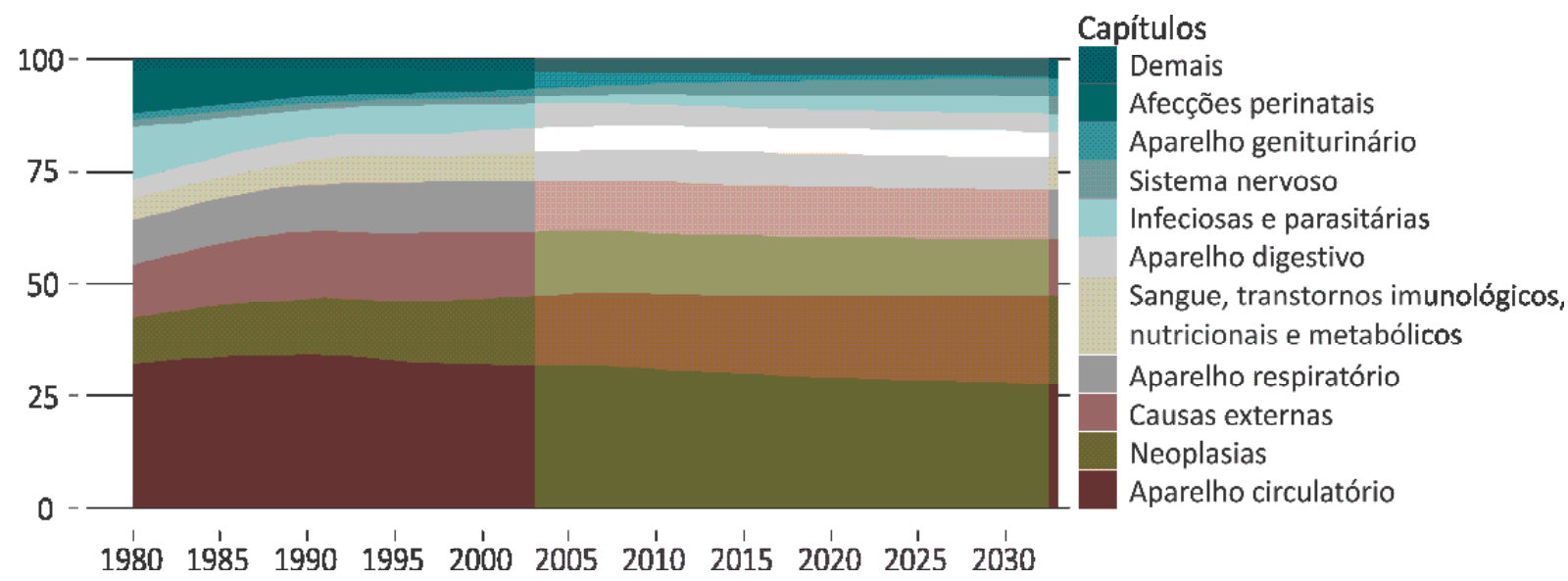

Fonte: elaborado pelos autores com dados do SIM para o período de 1980 a 2011 (Brasil, 2012c) e projeções para o período de 2012 a 2033. Estimativas populacionais construídas pelo IBGE (IBGE, 2008).

O comportamento da taxa de mortalidade padronizada por grupos de causa, ${ }^{1}$ indicador que mede o risco de se morrer por cada grupo, apresenta tendências similares. Observa-se uma redução projetada de 58,7\% na taxa de mortalidade pelas DAC que, ao variar de 273,9 para 113,1 por 100.000 habitantes, entre 1980 e 2033, reduz a diferença no início do período, em relação aos valores exibidos pelos grupos que ocupam a segunda e a terceira posição. Essa tendência é coerente com o já observado para a taxa de mortalidade por DAC nos anos recentes e demonstra que a combinação da redução de fatores de risco, a incorporação de protocolos mais adequados para o manejo clínico de algumas condições e a possibilidade de introdução de novas tecnologias podem reduzir o risco de morrer por várias condições relacionadas com as doenças crônicas não transmissíveis.

As neoplasias terão um aumento de 6,5\% em sua taxa de mortalidade, crescendo dos 79,9 por 100.000 habitantes, em 1980, para os 85,4 por 100.000 habitantes, em 2033. Apesar desse incremento, as neoplasias perderão o posto de segunda maior taxa de mortalidade para as causas externas (CE), em 2033, com um incremento de 40,6\%, passando dos 66,1 de 1980 para 92,9 por 100.000 habitantes. As afecções perinatais exibirão a maior redução para o período analisado, de 85,9\%, caindo de 24,8 para 3,5 por 100.000 habitantes (Gráfico 3).

\footnotetext{
${ }^{1}$ Foram utilizados os seguintes grupos: algumas doenças infecciosas e parasitárias (DIP), neoplasias, doenças do aparelho circulatório (DAC), doenças do aparelho respiratório (DAR), algumas afecções originadas no período perinatal (afecções perinatais), causas externas (CE) e demais causas definidas, de acordo com padronização proposta pela Ripsa (2008).
} 
Gráfico 3 - taxa de Mortalidade Padronizada por 100.000 habitantes para Grupos de Causa selecionados. Brasil - 1980, 1990, 2000, 2010, 2020 e 2033

Aparelho circulatório Neoplasias

Causas externas

Aparelho respiratório

Sangue, tr. imun., nutr. e metab.

Aparelho digestivo

Infeciosas e parasitárias

Sistema nervoso

Aparelho geniturinário

Afecções perinatais

Aparelho circulatório Neoplasias

Causas externas

Aparelho respiratório

Sangue, tr. imun., nutr. e metab.

Aparelho digestivo

Infeciosas e parasitárias Sistema nervoso

Aparelho geniturinário

Afecções perinatais

Aparelho circulatório Neoplasias

Causas externas

Aparelho respiratório

Sangue, tr. imun., nutr. e metab. Aparelho digestivo

Infeciosas e parasitárias

Sistema nervoso

Aparelho geniturinário

Afecções perinatais

Aparelho circulatório Neoplasias

Causas externas

Aparelho respiratório

Sangue, tr. imun., nutr. e metab.

Aparelho digestivo Infeciosas e parasitárias

Sistema nervoso

Aparelho geniturinário

Afecções perinatais

Aparelho circulatório Neoplasias

Causas externas

Aparelho respiratório

Sangue, tr. imun nutr. e metab.

Aparelho digestivo

Infeciosas e parasitárias

Sistema nervoso

Aparelho geniturinário

Afecções perinatais

Aparelho circulatório Neoplasias

Causas externas

Aparelho respiratório

Sangue, tr. imun., nutr. e metab. Aparelho digestivo

Infeciosas e parasitárias Sistema nervoso

Aparelho geniturinário Afecções perinatais

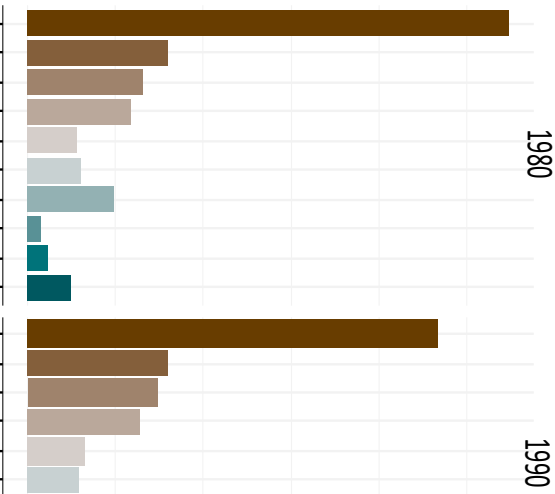

향

용

ㅇㅇㅇ
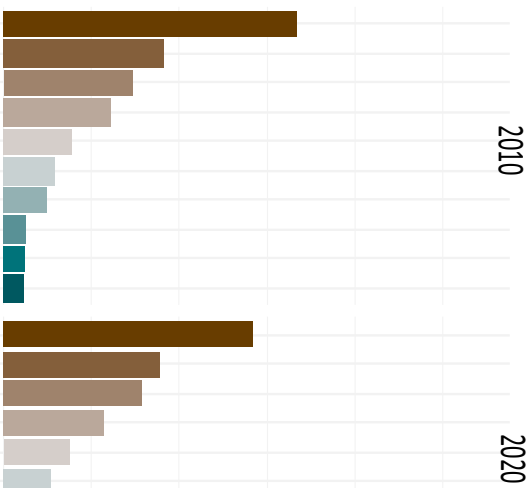

స్요

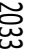

Fonte: elaborado pelos autores com dados do SIM para o período de 1980 a 2011 (Brasil, 2012c) e projeções para o período de 2012 a 2033. Estimativas populacionais construídas pelo IBGE (IBGE, 2008). 
O grupo das DAC, que envolve, entre outras causas de morte, as doenças isquêmicas do coração (DIC) e as doenças cerebrovasculares (DCV), é o que apresenta a maior mortalidade proporcional ao longo de todo o período. As DAC representavam 30,0\% de todas as mortes, no ano de 1980, registrando crescimento contínuo do seu peso relativo até o ano de 1991, quando obteve seu maior percentual em todo o período, de 34,1\%. A partir daí, experimenta uma redução continuada, e estima-se que, em 2033, representará $27,6 \%$ dos óbitos no país, mantendo ainda o posto de grupo com maior peso, ainda que perdendo importância relativa no conjunto das mortes no país, com uma redução de 19\% em relação ao valor registrado em 1991 (Gráfico 2).

Esse comportamento de redução das DAC também fica evidenciado quando se analisa seu comportamento pela taxa de mortalidade padronizada por 100.000 habitantes. A tendência observada é de redução da taxa desde o início do período, com uma forte acentuação a partir de meados dos anos 1980. A taxa que era de 273,9, em 1980, é projetada para 113,1 por 100.000 habitantes, em 2033, indicando uma redução de 58,7\%. Para essa tendência têm contribuído vários fatores, como a introdução de inovações no manejo clínico de algumas condições, ampliação do acesso ao diagnóstico e tratamento e redução do tabagismo, entre outros (Gráfico 4).

Gráfico 4 - Doenças do aparelho circulatório (DAC): taxa de mortalidade padronizada (2011) por 100 mil habitantes. Brasil - 1980-2033

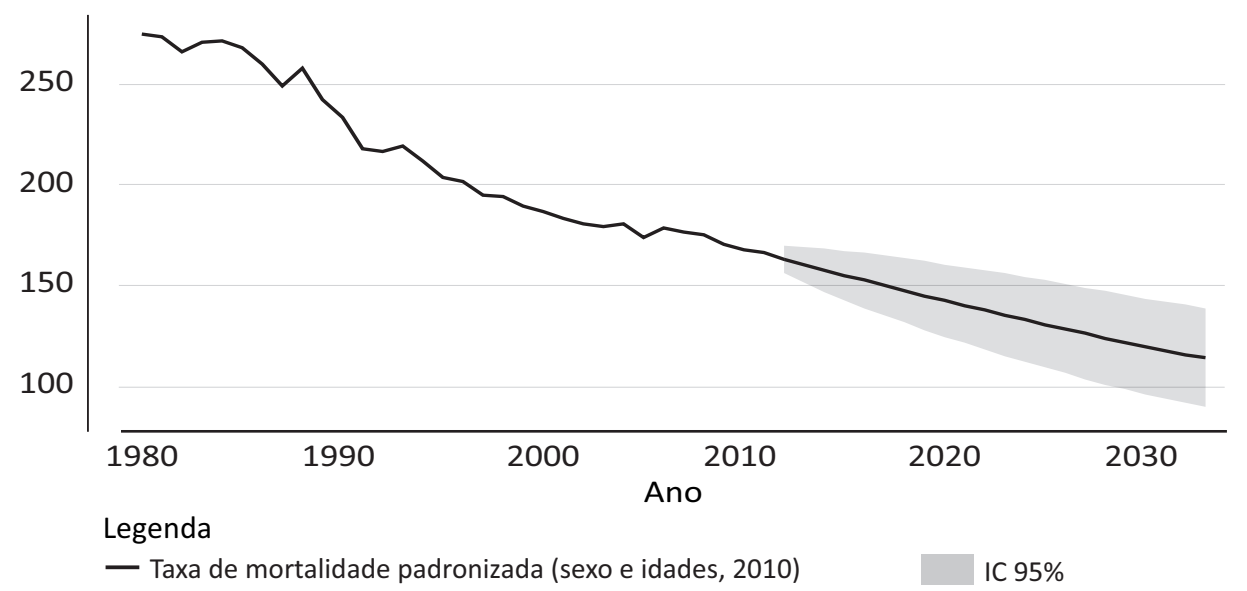

Fonte: elaborado pelos autores com dados do SIM para o período de 1980 a 2011 (Brasil, 2012c) e projeções para o período de 2012 a 2033. Estimativas populacionais construídas pelo IBGE (IBGE, 2008).

O segundo grupo de grandes causas mais importantes, pela mortalidade proporcional, apresentado no Gráfico 5, é o das neoplasias. Esse grupo que, assim como o das DAC, também é bastante influenciado pelo envelhecimento da população, tem seu peso incrementado de maneira consistente ao longo de todo o período, praticamente dobrando sua participação, dos 10,5\% do total de mortes em 1980 para os 19,8\% projetados para o ano de 2033, o maior crescimento previsto para esse período. Assim, os cânceres serão responsáveis por duas de cada dez mortes no país em 2033, sugerindo que também ocorrerá um crescimento importante da incidência das neoplasias, o que projeta uma maior demanda por acesso ao diagnóstico e às distintas modalidades de tratamento, com grande impacto sobre os serviços de saúde. 
Esse comportamento do grupo das neoplasias, um conjunto heterogêneo de condições decorrentes de distintos fatores de risco e uma grande disparidade no que diz respeito à disponibilidade de meios para sua prevenção e redução da letalidade, assim se apresenta porque sua taxa de mortalidade, que registra aumento entre 1980 e o início dos anos 2000, a partir de então passa por uma estabilização e, em seguida, tendência de redução até o fim do período, no ano de 2033. Entretanto, como essa redução no risco de morrer por neoplasias é bem menos acentuada do que aquela verificada para o grupo das DAC, a mortalidade proporcional por neoplasias crescerá durante esse período.

Gráfico 5 - Neoplasias: taxa de mortalidade padronizada (2011) por 100 mil habitantes. Brasil 1980-2033

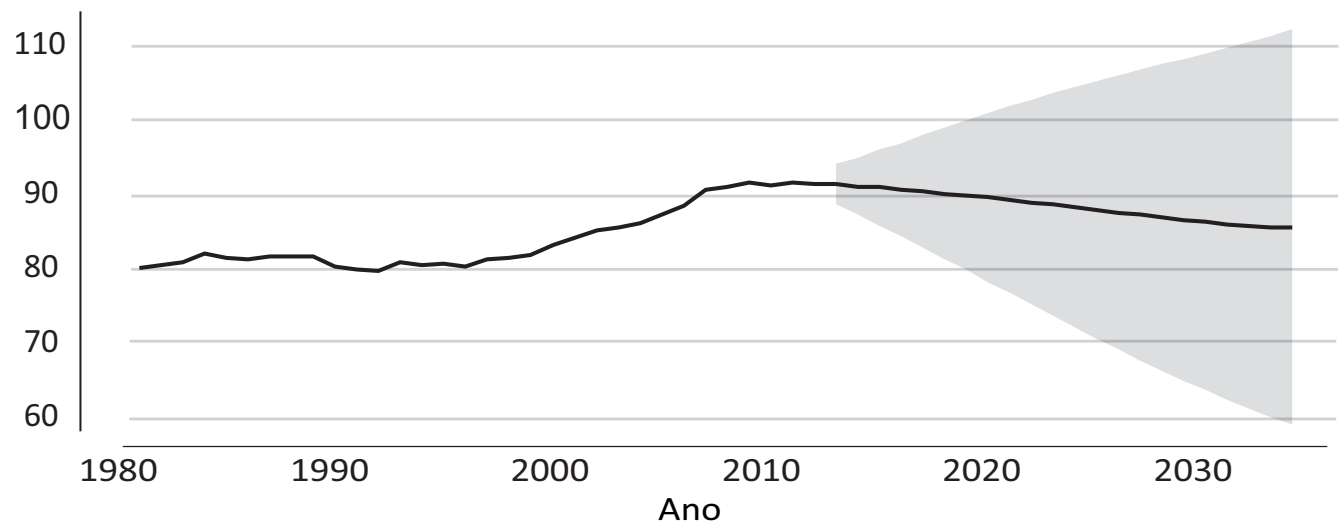

Legenda

— Taxa de mortalidade padronizada (sexo e idades, 2010)

IC $95 \%$

Fonte: elaborado pelos autores com dados do SIM para o período de 1980 a 2011 (Brasil, 2012c) e projeções para o período de 2012 a 2033. Estimativas populacionais construídas pelo IBGE (IBGE, 2008).

As causas externas, grupo que reúne as mortes por acidentes de transporte terrestre e por agressões, entre outras, ocupam a terceira posição entre os grupos com maior mortalidade proporcional, mantendo essa posição durante todo o período de 1980 a 2033 (Gráfico 2). Entre 1980 e 1996, as CE alcançaram expressivo crescimento do seu peso na mortalidade, passando dos $11,8 \%$ para $15,2 \%$ do total de mortes ocorridas no país. Desde 1997, a mortalidade proporcional pelas CE exibe uma discreta, porém progressiva, redução, devendo atingir os 13,1\% em 2033, configurando, ainda assim, importante contribuição para a mortalidade no Brasil.

Para a taxa de mortalidade, entretanto, as CE passarão por um incremento substancial de 40,6\% (Gráfico 6). Essa importância das CE é uma característica singular do perfil de mortalidade do Brasil e chama a atenção para o peso que têm sobre nossa situação de saúde, causas de lesões e mortes cujos determinantes envolvem complexos processos socioeconômicos, como a urbanização acelerada - que produziu grandes áreas na periferia das cidades com limitado acesso às políticas públicas - e a necessidade de ações mais efetivas voltadas para a redução dos ATT e, principalmente, das agressões.

A importância das mortes relacionadas às CE deve também ser considerada pelo fato de sua maior ocorrência recair, principalmente, em jovens do sexo masculino, produzindo relevante impacto 
na redução da expectativa de vida para esse sexo. Ainda mais, considerando-se a mortalidade como um proxy da morbidade por essas mesmas causas, é importante considerar a sobrecarga produzida, e que se ampliará nas próximas duas décadas, pelos ATT e agressões sobre os serviços de saúde. Tal encargo exigirá desde atendimentos de emergência, cirurgias, internações em unidades de terapia intensiva e reabilitação, com altos custos para o sistema de saúde e para as próprias famílias.

Gráfico 6 - Causas externas: taxa de mortalidade padronizada (2011) por 100 mil habitantes. Brasil $-1980-2033$

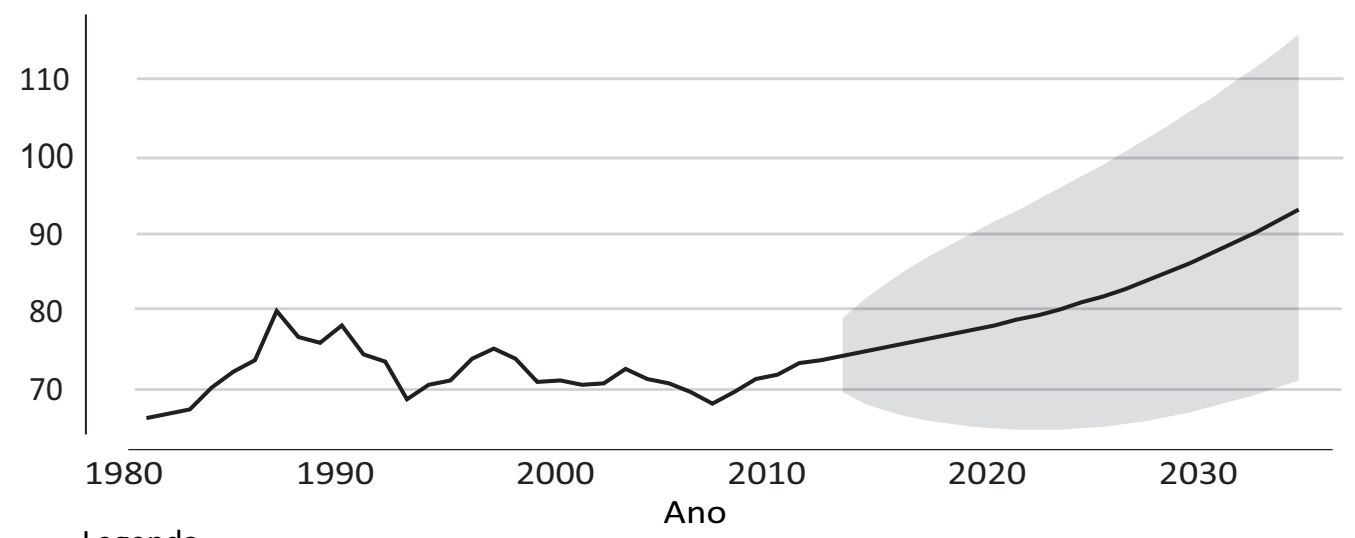

Legenda

- Taxa de mortalidade padronizada (sexo e idades, 2010)

IC $95 \%$

Fonte: elaborado pelos autores com dados do SIM para o período de 1980 a 2011 (Brasil, 2012c) e projeções para o período de 2012 a 2033. Estimativas populacionais construídas pelo IBGE (IBGE, 2008).

Para propiciar uma análise comparativa das principais causas de morte dos brasileiros com perfis internacionais de mortalidade, utilizou-se uma proposta de categorização de causas específicas de morte da OMS (2013a), tomando-se os dados do SIM para o ano de 2011 e as projeções realizadas para o ano de 2033.

O perfil complexo do processo saúde-doença no país se reflete na superposição de causas de morte específicas relacionadas com diferentes condicionantes e determinantes. Entre as dez causas líderes no Brasil para o ano de 2011 prevalecem as DCNT, dentre as quais as doenças isquêmicas e as cerebrovasculares figuram em primeiro e segundo lugares, com valores muito próximos no número de óbitos, sendo responsáveis por, aproximadamente, 116 e 113 mil mortes, no ano de 2011 (Gráfico 7).

Outras cinco DCNT integram a lista, o diabetes mellitus (65 mil óbitos), as doenças hipertensivas (52 mil óbitos), as doenças obstrutivas crônicas (45 mil óbitos), os cânceres de traqueia, brônquios e pulmões (25 mil óbitos) e a cirrose (22 mil óbitos). O único grupo de doenças infecciosas presente entre essas dez primeiras causas é o das infecções respiratórias inferiores, com cerca de 68 mil mortes. As agressões foram responsáveis por 52 mil óbitos e os acidentes de transporte por outros 44 mil, revelando o peso que assumem essas causas, muito relacionadas a condicionantes externos ao setor Saúde (Brasil, 2011). 
Gráfico 7 - Dez principais causas de morte. Brasil - 2011

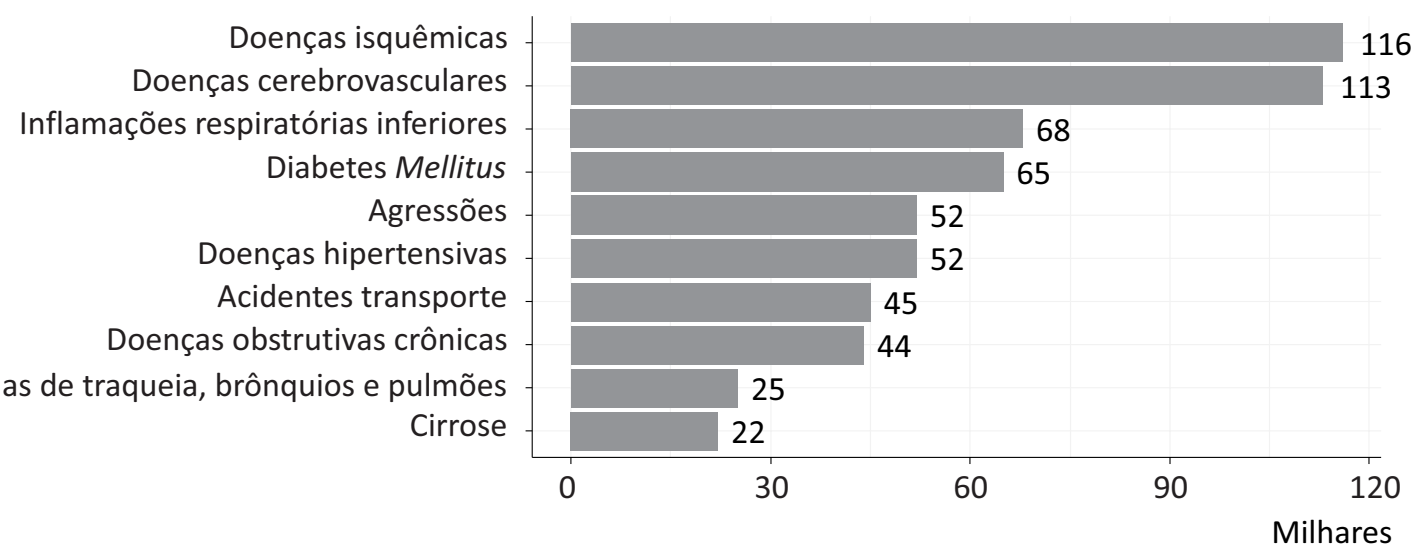

Fonte: elaborado pelos autores com dados do SIM (Brasil, 2012c).

Tal perfil é muito assemelhado ao que é exibido globalmente pelo agregado dos países de renda média/alta. Esse grupo de países tem, praticamente, a mesma lista para as dez principais causas de morte que o Brasil, apresentando apenas pequenas diferenças, como as duas primeiras causas que alternam suas posições entre o primeiro e segundo lugar, o maior peso nos outros países para as mortes por doença obstrutiva crônica e os cânceres de traqueia, brônquios e pulmões que, entre eles, ocupam a terceira e a quarta posição. Entre as duas listas há duas diferenças importantes: a presença, na lista brasileira, das mortes por agressões e por cirrose, ambas ausentes da lista global, que traz, por sua vez, o câncer de estômago e o câncer de fígado entre as dez causas líderes no grupo de países de renda média/alta (WHO, 2013b).

Para analisar as principais causas de morte em 2011 e suas projeções para 2033, tanto para o Brasil, como para cada uma das regiões, foram selecionadas as $14^{2}$ mais importantes causas no primeiro ano do período, medidas pela taxa de mortalidade, de maneira a permitir comparações inter-regionais (Gráfico 8). Nessa análise evidenciam-se as importantes diferenças presentes em 2011 relacionadas com os distintos perfis demográficos, condições socioeconômicas, acesso aos serviços de saúde, prevalência de fatores de risco para DCNT, entre outras dimensões que variam de maneira significativa entre as regiões.

\footnotetext{
${ }^{2}$ Para essa análise foram utilizadas as 14 causas de morte mais importantes, em vez das 10, para permitir melhor visualização das modificações que ocorrem quando se fazem as projeções para o ano de 2033.
} 
Gráfico 8 - Taxa de mortalidade por 100.000 habitantes das 15 principais causas de morte. Brasil e Regiões - 2011 e 2033

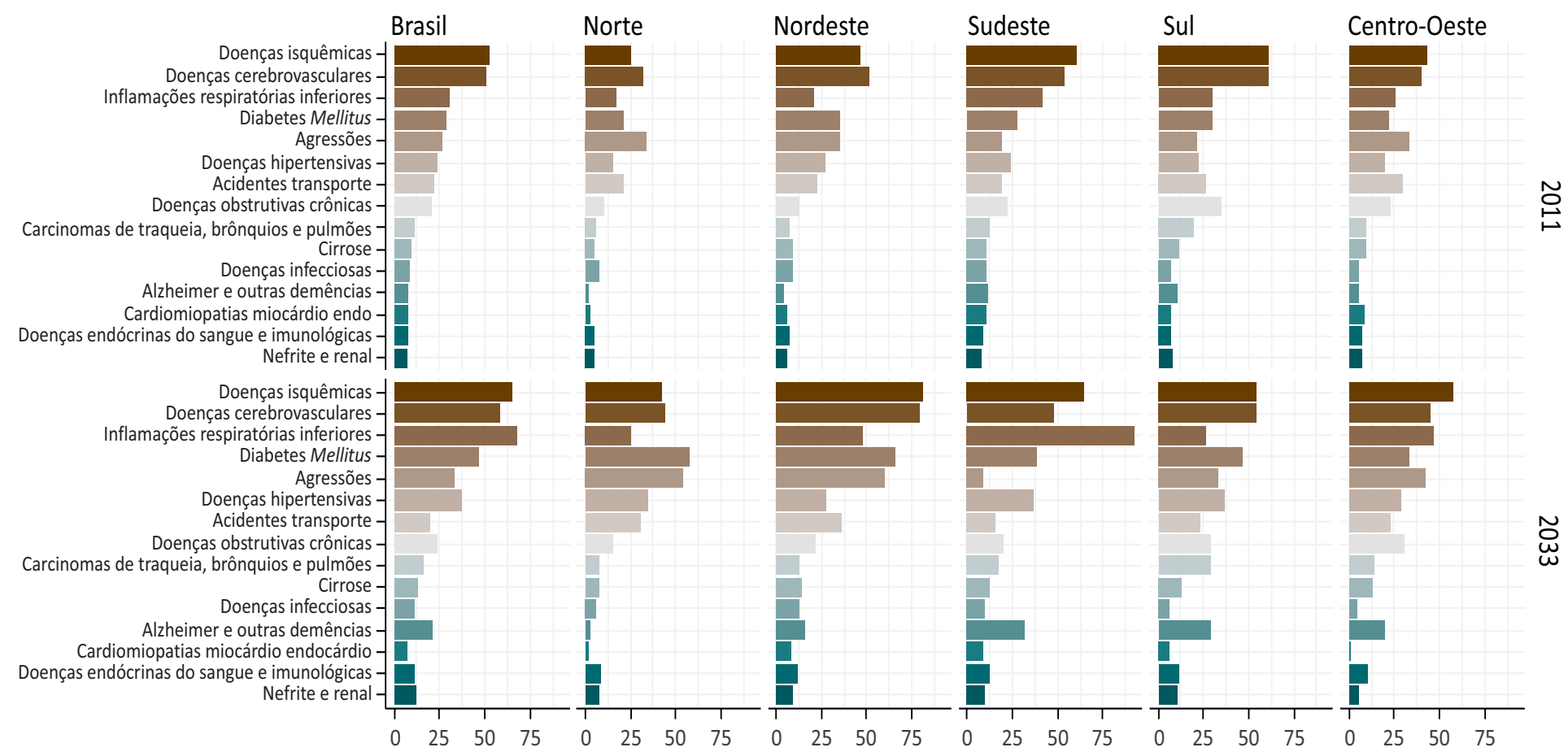

Fonte: elaborado pelos autores com dados do SIM para o período de 1980 a 2011 (Brasil, 2012c) e projeções para o período de 2012 a 2033. Estimativas populacionais construídas pelo IBGE (IBGE, 2008).

Destaca-se a importância das agressões na região Norte, principal causa de morte, com uma taxa de mortalidade de 34,2 por 100.000 habitantes, um pouco acima das doenças isquêmicas (32,4 por 100.000 habitantes), em segundo lugar. A taxa de mortalidade por agressões no Norte é 75,5\% maior que a do Sudeste (19,5 por 100.000 habitantes), que apresenta o menor valor para esse indicador entre todas as regiões. O Norte é a única região em que as mortes pelo grupo das demais doenças infecciosas estão entre as dez primeiras causas, ocupando a nona posição, com taxa de 7,6 por 100.000 habitantes.

Na região Nordeste as doenças isquêmicas, com taxa de 46,6 por 100.000 habitantes, também ocupam o segundo lugar, mas, de modo diverso ao que ocorre no Norte, em primeiro vêm as doenças cerebrovasculares com 51,3 por 100.000 habitantes. As mortes por agressões também estão em posição importante no Nordeste, quarto lugar, praticamente empatadas com a terceira causa, o diabetes mellitus, com taxas de 35,31 e 35,61 por 100.000 habitantes, respectivamente.

Na região Sudeste, as doenças isquêmicas, com taxa de 60,3 por 100.000 habitantes, aparecem na primeira posição, seguidas das doenças cardiovasculares (53,2 por 100.000 habitantes) e as infecções respiratórias inferiores (41,5 por 100.000 habitantes), que, nessa região, apresentam o maior valor para sua taxa de mortalidade. No Sudeste, diferentemente do Norte e Nordeste, com taxas muito reduzidas, de 1,5 e 4,0 por 100.000, respectivamente, as mortes por Alzheimer e outras demências já ocupam a $12^{\mathrm{a}}$ posição, com uma taxa de 11,5 por 100.000 habitantes. 
A doença obstrutiva crônica também se constitui, no Sudeste, em uma importante causa de morte, localizada na sexta posição, com uma taxa de 22,3 por 100.000 habitantes. Na região Sul repetemse algumas das características da região Sudeste, mas ressalta-se o maior peso relativo de algumas causas como a doença obstrutiva crônica, na quinta posição, com uma taxa de 28,7 por 100.000 habitantes, valor muito próximo do apresentado pelas causas localizadas nas terceira e quarta posições, as infecções respiratórias inferiores $(29,8)$ e o diabetes mellitus $(29,7)$.

Ainda no Sul, observa-se a importância da mortalidade pelos cânceres de traqueia, brônquio e pulmões, que apresentam nessa região sua maior taxa em todo o país, com 20 por 100.000 habitantes, refletindo prevalências mais elevadas de tabagismo. Semelhante ao observado no Sudeste, também na região Sul as mortes por Alzheimer e outras demências têm maior peso que nas outras regiões, despontando como a $11^{\text {a }}$ causa, com uma taxa de mortalidade de 10,9 por 100.000 habitantes. Tal circunstância está relacionada com o maior envelhecimento na estrutura etária da população dessas duas regiões, o que chama a atenção para o crescimento da importância dessa causa de morte no futuro próximo em todo o país.

No Centro-Oeste, destacam-se as agressões, padrão semelhante ao encontrado no Norte e no Nordeste, ocupando a terceira posição, com uma taxa de mortalidade de 33,4 por 100.000 habitantes. Os acidentes de transporte vêm em seguida, na quarta posição, com uma taxa de 30,0 por 100.000 habitantes, a mais alta posição e o maior valor da taxa para essa causa entre todas as regiões.

No Brasil, o risco de morrer por acidentes de transporte experimentou crescimento na última década, com taxa de mortalidade aumentando de 19,7 para 22,3 óbitos por 100 mil habitantes, entre os anos de 2002 e 2011 . O crescimento na taxa é bastante influenciado pelo aumento da frota de veículos, que praticamente dobrou de tamanho durante esse período, embora tenha havido uma redução da razão de óbitos por grupo de 10.000 veículos, de 9,2 para 6,1. A redução na razão de óbitos, entretanto, não diminui o impacto causado sobre o sistema de saúde, pois há, de fato, um incremento importante no número de mortes por essa causa, em decorrência de provável aumento também nas lesões relacionadas com os acidentes de transporte.

Algumas causas específicas no interior desse grupo, como a de morte de pedestres, apresentaram redução de $22,2 \%$ nesse período, enquanto as mortes de motociclistas, por sua vez, aumentaram em 166,7\% (Brasil, 2013a). Essa diferença no comportamento entre os distintos grupos de acidentes de transporte evidencia-se quando se analisam as tendências demonstradas no Gráfico 9. No início da série, em 1996, a taxa de mortalidade padronizada de pedestres (8,5 por 100.000 habitantes) era 18 vezes maior que a de motociclistas ( 0,5 por 100.000 habitantes) e três vezes maior que a de ocupantes de veículos (2,8 por 100.000 habitantes). Ao longo do período a distância vai se reduzindo, e, em 2011, já ocorre uma inversão, motociclistas lideravam o grupo de acidentes de transporte, com uma taxa de 5,8 por 100.000 habitantes, superando a de ocupantes (5,6 por 100.000 habitantes) e a de pedestres (4,6 por 100.000 habitantes).

No período projetado até 2033, essas tendências se consolidarão, caso não sejam adotadas políticas públicas para alterá-las. A taxa de mortalidade em motociclistas alcançará um valor de 14,3 por 100.000 habitantes, $36 \%$ maior que a taxa para ocupantes $(9,1$ por 100.000 habitantes). Apenas 
a mortalidade para pedestres projeta uma tendência de redução, alcançando $67,2 \%$ de diminuição entre 2012 e 2033, quando apresentará uma taxa de 2,7 por 100.000 habitantes.

Gráfico 9 - Taxa de mortalidade padronizada por 100.000 habitantes para motociclistas, ocupantes de veículos e pedestres. Brasil -1996-2033

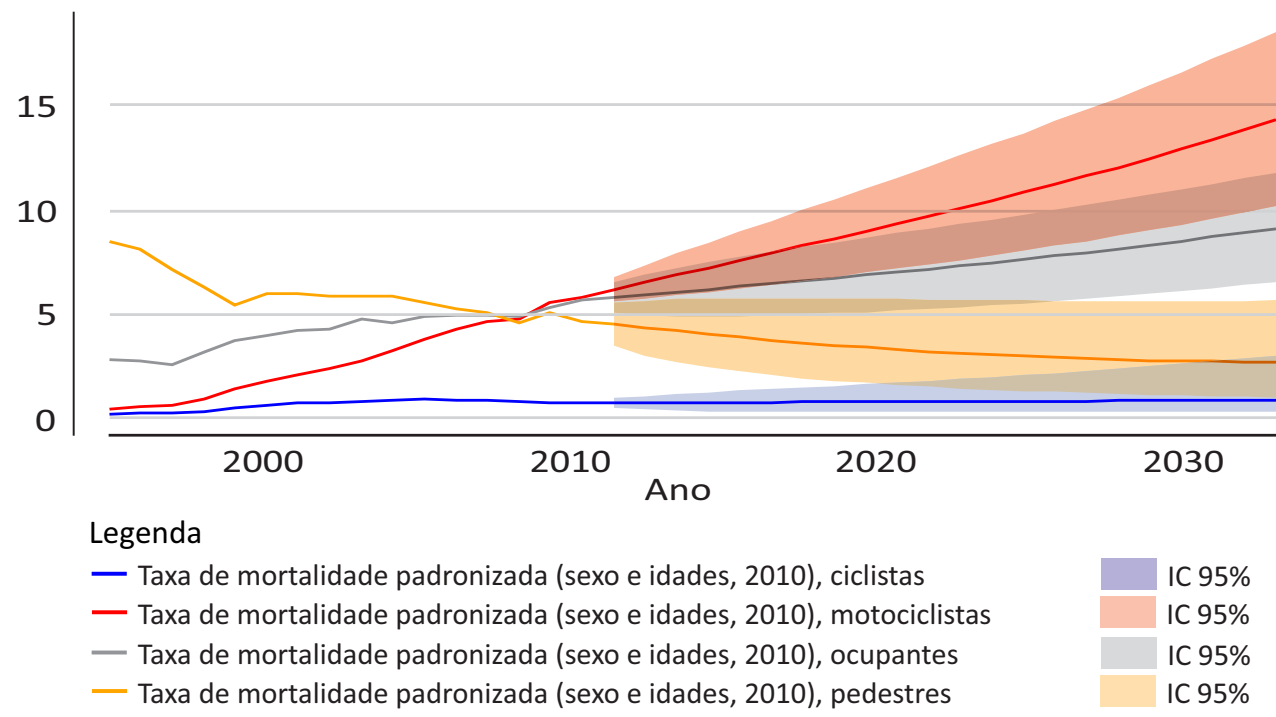

Fonte: elaborado pelos autores com dados do SIM para o período de 1980 a 2011 (Brasil, 2012c) e projeções para o período de 2012 a 2033. Estimativas populacionais construídas pelo IBGE (IBGE, 2008).

As projeções realizadas para o ano de 2033 para essas mesmas 14 causas específicas mais importantes de morte também mostram variações importantes. O maior aumento na taxa de mortalidade ocorrerá para Alzheimer e outras demências, com incremento de 165,6\%, atingindo 21,3 por 100.000 habitantes e situando-se como a oitava mais importante causa de óbito naquele ano. O peso dessa causa poderá ser muito maior, caso se confirmem achados recentes que estimaram as mortes por Alzheimer e outras demências em número até seis vezes maior que o registrado, em razão de dificuldades de diagnóstico e de registro adequados (James et al., 2014). Os resultados utilizados na projeção do crescimento para a mortalidade por Alzheimer e demências senis sugerem aumento correspondente na morbidade, uma vez que não se espera uma elevação da letalidade por essa doença nas próximas décadas. O impacto de tais dados deverá se refletir na necessidade de organização de serviços para atender a essa demanda crescente e complexa, envolvendo aspectos assistenciais, atendimentos domiciliares, preparação de cuidadores comunitários e familiares, entre outras ações.

A taxa de mortalidade pelo grupo das infecções respiratórias inferiores terá o segundo maior crescimento, de 118,3\%. Esse grupo envolve um conjunto de infecções, tanto de origem viral como bacteriana, que também pode ser bastante influenciado pelo envelhecimento da população, pois os idosos são mais vulneráveis às complicações da influenza e de outros quadros infecciosos. Entre essas dez causas líderes, as únicas que apresentarão redução na sua taxa de mortalidade serão as cardiopatias, miocardites e endocardites e os acidentes de transporte, ambos de 14,2\% (Gráfico 10). 
Gráfico 10 - Variação (\%) na taxa de mortalidade por 100.000 habitantes para as 14 maiores causas de morte. Brasil - 2011-2033

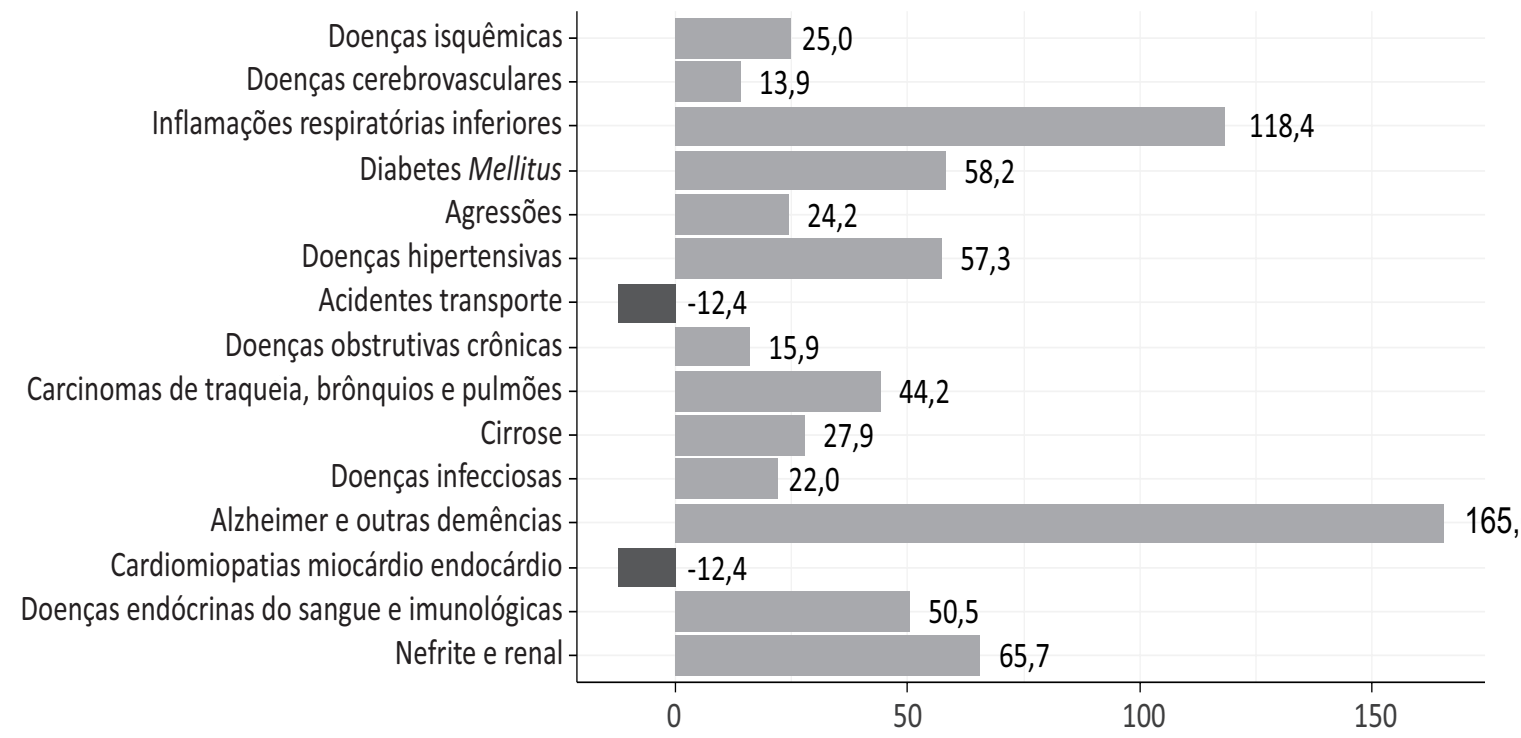

Fonte: elaborado pelos autores com dados do SIM para o período de 1980 a 2011 (Brasil, 2012c) e projeções para o período de 2012 a 2033. Estimativas populacionais construídas pelo IBGE (IBGE, 2008).

Nas projeções para 2033, além dessas mudanças observadas para o país, também serão registradas importantes alterações nas taxas de mortalidade dessas 15 principais causas para cada região (Gráfico 8). No Norte, o maior crescimento projetado será para o diabetes mellitus, que aumentará $167,1 \%$, atingindo uma taxa de 65,98 por 100.000 habitantes e assumindo o primeiro lugar entre as 15 principais causas de morte. As mortes por agressões, mantidas as tendências atuais, passarão para o segundo lugar, com uma taxa de 53,18 por 100.000 habitantes, um crescimento de 55,4\%.

O terceiro e quarto postos serão ocupados pelas doenças cerebrovasculares e pelas doenças isquêmicas do coração, com taxas de 43,85 e 42,64 por 100.000 habitantes, com crescimentos de $35,4 \%$ e $69,2 \%$, respectivamente. As duas causas que apresentarão tendência de redução em suas taxas de mortalidade, em 2033, serão o grupo das demais doenças infecciosas e o de cardiomiopatias, miocardites e endocardites, ambas com decréscimo de 20,7\%. Essas duas causas, efetivamente, podem ser bastante reduzidas com ampliação do acesso à atenção primária da saúde.

Na região Nordeste, tanto as doenças isquêmicas do coração como as doenças cerebrovasculares terão importante crescimento nas suas taxas de mortalidade e continuarão a representar as duas primeiras causas de morte, ocorrendo, entretanto, uma troca de posições. As doenças isquêmicas do coração passarão a ocupar o primeiro lugar, com uma taxa de 80,07 por 100.000 habitantes, um crescimento de $71,9 \%$ em relação ao ano de 2011; as doenças cerebrovasculares estarão na segunda posição, com taxa de 78,71 por 100.000 habitantes; e o diabetes mellitus manterá a terceira posição, com um crescimento de $84,5 \%$. As agressões continuarão como a quarta causa de morte nessa região, com taxa de 59,24 por 100.000 habitantes, um crescimento de $67,8 \%$, quando comparado ao de 2011. 
No Nordeste, as causas com o maior aumento relativo serão o Alzheimer e outras demências, cuja taxa de mortalidade aumentará em 295,7\%, atingindo 15,88 por 100.000 habitantes, passando a ocupar a nona posição. Nenhuma das 14 causas sofrerá redução em sua taxa até 2033 na região Nordeste, apenas a mortalidade por doenças hipertensivas permanecerá praticamente estabilizada, com um crescimento de apenas $2,1 \%$.

Na projeção realizada para o Sudeste, as causas com maior expansão serão as infecções respiratórias inferiores, com $122,3 \%$ de incremento, alcançando uma taxa de 92,15 por 100.000 habitantes e passando a ocupar o primeiro lugar, ao passo que o Alzheimer e outras demências aumentarão 175,0\% e ocuparão a sexta posição, com taxa de 31,69 por 100.000 habitantes. A mortalidade por agressões apresentará a maior redução entre as 14 causas mais importantes na região Sudeste, de 54,3\%, para 8,91 por 100.000 habitantes em 2033. Outras seis causas exibirão tendência de diminuição em sua taxa de mortalidade: as doenças cerebrovasculares (10,7\%), os acidentes de transporte (16,9\%), as doenças obstrutivas crônicas (10,9\%), as demais doenças infecciosas $(10,9 \%)$, as cardiomiopatias, miocardites e endocardites $(11,6 \%)$ e a nefrite e outras doenças renais $(11,4 \%)$.

Na região Sul, as duas primeiras posições entre as 14 causas mais importantes de mortalidade continuarão a ser ocupadas pelas doenças isquêmicas e doenças cerebrovasculares, com taxas de 54,49 e 54,07 por 100.000 habitantes, respectivamente, apesar de ambas sofrerem uma redução de 11,1\%, ao longo do período de 2011 a 2033. O diabetes mellitus manterá a terceira posição; porém, por experimentar um aumento de $56,4 \%$ nesse período, alcançará uma taxa de mortalidade de 46,50 por 100.000 habitantes, aproximando-se das duas primeiras. Chama a atenção, também na região Sul, o expressivo crescimento do Alzheimer e de outras demências, da ordem de 164\%, atingindo uma taxa de 28,65 por 100.000 habitantes e as doenças hipertensivas com crescimento de 64,2\%. Também deverão diminuir suas taxas as infecções respiratórias de vias inferiores (11,1\%), os acidentes de transporte $(11,1 \%)$, demais doenças infecciosas $(11,1 \%)$ e as cardiomiopatias, miocardites e endocardites $(12,6 \%)$.

No Centro-Oeste as doenças isquêmicas crescerão 33,9\% e continuarão como principal causa de morte, com uma taxa de 57,34 por 100.000 habitantes. As infecções respiratórias de vias inferiores, que apresentarão o segundo mais expressivo crescimento, de $81,2 \%$, passarão a ocupar a segunda posição, com taxa de 46,80 por 100.000 habitantes, superando as doenças cerebrovasculares, que crescerão apenas 12,5\% e estarão em terceiro lugar, com taxa de 44,61 por 100.000 habitantes. O incremento mais relevante nessa região também será na causa de morte por Alzheimer e outras demências, com aumento de 279,3\% e projeção de taxa de 19,60 por 100.000 habitantes, passando a ocupar a nona posição. A maior redução será no grupo das cardiomiopatias, miocardites e endocardites, de $89,7 \%$, seguido pelos acidentes de transportes, demais doenças infecciosas e nefrite e outras doenças renais, todos ao redor dos $22 \%$.

Mantidas as tendências atuais, o crescimento da proporção de idosos maiores de 65 anos na população produzirá demandas crescentes ao SUS de ações e serviços assistenciais relacionados a essa fase do ciclo da vida, particularmente em relação às DCNT; algumas condições da saúde mental como depressão, Alzheimer e outras demências; assistência domiciliar; e reabilitação. Essa tendência 
de crescimento da população de idosos no país poderá ser ainda maior se forem alcançadas reduções sustentáveis nas próximas duas décadas na mortalidade por acidentes e violências, causas importantes da redução da expectativa de vida entre os homens, atualmente, por concentrar sua carga de mortalidade exatamente entre os jovens.

A perspectiva de crescimento da morbimortalidade pelas DCNT, que deverá acentuar-se até 2033, exige que o SUS lidere e organize um conjunto de ações que contemplem a preparação dos profissionais da saúde para essa nova realidade demográfica e epidemiológica; a organização de ações e serviços de saúde para que se garanta o acesso ao diagnóstico precoce e ao tratamento oportuno e adequado; o aumento de alternativas de tratamento domiciliar; e a preparação de cuidadores familiares e comunitários para defrontar o aumento da população idosa pobre, entre outras ações.

\section{A melhora no nível de saúde e a redução das desigualdades regionais: o exemplo da mortalidade infantil}

A taxa de mortalidade infantil (TMI) tem sido um indicador universalmente utilizado para monitorar as condições de saúde das populações por sintetizar as múltiplas dimensões envolvidas no risco de um nascido vivo morrer antes de completar um ano, sendo um dos indicadores utilizados para medir o progresso da Meta 4 dos Objetivos de Desenvolvimento do Milênio. Entre outras condições que influenciam a TMI, encontram-se o acesso ao pré-natal e a qualidade desse cuidado, a assistência ao parto e o cuidado com o recém-nascido; o acesso à atenção primária de saúde e às vacinas; e a qualidade de vida da família, incluindo a renda, o acesso à educação, às condições adequadas de habitação e saneamento e às medidas de planejamento familiar.

No Brasil, nas décadas recentes, um conjunto de intervenções propiciaram o aumento do acesso às ações de saúde, redução da taxa de fecundidade, melhoria de condições sociais, entre outras, produzindo uma redução de 5,5\% ao ano no valor da TMI nas décadas de 1980 e 1990, além da diminuição da importante desigualdade regional revelada por esse indicador (Victora et al., 2011). Igualmente, para a taxa de mortalidade entre menores de 5 anos, ${ }^{3}$ o Brasil registrou uma expressiva queda na última década, sendo um dos países com as maiores reduções no período entre 1990 e 2012, de 6,6\% ao ano, diminuindo de 62 para 14 por 1.000 nascidos vivos, bem acima da taxa média de redução global nesse período, que foi de 2,9\% ao ano (UN IGME, 2013).

A TMI projetada para o ano de 2013 é de 13,8 por 1.000 nascidos vivos, uma redução de $65 \%$ se comparada à TMI observada em 1993, que era de 39,4 por 1.000 nascidos vivos. Os autores realizaram uma previsão por regressão exponencial para o período de 2013 a 2033, encontrando uma TMI estimada para este último ano de 6,7 por 1.000 nascidos vivos, uma redução de 54,5\% comparada ao ano de 2013 e de 84\% para o ano de 1993 (Gráfico 11).

Com esse valor para a TMI, o Brasil, que, em 2013, apresentava um índice maior que o da América do Sul e quase quatro vezes maior que o dos países desenvolvidos, em 2033 estará com uma TMI menor que a do continente e apenas 1,8 vezes maior que a projetada para os países desenvolvidos.

\footnotetext{
${ }^{3}$ A taxa de mortalidade em menores de 5 anos também é conhecida como Taxa de Mortalidade na Infância.
} 
Essa tendência de redução na TMI poderá evitar 17,8 mil óbitos infantis em 2033, comparando-se com o número observado em 2013, mesmo levando-se em conta a redução em quase $20 \%$ da população menor de 1 ano que ocorrerá nesse período.

Gráfico 11 - Taxa de mortalidade infantil observada, previsão média e intervalos de 80 e 95\%. Brasil - 1993-2033

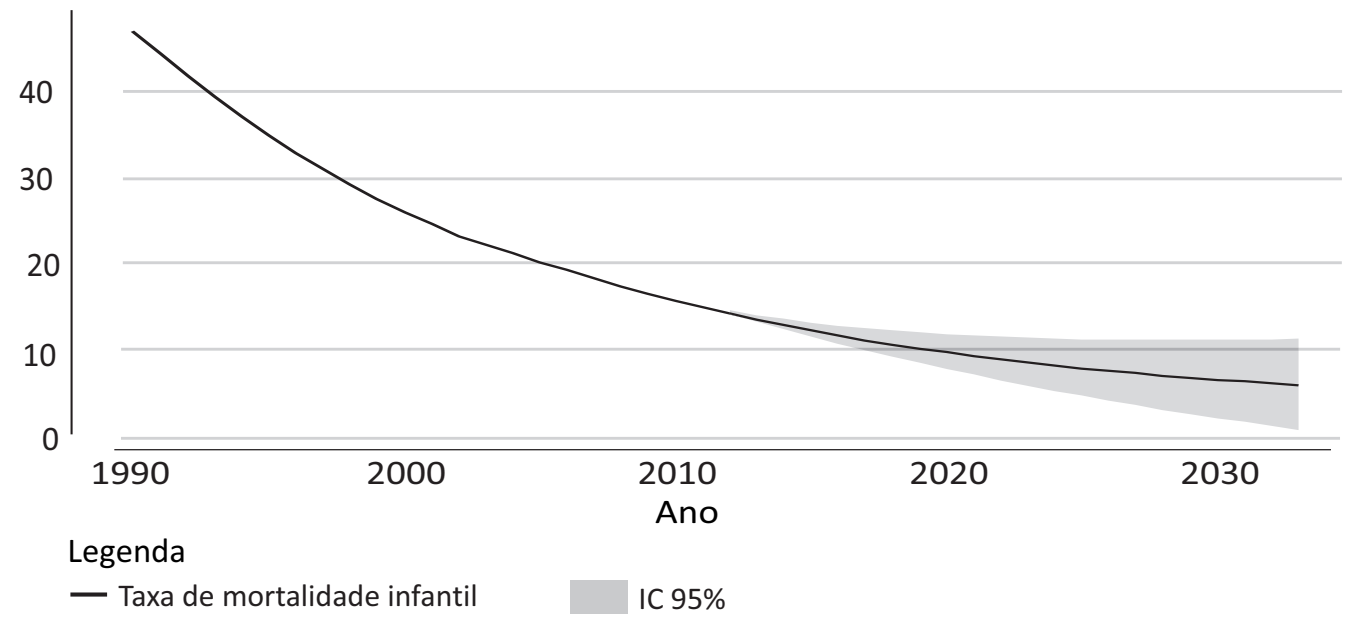

Fonte: Elaborado pelos autores com dados de mortalidade para o período de 1993 a 2012 (Ripsa, 2012) e previsão por regressão exponencial para o período de 2013 a 2033.

A desigualdade regional continuará sua tendência de redução, de acordo com a projeção realizada, com uma aproximação ainda maior entre os valores das distintas regiões, dado positivo e que poderá ser ainda mais favorecido com ações que incidam sobre estados e municípios que ainda apresentam valores elevados para esse indicador. Os maiores percentuais de redução na TMI, de 63\% e 58\%, respectivamente, deverão ser observados exatamente nas regiões que ainda têm as maiores taxas, que são o Norte e o Nordeste.

A região Centro-Oeste, de acordo com o modelo de predição utilizado, poderá apresentar o percentual de redução menos expressivo, de 39\%, aparecendo, por esse motivo, em 2033, com uma TMI de 8,9 por 1.000 nascidos vivos. Entretanto, essa previsão deve ser relativizada, por ser bastante influenciada pela maior força de redução desse indicador apresentada pelas regiões Norte e Nordeste, em comparação com o Centro-Oeste nas últimas décadas, o que influencia bastante o modelo. Além disso, deve-se levar em conta que a redução na mortalidade infantil tende a perder velocidade na medida em que esse indicador assume valores muito baixos, porque as causas que persistem são cada vez menos vulneráveis às intervenções mais simples, como as doenças congênitas de alta gravidade.

As diferenças proporcionais, entre a região de menor e maior valor, respectivamente, a Sul e a Centro-Oeste, chegarão a 30\%, em detrimento dos 41\% observados em 2013, entre as regiões Norte e Sul, então detentoras da maior e menor taxa, respectivamente (Tabela 1). 
Tabela 1 - Taxa de mortalidade infantil: estimativas para mundo, países desenvolvidos, América do Sul e Brasil pela ONU e estimativas para Brasil e regiões feitas pelos autores, para os anos de 1993, 2013 e 2033

\begin{tabular}{|c|c|c|c|c|c|c|c|c|c|c|}
\hline \multirow{4}{*}{ Anos } & \multicolumn{10}{|c|}{ Taxa de Mortalidade Infantil } \\
\hline & \multicolumn{4}{|c|}{$\begin{array}{c}\text { Estimativas - Mundo, Países Desenvolvidos, } \\
\text { América do Sul e Brasil* }\end{array}$} & \multicolumn{6}{|c|}{ Estimativas - Brasil ** } \\
\hline & \multirow{2}{*}{ Mundial } & \multirow{2}{*}{$\begin{array}{c}\text { Países } \\
\text { desenvolvidos }\end{array}$} & \multirow{2}{*}{$\begin{array}{c}\text { América } \\
\text { do Sul }\end{array}$} & \multirow{2}{*}{ Brasil } & \multirow{2}{*}{ Brasil } & \multicolumn{5}{|c|}{ Regiões } \\
\hline & & & & & & $\mathrm{N}$ & $\mathrm{NE}$ & SE & S & $\mathrm{CO}$ \\
\hline 1993 & 58,6 & 10,4 & 37,7 & 41,6 & 39,4 & 41,5 & 60,6 & 28,2 & 24,2 & 30,2 \\
\hline 2013 & 36,3 & 5,5 & 17,7 & 19,1 & 13,8 & 18,0 & 16,1 & 12,2 & 10,6 & 14,6 \\
\hline 2033 & 24,6 & 3,7 & 9,4 & 9,2 & 6,7 & 6,6 & 6,6 & 6,4 & 6,2 & 8,9 \\
\hline
\end{tabular}

Fonte: Tabela construída pelos autores com base nas Estimativas das Nações Unidas* (UN, 2012) e Estimativas Brasil ** construídas pelos autores com base nos dados de mortalidade infantil disponibilizados pela Ripsa (Ripsa, 2012) para os anos de 1993 a 2012, e previsão por regressão exponencial para os anos de 2013 e 2033.

Analisando com detalhes os componentes da mortalidade infantil, ficam evidentes as causas das mudanças ocorridas nas décadas recentes e os desafios que se colocarão, nesse particular, ao SUS. Assim, passamos a explorar as distintas características, comportamento e possível evolução desses componentes: a taxa de mortalidade neonatal, que pode ser precoce ( 0 a 6 dias de vida) ou tardia (7 a 27 dias) e a taxa de mortalidade pós-neonatal (28 a 364 dias) (Ripsa, 2012).

Grande parte da evolução na TMI observada recentemente no Brasil deve-se à redução obtida no componente pós-neonatal (Gráfico 12), bastante vulnerável às estratégias preventivas e assistenciais com alvo nas causas evitáveis e na melhoria das condições sociais e econômicas. Nesse componente da TMI, em que predominam algumas doenças infecciosas e parasitárias (DIP), como as diarreias, pneumonias e doenças evitáveis por vacina, entre os anos de 1993 e 2013 houve uma redução de 78,65\%, com contribuição mais acentuada das regiões Nordeste e Norte. Para o período de 2013 a 2033, projeta-se a continuidade dessa redução, embora em ritmo menor, de 51,54\%, o que levará, ao fim do período, a uma taxa específica projetada de 2,04 por 1.000 nascidos vivos, com as regiões Norte e Centro-Oeste apresentando as maiores taxas específicas. 
Gráfico 12 - Taxa de mortalidade infantil segundo componentes pós-neonatal, neonatal tardia e neonatal precoce, observada e previsão média. Brasil - 1993-2033

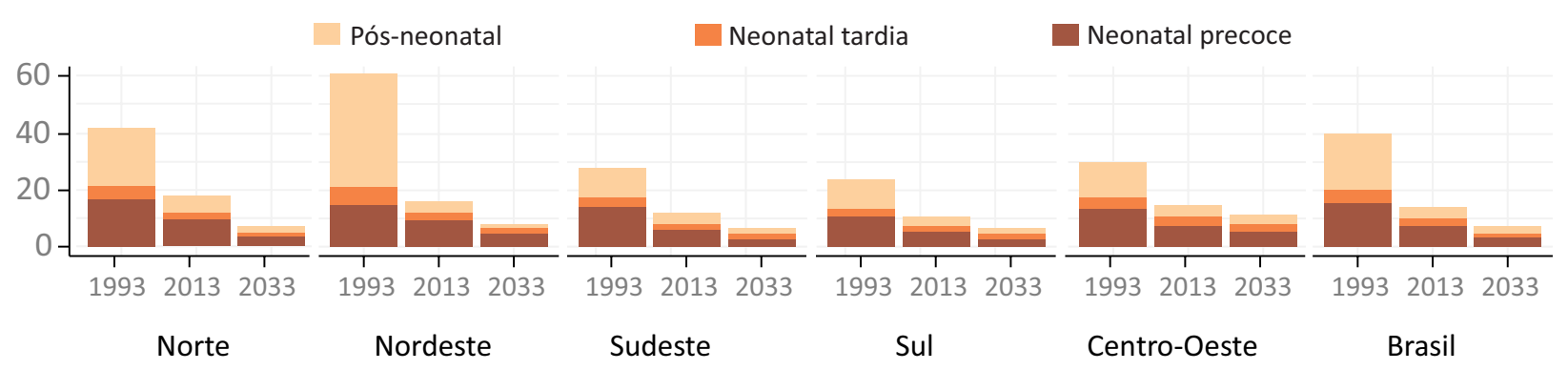

Fonte: elaborado pelos autores com dados de mortalidade para o período de 1993 a 2012 (Ripsa, 2012) e previsão por regressão exponencial para o período de 2013 a 2033.

Para os componentes de mortalidade neonatal precoce e tardia, a tendência de redução também se manterá com percentuais menores para o período de 2013 a 2033, quando comparado ao de 1993 a 2013. Na mortalidade neonatal precoce, o percentual de redução será de $54,0 \%$, alcançando o valor de 3,45 por 1.000 nascidos vivos. Para a mortalidade neonatal tardia, o valor em 2033 será de 1,65 por 1.000 nascidos vivos. O grande desafio na redução da mortalidade infantil para as próximas duas décadas se concentrará no óbito neonatal precoce, que deverá estar em torno de 3,45 por 1.000 nascidos vivos. Nesse componente deverão prevalecer, como causas líderes, as doenças congênitas e a prematuridade.

Nos últimos vinte anos, houve uma mudança importante nos componentes da mortalidade infantil em nosso país. Em 1993, a mortalidade pós-neonatal se destacava, com taxa de 19,72 por 1.000 nascidos vivos, ao passo que a taxa da mortalidade neonatal precoce era de 15,33. Em 2013, já se observa uma inversão do peso desses componentes, com taxas de 4,21 e 7,50, respectivamente.

Em 2033 essa situação persistirá, com a mortalidade neonatal precoce apresentando uma taxa de 3,45 , equivalente a $67 \%$ do total da mortalidade infantil naquele ano. Esse comportamento expressa a menor vulnerabilidade às ações assistenciais desse componente da mortalidade infantil, quando comparado aos demais. A tendência de permanência da importância das causas neonatais na TMI nas próximas duas décadas também é verificada em todas as regiões.

Entre 1990 e 2012 constatou-se uma redução de 37\% nas taxas de óbito neonatais no mundo, chegando a 21 óbitos neonatais para cada 1.000 nascidos vivos (UN IGME, 2013). Houve, entretanto, diferenças importantes nessa tendência quando se analisam as distintas regiões no mundo, algumas com uma redução mais expressiva, como os países desenvolvidos, de 8 para 4 óbitos por 1.000 nascidos vivos e a América Latina e Caribe, de 22 para 10 por 1.000 nascidos vivos. Nesse componente, o Brasil reduzirá a diferença em relação aos países desenvolvidos. Entretanto, ainda estaremos, em 2033, no nível dos países europeus no presente.

Um dos aspectos mais importantes a se levar em consideração nas políticas de redução da mortalidade infantil para os próximos anos será a necessidade da implantação de estratégias capazes de reduzir com maior eficácia as mortes neonatais, especialmente as precoces. Para a obtenção de impacto sobre as malformações congênitas e as perinatais, que são as causas mais frequentes desses 
óbitos (Lansky, 2009), serão necessários maiores investimentos financeiros e intervenções de maior complexidade do que os requeridos para reduzir a mortalidade pós-neonatal.

A efetivação do modelo de previsão das taxas de mortalidade infantil depende da adoção de políticas e programas que aumentem a cobertura e a qualificação da assistência equitativamente entre as regiões, de forma que se obtenham melhorias no acompanhamento da gravidez e o fortalecimento das estruturas assistenciais a parturientes e aos recém-natos de alto risco, o que se traduz em ações que vão desde o aprimoramento da Atenção Primária à Saúde até a ampliação do acesso a leitos de UTI neonatais, entre outras.

\section{O impacto sobre o adoecimento: fatores de risco e morbidade nas próximas duas décadas}

Com exceção do tabagismo, não há séries históricas longas para monitoramento dos principais fatores de risco para as DCNT, como a obesidade, a inatividade física, o abuso do álcool e a alimentação inadequada. Apenas mais recentemente, com a implantação do sistema de Vigilância de Fatores de Risco e Proteção para Doenças Crônicas por Inquérito Telefônico (Vigitel), em 2006, esses fatores de risco passaram a ser medidos nas capitais dos estados brasileiros.

Analisando-se essa série, é possível observar que alguns fatores de risco como o tabagismo e a inatividade física vêm apresentando redução ao longo desse período, mas apenas para o primeiro é possível, com base em estudos mais antigos, confirmar uma tendência de diminuição que provavelmente persistirá nas próximas décadas. O aumento da atividade física tem sido objeto de campanhas e iniciativas do setor público, como o programa Academia da Saúde, do Ministério da Saúde, em 2011, e vários programas municipais semelhantes que o antecederam; e de setores privados, consolidandose a percepção social sobre sua ação positiva como promotora da saúde e a garantia de priorização de gestores para sua implantação. Ao mesmo tempo, diversos estudos sobre a efetividade dessas experiências brasileiras de implantação de programas voltados a estimular a prática da atividade física têm indicado seu efeito positivo (Knuth et al., 2011), permitindo projetar que programas desse tipo tendem a ser ampliados nas próximas duas décadas, o que poderia dar sustentabilidade à redução da inatividade e produzir efeitos positivos na redução da obesidade e do sobrepeso, ou mesmo na velocidade de seu crescimento.

O tabagismo, importante fator de risco para os dois principais grupos de causa de morte por DCNT, as DAC e as neoplasias, tem apresentado uma diminuição sustentável nas últimas décadas, passando de uma prevalência, entre adultos, de 33,5\% em 1989, para 18,1\% em 2008 (Brasil, 2011).

O Vigitel encontrou nas capitais dos estados prevalência ainda menor, de $12,1 \%$ para o ano de 2012, com um valor maior para os homens (15,5\%) do que para as mulheres $(9,2 \%)$. Essa positiva redução na prevalência do tabagismo reflete algumas décadas de políticas públicas implantadas; entretanto, ainda há desafios para alcançar resultados melhores em grupos específicos, pois o Vigitel também indica uma forte desigualdade social, com a prevalência entre pessoas com até oito anos de escolaridade de $21,1 \%$, o que significa quase o dobro daquela encontrada entre os que têm 12 anos ou mais de estudo (12,2\%) (Brasil, 2013c). 
Outros fatores de risco, como o sobrepeso e a obesidade, ${ }^{4}$ vêm apresentando preocupante tendência ao crescimento, não apenas em nosso país, mas em praticamente todo o mundo nas décadas recentes, como resultado da combinação de mudanças no padrão alimentar, com a incorporação de alimentos industrializados de alto valor calórico em substituição à alimentação tradicional; e da maior tendência à inatividade física.

A obesidade e o sobrepeso medidos pelo Vigitel têm crescido cerca de um ponto percentual ao ano, nos últimos seis anos. Mantida a tendência atual, a obesidade entre crianças menores de 13 anos no Brasil alcançará o mesmo nível atualmente apresentado nos Estados Unidos daqui a uma década, com repercussões importantes sobre a saúde dessa geração. O padrão de desigualdade social apontado para o tabagismo também é encontrado para o sobrepeso e a obesidade, particularmente entre as mulheres, pois entre os homens essa diferença não é observada. As mulheres com menos de oito anos de escolaridade apresentam uma prevalência de sobrepeso de 57,4\%, enquanto entre as que têm mais de 12 anos de escolaridade, essa prevalência é de 40,2\%. Para a obesidade, a desigualdade é ainda mais intensa, com 22,9\% das mulheres com menos de oito anos de escolaridade nessa condição, quase o dobro do índice daquelas com mais de 12 anos de escolaridade (11,3\%) (Brasil, 2013c).

A manutenção dessa tendência, com o aumento progressivo da prevalência da obesidade e do sobrepeso, poderá contribuir para aumentar a morbimortalidade pelas DCNT, particularmente por condições e enfermidades como as DAC e complicações do diabetes mellitus. Em relação a esse agravo, em estudo no qual se estimou a prevalência global do diabetes mellitus e fez projeções sobre a doença para o futuro, Wild e colaboradores (2004) concluíram que o Brasil, que teria 4,6 milhões de pessoas com essa doença em 2004, passará a ter 11,3 milhões em 2030, o que representará uma importante pressão por serviços assistenciais.

Mantidas essas tendências, concentrando-se o tabagismo, a obesidade e o sobrepeso entre as pessoas com menos instrução e tomando-se a menor escolaridade como um proxy de pior condição social e maior dificuldade de acesso, observaremos, em 2033, uma concentração ainda maior das enfermidades e condições relacionadas com esses fatores de risco entre os mais pobres. Se não forem adotadas medidas efetivas para redução dos riscos, essa situação poderá contribuir para caracterizar, com mais contundência do que atualmente já ocorre, uma tríplice carga de enfermidade sobre os mais pobres, que reúnem, simultaneamente, os maiores riscos para as doenças transmissíveis, as doenças crônicas não transmissíveis e as causas externas. E poderá contribuir também para desacelerar o processo de redução das desigualdades sociais na saúde, ou até mesmo aumentá-las.

Estratégias adequadas para enfrentar essas questões complexas e com múltiplos determinantes serão essenciais para garantir a continuidade, até 2033, do movimento de redução das distâncias entre os grupos com maior e menor renda para indicadores-síntese, como expectativa de vida ao nascer e mortalidade infantil. O SUS deverá acelerar a implantação e buscar reduzir barreiras restritivas ao acesso de medidas preventivas, de rastreamento, assistenciais e de promoção da saúde que

\footnotetext{
${ }^{4}$ No estudo em que se baseou essa análise foi considerado com excesso de peso o indivíduo com índice de massa corporal (IMC) $\geq 25 \mathrm{~kg} / \mathrm{m}^{2}$ e obesidade o indivíduo com índice de massa corporal (IMC) $\geq 30 \mathrm{~kg} / \mathrm{m}^{2}$.
} 
têm se mostrado efetivas para promover hábitos mais saudáveis entre os grupos mais vulneráveis socialmente, além de fortalecer agendas multissetoriais que busquem superar seus determinantes.

\section{O desafio de fechar a agenda inconclusa e de responder às doenças emergentes}

As doenças infecciosas experimentaram uma diminuição importante do seu peso na mortalidade global desde o início do século passado. Em nosso país, nos anos 1930, nas capitais, essas doenças representavam 45,6\% da mortalidade, ao passo que hoje representam apenas 4,5\%. Tais avanços geraram expectativas de que esse declínio inexorável persistiria de maneira linear até um ponto de quase eliminação geral das DT, impulsionada pelos avanços tecnológicos propiciados pelos antibióticos e pelas vacinas.

O surgimento da Aids no início dos anos 1980, sua rápida disseminação global e forte impacto sobre a morbimortalidade, serviu como evidência de que, apesar dos tremendos avanços, o mundo ainda conviveria com as DT como importante problema de saúde pública. De acordo com levantamento realizado pela OMS, desde 1970, quarenta novas doenças foram identificadas, o que significa uma nova doença identificada ou reconhecida por ano. Algumas dessas doenças, como o ebola e a febre hemorrágica de Marburg, apesar de produzirem surtos com alta letalidade, ficaram restritas geograficamente, enquanto a Aids, por exemplo, só foi percebida no início dos anos 1980, quando já havia se disseminado globalmente.

Entretanto, além de algumas DT terem persistido e ainda produzirem importante impacto sobre a saúde pública, a percepção da sociedade valoriza, de maneira desproporcional, se comparadas apenas do ponto de vista estatístico, as mortes produzidas por DT em relação às DCNT e aos acidentes e violências, como se aquelas fossem completamente evitáveis, e por isso inaceitáveis, ao passo que estes se apresentam como mais naturais, e, portanto, socialmente mais aceitáveis. Também se deve levar em conta como contribuição para essa percepção social sobre as DT, o sentimento de insegurança que acompanha o surgimento de uma nova doença, além da percepção correta de que elas atualmente podem se disseminar mais rapidamente, graças ao aumento do trânsito de pessoas e mercadorias.

O SUS provavelmente defrontar-se-á, nas próximas duas décadas, com um quadro, em relação às DT, bastante modificado se comparado ao atual, podendo-se caracterizar três distintos grupos. A tendência de eliminação, como problema de saúde pública para o grupo de doenças para as quais se dispõe atualmente, ou se disporá brevemente, de instrumentos e estratégias eficazes, se fortalecerá, com redução drástica de sua carga, ou mesmo interrupção completa de sua transmissão.

Ao mesmo tempo, ainda que com redução importante de seu peso na morbimortalidade, persistirão DT para as quais os instrumentos de controle são limitados, caso não sejam desenvolvidas inovações importantes ao longo das próximas duas décadas. Por último, há o grupo das DT relacionadas com os novos agentes infecciosos que poderão emergir ou reemergir, produzindo impactos variáveis sobre a saúde da população, desde surtos localizados até a possibilidade de uma nova pandemia de influenza, além de problemas já existentes, mas que podem se expandir, como a resistência antimicrobiana.

No primeiro grupo está incluído um conjunto de doenças que já vem apresentando tendência importante de decréscimo em sua morbimortalidade nas últimas décadas e que pode ter a velocida- 
de dessa redução ainda mais acelerada, atingindo, várias delas, níveis de incidência e prevalência tão baixos que poderão ser consideradas eliminadas como problema de saúde pública. Sua carga de letalidade não representará mais um peso sobre os grupos populacionais e comunidades em que atualmente ocorrem, nem sobre o sistema de saúde nas próximas duas décadas.

Em relação a algumas doenças integrantes desse grupo, é possível ir ainda mais longe, pois, mantida a velocidade de redução já alcançada, e devido a seu já presente estágio de focalização, pode-se colocar como perspectiva a interrupção completa da transmissão e o consequente cenário de eliminação.

Para que esse cenário favorável se concretize será necessária a manutenção de estratégias e instrumentos inovadores, já incorporados nos anos recentes, além da garantia de rápida assimilação no país dos novos desenvolvimentos, buscando a redução do tempo entre seu surgimento, a produção de novas evidências e a sua implantação nas práticas de saúde pública.

Nessa situação encontram-se, por exemplo, a hanseníase e outras doenças transmissíveis que apresentam uma redução sustentável na sua incidência e mortalidade, e na incidência e prevalência, respectivamente. Isso tem produzido, ao mesmo tempo, uma concentração da carga dessas doenças entre os grupos populacionais com maior dificuldade de acesso aos serviços de saúde, por barreiras de diferente natureza, e que são diretamente afetadas pelos determinantes sociais, resultando em uma carga desproporcionalmente mais elevada entre os pobres e outras populações vulneráveis.

Ainda constituem esse primeiro grupo algumas DT como a hanseníase, as geo-helmintíases, a esquistossomose, o tracoma, a filariose e a oncocercose, doenças bastante relacionadas com precárias condições de vida, que já tem ocorrência focalizada em determinadas regiões e perspectiva de redução na sua carga nos anos recentes. Essa tendência deve acentuar-se nos próximos anos, com a utilização cada vez mais ampla dos novos instrumentos e estratégias mais eficazes já disponíveis.

Para algumas dessas doenças, como a filariose e a oncocercose, restritas a focos na região metropolitana de Recife e na população ianomâmi, respectivamente, bastará a manutenção das tendências atuais para que se encontrem eliminadas até 2020, persistindo, a partir de então, a necessidade de manutenção das ações de vigilância para prevenir o risco, ainda que improvável, de sua reintrodução.

A filariose é um bom exemplo de como a adoção da estratégia adequada, com a utilização de maneira mais apropriada dos instrumentos já existentes, pode acelerar significativamente a diminuição da carga dessas doenças transmissíveis relacionadas com a pobreza. Endêmica há décadas nos bairros pobres e produzindo importante impacto para a saúde pública em Recife, em 2003 essa doença apresentava um coeficiente de detecção de 61 casos por 100 mil habitantes. A partir daquele ano, houve a modificação da estratégia de enfrentamento, passando-se a adotar o tratamento coletivo em áreas de alta prevalência, cuja efetividade já estava demonstrada em estudos internacionais, mas ainda não utilizado no país; com isso, o índice caiu para 0,03 casos por 100 mil habitantes (Recife, 2010). Essa redução de 99,9\% em menos de uma década permite projetarse para muito breve a interrupção total da transmissão da filariose, eliminando-se o último foco existente no Brasil. 
As demais, ainda que não estejam completamente eliminadas em 2033, deverão ter uma aceleração importante na sua taxa de redução, com a ampliação de estratégias recentemente adotadas no país, como o tratamento coletivo em áreas de alta prevalência, quimioprofilaxia, maior eficiência na busca e tratamento de contatos, entre outras ações (Brasil, 2012a). Esse grupo de DT relacionado com a pobreza também poderá se beneficiar bastante com a melhoria progressiva da renda e das condições de moradia e saneamento, transformando-se em doenças de baixíssima prevalência, sem impacto significativo para a saúde pública e concentradas nos bolsões de pobreza que ainda persistirem.

Em relação à hanseníase, para a qual também há dificuldade em se estabelecer uma drástica redução em curto período de tempo, observa-se que a partir da introdução da poliquimioterapia (PQT) no início dos anos 1990, o país passou por uma redução consistente da taxa de prevalência, revertendo uma tendência de crescimento, observada entre 1985 e 1990, quando esse indicador variou de 16,4 por 10.000 habitantes para 19,5 por 10.000 habitantes (Brasil, 1999). Com essa nova ferramenta, aliada ao esforço de descentralização do acesso ao diagnóstico e tratamento que se intensificou na última década, imprimiu-se uma importante redução na prevalência nas duas décadas seguintes, alcançando os 75,9\% de diminuição entre 1990 e 2000 e de 66,9\% entre 2000 e 2010. No ano de 2012, a taxa foi de 1,56 por 10.000 habitantes, $92 \%$ menor que a apresentada em 1990 (Brasil, 2012a).

A partir da adoção de novas estratégias para identificar bolsões de transmissão até então ignorados pelos serviços de saúde, como a Campanha de Detecção de Hanseníase, realizada em abril de 2013 e prevista novamente para 2014, juntamente com a implantação de tratamento profilático de contatos, espera-se que progressivamente se alcance a interrupção das cadeias de transmissão persistentes e a carga dessa doença seja reduzida com mais velocidade ainda nos próximos anos.

Essa mesma tendência é esperada para a esquistossomose, as geo-helmintíases e o tracoma que, atualmente, já vêm concentrando-se em áreas rurais e bairros pobres nas periferias das grandes cidades do Nordeste onde as condições de saneamento ainda são bastante precárias. Provavelmente, essas doenças estarão eliminadas em 2033, ou apresentarão uma carga muito reduzida e concentrada, exigindo que se mantenham ações de prevenção e controle de maneira a conseguir a eliminação completa.

Essas previsões são baseadas no comportamento epidemiológico que essas doenças têm apresentado nos anos recentes e no impacto que poderá ser produzido pelas intervenções adotadas recentemente com o objetivo de produzir uma redução mais intensa, para os próximos anos. Desse modo, mesmo levando-se em conta que a velocidade de redução da incidência ou prevalência tende a ser menor quando o ponto de partida já não é de uma carga tão elevada, situação verificada atualmente, é muito provável que o cenário previsto se realize.

A tuberculose poderia ser considerada uma doença integrante do segundo grupo, mas podendo migrar para o primeiro, se alguns cenários favoráveis se confirmarem até 2033. Essa doença teve acelerada sua tendência de redução nas taxas de incidência e de mortalidade nos últimos dez anos, alcançando $24 \%$ de diminuição e atingindo os valores de 35,0 por 100.000 habitantes e 2,3 por 100.000 habitantes, respectivamente. Esse ritmo de redução permitiu ao Brasil alcançar a meta estabelecida 
no "Objetivo 6" dos Objetivos de Desenvolvimento do Milênio (ODM), de redução pela metade do número de óbitos pela doença entre 1990 e 2015, ainda em 2011, quatro anos antes, portanto, do compromisso global que foi assumido por todos os países (Brasil, 2012b).

Para que essa condição fosse alcançada, contribuíram a combinação de medidas de descentralização para ampliar o acesso ao diagnóstico e tratamento com maior integração com a Estratégia Saúde da Família e o impacto das políticas de redução da pobreza e pobreza extrema, entre outros fatores. Entretanto, como a redução da morbimortalidade ocorre de maneira mais lenta entre as populações mais vulneráveis que têm, por distintas razões, maiores dificuldades no acesso ao diagnóstico e tratamento, o risco de adoecer de tuberculose, atualmente, é cerca de três vezes maior entre os indígenas do que na média da população, 28 vezes maior entre as pessoas privadas de liberdade e pode ser até 67 vezes maior entre as pessoas vivendo em situação de rua (Brasil, 2012d).

A projeção para 2033 situa a taxa de incidência em torno de 31,7 por 100.000 habitantes. Entretanto, a continuidade da melhoria da condição social da população, produzindo ainda maior redução da pobreza; a incorporação de novas tecnologias como o teste rápido, implantado em escala nacional desde 2014; a crescente integração entre as ações de controle da tuberculose e da Aids; e a consolidação de ações específicas voltadas para as populações mais vulneráveis e áreas de alta incidência poderão impulsionar novos e mais elevados ritmos de redução da incidência e da mortalidade por tuberculose, sendo factível estimar que o valor possa estar próximo do limite inferior da projeção, ao redor dos 16 casos por 100.000 habitantes (Gráfico 13).

Para reforçar essa projeção mais otimista, deve-se também levar em conta a possibilidade do breve lançamento de novos esquemas de tratamento, alguns já em fase final de estudos clínicos, com tempo reduzido para apenas dois meses, ampliando bastante a adesão e, consequentemente, a taxa de cura, além da possibilidade de utilização de tratamentos profiláticos (Zumla, 2014). Essa perspectiva, aliada ao desenvolvimento de vacinas eficazes para proteger contra a infecção durante toda a vida, também pode contribuir para uma redução da carga da tuberculose ainda mais rápida do que a tendência projetada com base no comportamento da última década, possibilitando o alcance, em 2033, de uma incidência abaixo dos 10 casos por 100.000 habitantes, meta considerada ousada, mas proposta pela OMS para ser atingida globalmente em 2035 (WHO, 2007).

A taxa de mortalidade projetada para a tuberculose em 2033 é de 1,08 por 100.000 habitantes, o que situará esse indicador num nível muito próximo do que pode ser considerado como de doença em eliminação (taxa de mortalidade menor que 1 por 100.000 habitantes) (Gráfico 13). As inovações em estratégias e desenvolvimentos tecnológicos descritos anteriormente também poderão produzir alteração favorável nesse cenário, propiciando uma redução ainda maior na mortalidade por tuberculose. 
Gráfico 13 - Tuberculose: taxas de incidência e mortalidade por 100.000 habitantes. Brasil - 2000-2033

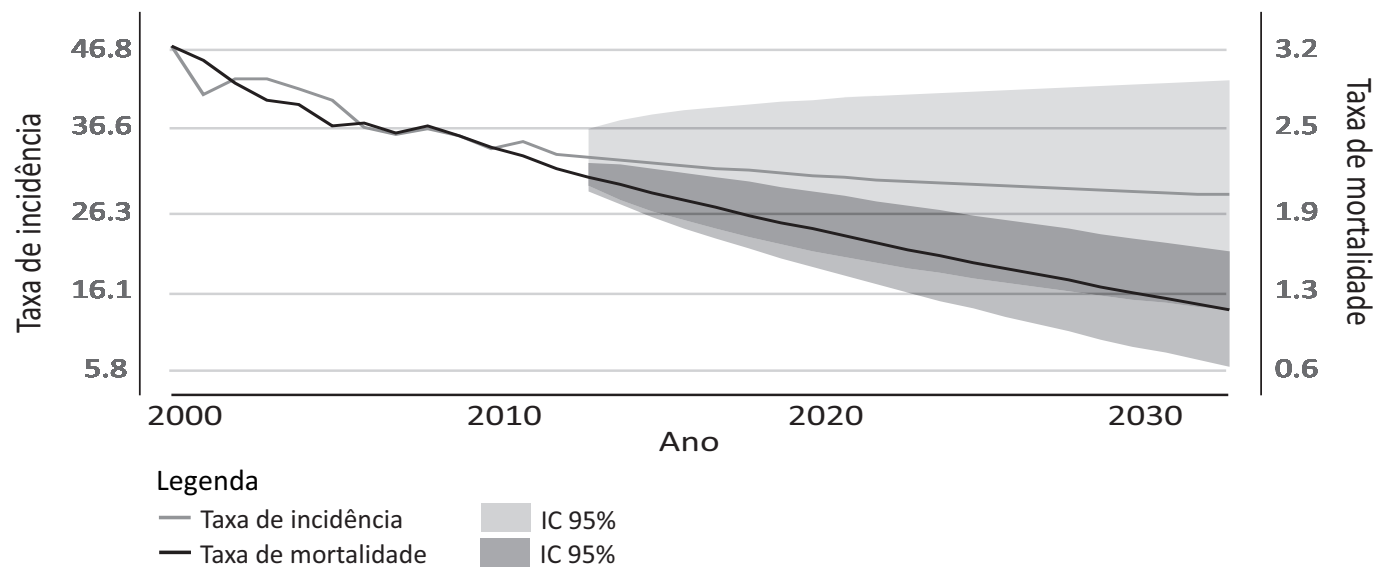

Fonte: elaborado pelos autores com dados do SIM (mortalidade) (Brasil, 2012c) e Sinan (incidência) (Brasil, 2012c) para o período de 2000 a 2012 e projeções para o período de 2012 a 2033. Estimativas populacionais construídas pelo IBGE (IBGE, 2008).

A Aids é a melhor representante do segundo grupo de DT entre aquelas que poderão ter sua carga de morbimortalidade reduzida, mas que, provavelmente, ainda se constituirão em importante problema de saúde pública em 2033, caso não surjam inovações capazes de alterar radicalmente o seu comportamento, como a descoberta de drogas capazes de curar a infecção pelo HIV e/ou uma vacina capaz de preveni-la.

Desde os primeiros casos identificados no país, em meados dos anos 1980, a Aids vem crescendo sua importância na morbimortalidade por DT. Atualmente, estima-se que a prevalência de infecção por HIV esteja em torno de 0,4\%, o que representa, aproximadamente, 718 mil pessoas vivendo com a infecção pelo HIV ou Aids no país. Entretanto, essa prevalência apresenta variações importantes, com nítida concentração em alguns grupos de maior vulnerabilidade para a transmissão do HIV, como usuários de drogas injetáveis, homens que fazem sexo com homens (HSH) e profissionais do sexo, nos quais a prevalência é estimada em 5,9\%, 10,5\% e 4,9\%, respectivamente, várias vezes mais elevada do que na população em geral. Também há concentração geográfica em grandes municípios, capitais e regiões metropolitanas, com $70 \%$ das pessoas que vivem com HIV/Aids morando em 130 municípios. Anualmente, estão sendo detectados aproximadamente 39.000 casos da doença e os 11.896 óbitos registrados, em 2012, colocam-na como a principal causa de morte entre as DT (Brasil, 2013b).

Entre a sua detecção e até o fim dos anos 1990, a Aids apresentou um comportamento de crescimento, modificações em seu perfil epidemiológico e expansão para todas as unidades federadas, próprios de um período de introdução da doença. Analisando-se a década mais recente, quando já se nota uma consolidação maior de alguns padrões, é possível ter uma melhor caracterização dessa epidemia.

A taxa de detecção de novos casos de Aids vem se mantendo relativamente estável, com um aumento de $2 \%$, na última década, ao redor de 20 casos por 100.000 habitantes. Entretanto há uma 
importante variação regional em relação aos valores e às tendências. A região Sul ostenta a maior taxa, de 30,9 por 100.000 habitantes, ao passo que o Nordeste, com 14,8, apresenta o menor valor. A região Sudeste teve uma diminuição de 18,6\% em sua taxa de detecção no período de 2003 a 2012, enquanto no Sul houve uma discreta redução de apenas 0,3\%. A região Norte foi a que apresentou o maior percentual de aumento na taxa de detecção, de 92,7\%, seguida pelo Nordeste (62,6\%) e Centro-Oeste (60,0\%). O Rio Grande do Sul $(41,4)$, Santa Catarina $(33,5)$, Amazonas $(29,2)$ e o Rio de Janeiro $(28,7)$ são os estados com as maiores taxas de detecção em 2012 (Brasil, 2013b).

Para a mortalidade também se encontram diferenças importantes entre as regiões. No conjunto do país, a taxa de mortalidade por 100.000 habitantes, em 2012, foi de 5,5. Entre as regiões, os valores variaram dos 7,7 por 100.000 habitantes registrados na região Sul, que apresentou a maior taxa, até os 4,0 por 100.000 habitantes no Nordeste, a menor. A taxa de mortalidade padronizada da Aids reduziu-se em 14\% no Brasil, no período de 2003 a 2012, mesma tendência encontrada nas regiões Sudeste e Sul, que diminuíram suas taxas de mortalidade em 31,7\% e 7,2\%, respectivamente. Entretanto, houve aumento nas regiões Norte $(60,0 \%)$, Nordeste $(33,3 \%)$ e Centro-Oeste $(4,4 \%)$ (Brasil, 2013b).

Nos anos recentes, o Brasil vem adotando estratégias para ampliar o conhecimento da população, com grande estímulo para a realização do teste sorológico, o que pode levar a uma redução importante do número de pessoas que desconhecem sua condição de viver com o HIV, estimado em até 150 mil. Essa ação, combinada com a adoção, em dezembro de 2013, de um novo protocolo que prevê a instituição do tratamento com antirretrovirais (ART) para qualquer pessoa adulta com testagem positiva para o HIV, independentemente de comprometimento do sistema imunológico, poderá produzir um grande impacto na redução da transmissão nos próximos anos. Essa estratégia, também conhecida como tratamento como prevenção, baseia-se nas evidências de redução a níveis baixíssimos da carga viral de pessoas em tratamento com ART, diminuindo muito as chances de transmissão (Brasil, 2013b).

A projeção realizada para o ano de 2033 (Gráfico 14) revela uma redução de 11,6\% na taxa de detecção de novos casos de Aids, atingindo o valor de 17,39 por 100.000 habitantes. Entretanto, essa projeção é baseada na tendência da última década, ainda não influenciada pelas medidas recentes que foram adotadas. Com a consolidação dessas novas ações e estratégias, é possível que se imprima maior velocidade de redução, sendo imaginável que sejam atingidas taxas próximas, ou mesmo abaixo, do menor valor estimado pelo modelo utilizado, em torno dos 7,6 por 100.000 habitantes.

Para a mortalidade, igualmente, projeta-se uma redução de percentual semelhante à da incidência, de 11,6\%, e, para 2033, uma taxa de 5,28 mortes por 100.000 habitantes. Entretanto, a instituição do tratamento com antirretrovirais em estágios cada vez mais iniciais da infecção, como estimulado pelo novo protocolo, pode ocasionar maior redução nessa taxa, atingindo níveis talvez mais baixos que o próprio valor mínimo projetado, de 4,36 por 100.000 habitantes. 
Gráfico 14 - Aids: taxas de incidência e de mortalidade por 100.000 habitantes. Brasil - 2000-2033

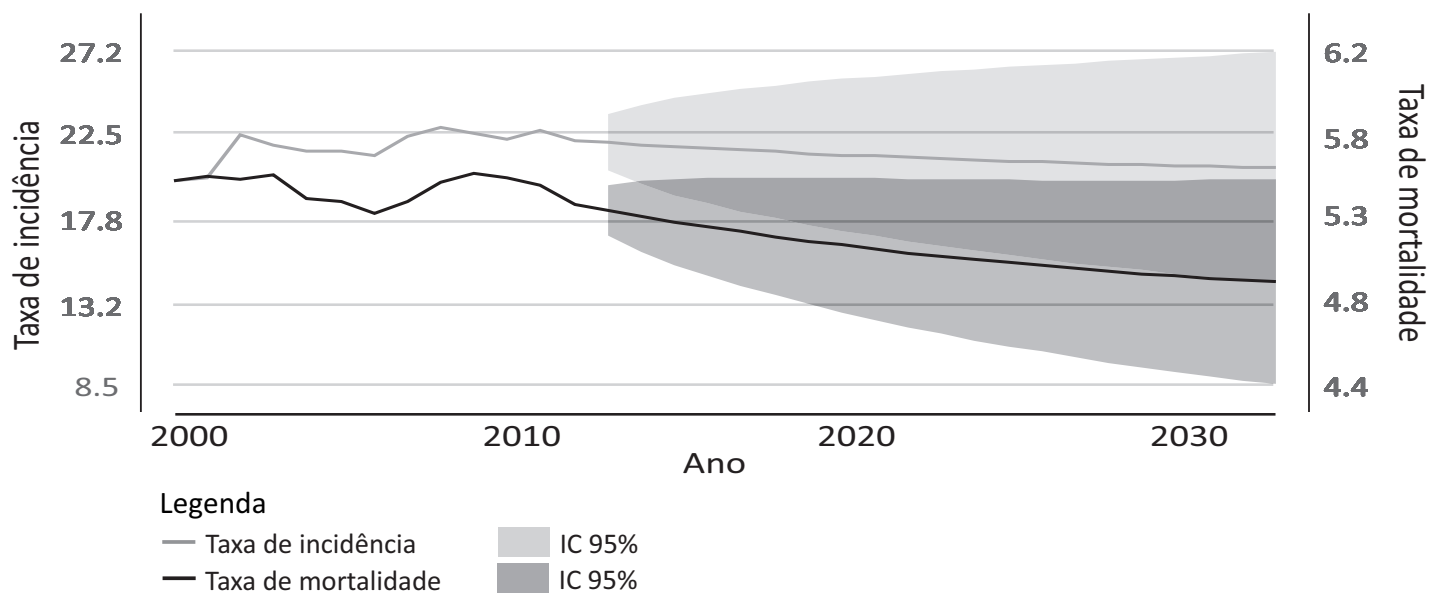

Fonte: elaborado pelos autores com dados do SIM (mortalidade) (Brasil, 2012c) e Sinan (incidência) (Brasil, 2012c) para o período de 2000 a 2012 e projeções para o período de 2012 a 2033. Estimativas populacionais construídas pelo IBGE (IBGE, 2008).

A Organização Mundial da Saúde (2014a) estima que cerca de 2,5 bilhões vivem em áreas sob o risco de epidemias de dengue em mais de 120 países, com a ocorrência de 50 a 100 milhões de infecções por ano. Essa doença, que até a década de 1970 era restrita a nove países com registro de epidemias, disseminou-se rapidamente por todo o globo, impulsionada por determinantes como a falta de infraestrutura urbana no que diz respeito ao acesso à água e ao manejo adequado do lixo, muito presentes nas cidades de países em desenvolvimento que experimentaram rápido processo de urbanização na metade final do século XX.

No Brasil, desde sua primeira ocorrência em 1986, a dengue tem produzido epidemias cíclicas relacionadas com a introdução de um novo sorotipo ou recirculação após grandes períodos de tempo, capazes de permitir novo acúmulo de suscetíveis. Esse comportamento da dengue dificulta a realização de estimativas confiáveis para a morbidade em períodos longos como duas décadas. Entretanto, é possível verificar, quanto à mortalidade, com a adoção de medidas de detecção precoce de sinais de agravamento e protocolos adequados de tratamento, que tem sido possível uma importante redução nos óbitos relacionados com essa doença, mesmo em anos de grande transmissão (Brasil, 2014a).

A dengue é uma das doenças com grande carga de morbidade que se encontra mais próxima da disponibilidade de uma vacina, o que poderá proporcionar uma alteração drástica na sua tendência até 2033. Atualmente, seis vacinas já se encontram em diferentes estágios de ensaios clínicos e, nos próximos cinco anos, algumas já poderão estar prontas para uso em saúde pública (DVI, 2014). O surgimento de vacinas provavelmente reduzirá de maneira importante a incidência da doença, sendo necessária, entretanto, a manutenção de outras medidas de controle, como ações sobre os vetores.

O terceiro grupo de comportamentos que as DT apresentarão nas próximas duas décadas é relativo às doenças emergentes. Na última década assistiu-se ao surgimento de vários novos vírus que produziram forte impacto sanitário, econômico e social. Em 12 de março de 2003, a OMS lançou um 
alerta internacional sobre um novo tipo de coronavírus, ${ }^{5}$ identificado no final de 2012, na China, e que produzia uma síndrome respiratória aguda grave (SRAG, ou SARS, como ficou conhecida por sua sigla em inglês de severe acute respiratory syndrome). Da Ásia, a doença disseminou-se rapidamente para 24 países, causando 8.096 casos e, com elevada letalidade, 774 óbitos. O surto foi contido em julho daquele mesmo ano, ocorrendo alguns casos em 2004 e, a partir de então, nenhum caso novo dessa doença (WHO, 2013c, 2014c). A SARS contribuiu para que a discussão do novo Regulamento Sanitário Internacional (RSI) fosse acelerada e tivesse sua aprovação na Assembleia Mundial da Saúde de 2005.

Ainda em 2003, também na Ásia, outro vírus, dessa vez um subtipo de influenza aviária, o A (H5N1), ultrapassa a barreira biológica e produz os primeiros casos de doença em humanos, também com muita gravidade. Desde 2003 até janeiro de 2014 foram confirmados laboratorialmente 650 casos em 15 países, com 386 mortes. Os casos, em sua quase totalidade, ocorreram em pessoas que tiveram contato com aves contaminadas, não se verificando transmissão sustentável entre humanos, até hoje. Por sua origem e pela gravidade dos casos, o A (H5N1) foi considerado um forte candidato a vírus pandêmico e continua sob monitoramento.

Outros vírus de influenza surgiram desde então, como o A (H7N9), em março de 2013, também um vírus de influenza aviária, mas de baixa patogenicidade, igualmente originário da China. Em 2009, oriunda do México, iniciou-se a primeira pandemia de influenza no século XXI, produzida pelo vírus A (H1N1) pdm09, que combina material genético de vírus humano, suíno e de aves. Desde agosto de 2010 confirmou-se o fim da pandemia, com o A (H1N1) pdm09 continuando a circular, porém como vírus sazonal (WHO, 2014c).

Outros vírus também foram identificados recentemente, como um novo coronavírus, em 2012, no Oriente Médio, o MERS-CoV (sigla em inglês para Middle East respiratory syndrome coronavirus), possivelmente por meio de camelos e dromedários infectados (WHO, 2014b), enquanto outros extrapolaram as áreas originais onde foram identificados, como o vírus chikungunya, em dezembro de 2013 no Caribe, colocando toda a região das Américas em alerta (Paho, 2014).

Em fevereiro de 2016 a OMS declarou que a comprovação da associação de infecção pelo vírus zika em mulheres grávidas com quadros neurológicos graves nos recém-nascidos - como microcefalias e outras - constituía emergência de saúde pública de interesse internacional. Ainda que esse vírus já fosse conhecido há décadas, essa associação, identificada no Brasil, revelou uma nova e severa ameaça que mudou completamente a estratégia de enfrentamento das epidemias causadas por esse vírus (WHO, 2016).

Esse panorama de emergência de novos vírus, principalmente através da interface humano-animal, não deverá se alterar até 2033, exigindo que os países reforcem sua capacidade de detecção rápida e resposta adequada. Ao mesmo tempo, com o avanço dos processos de integração econômica em escala regional e global, com redução de barreiras e facilitação do trânsito de pessoas ${ }^{6}$ e mercadorias, aumenta a possibilidade de disseminação rápida de vírus e bactérias, com importantes repercussões sanitárias e econômicas decorrentes da internacionalização de surtos e epidemias.

\footnotetext{
${ }^{5}$ Os coronavírus produzem doenças em humanos e em animais. Esse novo tipo do vírus ficou conhecido como coronavírus associado à SARS (SARS-CoV por sua sigla em inglês).

${ }^{6}$ A maior associação internacional de transporte aéreo, que responde por $86 \%$ do total de tráfego aéreo do mundo registra cerca de 1,9 bilhão de passageiros ao ano, dos quais 860 milhões fizeram voos internacionais (Iata, 2014).
} 


\section{Desafios Futuros para o SUS}

Tomando-se por base as análises da situação atual do perfil de morbimortalidade do Brasil, de suas tendências recentes e das projeções para o ano de 2033 realizadas neste capítulo, é possível sintetizar algumas questões centrais que o SUS deve levar em conta no seu planejamento e preparação:

- O impacto da rápida transição demográfica no país produzirá maior peso das DCNT, particularmente de alguns tipos de câncer e do Alzheimer e outras demências, exigindo respostas na organização dos serviços de saúde para ampliação da cobertura integral da atenção a esses problemas, incluindo desde as medidas preventivas, o diagnóstico precoce, o acesso aos medicamentos e tratamentos adequados até a reabilitação.

- A necessidade de que sejam ampliadas as estratégias de redução das desigualdades em saúde, de modo a manter e acelerar as tendências que vêm sendo observadas nas duas últimas décadas, tendo como principal exemplo o comportamento apresentado pela mortalidade infantil.

- A exigência de políticas públicas que atuem sobre os determinantes da saúde, com destaque para aqueles que têm impulsionado o crescimento de algumas das causas externas, como os acidentes de trânsito, e que sustentam a grande morbidade produzida por doenças como a dengue.

- A necessidade de fortalecimento contínuo da preparação para o enfrentamento das doenças emergentes que continuarão a surgir em todo o mundo.

Com base nas projeções realizadas, em 2033, o SUS enfrentará um cenário ainda mais complexo que o atual e sua preparação, já a partir do presente, será fundamental para um continuado, equitativo e sustentável aperfeiçoamento do nível de saúde de nossa população.

\section{Referências}

BRASIL. Ministério da Saúde. Secretaria de Vigilância em Saúde. Boletim Epidemiológico - Edição Especial. Brasília: Ministério da Saúde, Ano III, 1999. Disponível em: http://bvsms.saude.gov.br/bvs/periodicos/ boletim_epi_edicao_especial.pdf. Acesso em: 10 jan. 2014.

BRASIL. Ministério da Saúde. Instituto Nacional de Câncer. Pesquisa Especial de Tabagismo - PETab: relatório Brasil. Rio de Janeiro: Inca, 2011.

BRASIL. Ministério da Saúde. Secretaria de Vigilância em Saúde. Plano Integrado de Ações Estratégicas de Eliminação da Hanseníase, Filariose, Esquistossomose e Oncocercose como Problema de Saúde Pública, Tracoma como Causa de Cegueira e Controle das Geohelmintíases: plano de ação 2011-2015. Brasília: Ministério da Saúde, 2012a. (Série C. Projetos, Programas e Relatórios)

BRASIL. Ministério da Saúde. País atinge uma das metas do milênio com redução de mortes por tuberculose. Portal Brasil, 1 jun. 2012b. Disponível em: < www.brasil.gov.br/cidadania-e-justica/2012/06/pais-atinge-umadas-metas-do-milenio-com-reducao-de-mortes-por-tuberculose >. Acesso em: 10 jan. 2014.

BRASIL. Ministério da Saúde. Indicadores e Dados Básicos - Brasil - 2012, 2012c. Disponível em: <http:// tabnet.datasus.gov.br/cgi/idb2012/matriz.htm>. Acesso em: 18 jan. 2014.

BRASIL. Ministério da Saúde. Secretaria de Vigilância em Saúde. Boletim Epidemiológico Especial Tuberculose. Brasília: Ministério da Saúde, 2012d. Disponível em: < http://portalarquivos.saude.gov.br/images/pdf/2014/ julho/23/BE-2012-43-Mar--o---Especial-Tuberculose.pdf > . Acesso em: 4 ago. 2014. 
BRASIL. Ministério da Saúde. Secretaria de Vigilância em Saúde. Acidentes de transporte terrestre no Brasil: mortalidade, internação hospitalar e fatores de risco no período 2002 - 2012. Brasília: Ministério da Saúde, 2013a.

BRASIL. Ministério da Saúde. Secretaria de Vigilância em Saúde. Boletim Epidemiológico HIV-AIDS. Brasília: Ministério da Saúde, ano II, n. 1, 2013b. Disponível em: < http://www.aids.gov.br/sites/default/files/anexos/ publicacao/2013/55559/_p_boletim_2013_internet_pdf_p_51315.pdf >. Acesso em: 4 ago. 2014.

BRASIL. Ministério da Saúde. Secretaria de Vigilância em Saúde. Vigitel Brasil 2012: vigilância de fatores de risco e proteção para doenças crônicas por inquérito telefônico. Brasília: Ministério da Saúde, 2013c.

BRASIL. Ministério da Saúde. Portal da Saúde. Brasília, 2014a. Disponível em: < http://portalsaude.saude.gov. br/index.php/situacao-epidemiologica-dados-dengue >. Acesso em: 31 mar. 2014.

BRASIL. Ministério da Saúde. Indicadores de morbidade: prevalência de hanseníase. Disponível em: <http:// tabnet.datasus.gov.br/cgi/idb2012/d09.htm >. Acesso em: 10 jan. 2014b.

CORE TEAM, R. A Language and Environment for Statistical Computing. Vienna: Foundation for Statistical Computing, 2013.

CURRY, S. J.; BYERS, T. \& HEWITT, M. (Ed.). Fulfilling the Potential for Cancer Prevention and Early Detection: national cancer policy board. Washington: The National Academies Press, 2003.

DENGUE VACCINE INITIATIVE (DVI). Dengue Vaccine Initiative. Disponível em: < www.denguevaccines.org/ why-a-vaccine >. Acesso em: 12 fev. 2014.

HYNDMAN, R. J. E. forecast: Forecasting Functions for Time Series and Linear Models. Package version 2.08. 2010. Disponível em: <http://cran.r-project.org/package=forecast > . Acesso em: 12 jan. 2014.

INSTITUTO BRASILEIRO DE GEOGRAFIA E ESTATISTICA (IBGE). Projeção da População do Brasil por Sexo e Idade para o Período 2000/2060. Rio de Janeiro: IBGE, 2008. Disponível em: <www.ibge.gov.br/home/estatistica/ populacao/projecao_da_populacao/2013/default.shtm>. Acesso em: 12 jan. 2014.

INTERNATIONAL AIR TRANSPORT ASSOCIATION (IATA). International Air Transport Association. Disponível em: <www.iata.org > . Acesso em: 12 jan. 2014.

JAMES B. D. et al. Contribution of Alzheimer disease to mortality in the United States. Neurology, 82(12): 1.0451.050, 2014. Disponível em: <www.neurology.org/content/early/2014/03/05/WNL.0000000000000240>. Acesso em: 12 mar. 2014.

KNUTH A. G. et al. Avaliação de Programas de Atividade Física no Brasil: uma revisão de evidências em 17 experiências selecionadas. Brasília: Ministério da Saúde, 2011.

LANSKY, S. et al. Evolução da mortalidade infantil no Brasil - 1980 a 2005. In: BRASIL. Ministério da Saúde. Secretária de Vigilância em Saúde. Saúde Brasil 2008: 20 anos do Sistema Único de Saúde no Brasil. Brasília: Ministério da Saúde, 2009.

PAN AMERICAN HEALTH ORGANIZATION (PAHO). Pan American Health Organization. Disponível em: < www. paho.org/hq/index.php?option $=$ com_content\&view $=$ article\&id $=9053 \% 3$ Achikungunya\&catid $=4760 \% 3 \mathrm{Ahsd}$ 0111b-viral-diseases-chikungunya\&Itemid=39843\&lang=pt>. Acesso em: 15 mar. 2014.

RECIFE. Secretaria Municipal de Saúde. Boletim Epidemiológico das Grandes Endemias no Recife, 2009 - 2010, ano 1, n. 1., Recife, 2010.

REDE INTERAGENCIAL DE INFORMAÇÕES PARA A SAÚDE (RIPSA). Comitê Temático Interdisciplinar (CTI). Natalidade e Mortalidade: grupo de trabalho ad hoc. Relatório final. Brasília: Organização Pan-Americana da Saúde; 2000. Disponível em: < http://www.opas.org.br/informacao/UploadArq/gtnatmort_Relatorio_final\%5B1\%5D. pdf $>$. Acesso em: 10 jan. 2014.

REDE INTERAGENCIAL DE INFORMAÇÕES PARA A SAÚDE (RIPSA). Indicadores Básicos para a Saúde no Brasil: conceitos e aplicações. 2. ed. Brasília: Organização Pan-Americana da Saúde, 2008. 
REDE INTERAGENCIAL DE INFORMAÇÕES PARA A SAÚDE (RIPSA). Ficha de Qualificação de Indicadores, 2012. Disponível em: <http://fichas.ripsa.org.br/2012/categ/mortalidade/?l=pt_BR > . Acesso em: 12 jan. 2014.

TRAPLETTI A. \& HORNIK K. tseries: Time Series Analysis and Computational Finance. R package version 0.10-28. 2013. Disponível em: <http://cran.r-project.org/web/packages/tseries/index.html>. Acesso em: 16 jan. 2014.

UNITED NATIONS (UN). World Population Prospects The 2012 revision: methodology of the United Nations Population estimates and projections, 2012. Disponível em: < https://esa.un.org/unpd/wpp/Publications/ Files/WPP2012_Methodology.pdf>. Acesso em: 18 jan. 2014.

UNITED NATIONS INTER-AGENCY GROUP FOR CHILD MORTALITY ESTIMATION (UN IGME). Levels \& Trends in Child Mortalit. New York: United Nations Childen's Fund, 2013. Disponível em: <www.unicef.org/media/ files/2013_IGME_child_mortality_Report.pdf>. Acesso em: 14 jan. 2014.

VICTORA, C. G. et al. Saúde de mães e crianças no Brasil: progressos e desafios. Série Saúde no Brasil. The Lancet, 32-46, 2011. Disponível em: <www.thelancet.com/series/health-in-brazil >. Acesso em: 15 dez. 2013.

WILD S. H. et al. Global prevalence of diabetes: estimates for the year 2000 and projections for 2030. Diabetes Care, 27(10): 1.047-1.053, 2004.

WORLD HEALTH ORGANIZATION (WHO). The World Health Report 2007: a safer future: global public health security in the 21st century. Geneva: World Health Organization, 2007. Disponível em: <www.who.int/whr/2007/ whr07_en.pdf>. Acesso em: 4 ago. 2014.

WORLD HEALTH ORGANIZATION (WHO). Global Health Estimates: methods and data sources for global causes of death, 2000-2011. Geneva: World Health Organization, 2013a. Disponível em: <www.who.int/healthinfo/ global_burden_disease/GlobalCOD_method_2000-2011.pdf?ua=1>. Acesso em: 4 ago. 2014.

WORLD HEALTH ORGANIZATION (WHO). WHO Methods and Data Sources for Global Causes of Death 20002011. Geneva: World Health Organization, 2013b. Disponível em: <www.who.int/healthinfo/statistics/ GHE_TR2013-3_COD_MethodsFinal.pdf>. Acesso em: 4 ago. 2014.

WORLD HEALTH ORGANIZATION (WHO). Summary of probable SARS cases with onset of illness from 1 November 2002 to 31 July 2003. Disponível em: <www.who.int/csr/sars/country/table2004_04_21/en/>. Acesso em: $20 \mathrm{dez} .2013 \mathrm{c}$.

WORLD HEALTH ORGANIZATION (WHO). Dengue and severe dengue, n. 117, 2014a. Disponível em: <www. who.int/mediacentre/factsheets/fs117/en/ >. Acesso em: 30 mar. 2014.

WORLD HEALTH ORGANIZATION (WHO). Middle East respiratory syndrome coronavirus summary and literature update - as of 27 march 2014, 2014b. Disponível em: <www.who.int/csr/disease/coronavirus_infections/ MERS_CoV_Update_27_March_2014.pdf?ua=1>. Acesso em: 29 mar. 2014.

WORLD HEALTH ORGANIZATION (WHO). Global Influenza Programme. Disponível em: <www.who.int/ influenza/en/>. Acesso em: 15 mar. 2014c.

WORLD HEALTH ORGANIZATION (WHO). The top 10 causes of death. Updated July 2013. Disponível em: <www.who.int/mediacentre/factsheets/fs310/en/ > . Acesso em: 9 jan. 2014d.

WORLD HEALTH ORGANIZATION (WHO). WHO Director-General summarizes the outcome of the Emergency Committee regarding clusters of microcephaly and Guillain-Barré syndrome. Disponível em: < http://www. who.int/mediacentre/news/statements/2016/emergency-committee-zika-microcephaly/en/ > . Acesso em: 01 mar. 2017.

ZUMLA, A. I. et al. New antituberculosis drugs, regimens, and adjunct therapies: needs, advances, and future prospects. The Lancet, 14(4): 327-340, 2014. Disponível em: <http://dx.doi.org/10.1016/S1473-3099(13)70328-1> . Acesso em: 24 mar. 2014. 


\title{
OS RECURSOS FÍSICOS DE SAÚDE NO BRASIL: UM OLHAR PARA O FUTURO'
}

\author{
Isabela Soares Santos \\ Luisa Regina Pessôa \\ Juliana Pires Machado \\ Ana Cristina Marques Martins \\ Claudia Risso de Araujo Lima
}

Mapear a atual capacidade instalada de saúde no Brasil constitui um caminho estratégico de identificação e análise das necessidades de investimento para atender às demandas advindas das mudanças sociodemográficas, econômicas e epidemiológicas previstas para os próximos vinte anos até 2034 .

Cabe uma discussão semântica para identificar e nomear nosso objeto, conhecido como oferta de serviços de saúde, capacidade instalada de saúde, estrutura de serviços de saúde e, por fim, a denominação que optamos por utilizar: recursos físicos da saúde. Ainda é escassa a discussão acadêmica sobre qual o melhor termo, razão pela qual será dada uma breve explicação do motivo que nos levou a essa escolha para designar a capacidade instalada de saúde. Recursos físicos de saúde são parte da oferta de serviços da saúde, que engloba:

- recursos físicos: compreendem as edificações, suas instalações, equipamentos e mobiliários (Pessôa, 1996) que no Cadastro Nacional de Estabelecimentos de Saúde (CNES) estão expressos em leitos, serviços, equipamentos, entre outros;

- recursos humanos: quadro de profissionais existentes;

- recursos cognitivos/tecnológicos: conhecimento acumulado para exercer as atividades profissionais específicas visando operacionalizar e gerenciar a capacidade instalada;

- recursos materiais: insumos diversos, medicamentos e material médico-cirúrgico;

- recursos financeiros: custeio e capital;

- recursos de poder: viabilizam a inserção na rede de atenção, de modo credenciado e sustentável.

Não serão analisados dados sobre toda a oferta de serviços de saúde, uma vez que esta pressupõe a existência dos demais recursos relacionados anteriormente. Ainda, consideramos que os recursos humanos e os profissionais específicos da assistência (enfermeiros, médicos e outros profissionais da saúde) já estão contemplados em outro capítulo nesta obra.

\footnotetext{
${ }^{1}$ Agradecemos a disponibilidade para discussão e contribuição dos especialistas da equipe de Claudio Noronha na Coordenação de Prevenção e Vigilância do Instituto Nacional de Câncer José Alencar Gomes da Silva (Conprev/ Inca) e do pesquisador Walter Mendes Jr. do Departamento de Administração e Planejamento em Saúde da Escola Nacional de Saúde Pública Sergio Arouca da Fundação Oswaldo Cruz.
} 
Os recursos físicos compõem apenas uma das dimensões do parque tecnológico de saúde no Brasil, já que tecnologia de saúde envolve todas as formas de conhecimento que podem ser aplicadas para solução ou redução dos problemas de saúde de indivíduos ou populações. Um dos principais problemas atuais em grande parte dos hospitais brasileiros, no contexto de discussão das possibilidades de prospecção tecnológica, é o do baixíssimo número de profissionais capacitados voltados para a gestão do parque tecnológico da saúde - tanto para a avaliação tecnológica como para a incorporação de tecnologias - ou seja, pesquisadores, gerentes, profissionais da saúde e técnicos.

A incorporação de novas tecnologias de saúde no Brasil, em especial na rede pública, é muitas vezes realizada de forma inadequada, em face da fragilidade dessas incorporações. A gravidade dessa situação é ressaltada no resultado de auditoria do Tribunal de Contas da União, com ampla cobertura da mídia, no que se refere ao tema da assistência hospitalar no SUS: baseado no estudo abrangendo 116 hospitais públicos com mais de 50 leitos, que concentram aproximadamente 27.614 leitos (8,6\% do total de leitos na rede pública), em todos os estados da federação, identificaram-se os motivos para bloqueio ou indisponibilidade de leitos e serviços para uso da população (TCU, 2013; Anexo).

Parte dos problemas enfrentados na rede de saúde em relação aos seus recursos físicos é reflexo da carência de trabalhadores da construção civil e na área de máquinas e equipamentos envolvidos no processo operacional e de manutenção. Apesar de os estudos recentes não serem específicos do setor Saúde, a situação nesse setor pode ser mais grave, dada a insuficiente formação específica para a área. A carência desses profissionais é agravada pela insuficiência de médicos, enfermeiros e outros profissionais da saúde, caracterizando um problema a ser enfrentado pelas políticas públicas, com influência tanto sobre as tecnologias em uso como na incorporação de novas tecnologias.

\section{Contexto}

Em relação a expansão e transformação da estrutura de serviços de saúde do Brasil, envolvendo unidades públicas e privadas, é importante compreender os desafios do cenário atual em relação ao conjunto de recursos assistenciais. "É preciso apreender sua historicidade, seus determinantes, os valores e atores envolvidos, com vistas à elaboração de propostas que possam ser, de fato, estruturantes e coerentes com o conjunto das políticas públicas e de saúde" (Brasil, 2004c: 9).

Nesse contexto, um dos desafios é estabelecer ações para que haja uma melhor sinergia entre os valores e atores envolvidos, como a indústria de medicamentos, equipamentos e insumos, os serviços prestadores de assistência direta públicos e privados, as empresas prestadoras de serviços profissionais e de consultorias, os aparelhos formadores de profissionais, as entidades de pesquisa, os profissionais, as operadoras, as empresas que compram planos privados de saúde para seus trabalhadores, o governo e o cidadão (Vecina Neto \& Malik, 2007).

A rápida e crescente transformação da assistência médico-hospitalar a partir da década de 1980 e os avanços da tecnologia - sobretudo dos recursos para diagnóstico e terapia - têm ocorrido associados a um crescimento desordenado dos serviços intra-hospitalares, gerando reflexos na organização funcional das unidades de saúde. Esse problema tem se agravado pela falta de 
continuidade dos processos ao longo das diversas gestões de diretores de hospitais, secretários de saúde, interpostas no decorrer das décadas, de modo que a cada nova gestão se inicia um novo e diferente processo gerencial realizado por uma nova equipe. Os casos de maior continuidade são aqueles nos quais se cria uma inteligência na unidade, com funcionários estáveis e capacitados para realizar esse processo.

Ao mesmo tempo, a incorporação de máquinas e equipamentos na assistência à saúde cada vez mais requer espaços e instalações sofisticados e o cumprimento de muitas exigências de segurança. Sem mão de obra qualificada essa incorporação fica incompleta e o equipamento pode, muitas vezes, permanecer encaixotado. Tal questão nos leva à necessidade de dimensionar quantos equipamentos existentes estão efetivamente em uso. Em geral, os gestores de saúde investem recursos na aquisição de equipamentos e na construção de instalações físicas de saúde que nem sempre condizem com a quantidade e especificidade necessária de profissionais da saúde.

O trabalho de Pessôa (2009) informa que em países desenvolvidos cerca de 25 a $50 \%$ dos parques de equipamentos não estão sendo totalmente utilizados. As razões para o uso ineficiente são variadas e incluem: dificuldades na aquisição de materiais de consumo e de peças de reposição; falta de recursos humanos treinados; inadequada infraestrutura para instalação e operação ou demanda muito baixa de pacientes (Pessôa, 2009).

A desatenção a questões de conjugação da dimensão operacional ao pensamento estratégico de planejamento e organização da atenção à saúde acarreta o surgimento de problemas mesmo entre os aparelhos em uso, levando a situações de desperdício. Diante dessa situação, consideramos estratégico estabelecer prioridades de investimento considerando os aparelhos em uso ou sem uso e as lacunas de existência de aparelhos. Sempre que possível, esse olhar estará presente na avaliação sobre a disponibilidade de recursos físicos de saúde.

Considerando os dias atuais, é indiscutível que o processo de incorporação de tecnologias na assistência médico-hospitalar ocorre de modo acelerado, irreversível e implacável. Conforme Pessôa (2005), tal processo é marcado por quatro dimensões "estruturantes" que lhe imprimem maior grau de complexidade:

- a incorporação de máquinas e equipamentos não substitui a mão de obra existente;

- a incorporação de tecnologias para o apoio ao diagnóstico é cumulativa - uma nova tecnologia não prescinde da anterior;

- a incorporação de tecnologias de saúde pressupõe a formação e capacitação constante de operadores das mesmas; e

- a incorporação de tecnologias de saúde pressupõe cuidados redobrados com "a saúde" do parque tecnológico, tendo em vista sua confiabilidade.

A mesma dinâmica vem impulsionando as transformações das estruturas físicas e tecnológicas do setor Saúde, trazendo à tona dilemas profundos no que concerne aos desafios da alocação de recursos para tal finalidade. Considerando que países em desenvolvimento geralmente têm escassez de recursos e limitações de orçamento para a realização de investimentos em aquisição, operação 
e manutenção de equipamentos ou tecnologias médico-hospitalares, torna-se recomendável que a decisão de comprar um novo equipamento não se baseie apenas no conceito do que seria "bom ter", mas, sobretudo, no que seria "necessário ter" e no que seria "possível operar". Assim, ao lado dos recursos físicos existentes, é preciso considerar o processo de formação de profissionais da saúde e afins.

Outro ponto importante de ponderação sobre os recursos físicos de saúde é o das altas taxas de cobertura de plano privado de saúde da população brasileira. As taxas de coberturas estão associadas aos níveis de escolaridade, de renda e de emprego (sobretudo o formal), fazendo com que as capitais e as demais regiões mais populosas e desenvolvidas do país tenham maiores parcelas da população com plano privado. Essa população usa grande parte dos serviços referenciados pelo plano, que são privados, mas muitas vezes esses serviços atendem tanto ao SUS como aos planos e a quem puder pagar diretamente do bolso. Nesse sentido, o dimensionamento da distribuição da oferta de recursos físicos deve contemplar tanto a distribuição geográfica como a distribuição público-privada dos recursos.

Além dessas questões, é imprescindível considerar o processo de transição demográfica que transforma a sociedade brasileira, com crescimento mais lento do número de crianças e adolescentes e aumento da população em idade ativa e de pessoas idosas, alterando a estrutura etária da população (Oliveira \& Oneill, 2013). São fatores determinantes dos observados declínios dos níveis gerais de mortalidade e das quedas expressivas da fecundidade que alteram o padrão de uso e a necessidade de recursos físicos de saúde.

Esse processo não ocorre de forma similar nas regiões do país; a necessidade de oferta e disponibilidade de recursos físicos também é diferente entre as regiões. Tome-se como exemplo o processo tardio de envelhecimento das populações das regiões Norte e Nordeste do país, paralelamente à transição demográfica nas regiões Sul e Sudeste do país e as correspondentes consequências das mudanças no perfil de morbidade dessa população. No momento atual, os estados do Norte e Nordeste poderiam estar se preparando e elaborando estratégias para melhor equacionar seus problemas quando alcançarem o ponto da transição demográfica em que as regiões Sul e Sudeste já se encontram.

Ademais, ao pensar na estrutura de oferta, é preciso considerar uma nova distribuição qualitativa dos serviços, extrapolando as especialidades clássicas e prevendo a necessidade de maior oferta a populações mais envelhecidas, ou a indivíduos portadores de doenças crônicas, múltiplas morbidades ou necessidades especiais, que ganharam maior sobrevida nas últimas décadas (por exemplo, os bebês com autismo, síndrome de Down etc.). As transições demográfica e epidemiológica muito provavelmente levarão ao aumento, no futuro, da demanda por serviços como fisioterapia e logopedia, por exemplo, ou mesmo por serviços disponíveis para pacientes fora de possibilidades terapêuticas e que requerem cuidados paliativos.

O aumento da longevidade interfere na estrutura das famílias: no início do século XX era comum pelo menos um membro da família ser portador de tuberculose; no início do século XXI, as famílias dispõem de pelo menos um idoso que requer apoio. São mudanças na sociedade que demandam lugares para os idosos morarem que não sejam hospitais, mas com estrutura de apoio que reconfigure a atenção à saúde do idoso: novas formas de homecare que sirvam para idosos que morem sozinhos 
e maior atenção aos cuidadores, profissionais ou familiares cada vez mais necessários. Esse já é um problema da sociedade brasileira das regiões Sul e Sudeste do país, mas em razão do processo de mudança sociodemográfica e de morbimortalidade, ainda há tempo para prevenir as regiões Norte e Nordeste dos acontecimentos previstos com estrutura para enfrentá-los em melhores condições.

Assim, as mudanças demográficas ocorridas nos últimos anos, associadas às mudanças no padrão de morbimortalidade da população brasileira, são fatores conjunturais essenciais na análise das necessidades futuras da estrutura dos serviços de saúde.

Em relação ao padrão de morbimortalidade da população brasileira, observa-se que nas análises da situação de saúde da população brasileira identificam-se avanços importantes traduzidos na redução significativa de alguns problemas, com destaque para as retrações observadas nas taxas de mortalidade infantil, na taxa de desnutrição em crianças e na ocorrência das doenças infectocontagiosas, parasitárias e as imunopreveníveis (Oliveira \& Oneill, 2013; Barreto, 2013, Luna \& Silva, 2013).

Todavia, é uma tendência o aumento da obesidade em todas as faixas etárias. A obesidade está relacionada à ocorrência de doenças cardiovasculares, hipertensão, diabetes e outras. As doenças cardiovasculares, às quais se atribuem reduções na taxa de mortalidade (TM), ainda são uma das principais causas de óbito entre os brasileiros. Além disso, permanecem como um importante fator de morbidade, levando a uma grande demanda por serviços, inclusive internações hospitalares. O tratamento dessas doenças, dentre elas a obesidade, deve estar direcionado para políticas e ações de promoção de dietas saudáveis, estímulo à atividade física e inserção na vida social. Ao mesmo tempo, muitas vezes esses problemas de saúde estão associados à necessidade de atividades de reabilitação e de intervenções complexas quando da instalação da doença e suas sequelas (Barreto, 2012; Luna \& Silva, 2013).

Um grupo de doenças que tem impacto importante no perfil de morbimortalidade da população brasileira é o do câncer. Os diferentes tipos de câncer apresentam distintas tendências de mortalidade, algumas de redução e outras de aumento. Ressalta-se o aumento das TMs de câncer de próstata e a redução das TMs de câncer de estômago entre os homens. Nas mulheres, observa-se aumento das TMs de câncer de mama e de pulmão (Barreto, 2012; Luna \& Silva, 2013).

Outra questão que deve ser analisada em relação à estrutura de serviços de saúde é a demanda gerada pelos eventos provocados por causas externas (violências e acidentes). Nas últimas décadas, as diversas formas de violência e lesões estão entre os problemas de saúde que mais afligem os brasileiros. Os dois principais componentes, homicídios e acidentes de trânsito, são responsáveis por taxas de mortalidade muito superiores às de países desenvolvidos. Esses agravos, além do impacto sobre a mortalidade, geram grande demanda por serviços especializados de urgência/emergência relacionados ao trauma.

Também referentes ao trauma podemos citar as fraturas por fragilidades. De acordo com o presidente do $19^{\circ}$ Congresso Mineiro de Ortopedia ocorrido em 2014, o número de fraturas por fragilidade vem aumentando e estima-se que 30\% das pessoas com mais de 60 anos sofrerão quedas pelo menos uma vez ao ano, e em 5\% delas haverá uma fratura por fragilidade, mais comum no fêmur, vértebra ou punho (Congresso..., 2017). Esses dados seguramente impactam as estruturas de atenção ao trauma de média e alta complexidade. 
Em relação às ações de atenção ao parto, ainda que as taxas de fecundidade tenham se reduzido, permanecem problemas como a mortalidade materna, o aumento das já altas taxas de cesarianas, a prematuridade e as complicações no parto. Esse perfil de assistência está relacionado às políticas de saúde, ao comportamento médico e a interesses do mercado de medicamentos, equipamentos, bem como dos hospitais. Enquanto não se alterar o perfil das altas taxas de cesáreas e as correspondentes taxas de prematuridades e complicações evitáveis, esses fatores continuarão a gerar necessidade de UTI neonatal e de toda a atenção hospitalar envolvida.

Em relação às doenças neuropsiquiátricas, mesmo sem relevância para a questão da mortalidade, com base em evidências científicas, atesta-se uma alta e crescente prevalência na população, o que implica alterações significativas no cotidiano dos indivíduos, das famílias e da sociedade. Embora não tenhamos dados suficientes para inferir sobre as tendências de crescimento desse grupo de doenças, o processo de envelhecimento populacional teve como consequência o aumento dos quadros de demência em quatro vezes, isto é, de 1,8 para 7,0/100.000 habitantes, no período entre 1996 e 2007 (Oliveira \& Oneill, 2013; Barreto, 2013, Luna \& Silva, 2013).

Enfim, o objetivo de assinalar o quê e onde investir em capacidade instalada em saúde para melhor atender aos problemas de saúde da população brasileira nos próximos vinte anos requer uma capacidade do Estado de operacionalização das estratégias de expansão e reorganização do parque tecnológico do setor Saúde, de modo a superar os problemas advindos da insuficiência de recursos humanos, da dualidade público-privada, da transição demográfica e das alterações do perfil epidemiológico da população brasileira, que não se resolvem exclusivamente no setor Saúde.

Esse nó crítico direciona necessariamente para uma articulação com soluções intersetoriais. Quaisquer que sejam nossos projetos de investimento no setor Saúde, em grande parte dos casos estarão implicadas ações tais como construir ou adequar espaços para atender as demandas tecnológicas, demográficas, ou epidemiológicas da população brasileira.

\section{Metodologia}

O estudo foi realizado em duas etapas complementares: revisão bibliográfica e análise dos dados sobre recursos físicos.

\section{Revisão bibliográfica}

Tendo como objetivo descrever a situação atual e identificar os principais problemas e recursos explorados em outras análises sobre a rede assistencial, realizou-se um levantamento de publicações de natureza variada sobre o tema. Pesquisaram-se estudos existentes sobre evolução, tendências e projeções nas áreas de sociodemografia e economia, políticas públicas e situação epidemiológica no Brasil. Diversos capítulos do livro A Saúde no Brasil em 2030: diretrizes para a prospecção estratégica do sistema de saúde brasileiro contribuíram para nortear essa seleção. Também se empreenderam revisão bibliográfica e levantamento de publicações na mídia (jornais e revistas).

Na revisão bibliográfica foram consultadas as bases de dados de artigos científicos Medline, Lilacs e Google e selecionados estudos que tinham como objetivo analisar a oferta de serviços e que 
utilizaram dados da Pesquisa Assistência Médico-Sanitária (AMS) do Instituto Brasileiro de Geografia e Estatística (IBGE) ou do CNES com análises próprias e não apenas descrição de outras análises. Aplicaram-se os seguintes termos:

- Medline: Health Services Accessibility (Availability of Health Services, Health Services Availability, Accessibility, Health Services, Access to Health Care, Accessibility of Health Services, Health Services Geographic Accessibility); Health Care Rationing; provision of health service; Brazil e Brazilian (brazil*).

- Lilacs: Serviços de saúde, estatísticas; dados; acesso aos Serviços de Saúde; Brasil, Brasil*; disponibilidade de serviços de saúde, AMS; IBGE.

\section{Análise dos dados sobre recursos físicos}

A seleção dos principais agravos que afetarão a população em 2034 e os correspondentes recursos físicos de saúde para seu enfrentamento foram subsidiados pela revisão bibliográfica. Os achados da revisão foram organizados de maneira que indicassem algumas áreas da saúde que possivelmente serão importantes objetos de atenção para o SUS em 2034. Além disso, buscou-se o alinhamento com as análises de outros textos deste volume. Por fim, foram selecionados: gestação e parto de alto risco, saúde do idoso, trauma, doença renal, doença cardíaca e oncologia.

Além da análise para os grupos selecionados, considerou-se também a necessidade de se observarem recursos físicos estratégicos na organização da assistência à saúde da população. Exploraramse dados relacionados à rede para assistência da população em suas diversas fases de vida: saúde neonatal, saúde infantil, saúde da mulher e obstetrícia, saúde do adulto e do idoso, e as informações que serão apresentadas a seguir excluem aquelas relacionadas a parto e saúde do idoso.

\section{Fonte de dados}

As informações sobre população utilizadas para construir indicadores de disponibilidade foram obtidas na página do Departamento de Informática do SUS (Datasus). Esses dados se referem às estimativas de população para os períodos intercensitários, disponíveis até o ano de 2012 no tabulador Tabnet à época da extração dos dados.

Uma fonte importante de informações sobre recursos físicos de saúde no Brasil é a AMS, realizada pelo IBGE com apoio do Ministério da Saúde. Essa pesquisa tem como objetivo traçar o perfil dos estabelecimentos de saúde públicos e privados, com ou sem internação, instalados no país (IBGE, 2010). Tem sido aplicada como fonte de informações por diversos estudos científicos que abordam temas relativos à rede de atenção à saúde. Diante de sua metodologia consolidada, espera-se que os resultados obtidos pela AMS sejam fiéis à realidade da rede instalada no país. Entretanto, sua última edição data de 2009, o que se considerou inadequado para retratar a situação atual dos recursos físicos de saúde. Além disso, dados de estabelecimentos não são disponibilizados individualmente pela AMS, o que impossibilitaria a elaboração de análises com dados cruzados de outras fontes.

Outra importante fonte de dados é o CNES, sob gestão do Ministério da Saúde, que contém informações sobre a estrutura física e funcional dos estabelecimentos de saúde públicos e privados no 
país. Passou em 2003 a ser o sistema de informação oficialmente utilizado pelo SUS para o pagamento dos serviços realizados, substituindo um conjunto de campos sobre estabelecimentos que faziam parte do SIH/SUS e do SIA/SUS (Opas, 2008; Carvalho, 2004). De acordo com os atos normativos que o regem, a validação das informações é de responsabilidade do gestor de saúde local, podendo opcionalmente o preenchimento das fichas de cadastramento ser realizado pelos gestores das unidades de saúde (Brasil, 2000a). No setor Saúde Suplementar, desde julho de 2003, estabeleceu-se a obrigatoriedade de cadastramento no CNES para a celebração de contratos entre operadoras de planos de saúde e prestadores de serviços (ANS, 2003). Desde 2004 tornou-se obrigatório o fornecimento do número CNES de todos os prestadores da rede de serviços próprios ou contratados, vinculados a qualquer plano de saúde cadastrado na ANS, para fins de concessão de autorização de funcionamento das operadoras de planos de saúde (ANS, 2004).

Atualmente os maiores desafios do CNES se relacionam a atualização e validação das características de estabelecimentos informadas, especialmente à manutenção de diversas informações funcionais e referentes a programas específicos, a serem registradas no CNES. Apesar disso, em análise recente, Machado (2014) observou o preenchimento completo e consistente dos campos de dados cadastrais de estabelecimentos com internação entre 2008 e 2010, inclusive na comparação destes campos com os similares coletados pela AMS. Outra pesquisa já havia destacado a importância desse cadastro nacional como base para os sistemas de informação sobre assistência à saúde no Brasil, enfatizando sua aplicação na auditoria de serviços, estruturas físicas e recursos humanos (Nascimento, 2012).

Optou-se por utilizar apenas os dados do CNES, considerando o seu ganho de estabilidade nos últimos anos, a disponibilidade de dados individualizados de estabelecimentos, e também as diferenças conceituais entre AMS e CNES que não possibilitaram a construção de séries históricas agregando dados das duas fontes. Isso impediu a aplicação de metodologias mais robustas para a obtenção de projeções. Assim, no lugar de projeções para os próximos vinte anos, elaborou-se um retrato da situação atual.

Foram utilizados os arquivos de dados disponibilizados publicamente na página de internet do Datasus. ${ }^{2}$ O número do CNES e o código IBGE do município foram aplicados como chaves na vinculação das informações.

\section{Análise dos dados}

Foram identificados os recursos necessários para a execução da assistência à saúde da população nas diversas fases da vida, bem como para atender às condições de saúde selecionadas a partir da revisão realizada. Para isso, foram pesquisados atos normativos e estudos científicos especializados em cada tema. Em seguida, foram analisadas as informações disponibilizadas no CNES, selecionando-se aquelas que mais se aproximassem das questões de interesse, com ênfase nos recursos hospitalares. Os hospitais foram categorizados por porte de leitos totais, considerando políticas e portarias existentes, e por porte de leitos de UTI conforme listado no Quadro 1.

\footnotetext{
${ }^{2}$ Ver $<$ cnes.datasus.gov.br $>$.
} 
Quadro 1 - Dados para análise das estruturas por fases da vida e condições selecionadas

\section{Hospitais por porte (por natureza jurídica)}

1.1 Porte de leitos (total existente, excluindo complementares, psiquiatria, acolhimento noturno e hospital-dia)

- Categoria 1: até 12 leitos (Política de Unidades Mistas)

- Categoria 2: de 13 a 49 leitos (hospital de pequeno porte - portaria n. 1.044/2004)

- Categoria 3: de 50 a 79 leitos

- Categoria 4: de 80 a 99 leitos

- Categoria 5: de 100 a 149 leitos

- Categoria 6: de 150 a 199 leitos

- Categoria 7: de 200 a 299 leitos

- Categoria 8: 300 ou mais leitos

1.2 Porte de leitos de UTI (adulto, pediátrico, neonatal)

- Categoria 1: até 5 leitos

- Categoria 2: de 6 a 10 leitos

- Categoria 3: 11 ou mais leitos

\section{Condições selecionadas}

Trauma de média complexidade

Trauma de alta complexidade

Doença renal

Doença cardíaca

Por meio da base cadastral do CNES buscou-se descrever os estabelecimentos existentes segundo localização geográfica (com ênfase nos municípios) e segundo características selecionadas: natureza jurídica, tipo de atendimento prestado, tipo de estabelecimento. Essas variáveis foram recategorizadas, tendo como objetivo agregar dados muito detalhados e selecionar apenas aqueles que se enquadrassem no escopo deste estudo. Observaram-se os leitos existentes nas unidades segundo tipos e subtipos, excluindo-se da análise os leitos de psiquiatria, acolhimento noturno e hospital-dia. Averiguou-se ainda a disponibilidade dos leitos para o SUS, classificando-os em SUS e Não SUS. Foram selecionados, para elaboração dos mapas, os equipamentos de interesse em uso, não sendo considerados os existentes e fora de uso. Todas as categorias, filtros e agregações utilizadas estão descritas no Quadro 2. Por exemplo, para hospital geral ou especializado foram considerados os conteúdos relativos aos campos 5 e 7, como demonstrado no quadro a seguir. 
Quadro 2 - Categorias, campos e códigos do CNES utilizados nos filtros e referências para a seleção de recursos a serem analisados

\begin{tabular}{|c|c|c|}
\hline $\begin{array}{l}\text { Informação } \\
\text { analisada }\end{array}$ & Recursos físicos de saúde analisados e códigos dos filtros aplicados & Referências \\
\hline $\begin{array}{l}\text { Características } \\
\text { de hospitais }\end{array}$ & $\begin{array}{l}\text { • Natureza jurídica (campo "natureza") } \\
\text { Incluídos agregados: } \\
\text { 1,2,3,4,5,6: público } \\
\text { 11: privado sem fins lucrativos } \\
\text { 7,8,9,10,12: privado com fins lucrativos } \\
\text { - Tipo de atendimento prestado (campo "atendimento_prestado") } \\
\text { Incluídos: } \\
\text { 1- internação; } \\
\text { 2- ambulatorial; } \\
\text { 3- serviços de apoio diagnóstico e terapêutico (SADT); } \\
\text { 4- urgência. } \\
\text { - Tipo de estabelecimento (campo "tipo_unidade") } \\
\text { Incluídos agregados: } \\
\text { 1,2: centro ou posto de saúde } \\
\text { 4,36: policlínica, clínica ou ambulatório especializado } \\
\text { 5,7: hospital geral ou especializado } \\
\text { 20,21: pronto-socorro geral, pronto-socorro especializado } \\
\text { 39: unidade de SADT }\end{array}$ & \\
\hline $\begin{array}{l}\text { Características } \\
\text { de leitos }\end{array}$ & $\begin{array}{l}\text { - Tipo de leito (campo "tp_leito") } \\
\text { Incluídos: } \\
\text { 1- cirúrgicos; } \\
\text { 2- clínicos; } \\
\text { 3- obstétricos; } \\
\text { 4- pediátricos; } \\
\text { 5- outras especialidades; } \\
\text { 7- complementar. } \\
\text { Excluídos: } \\
\text { 6- hospital-dia. } \\
\text { - Subtipo de leito (campo "co_leito") } \\
\text { Incluídos agregados: } \\
\text { 74,75,76: UTI adulta } \\
\text { 77,78,79: UTI pediátrica } \\
\text { 80,81,82: UTI neonatal } \\
\text { Excluídos: } \\
\text { 84: acolhimento noturno } \\
\text { 47: psiquiatria } \\
\text { Incluídos todos os demais } \\
\text { - SUS e Não SUS (campos “qt_exist" e "qt_SUS") } \\
\text { SUS = qt_SUS } \\
\text { Não SUS = qt_exist - qt_SUS }\end{array}$ & $\begin{array}{l}\text { Manual CNES } 2008 \text { e } \\
\text { Manual CNES } 2006 \text {. } \\
\text { Disponível em: <cnes. } \\
\text { datasus.gov.br>. } \\
\text { Acesso em: } 30 \text { jun. } \\
2014\end{array}$ \\
\hline Equipamentos & $\begin{array}{l}\text { - Equipamentos } \\
\text { Incluídos agregados: } \\
\text { 2,3,17: mamografia } \\
\text { 4,5,6: raios X } \\
\text { 10: raios X para hemodinâmica } \\
\text { 11: tomografia computadorizada } \\
\text { 12: ressonância magnética } \\
\text { 13,14,15: ultrassonografia } \\
\text { 76: circulação extracorpórea } \\
\text { 77: hemodiálise } \\
\text { bomba de cobalto (arquivos de dados complementares) }\end{array}$ & \\
\hline
\end{tabular}


Quadro 2 - Categorias, campos e códigos do CNES utilizados nos filtros e referências para a seleção de recursos a serem analisados (cont.)

\begin{tabular}{|c|c|c|}
\hline & $\begin{array}{l}\text { - Selecionaram-se estabelecimentos com atendimento hospitalar. A presença } \\
\text { de cinco itens estruturais foi observada em cada um deles, atribuindo-se uma } \\
\text { pontuação de } 0 \text { a } 5 \text { de acordo com o número de estruturas existentes. } \\
\text { - Itens de estrutura analisados: }\end{array}$ & $\begin{array}{l}\text { Política Nacional de } \\
\text { Atenção às Urgências } \\
\text { (2006); } \\
\text { Portaria GM n. } 2.048 \\
\text { de } 5 \text { de novembro de } \\
\text { 2002; }\end{array}$ \\
\hline $\begin{array}{l}\text { Trauma - média } \\
\text { complexidade }\end{array}$ & $\begin{array}{l}\text { - Leitos: UTI (co_leito = 74,75,76), hospitais com mais de } 100 \text { leitos. } \\
\text { - Equipamentos: tomografia computadorizada (11). } \\
\text { - Serviços: assistência de alta complexidade em neurocirurgia (105- serviço } \\
\text { de assistência de alta complexidade em neurocirurgia - exige neurocirurgia e } \\
\text { traumatologia), hemoterapia (serviço 128). }\end{array}$ & $\begin{array}{l}\text { "Abordagem } \\
\text { ao Paciente } \\
\text { Politraumatizado: } \\
\text { protocolos clínicos" } \\
\text { (Secretaria de Estado } \\
\text { de Saúde de Minas } \\
\text { Gerais, 2011); e } \\
\text { Portaria n. 1.366, de } 8 \\
\text { de julho de } 2013 \text {. }\end{array}$ \\
\hline $\begin{array}{l}\text { Trauma - alta } \\
\text { complexidade }\end{array}$ & $\begin{array}{l}\text { - Selecionaram-se estabelecimentos com atendimento hospitalar. A presença } \\
\text { de oito itens estruturais foi observada em cada um deles, atribuindo-se uma } \\
\text { pontuação de } 0 \text { a } 8 \text { de acordo com o número de estruturas existentes. } \\
\text { - Itens de estrutura analisados: } \\
\text { - Leitos: UTI (co_leito=74,75,76), hospitais com mais de } 100 \text { leitos. } \\
\text { - Equipamentos: tomografia computadorizada (11), ressonância magnética (12). } \\
\text { - Serviços: assistência de alta complexidade em neurocirurgia (105- serviço } \\
\text { de assistência de alta complexidade em neurocirurgia - exige neurocirurgia e } \\
\text { traumatologia), hemoterapia (serviço 128), radiologia intervencionista (serviço } \\
\text { 121, classe 006), reabilitação (serviço 135). }\end{array}$ & $\begin{array}{l}\text { Política Nacional de } \\
\text { Atenção às Urgências } \\
\text { (2006); } \\
\text { Portaria GM n. } 2.048 \\
\text { de } 5 \text { de novembro de } \\
2002 \text {; } \\
\text { "Abordagem } \\
\text { ao Paciente } \\
\text { Politraumatizado: } \\
\text { protocolos clínicos" } \\
\text { (SES/MG, 2011); e } \\
\text { Portaria n.1.366, de } 8 \\
\text { de julho de 2013. }\end{array}$ \\
\hline Doença renal & $\begin{array}{l}\text { - Selecionaram-se estabelecimentos com ou sem atendimento hospitalar. Foram } \\
\text { analisados os estabelecimentos com equipamento de hemodiálise, segundo } \\
\text { habilitação em nefrologia e para transplante de rim. } \\
\text { - Itens de estrutura analisados: } \\
\text { - Equipamento de hemodiálise (77) } \\
\text { - Habilitação como "Unidade de Assistência de Alta Complexidade em Nefrologia } \\
\text { (1501 Serviço de Nefrologia)" ou Habilitação como "Centro de Referência de Alta } \\
\text { Complexidade em Nefrologia" (1502) } \\
\text { - Habilitação para transplante de rim (2408) }\end{array}$ & $\begin{array}{l}\text { Portaria n. } 1168 / \mathrm{GM} \\
\text { de } 15 \text { de junho de } \\
2004 \text {; } \\
\text { Portaria SAS/MS n. } \\
211 \text {, de } 15 \text { de junho } \\
\text { de } 2004 \text {; } \\
\text { e Portaria SE/SAS n. } \\
55 \text { de } 29 \text { de agosto de } \\
2001 .\end{array}$ \\
\hline Doença cardíaca & $\begin{array}{l}\text { - Selecionaram-se estabelecimentos com atendimento hospitalar, habilitados para } \\
\text { a realização de cirurgia cardíaca em adulto ou pediatria. A presença de UTI e } \\
\text { circulação extracorpórea foi observada para cada estabelecimento. } \\
\text { - Itens de estrutura analisados: } \\
\text { - Serviços: cirurgia cardiovascular adulto (serviço 116, classe 002) ou cirurgia } \\
\text { cardiovascular pediátrica (serviço } 116 \text {, classe } 003 \text { ). } \\
\text { - Leitos: UTI adulta (co_leito=74,75,76) ou UTI pediátrica (co_ } \\
\text { leito=77,78,79,80,81,82) } \\
\text { - Equipamentos: circulação extracorpórea (76) }\end{array}$ & $\begin{array}{l}\text { Portaria n. } 210 \text { de } 15 \text { de } \\
\text { junho de } 2004\end{array}$ \\
\hline
\end{tabular}


Para as análises de estruturas envolvendo leitos para internação, construiu-se uma base de dados com todos os estabelecimentos cujo campo "tipo de atendimento prestado" no CNES estava definido como "com internação". Entre esses, foram excluídos os estabelecimentos sem leitos. Nessa base, foram incluídas todas as variáveis relativas a hospitais e leitos. Também foram construídas bases específicas para as análises de equipamentos, serviços e condições de saúde selecionadas.

\section{Resultados da Etapa de Revisão Bibliográfica}

A oferta de serviços no país é amplamente desigual, concentrando-se nas regiões Sudeste e Sul, principalmente para serviços de média e alta complexidade e para a disponibilização de mão de obra qualificada. Relata-se, nos estudos, a existência de grandes áreas com deficiências absolutas em equipamentos, instalações físicas e recursos humanos, mesmo para unidades de saúde com baixos níveis de complexidade (Rodrigues, Amaral \& Simões, 2007; Cazelli et al., 2002).

Dados de 2010 indicavam que as unidades de atenção básica e as de emergência eram, em geral, públicas, enquanto os hospitais, ambulatórios e serviços de apoio diagnóstico e terapêutico (SADT) eram, em sua maioria, privados, mas com uma parcela importante desses recursos contratados pelo SUS (Paim et al., 2011). Ressalta-se um crescimento da estrutura de serviços ambulatoriais públicos em todo o país, embora permaneçam as desigualdades regionais e a baixa capacidade resolutiva dessas unidades. Tal crescimento esteve associado ao intenso processo de descentralização que destinou maior responsabilidade aos municípios na gestão dos serviços de saúde nos últimos vinte anos (Paim et al., 2011; Costa \& Costa, 2002; Viacava \& Bahia, 2002; Mendes et al., 2012), junto com a implantação do Programa Saúde da Família, atual Estratégia Saúde da Família (ESF).

Há características importantes a considerar nas análises dos serviços ambulatoriais privados, como a feita por Viacava e Bahia (2002), limitadas no que se refere aos atendimentos vinculados às operadoras de planos privados de saúde, uma vez que os consultórios particulares, que representam o principal recurso da assistência ambulatorial das operadoras de planos privados, não estavam incluídos na pesquisa da AMS 92/99 e apenas nos últimos anos foram incorporados ao CNES.

A maior parte da oferta de leitos hospitalares e de unidades prestadoras de SADT era de propriedade privada. Contudo, a maioria desses leitos privados mantinha contrato pelo SUS (Santos, Ugá \& Porto, 2008). Identifica-se, nos últimos anos, a redução na oferta de leitos hospitalares, o que relativiza o peso dos hospitais no modelo assistencial brasileiro. Tal redução ocorreu de forma desigual entre os serviços privados e os públicos. Além disso, em 2004, apenas 2,2\% dos leitos nacionais eram de UTI e 22,8\% estavam em hospitais com menos de cinquenta leitos, menos efetivos e eficientes que os hospitais maiores (Mendes et al., 2012; Paim et al., 2011; Vecina Neto \& Malik, 2007; La Forgia \& Couttolenc, 2009).

Mesmo com a proeminência do SUS e a legitimidade constitucional do Estado brasileiro para garantir que o interesse público viesse a ser orientador do sistema de saúde, na prática o sistema de saúde brasileiro é constituído pelos setores público e privado, e as interações entre eles formam uma rede complexa de prestadores e compradores de serviços que competem entre si, gerando resultados negativos para a equidade e o acesso aos serviços de saúde, bem como para as condições de saúde 
da população (Paim et al., 2011; Santos, Ugá \& Porto, 2008). Nesse cenário está também uma parcela dos usuários dos serviços financiados pelo SUS e outra de planos privados, com maior poder aquisitivo e mais amplo acesso, e que ainda podem usar tanto os serviços financiados pelos planos de saúde em prestadores privados, como os financiados pelo SUS, seja em prestadores privados ou públicos (Santos, Santos \& Borges, 2013).

Tomando por base a análise da produção de serviços de saúde no período de 1999 a 2009, Mendes e colaboradores (2012) identificaram redução no número de internações pagas pelo SUS, ampliação da assistência ambulatorial, crescimento da assistência de alta complexidade ambulatorial e hospitalar e distribuição dos leitos e das internações nas especialidades não adequada às necessidades da população. Segundo os autores, o processo parece não levar em consideração as transformações exigidas pelo momento de transição demográfica, social e epidemiológica no Brasil (Mendes et al., 2012).

\section{Evolução da oferta da estrutura de serviços de saúde no Brasil de 1900 a 2000}

A trajetória da expansão da estrutura de serviços físicos de saúde ao longo do século XX foi analisada em Pessôa (2005) por meio dos dados de 2002 do CNES. Nos Gráficos 1, 2 e 3 são apresentadas as evoluções do número de unidades de saúde (SADT, unidades com internação e unidades sem internação), considerando a data de início de atividades.

No Gráfico 1, demonstra-se ligeiro decréscimo na curva de expansão das unidades hospitalares do SUS a partir de 1970, em detrimento do crescimento do número total de unidades, sugerindo que o setor privado continuou investindo na expansão de suas unidades hospitalares, embora em menor ritmo que nas décadas passadas.

Gráfico 1 - Evolução do número de unidades de saúde com internação, segundo década de início de atividade. Brasil - século XVI a XX

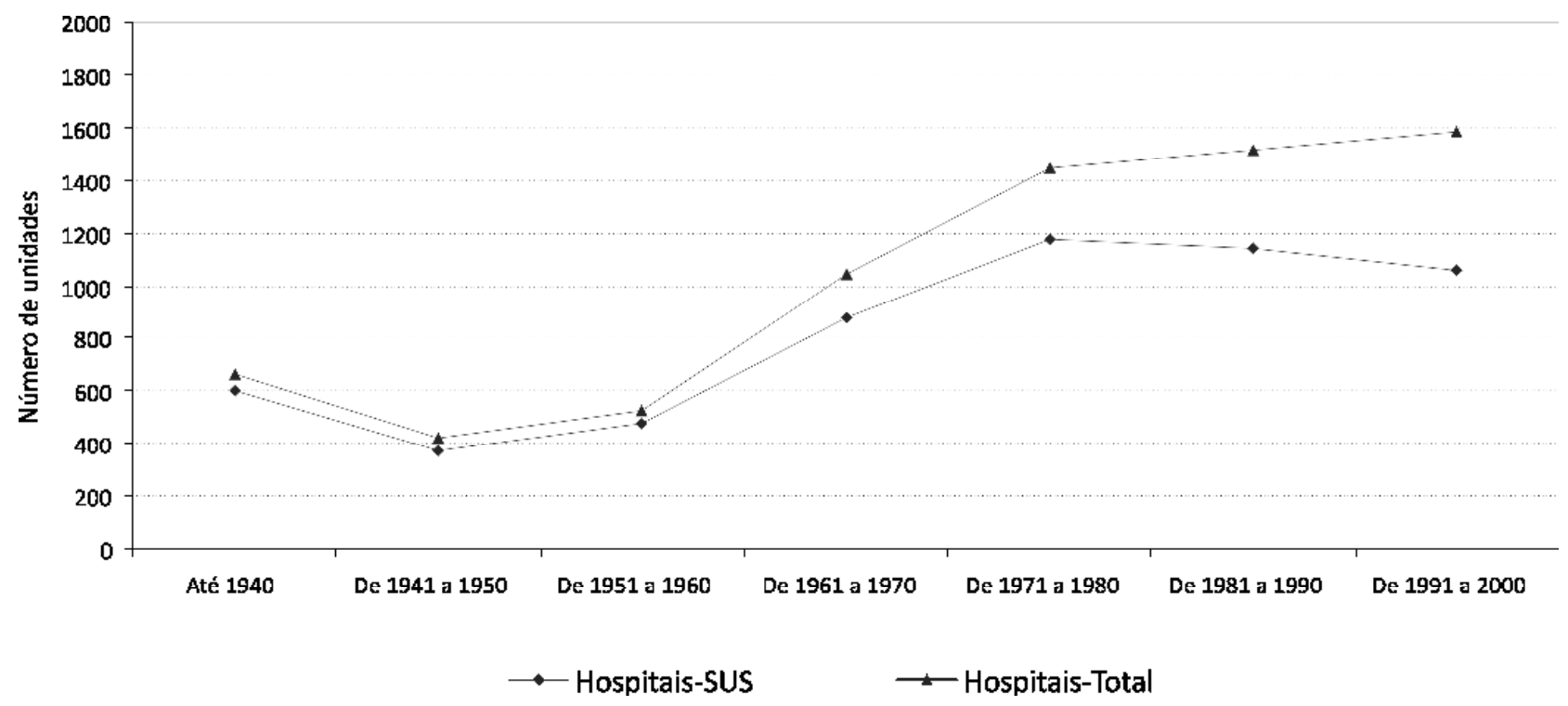

Fonte: Pessôa (2005). 
Por sua vez, no Gráfico 2, relativo à expansão das unidades sem internação, além de delinear-se a expressiva expansão das unidades SUS em contrapartida às da iniciativa privada, evidencia-se o crescimento desse tipo de unidade, sugerindo ainda uma tendência de continuidade.

Gráfico 2 - Evolução do número de unidades de saúde sem internação, segundo década de início de atividade. Brasil - século XVI a XX

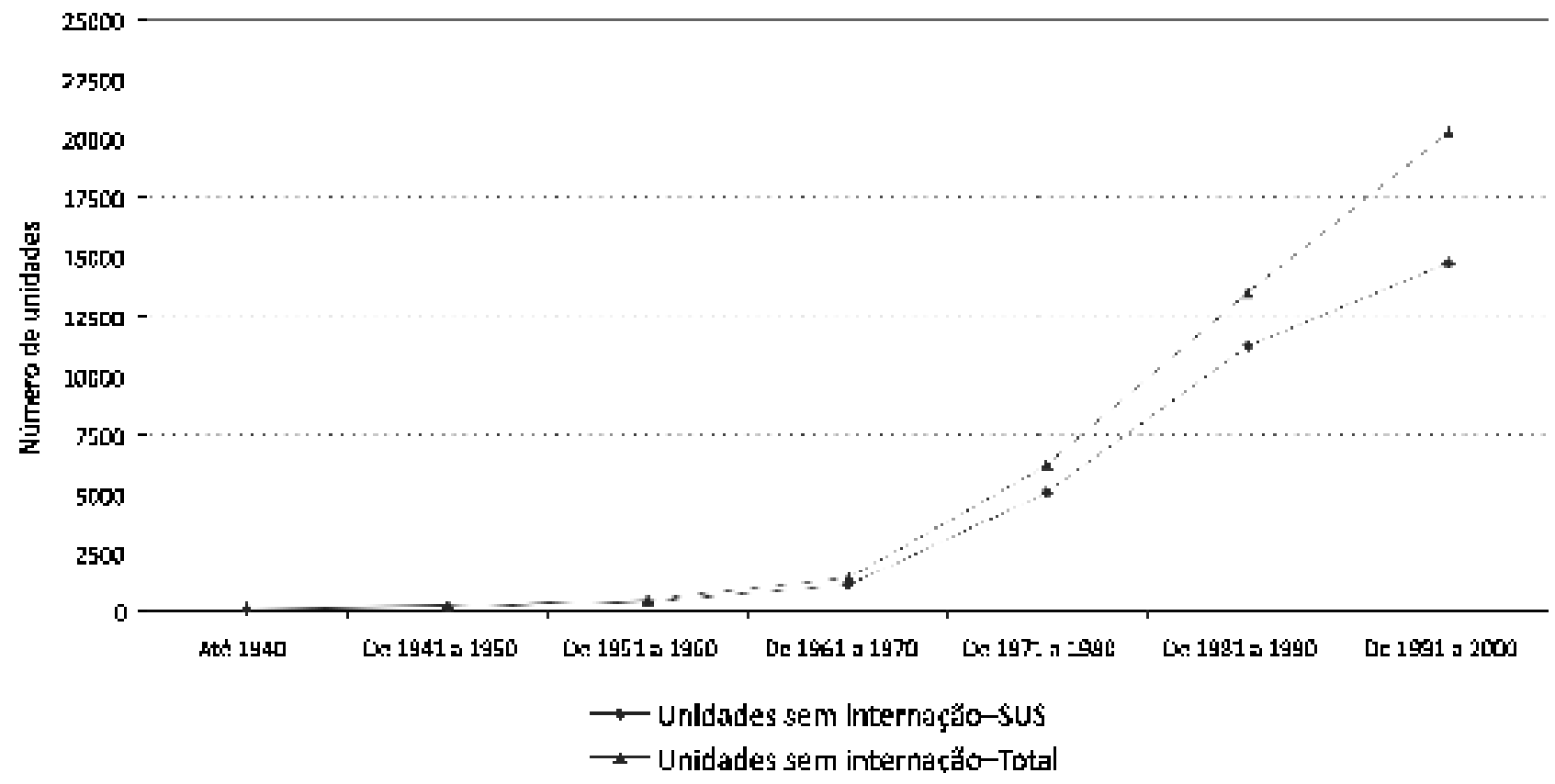

Fonte: Pessôa (2005).

No Gráfico 3, expressa-se a desigualdade do crescimento entre a estrutura de serviços SUS e o setor privado no que diz respeito aos SADT, um dos atuais pontos de estrangulamento da atenção à saúde pela estrutura de serviços SUS, tanto em relação à média como à alta complexidade. Do total de 13.484 unidades desse tipo, apenas 5.218 oferecem serviços ao SUS. 
Gráfico 3 - Evolução do número de unidades de saúde de SADT, segundo década de início de atividade. Brasil - século XVI a XX

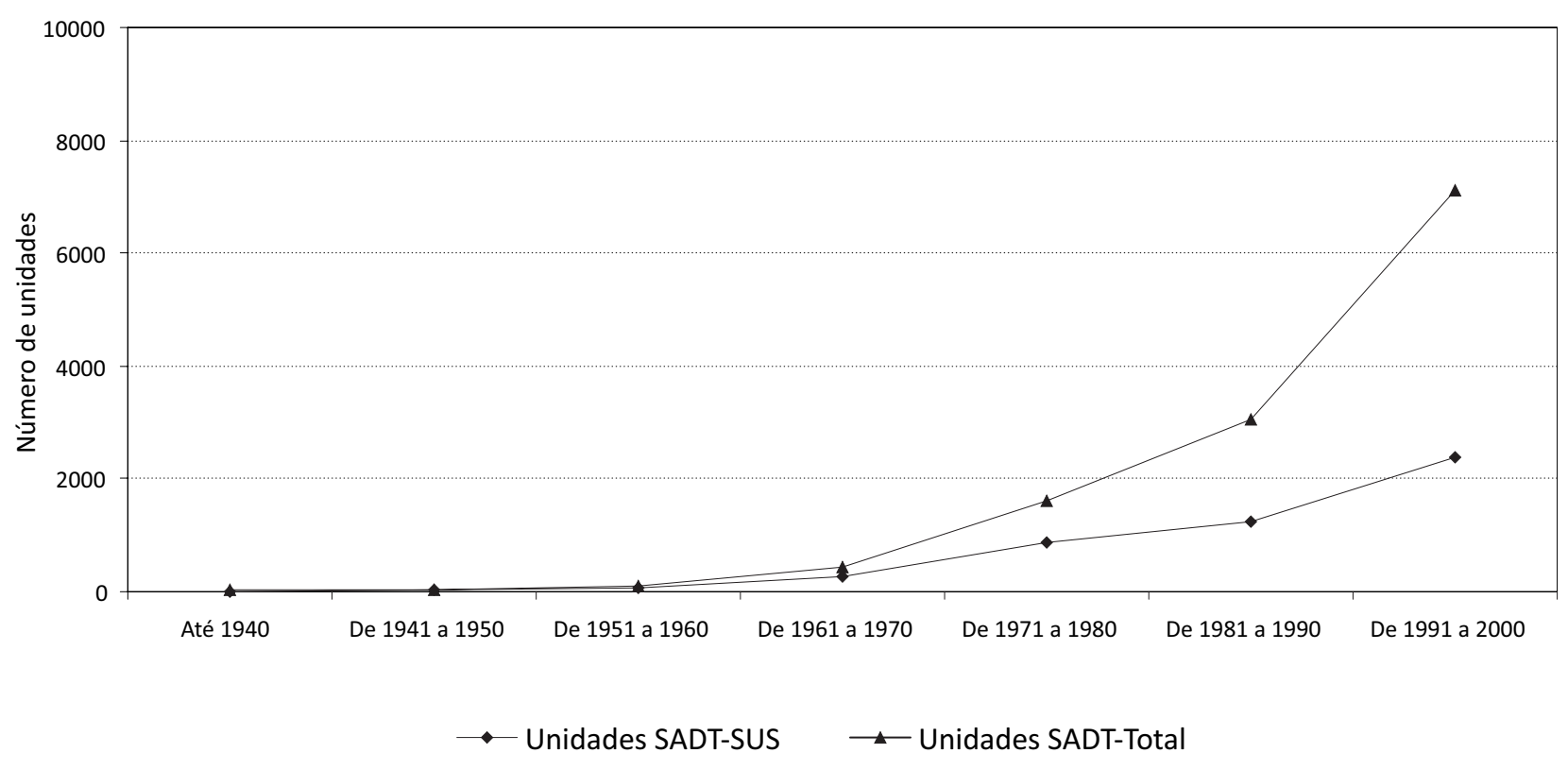

Fonte: Pessôa (2005).

As transformações ocorridas no século XX podem ser organizadas em períodos (Pessôa, 2005), que se destacam a seguir.

Entre 1901 e 1940: a virada do século XIX foi marcada por inúmeros avanços, em todos os campos do conhecimento, com a incorporação de novos saberes e técnicas. As transformações nos hospitais são intensas e profundas, tendo-se dado um salto para a modernidade. Nesse período prevalecem ainda as instituições filantrópicas e, na década de 1930, inicia-se a construção de sanatórios de tuberculose pelas instâncias estaduais, que configuram novo componente importante na oferta de serviços para aquele problema de saúde.

Entre 1941 e 1970: período marcado pela Campanha da Borracha, na Amazônia, determinante para a criação do Serviço Especial de Saúde Pública (Sesp), posteriormente denominada Fundação Serviços de Saúde Pública (FSESP), em 1942. A FSESP atuou como financiadora da expansão da estrutura de serviços de Atenção Primária à Saúde (APS), construindo postos e centros de saúde e unidades mistas no interior. O Ministério da Saúde, criado em 1953, financiou a construção de sanatórios de tuberculose em todo o país. É nesse contexto que tem início o delineamento mais expressivo da expansão da estrutura pública de saúde, sobretudo a de natureza municipal.

Entre 1971 e 1990: este período está sob a égide da incorporação de novas tecnologias e da crise de financiamento no setor Saúde, iniciada no fim da década de 1970, que interfere fortemente na capacidade de o Estado custear as unidades existentes e traz à tona a crescente necessidade de racionalização na expansão da estrutura pública de serviços de saúde. 
Nesse contexto, impôs-se aos financiadores da expansão a necessidade de compartilhar os sistemas de engenharia, reforçando as teses de organização do sistema já apresentadas no Reino Unido no Relatório Dawson, de 1920 (Kuschnir \& Chorny, 2010), dando origem, aqui no Brasil, a partir da década de 1970, aos primeiros movimentos de regionalização, hierarquização e descentralização de serviços, de modo a imprimir ao sistema de saúde a noção de territórios de saúde.

Nesse período a noção de estrutura/rede de saúde passou a permear os investimentos para a expansão e transformação das unidades de saúde. Três grandes projetos de investimentos subsidiaram essa transformação: o Programa de Interiorização das Ações de Saúde e Saneamento (Piass), o Fundo de Apoio ao Desenvolvimento Social da Caixa Econômica, vinculado ao Plano de Localização de Unidades de Saúde (Plus) e ao Projeto Nordeste. No âmbito da formação de capital humano para a saúde, destacam-se o Movimento Larga Escala e o Programa de Preparação Estratégica do Pessoal de Saúde (PPREPS). O período foi marcado, ainda, pelas Ações Integradas de Saúde (AIS) que, na década de 1980, também impulsionaram o crescimento de unidades básicas de saúde.

A partir da década de 1980, em relação à incorporação na área de diagnóstico por imagem, por exemplo, estabeleceu-se um grande problema na operacionalização das políticas quando os hospitais da estrutura física do SUS, alguns do início do século XX, passaram a ter que acomodar tomógrafos, ressonâncias magnéticas, angiografia e ultrassonografia, em espaços previamente inexistentes, uma vez que na época de concepção da maioria dessas unidades se considerava apenas a existência de aparelhos de raios $\mathrm{X}$ simples. A mudança tecnológica no corpo físico dos aparelhos foi tão grande que na década de 1980 um aparelho de ressonância pesava trinta toneladas, ao passo que hoje pesa dez toneladas, ou seja, em vinte anos perdeu vinte toneladas.

Entre 1990 e 2000: o período foi marcado pelos investimentos do projeto Reforço à Reorganização do Sistema Único de Saúde (Projeto ReforSUS) e do Programa Saúde da Família (PSF). Desenvolveram-se, também, o Projeto de Profissionalização de Trabalhadores da Área de Enfermagem (Profae), voltado para a formação e a capacitação de trabalhadores da saúde, o Projeto de Vigilância em Saúde no SUS (VigiSUS), além de outros, de âmbito estadual ou municipal. Foram instituídas as Normas Operacionais 93 e 96, ambas de caráter municipalista, reforçando a importância da gestão municipal na organização de sua estrutura de serviços.

\section{Resultados da Etapa de Análise dos Dados sobre Recursos Físicos: a oferta da estrutura de serviços de saúde no Brasil em 2013}

Em dezembro de 2013 havia mais de 44 mil postos e centros de saúde, cerca de 41 mil policlínicas e clínicas especializadas, 20 mil estabelecimentos de SADT, 6,3 mil hospitais e 1 mil prontos-socorros.

A distribuição dos estabelecimentos difere nas regiões do país, especialmente para aqueles relacionados ao cuidado ambulatorial. No Sul e Sudeste, os consultórios eram mais de $60 \%$ dos estabelecimentos registrados, enquanto no Norte e Nordeste eram pouco mais de $32 \%$. Já os postos e centros de saúde que totalizavam 36\% dos estabelecimentos no Norte e Nordeste, variavam entre 12\%, 14\% e 15\% nas regiões Sudeste, Sul e Centro-Oeste respectivamente (Gráfico 4). 
Gráfico 4 - Número de estabelecimentos de saúde segundo tipo e grandes regiões. Brasil - 2013

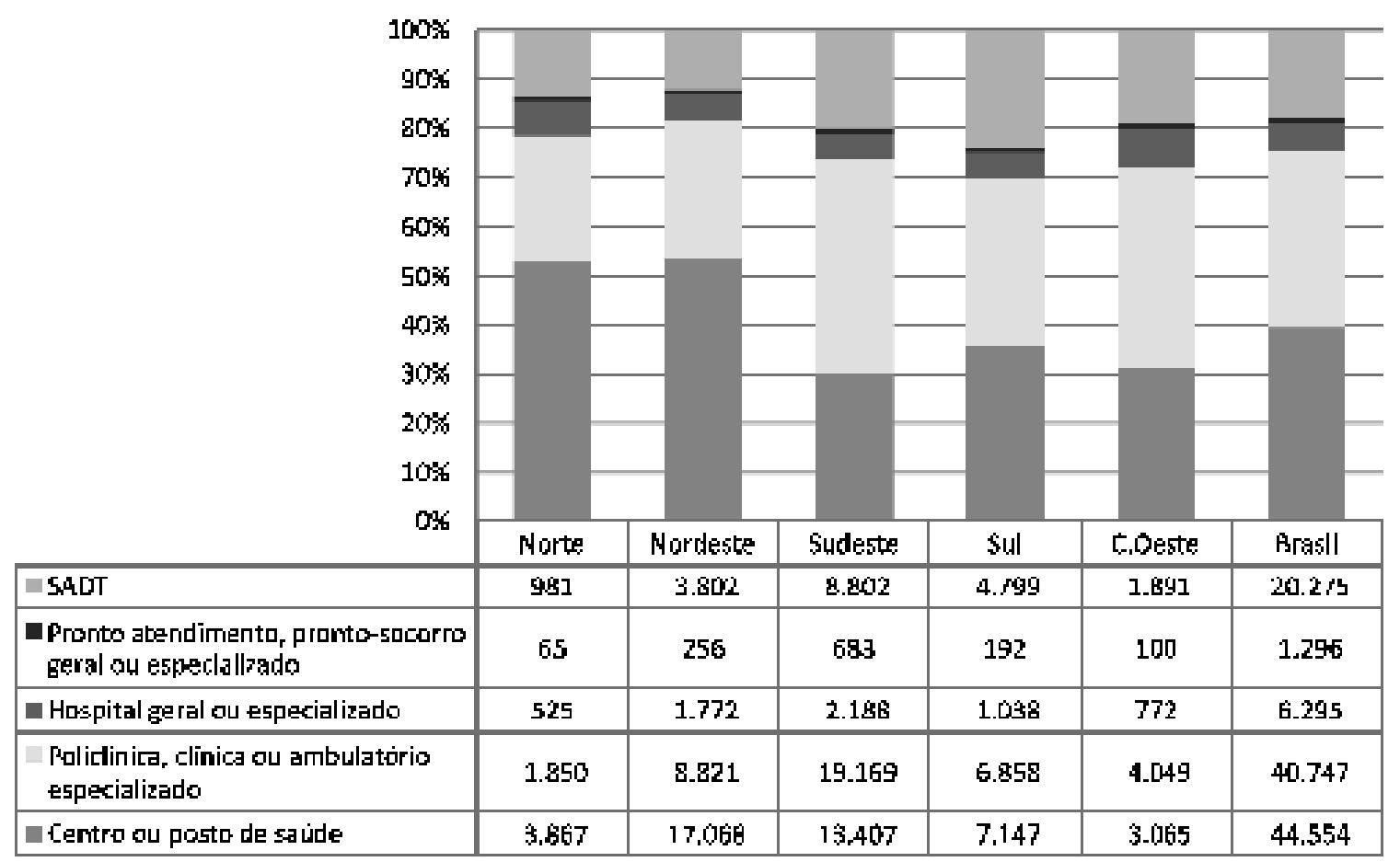

Fonte: elaborado pelas autoras, com base em dados do CNES referentes ao ano de 2013 (Brasil, 2014).

Observa-se que os centros de saúde, postos de saúde, centros de atenção psicossocial (Caps), prontos-socorros e unidades de pronto atendimento eram majoritariamente públicos. Já os consultórios, clínicas especializadas, ambulatórios especializados, policlínicas e SADT eram majoritariamente privados com fins lucrativos. Os hospitais gerais e especializados de natureza pública e os de natureza privada com fins lucrativos existiam em proporções semelhantes. Os estabelecimentos privados sem fins lucrativos eram em sua maioria hospitais gerais e clínicas especializadas. Nas regiões Norte e Nordeste, havia proporcionalmente menos estabelecimentos privados de saúde que nas demais regiões (Tabela 1). 
Tabela 1 - Estabelecimentos segundo natureza jurídica e tipo. Brasil e Regiões - 2013

\begin{tabular}{|c|c|c|c|c|c|c|}
\hline Região & $\begin{array}{l}\text { Natureza } \\
\text { Jurídica }\end{array}$ & $\begin{array}{c}\text { Centro ou } \\
\text { posto de saúde }\end{array}$ & $\begin{array}{l}\text { Policlínica, } \\
\text { clínica ou } \\
\text { ambulatório } \\
\text { especializado }\end{array}$ & $\begin{array}{c}\text { Hospital } \\
\text { geral ou } \\
\text { especializado }\end{array}$ & $\begin{array}{c}\text { Pronto } \\
\text { atendimento, } \\
\text { pronto-socorro } \\
\text { geral ou } \\
\text { especializado }\end{array}$ & SADT \\
\hline \multirow{3}{*}{ Norte } & Público & 3.834 & 277 & 284 & 56 & 113 \\
\hline & $\begin{array}{l}\text { Priv. sem fins } \\
\text { lucrativos }\end{array}$ & 8 & 42 & 32 & - & 10 \\
\hline & $\begin{array}{l}\text { Priv. com fins } \\
\text { lucrativos }\end{array}$ & 25 & 1.531 & 209 & 9 & 858 \\
\hline \multirow{3}{*}{ Nordeste } & Público & 16.755 & 1.450 & 918 & 180 & 485 \\
\hline & $\begin{array}{l}\text { Priv. sem fins } \\
\text { lucrativos }\end{array}$ & 36 & 223 & 263 & 5 & 17 \\
\hline & $\begin{array}{l}\text { Priv. com fins } \\
\text { lucrativos }\end{array}$ & 277 & 7.148 & 591 & 71 & 3.300 \\
\hline \multirow{3}{*}{ Sudeste } & Público & 13.239 & 2.450 & 509 & 579 & 477 \\
\hline & $\begin{array}{l}\text { Priv. sem fins } \\
\text { lucrativos }\end{array}$ & 40 & 705 & 837 & 14 & 141 \\
\hline & $\begin{array}{l}\text { Priv. com fins } \\
\text { lucrativos }\end{array}$ & 128 & 16.014 & 842 & 90 & 8.184 \\
\hline \multirow{3}{*}{ Sul } & Público & 7.033 & 653 & 249 & 147 & 155 \\
\hline & $\begin{array}{l}\text { Priv. sem fins } \\
\text { lucrativos }\end{array}$ & 32 & 576 & 467 & 8 & 76 \\
\hline & $\begin{array}{l}\text { Priv. com fins } \\
\text { lucrativos }\end{array}$ & 82 & 5.629 & 322 & 37 & 4.568 \\
\hline \multirow{3}{*}{$\begin{array}{l}\text { Centro- } \\
\text { Oeste }\end{array}$} & Público & 3.034 & 440 & 289 & 79 & 144 \\
\hline & $\begin{array}{l}\text { Priv. sem fins } \\
\text { lucrativos }\end{array}$ & - & 74 & 95 & - & 15 \\
\hline & $\begin{array}{l}\text { Priv. com fins } \\
\text { lucrativos }\end{array}$ & 25 & 3.535 & 388 & 21 & 1.732 \\
\hline \multirow{3}{*}{ Brasil } & Público & 43.895 & 5.270 & 2.249 & 1.041 & 1.374 \\
\hline & $\begin{array}{l}\text { Priv. sem fins } \\
\text { lucrativos }\end{array}$ & 116 & 1.620 & 1.694 & 27 & 259 \\
\hline & $\begin{array}{l}\text { Priv. com fins } \\
\text { lucrativos }\end{array}$ & 537 & 33.857 & 2.352 & 228 & 18.642 \\
\hline
\end{tabular}

Fonte: elaborado pelos autores, com base em dados do CNES referentes ao ano de 2013 (Brasil, 2014). 


\section{Estabelecimentos de saúde por porte de leitos}

O Brasil tinha, em 2013, aproximadamente 6.500 unidades de saúde (US) com leitos disponíveis para internação, incluindo os leitos de UTI e excluindo aqueles só com leitos de psiquiatria, leitos-dia e leito de acolhimento noturno.

A análise do Gráfico 5 e Tabela 2 indica que aproximadamente 80\% dos estabelecimentos que oferecem internação contavam com menos de cem leitos.

Além disso, entre os municípios que apresentavam unidades de saúde com internação, 87\% dispunham apenas de unidades com menos de cem leitos. Apenas $2 \%$ dos estabelecimentos tinham mais de 300 leitos, distribuídos em apenas $2 \%$ dos municípios que ofereciam internação.

Gráfico 5 - Distribuição de estabelecimentos com internação por número de leitos. Brasil - 2013

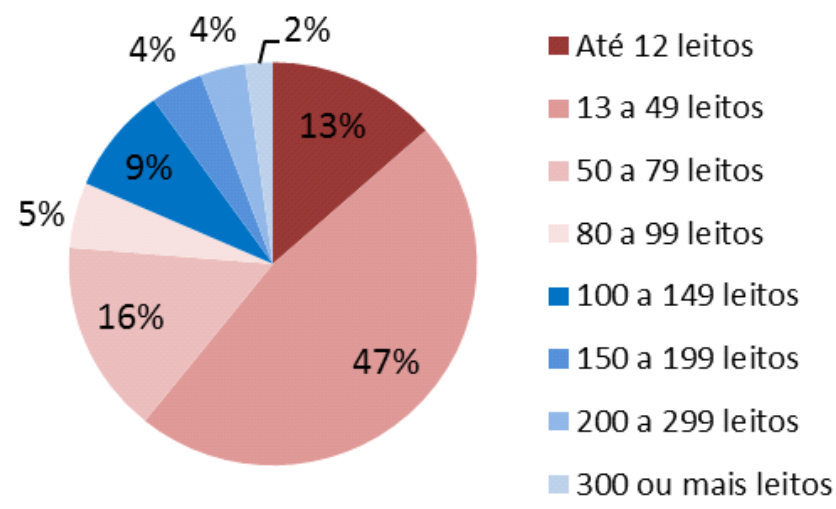

Fonte: elaborado pelos autores, com base em dados do CNES referentes ao ano de 2013 (Brasil, 2014).

Tabela 2 - Número e percentual de estabelecimentos e de municípios segundo número de leitos disponibilizados. Brasil - 2013

\begin{tabular}{|l|c|r|r|r|}
\hline Número de leitos & $\begin{array}{c}\text { N. de } \\
\text { estabelecimentos }\end{array}$ & \multicolumn{1}{c|}{$\%$} & N. de municípios & $\%$ \\
\hline Até 12 leitos & 896 & 13,5 & 304 & 8,6 \\
\hline 13 a 49 leitos & 3.141 & 47,3 & 2.062 & 58,6 \\
\hline 50 a 79 leitos & 1.029 & 15,5 & 544 & 15,5 \\
\hline 80 a 99 leitos & 349 & 5,3 & 140 & 4,0 \\
\hline 100 a 149 leitos & 567 & 8,5 & 229 & 6,5 \\
\hline 150 a 199 leitos & 278 & 4,2 & 103 & 2,9 \\
\hline 200 a 299 leitos & 237 & 3,6 & 82 & 2,3 \\
\hline 300 ou mais leitos & 144 & 2,2 & 57 & 1,6 \\
\hline Total & 6.641 & 100,0 & 3.521 & 100,0 \\
\hline
\end{tabular}

Fonte: elaborado pelas autoras, com base em dados do CNES referentes ao ano de 2013 (Brasil, 2014). 
As unidades de saúde (US) com internação estavam distribuídas em aproximadamente 3.500 municípios. Observa-se, na região central do país, um vazio importante na oferta de leitos de internação. A Figura 6 permite observar a distribuição espacial das unidades de saúde segundo número de leitos.

A cor branca representa os municípios que não dispunham de estabelecimentos com internação. Na Figura 1A utilizou-se a maior classe disponível. Nos demais (B, C, D e E) para uma melhor visualização, as unidades de saúde foram agrupadas em: B) US com até 49 leitos; C) US com 50-99 leitos; D) US com 100-299 leitos; e E) US com 300 ou mais leitos. É possível observar que a área assinalada no mapa concentra os estabelecimentos de maior porte, o que pode ser explicado pela característica desses locais de concentração do emprego, indústria, nível de renda e escolaridade, sistema viário etc.

Figura 1 - Distribuição dos estabelecimentos com internação segundo número de leitos por município. Brasil - 2013

A. Distribuição segundo maior classe disponível

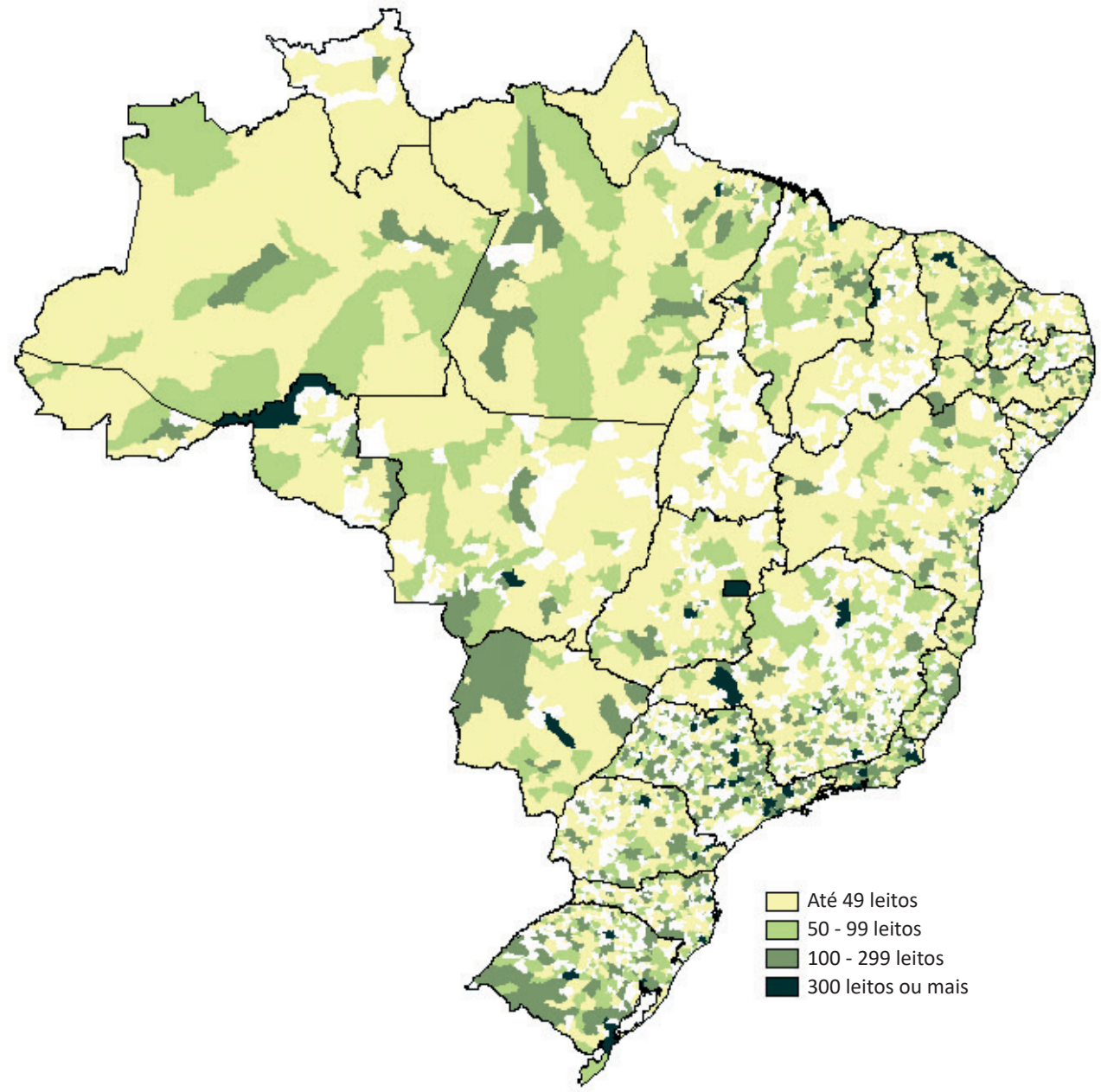


B. Até 49 leitos

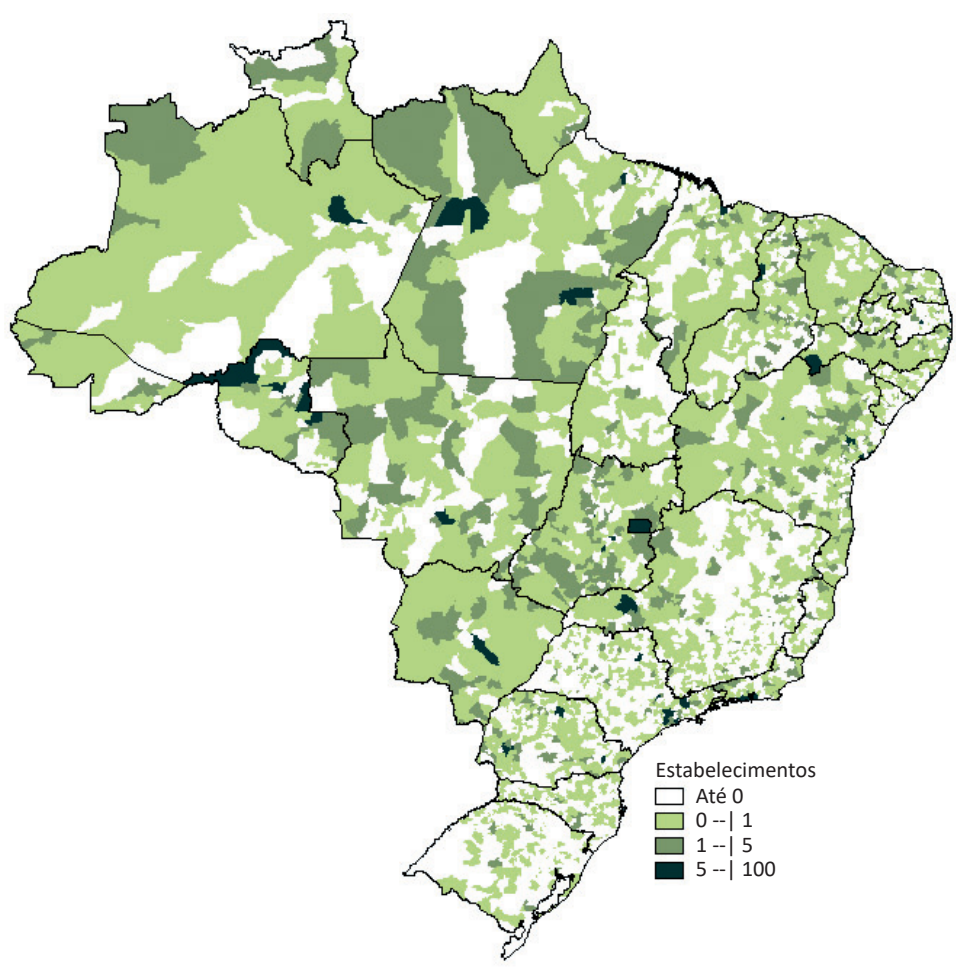

D. 100-299 leitos

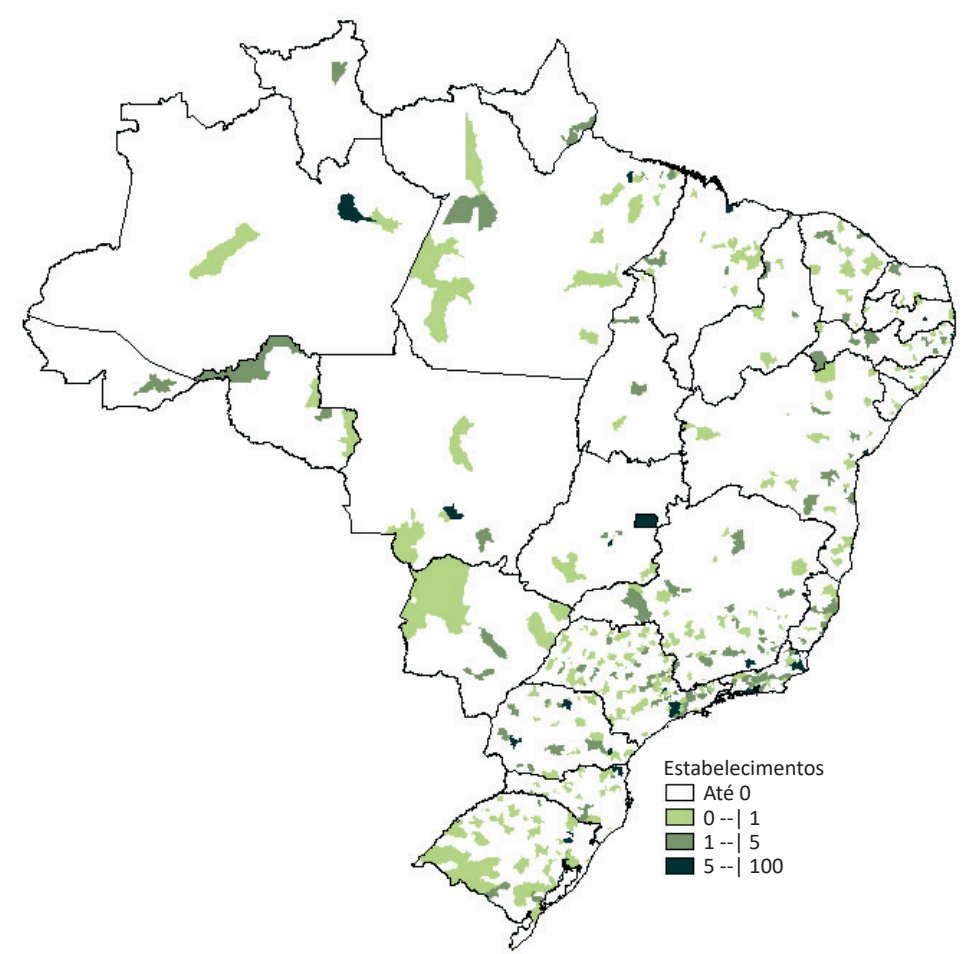

C. 50-99 leitos

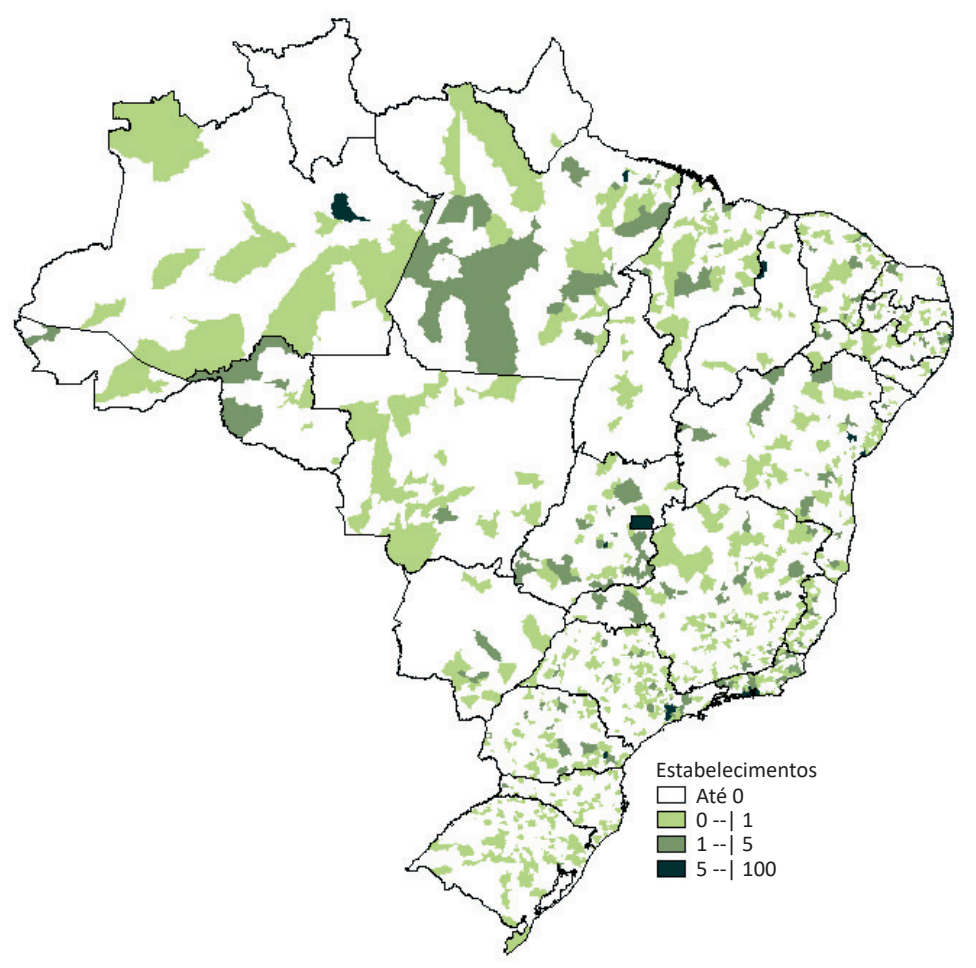

E. 300 leitos ou mais

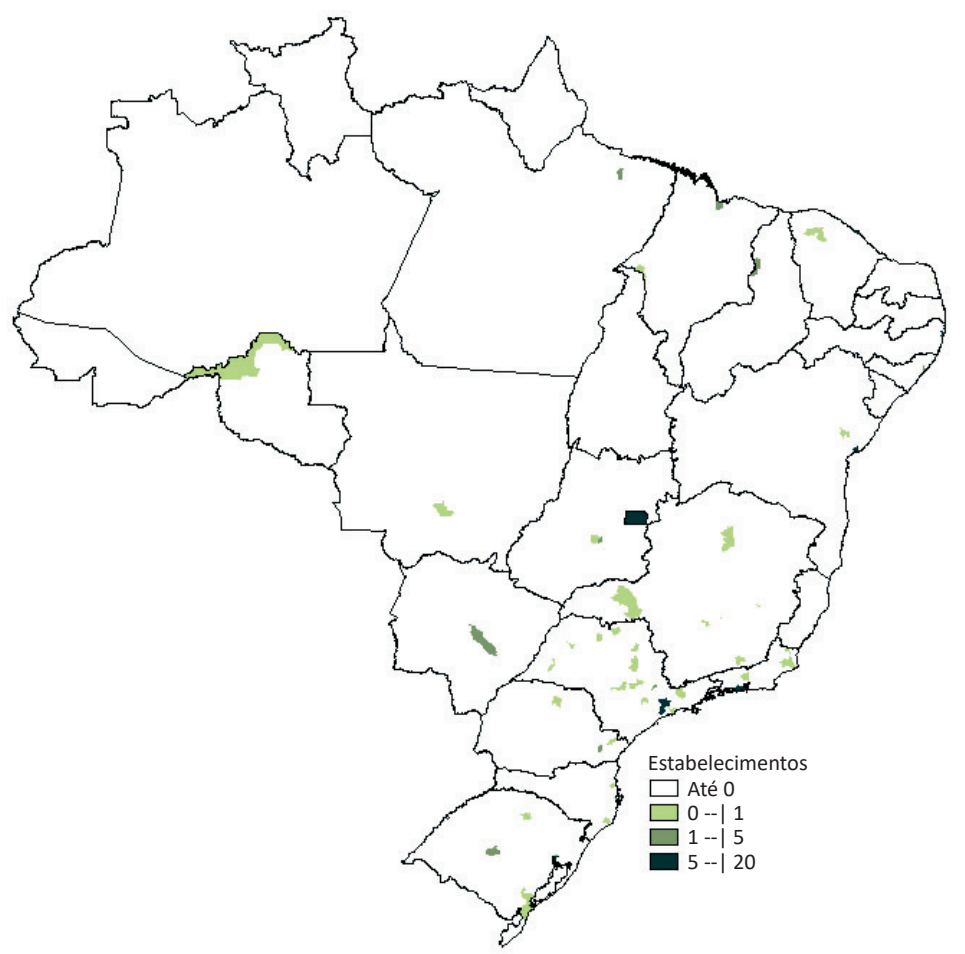

Fonte: elaborado pelas autoras, com base em dados do CNES referentes ao ano de 2013 (Brasil, 2014). 


\section{Leitos para internação}

No Brasil, em 2013, estavam disponíveis em torno de 430 mil leitos, sendo 296.131 leitos SUS (68\%) e 135.909 Não SUS (32\%). Mas essa distribuição é desigual, pois quando analisados os cinquenta municípios com o maior número de leitos no total, segundo classificação SUS ou Não SUS, observou-se que a oferta de leitos Não SUS é superior à oferta de leitos SUS em algumas cidades que dispunham de mais de 1.000 leitos (como Rio de Janeiro, Niterói e Santos), enquanto em outras cidades havia maior disponibilidade de leitos SUS do que Não SUS (por exemplo: São Paulo, Belo Horizonte, Fortaleza e Salvador).

A Figura 2 permite observar a distribuição dos municípios que ofertavam leitos de internação por SUS, Não SUS e ambos, simultaneamente. Apesar de ser possível verificar algumas áreas brancas, significando ausência de oferta de leitos de internação, percebe-se que a maior parte dos municípios dispunha de leitos SUS e Não SUS. Na região central e no sertão do país, observam-se alguns municípios onde só existia a oferta de leitos Não SUS, próximos a áreas sem qualquer oferta de leitos para internação.

Figura 2 - Leitos gerais Não SUS, SUS e ambos por município. Brasil - 2013

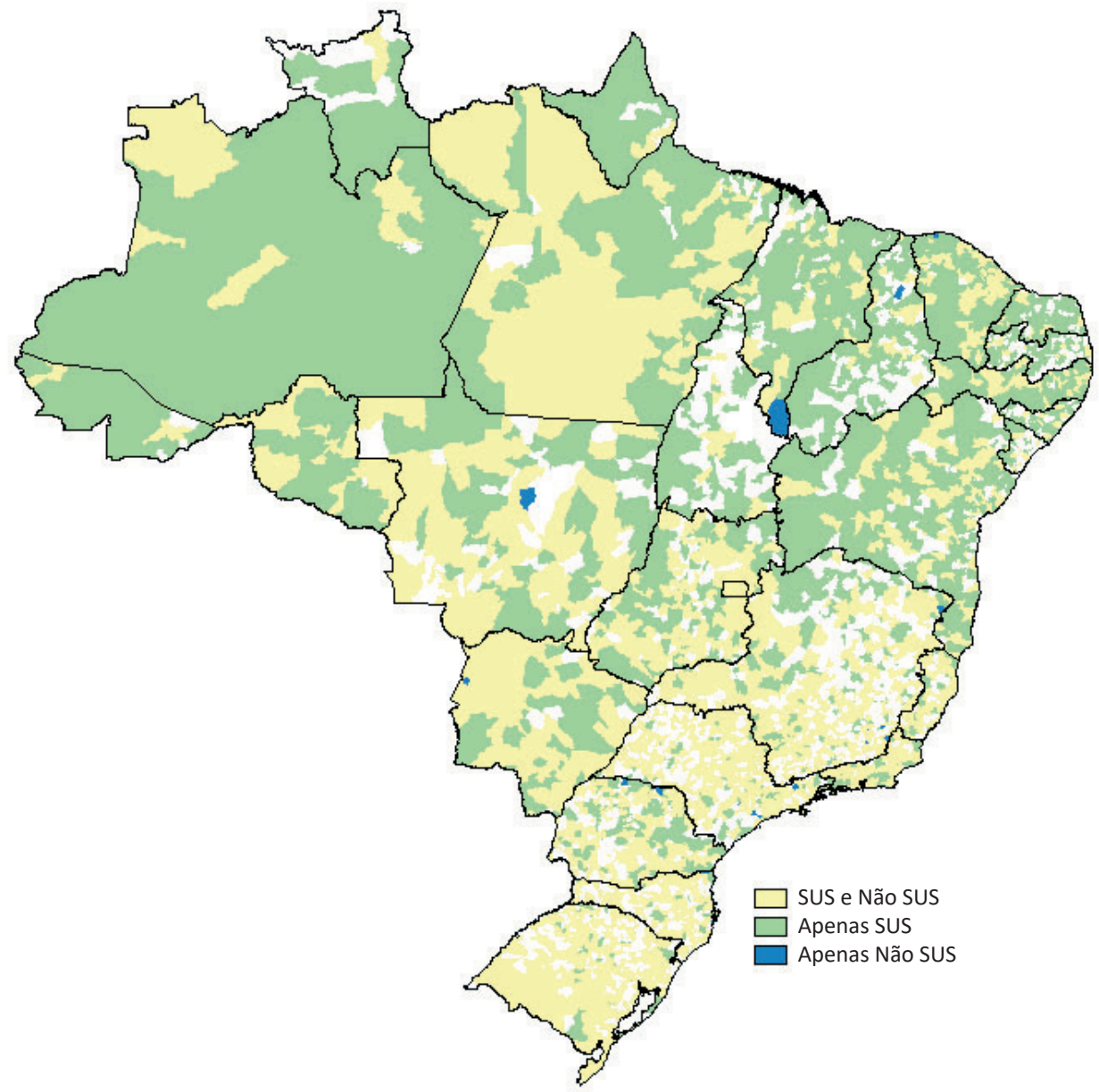

Fonte: elaborado pelas autoras, com base em dados do CNES referentes ao ano de 2013 (Brasil, 2014). 
Destaca-se que 19 municípios só dispunham de leitos Não SUS. ${ }^{3}$ Em 1.759 municípios apenas o SUS oferecia internação. Em 1.701 municípios eram oferecidos leitos SUS e Não SUS. A oferta de leitos SUS era maior em 1.537 municípios (216.070), representando mais do que o dobro da oferta Não SUS (97.229). Nos 163 municípios restantes com leitos para internação a oferta de leitos Não SUS (38.222 leitos) era 36\% maior que a oferta SUS (27.996 leitos). Mesmo sabendo que 80\% dos hospitais brasileiros têm menos de 100 leitos e que, destes, a maioria são leitos SUS, uma análise que permita fazer inferências sobre municípios ou hospitais onde investir requer um estudo mais aprofundado.

\section{Leitos de UTI}

No ano de 2013 havia 37.968 leitos de UTI distribuídos em 1.887 estabelecimentos e em 510 municípios (Tabela 3). Esses leitos de UTI estavam divididos entre SUS (18.970 - 50,3\%) e Não SUS (18.998 - 49,7\%).

Tabela 3 - Número e percentual de estabelecimentos e de municípios segundo número de leitos de UTI disponibilizados. Brasil -2013

\begin{tabular}{|l|c|c|c|c|}
\hline N. de Leitos & Estabelecimento & $\%$ & Município & $\%$ \\
\hline Até 5 leitos & 202 & 10,7 & 32 & 6,3 \\
\hline 6 a 10 leitos & 611 & 32,4 & 173 & 33,9 \\
\hline 11 ou mais & 1.074 & 56,9 & 305 & 59,8 \\
\hline Total & 1.887 & 100,0 & 510 & 100,0 \\
\hline
\end{tabular}

Fonte: elaborado pelas autoras, com base em dados do CNES referentes ao ano de 2013 (Brasil, 2014).

A oferta de leitos de UTI Não SUS, em alguns municípios centrais como São Paulo, Rio de Janeiro, Brasília e Niterói, era bastante superior à oferta de leitos SUS.

Na Figura 3 observam-se grandes vazios na oferta de leitos de UTI. Os leitos Não SUS estavam presentes em 374 municípios, sendo a única oferta de leito de UTI disponível em 49 municípios do país, com 642 leitos.

\footnotetext{
${ }^{3}$ São eles, com os respectivos códigos do IBGE: 210050 Alto Parnaíba, 221065 Sigefredo Pacheco, 230725 Jijoca de Jericoacoara, 311787 Confins, 314210 Miradouro, 314820 Patrocínio do Muriaé, 315130 Piraúba, 350380 Artur Nogueira, 352620 Juquitiba, 355480 Tremembé, 411095 Itaipulândia, 412390 Santa Mariana, 412450 Santo Inácio, 420580 Garuva, 421190 Palhoça, 430930 Guaíba, 500520 Ladário, 510100 Araguaiana, 510850 Vera.
} 
Figura 3 - Municípios por disponibilidade de leitos de UTI SUS, Não SUS e ambos. Brasil -2013

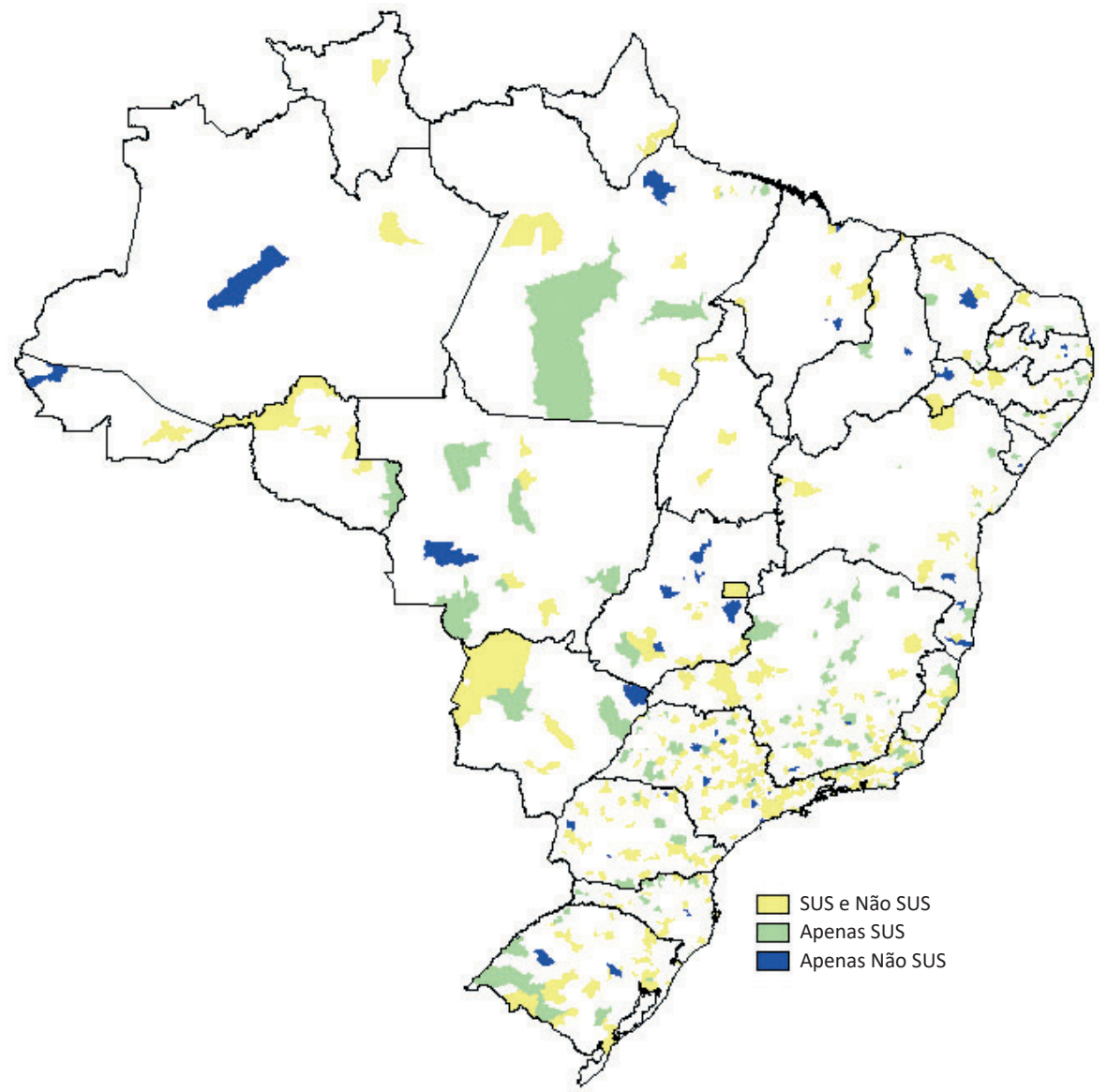

Fonte: elaborado pelas autoras, com base em dados do CNES referentes ao ano de 2013 (Brasil, 2014).

\section{Disponibilidade de estruturas para condições selecionadas}

\section{Leitos ortopédicos e neurocirúrgicos}

Por relacionarem-se ao serviço de alta complexidade do trauma, foram organizados e apresentados nesta seção os leitos de ortopedia e de neurocirurgia. Embora não sejam exclusivos para o tratamento do trauma, são indispensáveis para a atenção a essa condição.

No ano de 2013, aproximadamente 16.700 leitos ortopédicos eram oferecidos no país, sendo em torno de $80 \%$ ofertados pelo SUS. Os leitos ortopédicos estavam distribuídos em aproximadamente 640 municípios. Aproximadamente $25 \%$ dos municípios dispunham de apenas dois leitos, $50 \%$ disponibilizavam entre três e sete, $25 \%$ apresentavam entre oito e 17 leitos e $25 \%$ dispunham de 18 ou mais leitos. Os municípios de Rio de Janeiro e São Paulo dispunham de aproximadamente 1.200 leitos ortopédicos, cada um.

Os quase 5.000 leitos de neurocirurgia estavam distribuídos em 224 municípios. Aproximadamente $70 \%$ dos leitos eram ofertados pelo SUS. Em torno de $25 \%$ dos municípios tinham apenas 
três leitos, aproximadamente 25\% tinham entre quatro e seis, 25\% dispunham entre sete e 16 leitos e $25 \%$ tinham mais de 16 leitos, conforme Figuras 4 e 5.

Figura 4 - Leitos cirúrgicos de ortopedia segundo SUS, Não SUS e ambos. Municípios brasileiros - 2013

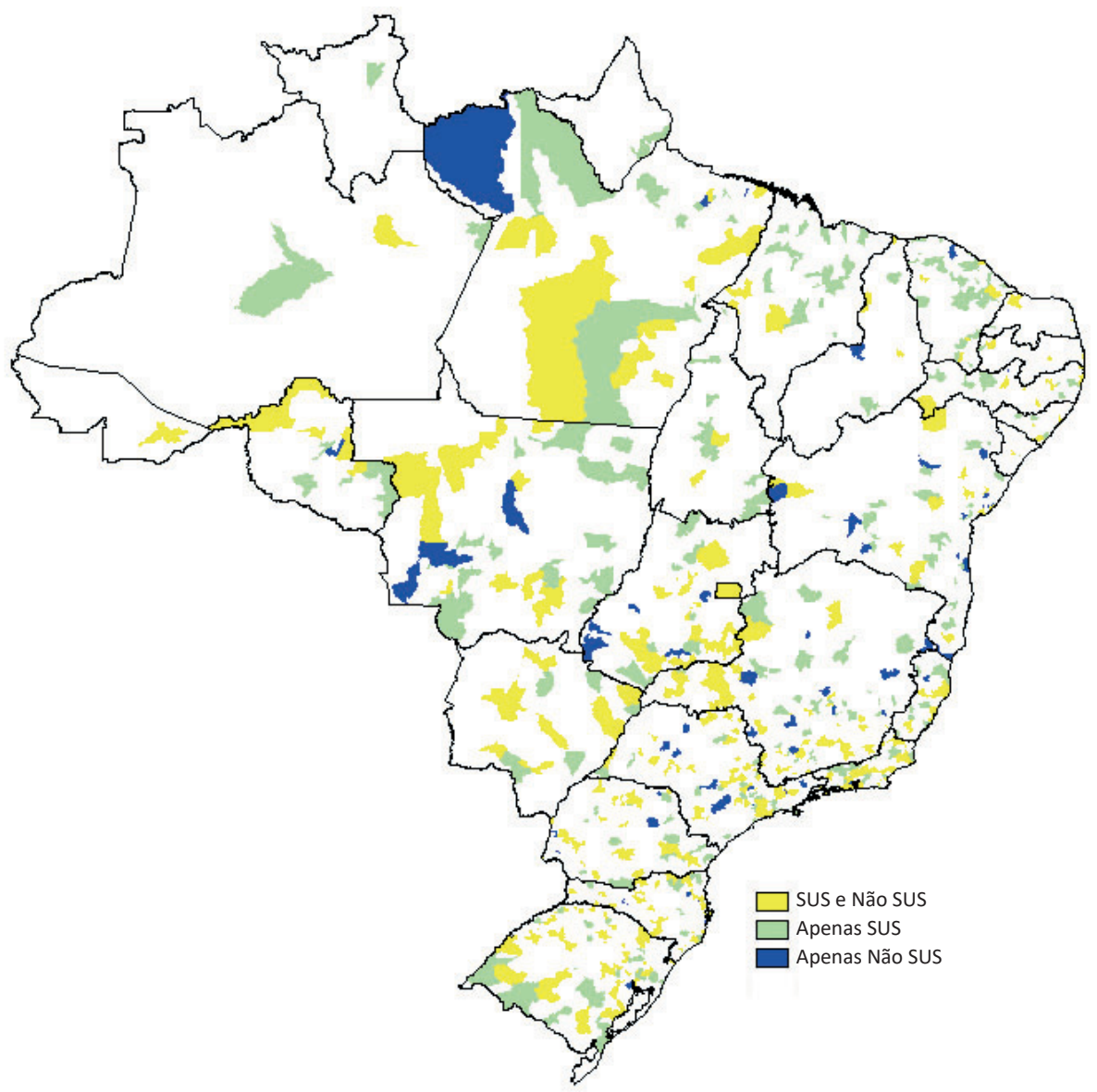

Fonte: elaborado pelas autoras, com base em dados do CNES referentes ao ano de 2013 (Brasil, 2014). 
Figura 5 - Leitos neurocirúrgicos segundo SUS, Não SUS e ambos. Municípios brasileiros - 2013

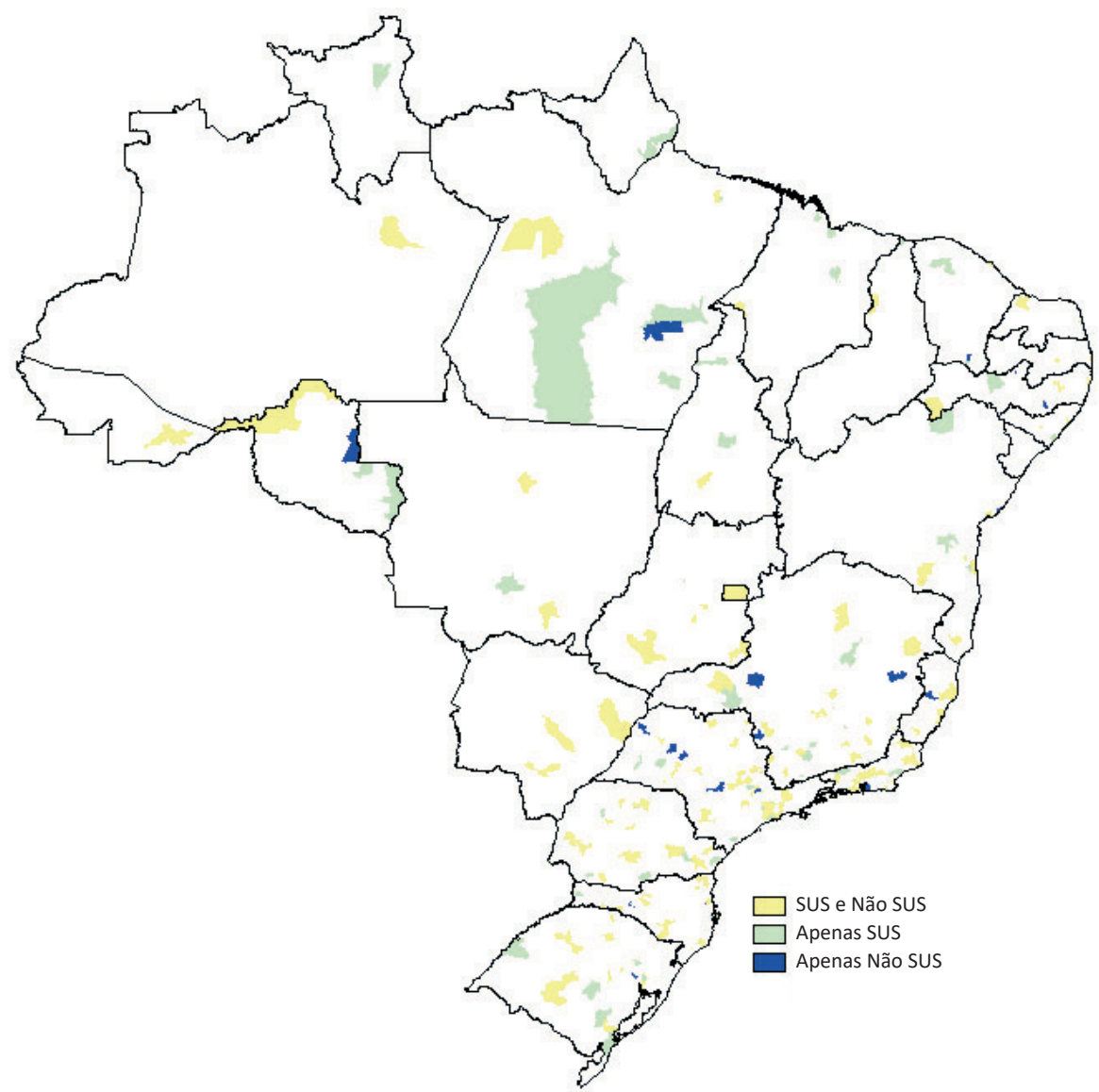

Fonte: elaborado pelas autoras, com base em dados do CNES referentes ao ano de 2013 (Brasil, 2014).

\section{Trauma}

Para que uma unidade de saúde esteja habilitada ao atendimento do trauma, segundo a política nacional do trauma, exige-se: disponibilidade de UTI, porte de mais de cem leitos, tomografia computadorizada, ressonância magnética, assistência de alta complexidade em neurocirurgia (este serviço inclui neurocirurgia e traumatologia, bem como os leitos de internação relacionados), hemoterapia, radiologia intervencionista, ou reabilitação. Essas oito estruturas foram analisadas em conjunto, pois se relacionam ao atendimento de trauma de alta complexidade. Quanto ao trauma de média complexidade, analisaram-se cinco de oito estruturas: disponibilidade de UTI, porte de mais de cem leitos, tomografia computadorizada, serviço de alta complexidade em neurocirurgia e hemoterapia.

\section{Estruturas específicas para a atenção ao trauma de alta complexidade}

Em relação às estruturas específicas para atenção ao trauma de alta complexidade, apenas 41 hospitais em 30 municípios detinham os oito itens necessários para habilitação ao atendimento ao trauma de alta complexidade, um número muito baixo diante da necessidade da população em de- 
corrência da transição demográfica. Já 99 hospitais em 64 municípios contavam com sete das oito estruturas analisadas.

Se fossem alocados recursos em cinquenta dos 99 hospitais com déficit de apenas uma das estruturas analisadas (um por município, em que o hospital com maior estrutura disponível dispõe de sete das oito analisadas), o Brasil mais que dobraria o número de municípios com capacidade de assistência ao trauma de alta complexidade, passando de trinta para oitenta municípios cobertos (Gráfico 6).

Gráfico 6 - Hospitais e municípios segundo número de estruturas existentes para trauma de alta complexidade. Brasil - 2013

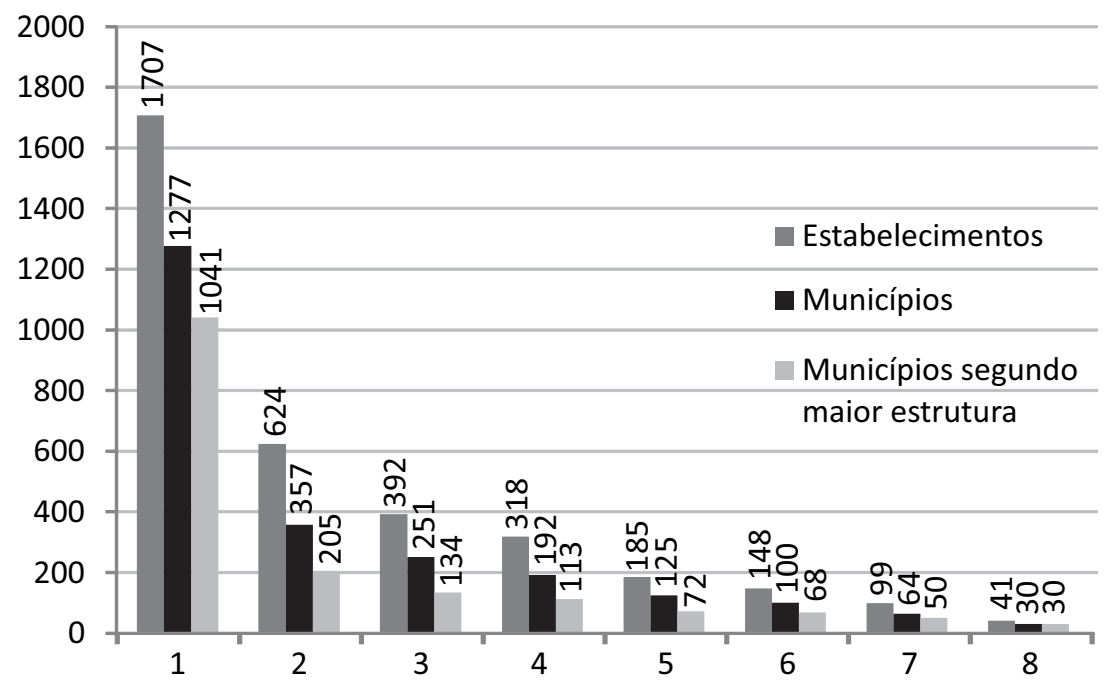

Fonte: elaborado pelas autoras, com base em dados do CNES referentes ao ano de 2013 (Brasil, 2014).

A categorização dos municípios com sete ou oito das oito estruturas para atendimento do trauma complexo indica a escassez de hospitais disponíveis para esse atendimento nas regiões Norte e Nordeste, além da concentração desses hospitais nas regiões Sudeste e Sul, especialmente nos municípios de São Paulo, Rio de Janeiro, Porto Alegre, Salvador, Belo Horizonte, Santos e Recife, com ao menos um hospital contendo as oito estruturas analisadas, além do maior número de hospitais com sete ou oito das estruturas selecionadas para análise. Em 14 municípios, havia pelo menos uma unidade de saúde com sete estruturas e também uma unidade de saúde com oito estruturas. Nesses municípios estavam 37 hospitais com sete das oito estruturas analisadas (Figura 6). 
Figura 6 - Municípios segundo estabelecimentos com sete ou oito estruturas das oito estruturas para trauma complexo. Brasil - 2013

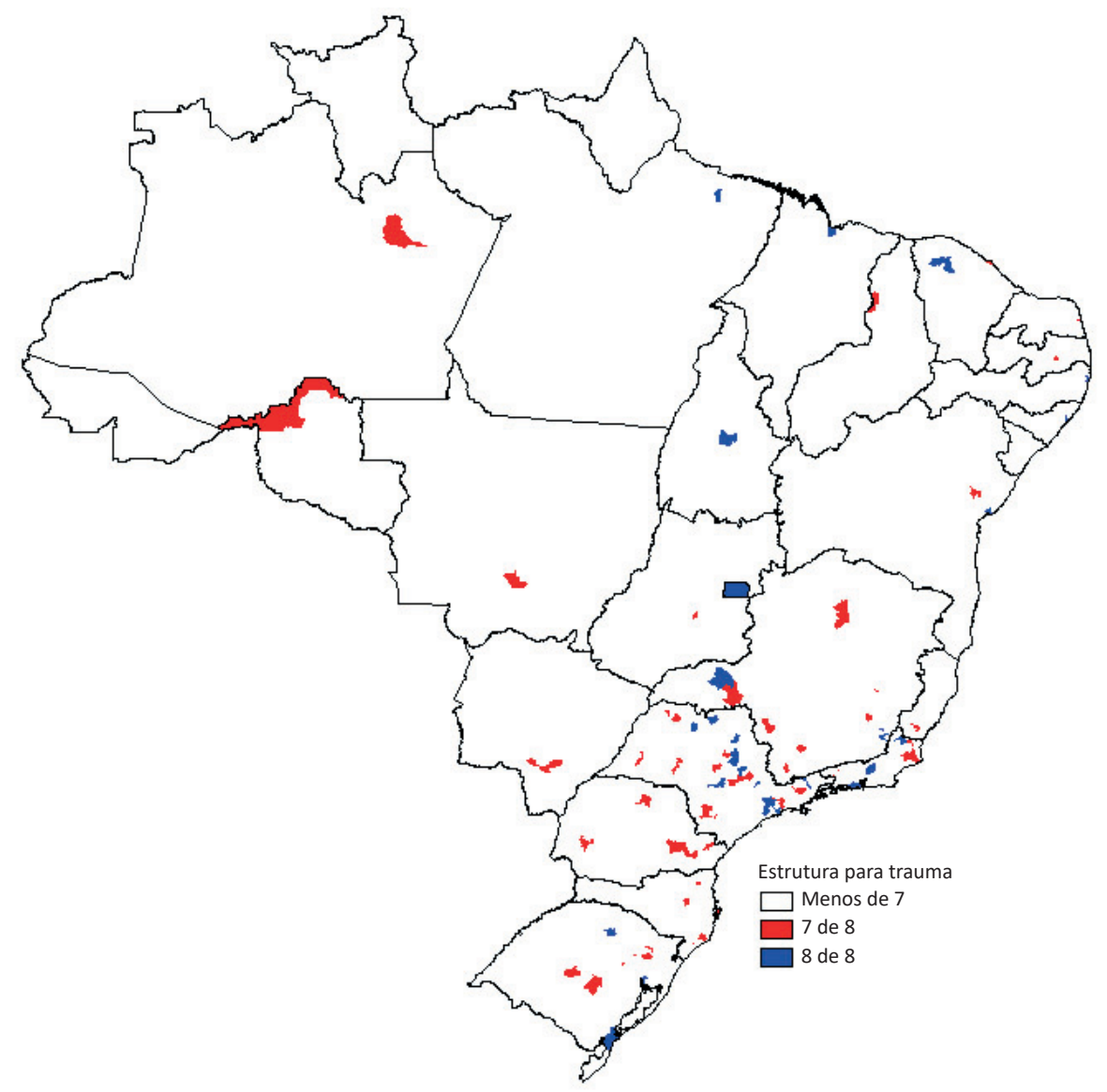

Fonte: elaborado pelas autoras, com base em dados do CNES referentes ao ano de 2013 (Brasil, 2014).

Entre os 41 estabelecimentos com as oito estruturas, 17 eram públicos, 21 eram privados sem fins lucrativos e três privados com fins lucrativos. Já entre os 99 estabelecimentos com sete das oito estruturas, 34 eram públicos, 56 privados sem fins lucrativos e nove privados com fins lucrativos.

Observando-se apenas hospitais com sete das oito estruturas analisadas, no Gráfico 7, identificam-se as seguintes deficiências, em ordem de volume: radiologia intervencionista (39 hospitais), ressonância magnética (trinta hospitais), reabilitação (16 hospitais), hemoterapia (nove hospitais), neurocirurgia e ortopedia-traumatologia (quatro hospitais), mais de cem leitos (um hospital). 
Gráfico 7 - Hospitais com sete estruturas para trauma complexo segundo estrutura deficiente. Brasil $-2013$

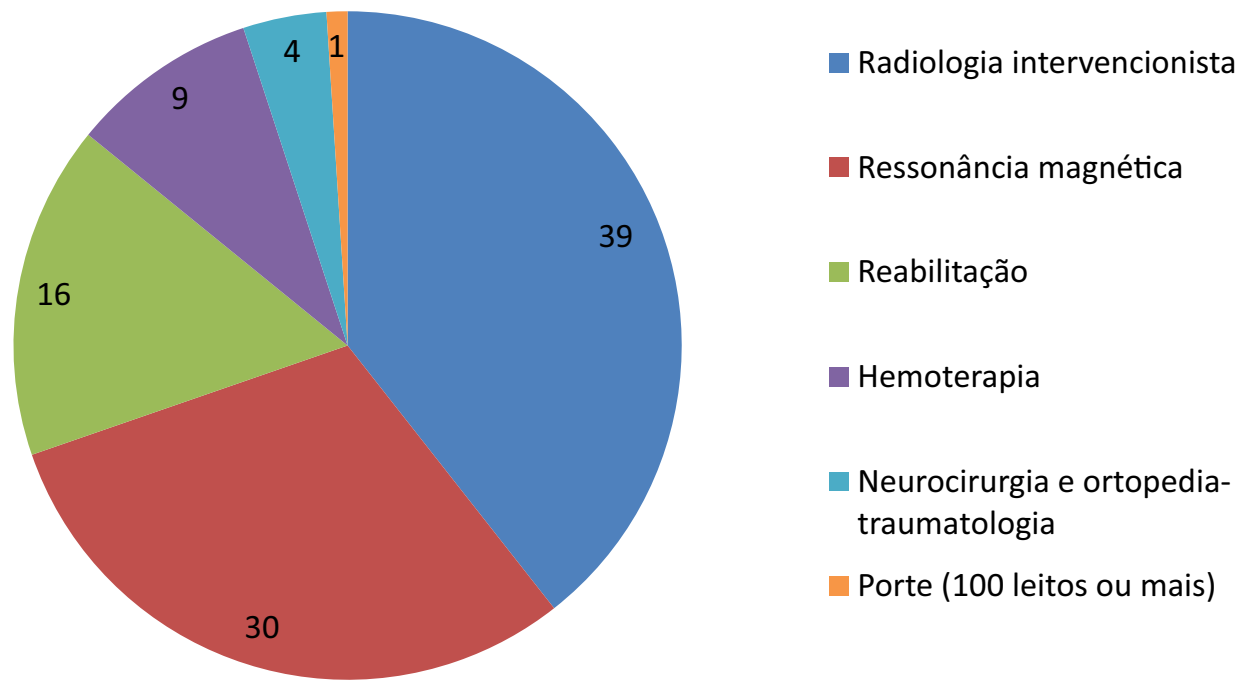

Fonte: elaborado pelas autoras, com base em dados do CNES referentes ao ano de 2013 (Brasil, 2014).

\section{Estruturas específicas para a atenção ao trauma de média complexidade}

Para análise das estruturas do trauma de média complexidade, consideraram-se cinco estruturas: disponibilidade de UTI, porte de mais de cem leitos, tomografia computadorizada, serviço de alta complexidade em neurocirurgia e hemoterapia.

Existiam 245 estabelecimentos que contemplavam as cinco estruturas, distribuídos em 140 municípios (Gráfico 8). Com quatro dessas cinco estruturas, eram 343 estabelecimentos em 196 municípios. Havia um número extremamente reduzido de hospitais com esse atendimento nas regiões Norte e Nordeste, e uma situação um pouco melhor na região Sudeste, especialmente no estado de São Paulo.

São Paulo, Rio de Janeiro, Belo Horizonte, Brasília, Salvador, Recife, Porto Alegre e Manaus se destacam com o maior número de hospitais com quatro ou cinco das estruturas analisadas (Figura 7). 
Gráfico 8 - Hospitais e municípios segundo número de estruturas existentes para trauma de média complexidade. Brasil - 2013

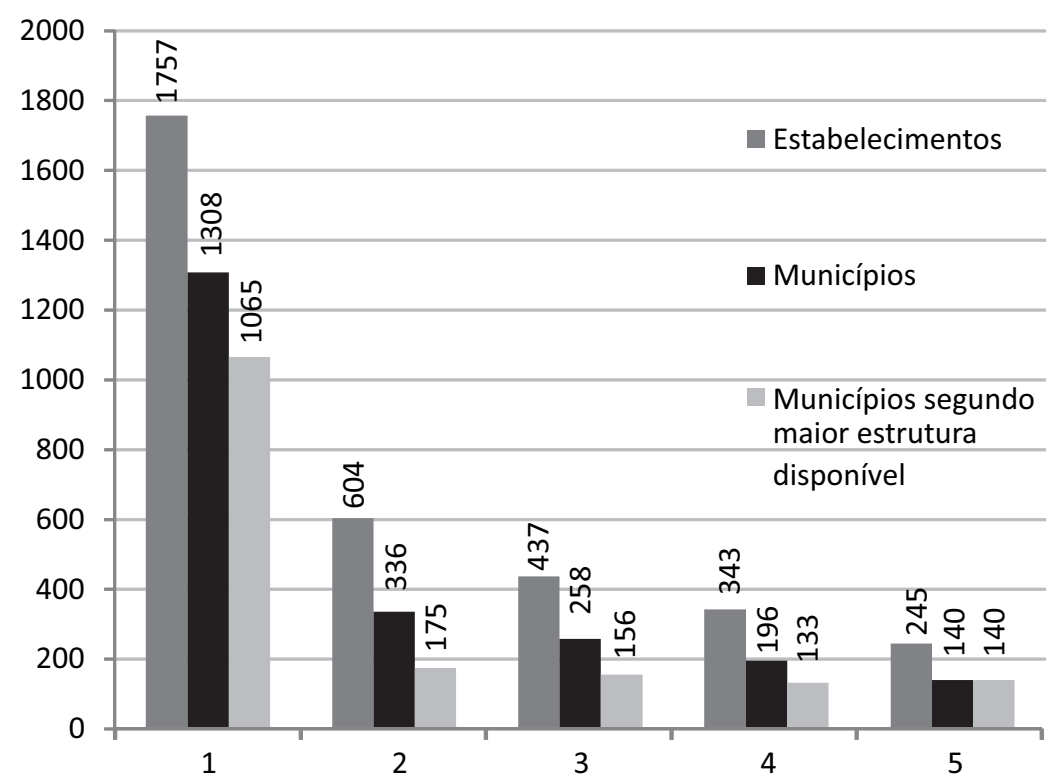

Fonte: elaborado pelas autoras, com base em dados do CNES referentes ao ano de 2013 (Brasil, 2014).

Figura 7 - Municípios segundo estabelecimentos com quatro ou cinco estruturas das 5 estruturas para trauma de média complexidade. Brasil - 2013

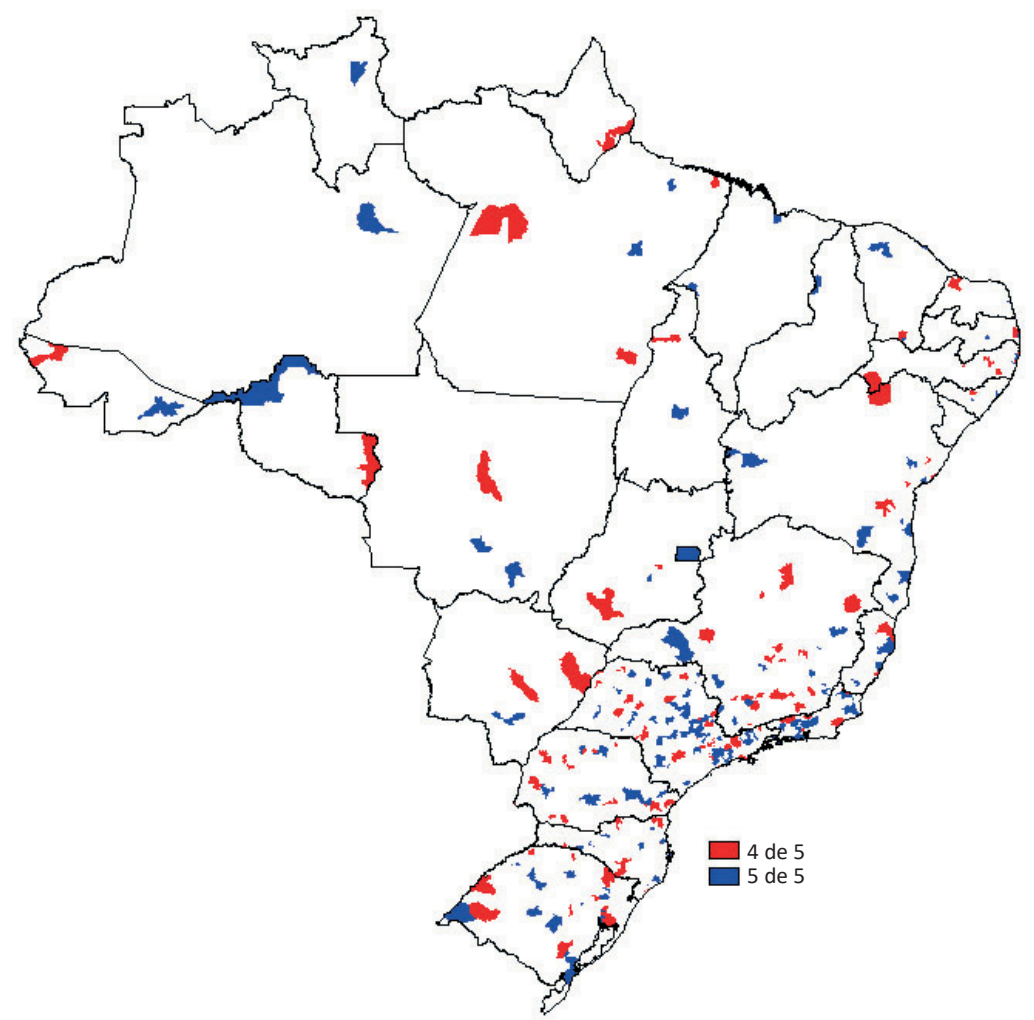

Fonte: elaborado pelas autoras, com base em dados do CNES referentes ao ano de 2013 (Brasil, 2014). 
Entre os 245 estabelecimentos com as cinco estruturas, 102 eram públicos, 122 privados sem fins lucrativos e 21 privados com fins lucrativos. Já entre os 343 estabelecimentos com quatro das cinco estruturas, 136 eram públicos, 156 privados sem fins lucrativos e 51 privados com fins lucrativos.

Observando-se apenas hospitais com quatro das cinco estruturas analisadas (Gráfico 9), identificaram-se as seguintes deficiências, em ordem de volume: neurocirurgia e ortopedia-traumatologia (237 hospitais), hemoterapia (51 hospitais), tomografia computadorizada (26 hospitais), mais de cem leitos (24 hospitais) e presença de UTI (cinco hospitais).

Gráfico 9 - Número de hospitais com quatro das cinco estruturas para trauma de média complexidade, segundo deficiência. Brasil - 2013

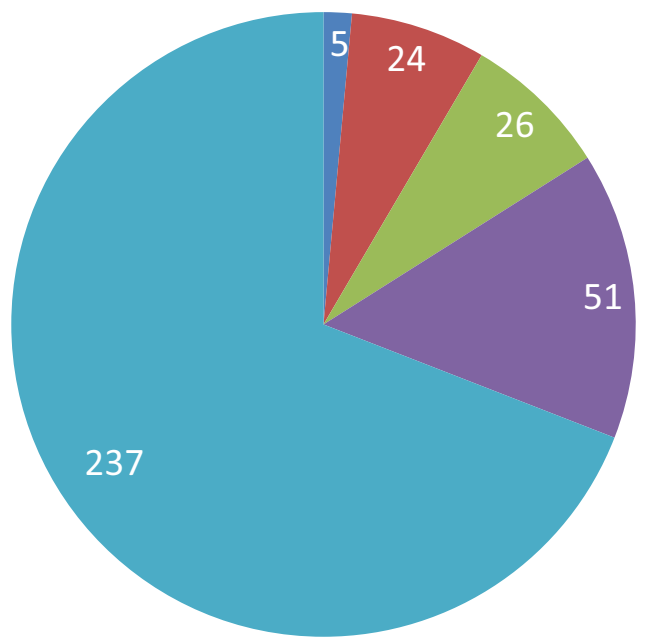

Porte (100 leitos ou mais)

Tomografia computadorizada

Hemoterapia

Neurocirurgia e ortopedia-

traumatologia

Fonte: elaborado pelas autoras, com base em dados do CNES referentes ao ano de 2013 (Brasil, 2014).

\section{Doença renal}

\section{Estruturas específicas para a atenção ao doente renal}

Em relação às estruturas específicas para a atenção ao doente renal, dos 21,2 mil equipamentos para hemodiálise cadastrados no CNES, cerca de vinte mil estão informados como equipamentos em uso, distribuídos em 404 municípios. Destacam-se com o maior número os municípios de São Paulo, Rio de Janeiro, Belo Horizonte, Recife, Fortaleza e Brasília. Em sua grande maioria, os municípios que dispunham desses equipamentos atendiam pacientes SUS e Não SUS.

Pouco mais de três mil equipamentos estavam em estabelecimentos não habilitados como unidades ou centros de referência de alta complexidade em nefrologia, e 47 municípios apenas tinham equipamentos em unidades não habilitadas (Figura 8). 
Figura 8 - Estabelecimentos com equipamento de hemodiálise segundo habilitação. Brasil - 2013

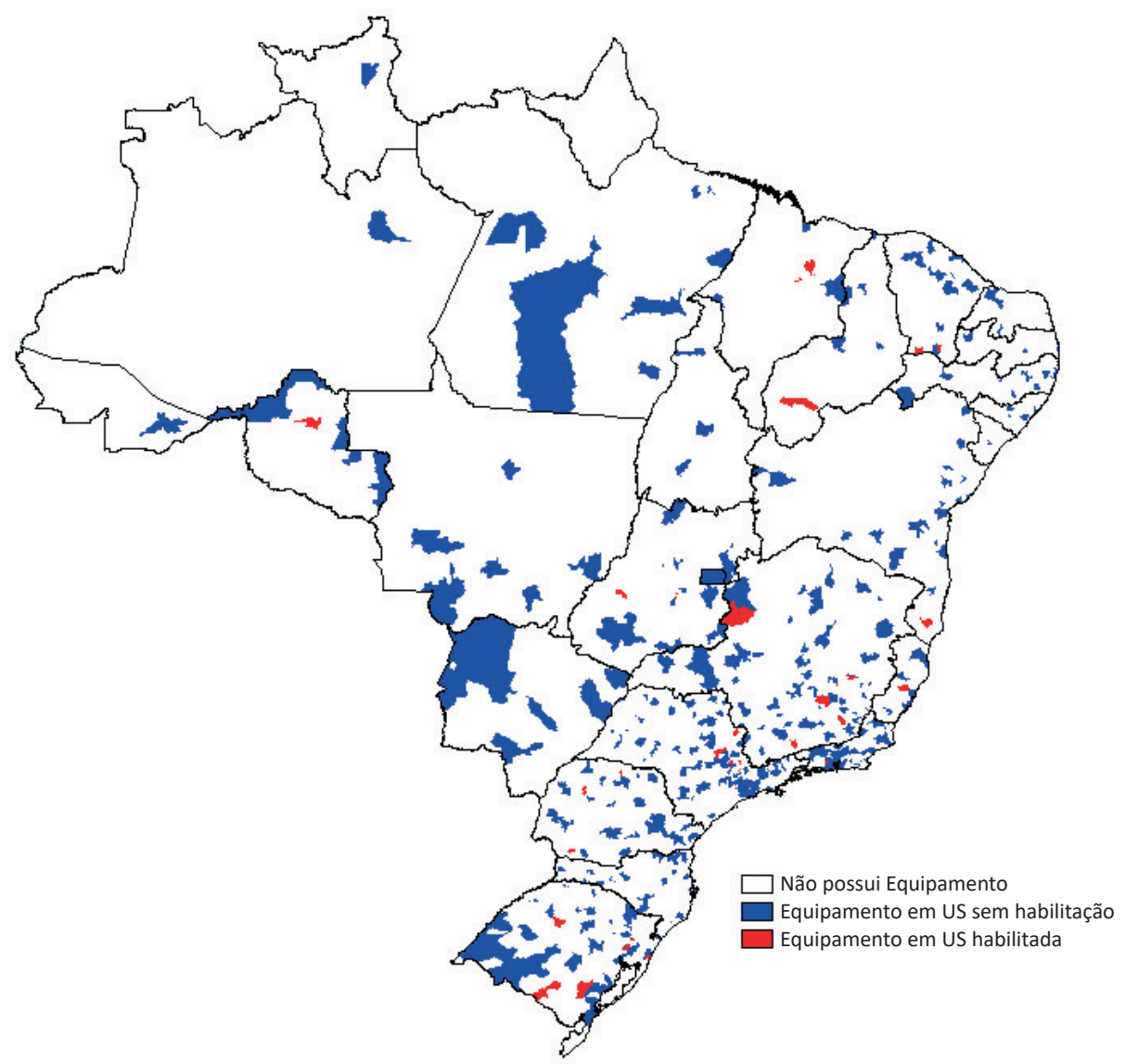

Fonte: elaborado pelas autoras, com base em dados do CNES referentes ao ano de 2013 (Brasil, 2014).

Em 2013 existiam cadastrados no CNES 143 estabelecimentos habilitados em transplante renal, distribuídos em 68 municípios de 23 estados. No Sul havia a maior disponibilidade desse serviço, e no Norte a menor. Os estados de Rondônia, Roraima, Amapá e Tocantins não contavam com serviço habilitado para transplante renal (Figura 9). 
Figura 9 - Municípios com serviço de transplante renal. Brasil - 2013

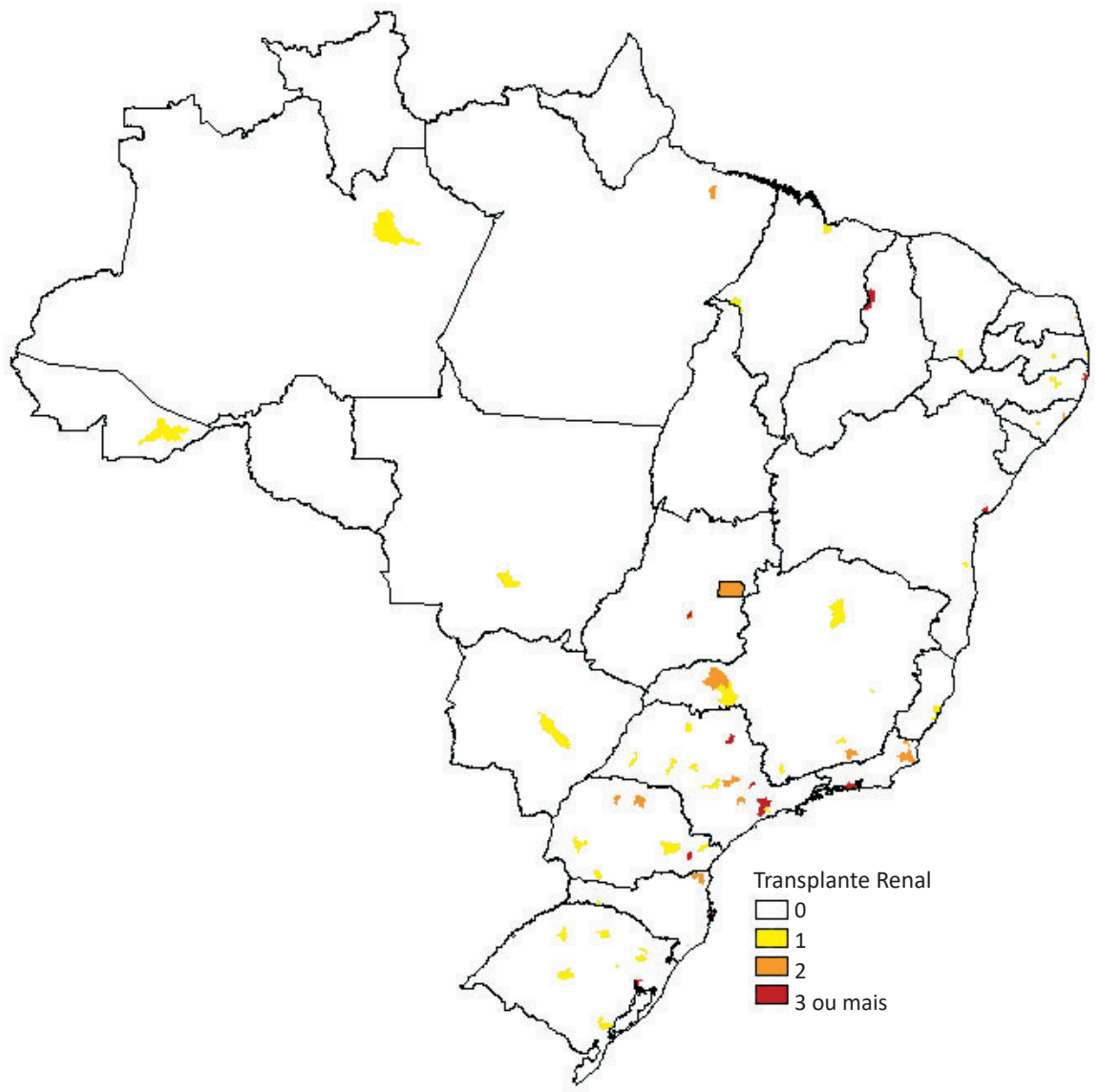

Fonte: elaborado pelas autoras, com base em dados do CNES referentes ao ano de 2013 (Brasil, 2014).

A maioria (mais de 70\%) dos equipamentos para hemodiálise do país está em estabelecimentos de natureza privada com fins lucrativos (Gráfico 10). Em Roraima e no Sergipe havia apenas equipamentos em estabelecimentos dessa natureza. Equipamentos em estabelecimentos públicos constituíam a minoria, não alcançando $8 \%$ do total.

Dos estabelecimentos habilitados para transplante renal, 50\% eram privados sem fins lucrativos e 27\% eram públicos. Amazonas, Alagoas, Paraíba, Sergipe, Alagoas, Espírito Santo, Paraná, Mato Grosso do Sul e Mato Grosso não dispunham de estabelecimentos públicos aptos para realizar transplante renal, mas sim estabelecimentos privados. 
Gráfico 10 - Equipamentos para hemodiálise e serviços habilitados para transplante renal segundo natureza jurídica do estabelecimento. Brasil - 2013

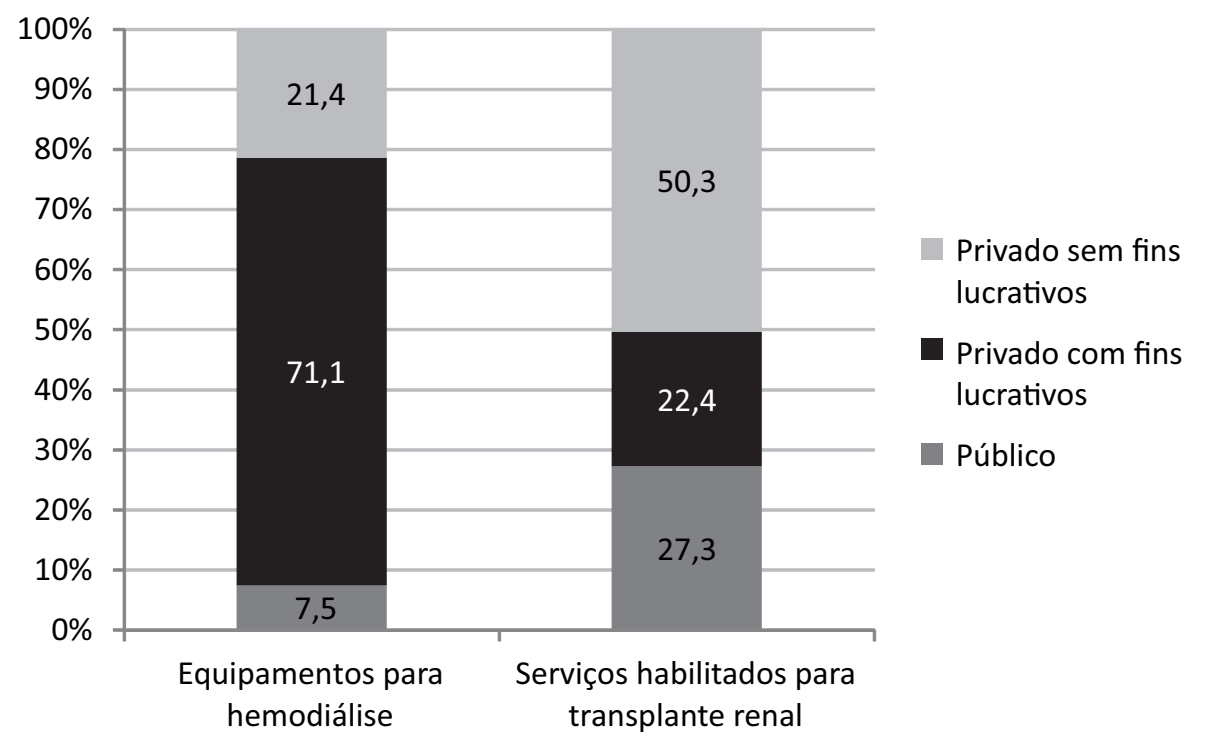

Fonte: elaborado pelas autoras, com base em dados do CNES referentes ao ano de 2013 (Brasil, 2014).

\section{Doenças cardíacas}

\section{Leitos clínicos de cardiologia}

Em relação aos leitos clínicos de cardiologia, em 2013 estavam disponíveis 7.730 leitos clínicos de cardiologia, sendo em torno de 60\% (4.522) oferecidos pelo SUS em todas as regiões do Brasil, embora com muitos vazios principalmente nas regiões Norte e Nordeste (Figura 10). Os leitos clínicos de cardiologia estavam distribuídos em 404 municípios. Em torno de 30\% desses municípios contavam com até dois leitos, aproximadamente $20 \%$ tinham entre três e cinco leitos, em torno de $25 \%$ entre seis e 13 leitos, e $25 \%$, 14 ou mais leitos.

Há em torno de oitenta municípios que oferecem, exclusivamente, leitos clínicos de cardiologia Não SUS. Entre eles, destacam-se São Gonçalo (RJ), Cruz das Almas e Olinda (PE), Osasco, São José do Rio Preto e São José dos Campos (SP).

Para analisar os municípios que oferecem leitos clínicos de cardiologia exclusivos SUS, a Figura 10 permite identificar a dispersão da presença desses leitos, que não se restringe às capitais ou regiões litorâneas. 
Figura 10 - Municípios com leitos clínicos de cardiologia. Brasil - 2013

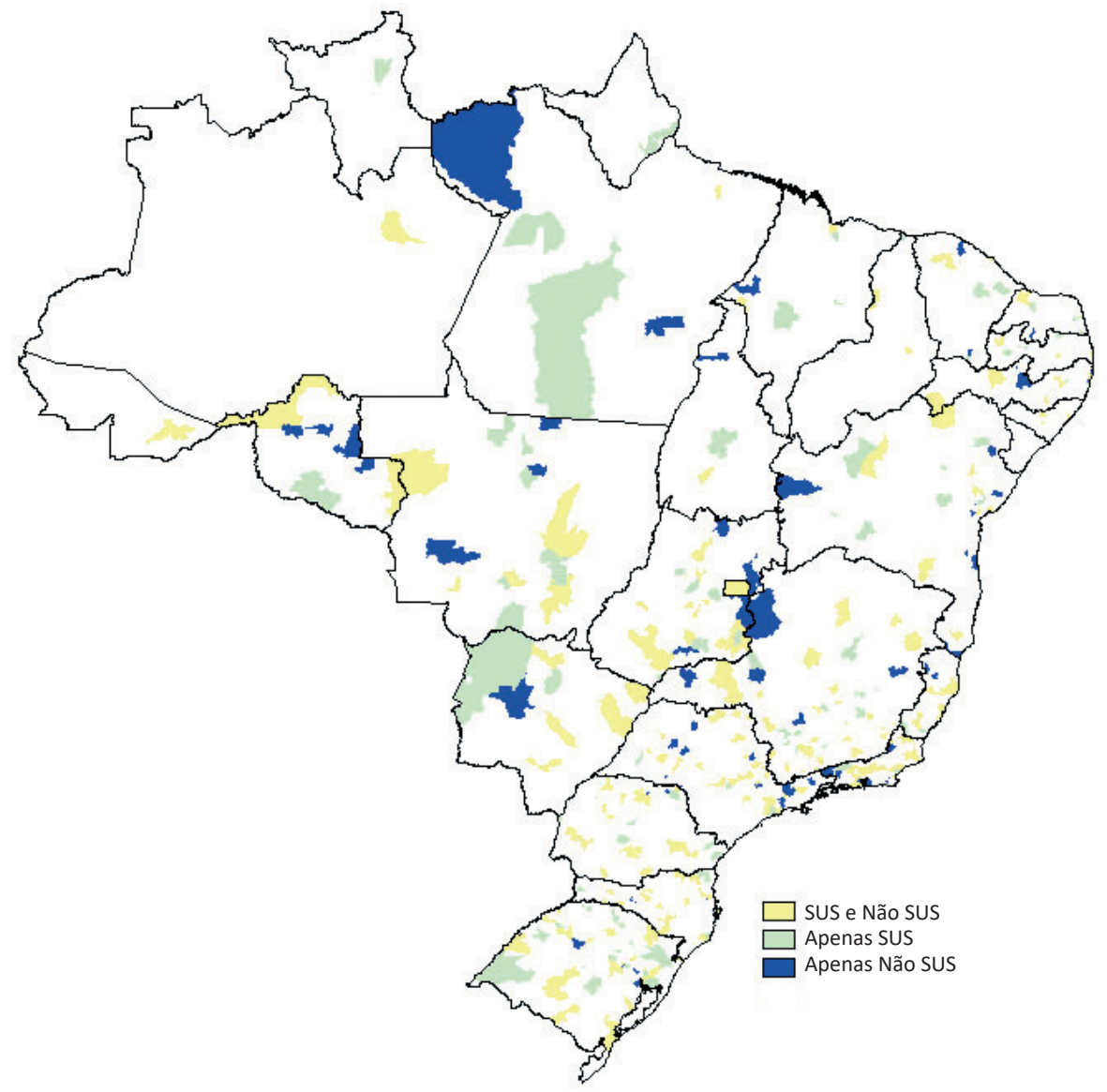

Fonte: elaborado pelas autoras, com base em dados do CNES referentes ao ano de 2013 (Brasil, 2014).

\section{Leitos cirúrgicos de cardiologia}

No caso dos leitos cirúrgicos de cardiologia, em 2013 eram ofertados 5.476 leitos cirúrgicos de cardiologia em 176 municípios. Desses leitos, 3.106 (57\%) eram SUS e 2.370 (43\%) Não SUS. Em 46 municípios a oferta é exclusiva Não SUS. Em Niterói e em Feira de Santana a oferta de leitos Não SUS chega a ser superior em dez vezes e cinco vezes à oferta de leitos SUS, respectivamente. Em Curitiba, Belém e Salvador a oferta da rede privada também era expressiva, próxima do dobro da quantidade de leitos SUS. À semelhança dos leitos clínicos de cardiologia, observam-se grandes áreas vazias em todo o país, principalmente nas regiões Norte, Nordeste e Centro-Oeste (Figura 11). 
Figura 11 - Leitos de cirurgia cardíaca. Municípios Brasileiros - 2013

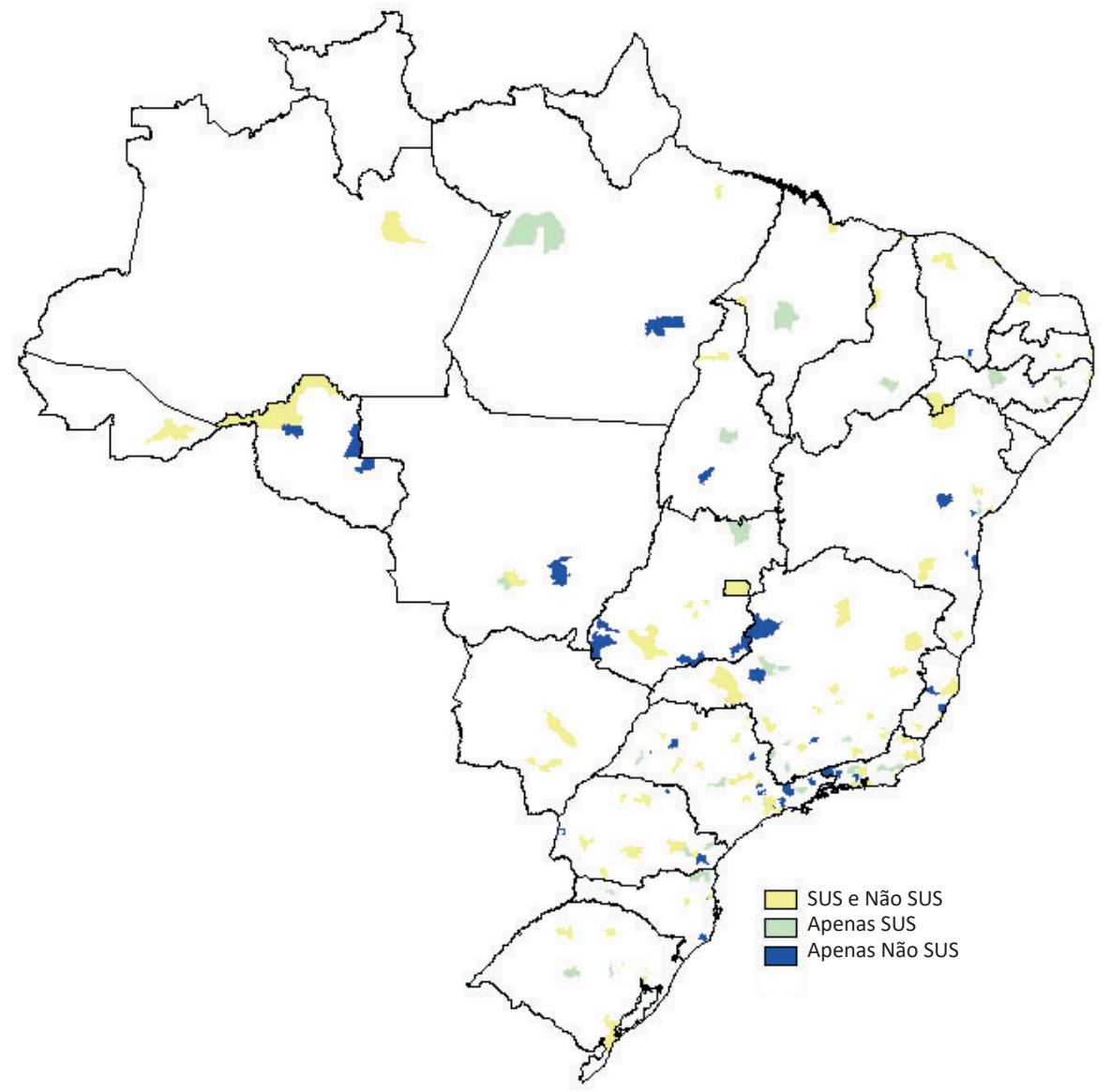

Fonte: elaborado pelas autoras, com base em dados do CNES referentes ao ano de 2013 (Brasil, 2014).

\section{Hemodinâmica}

Em relação à hemodinâmica, a Figura 12 mostra a distribuição dos equipamentos de hemodinâmica no Brasil por município. Em torno de 740 equipamentos estavam distribuídos em 190 municípios em 2013. Aproximadamente 50\% desses municípios tinham apenas um equipamento, 30\% tinham dois equipamentos e $20 \%$ tinham três ou mais equipamentos.

Em 17 municípios, menos de 100\% dos equipamentos existentes estavam registrados como em funcionamento. Destaca-se que em um município menos da metade dos equipamentos estava em uso. Como já salientado na análise de outros equipamentos, o registro do dado "em uso" carece de validação, pois essa informação é importante para indicar possíveis pontos de estrangulamento da capacidade de oferta e orientar possíveis investimentos específicos para realocação de recursos físicos ou de aporte de recursos. 
Figura 12 - Distribuição dos equipamentos de hemodinâmica, por município. Brasil -2013

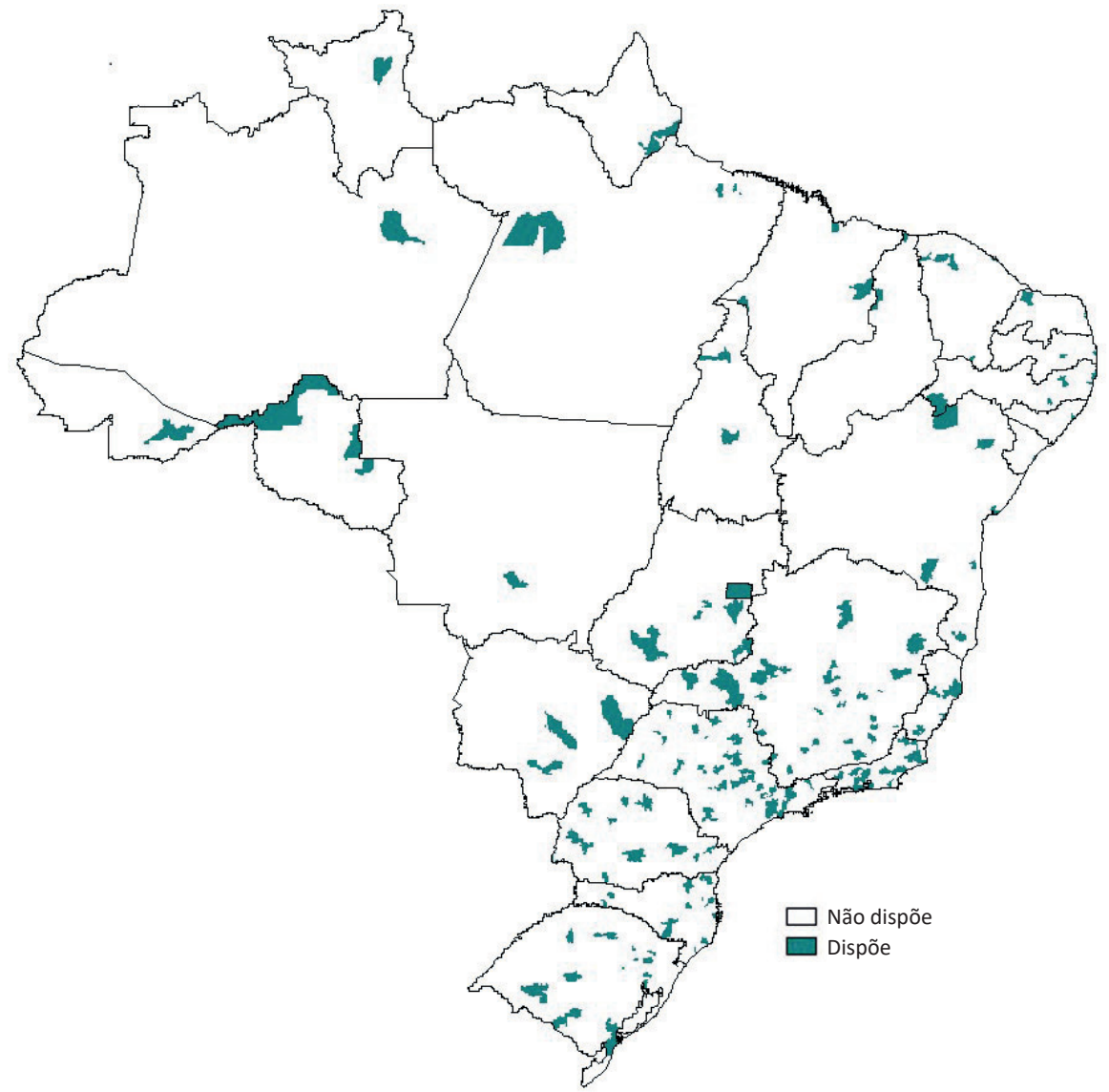

Fonte: elaborado pelas autoras, com base em dados do CNES referentes ao ano de 2013 (Brasil, 2014).

\section{Circulação extracorpórea}

No caso da circulação extracorpórea, em 2013 eram 1.287 aparelhos em uso, distribuídos em 235 municípios, conforme distribuição espacial apresentada na Figura 13. Entre os municípios com o equipamento, em torno de 50\% dispunham de apenas um, $25 \%$ apresentavam entre dois e três e $25 \%$, quatro ou mais. Destaca-se que Natal tinha 249 equipamentos (31 equipamentos/100 mil habitantes), ao passo que São Paulo tinha 116 e Rio de Janeiro 66 (1 equipamento/100 mil habitantes), indicando possível não atualização no CNES ou distorção de oferta. 
Figura 13 - Distribuição dos equipamentos de circulação extracorpórea, por município. Brasil - 2013

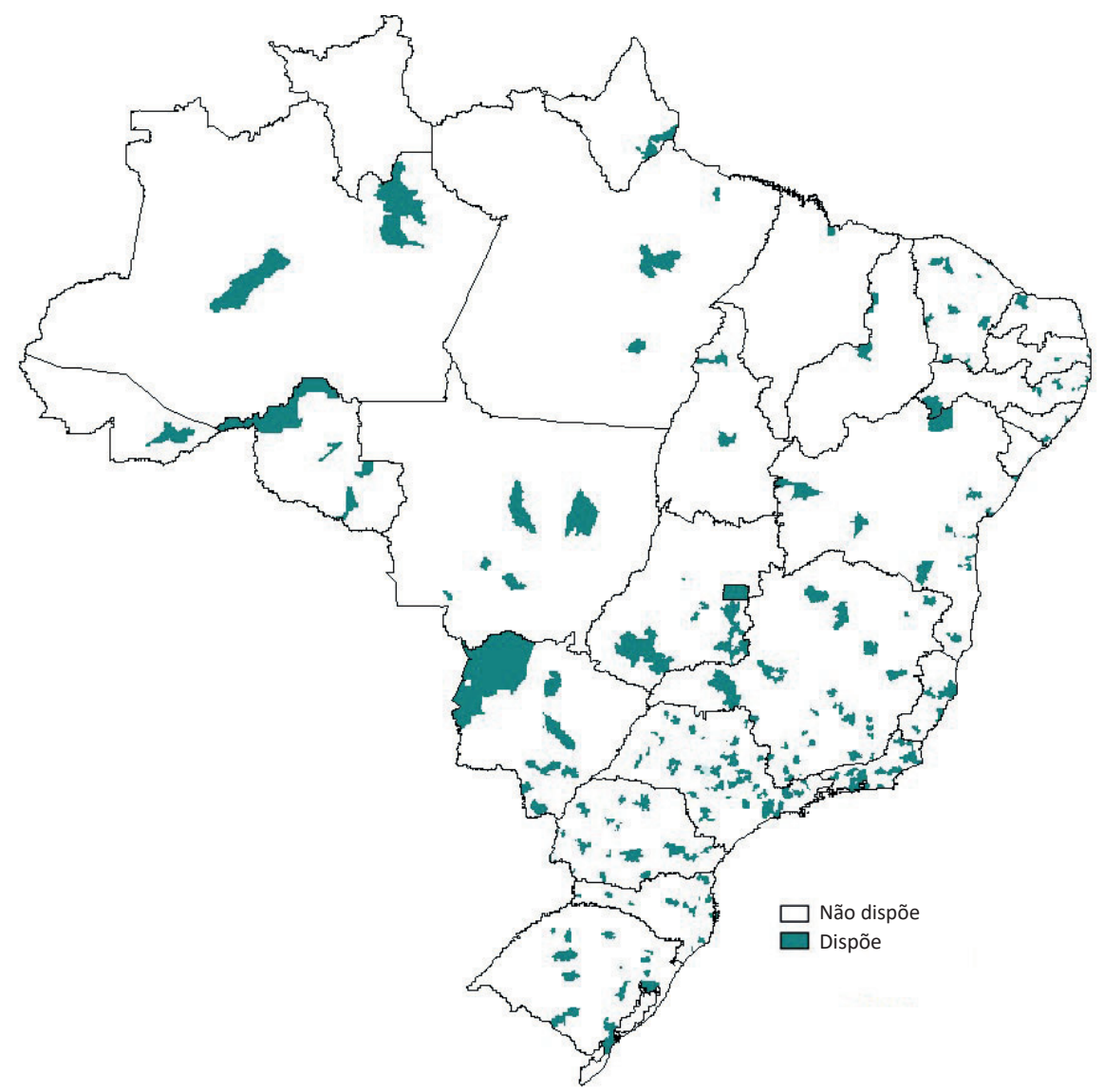

Fonte: elaborado pelas autoras, com base em dados do CNES referentes ao ano de 2013 (Brasil, 2014).

\section{Estruturas específicas para a cirurgia cardíaca}

Em relação à cirurgia cardíaca, em 2013 existiam 546 estabelecimentos habilitados para a realização de cirurgia cardíaca no Brasil, dos quais 187 estavam cadastrados como serviços que realizam procedimentos em pediatria e 359 em adulto. Esses estabelecimentos estavam distribuídos em 156 municípios de 25 estados, com destaque para Rio de Janeiro, São Paulo, Belo Horizonte, Fortaleza, Salvador e São Luís, onde havia o maior número de estabelecimentos com esses serviços (Figura 14).

Dos estabelecimentos com cirurgia cardíaca em pediatria, 33,7\% eram de natureza privada com fins lucrativos e entre os estabelecimentos com cirurgia cardíaca para adulto, 37,9\% eram privados com fins lucrativos (Gráfico 11). 
Figura 14 - Municípios com serviço de cirurgia cardíaca. Brasil - 2013

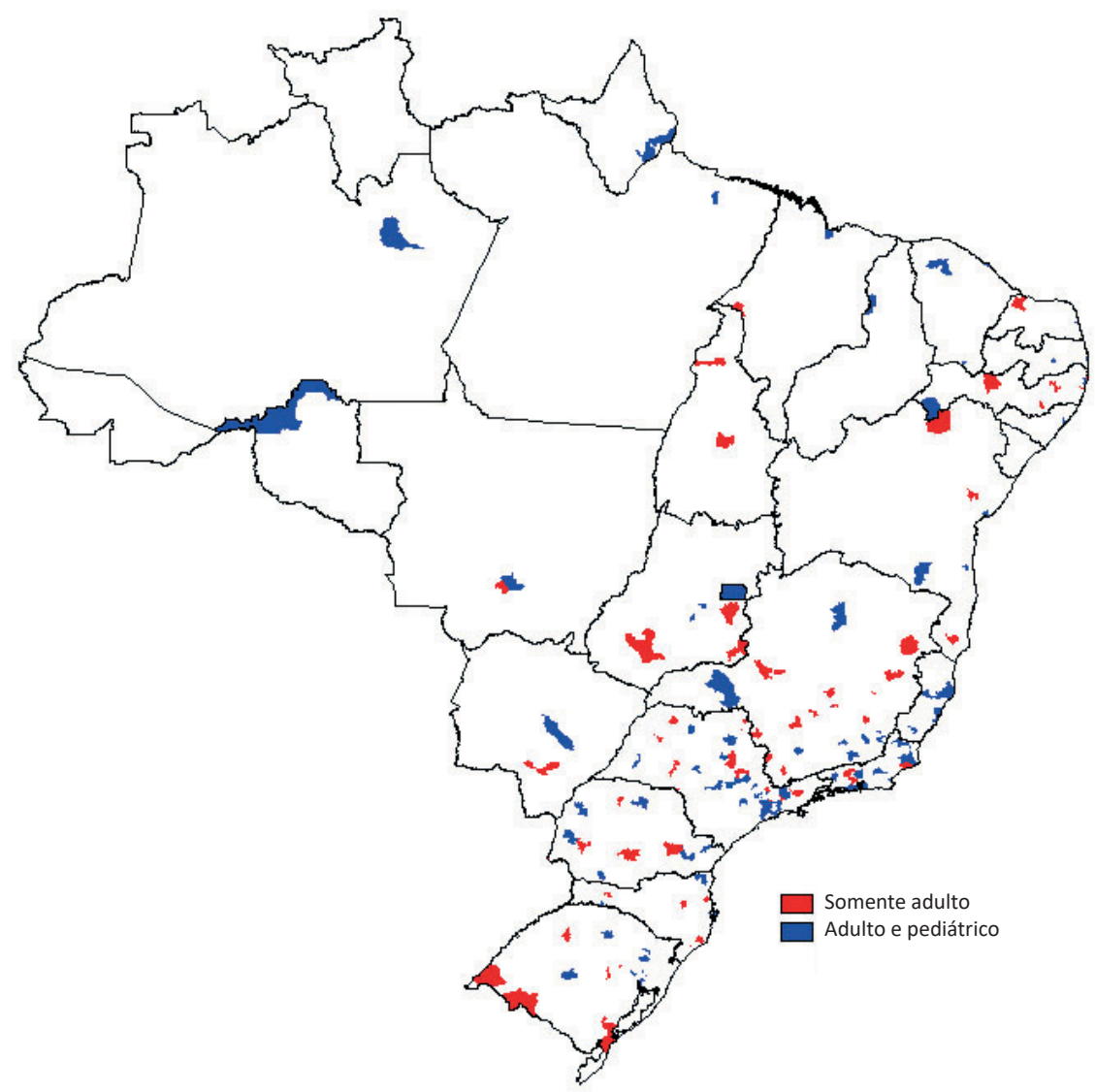

Fonte: elaborado pelas autoras, com base em dados do CNES referentes ao ano de 2013 (Brasil, 2014).

Gráfico 11 - Serviços habilitados para cirurgia cardíaca, por natureza jurídica. Brasil - 2013

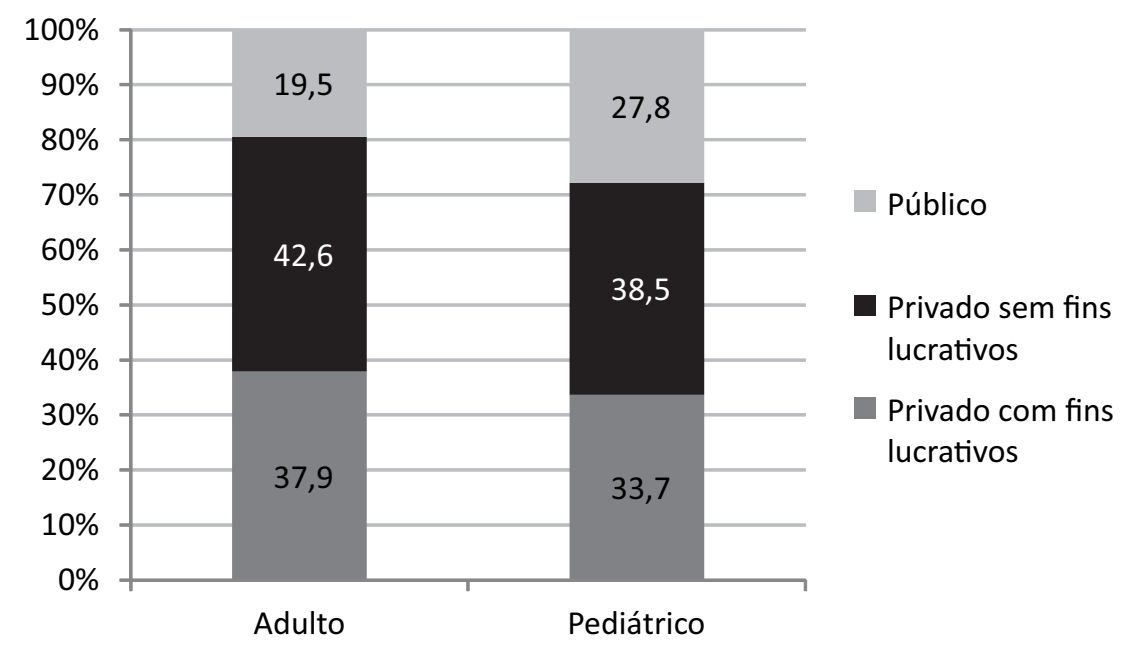

Fonte: elaborado pelas autoras, com base em dados do CNES referentes ao ano de 2013 (Brasil, 2014). 
Observa-se a existência de estabelecimentos com serviço de cirurgia cardíaca sem todas as estruturas necessárias para a realização de cirurgias de mais alta complexidade e risco: $36 \%$ dos serviços de cirurgia cardíaca pediátrica não contavam com UTI pediátrica, 6\% dos serviços de cirurgia cardíaca adulto sem UTI adulto, 31\% dos serviços totais sem dispor de raios X para hemodinâmica, e 27\% dos serviços totais não tinham equipamento de circulação extracorpórea (Gráfico 12).

Gráfico 12 - Serviços de cirurgia cardíaca segundo deficiências. Brasil - 2013

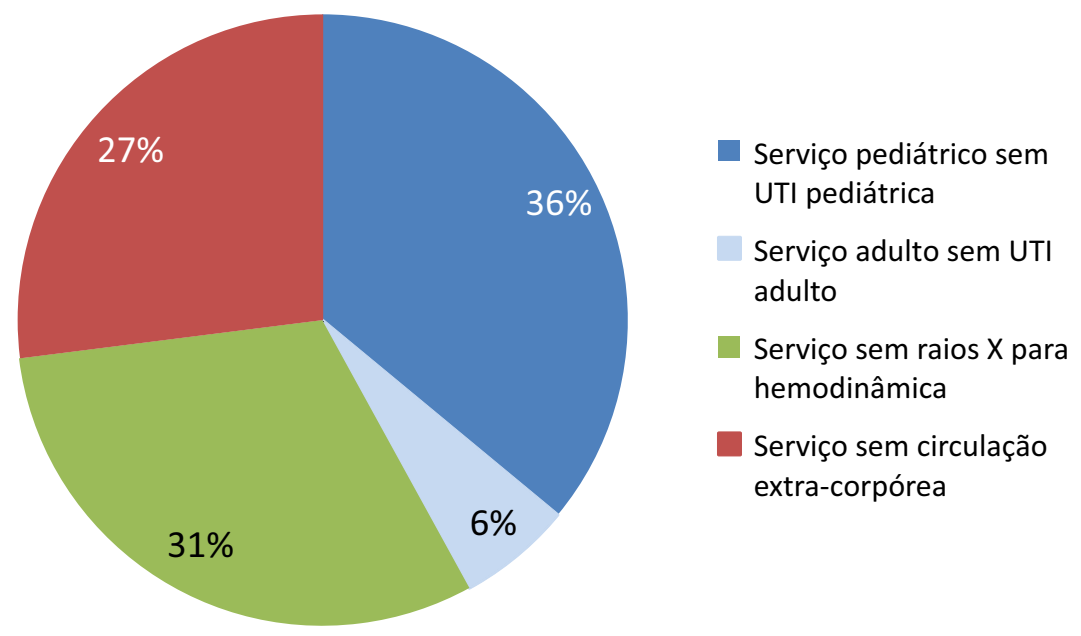

Fonte: elaborado pelas autoras, com base em dados do CNES referentes ao ano de 2013 (Brasil, 2014).

\section{Considerações Finais}

No fim de 2013, o Sistema de Saúde Brasileiro contava com 112.300 unidades de saúde, entre públicas, privadas sem fins lucrativos e privadas com fins lucrativos, segundo informações do CNES. Dessas, mais de 44 mil eram postos e centros de saúde, majoritariamente públicos, cerca de 41 mil policlínicas e clínicas especializadas e vinte mil unidades para SADT, em sua maioria privadas com fins lucrativos, mais de seis mil hospitais gerais e especializados em proporções semelhantes de vinculação aos setores públicos e privados com fins lucrativos, e cerca de mil prontos-socorros, em grande parte públicos.

Por um lado, os desafios relacionados às mudanças nos padrões sociodemográficos e epidemiológicos observados no Brasil geram impactos importantes sobre o planejamento e a organização da rede de atenção à saúde, envolvendo as unidades SUS e Não SUS.

Por outro lado, as invenções ${ }^{4}$ no campo da genômica, da bioengenharia, dos insumos e medicamentos, bem como das tecnologias de processo, que no século passado demoravam a se transformar

\footnotetext{
${ }^{4}$ Consideramos invenção o ato de criar uma nova tecnologia, processo ou objeto, ou um aperfeiçoamento de tecnologias, processos e objetos preexistentes.
} 
em inovação, ${ }^{5}$ hoje chegam ao mercado e são incorporadas nas unidades de saúde com enorme velocidade, desafiando-as em seus processos de transformação física.

Todos esses desafios têm influência tanto na definição dos investimentos em novas estruturas como na regulação e reorganização das estruturas existentes, que é o principal ponto com o qual buscamos contribuir com subsídios para o processo de planejamento e reorganização da rede de saúde do SUS.

Em relação a essa rede SUS, segundo diagnóstico do Primeiro Seminário de Gestão de Tecnologias e Inovação em Saúde, ocorrido em fevereiro de 2009, apesar dos avanços do SUS os problemas de gestão da saúde são ainda significativos. Uma das questões mais importantes se refere ao desenvolvimento tecnológico baseado na transferência de tecnologia e realizado quase sempre de forma incompleta. Ou seja, não é acompanhado por modificações que permitam a apropriação daquela tecnologia pela rede de saúde, envolvendo sua adaptação à situação organizacional, econômica, social e cultural do país e do sistema de saúde local.

Esse fato, além de encarecer os serviços de saúde, aumenta o risco à integridade do usuário da tecnologia e compromete a relação de complementaridade entre a estrutura pública e a privada de serviços de saúde, pois:

Saúde, ciência e tecnologia são requisitos para o desenvolvimento econômico e social (...) os países em desenvolvimento (...) terão de organizar sistemas de pesquisa em saúde baseados em prioridades sanitárias e assegurar a incorporação dos resultados às políticas e ações de saúde. Avanços na área biomédica, em particular em genômica, abrem novas oportunidades, mas impõem desafios adicionais (Morel, 2004: 261).

Assim, cada vez mais se torna necessária maior articulação entre as políticas de saúde e as políticas de educação, econômica, industrial, comercial e de ciência e tecnologia, de modo a reduzir a dependência tecnológica na área da saúde e promover a pesquisa e o desenvolvimento de bens que atendam às necessidades de saúde da população brasileira. Nesse mister, ainda segundo Morel:

Levar uma descoberta à sociedade, ou seja, transformar uma invenção em inovação, é um processo extremamente complexo e que depende do desempenho dos chamados sistemas nacionais de inovação. Há que se considerar não só as etapas estritamente pós-invenção (desenvolvimento tecnológico, ensaios pré-clínicos e clínicos, registro pelas agências reguladoras, fabricação e distribuição), mas também o sistema legal, o de propriedade intelectual e o regulador, assim como os mecanismos de financiamento. (...) Precisa-se, sobretudo, de clara decisão política (Morel, 2004).

Em relação à incorporação na rede de saúde brasileira de tecnologias ofertadas ao mercado desde a década de 1990, observou-se baixa complexidade na maior parte da rede do país, ilustrada em especial pela organização das unidades hospitalares, nas quais, das 6.641 existentes, aproximadamente 80\% dispunham de menos de 100 leitos, o que gera problemas relacionados a escala. Dessas unidades, 13\% tinham menos que 12 leitos; 47\% entre 13 e 49 leitos; 15\% entre 50 e 79 leitos; 5\% entre 80 e 99 leitos; $11 \%$ entre 111 a 299 leitos; e apenas $2 \%$ dos estabelecimentos apresentavam mais de 300 leitos.

${ }^{5}$ Consideramos inovação aquela invenção que chega no mercado. 
No caso específico dos leitos de UTI, a fim de responder às novas demandas de forma resolutiva, especialistas no tema indicam que a proporção de leitos de UTI, hoje estabelecida em portaria ministerial entre $4 \%$ e $10 \%$, tende a aumentar em razão das mudanças discutidas, devendo ainda nesta década alcançar 30\% dos leitos de hospitais de alta complexidade. Além disso, por meio de estudos, revela-se maior efetividade de unidades hospitalares com mais de cem leitos, em que a escala imprime qualidade e segurança. Uma importante questão que se coloca, pois, é a de como conciliar essas diretrizes com a realidade existente, em que o montante de $80 \%$ da rede hospitalar brasileira oferece menos de cem leitos e $61 \%$ menos de cinquenta leitos?

Em relação à complexidade dos recursos físicos disponibilizados, observa-se desequilíbrio entre a oferta de leitos SUS (disponíveis ao SUS) e Não SUS (não disponíveis ao SUS, ou seja, disponíveis ao pagamento privado direto ou por meio de planos privados de saúde), inclusive com diferenças proporcionais entre eles quando focalizada a participação dos leitos de UTI: a relação leitos UTI/ leitos gerais SUS era de 6\%, ao passo que essa relação nos leitos Não SUS era de 14\%.

Além do desequilíbrio entre leitos SUS e Não SUS e de um percentual muito baixo dos leitos de UTI em relação aos leitos existentes, existem grandes vazios na oferta dos leitos de UTI, com variações regionais: 5\% dos leitos da região Norte eram de UTI e na região Sul eram 8\%.

Em relação ao total de hospitais, 794 ofereciam UTI neonatal e estavam distribuídos em 284 municípios, e em quase a metade dos hospitais os serviços de UTI neonatal disponibilizavam entre seis e dez leitos. No caso dos leitos de UTI infantil, eram 605 hospitais que dispunham desse tipo de leito, distribuídos em 226 municípios, e quase a metade com menos de cinco leitos.

Em relação aos leitos de UTI adulto, estavam presentes em 1.690 hospitais, distribuídos em 224 municípios, em situação melhor do que as anteriores. Em 44\% dos hospitais os serviços de UTI para adultos tinham de seis a dez leitos e em 42\% dispunham de mais de 11 leitos, imprimindo maior complexidade aos recursos físicos existentes, caso existam os demais recursos necessários para a oferta desses serviços à população.

Algumas conclusões, se aprofundadas, como o caso da relação de leitos de UTI SUS e Não SUS, podem ser explicadas pelo mercado de venda de serviços ao SUS, e na relação de poder local, que investe no setor privado com garantia de venda ao SUS.

Entretanto, essa dificuldade na incorporação de tecnologias disponibilizadas ao mercado já há duas ou três décadas também pode ser explicada pela insuficiência quantitativa e qualitativa de profissionais para operar e manter tais tecnologias, como já destacado anteriormente.

Em relação às possibilidades de novas incorporações para atender tanto à transição sociodemográfica como à epidemiológica, diversos municípios dispunham de unidades de saúde com quase todas as estruturas necessárias para atender às condições analisadas. Potenciais investimentos nessas unidades poderiam contribuir para a criação de novos centros de atendimento a tais condições, diminuindo a distância entre a situação atual e a situação desejada.

No entanto, esse tema exige estudo detalhado, envolvendo especialistas, planejadores e gestores que explorem as características locais mais relevantes para o processo de mudança de complexidade 
e resolutividade da atenção provida por determinado município, com sustentabilidade. Por exemplo, a nosso ver, em relação ao trauma, os projetos de investimentos deveriam concentrar-se nas áreas onde há maior incidência de causas externas, associados à existência de trabalhadores para os novos recursos físicos incorporados, recursos de custeio para insumos e serviços, e inserção na malha local, por meio das pactuações necessárias ao credenciamento, transformando o investimento, realmente, em ampliação e/ou transformação da oferta.

A seguir destacaremos alguns aspectos que consideramos relevantes nos resultados apresentados para as condições analisadas: trauma de alta e média complexidade, doenças cardíacas e doenças renais.

\section{Trauma de alta e média complexidade}

Apenas 41 hospitais em trinta municípios estavam provistos das oito condições necessárias para serem habilitados como centro de referência em trauma de alta complexidade: ter mais de cem leitos, dispor de UTI, de tomografia computadorizada, de ressonância magnética, de assistência de alta complexidade em neurocirurgia (incluindo neurocirurgia e traumatologia), de hemoterapia, de radiologia intervencionista e de reabilitação.

Em 99 estabelecimentos de 64 municípios, encontraram-se sete das oito estruturas analisadas. E se escolhermos um estabelecimento por município que tenha maior estrutura disponível em sete das oito analisadas, chegamos a cinquenta dos 99 estabelecimentos com déficit de apenas uma das estruturas analisadas, o que poderia orientar a alocação de recursos para incorporação da tecnologia deficitária. Com isso, o Brasil mais que dobraria o número de municípios com capacidade de assistência ao trauma de alta complexidade, passando de trinta para oitenta municípios cobertos, uma grande mudança no perfil da oferta de serviços que atendem a importante demanda.

Destaca-se que a oferta de recursos físicos para a emergência em trauma é majoritariamente feita pelo SUS, uma vez que dos 41 hospitais com as oito estruturas, 17 são públicos, 21 são privados sem fins lucrativos e três privados com fins lucrativos. O mesmo padrão pode ser observado para a média complexidade, pois entre os 99 estabelecimentos com sete das oito estruturas, 34 são públicos, 56 privados sem fins lucrativos e nove privados com fins lucrativos.

\section{Doenças renais}

Dos 21 mil equipamentos para hemodiálise cadastrados no CNES, cerca de 19,9 mil estão informados como equipamentos em uso. Esses últimos estão distribuídos em 404 municípios, destacando-se com maior número nos municípios de São Paulo, Rio de Janeiro, Belo Horizonte, Recife, Fortaleza e Brasília, evidenciando uma concentração desses recursos físicos.

O desequilíbrio segundo natureza jurídica das unidades de saúde, já demonstrado no presente trabalho, também ficou patente nas análises no caso da hemodiálise, em que a maior parte dos equipamentos disponíveis no país está em unidades privadas com fins lucrativos. 


\section{Doenças cardíacas}

Em torno de 60\% do total de leitos clínicos e cirúrgicos destinados para doenças cardíacas estavam vinculados ao SUS, o que mostra que a população tem uma forte dependência desses serviços por parte do setor privado. Ao contrário do que se pensa, a doença coronariana é cada vez mais incidente nas populações de baixa renda, para as quais há menos disponibilidade de assistência, com ainda precária disponibilidade de serviços do SUS especializados nessa área (Marmot et al., 1999; Lynch et al., 2006). Com mais de $40 \%$ da oferta de leitos cardíacos vinculada ao setor privado, constitui uma área da assistência com grande potencial de gerar lucros para o setor privado, com o risco de, se o SUS continuar com esse grau de dependência da oferta do setor privado, ter de pagar os valores mais caros (de mercado) para esses serviços. Por exemplo, a hemodinâmica, por estar sendo oferecida cada vez mais pelo setor privado, vem seguindo a tendência da hemodiálise.

\section{Olhando o futuro}

Os caminhos para as transformações a serem realizadas nos recursos físicos de saúde para as próximas décadas, de modo a ajustar a capacidade às necessidades sociodemográficas e epidemiológicas e às ofertas tecnológicas disponibilizadas pelo desenvolvimento e pelas inovações tecnológicas são desafiadores.

No fim do século passado e nestas primeiras décadas do século XXI, incorporar tecnologias e/ ou reorganizar a oferta de recursos físicos, sobretudo no âmbito das unidades de saúde públicas, traduz-se em um processo complexo, que esbarra em trâmites burocráticos e torna lenta a conclusão do investimento. É neste contexto, de busca constante pelos avanços do futuro para o planejamento e o projeto do presente, que se inserem os estudos prospectivos.

Segundo Martin (1995), os estudos prospectivos se distanciam da ideia de previsão, quando se apresentam como processos coletivos que se repetem continuamente e seguem sofisticados rituais metodológicos. A atitude, o objetivo e o método fazem a diferença porque mesmo admitindo o risco de erro, o erro também é de natureza diversa, uma vez que neste caso o processo incorpora a mudança de opinião no próprio método e exige acompanhamento, contrachecagem e revisão permanente.

A opinião coletiva, a autorizada mudança de opinião e o caráter de permanência do processo dão maior credibilidade ao resultado, pelo menos até que se produza um novo que o atualize ou corrija. A concepção de prospecção (foresight) como processo a identifica como sendo uma

tentativa sistemática de olhar no longo prazo para o futuro em ciência, tecnologia, na economia e na sociedade, com o objetivo de identificar áreas estratégicas e as tecnologias genéricas emergentes com potencial para produzir os grandes benefícios econômicos e sociais. (Martin, 1995: 140)

Conforme Caruso e Tigre (2004), a prospecção tecnológica pode ser entendida ainda como um meio sistemático de mapear desenvolvimentos científicos e tecnológicos futuros capazes de influenciar de forma significativa uma indústria, a economia ou a sociedade como um todo. Diferentemente das atividades de previsão clássica, que se dedicam a antecipar um futuro suposto como único, os exercícios de prospecção são construídos a partir da premissa de que são vários os futuros possíveis. 
Com base no suposto que as ações presentes alteram o futuro, como ocorre com a inovação tecnológica, avanços tecnológicos futuros dependem de modo complexo e imprevisível de decisões alocativas tomadas no presente por um conjunto relativamente grande de agentes. Os exercícios de prospecção, então, funcionam como meio de atingir dois objetivos:

- preparar os atores na indústria para aproveitar ou enfrentar oportunidades ou ameaças futuras e;

- desencadear um processo de construção, no presente, de um futuro desejável.

Nesse sentido podemos pensar que o sucesso na introdução de novas tecnologias depende fundamentalmente da capacidade das organizações de absorver eficientemente novos equipamentos, sistemas e processos produtivos. Isso inclui a incorporação de novas rotinas, procedimentos e informações técnicas que, para serem efetivamente adotados, dependem da capacidade dos recursos humanos de transformar informação em conhecimento. Assim, a difusão de novas tecnologias está diretamente associada ao desenvolvimento de novas capacidades cognitivas para solucionar problemas na introdução, otimização e adaptação de tecnologias específicas ao ambiente de trabalho.

A análise prospectiva em geral se apoia na premissa da complexidade e na necessidade de explorar e entender essa teia de relações complexas, para então estabelecer possíveis alternativas de futuro. Ocorre que em muitos casos as técnicas empregadas não distinguem graus de hierarquias entre as variáveis, setores e eventos, ou seja, não consideram o caráter sistêmico das relações entre esses elementos, tornando difícil a criação de um marco lógico sobre o passado e o presente, que possa apoiar a formulação de hipóteses de futuros plausíveis. Alguns argumentos podem variar, mas no caso da tecnologia há certa convicção de que o elevado custo do investimento em ciência e tecnologia e a falta de recursos no setor público exigem fazer escolhas.

$\mathrm{Na}$ área da saúde, essas escolhas assumem dimensão de políticas públicas quando inseridas nas questões da necessidade de incorporação cotidiana de tecnologias nos hospitais gerais e especializados, centros de saúde e hospitais de alta complexidade no SUS, desta forma,

caberá ao gestor do sistema de saúde tomar decisões que têm efeitos práticos, partindo da constatação de que os recursos efetivamente disponíveis são de fato escassos, e da premissa de que seja moralmente legítimo proceder a alguma forma de 'racionamento' na alocação. (Schramm, 2000: 45)

Para os resultados de pesquisa de fato subsidiarem a tomada de decisão e a elaboração de políticas públicas mais adequadas para resolver as necessidades de oferta de recursos físicos de saúde, deverão necessariamente contemplar uma abordagem intersetorial. Nesse caso, não estamos falando apenas dos setores tradicionais como educação, cultura, meio ambiente etc., mas das realidades de cada município como potencial polo de cada serviço.

A ideia de investir em recursos físicos de saúde passa tanto pela necessidade de saúde da população, como pela capacidade da região de manter essa oferta. Por exemplo, a decisão de investir na aquisição de determinado recurso em um município requer a existência de pessoas capacitadas tanto para operarem esse recurso (médicos/especialidade médica, enfermeiros, técnicos de laboratório, físicos etc.) como para mantê-lo (tecnólogo biomédico, técnicos de elétrica etc.) em perfeito estado de funcionamento garantindo qualidade, segurança e efetividade do serviço prestado à população. 
Nesse contexto, para o cotejamento entre novas ofertas de recursos físicos e possibilidades de recursos humanos, é necessária uma parceria do Ministério da Saúde com o Ministério da Educação para definição de programas de formação em quantidade, perfil e localização estratégicos para a reorganização do sistema de saúde.

É por tal motivo que todo investimento deverá ser previamente analisado diante da complexa realidade do local de oferta, uma vez que essa realidade orientará se o investimento deverá ser para a aquisição de novos recursos - sejam novos ou realocados, vindos de outros municípios que não têm as condições necessárias para ofertar o recurso - ou para o conserto, manutenção e/ou criação de estrutura de serviços no intuito de oferecer determinado recurso físico. Com isso, a recomendação é que, inicialmente, seria oportuno ter a garantia de que os recursos existentes nominados pelo CNES estejam realmente em uso. Pode ser mais interessante para o país colocar em uso o que já existe, mesmo que necessite de alguma reestruturação ou realocação, pela migração dos recursos de um local para outro, do que realizar investimentos de aquisição de novos recursos ou unidades, por exemplo.

\section{Referências}

AGÊNCIA NACIONAL DE SAÚDE SUPLEMENTAR (ANS). Resolução Normativa - RN n. 42, de 4 de julho de 2003. Estabelece os requisitos para a celebração dos instrumentos Jurídicos firmados entre as operadoras de planos de assistência à saúde e prestadores de serviços hospitalares. Rio de Janeiro: ANS, 2003.

AGÊNCIA NACIONAL DE SAÚDE SUPLEMENTAR (ANS). Resolução Normativa - RN n. 85, de 7 de dezembro de 2004. Dispõe sobre a concessão de Autorização de Funcionamento das Operadoras de Planos de Assistência à Saúde, e dá outras providências. Rio de Janeiro: ANS, 2004.

BARRETO, M. L. Esboços para um cenário das condições de saúde da população brasileira 2022/2030. In: GADELHA, P.; CARVALHO, J. N. \& PEREIRA, T. R. (Orgs.). A Saúde no Brasil em 2030: diretrizes para a prospeç̧ão estratégica do sistema de saúde brasileiro. Rio de Janeiro: Fiocruz, Ipea, Ministério da Saúde, Secretaria de Assuntos Estratégicos da Presidência da República, 2013.

BRASIL. Ministério da Saúde. Portaria GM/MS n. 376 de 03 de outubro de 2000. Aprova a Ficha Cadastral dos Estabelecimentos de Saúde e o Manual de Preenchimento, bem como a criação do Banco de Dados Nacional de Estabelecimentos de Saúde. Brasília, Diário Oficial da União, 2000a.

BRASIL. Ministério da Saúde. Portaria GM/MS n. 511 de 29 dez. 2000. Determina o recadastramento de Estabelecimentos de Saúde. Brasília, Diário Oficial da União, 2000b.

BRASIL. Ministério da Saúde. Portaria SE/SAS n. 55 de 29 ago. 2001. Alteram procedimentos das tabelas SUS segundo o regulamento técnico para o funcionamento dos serviços de diálise e as normas para cadastramento desses serviços junto ao Sistema Único de Saúde. Brasília, Diário Oficial da União, 2001.

BRASIL. Ministério da Saúde. Portaria GM 2.048 de 5 nov. 2002. Aprova o Regulamento Técnico dos Sistemas Estaduais de Urgência e Emergência. Brasília, Diário Oficial da União, 2002.

BRASIL. Ministério da Saúde. Portaria n. 1168/GM de 15 jun. 2004. Institui a Política Nacional de Atenção ao Portador de Doença Renal, a ser implantada em todas as unidades federadas, respeitadas as competências das três esferas de gestão. Brasília, Diário Oficial da União, 2004a.

BRASIL. Ministério da Saúde. Portaria n. 210 de 15 jun. 2004. Define Unidades de Assistência em Alta Complexidade Cardiovascular e os Centros de Referência em Alta Complexidade Cardiovascular e suas aptidões e qualidades. Brasília, Diário Oficial da União, 2004b. 
BRASIL. Ministério da Saúde. Secretaria de Atenção à Saúde. Reforma do Sistema da Atenção Hospitalar Brasileira. Brasília: Ministério da Saúde, 2004c.

BRASIL. Ministério da Saúde. Portaria n. 1.366, de 8 jul. 2013. Estabelece a organização dos Centros de Trauma, estabelecimentos de saúde integrantes da Linha de Cuidado ao Trauma da Rede de Atenção às Urgências e Emergências (RUE) no âmbito do Sistema Único de Saúde (SUS). Brasília, Diário Oficial da União, 2013.

BRASIL. Ministério da Saúde. Secretaria de Atenção à Saúde. Cadastro Nacional dos Estabelecimentos de Saúde do Brasil - CNES, 2014. Disponível em:<http://cnes.datasus.gov.br/>. Acesso em: 21 jun. 2017.

CARUSO, L. A. \& TIGRE, P. B. (Orgs.). Modelo Senai de Prospecção: documento metodológico. Montevideo: OIT, Cinterfor, 2004.

CARVALHO, C. A. Cadastro Nacional de Estabelecimentos de Saúde - CNES: seu desenvolvimento, implantação e uma proposta para sua manutenção, 2004. Dissertação de Mestrado, Rio de Janeiro: Escola Nacional de Saúde Pública Sérgio Arouca, Fundação Oswaldo Cruz.

CAZELLI, C. M. et al. Análise das desigualdades regionais na oferta de serviços de saúde no Brasil: pesquisa da assistência médico-sanitária, 1992 e 1999. Saúde em Debate, 26(61): 198-209, 2002.

CONGRESSO mineiro de ortopedia debate fraturas nos idosos. Medicina \& Saúde. Belo Horizonte, 21 jul. 2014. Disponível em: < http://www.portalmedicinaesaude.com.br/blog_single50.html >. Acesso em: 19 fev. 2017.

COSTA, N. R. \& COSTA, L. F. P. Avaliação de programa de atenção à saúde: incentivo à oferta de atenção ambulatorial e a experiência da descentralização no Brasil. Ciência \& Saúde Coletiva, 7(4): 907-923, 2002.

LA FORGIA, G. M. \& COUTTOLENC, B. F. Desempenho Hospitalar no Brasil: em busca da excelência. São Paulo: Singular, 2009.

INSTITUTO BRASILEIRO DE GEOGRAFIA E ESTATÍSTICA (IBGE). Estatísticas da Saúde. Assistência Médicosanitária 2009. Rio de Janeiro: IBGE, 2010. Disponível em: < http://www.ibge.gov.br/home/estatistica/ populacao/condicaodevida/ams/2009/ams2009.pdf>. Acesso em: 26 abr. 2014.

KUSCHNIR, R. \& CHORNY, A. H. Redes de atenção à saúde: contextualizando o debate. Ciência \& Saúde Coletiva, 15(5): 2.307-2.316, 2010.

LUNA, E. J. A. \& SILVA JUNIOR, J. B. Doenças Transmissíveis, Endemias, Epidemias e Pandemias. In: GADELHA, P.; CARVALHO, J. N. \& PEREIRA, T. R. (Orgs.). A Saúde no Brasil em 2030: diretrizes para a prospecção estratégica do sistema de saúde brasileiro. Rio de Janeiro: Fiocruz, Ipea, Ministério da Saúde, Secretaria de Assuntos Estratégicos da Presidência da República, 2013.

LYNCH, J. et al. Explaining the social gradient in coronary heart disease: comparing relative and absolute risk approaches. Journal of Epidemiology and Community Health, 60(5): 436-441, 2006.

MACHADO, J. P. O Arranjo Público-Privado no Brasil e a Qualidade da Assistência Hospitalar em São Paulo e no Rio Grande do Sul, 2014. Tese de Doutorado, Rio de Janeiro: Escola Nacional de Saúde Pública Sérgio Arouca, Fundação Oswaldo Cruz.

MARMOT, M. G. et al. Health inequalities among British civil servants: the Whitehall II study. The Lancet, 337(8.754): 1.387-1.393, 1999.

MARTIN, B. R. Foresight in science and technology. Echnology Analysis \& Strategic Management, 7(2): 139-167, 1995.

MENDES, A. C. G. et al. Assistência pública de saúde no contexto da transição demográfica brasileira: exigências atuais e futuras. Cadernos Saúde Pública, 28(5): 955-964, 2012.

MOREL, C. M. A pesquisa em saúde e os objetivos do milênio: desafios e oportunidades globais, soluções e políticas nacionais. Ciência \& Saúde Coletiva, 9(2): 261-270, 2004. 
MOREL, C. M. Alguns países em desenvolvimento, entre eles o Brasil, têm alcançado grandes avanços em inovação tecnológica. Entrevista à Agência Fiocruz de Notícias. Jornal da Ciência. Rio de Janeiro, 4 ago. 2005. Disponível em: <www.jornaldaciencia.org.br/edicoes/?url=http://jcnoticias.jornaldaciencia.org.br/category/ pdf/> . Acesso em: 23 out. 2014.

NASCIMENTO, E. G. Q. A Importância do Cadastro Nacional de Estabelecimentos de Saúde (CNES) como Instrumento na Auditoria em Saúde, 2012. Monografia de Especialização, Curitiba: Faculdades Pequeno Príncipe.

OLIVEIRA, A. T. R. \& ONEILL, M. M. V. C. Cenário sociodemográfico em 2022/2030 e distribuição territorial da população: uso e ocupação do solo. In: GADELHA, P.; CARVALHO, J. N. \& PEREIRA, T. R. (Orgs.). A Saúde no Brasil em 2030: diretrizes para a prospecção estratégica do sistema de saúde brasileiro. Rio de Janeiro: Fiocruz, Ipea, Ministério da Saúde, Secretaria de Assuntos Estratégicos da Presidência da República, 2013.

ORGANIZAÇÃO PAN-AMERICANA DA SAÚDE (OPAS). Rede Interagencial de Informação para a Saúde. Indicadores básicos para a saúde no Brasil: conceitos e aplicações. Brasília: Opas, 2008.

PAIM, J. et al. O Sistema de Saúde Brasileiro: história, avanços e desafios. The Lancet, 11-31, 2011. (Série Saúde no Brasil 1)

PESSÔA, L. R. Terceirização nos Hospitais Públicos: mais um problema ou uma possível solução, 1996. Dissertação de Mestrado, Rio de Janeiro: Escola Nacional de Saúde Pública Sérgio Arouca, Fundação Oswaldo Cruz.

PESSÔA, L. R. Mergulho em Montes Claros: desafios da alocação de recursos na rede SUS, 2005. Tese de Doutorado, Rio de Janeiro: Escola Nacional de Saúde Pública Sergio Arouca, Fundação Oswaldo Cruz.

PESSÔA, L. R. (Org.). Unidade de Aprendizagem Arquitetura e Engenharia. Rio de Janeiro: EAD, Ensp/Fiocruz, 2009.

RODRIGUES, C. G; AMARAL, P. V. M. \& SIMÕES R. F. Rede urbana da oferta de saúde: uma análise multivariada macrorregional - Brasil, 2002. Revista de Desenvolvimento Econômico, 9(16): 1.516-1.684, 2007.

SANTOS, I. S.; SANTOS, M. A. B. \& BORGES, D. C. L. Mix público-privado no sistema de saúde brasileiro: realidade e futuro do SUS. In: GADELHA, P.; CARVALHO, J. N. \& PEREIRA, T. R. (Orgs.). A Saúde no Brasil em 2030: diretrizes para a prospecção estratégica do sistema de saúde brasileiro. Rio de Janeiro: Fiocruz, Ipea, Ministério da Saúde, Secretaria de Assuntos Estratégicos da Presidência da República, 2013.

SANTOS, I. S.; UGÁ, M. A. D. \& PORTO, S. M. O mix público-privado no sistema de saúde brasileiro: financiamento, oferta e utilização de serviços de saúde. Ciência \& Saúde Coletiva, 13(5): 1.431-1.440, 2008.

SCHRAMM, F. R. Bioética, economia e saúde: direito à assistência, justiça social, alocação de recursos. Revista Brasileira de Cancerologia, 46(1): 41-47, 2000.

TRIBUNAL DE CONTAS DA UNIÃO (TCU). Relatório de Levantamento - FiscSaúde (TC 032.624/2013-1). Brasília: TCU, 2013. Disponível em: <https://contas.tcu.gov.br/juris/Web/Juris/ConsultarTextual2/Index. faces?textoPesquisa $>$. Acesso em: 4 maio 2014.

VECINA NETO, G; MALIK, A. M. Tendências na assistência hospitalar. Ciência \& Saúde Coletiva, 12(4): 825-839, 2007.

VIACAVA, F. \& BAHIA, L. Oferta de Serviços de Saúde: uma análise da pesquisa assistência médico-sanitária (AMS) de 1999. Brasília: Ipea, 2002. (Texto para discussão n. 915) 


\section{ANEXO}

Quadro 1 - Resultado da auditoria do TCU em amostra de hospitais

\begin{tabular}{|c|c|}
\hline $\begin{array}{l}\% \text { DAS UNIDADES } \\
\text { VISITADAS }\end{array}$ & PRINCIPAIS PROBLEMAS APONTADOS PELOS GESTORES \\
\hline \multicolumn{2}{|r|}{ RECURSOS HUMANOS } \\
\hline $81 \%$ & Apresentam deficit no quadro de pessoal (médicos,enfermeiros, outros). \\
\hline $81 \%$ & $\begin{array}{l}\text { Falta de pessoal é o problema para bloqueio de leitos ( } 47 \% \text { do total de leitos } \\
\text { bloqueados). }\end{array}$ \\
\hline $63 \%$ & Absenteísmo dos profissionais provoca impactos à prestação de serviços. \\
\hline \multicolumn{2}{|r|}{$\begin{array}{c}\text { MEDICAMENTOS E INSUMOS } \\
\text { (medicamentos, roupas hospitalares, seringas, ataduras, fios cirúrgicos) }\end{array}$} \\
\hline $56 \%$ & $\begin{array}{l}\text { Falta ou insuficiências por falhas em licitações (deficiência na estimativa de } \\
\text { quantitativos). }\end{array}$ \\
\hline $53 \%$ & Carência de instrumentos de gestão (controle de solicitação, saída e distribuição). \\
\hline $48 \%$ & Falta de instrumentos ou mobiliário básico para prestação de serviços. \\
\hline $39 \%$ & Desperdício por práticas inadequadas dos profissionais. \\
\hline \multicolumn{2}{|r|}{$\begin{array}{l}\text { EQUIPAMENTOS } \\
\text { (monitores, ventiladores pulmonares, tomógrafos,mamógrafos) }\end{array}$} \\
\hline $77 \%$ & $\begin{array}{l}\text { Bloqueio de leitos por falta de equipamentos mínimos ( } 11 \% \text { do total de leitos } \\
\text { bloqueados). }\end{array}$ \\
\hline $59 \%$ & Atendimento inadequado em função de equipamentos antigos ou desatualizados. \\
\hline $45 \%$ & Ausência ou deficiência de contratos de manutenção. \\
\hline $22 \%$ & $\begin{array}{l}\text { Equipamentos de alto custo não utilizados ou subutilizados por falta de } \\
\text { profissionais. }\end{array}$ \\
\hline \multicolumn{2}{|r|}{ ESTRUTURA FÍSICA E MANUTENÇÃO PREDIAL } \\
\hline $73 \%$ & Estrutura física inadequada e/ou falta de manutenção predial. \\
\hline $59 \%$ & Principal motivo para bloqueio de leitos (18\% do total de leitos bloqueados). \\
\hline $45 \%$ & Contrato de manutenção predial não atende a todas as necessidades da unidade. \\
\hline $25 \%$ & Não possuem local adequado para guarda de cadáveres. \\
\hline
\end{tabular}

Fonte: TCU, 2013. 



\title{
POLOS E FLUXOS DE DESLOCAMENTO DE PACIENTES PARA INTERNAÇÃO HOSPITALAR E PROCEDIMENTOS SELECIONADOS NO SISTEMA ÚNICO DE SAÚDE
}

\author{
Diego Ricardo Xavier, Vanderlei Pascoal de Matos \\ Mônica de Avelar Figueiredo Mafra Magalhães \\ Jaime Gregorio Bellido, Wisley Velasco \\ Francisco Viacava
}

A extensão territorial do Brasil, a história e o dinamismo de sua ocupação, a grande diversidade de biomas e a utilização de seus espaços colocam grandes desafios para a organização equitativa e integrada de recursos para atendimento das necessidades sociais de sua população. No caso das respostas aos problemas de saúde, a multiplicidade de recursos requeridos, a diversidade de sua complexidade tecnológica e sua necessária articulação e integração, o exame de sua distribuição espacial e o uso que a eles é dado, são essenciais para uma apreciação de sua capacidade presente e planejamento de longo prazo.

No contexto da iniciativa de prospecção estratégica do sistema de saúde, articulada pela Fundação Oswaldo Cruz, são discutidos e reafirmados princípios que devem presidir as políticas de saúde no país (Noronha \& Pereira, 2013). No caso específico da distribuição territorial, embora a lei n. 8.080/1990 tenha estabelecido em seu artigo $8^{\circ}$ que "as ações e serviços de saúde, executados pelo Sistema Único de Saúde (SUS) (...) serão organizados de forma regionalizada e hierarquizada em níveis de complexidade crescente" (Brasil, 1990), apenas a partir do fim dos anos 1990 têm início, em escala nacional, os processos formais de definição de regiões de saúde (Lima et al., 2012). Esse processo se desenvolveu dentro dos limites das unidades federadas por agrupamentos de municípios agregados fundamentalmente por vizinhança, existência de polos socioeconômicos e, em certa medida, pela distribuição da oferta dos diferentes tipos de serviços de saúde.

A acelerada mudança demográfica e epidemiológica ocorrida a partir da segunda metade do século XX, com o envelhecimento populacional e o predomínio das doenças crônico-degenerativas, temas abordados em profundidade também no contexto da iniciativa Brasil Saúde Amanhã (Fundação Oswaldo Cruz, 2013), particularmente por Ouverney e Noronha (2013), vem impondo a necessidade de se repensar o modelo de organização do sistema de saúde.

Uma vez que a integralidade do acesso aos serviços passa a ser requisito essencial para responder as necessidades de saúde das populações, a identificação e superação das barreiras para o acesso e uso se tornam imprescindíveis. Jacobs e colaboradores (2012) fazem uma revisão cuidadosa dos esquemas analíticos de identificação, destacando as barreiras geográficas derivadas da localização e da capacidade da oferta e a distância, tempo e custo do transporte. 
A distância existente entre a residência dos pacientes e o local de atendimento, decorrente da grande dimensão territorial do país assinalada anteriormente (Unglert, Rosenburg \& Junqueira, 1987) vem sendo analisada por vários autores. Oliveira, Carvalho e Travassos (2004) fizeram um esforço pioneiro para mapear as redes reais de atenção que estavam sendo definidas pelo deslocamento das pessoas para o atendimento pelo SUS. Esse tipo de estudo permite a identificação de vazios assistenciais, contribuindo para a elaboração de estratégias de longo prazo para superação ou minimização dessas barreiras de acesso. O mesmo estudo revela a formação de redes distintas que variam com os diferentes níveis de complexidade dos recursos assistenciais. Em outro estudo, Oliveira e colaboradores (2011) ressaltaram a importância de identificar os polos de atendimento, as distâncias percorridas por pacientes para obter cuidado de saúde e o volume de pessoas envolvido nesses deslocamentos.

A teoria dos grafos é uma abordagem matemática para ordenar grupamentos de registros por localidade, magnitude e/ou direção de fluxos de pacientes. O primeiro grafo da história foi desenvolvido pelo matemático Leonhard Euler (1736) para solucionar o seguinte problema teórico como atravessar todas as pontes da cidade de Königsberg sem repetição de pontes. Euler tratou as pontes como arestas e suas intersecções como vértices, solucionando a questão (Diestel, 2005). A aplicação computacional da teoria dos grafos permite de forma mais facilitada criar e analisar mapas de fluxos de pacientes que relacionam o destino do atendimento (local) e a origem do paciente (residência), além de apontar possíveis polos e redes de atendimento em saúde.

Os objetivos desta pesquisa foram analisar o volume de internações hospitalares e de procedimentos diagnósticos e terapêuticos em pacientes não hospitalizados no SUS e estabelecer o fluxo desses pacientes no território nacional. As internações hospitalares foram classificadas em dois grupos de diferente complexidade: baixa-média (BMC) e alta (AC). Buscou-se estudar as diversas situações de concentração de internações e procedimentos nos municípios brasileiros, no período de 2010 a 2012 .

Para a análise dos fluxos, elaborou-se um grafo que considera os deslocamentos de pacientes dos municípios com menor frequência de procedimentos realizados para aqueles com maior frequência desses mesmos procedimentos. Com isso, observou-se a dominância do fluxo e o local de atração e concentração de pacientes evidenciando o polo de atendimento.

Na primeira parte é feita uma descrição do método empregado no estudo. Na segunda parte são apresentados os resultados das análises efetuadas, respectivamente, para o conjunto e para subgrupos de internações hospitalares e procedimentos diagnósticos e terapêuticos selecionados. Na última parte, são indicadas algumas conclusões do trabalho.

\section{Formação dos Fluxos e dos Grupos de Procedimentos}

Neste estudo utilizaram-se duas bases de dados: o Sistema de Informação Hospitalar (SIH) para as internações hospitalares do SUS e o Sistema de Informação Ambulatorial (SIA) para os procedimentos diagnósticos e terapêuticos selecionados. Essas bases são geridas pelo Ministério da Saúde, por intermédio da Secretaria de Assistência à Saúde, em conjunto com as secretarias estaduais municipais de saúde, sendo processadas pelo Departamento de Informática do SUS (Datasus), da Secretaria Executiva do Ministério da Saúde. As unidades hospitalares participantes do SUS (públicas 
ou privadas conveniadas) enviam as informações das internações efetuadas através do formulário Autorização de Internação Hospitalar (AIH) para os gestores municipais ou estaduais. Essas informações são processadas no Datasus, gerando os créditos referentes aos serviços prestados e formando uma base de dados bastante robusta, contendo dados de grande parte das internações hospitalares realizadas no Brasil.

Os registros de internações hospitalares e procedimentos diagnósticos e terapêuticos entre 2010 e 2012 do SIH foram utilizados na construção dos grupos de complexidade baixa-média, alta e grupos de serviços de apoio diagnóstico e terapêutico (SADT) (Quadro 1). As internações foram classificadas segundo especialidades médico-cirúrgicas, gênero e grupos etários específicos e agrupadas por grau de complexidade.

Para seleção dos registros e criação do fluxo de pacientes foram seguidas as etapas apresentadas no fluxograma da Figura 1.

Quadro 1 - Grupos de internações hospitalares e procedimentos diagnósticos e terapêuticos realizados pela rede de estabelecimentos de saúde

\section{I - Grupos de procedimentos para baixa-média} complexidade: internações

1) Pediatria - Internação clínica (0-15 anos)

2) Pediatria - Internação cirúrgica (0-15 anos)

3) Mulher - Internação ginecológica clínica ou cirúrgica (mulheres de 15 anos ou mais)

4) Mulher - Internação obstétrica para parto normal (mulheres de 15 a 49 anos)

5) Mulher - Internação obstétrica para parto cesariano (mulheres de 15 a 49 anos)

6) Mulher - Internação obstétrica para curetagem pós-aborto (mulheres de 15 a 49 anos)

7) Adulto - Internação clínica (todos, 15 a 64 anos)

8) Adulto - Internação cirúrgica de baixa e média complexidade (todos, 15 a 64 anos)

9) Idoso - Internação clínica (65 anos ou mais)

10) Idoso - Internação cirúrgica (65 anos ou mais)

11) Trauma - Internação clínica ou cirúrgica em todas as idades

II - Grupos de procedimentos diagnósticos e terapêuticos: SADT

12) SADT - Tomografia computadorizada

13) SADT - Ressonância magnética

14) SADT - Mamografia

15) SADT - Quimioterapia

16) SADT - Radioterapia
III - Grupos de procedimentos de AC

17) Angioplastia

18) Cirurgia de revascularização do miocárdio

20) Internação em UTI adulto

21) Internação em UTI pediátrica

22) Internação em UTI neonatal

23) Transplante de córnea

24) Transplante de rim

25) Transplante de demais órgãos sólidos

26) Transplante de medula óssea

27) Neurocirurgia

28) Cirurgia ortopédica do joelho

29) Cirurgia ortopédica do quadril

30) Cirurgia oncológica de útero e ovário

31) Cirurgia oncológica de mama

32) Cirurgia oncológica de próstata

33) Cirurgia oncológica de tireoide

34) Cirurgia oncológica de cólon e reto

35) Cirurgia oncológica de estômago 
Figura 1 - Esquema para seleção dos registros e criação dos fluxos de pacientes

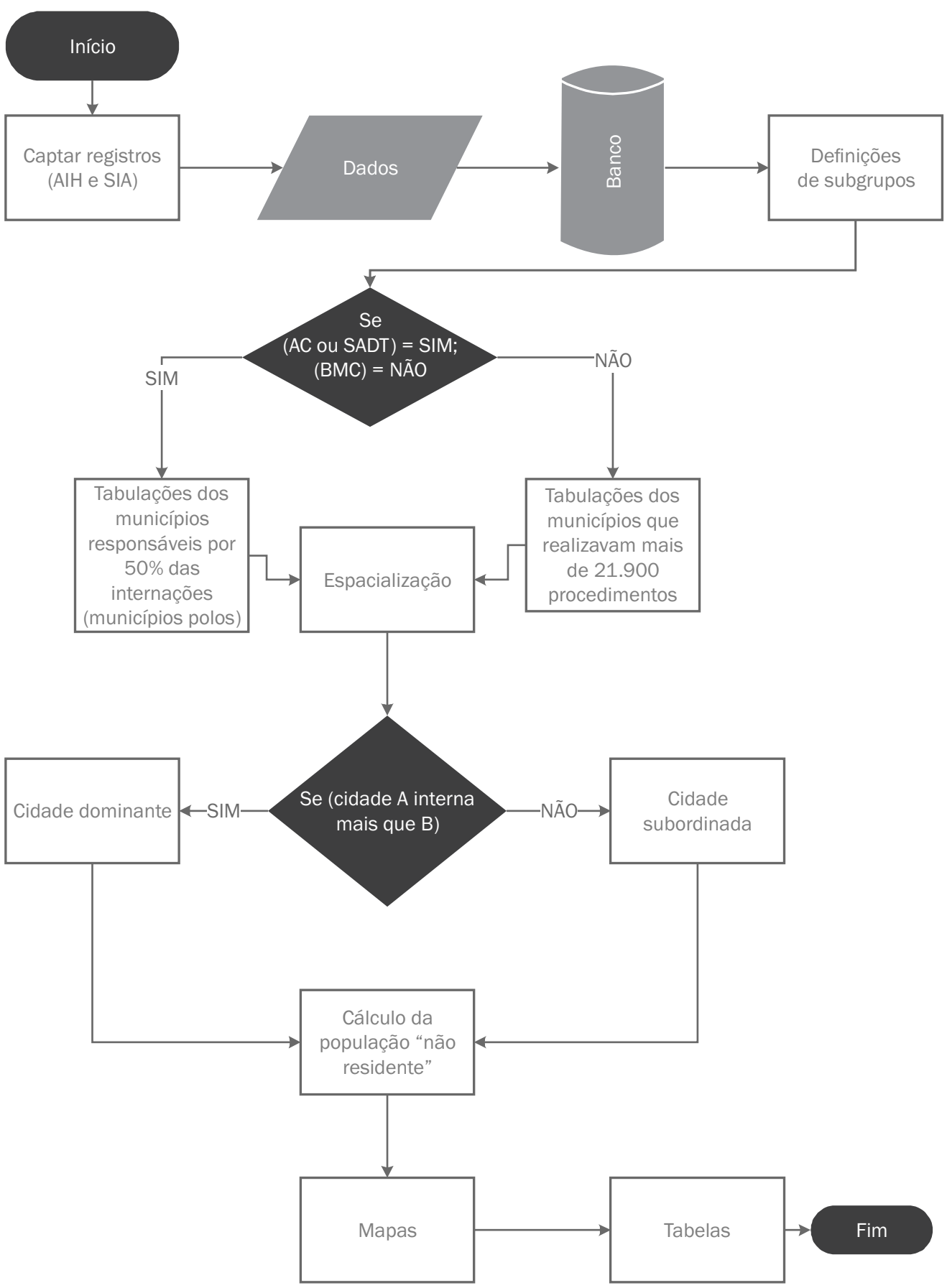

Fonte: adaptado de Diestel (2005). 
Os registros de internações e dos principais procedimentos diagnósticos e terapêuticos foram reunidos e gerenciados no Postgresql. ${ }^{1}$ Consideraram-se os dois grandes grupos de internações por classe de complexidade e o grupo de procedimentos diagnósticos e terapêuticos. Esses três grupos foram subdivididos em função de como se manifesta o volume de pacientes, por especialidade da internação e tipo de procedimento, levando-se em conta as situações de concentração em determinados municípios e as situações em que esse volume está disperso entre municípios.

Para a criação de subgrupos de internação hospitalar em cada classe de complexidade, utilizou-se como critério selecionar as especialidades de maior representatividade, com 50\% ou mais dos atendimentos. Um exemplo prático é o da composição do subgrupo de "pediatria - internação clínica", em que foram agregados procedimentos de:

- tratamento de pneumonias ou influenza (gripe);

- tratamento de doenças infecciosas e intestinais;

- tratamento das doenças crônicas de vias aéreas inferiores;

- tratamento de outros transtornos relacionados ao período perinatal;

- tratamento de transtornos relacionados com a duração da gestação e com o crescimento fetal.

Em seguida, quando a relação de procedimentos era muito diversificada foram selecionados apenas os vinte primeiros itens da "Tabela de Procedimentos do SUS" (2008).

Na primeira caixa de condição do fluxograma temos: se o grupo de procedimentos condiz com AC ou SADT é aplicada uma tabulação de número de municípios responsáveis por até $50 \%$ das internações de alta complexidade ou exames SADT. Quando a condição é negativa (grupo de procedimento BMC) os dados foram tabulados para municípios que realizaram no mínimo 21.900 (ocupação de 80\% dos leitos, média de quatro dias por internação, 7.300 por ano), considerando as internações no período.

$\mathrm{Na}$ fase seguinte, realizou-se o processo de espacialização dos dados tabulares. Assim, cada conjunto de registros recebe uma geometria para cada identidade espacial. Na segunda caixa de condição do fluxograma foi feita a classificação dos municípios polos pela condição, se a cidade B envia pacientes para cidade A, e B tem um volume de internação menor que A, então a cidade A é considerada dominante e a cidade B é considerada subordinada (Nystuen \& Dacey, 1961). Com base nas derivações da teoria de Euler, é possível construir um grafo chamado de orientado, no qual suas arestas apresentam uma direção definida. Num grafo orientado é possível ir do ponto A ao ponto B, entretanto, não é possível realizar o caminho inverso através da mesma aresta (Diestel, 2005). Dadas essas relações topológicas aplicadas na etapa de espacialização descrita no fluxograma, foi possível realizar uma análise de fluxos entre localidades, pois, uma linha une um par de pontos sempre que aceita a condição intitulada desigualdade triangular ou transitividade.

Segundo a teoria dos grafos, a rede de estrutura geográfica tem como suporte a abstração de um grafo $\mathrm{G}=[\mathrm{N}, \mathrm{A}, \phi]$, onde $\mathrm{N}$ é um conjunto de nós (municípios polarizadores da demanda de saúde), A é um conjunto de arcos (caminho do município de residência até municípios de atendimento), e $\phi(\mathrm{a})=(\mathrm{u}, \mathrm{v})$ é uma função de incidência que associa cada arco a $\in \mathrm{A}$ e a um par de nós $(\mathrm{u}, \mathrm{v}) \in \mathrm{N}$.

\footnotetext{
${ }^{1}$ PostgreSQL é um sistema gerenciador de banco de dados objeto relacional (SGBDOR), desenvolvido como projeto de código aberto.
} 
No caso geográfico, os nós podem estar associados a uma localização (x,y) do espaço para fins de referência (Bondy \& Murty, 1976).

Atualmente, técnicas de hierarquias de rede permitem identificar onde ocorrem as centralidades da rede e os nós principais. Isso condensa a base conceitual para avanço nas discussões dos processos sociais de indicadores de ordem espacial na estrutura regional. Oliveira, Carvalho e Travassos (2004) descrevem o processo de classificação topológica das redes considerando a estrutura determinada pelos fluxos dominantes, evidenciando a estrutura hierárquica da rede e ainda descrevendo relações internas e externas em cada rede.

Na AC exploraram-se 18 subgrupos, na BMC, 11 subgrupos e no SADT, cinco subgrupos. Sobre os procedimentos de SADT, optou-se por não agregar o número de procedimentos dentre todos os municípios já que a natureza diagnóstica e terapêutica varia desde procedimentos diagnósticos relativamente simples, como mamografias, a procedimentos terapêuticos com elevada complexidade, como radioterapia e quimioterapia.

A partir dos fluxos de deslocamento de pacientes, procedeu-se à seleção dos principais municípios que realizaram o maior volume de atendimentos segundo a frequência para cada grupo de complexidade analisada. No caso da alta complexidade, após um levantamento exploratório preliminar, decidiu-se analisar os vinte primeiros municípios que mais realizaram procedimentos. Esse ponto de corte contabiliza os municípios que realizaram $50 \%$ do total de procedimentos no país, com exceção de um subgrupo AC que contempla as cirurgias cardíacas valvulares de frequência irrisória. Esse mesmo ponto de corte foi aplicado nos procedimentos de SADT entre os quais apenas a mamografia foi uma exceção, já que nesse caso foram 68 municípios responsáveis por 50\% dos exames realizados no país.

Ao fim do fluxograma foram tabuladas as proporções de atendimentos de população não residente segundo frequência e fluxos dos pacientes não residentes, considerando como deslocamento de pacientes apenas o envio de indivíduos dos quais o município de origem apresenta volume de atendimentos menor que o ocorrido no município de destino.

Os mapas de fluxos procuram relacionar o destino e a origem do atendimento, além de indicar possíveis polos e redes de atendimento, segundo procedimentos analisados. O cálculo de fluxo foi elaborado de forma que fluxos eventuais, que são aqueles segundo os quais o paciente se desloca para um município com menor frequência (ou seja, pessoas que saem de grandes municípios para tratamento em pequenos municípios), não fossem computados. As legendas foram construídas segundo quartis e apresentadas em seis classes. Na elaboração das legendas, descartaram-se as classes com fluxos de valores muito baixos. Por conta disso, pode-se verificar que embora não sejam apresentadas as seis classes em alguns mapas, a distribuição seguiu a mesma metodologia para todos os mapas.

Os resultados são apresentados através de tabulação e mapeamento considerando a frequência de atendimentos nos municípios e o fluxo de pacientes não residentes para cada um dos subgrupos de complexidade. Foram elaborados dois tipos de mapas e tabelas para os 36 grupos de procedimentos. Um apresenta a distribuição segundo frequência de procedimentos realizados e outro apresenta os fluxos de atendimentos considerando o município de residência dos pacientes. 


\section{Resultados}

\section{Municípios responsáveis pela maior parte das internações hospitalares e procedimentos diagnósticos e terapêuticos}

A situação de concentração da atenção é diretamente proporcional à complexidade das internações e dos procedimentos. De modo geral, é possível classificar os fluxos de pacientes segundo os procedimentos analisados e as distâncias percorridas da seguinte forma: BMC - pequenas distâncias percorridas pelos pacientes e polos intraestaduais; SADT e AC - fluxos intensos dependendo da especialidade, e distâncias maiores, indicando polos nacionais.

Por meio de uma listagem de códigos atribuídos a cada grupo de procedimentos foi possível identificar os municípios responsáveis pela maior frequência de atendimentos para cada conjunto de procedimentos. Inicialmente, procurou-se identificar quais seriam os municípios que no conjunto atenderiam pelo menos 50\% da demanda nacional. Como se vê na Tabela 1, no caso dos procedimentos de alta complexidade, é extremamente baixo o número de municípios brasileiros que em conjunto realizam 50\% dos procedimentos. No caso dos SADT, a concentração do atendimento também é grande, excetuado o caso da mamografia.

Tabela 1 - Número de municípios que atenderam 50\% das internações e procedimentos diagnósticos e terapêuticos. Brasil - 2010 a 2012

\begin{tabular}{|c|c|}
\hline Procedimentos & $\mathrm{N}^{\circ}$ municípios \\
\hline \multicolumn{2}{|l|}{ Alta Complexidade } \\
\hline Angioplastia & 20 \\
\hline Cirurgia de revascularização do miocárdio & 12 \\
\hline Internação em UTI adulta & 36 \\
\hline Internação em UTI pediátrica & 14 \\
\hline Internação em UTI neonatal & 27 \\
\hline Transplante de córnea & 8 \\
\hline Transplante de rim & 5 \\
\hline Transplante de demais órgãos sólidos & 4 \\
\hline Transplante de medula óssea & 4 \\
\hline Neurocirurgia & 21 \\
\hline Cirurgia ortopédica do joelho & 21 \\
\hline Cirurgia ortopédica do quadril & 34 \\
\hline Cirurgia oncológica de útero e ovário & 12 \\
\hline Cirurgia oncológica de mama & 13 \\
\hline Cirurgia oncológica de próstata & 8 \\
\hline Cirurgia oncológica de tireoide & 8 \\
\hline Cirurgia oncológica de cólon e reto & 13 \\
\hline Cirurgia oncológica de estômago & 15 \\
\hline
\end{tabular}


Tabela 1 - Número de municípios que atenderam 50\% das internações e procedimentos diagnósticos e terapêuticos. Brasil - 2010 a 2012 (cont.)

\begin{tabular}{l|c|}
\hline \multicolumn{1}{|c|}{$\quad$ Procedimentos } & $N^{\circ}$ municípios \\
\hline SADT & \\
\hline Tomografia computadorizada & 26 \\
\hline Ressonância magnética & 17 \\
\hline Mamografia & 68 \\
\hline Quimioterapia & 19 \\
\hline Radioterapia & 19 \\
\hline Baixa-média complexidade & \\
\hline Pediatria - Internação clínica (0-15 anos) & $25^{*}$ \\
\hline Pediatria - Internação cirúrgica (0-15 anos) & $33^{*}$ \\
\hline Mulher - Internação ginecológica clínica (15 anos ou mais) & $129^{*}$ \\
\hline Mulher - Internação obstétrica para parto normal (15 a 49 anos) & $116^{*}$ \\
\hline Mulher - Internação obstétrica para parto cesariano (15 a 49 anos) & $101^{*}$ \\
\hline Mulher - Internação obstétrica para curetagem pós-aborto (15 a 49 anos) & $69^{*}$ \\
\hline Adulto - Internação clínica (15 a 64 anos) & $261^{*}$ \\
\hline Adulto - Internação cirúrgica BMC (15 a 64 anos) & $103^{*}$ \\
\hline Idoso - Internação clínica (65 anos ou mais) & $321^{*}$ \\
\hline Idoso - Internação cirúrgica (65 anos ou mais) & $63^{*}$ \\
\hline Trauma - Internação clínica ou cirúrgica em todas as idades & $56^{*}$ \\
\hline
\end{tabular}

*número de municípios responsáveis por mais de 21.900 atendimentos - unidade de saúde com cem leitos apresentando ocupação de $80 \%$ dos leitos e média de quatro dias por internação, o que significa cerca de 7.300 internações por ano.

\section{Municípios segundo tipos de procedimentos de alta complexidade atendidos}

Outra forma de caracterizar a importância dos municípios para o atendimento da demanda determinada pelas necessidades de saúde pode ser baseada na capacidade de atendimento para o conjunto de subgrupos ou parte deles em cada grupo de complexidade.

No Gráfico 1 são apresentados os municípios com a maior frequência de procedimentos de alta complexidade realizados, número de especialidades atendidas pelos municípios, proporção de atendimentos do município em relação ao total do país e a proporção acumulada. No país, trinta municípios são responsáveis por 50\% das internações de alta complexidade atendidas pelo sistema público de saúde. Dentre as especialidades não realizadas destacam-se o transplante de demais órgãos sólidos e o transplante de medula óssea, ambos os procedimentos realizados por apenas 25 municípios no país e com frequência de atendimento irrisória. 
Gráfico 1 - Municípios que responderam por 50\% dos atendimentos de alta complexidade e número de subgrupos nos quais aparecem como mais importantes. Brasil - 2010 a 2012

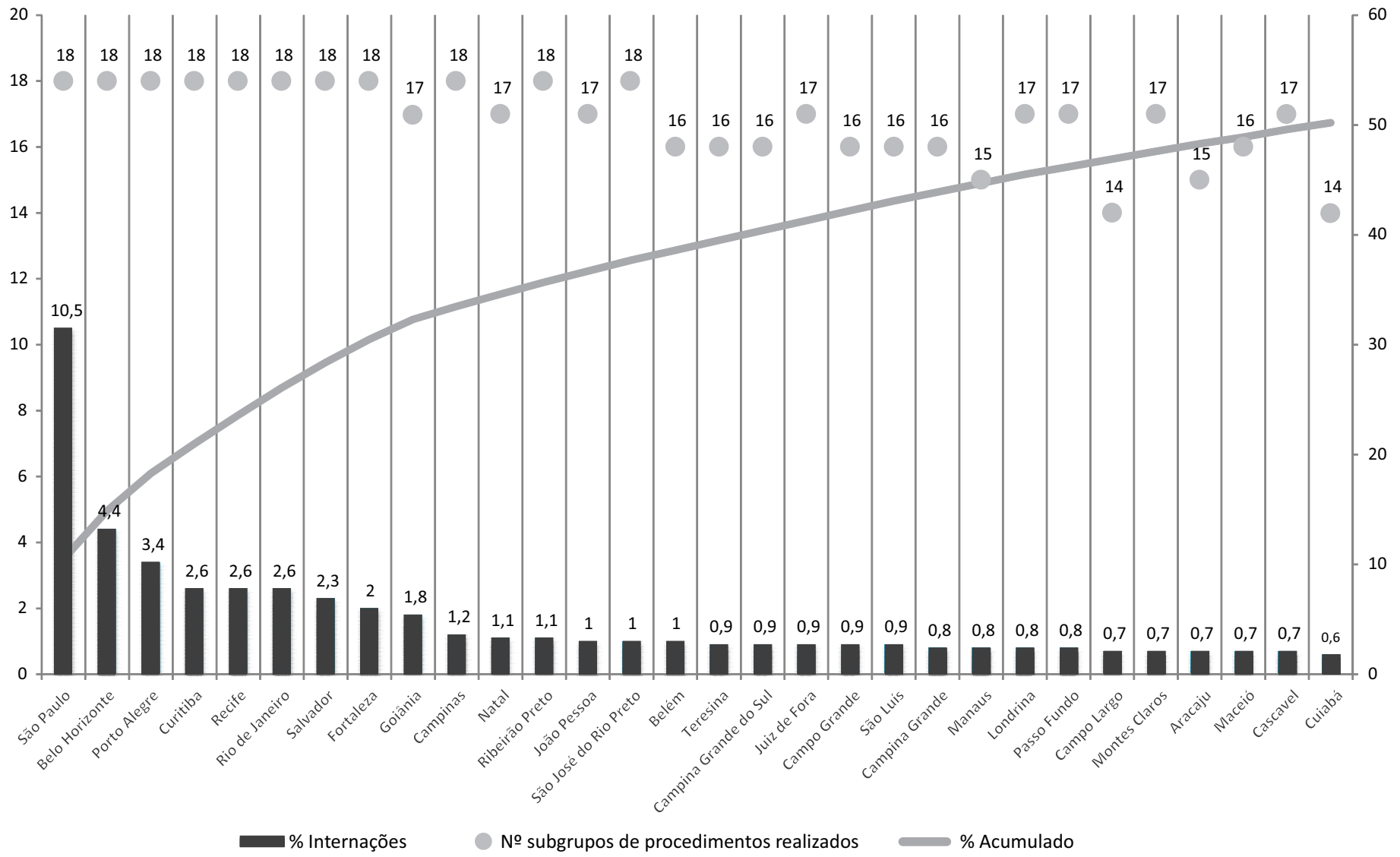

Fonte: Datasus.

Municípios mais desenvolvidos economicamente realizam todos os grupos de procedimentos, sobretudo com maior volume de procedimentos mais complexos. Nas listagens dos municípios também é possível observar que os municípios mais populosos se encontram sempre presentes. Embora as capitais constem em quase todas as listagens de municípios, verificam-se situações em que a população do município parece ser mais preponderante, o que é mais comum nos procedimentos de baixa complexidade. Nos níveis mais altos de complexidade, nos quais é maior o percentual de atendimento a não residentes, municípios das capitais se apresentam como polos mais importantes.

No Gráfico 2 são listados os trinta municípios com maior frequência de atendimentos de alta complexidade e é indicada a proporção de atendimentos realizados segundo residentes e não residentes no período de 2010 a 2012. Esses municípios respondem por 50\% dos atendimentos no país. O município de São Paulo foi o que mais realizou procedimentos de alta complexidade no período, cerca de 247 mil, correspondendo a 10\% do total de atendimentos no país. Entretanto, apenas 13\% desse volume decorre de pacientes oriundos de outros municípios. O município de Cuiabá foi o responsável pelo maior volume de atendidos não residentes no município, com cerca de $16 \%$, seguido de Porto Alegre, Recife, Campinas e Campina Grande do Sul com 15\% dos pacientes oriundos de outros 
municípios. Para todo o conjunto dos trinta municípios listados, a média de atendidos residentes em outros municípios foi de cerca de 10\%. Os municípios de Aracaju, Campina Grande, Fortaleza, São Luís e Manaus atenderam cerca de 1\% de pacientes não residentes.

Gráfico 2 - Municípios com as maiores frequências de internação de alta complexidade e proporção de não residentes atendidos. Brasil - 2010 a 2012

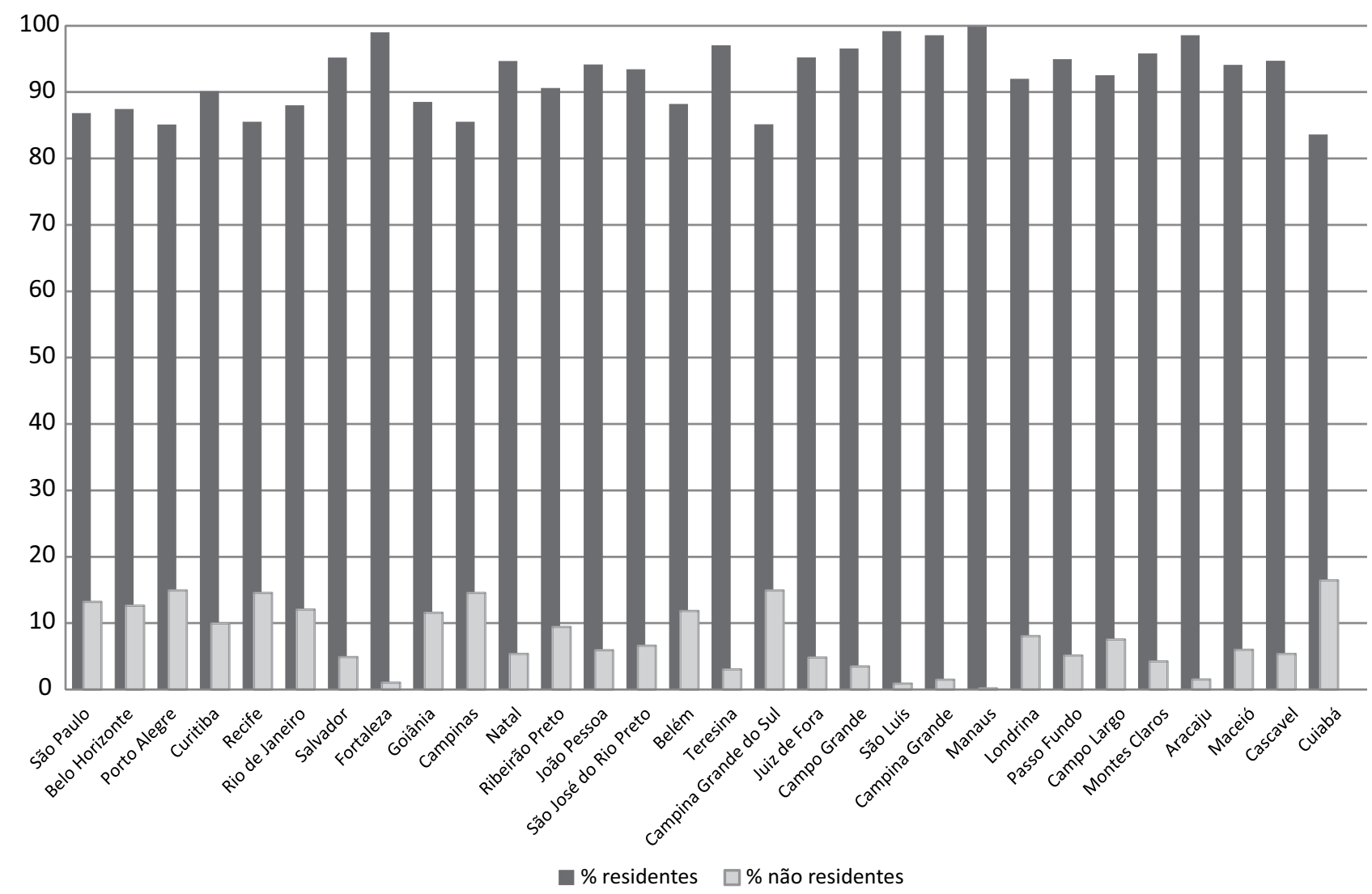

Fonte: SIH.

Na baixa-média complexidade notam-se semelhanças das redes de atenção quando se observam os mapas relativos a internações pediátricas clínicas e cirúrgicas, internações clínicas de adultos e internações para parto cesáreo. Nessas situações observa-se provavelmente a existência de leitos hospitalares de baixo grau de complexidade. No mesmo sentido, as cidades polos para as internações por procedimentos cirúrgicos em idosos, adultos e traumas parecem semelhantes.

Quando observados os principais municípios segundo frequência de atendimentos, destacam-se como polos: as capitais do Sudeste; no Nordeste, as cidades de Fortaleza, Recife e Salvador; no Sul, Porto Alegre e Curitiba; no Norte, Manaus; e no Centro-Oeste, Goiânia e Brasília. Esse comportamento pode ser atribuído ao número de habitantes residentes e dependentes de serviços nessas localidades. Mas também surgem nas análises alguns municípios como Ananindeua, São Gonçalo, Belford Roxo, Campinas, Ribeirão Preto e alguns outros municípios de regiões metropolitanas que se destacam pelo volume de internações. 
Os fluxos de internação para baixa-média complexidade geralmente descrevem pequenos trajetos percorridos para atendimento. Em procedimentos cirúrgicos os fluxos parecem ser mais intensos em comparação aos procedimentos clínicos. Observa-se isso claramente quando comparados os mapas de fluxo de internação para causas pediátricas clinicas e cirúrgicas. No caso dos partos, observam-se polos semelhantes de atendimentos, embora os partos cesarianos apresentem fluxos mais intensos, sobretudo na região Nordeste.

É importante analisar os procedimentos de SADT separadamente. No caso das mamografias, observa-se além de grandes capitais como São Paulo, Rio de Janeiro, Salvador, Recife, Fortaleza e Vitória, cidades de médio porte como Barretos, Joinville, Campinas, Guarulhos e São Bernardo do Campo que se destacam quanto ao maior volume de atendimentos.

No caso dos procedimentos de quimioterapia e radioterapia os polos de atendimento são muito semelhantes em sua distribuição espacial. Nesses procedimentos, as capitais do Nordeste, Sudeste e Sul do país sobressaem. Entretanto, destacam-se também cidades com referência para tratamento oncológico como Barretos, Cascavel, Jaú, Campina Grande do Sul, Sorocaba e Ribeirão Preto. Os mapas de fluxo para esses procedimentos revelam maiores distâncias percorridas, sobretudo porque pacientes do Norte e do Centro-Oeste do país buscam atendimento em municípios do Sul e Sudeste.

Os procedimentos de tomografia computadorizada e ressonância magnética contam com polos similares de atendimento. No entanto, os procedimentos de tomografia computadorizada parecem estar mais dispersos em vários municípios do território nacional, ao passo que a ressonância magnética indica estar mais concentrada em um número menor de municípios. Por conta disso, quando se observa o fluxo de pacientes, no caso das ressonâncias magnéticas, as distâncias percorridas são maiores, por outro lado nas tomografias os fluxos parecem ser mais regionais, com menores distâncias percorridas.

\section{Municípios segundo atenção a residentes e não residentes por grupos de procedimentos}

São listadas abaixo algumas das principais causas de internações no país na perspectiva de comportamento da demanda para o serviço de saúde e prognóstico de evolução dos quadros de oferta segundo projeções aceitáveis e pautadas no comportamento e composição etária de países desenvolvidos. Os procedimentos escolhidos também buscam uma aproximação com a oferta e o acesso a serviços de saúde centrados em grupos populacionais vulneráveis. Para isso são apresentados procedimentos de baixa-média e alta complexidade e serviços de apoio, diagnóstico e terapêutico.

\section{BMC: pediatria - internação clínica e cirúrgica}

Entre os procedimentos BMC é possível ilustrar, com base na análise de internações pediátricas, um quadro geral que se manifesta nos demais procedimentos com este nível de complexidade. Observa-se nesses procedimentos que a intensidade do fluxo é diretamente proporcional à complexidade do atendimento e os polos seguem uma hierarquia que respeita os limites administrativos das unidades da federação. Entretanto, polos de atendimento em áreas de fronteiras de estados e, sobretudo, quando apresentam centros de referências importantes, demonstram uma configuração 
que segue uma lógica que não respeita uma hierarquia administrativa de unidade federada para o fluxo de pacientes.

Na Tabela 2 estão listados os vinte municípios que mais realizaram internações cirúrgicas pediátricas tanto para residentes quanto para não residentes no período de 2010 a 2012 . Entre os que mais atenderam residentes, esse conjunto de municípios responde por $1 / 3$ do volume total de internações no país. Observa-se que o município de São Paulo atendeu 6\% dos pacientes, seguido de Recife, Salvador, Curitiba, Rio de Janeiro, Fortaleza e Belo Horizonte. Esses municípios concentram cerca de $20 \%$ dos atendimentos realizados no território nacional. Destaca-se que na tabela são listadas apenas capitais entre os municípios com maior número de internações para residentes, exceto a cidade de Paulista (PE), próxima a Olinda (PE).

Também se verificam na tabela os municípios que mais atenderam pacientes que tiveram que se deslocar do seu município de residência. Foram quase dois milhões de atendimentos cirúrgicos pediátricos ocorridos no período, desses, mais de 360 mil provenientes de pacientes que buscaram atendimento em outros municípios. Os vinte municípios que mais atenderam pacientes não residentes respondem por mais de $46 \%$ dos pacientes que tiveram que se deslocar. Somente o município de Recife recebeu cerca de 7\% desse total, seguido de Curitiba com cerca de 5\%, São Paulo, Belo Horizonte e Porto Alegre, em torno de 3\% dos atendimentos. Os municípios de Paulista (PE), Vitória de Santo Antão (BA), Campo Largo (PR), Diadema (SP), Vila Velha (ES) e Ribeirão Preto (SP) registram importante número de pacientes oriundos de outros municípios. Cerca de metade das internações pediátricas cirúrgicas que ocorreram em Recife foram de pacientes vindos de outros municípios. Essa situação é semelhante em alguns outros municípios de pequeno porte, entretanto, nas grandes capitais, entre um quarto e um sexto dos pacientes atendidos são oriundos de outros municípios.

Tabela 2 - Frequência e fluxo de pacientes de pediatria cirúrgica nos vinte municípios com maior número de atendimentos. Brasil - 2010 a 2012

\begin{tabular}{|l|c|c|c|}
\hline \multicolumn{1}{|c}{ Municípios } & $\begin{array}{c}\mathrm{N}^{\mathrm{o}} \mathrm{de} \\
\text { atendimentos }\end{array}$ & $\%$ & $\begin{array}{c}\% \\
\text { Acumulado }\end{array}$ \\
\hline São Paulo & 119.490 & 5,71 & 5,71 \\
\hline Recife & 57.276 & 2,74 & 8,44 \\
\hline Salvador & 49.489 & 2,36 & 10,81 \\
\hline Curitiba & 48.075 & 2,30 & 13,10 \\
\hline Rio de Janeiro & 47.994 & 2,29 & 15,39 \\
\hline Fortaleza & 43.227 & 2,06 & 17,46 \\
\hline Belo Horizonte & 37.399 & 1,79 & 19,25 \\
\hline Porto Alegre & 28.124 & 1,34 & 20,59 \\
\hline Belém & 28.023 & 1,34 & 21,93 \\
\hline São Luís & 24.939 & 1,19 & 23,12 \\
\hline
\end{tabular}

\begin{tabular}{|l|r|c|c|}
\hline \multicolumn{1}{|c|}{ Municípios } & $\begin{array}{c}N^{\circ} \text { não } \\
\text { residentes }\end{array}$ & $\%$ & $\begin{array}{c}\% \\
\text { Acumulado }\end{array}$ \\
\hline Recife & 25113 & 6,90 & 6,90 \\
\hline Curitiba & 17330 & 4,76 & 11,66 \\
\hline São Paulo & 13318 & 3,66 & 15,32 \\
\hline Belo Horizonte & 11861 & 3,26 & 18,58 \\
\hline Porto Alegre & 11541 & 3,17 & 21,75 \\
\hline Rio de Janeiro & 10169 & 2,79 & 24,54 \\
\hline Salvador & 9541 & 2,62 & 27,17 \\
\hline Vitória & 8455 & 2,32 & 29,49 \\
\hline Fortaleza & 7238 & 1,99 & 31,48 \\
\hline Goiânia & 6901 & 1,90 & 33,37 \\
\hline
\end{tabular}


Tabela 2 - Frequência e fluxo de pacientes de pediatria cirúrgica nos vinte municípios com maior número de atendimentos. Brasil - 2010 a 2012 (cont.)

\begin{tabular}{|c|c|c|c|c|c|c|c|}
\hline Municípios & $\begin{array}{c}\mathrm{N}^{\circ} \text { de } \\
\text { atendimentos }\end{array}$ & $\%$ & $\begin{array}{c}\% \\
\text { Acumulado }\end{array}$ & Municípios & $\begin{array}{l}\mathrm{N}^{\mathrm{o}} \text { não } \\
\text { residente }\end{array}$ & $\%$ & $\begin{array}{c}\% \\
\text { Acumulado }\end{array}$ \\
\hline Manaus & 24.234 & 1,16 & 24,28 & São Luís & 6147 & 1,69 & 35,06 \\
\hline Maceió & 22.283 & 1,06 & 25,34 & Belém & 5836 & 1,60 & 36,67 \\
\hline Goiânia & 21.913 & 1,05 & 26,39 & Natal & 5650 & 1,55 & 38,22 \\
\hline Natal & 18.651 & 0,89 & 27,28 & Paulista & 5019 & 1,38 & 39,60 \\
\hline Teresina & 17.583 & 0,84 & 28,12 & $\begin{array}{l}\text { Vitória de Santo } \\
\text { Antão }\end{array}$ & 4862 & 1,34 & 40,93 \\
\hline João Pessoa & 16.187 & 0,77 & 28,89 & Campo Largo & 4620 & 1,27 & 42,20 \\
\hline Ribeirão Preto & 15.610 & 0,75 & 29,64 & Teresina & 4120 & 1,13 & 43,33 \\
\hline Brasília & 15.022 & 0,72 & 30,35 & Diadema & 4022 & 1,11 & 44,44 \\
\hline Aracaju & 13.991 & 0,67 & 31,02 & Vila Velha & 3951 & 1,09 & 45,52 \\
\hline Paulista & 13.859 & 0,66 & 31,68 & Ribeirão Preto & 3838 & 1,05 & 46,58 \\
\hline
\end{tabular}

Fonte: SIH

Na Figura 2 apresenta-se a comparação da distribuição gráfica do fluxo de internações clínicas pediátricas segundo o município de atendimento no período de 2010 a 2012 . Observa-se que nas internações pediátricas clínicas nas regiões Norte, Centro-Oeste e interior do Nordeste do país as capitais estaduais polarizam o fluxo de pacientes. Nas regiões Sudeste, Sul e região litorânea do Nordeste são observados municípios de médio porte que polarizam municípios vizinhos menores, determinando uma distribuição da rede de forma mais homogênea, e consequentemente distâncias mais curtas a percorrer dentro de uma mesma unidade federativa. No Nordeste, destacam-se as cidades de Recife, Fortaleza e São Luís como polos importantes de internação para municípios do interior dos estados.

No caso das internações cirúrgicas, de modo geral, os estados demonstram uma convergência dos fluxos de pacientes para as capitais e para cidades de médio porte dentro do limite da unidade federada. No entanto, observam-se fluxos mais intensos e deslocamentos maiores que o das internações clínicas. A lógica de regionalização já demonstra distorção em áreas limítrofes de estados e a resolutividade local não parece mais tão evidente quanto no caso das internações clínicas. Destaca-se o fluxo de pacientes do oeste do Paraná para a capital Curitiba, e do interior de Pernambuco, norte da Bahia e Paraíba para Recife. No sul do país parece ocorrer fluxo de pacientes do extremo sul do estado para Porto Alegre. Alguns estados como Bahia, São Paulo e Minas Gerais apresentam fluxos em que a polaridade da capital estadual não é tão notória, conformando regiões de deslocamento diferenciadas dentro da unidade federada e, consequentemente, mais polos de referência. 
Figura 2 - Fluxo de pacientes de pediatria cirúrgica e clínica por municípios, para atendimento no país no período de 2010 a 2012

FLUXO DE ATENDIMENTOS PARA

"PEDIATRIA - INTERNAÇÃO CIRÚRGICA" EM MENORES DE 15 ANOS NO TRIÊNIO 2010-2012

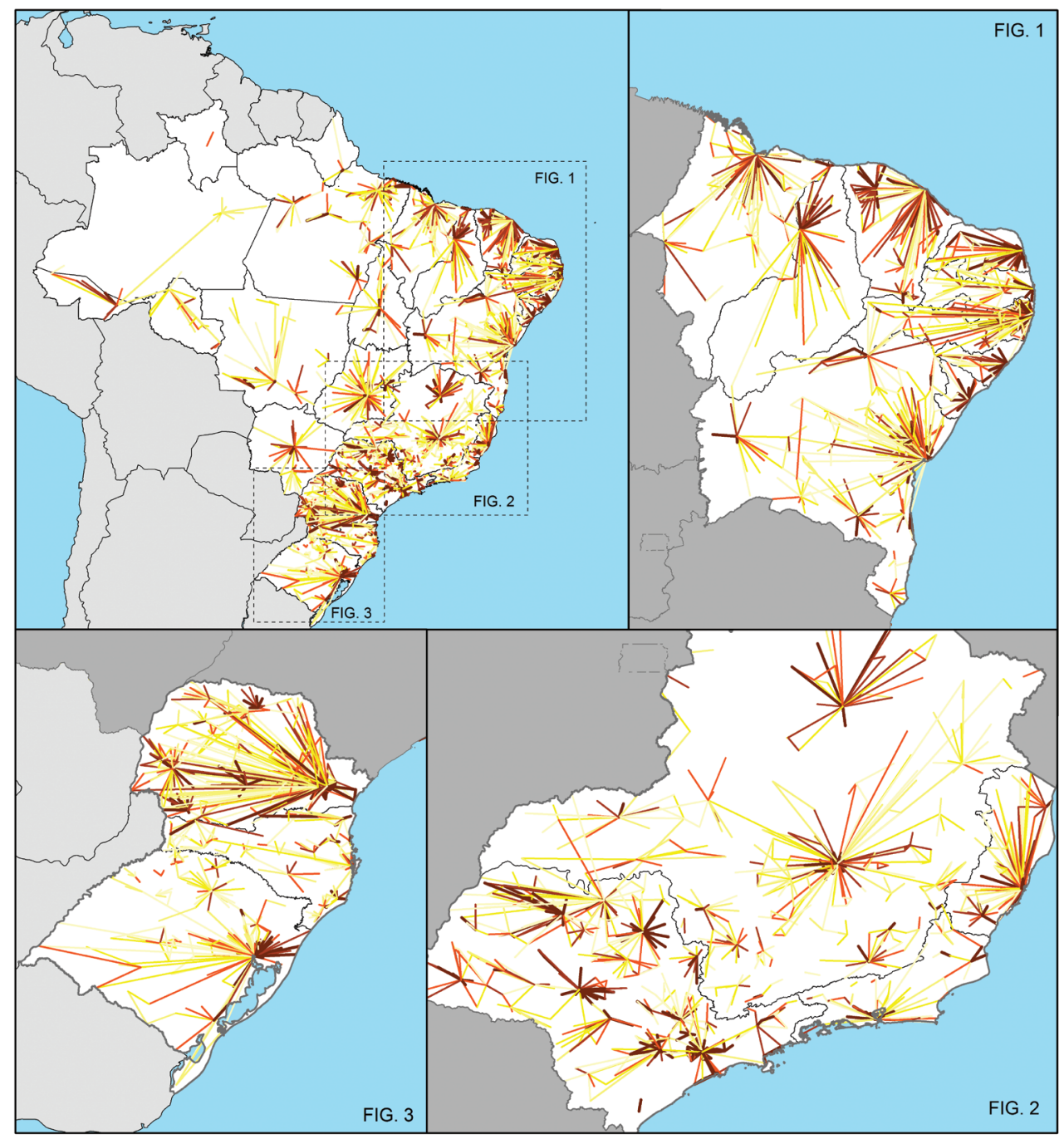

Legenda

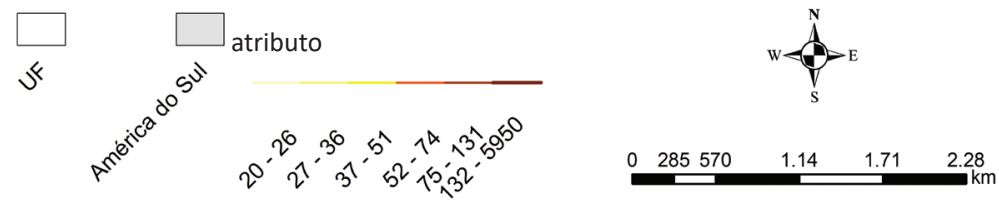


Figura 2 - Fluxo de pacientes de pediatria cirúrgica e clínica por municípios, para atendimento no país no período de 2010 a 2012 (cont.)

FLUXO DE ATENDIMENTOS PARA

"PEDIATRIA - INTERNAÇÃO CLÍNICA" EM MENORES DE 15 ANOS NO TRIÊNIO 2010-2012

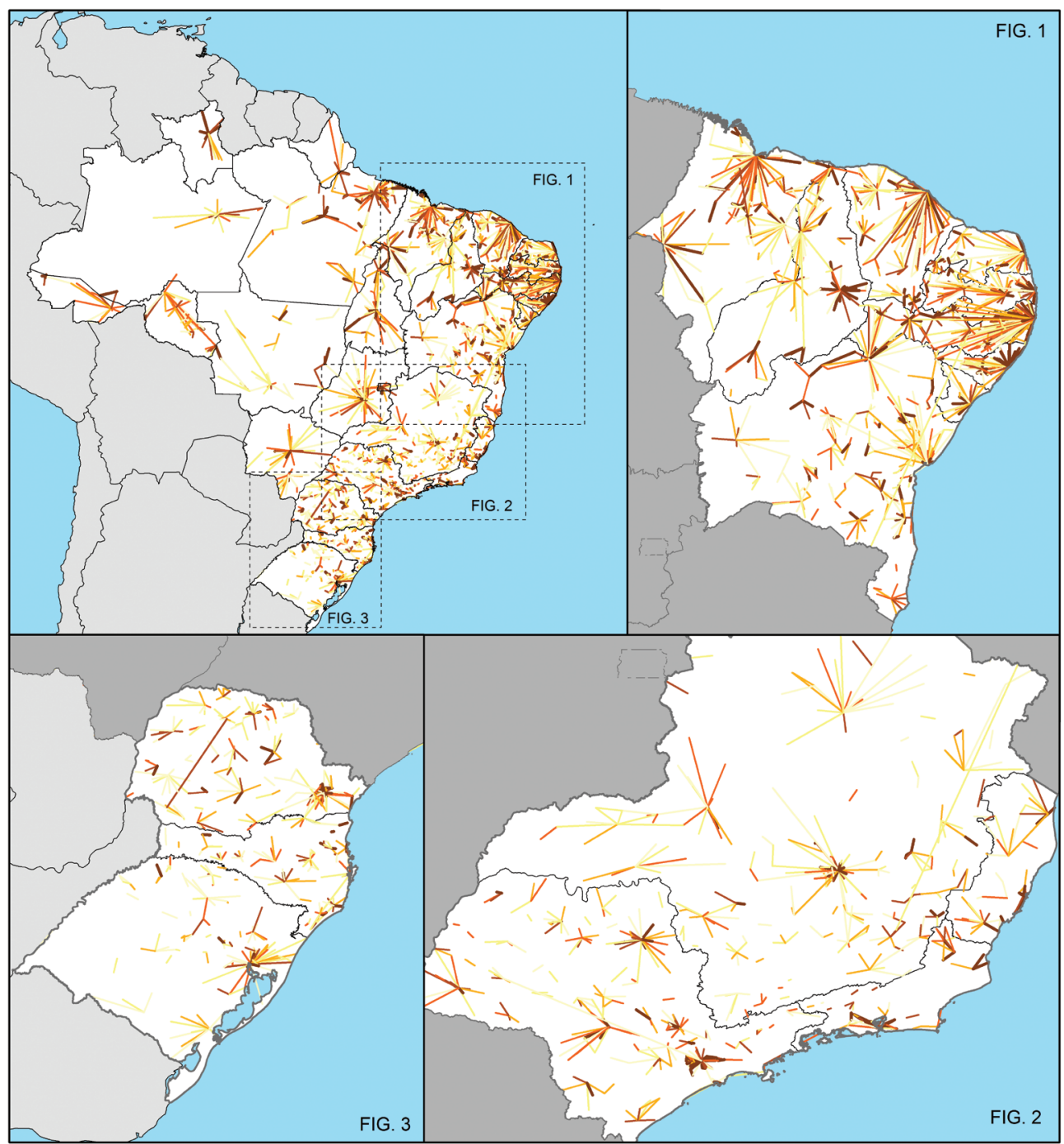

Legenda
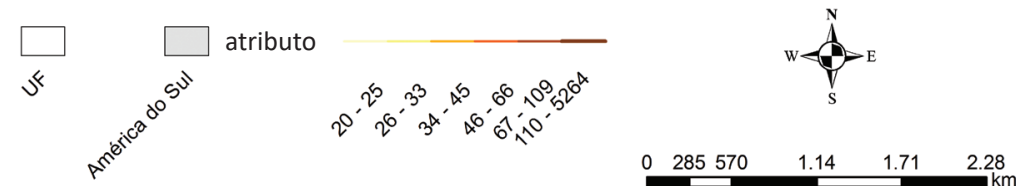
No Brasil, as principais causas de internação pediátrica clínica foram as pneumonias e as doenças intestinais, que juntas responderam por mais de um milhão e meio de internações no período. No caso das internações pediátricas cirúrgicas os principais procedimentos realizados foram amigdalectomia com adenoidectomia, postectomia e apendicectomia, correspondendo a pouco mais de 250 mil procedimentos. Com relação às internações cirúrgicas, as principais causas de internações são cirurgias que não demandam centros cirúrgicos complexos, e poderiam ser realizadas no município de residência, se este contasse com um mínimo de estrutura capaz de realizar o procedimento.

\section{BMC: trauma - internação clínica ou cirúrgica}

Os traumatismos, principalmente cranioencefálicos e os politraumatizados, estão diretamente relacionados aos acidentes de trânsito, agressões físicas, quedas e lesões por arma de fogo. Na Tabela 3 estão listados os vinte municípios que mais realizaram internações clínicas ou cirúrgicas BMC para traumas (excluídos procedimentos mal definidos, não especificados, diagnósticos, placas ou pinos) no período de 2010 a 2012. Esses municípios respondem por mais de 33\% do volume total de internações no país. Observa-se que o município de São Paulo atendeu cerca de 6,5\% dos pacientes, seguido de Recife, Belo Horizonte, Salvador, Fortaleza, Goiânia e Curitiba. Tais municípios concentram cerca de $20 \%$ dos atendimentos realizados no território nacional. Além das capitais, destacam-se os municípios de Paulista (PE), Ribeirão Preto e Bauru, ambos no estado de São Paulo. Cerca de 26\% dos procedimentos foram realizados em pacientes tratados fora do município de residência. Os vinte municípios do país que mais receberam pacientes de outros municípios respondem por cerca de 41\% dos pacientes que tiveram que se deslocar em busca de atendimento. Os municípios de Recife, Belo Horizonte, Goiânia, Salvador e São Paulo somam cerca de $20 \%$ desse total. No município de Recife mais de 50\% dos atendimentos para internação clínica e cirúrgica por trauma são decorrentes de pacientes não residentes no município, em Belo Horizonte 41\%, em Goiânia 45\% e em São Paulo 12\%.

Tabela 3 - Frequência e fluxo de pacientes de traumatologia segundo os vinte municípios com maior número de atendimento no país no período de 2010 a 2012

\begin{tabular}{|l|c|c|c|}
\hline \multicolumn{1}{|c|}{ Municípios } & $\begin{array}{c}\text { No de } \\
\text { atendimentos }\end{array}$ & $\%$ & $\begin{array}{c}\% \\
\text { Acumulado }\end{array}$ \\
\hline São Paulo & 128.348 & 6,5 & 6,5 \\
\hline Recife & 58.649 & 3,0 & 9,4 \\
\hline Belo Horizonte & 49.818 & 2,5 & 11,9 \\
\hline Salvador & 47.383 & 2,4 & 14,3 \\
\hline Fortaleza & 44.068 & 2,2 & 16,5 \\
\hline Goiânia & 43.775 & 2,2 & 18,7 \\
\hline Curitiba & 42.079 & 2,1 & 20,9 \\
\hline Rio de Janeiro & 36.194 & 1,8 & 22,7 \\
\hline Belém & 24.279 & 1,2 & 23,9 \\
\hline Porto Alegre & 22.479 & 1,1 & 25,0 \\
\hline Natal & 22.080 & 1,1 & 26,1 \\
\hline
\end{tabular}

\begin{tabular}{|l|c|c|c|}
\hline \multicolumn{1}{|c|}{ Municípios } & $\begin{array}{c}\mathrm{N}^{\mathrm{o}} \text { não } \\
\text { residentes }\end{array}$ & $\%$ & $\begin{array}{c}\% \\
\text { Acumulado }\end{array}$ \\
\hline Recife & 29.349 & 5,5 & 5,5 \\
\hline Belo Horizonte & 20.632 & 3,9 & 9,4 \\
\hline Goiânia & 19.957 & 3,8 & 13,2 \\
\hline Salvador & 17.857 & 3,4 & 16,6 \\
\hline São Paulo & 15.991 & 3,0 & 19,6 \\
\hline Curitiba & 13.619 & 2,6 & 22,2 \\
\hline Fortaleza & 13.492 & 2,5 & 24,7 \\
\hline Belém & 9.686 & 1,8 & 26,6 \\
\hline Porto Alegre & 8.806 & 1,7 & 28,2 \\
\hline Vitória & 8.366 & 1,6 & 29,8 \\
\hline Teresina & 7.661 & 1,4 & 31,3 \\
\hline
\end{tabular}


Tabela 3 - Frequência e fluxo de pacientes de traumatologia segundo os vinte municípios com maior número de atendimento no país no período de 2010 a 2012 (cont.)

\begin{tabular}{|c|c|c|c|c|c|c|c|}
\hline Municípios & $\begin{array}{c}\mathrm{N}^{\mathrm{o}} \mathrm{de} \\
\text { atendimentos }\end{array}$ & $\%$ & $\begin{array}{c}\% \\
\text { Acumulado }\end{array}$ & Municípios & $\begin{array}{l}\mathrm{N}^{\mathrm{O}} \text { não } \\
\text { residentes }\end{array}$ & $\%$ & $\begin{array}{c}\% \\
\text { Acumulado }\end{array}$ \\
\hline Teresina & 20.624 & 1,0 & 27,2 & Natal & 7.504 & 1,4 & 32,7 \\
\hline Campo Grande & 18.412 & 0,9 & 28,1 & Bauru & 7.450 & 1,4 & 34,1 \\
\hline Ribeirão Preto & 17.867 & 0,9 & 29,0 & Barbalha & 6.983 & 1,3 & 35,4 \\
\hline Paulista & 17.027 & 0,9 & 29,9 & Paulista & 6.123 & 1,2 & 36,6 \\
\hline Manaus & 16.046 & 0,8 & 30,7 & Rio de Janeiro & 5.693 & 1,1 & 37,6 \\
\hline João Pessoa & 14.284 & 0,7 & 31,4 & Ananindeua & 5.499 & 1,0 & 38,7 \\
\hline Bauru & 14.208 & 0,7 & 32,1 & Ribeirão Preto & 5.461 & 1,0 & 39,7 \\
\hline São Luís & 13.746 & 0,7 & 32,8 & João Pessoa & 5.122 & 1,0 & 40,7 \\
\hline Vitória & 13.306 & 0,7 & 33,5 & $\begin{array}{l}\text { Mogi das } \\
\text { Cruzes }\end{array}$ & 4.872 & 0,9 & 41,6 \\
\hline
\end{tabular}

Obs: não incluídos procedimentos mal definidos, não especificados, diagnósticos, e retiradas de placas ou pinos. Fonte: SIH

Na Figura 3 verifica-se a distribuição gráfica do número de internações clínicas ou cirúrgicas para traumas segundo o município de atendimento e fluxo de deslocamento do paciente no período de 2010 a 2012. Os quadrados proporcionais em vermelho destacam os municípios citados na tabela anterior e que apresentam a maior frequência de internações. Nos círculos proporcionais em amarelo, os demais municípios que tiveram internação clínica ou cirúrgica por trauma no período. Observa-se que na região Sudeste, Sul e litoral do Nordeste a frequência das internações está distribuída de forma mais concentrada nas capitais e em cidades de médio porte, principalmente, no norte do Paraná, São Paulo, Rio Grande do Sul, sul de Minas Gerais, leste de Santa Catarina e litoral nordestino. As regiões Centro-Oeste, Norte e interior do Nordeste têm maior volume de internações somente nas capitais estaduais.

Na distribuição gráfica do fluxo de internações clínicas e cirúrgicas por traumas, segundo o município de atendimento, observa-se que, além das capitais, outros municípios dentro das unidades federadas polarizam os atendimentos. Os fluxos nos municípios do Nordeste e de São Paulo apresentam distribuição espacial similar à encontrada nas internações cirúrgicas em adultos. No estado de Minas Gerais e Sul do país observam-se fluxos menores, bem como no Centro-Oeste e Norte do país. 
Figura 3 - Frequência e fluxo de pacientes atendidos por trauma segundo municípios, 2010 a 2012

TOTAL DE ATENDIMENTOS PARA

"TRAUMA - INTERNAÇÃO CLÍNICA OU CIRÚRGICA" EM TODAS AS IDADES NO TRIÊNIO 2010-2012

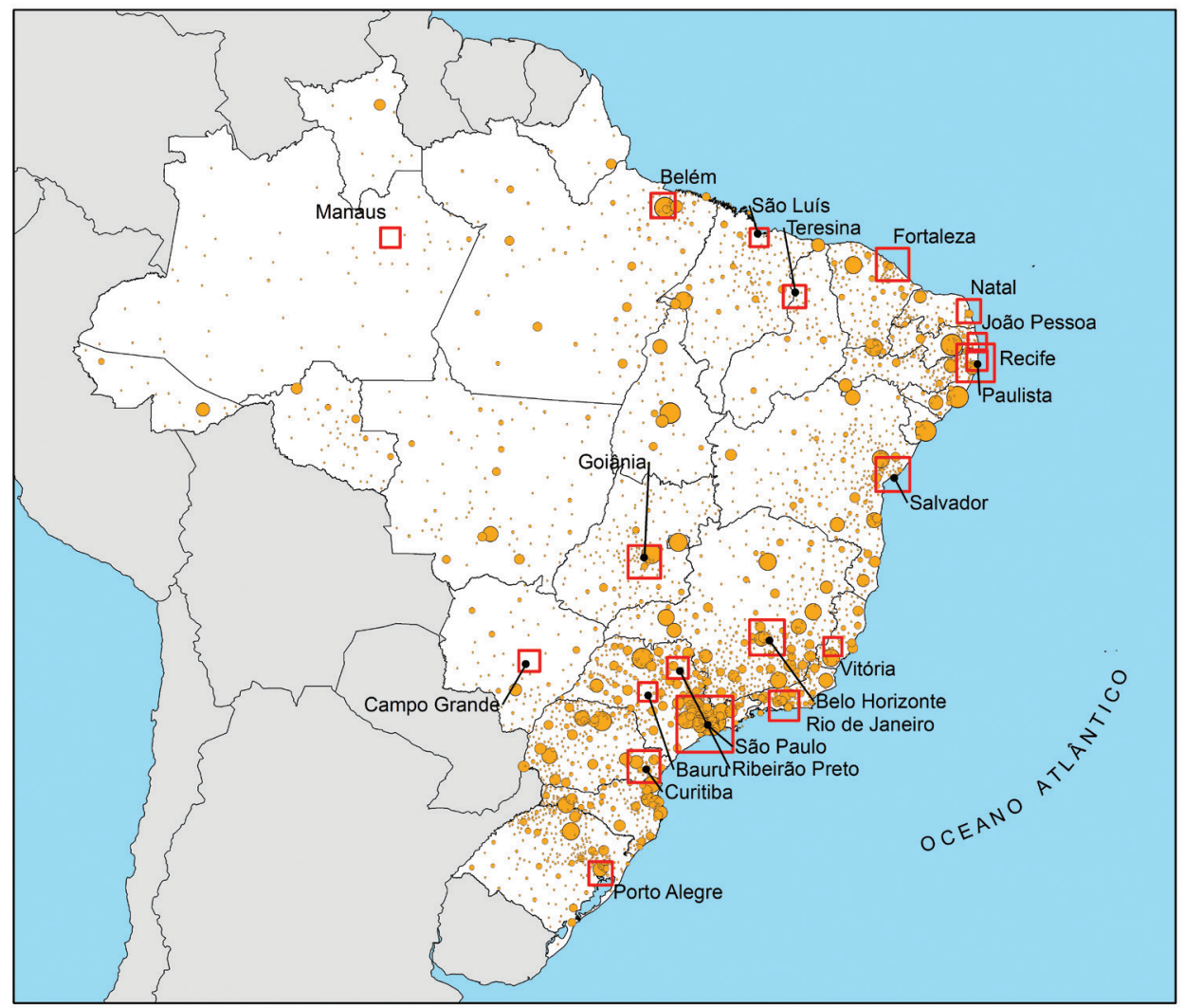

Legenda

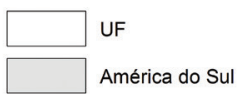

Símbolos proporcionais a frequência de internações

O $\quad 13.000$

- 6.500

- 3.250

20 municípios com maior número de internações

130.000

65.000

ㅁ 32.500

$\begin{array}{llll}220440 & 880 & 1.32 & 1.76\end{array}$

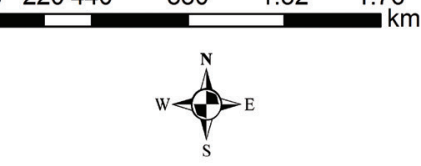


Figura 3 - Frequência e fluxo de pacientes atendidos por trauma segundo municípios, 2010 a 2012 (cont.)

FLUXO DE ATENDIMENTOS PARA

"TRAUMA - INTERNAÇÃO CLÍNICA OU CIRÚRGICA" EM TODAS AS IDADES NO TRIÊNIO 2010-2012

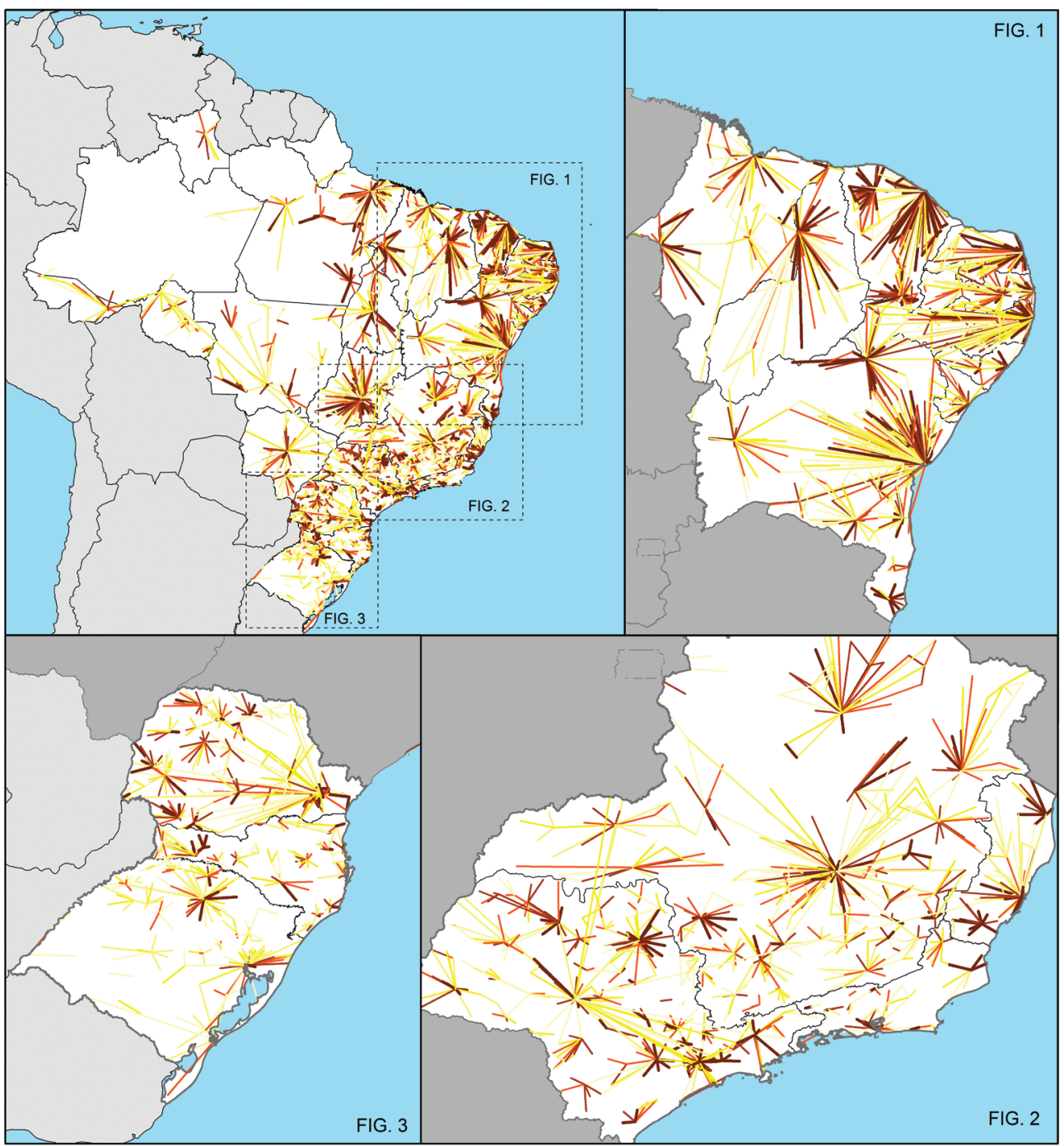

Legenda
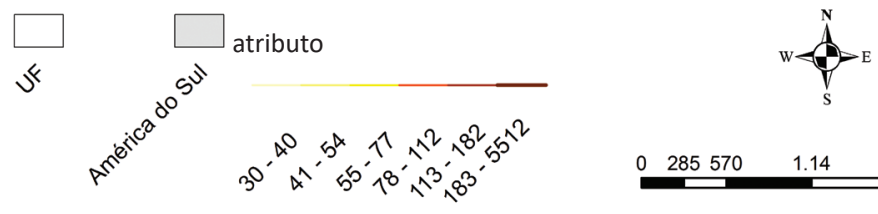

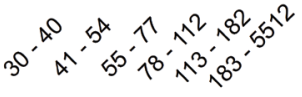

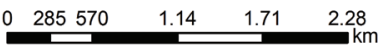




\section{SADT: mamografia}

O câncer de mama é a principal causa de morte por neoplasias entre mulheres adultas no país, e o risco de óbito aumenta à medida que as mulheres envelhecem (Lima-Costa, Peixoto \& Giatti, 2004). A mamografia é o método de monitoramento e rastreamento precoce mais eficaz para detecção do câncer de mama.

Na Tabela 4 estão listados os vinte municípios que mais realizaram procedimentos de mamografia no Brasil no período de 2010 a 2012. Esses municípios respondem por mais de 30\% do volume total de procedimentos realizados no país, que foi de 10.376.727. Observa-se que o município de São Paulo atendeu quase $8 \%$ dos pacientes, seguido de Salvador, Curitiba e Belo Horizonte. Tais municípios concentram cerca de $15 \%$ dos atendimentos realizados no território nacional. Além das capitais, destacam-se os municípios de Barretos (SP), Cascavel (PR), Guarulhos (SP), Campinas (SP), Joinville (SC) e São Bernardo do Campo (SP).

Mamografias realizadas fora do município de residência totalizam cerca de $4 \%$ em relação ao total. Na Tabela 4 também listam-se os vinte municípios do país que mais receberam pacientes de outros municípios e que correspondem a cerca de 60\% dos pacientes que tiveram de se deslocar em busca de atendimento. Os pacientes atendidos em Barretos (SP) totalizam cerca de 13\% dos pacientes atendidos fora do município de residência, e em adição aos atendidos em Recife, Salvador e São Paulo, agregam mais de $30 \%$ dos pacientes que realizaram o procedimento fora do município de residência. No total, cerca de 39\% dos atendidos em Barretos (SP) eram residentes de outros municípios; em Recife eram 19\% e em Salvador, 7\%.

Tabela 4 - Frequência de mamografias realizadas nos vinte principais municípios em residentes e não residentes. Brasil - 2010 a 2012

\begin{tabular}{|l|c|c|c|}
\hline \multicolumn{1}{|c}{ Municípios } & $\begin{array}{c}\mathrm{N}^{\mathrm{o}} \mathrm{de} \\
\text { atendimentos }\end{array}$ & $\%$ & $\begin{array}{c}\% \\
\text { Acumulado }\end{array}$ \\
\hline São Paulo & 818.055 & 7,9 & 7,9 \\
\hline Salvador & 344.878 & 3,3 & 11,2 \\
\hline Curitiba & 204.629 & 2,0 & 13,2 \\
\hline Belo Horizonte & 164.094 & 1,6 & 14,8 \\
\hline Porto Alegre & 157.632 & 1,5 & 16,3 \\
\hline Recife & 132.767 & 1,3 & 17,6 \\
\hline Barretos & 129.439 & 1,2 & 18,8 \\
\hline Rio de Janeiro & 124.907 & 1,2 & 20,0 \\
\hline Fortaleza & 115.436 & 1,1 & 21,1 \\
\hline Goiânia & 111.378 & 1,1 & 22,2 \\
\hline Manaus & 110.333 & 1,1 & 23,3 \\
\hline Maceió & 106.534 & 1,0 & 24,3 \\
\hline Cascavel & 88.831 & 0,9 & 25,1 \\
\hline Guarulhos & 88.490 & 0,9 & 26,0 \\
\hline
\end{tabular}

\begin{tabular}{|l|r|r|c|}
\hline \multicolumn{1}{|c}{ Municípios } & $\begin{array}{c}\text { No Não } \\
\text { residentes }\end{array}$ & \multicolumn{1}{c}{$\%$} & $\begin{array}{c}\% \\
\text { Acumulado }\end{array}$ \\
\hline Barretos & 51.705 & 13,85 & 13,85 \\
\hline Recife & 25.623 & 6,86 & 20,72 \\
\hline Salvador & 25.188 & 6,75 & 27,46 \\
\hline São Paulo & 16.235 & 4,35 & 31,81 \\
\hline Porto Alegre & 15.904 & 4,26 & 36,07 \\
\hline Pinhais & 12.097 & 3,24 & 39,31 \\
\hline Vitória & 11.138 & 2,98 & 42,30 \\
\hline Taboão da Serra & 7.407 & 1,98 & 44,28 \\
\hline Santos & 6.877 & 1,84 & 46,12 \\
\hline Sorocaba & 6.500 & 1,74 & 47,87 \\
\hline Giruá & 6.402 & 1,72 & 49,58 \\
\hline Curitiba & 6.223 & 1,67 & 51,25 \\
\hline Itapevi & 5.433 & 1,46 & 52,70 \\
\hline Campinas & 5.015 & 1,34 & 54,05 \\
\hline
\end{tabular}


Tabela 4 - Frequência de mamografias realizadas nos vinte principais municípios em residentes e não residentes. Brasil - 2010 a 2012 (cont.)

\begin{tabular}{|c|c|c|c|c|c|c|c|}
\hline Municípios & $\begin{array}{c}\mathrm{N}^{\mathrm{o}} \mathrm{de} \\
\text { atendimentos }\end{array}$ & $\%$ & $\begin{array}{c}\% \\
\text { Acumulado }\end{array}$ & Municípios & $\begin{array}{l}\mathrm{N}^{\mathrm{O}} \text { Não } \\
\text { residentes }\end{array}$ & $\%$ & $\begin{array}{c}\% \\
\text { Acumulado }\end{array}$ \\
\hline Vitória & 85.912 & 0,8 & 26,8 & $\begin{array}{l}\text { São João de } \\
\text { Meriti }\end{array}$ & 4.702 & 1,26 & 55,31 \\
\hline Sorocaba & 85.205 & 0,8 & 27,6 & Salto Grande & 4.615 & 1,24 & 56,54 \\
\hline Campinas & 82.002 & 0,8 & 28,4 & Cascavel & 3.999 & 1,07 & 57,61 \\
\hline Natal & 76.418 & 0,7 & 29,2 & $\begin{array}{l}\text { Conselheiro } \\
\text { Lafaiete }\end{array}$ & 3.728 & 1,00 & 58,61 \\
\hline Joinville & 73.757 & 0,7 & 29,9 & Jundiaí & 3.652 & 0,98 & 59,59 \\
\hline $\begin{array}{l}\text { São Bernardo } \\
\text { do Campo }\end{array}$ & 73.715 & 0,7 & 30,6 & Sapiranga & 3.636 & 0,97 & 60,57 \\
\hline
\end{tabular}

Na Figura 4 percebe-se a distribuição gráfica do número de procedimentos de mamografias realizadas segundo o município de atendimento no período de 2010 a 2012. Os quadrados proporcionais em vermelho destacam os municípios citados na tabela anterior e que apresentam a maior frequência de mamografias realizadas. Os círculos proporcionais em amarelo indicam os demais municípios que realizaram o procedimento. Observa-se concentração na frequência de procedimentos nos municípios das regiões Sul e Sudeste, principalmente, no leste do estado do Paraná, norte do estado de São Paulo, Rio de Janeiro e sul de Minas Gerais. A região litorânea do Nordeste e a cidade de Manaus, no Norte do país, também apresentaram elevado número de procedimentos realizados.

Quanto à distribuição gráfica do fluxo dos atendimentos de mamografias, observa-se que os fluxos mais intensos se deslocam do interior do estado da Bahia para a capital do estado. Outro polo importante, mas com menor volume de deslocamentos é observado no norte do estado de São Paulo, que recebe pacientes das regiões Norte, Nordeste e Centro-Oeste. Os demais fluxos têm comportamento regional, com poucas distâncias percorridas e pequeno volume de pacientes. 
Figura 4 - Frequência e fluxo de pacientes para realização de mamografias por municípios. Brasil 2010 a 2012
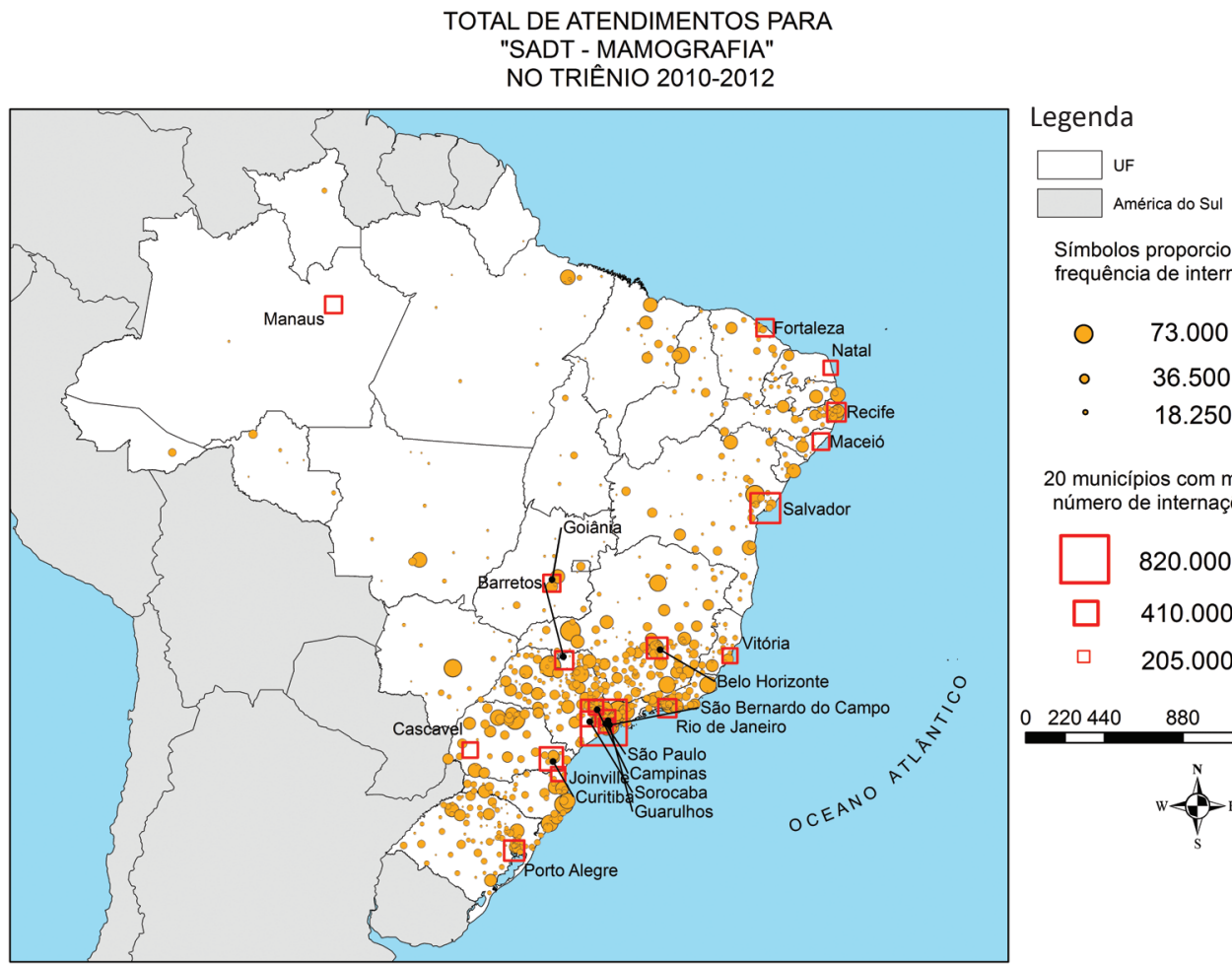

$$
\begin{array}{cc}
\begin{array}{c}
\text { Simbolos proporcionais a } \\
\text { frequência de internações }
\end{array} \\
\text { ○ } & 73.000 \\
\circ & 36.500 \\
\text { - } & 18.250
\end{array}
$$

20 municípios com maior número de internações
$\square$
820.000
$\square \quad 410.000$
205.000

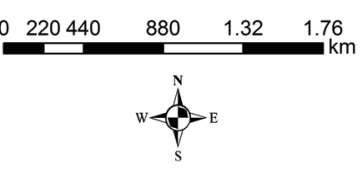

FLUXO DE ATENDIMENTOS PARA "SADT - MAMOGRAFIA" NO TRIÊNIO 2010-2012

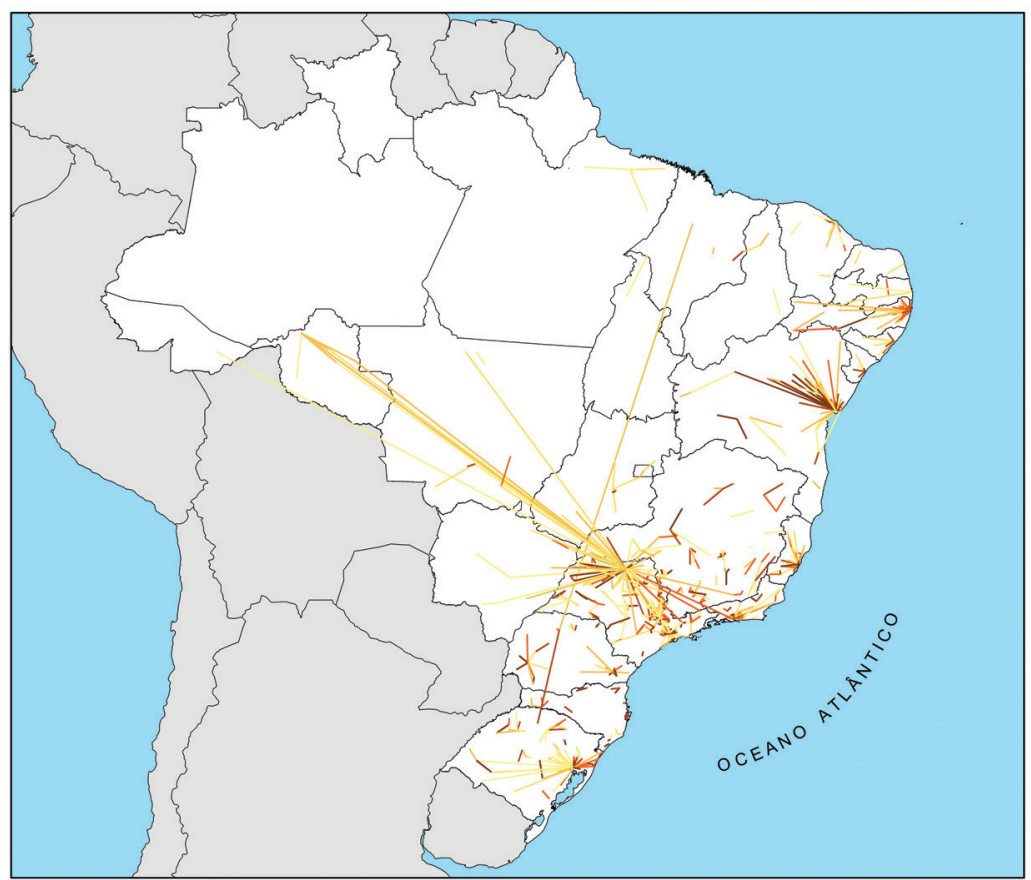

Legenda

Total de atendimentos atributo
$30-46$
$47-76$
$77-142$
- $143-303$
- $304-800$
- $801-12095$
$\square$ UF
América do Sul

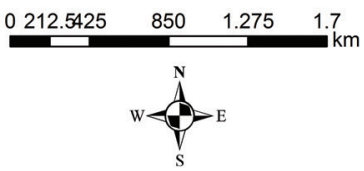


O volume de mamografias realizadas estava muito abaixo do esperado para a população feminina brasileira. Velasco e colaboradores (2014) avaliaram regionais de saúde no estado de Goiás e constataram que algumas não realizavam o exame de mamografia, com isso as mulheres que dispunham apenas do sistema público de saúde tinham de se deslocar de seu município de residência em busca de atendimento, o que em última análise sobrecarregava outros centros diagnósticos. Foi possível concluir que muitas das pacientes acabavam por não ter acesso ao procedimento por meio do sistema público de saúde.

\section{Alta complexidade: cirurgia oncológica de mama}

Assim como o apresentado nas mamografias, observa-se um volume baixo de cirurgias oncológicas de mama realizadas. Os vinte municípios listados com mais cirurgias oncológicas de mama no Brasil no período de 2010 a 2012 respondem por mais de 61\% do volume total no país. Possivelmente, esse número é subestimado já que muitas pacientes devem recorrer ao sistema privado de saúde quando se deparam com uma situação de diagnóstico de neoplasia mamária. Observando apenas o volume de mamografia, Lima-Costa e Matos (2007) ao analisar dados da Pesquisa Nacional por amostra de Domicílios (Pnad) concluíram que, entre as pacientes que detinham plano de saúde, cerca de 74\% realizaram o exame de mamografia, ao passo que entre as que dependiam apenas do serviço público essa proporção foi de 35\%. Essa busca pelo serviço privado deve repetir-se de forma mais acentuada para a cirurgia oncológica da mama que, no período, registrou em três anos apenas 22 mil procedimentos realizados pelo SUS. Observa-se que o município do Rio de Janeiro atendeu $10 \%$ das cirurgias, seguido de São Paulo, Recife, Fortaleza e Campinas. Esses cinco municípios concentram 32\% das cirurgias realizadas no território nacional. Além das capitais assinaladas na tabela, destacam-se os municípios de Barretos e Jaú no estado de São Paulo e Londrina no estado do Paraná (Tabela 5).

Quando observado o fluxo de pacientes para realização da cirurgia oncológica de mama no período de 2010 a 2012, observa-se que das 22 mil cirurgias ocorridas no período, $2 \%$ dos pacientes se deslocaram para realizá-las. O município de São Paulo recebeu mais 16,5\% do total, seguido de Vitória com 12\% e Jaú, Barretos e Recife, com 11\%, 11\% e 9\%, respectivamente.

Tabela 5 - Frequência e fluxo de pacientes para cirurgia oncológica de mama segundo municípios. Brasil - 2010 a 2012

\begin{tabular}{|c|c|c|c|c|c|c|c|}
\hline Municípios & $\begin{array}{c}\mathrm{N}^{\mathrm{o}} \text { de } \\
\text { atendimentos }\end{array}$ & $\%$ & $\begin{array}{c}\% \\
\text { Acumulado }\end{array}$ & Municípios & $\begin{array}{l}\mathrm{N}^{\circ} \mathrm{Não} \\
\text { residentes }\end{array}$ & $\%$ & $\begin{array}{c}\% \\
\text { Acumulado }\end{array}$ \\
\hline Rio de Janeiro & 2118 & 9,60 & 9,60 & São Paulo & 67 & 16,50 & 16,50 \\
\hline São Paulo & 1769 & 8,02 & 17,61 & Vitória & 47 & 11,58 & 28,08 \\
\hline Recife & 1433 & 6,49 & 24,11 & Jaú & 44 & 10,84 & 38,92 \\
\hline Fortaleza & 1079 & 4,89 & 29,00 & Barretos & 43 & 10,59 & 49,51 \\
\hline Campinas & 653 & 2,96 & 31,96 & Recife & 37 & 9,11 & 58,62 \\
\hline Barretos & 586 & 2,66 & 34,61 & Rio de Janeiro & 35 & 8,62 & 67,24 \\
\hline João Pessoa & 574 & 2,60 & 37,21 & Santos & 27 & 6,65 & 73,89 \\
\hline Belo Horizonte & 550 & 2,49 & 39,70 & Campinas & 19 & 4,68 & 78,57 \\
\hline
\end{tabular}


Tabela 5 - Frequência e fluxo de pacientes para cirurgia oncológica de mama segundo municípios. Brasil - 2010 a 2012 (cont.)

\begin{tabular}{|l|c|c|c|}
\hline \multicolumn{1}{|c|}{ Municípios } & $\begin{array}{c}\mathrm{N}^{\mathrm{o}} \text { de } \\
\text { atendimentos }\end{array}$ & $\%$ & $\begin{array}{c}\% \\
\text { Acumulado }\end{array}$ \\
\hline Natal & 509 & 2,31 & 42,01 \\
\hline Vitória & 509 & 2,31 & 44,32 \\
\hline Curitiba & 497 & 2,25 & 46,57 \\
\hline Porto Alegre & 468 & 2,12 & 48,69 \\
\hline Jaú & 451 & 2,04 & 50,73 \\
\hline Belém & 392 & 1,78 & 52,51 \\
\hline Teresina & 391 & 1,77 & 54,28 \\
\hline Manaus & 386 & 1,75 & 56,03 \\
\hline Brasília & 325 & 1,47 & 57,50 \\
\hline Londrina & 308 & 1,40 & 58,90 \\
\hline Maceió & 280 & 1,27 & 60,17 \\
\hline Goiânia & 280 & 1,27 & 61,44 \\
\hline
\end{tabular}

\begin{tabular}{|l|c|c|c|}
\hline \multicolumn{1}{|c|}{ Municípios } & $\begin{array}{c}\mathrm{N}^{0} \text { Não } \\
\text { residentes }\end{array}$ & $\%$ & $\begin{array}{c}\% \\
\text { Acumulado }\end{array}$ \\
\hline Curitiba & 12 & 2,96 & 81,53 \\
\hline Natal & 8 & 1,97 & 83,50 \\
\hline Porto Alegre & 8 & 1,97 & 85,47 \\
\hline Cabo Frio & 7 & 1,72 & 87,19 \\
\hline Campo Grande & 6 & 1,48 & 88,67 \\
\hline Belo Horizonte & 5 & 1,23 & 89,90 \\
\hline Santo André & 5 & 1,23 & 91,13 \\
\hline Botucatu & 4 & 0,99 & 92,12 \\
\hline Arapongas & 4 & 0,99 & 93,10 \\
\hline Campina & 4 & 0,99 & 94,09 \\
\hline Grande do Sul & 3 & 0,74 & 94,83 \\
\hline Belém & 3 & 0,74 & 95,57 \\
\hline Cascavel & & & \\
\hline
\end{tabular}

Fonte: SIH.

Na Figura 5 apresenta-se a distribuição gráfica do número de cirurgias oncológicas de mama segundo o município de atendimento no período de 2010 a 2012. Os quadrados proporcionais em vermelho destacam os municípios citados na tabela e que contam com a maior frequência de cirurgias. Os círculos proporcionais em amarelo indicam os demais municípios que fizeram cirurgias no período. Observa-se que partes das regiões Sudeste, Sul e litoral do Nordeste registram ocorrências de cirurgias de forma mais distribuída em seus municípios; no restante do país as frequências estão mais dispersas, localizadas principalmente nas capitais dos estados.

Observa-se na distribuição gráfica que nas regiões Sul, Sudeste e litoral do Nordeste alguns municípios polarizam o fluxo de pacientes, de uma forma mais regional ou microrregional, com poucas setas e intensidade. Também é possível verificar pessoas se deslocando das regiões Norte e CentroOeste em busca de atendimento no município de Barretos, formando um polo nacional. Apenas $2 \%$ dos pacientes para cirurgias oncológicas de mama buscaram atendimento em outros municípios, um número muito baixo considerando que a complexidade do procedimento é alta e não disponível na grande maioria de municípios do país. 
Figura 5 - Frequência e fluxo de pacientes para cirurgia oncológica de mama por municípios. Brasil -2010 a 2012

FLUXO DE ATENDIMENTOS PARA

"ALTA COMPLEXIDADE - CIRURGIA ONCOLÓGICA DE MAMA"

EM TODAS AS IDADES NO TRIÊNIO 2010-2012

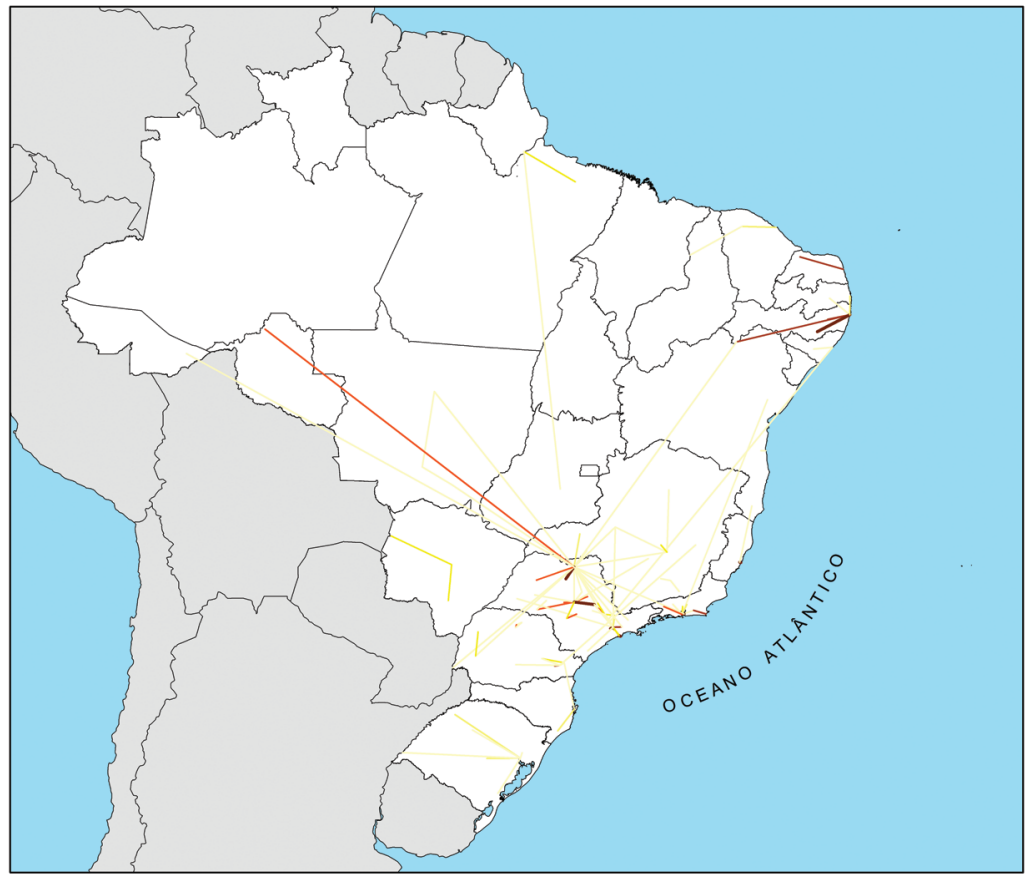

Legenda

atributo

1

2

3

$-4-6$

$-7-10$

$-11-46$

$\square$ UF

$\square$ América do Sul

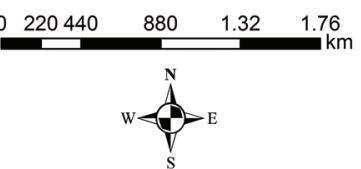

TOTAL DE ATENDIMENTOS PARA

"ALTA COMPLEXIDADE - CIRURGIA ONCOLÓGICA DE MAMA" EM TODAS AS IDADES NO TRIÊNIO 2010-2012

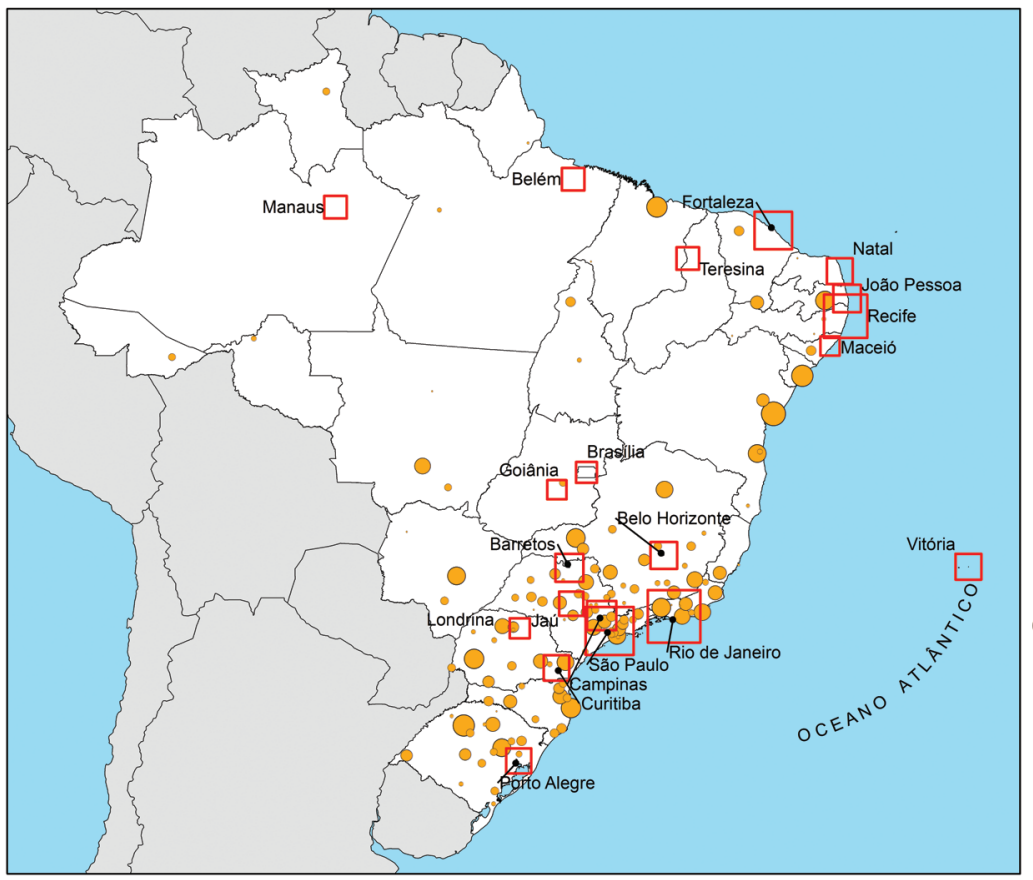

Legenda

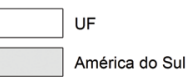

Símbolos proporcionais para frequência de internações

○ 280

- 140

- 70

20 municípios com maio número de internações

प 2.100

$\square \quad 1.050$

525

$\begin{array}{lllll}220440 & 880 & 1.32 & 1.76\end{array}$

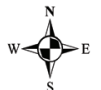




\section{Alta complexidade: angioplastia e revascularização do miocárdio}

Na Tabela 6 estão listados os vinte municípios que mais realizaram angioplastias no Brasil no período de 2010 a 2012. No período foram realizados 183.199 procedimentos e esses vinte municípios respondem por $51 \%$ do volume total de angioplastia no país. Observa-se que o município de São Paulo atendeu 12,3\% dos pacientes, seguido de Porto Alegre, Belo Horizonte, Passo Fundo e Fortaleza. Esses cinco municípios concentram $27 \%$ dos atendimentos realizados no território nacional. Além das capitais apresentadas na tabela, destacam-se os municípios de Passo Fundo, no interior do estado de Rio Grande do Sul, São José do Rio Preto e Ribeirão Preto, no interior do estado de São Paulo, Montes Claros e Juiz de Fora no interior de Minas Gerais, Sobral no estado do Ceará, Campina Grande do Sul, Arapongas e Ponta Grossa, no estado do Paraná.

Também são listados os vinte municípios do país que mais receberam pacientes de outros municípios para atendimento; totalizando quase $100 \%$ dos pacientes que tiveram que se deslocar em busca de atendimento. O município de São Paulo recebeu cerca de 36\% do total, seguido de Porto Alegre, com 17\%, São José (SC) e Rio de Janeiro com 6\%. Os municípios de Vila Velha (ES), Niterói (RJ) e Goiânia (GO) registraram importante número de pacientes oriundos de outros municípios.

Tabela 6 - Frequência de angioplastia, segundo municípios. Brasil - 2010 a 2012

\begin{tabular}{|c|c|c|c|c|c|c|c|}
\hline Municípios & $\begin{array}{c}\mathrm{N}^{\mathrm{o}} \text { de } \\
\text { atendimentos }\end{array}$ & $\%$ & $\begin{array}{c}\% \\
\text { Acumulado }\end{array}$ & Municípios & $\begin{array}{l}\mathrm{N}^{\circ} \text { Não } \\
\text { residentes }\end{array}$ & $\%$ & $\begin{array}{c}\% \\
\text { Acumulado }\end{array}$ \\
\hline São Paulo & 22.541 & 12,3 & 12,3 & São Paulo & 1.741 & 36,44 & 36,44 \\
\hline Porto Alegre & 10.644 & 5,8 & 18,11 & Porto Alegre & 811 & 16,97 & 53,41 \\
\hline Belo Horizonte & 5.812 & 3,2 & 21,29 & São José & 327 & 6,84 & 60,26 \\
\hline Passo Fundo & 5.640 & 3,08 & 24,37 & Rio de Janeiro & 297 & 6,22 & 66,47 \\
\hline Fortaleza & 5.602 & 3,06 & 27,42 & Vila Velha & 243 & 5,09 & 71,56 \\
\hline Curitiba & 5.562 & 3,04 & 30,46 & Niterói & 187 & 3,91 & 75,47 \\
\hline Goiânia & 4.242 & 2,32 & 32,77 & Goiânia & 169 & 3,54 & 79,01 \\
\hline Recife & 3.645 & 1,99 & 34,76 & Lajeado & 161 & 3,37 & 82,38 \\
\hline Rio de Janeiro & 3.258 & 1,78 & 36,54 & Recife & 150 & 3,14 & 85,52 \\
\hline Natal & 3.004 & 1,64 & 38,18 & Curitiba & 101 & 2,11 & 87,63 \\
\hline $\begin{array}{l}\text { São José do Rio } \\
\text { Preto }\end{array}$ & 2.755 & 1,5 & 39,69 & Santo André & 75 & 1,57 & 89,2 \\
\hline Montes Claros & 2.737 & 1,49 & 41,18 & Salvador & 69 & 1,44 & 90,64 \\
\hline Sobral & 2.624 & 1,43 & 42,61 & Marília & 44 & 0,92 & 91,57 \\
\hline Salvador & 2.433 & 1,33 & 43,94 & Belo Horizonte & 34 & 0,71 & 92,28 \\
\hline Ribeirão Preto & 2.265 & 1,24 & 45,18 & Cabo Frio & 34 & 0,71 & 92,99 \\
\hline $\begin{array}{l}\text { Campina Grande } \\
\text { do Sul }\end{array}$ & 2.179 & 1,19 & 46,37 & $\begin{array}{l}\text { Campina } \\
\text { Grande do Sul }\end{array}$ & 33 & 0,69 & 93,68 \\
\hline Arapongas & 1.967 & 1,07 & 47,44 & Rio Grande & 32 & 0,67 & 94,35 \\
\hline Juiz de Fora & 1.965 & 1,07 & 48,51 & Barra Mansa & 21 & 0,44 & 94,79 \\
\hline Maceió & 1.836 & 1 & 49,52 & Taubaté & 21 & 0,44 & 95,23 \\
\hline Ponta Grossa & 1.830 & 1 & 50,51 & Ijuí & 19 & 0,4 & 95,63 \\
\hline
\end{tabular}

Fonte: SIH. 
Na Figura 6, a distribuição gráfica do número de angioplastias segundo o município de atendimento no período de 2010 a 2012. Os quadrados proporcionais em vermelho destacam os municípios citados na tabela com a maior frequência de cirurgias. Nos círculos proporcionais em amarelo, os demais municípios que tiveram cirurgias de angioplastia no período. Observa-se que nas regiões Sudeste e Sul a frequência dos procedimentos está distribuída de forma que alguns municípios apresentam importante volume de procedimentos realizados; por outro lado, nas regiões Centro-Oeste, Norte e Nordeste apenas as capitais realizam o procedimento e na maioria delas o volume de atendimento é muito pequeno.

A distribuição gráfica do fluxo de angioplastia segundo o município de atendimento no período de 2010 a 2012 também é apresentada na figura. Nas regiões Sul, Sudeste e litoral do Nordeste algumas capitais estaduais recebem fluxo de pacientes. Nas regiões Sudeste, Sul e região litorânea do Nordeste são observados municípios que formam polos regionais, com exceção de São Paulo, que se mostra como importante polo nacional - o deslocamento dos pacientes é caracterizado por distâncias consideráveis percorridas para a obtenção do atendimento nesse município. Contudo, cabe ressaltar que o volume de pacientes deslocados em busca de atendimento é irrisório, quando consideramos que apenas 2,6\% tiveram que buscar atendimento fora do município de residência.

Figura 6 - Frequência e fluxo de angioplastia por municípios. Brasil - 2010 a 2012

FLUXO DE ATENDIMENTOS PARA "ALTA COMPLEXIDADE - ANGIOPLASTIA" EM TODAS AS IDADES NO TRIÊNIO 2010-2012

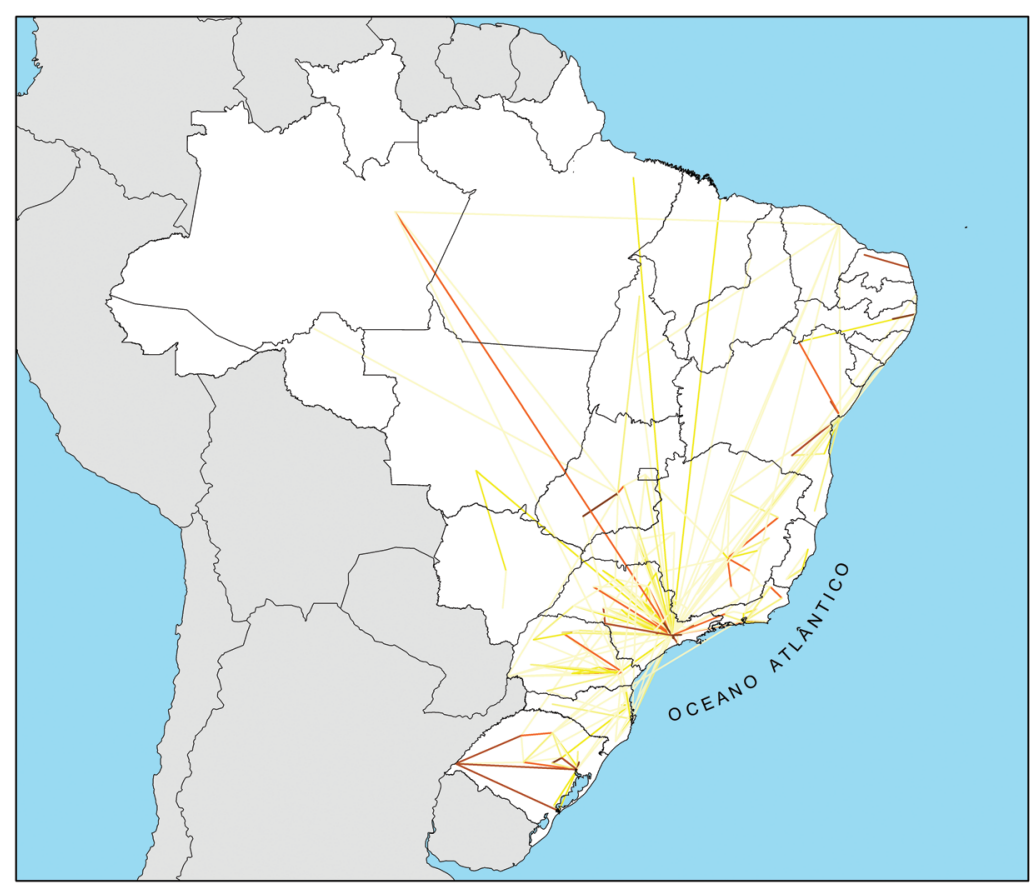

Legenda

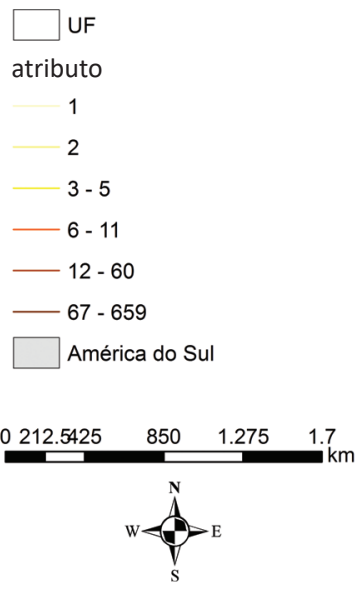


Figura 6 - Frequência e fluxo de angioplastia por municípios. Brasil - 2010 a 2012 (cont.)

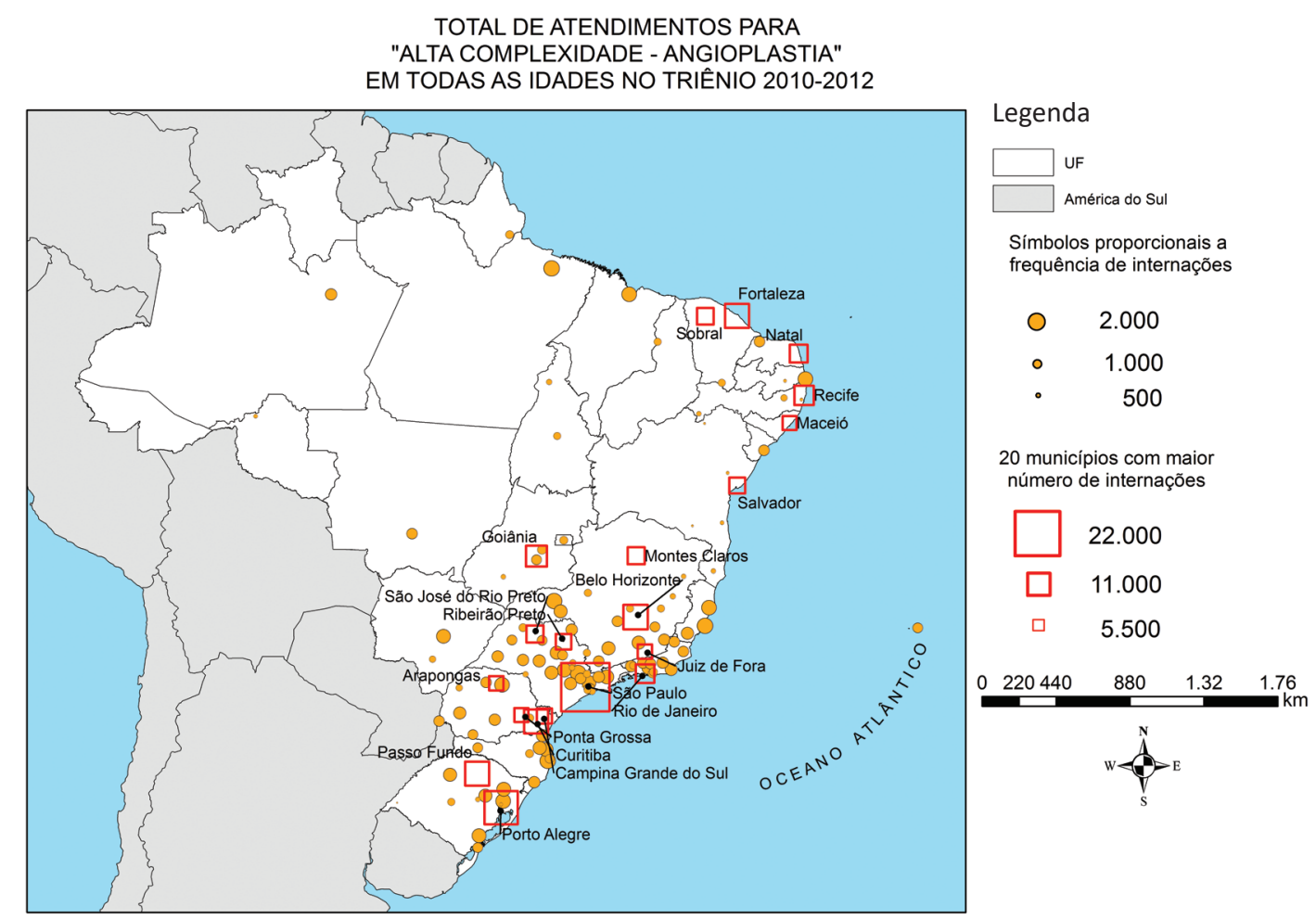

Na Tabela 7 estão listados os vinte municípios que mais realizaram cirurgias de revascularização do miocárdio no Brasil no período de 2010 a 2012. Tais municípios respondem por 60\% do volume total de cirurgias de revascularização do miocárdio no país. Observa-se que o município de São Paulo atendeu 21\% dos pacientes, seguido de Campina Grande do Sul, Porto Alegre, Belo Horizonte e Curitiba. Somente esses cinco municípios concentram cerca 35\% dos atendimentos realizados no território nacional.

Consta, ainda, na Tabela 7, o número de cirurgias de revascularização do miocárdio no município de destino de atendimento no período de 2010 a 2012, ou seja, são computados apenas pacientes que tiveram que se deslocar do seu município de residência. Das cerca de setenta mil cirurgias ocorridas no período, $6 \%$ dos pacientes tiveram que se deslocar para realizar a cirurgia. O conjunto dos vinte municípios citados na tabela atendeu cerca de $100 \%$ dos pacientes deslocados. O município de São Paulo recebeu 34\% do total, seguido de Campina Grande do Sul (PR) com 32\%, Porto Alegre, Rio de Janeiro e Recife, com 6\%, 5\% e 3,5\%, respectivamente. Os municípios de Campos dos Goitacazes (RJ), Goiânia e Vila Velha (ES) apresentam importante número de pacientes oriundos de outros municípios. 
Tabela 7 - Frequência e fluxo de pacientes para cirurgias de revascularização do miocárdio, segundo municípios. Brasil - 2010 a 2012

\begin{tabular}{|c|c|c|c|c|c|c|c|}
\hline Municípios & $\begin{array}{c}\mathrm{N}^{\mathrm{o}} \text { de } \\
\text { atendimentos }\end{array}$ & $\%$ & $\begin{array}{c}\% \\
\text { Acumulado }\end{array}$ & Municípios & $\begin{array}{l}\mathrm{N}^{\circ} \text { Não } \\
\text { residentes }\end{array}$ & $\%$ & $\begin{array}{c}\% \\
\text { Acumulado }\end{array}$ \\
\hline São Paulo & 14.417 & 20,54 & 20,54 & São Paulo & 1.392 & 33,77 & 33,77 \\
\hline $\begin{array}{l}\text { Campina } \\
\text { Grande do Sul }\end{array}$ & 2.936 & 4,18 & 24,73 & $\begin{array}{r}\text { Campina } \\
\text { Grande do Sul }\end{array}$ & 1.318 & 31,97 & 65,74 \\
\hline Porto Alegre & 2.650 & 3,78 & 28,5 & Porto Alegre & 241 & 5,85 & 71,59 \\
\hline Belo Horizonte & 2.160 & 3,08 & 31,58 & Rio de Janeiro & 199 & 4,83 & 76,42 \\
\hline Curitiba & 2.013 & 2,87 & 34,45 & Recife & 141 & 3,42 & 79,84 \\
\hline Recife & 1.960 & 2,79 & 37,24 & $\begin{array}{r}\text { Campos dos } \\
\text { Goytacazes }\end{array}$ & 110 & 2,67 & 82,51 \\
\hline Rio de Janeiro & 1.746 & 2,49 & 39,73 & Goiânia & 109 & 2,64 & 85,15 \\
\hline Arapongas & 1.743 & 2,48 & 42,22 & Vila Velha & 82 & 1,99 & 87,14 \\
\hline Fortaleza & 1.731 & 2,47 & 44,68 & Curitiba & 72 & 1,75 & 88,89 \\
\hline Goiânia & 1.333 & 1,9 & 46,58 & São José & 61 & 1,48 & 90,37 \\
\hline Salvador & 1.319 & 1,88 & 48,46 & Salvador & 53 & 1,29 & 91,65 \\
\hline Teresina & 1.164 & 1,66 & 50,12 & Belo Horizonte & 41 & 0,99 & 92,65 \\
\hline Campo Grande & 1.100 & 1,57 & 51,69 & Arapongas & 41 & 0,99 & 93,64 \\
\hline Natal & 1.022 & 1,46 & 53,14 & Lajeado & 38 & 0,92 & 94,57 \\
\hline Montes Claros & 959 & 1,37 & 54,51 & Rio Grande & 29 & 0,7 & 95,27 \\
\hline Belém & 885 & 1,26 & 55,77 & Niterói & 27 & 0,66 & 95,92 \\
\hline Ponta Grossa & 779 & 1,11 & 56,88 & Marília & 24 & 0,58 & 96,51 \\
\hline Bauru & 745 & 1,06 & 57,94 & Nova Friburgo & 16 & 0,39 & 96,89 \\
\hline Vila Velha & 741 & 1,06 & 59 & Ipatinga & 15 & 0,36 & 97,26 \\
\hline Criciúma & 695 & 0,99 & 59,99 & Bauru & 13 & 0,32 & 97,57 \\
\hline
\end{tabular}

Fonte: SIH.

No primeiro mapa da Figura 7, apresenta-se a distribuição gráfica do número de cirurgias de revascularização do miocárdio segundo o município de atendimento no período de 2010 a 2012. Os quadrados proporcionais em vermelho destacam os municípios citados na tabela com a maior frequência de internações. Os círculos proporcionais em amarelo apresentam os demais municípios que tiveram internação cirúrgica realizada no período. Observa-se que nas regiões Sudeste, Sul e litoral do Nordeste estão concentrados os procedimentos realizados no período.

No segundo mapa, a distribuição gráfica do fluxo de cirurgias de revascularização do miocárdio sugere que nas regiões Sul, Sudeste e litoral do Nordeste do país alguns municípios polarizam o fluxo de pacientes e formam polos regionais, a exceção de São Paulo que se mostra como um polo nacional onde se observa que são percorridas distâncias consideráveis para a obtenção do atendimento. Contudo, o volume de pacientes deslocados é muito pequeno. 
Figura 7 - Frequência e fluxo de cirurgias de revascularização do miocárdio, segundo municípios para atendimento. Brasil - 2010 a 2012

FLUXO DE ATENDIMENTOS PARA

"ALTA COMPLEXIDADE - CIRURGIA DE REVASCULARIZAÇÃO DO MIOCÁRDIO" EM TODAS AS IDADES NO TRIÊNIO 2010-2012

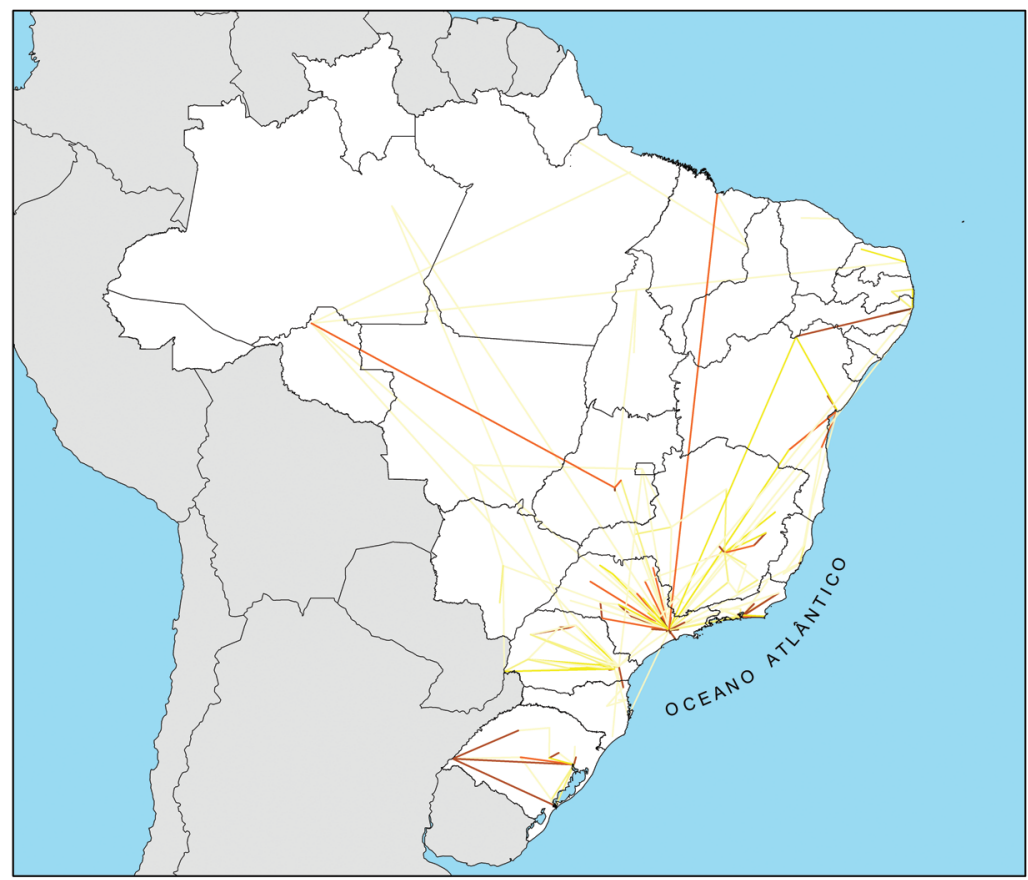

Legenda

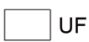

atributo

1

2

$-3-5$

$-6-11$

$-12-60$

$-67-659$

América do Sul

212.5425

$850 \quad 1.275$

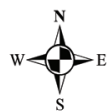

TOTAL DE ATENDIMENTOS PARA

"ALTA COMPLEXIDADE - CIRURGIA DE REVASCULARIZAÇÃO DO MIOCÁRDIO" EM TODAS AS IDADES NO TRIÊNIO 2010-2012

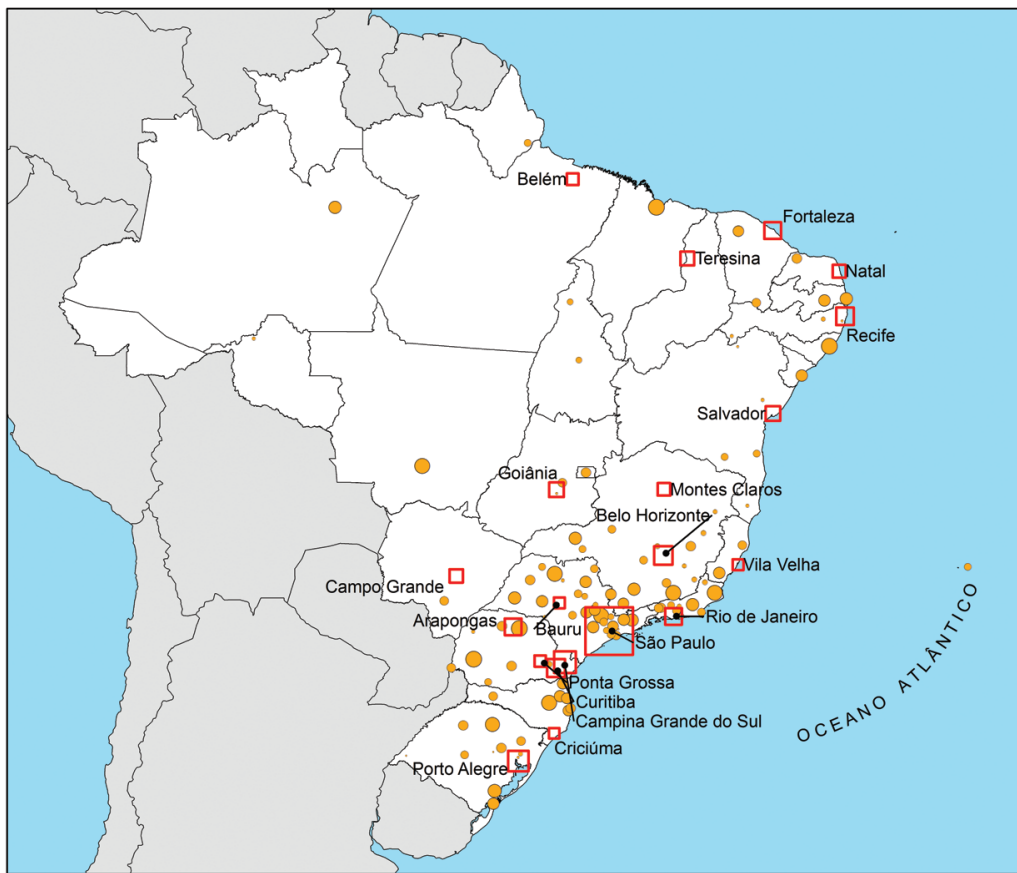

\section{Legenda}

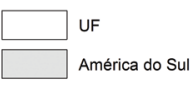

Símbolos proporcionais a frequência de internações

$\begin{array}{cc}\circ & 700 \\ \circ & 350 \\ \circ & 175\end{array}$

20 municípios com maior número de internações

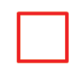

15.000

7.500

$\square \quad 3.500$

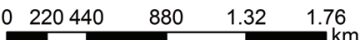


No Brasil, o número total de cirurgias de revascularização do miocárdio no período de 2010 a 2012 foi de 70.175 cirurgias. Se considerarmos o número total de angioplastias e de cirurgias de revascularização de miocárdio, temos que no Brasil no período entre 2010 a 2012 foram realizados 253.374 procedimentos, cerca de $28 \%$ das cirurgias coronárias por meio de revascularização do miocárdio e $72 \%$ por angioplastias, enquanto que no mundo, em 1999, essa proporção foi de $35 \%$ e 65\%, respectivamente (OECD, 2003).

\section{Alta complexidade: cirurgia ortopédica do quadril}

As intervenções cirúrgicas no quadril estão relacionadas, em sua maioria, a fraturas oriundas de quedas e osteoporose.

Na Tabela 8 listam-se os vinte municípios que realizaram o maior número de cirurgias ortopédicas de quadril no Brasil no período de 2010 a 2012. Tais municípios respondem por mais de 40\% do volume total no país. Observa-se que o município de São Paulo atendeu 9\% das cirurgias ortopédicas, seguido de Belo Horizonte, Rio de Janeiro, Porto Alegre e Fortaleza. Esses cinco municípios concentram quase um terço das cirurgias realizadas no território nacional. Além das capitais apresentadas na tabela, destacam-se os municípios de Passo Fundo, Canoas e Rio Grande, no Rio Grande do Sul; Sorocaba, São José do Rio Preto, Bauru e Ribeirão Preto, no estado de São Paulo; e Cascavel e Campina Grande do Sul, no Paraná.

Consta, ainda, o número de cirurgias ortopédicas de quadril para pacientes que tiveram que se deslocar do seu município de residência. Das 51 mil cirurgias ocorridas no período, em 12\% houve deslocamento dos pacientes. O conjunto dos vinte municípios citados atendeu $62 \%$ dos pacientes deslocados. Os municípios de São Paulo, Rio de Janeiro e Belo Horizonte receberam 11\% do total, cada um, seguidos de Porto Alegre com 5\% e Vitória 2,7\%. Outros municípios que apresentaram um número importante de atenção a não residentes foram: Curitiba, Rio Grande (RS) e Mogi das Cruzes (SP).

Tabela 8 - Frequência e fluxo de pacientes para cirurgia ortopédica do quadril, segundo municípios. Brasil - 2010 a 2012

\begin{tabular}{|c|c|c|c|c|c|c|c|}
\hline Municípios & $\begin{array}{c}\mathrm{N}^{\mathrm{o}} \text { de } \\
\text { atendimentos }\end{array}$ & $\%$ & $\begin{array}{c}\% \\
\text { Acumulado }\end{array}$ & Municípios & $\begin{array}{l}\mathrm{N}^{\circ} \text { não } \\
\text { residentes }\end{array}$ & $\%$ & $\begin{array}{c}\% \\
\text { Acumulado }\end{array}$ \\
\hline São Paulo & 4.574 & 8,95 & 8,95 & São Paulo & 683 & 11,13 & 11,13 \\
\hline Belo Horizonte & 2.587 & 5,06 & 14,01 & Rio de Janeiro & 680 & 11,09 & 22,22 \\
\hline Rio de Janeiro & 2.563 & 5,02 & 19,03 & Belo Horizonte & 663 & 10,81 & 33,03 \\
\hline Porto Alegre & 1.375 & 2,69 & 21,72 & Porto Alegre & 313 & 5,10 & 38,13 \\
\hline Fortaleza & 1.001 & 1,96 & 23,68 & Vitória & 164 & 2,67 & 40,81 \\
\hline Curitiba & 943 & 1,85 & 25,52 & Curitiba & 153 & 2,49 & 43,30 \\
\hline Salvador & 888 & 1,74 & 27,26 & Rio Grande & 143 & 2,33 & 45,63 \\
\hline Natal & 732 & 1,43 & 28,69 & $\begin{array}{l}\text { Mogi das } \\
\text { Cruzes }\end{array}$ & 98 & 1,60 & 47,23 \\
\hline Goiânia & 677 & 1,32 & 30,02 & Natal & 88 & 1,43 & 48,66 \\
\hline
\end{tabular}


Tabela 8 - Frequência e fluxo de pacientes para cirurgia ortopédica do quadril, segundo municípios. Brasil - 2010 a 2012 (cont.)

\begin{tabular}{|c|c|c|c|c|c|c|c|}
\hline Municípios & $\begin{array}{c}\mathrm{N}^{\mathrm{o}} \mathrm{de} \\
\text { atendimentos }\end{array}$ & $\%$ & $\begin{array}{c}\% \\
\text { Acumulado }\end{array}$ & Municípios & $\begin{array}{l}\mathrm{N}^{\mathrm{o}} \text { não } \\
\text { residentes }\end{array}$ & $\%$ & $\begin{array}{c}\% \\
\text { Acumulado }\end{array}$ \\
\hline Passo Fundo & 645 & 1,26 & 31,28 & Passo Fundo & 88 & 1,43 & 50,10 \\
\hline Rio Grande & 604 & 1,18 & 32,46 & Sorocaba & 85 & 1,39 & 51,48 \\
\hline Sorocaba & 532 & 1,04 & 33,50 & Cuiabá & 84 & 1,37 & 52,85 \\
\hline Vitória & 498 & 0,97 & 34,48 & $\begin{array}{l}\text { Presidente } \\
\text { Prudente }\end{array}$ & 81 & 1,32 & 54,17 \\
\hline $\begin{array}{l}\text { São José do } \\
\text { Rio Preto }\end{array}$ & 461 & 0,90 & 35,38 & Goiânia & 80 & 1,30 & 55,48 \\
\hline Teresina & 438 & 0,86 & 36,24 & Taubaté & 74 & 1,21 & 56,68 \\
\hline Canoas & 429 & 0,84 & 37,08 & Santo André & 73 & 1,19 & 57,87 \\
\hline Cascavel & 421 & 0,82 & 37,90 & Campinas & 71 & 1,16 & 59,03 \\
\hline $\begin{array}{l}\text { Campina } \\
\text { Grande do Sul }\end{array}$ & 416 & 0,81 & 38,72 & $\begin{array}{l}\text { Cabo de Santo } \\
\text { Agostinho }\end{array}$ & 70 & 1,14 & 60,17 \\
\hline Bauru & 412 & 0,81 & 39,52 & Paulista & 69 & 1,12 & 61,30 \\
\hline Ribeirão Preto & 405 & 0,79 & 40,31 & Tubarão & 69 & 1,12 & 62,42 \\
\hline
\end{tabular}

Fonte: SIH.

Na Figura 8, por meio da distribuição gráfica do número de cirurgias ortopédicas do quadril, segundo o município de atendimento, no período de 2010 a 2012 se observa que partes das regiões Sudeste, Sul e litoral do Nordeste apresentam frequências de cirurgias de forma mais concentrada em seus municípios; no restante do país as frequências se mostram mais dispersas, localizadas principalmente nas capitais dos estados. Na mesma figura é apresentada a distribuição gráfica do fluxo de cirurgia ortopédica do quadril segundo o município de atendimento no período de 2010 a 2012, observando-se que a cidade do Rio de Janeiro forma um polo nacional. 
Figura 8 - Frequência e fluxo de pacientes em cirurgia ortopédica de quadril adulto por municípios. Brasil - 2010 a 2012

FLUXO DE ATENDIMENTOS PARA

"ALTA COMPLEXIDADE - CIRURGIA ORTOPÉDICA DO QUADRIL" EM TODAS AS IDADES NO TRIÊNIO 2010-2012

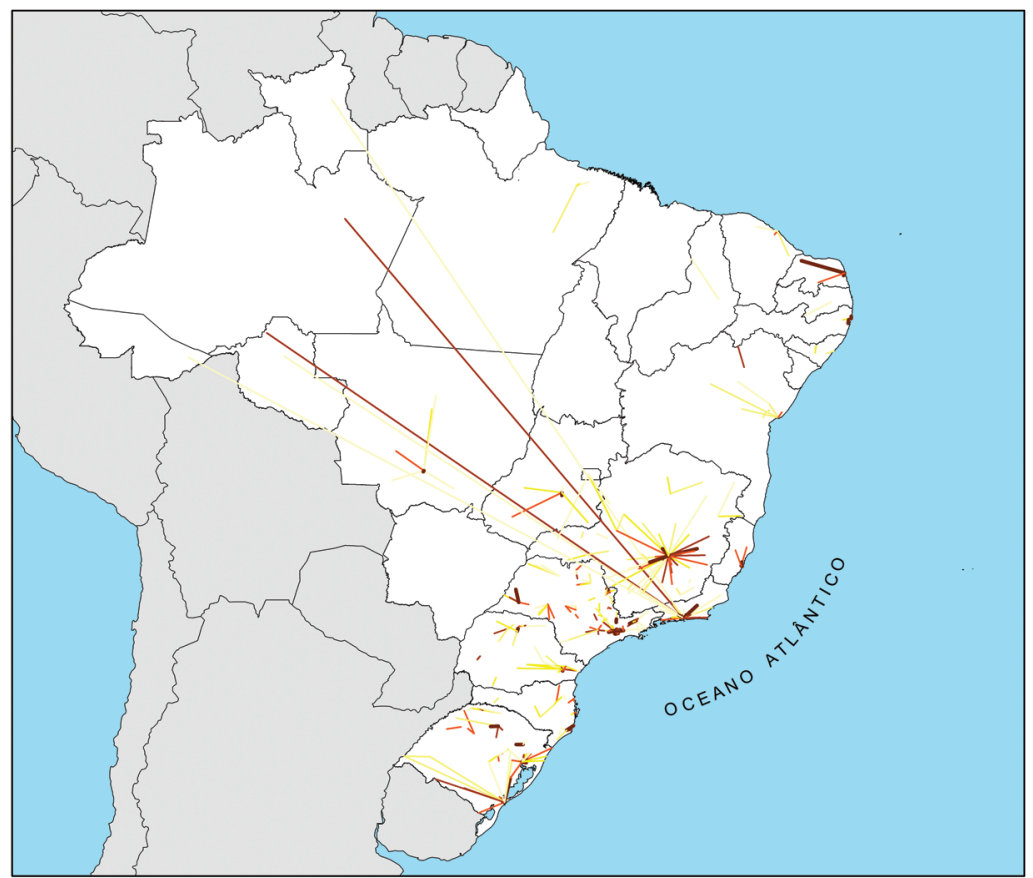

Legenda

atributo

5

$6-7$

$8-10$

$-11-14$

$-15-23$

$-24-128$

$\square$ UF

$\square$ América do Sul

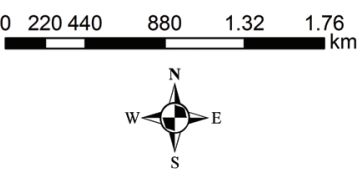

TOTAL DE ATENDIMENTOS PARA

"ALTA COMPLEXIDADE - CIRURGIA ORTOPÉDICA DO QUADRIL" EM TODAS AS IDADES NO TRIÊNIO 2010-2012

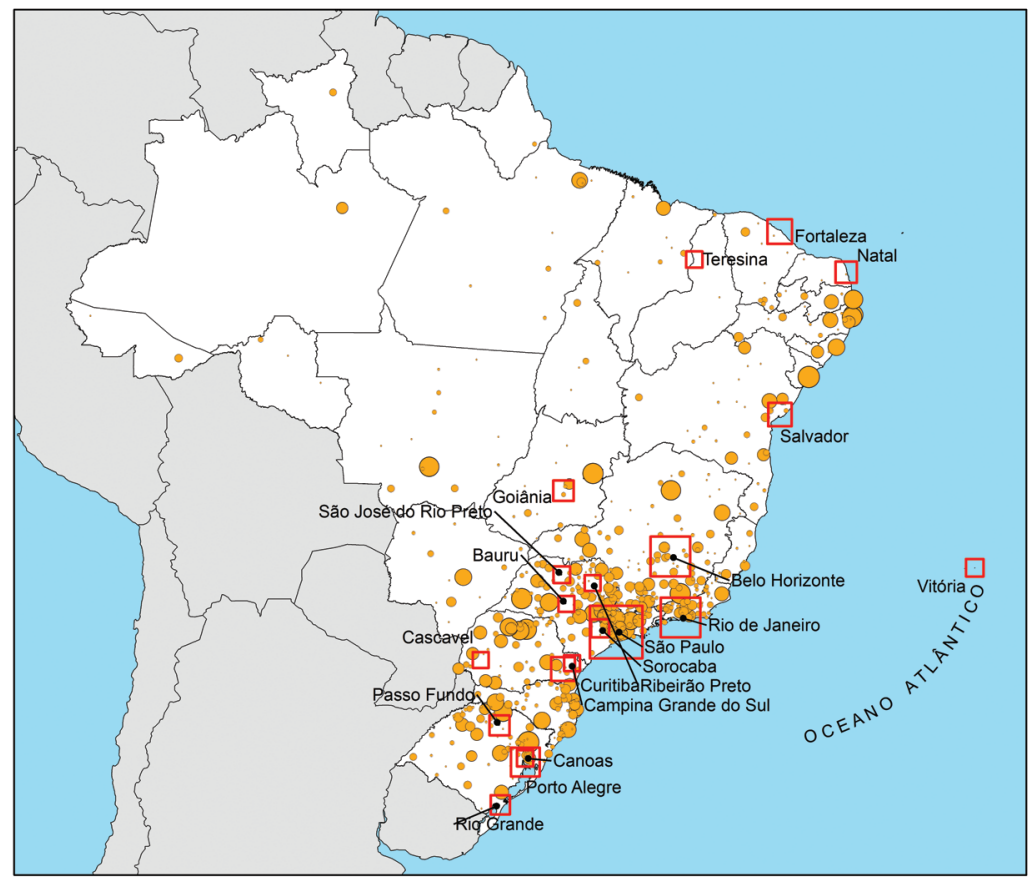

Legenda

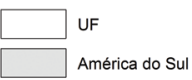

Símbolos proporcionais para frequência de internações

○ 360

- 180

- 90

20 municípios com maior número de internações
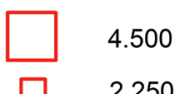

$\square$

1.125
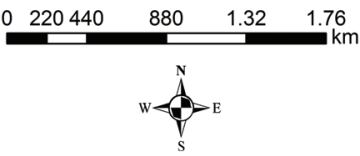


\section{Conclusões}

Como conclusão, é possível afirmar que os municípios mais populosos se encontram, na maioria das vezes, presentes na listagem dos primeiros vinte municípios, quando considerado o volume de internações de alta complexidade. Embora as capitais estejam presentes em quase todas as listagens de volume e de municípios-polo, verificam-se municípios em que o tamanho da população foi determinante para a inclusão nessas listagens. Tais casos ocorrem mais comumente nas internações de baixa-média complexidade. Entretanto, alguns municípios de médio porte populacional se caracterizam como referência para alguns subgrupos de internação, principalmente aqueles de alta complexidade. Os municípios que concentram as internações de maior complexidade apresentam maior percentual de atendimento a não residentes.

A concentração de atendimentos é diretamente relacionada à sua complexidade, ou seja, quanto mais complexo, maior a concentração. De modo geral, é possível classificar os fluxos de pacientes segundo os procedimentos analisados e as distâncias percorridas da seguinte forma:

- Internações de baixa-média complexidade apresentam pequenas distâncias percorridas pelos pacientes e conformam polos intraestaduais.

- Internações de alta complexidade e procedimentos diagnósticos e terapêuticos apresentam fluxos intensos e distâncias maiores, variando entre especialidade e tipo de procedimento realizado, indicando a existências de polos nacionais.

Nos procedimentos de alta complexidade, observa-se que vinte municípios, em geral, são responsáveis por mais de 50\% das internações, independentemente da especialidade analisada. Ou seja, no país, esses vinte municípios são referência para atendimento de alta complexidade.

Os polos para atendimento de cirurgia ortopédica do quadril parecem coincidir com os de neurocirurgia em algumas regiões do país, sobretudo no Sudeste e Sul. É importante ressaltar que as cirurgias ortopédicas de joelho não apresentam os mesmos polos que as cirurgias ortopédicas de quadril. ${ }^{2}$ Os municípios principais com internação para realização de angioplastia e revascularização do miocárdio também são os mesmos polos de atendimento. Considerando as internações oncológicas em geral, destacam-se os polos de municípios no interior do estado de São Paulo, região de Barretos, Ribeirão Preto e São José do Rio Preto, além de municípios no oeste do estado do Paraná.

Os fluxos de internação para baixa-média complexidade geralmente descrevem pequenos trajetos percorridos para atendimento. Em procedimentos cirúrgicos, os fluxos parecem ser mais intensos em comparação aos procedimentos clínicos.

Quanto aos procedimentos diagnósticos e terapêuticos, é importante analisá-los separadamente. No caso da mamografia, observa-se além de grandes capitais como São Paulo, Rio de Janeiro, Salvador, Recife, Fortaleza e Vitória, algumas cidades de médio porte como Barretos, Joinville, Campinas, Guarulhos e São Bernardo do Campo que se destacam pelo alto volume de atendimentos.

\footnotetext{
${ }^{2}$ Ver Relatório de pesquisa do projeto Saúde Amanhã (Xavier et al., 2014).
} 
O comportamento do fluxo de pacientes pode ser explicado como resultado do próprio processo de urbanização maciça, que embora produza cinturões de miséria em uma escala micro, acaba por facilitar o acesso de grandes contingentes populacionais em busca de recursos. Em alguns casos a oferta maior de serviços especializados em cidades de maior porte ocorre dentro do contexto de conurbação, ou seja, a extensão contínua e eventual encontro das áreas urbanizadas de dois ou mais municípios (Monte-Mor et al., 1997), como no caso da região metropolitana de São Paulo. Essa característica é observada para além de áreas metropolitanas dentro de uma mesma unidade da federação, como no caso de Petrolina e Juazeiro na região Nordeste do país, e tantos outros centros populacionais limítrofes entre estados. Nesse caso, deve-se observar a resolução apresentada para a nova regionalização da saúde, que entre outros aspectos contempla a criação de regiões de saúde interestaduais, compostas por municípios limítrofes de mais de um estado, instituídas por ato conjunto dos respectivos estados em articulação com os municípios (Brasil, 2011).

O desenvolvimento econômico nem sempre representa uma melhoria linear para o setor Saúde, e é exatamente quando isso não ocorre que se observa situação de desigualdade. Em outras situações, a lógica econômica pode não expressar a melhoria no setor Saúde, tampouco a centralidade para o serviço de saúde. Oliveira e colaboradores (2011) evidenciaram, através da avaliação de fluxos de pacientes para tratamento de câncer, que municípios como Barretos e Jaú no interior do estado de São Paulo, por exemplo, apresentaram grande relevância para o tratamento oncológico e representam polos de atendimento de referência para o país.

A rede de deslocamento de pacientes pode servir de subsídio para descrever como ocorrem as conexões e como se expressa a distribuição do atendimento à saúde, e também para descrever desigualdades geográficas no acesso, explicadas seja pela disponibilidade de serviços, seja pela estruturação da oferta que marginaliza (no sentido espacial da palavra) e priva populações mais pobres dos ganhos que o desenvolvimento econômico traz ao espaço social.

Por último, é importante considerar que várias redes de serviços de saúde estão sobrepostas para diferentes tipos de atendimento e essas são informações fundamentais, provavelmente usadas, para a definição das regiões de saúde pelas unidades da federação, tanto pela possibilidade de incluir municípios-polos e os deslocamentos de pacientes e, sobretudo, para orientar o encaminhamento de pacientes residentes em outras regiões de saúde. Na perspectiva de complexidade do atendimento torna-se inviável implantar serviços de alta complexidade em todos os municípios e regiões de saúde do país. Dessa forma, uma alternativa seria aumentar a oferta de atendimento de alta complexidade em grandes centros e tornar possível e otimizado o deslocamento dos pacientes em busca de atendimentos. 


\section{Referências}

BONDY, J. A. \& MURTY, U. S. R. Graph Theory with Applications. London: Macmillan, 1976.

BRASIL. Presidência da República. Lei n. 8080, de 19 set. 1990. Dispõe sobre as condições para a promoção, proteção e recuperação da saúde, a organização e o funcionamento dos serviços correspondentes e dá outras providências. Disponível em <www.planalto.gov.br/ccivil_03/leis/18080.htm>. Acesso em: 20 abr. 2015.

BRASIL. Decreto n. 7.508, de 28 jun. 2011. Regulamenta a Lei n. 8.080, de 19 set. 1990, para dispor sobre a organização do Sistema Único de Saúde - SUS, o planejamento da saúde, a assistência à saúde e a articulação interfederativa, e dá outras providências. Brasília, Diário Oficial da União, 2011. Disponível em: <www.planalto. gov.br/ccivil_03/_ato2011-2014/2011/decreto/D7508.htm>. Acesso em: 20 abr. 2015.

DEPARTAMENTO DE INFORMATICA DO SUS (DATASUS). Departamento de Informatica do SUS. Disponível em: <http://datasus.saude.gov.br/>.

DIESTEL, R. Graph Theory. 3. ed. New York: Springer, 2005.

FUNDAÇÃO OSWALDO CRUZ. Saúde Amanhã: o projeto, 2013. Disponível em: <www.saudeamanha.fiocruz. br>. Acesso em: 20 abr. 2015.

JACOBS, B. et al. Addressing access barriers to health services: an analytical framework for selecting appropriate interventions in low-income Asian countries. Health Policy and Planning, 27: 288-300, 2012.

LIMA-COSTA, M. F. \& MATOS, D. L. Prevalência e fatores associados à realização da mamografia na faixa etária de 50-69 anos: um estudo baseado na Pesquisa Nacional por Amostra de Domicílios (2003). Cadernos de Saúde Pública, 23(7): 1.665-1.673, 2007.

LIMA-COSTA, M. F.; PEIXOTO, S. V.; GIATTI, L. Tendências da mortalidade entre idosos brasileiros (1980-2000). Epidemiologia e Serviços de Saúde, 13: 217-228, 2004.

LIMA, L. et al. Regionalização da saúde no Brasil. In: GIOVANELLA, L. et al. (Orgs.). Políticas e Sistemas de Saúde no Brasil. 2. ed. rev. e ampl. Rio de Janeiro: Editora Fiocruz, 2012.

MONTE-MÓR, R. L. M. et al. Ocupação do Território e Estrutura Urbana. In: PAULA, J. A. (Coord.). Biodiversidade, População e Economia: uma região de mata atlântica. Belo Horizonte: UFMG/Cedeplar, ECMCX, PADCT/Ciamb, 1997.

NORONHA, J. \& PEREIRA, T. Princípios do sistema de saúde brasileiro. In: GADELHA, P.; CARVALHO, J. N. \& PEREIRA, T. R. (Orgs.). A Saúde no Brasil em 2030: diretrizes para a prospeç̧ão estratégica do sistema de saúde brasileiro. Rio de Janeiro: Editora Fiocruz, Ipea, Ministério da Saúde, Secretaria de Assuntos Estratégicos da Presidência da República, 2013.

NYSTUEN, J. D. \& DACEY, M. F. A graph theory interpretation of nodal regions. Papers and Proceedings of the Regional Science Association, 7: 29-42, 1961.

OLIVEIRA, E. X. G.; CARVALHO, M. S. \& TRAVASSOS, C. Territórios do Sistema Único de Saúde - mapeamento das redes de atenção hospitalar. Cadernos de Saúde Pública, 20(2): 386-402, 2004.

OLIVEIRA, E. X. G.; TRAVASSOS, C. \& CARVALHO, M. S. Acesso à internação hospitalar nos municípios brasileiros em 2000: territórios do Sistema Único de Saúde. Cadernos de Saúde Pública, 20, supl. 2: S298-309, 2004.

OLIVEIRA, E. X. G. et al. Acesso à assistência oncológica: mapeamento dos fluxos origem-destino das internações e dos atendimentos ambulatoriais. O caso do câncer de mama. Cadernos de Saúde Pública, 27(2): 317-326, 2011.

ORGANISATION FOR ECONOMIC CO-OPERATION AND DEVELOPMENT (OECD). Study of cross-national differences in the treatment, costs and outcomes of ischaemic heart disease. OECD Health Working Papers, 3. Paris: OECD, 2003. (Delsa/Elsa/WD/HEA, 2003) 
OUVERNEY, A. M. \& NORONHA, J. Modelos de organização e gestão da atenção à saúde: redes locais, regionais e nacionais. In: GADELHA, P.; CARVALHO, J. N. \& PEREIRA, T. R. (Orgs.). A Saúde no Brasil em 2030: diretrizes para a prospecção estratégica do sistema de saúde brasileiro. Rio de Janeiro: Editora Fiocruz, Ipea, Ministério da Saúde, Secretaria de Assuntos Estratégicos da Presidência da República, 2013.

SISTEMA DE INFORMAÇÃO HOSPITALAR DO SUS (SIH). Disponível em:<http://www2.datasus.gov.br/ DATASUS/index.php?area $=0901>$.

UNGLERT, C. V. S.; ROSENBURG, C. P. \& JUNQUEIRA, C. B. Acesso aos serviços de saúde: uma abordagem de geografia em saúde pública. Revista de Saúde Pública, 21(5): 439-446, 1987.

VELASCO, W. et al. Acesso ao SUS: modelagem de indicadores de fluxos dos atendimentos de média complexidade - o caso da mamografia. In: CONGRESSO BRASILEIRO DE ENGENHARIA BIOMÉDICA, XXIV, 13-17 out. 2014, Uberlândia.

XAVIER, D. R. et al. Polos e fluxos de deslocamento de pacientes para internação hospitalar e procedimentos selecionados no Sistema Único de Saúde. Relatório de Pesquisa Projeto Saúde Amanhã. Rio de Janeiro: Fiocruz, 2014. 



\title{
SEGMENTOS INSTITUCIONAIS DE GESTÃO EM SAÚDE: DESCRIÇÃO, TENDÊNCIAS E CENÁRIOS PROSPECTIVOS
}

\author{
Ana Luiza d'Ávila Viana \\ Alcides Silva de Miranda \\ Hudson Pacifico da Silva
}

Nos últimos 25 anos, dois fenômenos emergem com força na política de saúde, com impactos distintos segundo regiões e estados brasileiros: primeiro, a descentralização da formulação, gestão e implementação da política de saúde; segundo, o crescimento do número e tipo de atores envolvidos com a oferta e gestão de serviços, de forma a incrementar tanto o papel e a importância de atores não governamentais nas atividades envolvidas com a implementação de políticas e ações quanto o surgimento de diversos tipos de empresariamento da gestão e oferta de serviços. Ao mesmo tempo, as ideias gerencialistas (ênfase nas ações de melhor custo-benefício) para a governança operacional ${ }^{1}$ do sistema de saúde foram difundidas e passaram a ter centralidade na política.

Esses dois fenômenos, a descentralização do poder regulatório e decisório para os níveis subnacionais de governo e a proliferação das atividades de empresariamento da oferta de serviços, foram contemporâneos e estratégicos para a conformação de um sistema nacional de saúde e introduziram ciclos diferenciados ao longo da trajetória de implementação do Sistema Único de Saúde (SUS) - um ciclo que cobre os anos 1990, voltado para incrementar a descentralização com foco nos municípios; e outro, já nos anos 2000, de maior ênfase na estratégia de regionalização de forma a superar os entraves advindos das grandes desigualdades na oferta de serviços.

Resta saber como os dois fenômenos se inter-relacionam e, mais importante, o que explica o surgimento do segundo fenômeno, tendo em vista a vasta literatura nacional e internacional sobre o protagonismo dos processos de descentralização nas reformas dos sistemas de saúde, desde a década de 1980, porém com poucas menções sobre o segundo fenômeno e hipóteses sobre a sua contemporaneidade com o processo de descentralização, no caso da literatura nacional. Já a literatura internacional enfatiza a crescente importância do nível local e sua relação com atores horizontais e verticais, com mudança na relação local-nacional, desburocratização e um formato organizacional menos hierárquico e mais reticular e horizontal ou com delegação para as organizações privadas, que aumentaram seu protagonismo como forças/atores relevantes nas políticas de proteção social.

\footnotetext{
${ }^{1}$ Governança operacional, diretiva e constitutiva (Hupe \& Hill, 2006) se refere a diferentes funções no processo (de conformação) das políticas públicas. Constitutiva se refere à formulação de um arcabouço jurídico e institucional; diretiva, ao processo decisório; e operativa, ao processo de prestação dos serviços.
} 
A construção dessa governança multinível² ocorre em diversos tipos de relações intra e interinstituições, como devolução (para um ente subnacional), governo conjunto (joint-up government) ou governo holístico (whole-of-government), quando se inicia na esfera pública e transborda para outros atores, na forma de uma governança compartilhada (shared governance). Com isso, o tradicional modelo burocrático hierárquico, com base em cadeias de comando e na separação de competências e responsabilidades, deixa de ser o único formato que rege as relações intra e interinstitucionais, ao mesmo tempo que emergem relações de rede (negociação, contratos e consórcios) e de mercado.

A coordenação das políticas passa a ser a grande preocupação, tendo em vista que as regiões e o local são perpassados por três tipos de relação intra e interinstitucional: a governança burocrática hierárquica (papel da autoridade pública para definir prioridades e fronteiras de direito); a governança de rede (relação entre público e privado social) e a governança de mercado (relação entre público e privado de mercado).

Aqui estamos trabalhando com o conceito de governança elaborado por Richard e Smith (2002), que a define como um instrumento para iluminar a mudança de natureza do processo político nas décadas recentes, em particular a entrada de múltiplos atores na ação de fazer políticas públicas. Esse conceito é completado pela definição de Milward e Provan (2000), para quem a governança objetiva criar mecanismos - recursos, contratos e acordos - complementares à autoridade e às sanções da esfera pública. Dessa forma, o uso do conceito de governança auxilia na compreensão das múltiplas variáveis e multiníveis de ações que influenciam o desempenho de uma determinada política pública.

Uma linha forte de argumento relaciona os dois temas - descentralização e empresariamento - com o enfraquecimento do poder do Estado nacional, o advento de profundas modificações nas economias capitalistas (com aprofundamento da globalização) e a hegemonia das ideias neoliberais. Outro aspecto também destacado é a crescente importância da new public management (NPM) nas formas de organização do setor público, como será destacado mais adiante.

As mudanças no sistema econômico, particularmente o crescimento dos serviços, a internacionalização dos circuitos produtivos, a intensificação dos processos de concentração, financeirização e internacionalização do setor de serviços, bem como as mudanças no mercado de trabalho e em aspectos sociodemográficos, respondem, em parte, pelas inadequações dos sistemas de saúde e o surgimento de novas necessidades, forçando reformas importantes na forma de organização e prestação dos serviços de saúde.

A literatura internacional é pródiga em relacionar descentralização e o empresariamento com os fenômenos mencionados anteriormente, de forma a caracterizar o sistema de proteção social como fragmentado - do ponto de vista institucional -, heterogêneo e desigual, do ponto de vista territorial e em razão da perda de importância dos mecanismos de governança burocrática-hierárquica sob comando estatal.

\footnotetext{
${ }^{2}$ Governança multinível (ou de múltiplos níveis) enfatiza o compartilhamento de poder entre níveis de governo com nenhum centro de autoridade acumulada e cujas relações são caracterizadas pela interdependência mútua de recursos de todos - e não pela competição por recursos escassos (Smith, 2010).
} 
Para o Brasil e, em particular, para a política de saúde, o que nos parece vital é ter uma perspectiva integrada para análise dos dois fenômenos (descentralização e empresariamento), de modo a compreender sua presença diferenciada no território nacional, seus ciclos de expansão e seus condicionantes histórico-estrutural, político-institucional e conjuntural, e, principalmente, desenhar cenários futuros.

Nossa tarefa aqui é de outra ordem: relacionar na área da saúde esses dois processos no intuito de discutir a evolução futura dos modelos de gestão levando em consideração as variáveis que influenciam ambos os processos e são capazes de identificar e localizar situações ou tipos de descentralização e empresariamento presentes no território nacional.

São importantes as variáveis histórico-estruturais (de path dependence), ao lado do desenvolvimento de governanças multiníveis no processo de descentralização e empresariamento, que conformam situações de maior ou menor presença da esfera privada, de relações de rede e de mercado e de legitimidade e afirmação do modelo burocrático sobre os demais (ou não).

A seguir elencamos três variáveis que influenciam os modelos de gestão em saúde:

- aspectos de path dependence na relação público-privada na oferta de serviços de saúde e evolução recente;

- governança constitutiva e diretiva do sistema de saúde (incentivo à conformação de novos tipos de arranjos público-privados, alcance da regulação e pertinência dos instrumentos regulatórios);

- conjunturas específicas e locais nas quais se destaca a questão do (sub)financiamento (custeio e investimento) do sistema de saúde nos níveis locais e regionais.

A pergunta pertinente é se o empresariamento foi apoiado por um forte processo normativo nacional ou se deve a políticas estaduais, fortemente presentes em alguns períodos específicos, vinculadas (ou não) a coalizões políticas estaduais de espectro ideológico definido. Também cabe perguntar qual é o papel da regulação pública estatal nesse processo, isto é, a governança constitutiva e diretiva foi expandida por meio de instrumentos regulatórios próprios e de amplo consenso social e político?

Do ponto de vista das variáveis vinculadas ao path dependence, temos uma configuração histórica de predomínio da oferta privada (internação) nos estados do Sul do Brasil, em oposição a um protagonismo da presença pública no extremo oposto, estados do Norte e Nordeste do país, e uma situação intermediária, de presença mista, pública e privada, nos estados do Sudeste. ${ }^{3}$ Esse é um padrão histórico, e se o poder explicativo da variável path dependence for forte, o empresariamento estaria mais presente nas regiões Sul e Sudeste - e teria baixa penetração nos estados do Norte e Nordeste. Por outro lado, os incentivos (traduzidos em leis e decretos estaduais e municipais) para

\footnotetext{
3 Dados para 2012 indicam que 83,5\% das internações no Norte e Nordeste, onde vivem 35\% da população brasileira, são realizadas por instituições públicas; no Sul, ao contrário, as internações privadas são maioria e somente 7,5\% das internações ocorrem em entidades públicas (reside nessa macrorregião brasileira 21\% da população); já no Sudeste, as internações públicas configuram 46,1\%, portanto uma oferta mista, e ali residem $43 \%$ da população brasileira (Viana et al., 2013).
} 
criação de novos arranjos público-privados tiveram início nos estados do Sudeste, ${ }^{4}$ porém em anos recentes (pós-2004) houve difusão desse modelo para alguns estados do Nordeste (Bahia, Sergipe e Pernambuco) e do Norte (Roraima, por exemplo).

Há proliferação de microacordos (particularistas e clientelistas) por todos os estados sem regras claras de desempenho, metas e eficiência na contratualização dessas entidades privadas, como característica forte em algum estado ou região específica.

A criação de instrumentos regulatórios também não se destaca em nenhum nível de governo e mesmo as atuais deliberações nacionais para a estratégia de regionalização só indicam que deva ser incluído o setor privado nas atividades de planejamento, mas não enseja a criação, em todas as instâncias, de instrumentos claros de regulação e mesmo de sanção/punição e incentivo (prêmio).

A questão do financiamento se distingue regionalmente, no tocante ao financiamento de custeio, porém é uma constante a baixa participação do investimento no gasto público em saúde. Os estados que se destacam no alto financiamento estadual da política de saúde estão localizados nas regiões Norte e Sudeste (ênfase para São Paulo e Tocantins): já o alto financiamento municipal se encontra nos estados da região Centro-Oeste (tanto Mato Grosso quanto Mato Grosso do Sul), e também na região Sudeste, nos estados de São Paulo, Rio de Janeiro e Minas Gerais.

Portanto, níveis altos ou baixos de financiamento estadual não influenciam as decisões de empresariamento. Da mesma forma, tanto o alto ou baixo financiamento municipal pode influenciar a adoção de processos de contratualização para oferta e gestão dos serviços de saúde. Isto é, o financiamento não é uma variável forte de explicação desse processo porque ele pode ocorrer nos dois extremos do ciclo - períodos de alta e baixa disponibilidade de recursos.

A voz corrente associa o processo de empresariamento ao problema de escassez de recursos, porém, como pode ser visto, o mesmo acontece em todas as situações, seja na esfera estadual ou municipal. Pode ser que o início do processo tenha ocorrido em situações de dificuldades para as finanças estaduais e/ou municipais (segunda metade dos anos 1990), como parece ser o caso de São Paulo, porém, há estudos, mesmo para o estado de São Paulo, nos quais se demonstram que as decisões foram influenciadas por um quadro mais complexo do que o problema financeiro isoladamente. ${ }^{5}$

O Quadro 1 a seguir sintetiza as situações das variáveis utilizadas, fruto de pesquisa com dados secundários extraídos de pesquisas recentes e fontes diversas, como teses e artigos. Da mesma forma, a pesquisa empírica desse texto informa a construção do quadro-resumo.

As variáveis com maior força explicativa são aquelas referentes ao processo de governança constitutiva (incentivo jurídico institucional para criação de novos arranjos) e a questão do baixo investimento público para ampliação da capacidade instalada, principalmente na área hospitalar e de serviços de apoio diagnóstico e terapêutico (SADT). De todo modo, a descentralização foi peça importante para o surgimento do fenômeno do empresariamento porque concedeu grau de autonomia para as esferas subnacionais de governo no tocante a formulação, gestão e implementação de políticas.

\footnotetext{
${ }^{4}$ Em São Paulo, a primeira Organização Social de Saúde é de 1995.

${ }^{5}$ Conferir Pahim (2009).
} 
Quadro 1 - Resumo das variáveis que influenciam os modelos de gestão

\begin{tabular}{|c|c|c|c|c|c|}
\hline \multirow{2}{*}{ Variável } & \multicolumn{5}{|c|}{ Regiões } \\
\hline & Norte & Nordeste & Centro-Oeste & Sudeste & Sul \\
\hline Path Dependence ${ }^{6}$ & Público & Público & Público & Misto & Privado \\
\hline $\begin{array}{l}\text { Governança } \\
\text { constitutiva } \\
\text { (incentivo à criação } \\
\text { de novos arranjos } \\
\text { público-privado) }\end{array}$ & Fraca & Média & Média & Forte & Forte \\
\hline $\begin{array}{l}\text { Governança diretiva } \\
\text { (regulação) }\end{array}$ & Fraca & Fraca & Fraca & Média & Média \\
\hline $\begin{array}{l}\text { Governança } \\
\text { operacional } \\
\text { (mecanismos de } \\
\text { regulação) }\end{array}$ & Fraca & Fraca & Fraca & Fraca & Fraca \\
\hline $\begin{array}{l}\text { Financiamento } \\
\text { regional e local } \\
\text { (investimento) }\end{array}$ & Baixo & Baixo & Baixo & Baixo & Baixo \\
\hline $\begin{array}{l}\text { Financiamento } \\
\text { regional e local } \\
\text { (custeio) }^{7}\end{array}$ & $\begin{array}{c}\text { Estadual } \\
\text { elevado e } \\
\text { municipal baixo }\end{array}$ & $\begin{array}{l}\text { Médio e baixo } \\
\text { estadual e } \\
\text { médio e baixo } \\
\text { municipal }\end{array}$ & $\begin{array}{l}\text { Baixo estadual } \\
\text { e elevado } \\
\text { municipal }\end{array}$ & $\begin{array}{l}\text { Estadual elevado } \\
\text { e elevado e } \\
\text { médio municipal } \\
\text { (exceção: RJ e } \\
\text { MG, de baixo } \\
\text { estadual e elevado } \\
\text { municipal) }\end{array}$ & $\begin{array}{c}\text { Médio ou } \\
\text { baixo estadual } \\
\text { e médio } \\
\text { ou baixo } \\
\text { municipal }\end{array}$ \\
\hline
\end{tabular}

Diante desse quadro, como desenhar cenários futuros que possam alterar o quadro atual ou mantê-lo de forma semelhante ou agravado?

Um primeiro cenário, otimista, pode vislumbrar as possibilidades de incremento do investimento público com maior autossuficiência em capacidade instalada, instalação de regras mais claras de controle e supervisão do processo de empresariamento e anulação ou neutralização dos aspectos clientelísticos, particularistas e locais na contratualização de entidades privadas. Por outro lado, teríamos uma melhor legitimidade do modelo burocrático em conjunto com o modelo de rede e a consequente diminuição da participação do modelo mercado. Esse cenário pressupõe o aprofundamento do processo de regionalização e a criação de regras claras de corresponsabilidades no planejamento regional. A coordenação da gama de instituições e atores pode ser facilitada pelo reforço e pela criação de instrumentos de contratualização administrados por novos espaços interinstitucionais.

Tal cenário é altamente dependente dos seguintes fatores: expansão do investimento público; criação e reforço da governança em rede e burocrática; qualificação de novos instrumentos de planejamento territorial, de forma a diminuir o grau de fragmentação, o desperdício e a heterogeneidade; aprofundamento do processo de regionalização na saúde; e apoio forte dos estados nesse processo.

\footnotetext{
${ }^{6}$ Ver Viana e colaboradores (2013).

7 Dados extraídos de Levi e Scatena (2011).
} 
No extremo oposto, a regionalização não se implementa de forma forte e a fragmentação passa a ser o traço dominante do sistema. O baixo investimento público impede o recuo do processo de empresariamento para oferta de serviços, e microcontratos se proliferam sem regras claras e ao sabor das decisões das elites locais, com baixo consenso social e político. O modelo de mercado se torna predominante e o papel das redes, assim como a gestão burocrática, se enfraquece.

A situação intermediária seria constituída pela adoção do primeiro modelo em algumas regiões e estados, e o segundo nas regiões mais pobres do país, mantendo uma dualidade ao longo do território, o que é característico de alguns sistemas de saúde europeus - forte regulação no Norte e no Centro, com algum grau de participação privada na oferta e gestão de serviços; e baixa regulação, em situações de baixa e alta participação do setor privado, no Sul do país (como acontece na Itália, por exemplo).

Apresentamos, a seguir, o percurso utilizado para a identificação desses cenários: uma breve revisão bibliográfica para contextualizar as mudanças ocorridas no âmbito do Estado no período recente e seus reflexos nos sistemas de saúde; um levantamento empírico com base nos dados disponíveis no Cadastro Nacional de Estabelecimentos de Saúde (CNES) para definir os segmentos institucionais de gestão em saúde no Brasil; e, finalmente, os prováveis cenários para os tipos identificados.

\section{Mudanças nas Funções do Estado Contemporâneo e suas Implicações para a Gestão Pública e os Sistemas de Saúde}

O conjunto das transformações ocorridas no âmbito do Estado nos últimos trinta anos está relacionado à crise de um determinado padrão de intervenção estatal, que se consolidou após a Segunda Guerra Mundial e entrou em declínio a partir da década de 1970, por conta da perda de dinamismo das principais economias ocidentais. Esse padrão foi marcado por políticas ativas de intervenção estatal, com o objetivo de promover crescimento econômico e, ao mesmo tempo, assegurar níveis mínimos de equidade por meio de políticas de acesso a bens e serviços públicos mediante a construção de uma ampla rede de proteção social.

Essas políticas passaram a ser duramente criticadas nas últimas décadas do século XX. Em sua essência, as críticas enfatizavam a ineficiência da intervenção estatal na atividade econômica, identificando a imperfeição do Estado como parte fundamental do problema. Essa imperfeição, por sua vez, estava associada à própria natureza do Estado, constituído por um grande número de atores com interesses próprios e comportamento caracterizado por estratégias de maximização de interesses pessoais, tornando o próprio Estado refém desses interesses, nem sempre coincidentes com os da sociedade.

Questões relacionadas à delimitação do tamanho do Estado, à redefinição do seu papel regulador, ao fortalecimento da capacidade de implementar adequadamente as políticas públicas e ao aumento da capacidade política de governar passaram a integrar a agenda de reformas nos anos 1980 e 1990. Essas quatro questões seriam justificadas pela própria crise de legitimidade do Estado, cujas manifestações mais evidentes seriam a crise fiscal, o esgotamento do modo de intervenção estatal na atividade econômica e a superação da forma burocrática de administrar as organizações públicas. 
A redução do tamanho do Estado deveria ser feita mediante programas de privatização de empresas estatais que atuavam nas atividades de produção de bens e serviços para o mercado, transferência de serviços sociais e científicos para associações civis sem fins lucrativos (publicização) e terceirização das atividades auxiliares e de apoio. A redefinição do seu papel regulador estaria associada à adoção de mecanismos para reduzir o custo do cumprimento das regulamentações para o setor privado, ao mesmo tempo que se buscaria tornar mais transparentes as regras de funcionamento dos mercados, estimulando assim sua eficiência. Já a questão da governança estatal estava associada à resolução da crise fiscal do Estado, ao fortalecimento das instituições públicas responsáveis pela formulação e execução das políticas e à modernização e eficiência da administração pública. Finalmente, o aumento da governabilidade seria alcançado por meio de instrumentos capazes de elevar a legitimidade do Estado perante a sociedade e da adequação das instituições políticas para a intermediação dos interesses (Pereira, 1997).

Reformar o Estado e suas instituições se tornou então requisito para se alcançar padrões de governabilidade e governança na maioria dos países desenvolvidos. A busca pelo êxito na promoção de padrões mais eficientes de gestão fiscal e maior redistribuição de recursos e responsabilidades moldou os contornos das políticas de reforma do Estado nos países da OCDE (Rezende, 2005). Programas nacionais de reforma - como o National Performance Review, nos Estados Unidos, e o Next Steps, na Inglaterra - fundaram as bases do discurso gerencialista, de acordo com o qual a busca pela eficiência (fazer mais com menos) se tornou condição fundamental para a organização e o funcionamento do Estado. Do ponto de vista operacional, as mudanças institucionais desencadearam um conjunto amplo de reformas, voltadas para: a emergência e o desenvolvimento de políticas de reformulação da administração pública, das relações trabalhistas, do Judiciário, do Legislativo e dos mecanismos regulatórios; a modernização tributária; os programas massivos de privatização; e a revisão das relações entre governos centrais e subnacionais, especialmente em países organizados de forma federativa. ${ }^{8}$

Essas mudanças estão alinhadas com os preceitos da NPM, que consiste na transferência de conceitos, ferramentas e técnicas de gestão do setor privado para o setor público (Ferlie et al., 1999). As reformas nos países centrais, inspiradas nos modelos e preceitos da NPM, geraram resultados bastante diversos, tendo sido marcados por conflitos estruturais que derivaram da própria formulação e implementação dessas políticas. Embora os exemplos de países como Estados Unidos e Inglaterra tenham se tornado paradigmáticos, a realidade mostra que os Estados mais ricos continuaram a exibir padrões marcados por forte intervenção social e econômica, a despeito de uma retórica de reforma (Rezende, 2005).

Ainda que os preceitos da NPM tenham obtido grande centralidade no período recente, autores como Osborne (2010) entendem que ela representa um estágio transitório na trajetória de evolução entre a administração pública tradicional e a nova governança pública. O argumento central é que a

\footnotetext{
${ }^{8}$ Autores como Majone (1999) destacam que esse processo foi marcado por uma progressiva substituição do Estado positivo (intervencionista) por um Estado regulador, isto é, uma alteração da própria forma de regulação, uma vez que a regulação baseada na propriedade pública estatal, historicamente adotada por muitos países para o desenvolvimento de setores caracterizados como monopólios naturais, passou a ser substituída pela regulação por delegação, na qual o poder decisório é delegado para instituições independentes, como é o caso das agências reguladoras, que formulam e aplicam regras para o funcionamento desses mercados.
} 
implementação das políticas públicas e a prestação de serviços públicos passaram por três regimes diferentes: administração pública tradicional, baseada no modelo burocrático de administração, predominante do final do século XIX até meados dos anos 1980 nos países desenvolvidos; new public management, associada ao modelo gerencialista de administração, cujas diretrizes passaram a predominar a partir dos anos 1990; e nova governança pública, correspondente a um modelo pluralista de administração, que estaria no centro da discussão a partir do século XXI. ${ }^{9}$

\section{Reflexo das Reformas nos Modernos Sistemas de Proteção Social e de Saúde}

As transformações ocorridas no âmbito do Estado colocaram em discussão a pertinência dos sistemas de proteção social consolidados durante o século XX nos principais países desenvolvidos. Para Mérrien (1994), a crise financeira do Estado, impondo limitações para a base de financiamento dos gastos sociais, estaria na origem da chamada crise do Estado de bem-estar social (welfare state), cujo desenvolvimento histórico pode ser decomposto em três períodos distintos: construção e desenvolvimento; estabilidade; e crise.

A fase de construção teria se iniciado no fim do século XIX, podendo ser descrita como uma fase de emergência e de elaboração de novos paradigmas das políticas sociais, com discussões sobre os limites da proteção social, as categorias sociais que deveriam ser beneficiadas, o montante das contribuições, os riscos que deveriam ser cobertos e o modo de gestão do sistema. A fase seguinte, de estabilização, teria começado após a Segunda Guerra Mundial, marcada pela expansão dos mecanismos de proteção social em praticamente todos os países desenvolvidos, amparada por políticas econômicas de ampliação dos gastos públicos e situação de pleno emprego. Finalmente, a fase da crise teria iniciado na década de 1980, com a ascensão do pensamento neoliberal, num contexto caracterizado pela crise financeira dos Estados e pela emergência de problemas globais (e não setoriais).

Alguns resultados dessa crise foram documentados por Pierson (1998), que identificou mudanças nos benefícios sociais para os países da OCDE ao longo das décadas de 1980 e 1990. Dentre as mudanças identificadas pelo autor, destaca-se a retração de titularidades no valor dos benefícios (queda no valor real), no acesso aos programas (adoção de testes de meios e critérios mais duros de elegibilidade) e na introdução de formas de copagamento para utilização dos serviços. Ainda que essas mudanças não tenham sido implementadas igualmente por todos os países, elas abrangeram muitas áreas de intervenção do Estado na área social: aposentadorias (aumento da idade para se aposentar, extensão do período para requerer aposentadoria plena, redução da base para ajuste dos benefícios com base na inflação e teste de meios para aposentadoria); incapacidade (testes mais estritos de incapacidade, novos limites de duração e benefícios reduzidos); desemprego (elegibilidade reduzida e redução na duração e no nível dos benefícios); e benefícios para famílias (valor real declinante e elegibilidade decrescente).

\footnotetext{
${ }^{9}$ O autor reconhece que se trata de uma simplificação teórica, na medida em que elementos de cada regime ou modelo podem e vão coexistir ou se sobrepor aos elementos de outros.
} 
Apesar do constrangimento financeiro imposto às políticas sociais, diversos autores questionam o suposto desmantelamento ou recuo dos sistemas de proteção social dos países centrais em razão das políticas de ajuste macroeconômico. Draibe e Henrique (1988), em artigo no qual analisam a contribuição de diversos autores para o entendimento da crise do welfare state, argumentam que, apesar das pressões por mudanças, não é possível afirmar que houve esgotamento de uma dada forma de intervenção social do Estado. Já Pierson (1994) destaca que o alto grau de consolidação dos benefícios sociais nos países centrais (grau de enraizamento das políticas sociais nas diferentes sociedades) possibilitou a formação de uma ampla rede de interesses que foi capaz de minimizar ou mesmo neutralizar as tentativas de mudanças propostas pela agenda de reforma dos anos 1990 . Por outro lado, indicadores relativos ao montante e à composição do gasto social ${ }^{10}$ revelam que, ao contrário do esperado, houve expansão do gasto social público nas últimas décadas, além de relativa estabilidade na dimensão qualitativa do gasto (Castles, 2004). ${ }^{11}$

Os sistemas de saúde também foram afetados, em alguma medida, pela crise do Estado e dos sistemas de proteção social. De fato, a literatura sobre o tema identifica a existência de duas ondas de reformas nos sistemas de saúde, distintas em sua natureza: as reformas dos anos 1970-80, impulsionadas pelo imperativo macroeconômico de controle das despesas nacionais com o setor Saúde, e a agenda de reformas da década de 1990, cujas características estão associadas ao estabelecimento de inovações capazes de criar um ambiente institucional favorável à melhoria da eficiência dos prestadores de serviços de saúde.

Dado o quadro mais geral da crise dos sistemas de saúde, muitos países migraram de um modelo verticalizado para um modelo contratual de financiamento e provisão dos serviços, o que serviu como um estímulo complementar às políticas de controle de gastos no nível macroeconômico, gerando iniciativas de fortalecimento da eficiência e da capacidade de resposta aos usuários no nível microeconômico (Ham, 1997). A introdução de mecanismos mais alinhados com o mercado, o fortalecimento da gestão dos serviços de saúde e a adoção de incentivos orçamentários para melhorar o desempenho foram as principais medidas empregadas para a implementação dessas políticas.

O crescimento contínuo dos gastos com bens e serviços de saúde nas últimas décadas, num contexto de restrição dos orçamentos públicos, foi um dos fatores que impulsionaram as reformas nos sistemas de saúde. Como bem destacado por Médici (1995), a expansão horizontal e vertical da cobertura, a incorporação de inovações tecnológicas, a transição demográfica e a transição epidemiológica estão entre as principais causas responsáveis por esse crescimento.

Além dos limites impostos pela insuficiência de recursos, é necessário destacar que as reformas dos sistemas de saúde ocorreram em um momento de construção de uma determinada "agenda internacional para as políticas de saúde" (Mattos, 2001), formada pela oferta de ideias produzidas pelo conjunto de agências que integram a comunidade internacional de ajuda ao desenvolvimento, com destaque para o Banco Mundial e para a Organização Mundial da Saúde (OMS). Segundo

\footnotetext{
${ }^{10}$ Indicadores quantitativos: gasto social como \% do PIB; gasto social sobre o gasto público total; gasto social real per capita; e gasto social real por dependente.

${ }^{11}$ Indicadores qualitativos: mudança estrutural (composição do gasto); cortes em programas; e residualização dos welfare states.
} 
Mattos (2001), tanto o Banco Mundial como a OMS ensejaram, ao longo das décadas de 1980-90, apresentar um conjunto de recomendações e sugestões sobre as reformas dos sistemas de saúde e sobre as próprias atribuições dos governos no setor, mediante um considerável esforço de pesquisa conduzido por técnicos altamente especializados das duas agências.

Esse esforço de pesquisa procurou oferecer critérios para distinguir, entre as diversas experiências de reformas em curso, aquelas que seriam, na visão do Banco Mundial e da OMS, mais adequadas aos países em desenvolvimento, servindo como parâmetros para a alocação de recursos e privilegiando aqueles países alinhados com as recomendações propostas. Dessa forma, a oferta de ideias dessas duas agências cumpriu, de certa forma, o papel de disciplinar as políticas dos países em desenvolvimento, "quer pela força das ideias supostamente universais, quer pelo constrangimento indireto, análogo ao aplicado por vários agentes econômicos privados que atuam nos mercados financeiros internacionais" (Mattos, 2001: 388).

De modo geral, a resposta dos principais países à crise dos sistemas de saúde tem sido a adoção de mecanismos para ampliar o controle sobre os custos e a ênfase na utilização de métodos mais eficientes de gestão, aliados à tendência de separação entre o financiamento e a provisão de serviços, sem alterar, entretanto, a natureza pública da política de saúde. Segundo Dain (2000), as experiências dos países latino-americanos evidenciaram a adoção de diferentes alternativas de encaminhamento da questão. Assim, enquanto alguns países implementaram mudanças bruscas em seus sistemas de saúde, associadas à privatização dos serviços, outros mantiveram praticamente inalteradas suas políticas de saúde. Essa constatação é confirmada por dados levantados para 33 países da América Latina e Caribe de acordo com os quais os sistemas de saúde desses países apresentam grande heterogeneidade no que diz respeito aos níveis de gastos totais com saúde, incluindo a participação dos gastos governamentais e do setor privado no sistema (Nepp, 2003).

A análise do conjunto de reformas efetuadas pelos principais países da Europa e das Américas permite identificar duas importantes lições (Silva, 2003). A primeira lição seria a inexistência de uma tendência consolidada de financiamento e gestão dos sistemas de saúde, sendo impossível demonstrar a superioridade de modelos baseados exclusivamente nas regras de mercado ou, ao contrário, de modelos plenamente estatais. Dessa forma, o desafio anunciado desde a segunda metade da década de 1990 seria o de superar a velha dicotomia Estado versus mercado, mediante a adoção de novos instrumentos de política capazes de integrar adequadamente as capacidades pública e privada.

A segunda lição estaria relacionada com o fato de que as reformas dos sistemas de saúde teriam envolvido mudanças tanto no nível macro das políticas de saúde como no nível micro das organizações. No nível macro, realizaram-se modificações no sentido de propiciar maior contenção de custos e ampliar o processo de descentralização dos serviços para as esferas locais e regionais. No plano das organizações, procurou-se separar o financiamento da prestação de serviços, por meio da introdução de mecanismos de competição administrada, a fim de aumentar a eficiência dos serviços e sua resolutividade. A combinação desses dois níveis teria envolvido as modificações descritas a seguir. 


\section{Mudanças na Gestão Pública Brasileira e Reflexos na Política Social e de Saúde}

No Brasil, a mudança de orientação nas funções do Estado entrou para a agenda governamental e ganhou força a partir da década de 1990, com os processos de reforma administrativa e de privatização de empresas estatais. Entretanto, como bem destacado por Abrucio (2007), esse processo teve início com o fim do período militar, durante os anos 1980, num contexto de crise do regime autoritário e, sobretudo, da derrocada do modelo nacional-desenvolvimentista. Partia-se da constatação de que os militares haviam potencializado os problemas históricos da administração pública brasileira - descontrole financeiro, falta de responsabilização dos governantes e burocratas perante a sociedade, politização indevida da burocracia nos estados e municípios, além da fragmentação excessiva das empresas públicas, com a perda de foco de atuação governamental - e que, portanto, era necessário encontrar soluções que dessem conta do novo momento histórico.

Do ponto de vista da gestão pública, três conjuntos de mudanças foram introduzidos pela Constituição de 1988 no sentido de combater o legado deixado pelos militares: a democratização do Estado, por meio do fortalecimento do controle externo da administração pública e do reforço dos princípios da legalidade e da publicidade; a descentralização das políticas públicas, o que abriu oportunidades para maior participação social e para inovações no campo da gestão pública, levando em conta a realidade e as potencialidades locais; e a profissionalização da burocracia, mediante adoção do princípio da seleção meritocrática e universal, consubstanciada pelo concurso público. Entretanto, a implementação dessas mudanças ocasionou diversos problemas nas décadas seguintes, redundando no papel figurativo de muitos mecanismos de controle e de participação social (tribunais de contas e conselhos de políticas públicas), em relações intergovernamentais conflituosas e não cooperativas (federalismo compartimentalizado) e na persistência de um número elevado de cargos em comissão no funcionalismo público (Abrucio, 2007).

A modernização da gestão pública no Brasil foi fortemente influenciada por experiências e recomendações importadas de outros países e contextos. Como bem destacam Tenório e Saravia (2006), a publicação em português do livro de Osborne e Gaebler (1994) teria exercido grande influência por aqui, com a premissa de que o empreendedorismo é uma característica da iniciativa privada que deveria transformar a gestão pública. Governo empreendedor ou inovador seria aquele que emprega os recursos de modo a maximizar a produtividade e a eficiência. Alguns adjetivos utilizados permitem verificar a direção das recomendações: governo catalisador, pertencente à comunidade, competitivo, orientado por missões, de resultados, orientado ao cliente, empreendedor, preventivo, descentralizado, orientado para o mercado e reinventado.

Viana e Silva (2012) sugerem que as mudanças implementadas estão associadas a três períodos distintos, caracterizados por diferentes institucionalidades da política social no Brasil após a Constituição de 1988: uma institucionalidade neoliberal, durante os governos Collor (1990-1992), Franco (1992-1994) e Cardoso (1995-2002); uma institucionalidade de transição, durante o primeiro governo Lula (2003-2006); e a institucionalidade neodesenvolvimentista, a partir do segundo governo Lula (2007-2010). As características de cada período tendem a ser diferentes do ponto de vista político e 
econômico, assim como as interligações entre as políticas econômica e social, as estratégias-chave, o público-alvo, as formas e os agentes da provisão de serviços, e o tipo de financiamento desenhado para a política social e, em especial, para a política de saúde.

No período de institucionalidade neoliberal, a política social teve como estratégia-chave a descentralização, associada ao incentivo às parcerias público-privadas, ao estímulo ao controle social e à adoção de ações focalizadas em regiões e populações mais pobres. Já no último período (neodesenvolvimentista), as políticas com recortes territoriais (regionais, urbanas, metropolitanas) assumiram maior protagonismo, assim como maiores investimentos públicos em saneamento, habitação e saúde (federais e estaduais), mantendo-se o estímulo às parcerias público-privadas e a seletividade de programas direcionados para o combate à pobreza.

A política de saúde também pode ser diferenciada segundo esses mesmos períodos. A descentralização, acompanhada pela ênfase na atenção primária (via expansão da Estratégia Saúde da Família - ESF) principalmente para as regiões e populações mais pobres, constituiu o aspecto-chave da institucionalidade neoliberal. No período marcado pela institucionalidade neodesenvolvimentista, a regionalização assumiu maior centralidade, aliada à expansão do investimento público voltado para a ampliação de equipamentos de saúde (unidades de pronto atendimento), assim como para o estímulo ao fortalecimento do complexo econômico-industrial da saúde e do componente científico e tecnológico da política de saúde. Destaque deve ser dado para o papel crescente que as diversas organizações privadas (clínicas e hospitais privados, planos de saúde, organizações sociais etc.) passam a ter na oferta, no acesso e na gestão de serviços de saúde no país. No Quadro 2 sintetizam-se as principais características da política de saúde nos diferentes períodos.

Quadro 2 - Principais características da política de saúde no Brasil durante as diferentes institucionalidades

\begin{tabular}{|c|c|c|}
\hline $\begin{array}{c}\text { Neoliberal } \\
(1990-2002)\end{array}$ & $\begin{array}{c}\text { Transição } \\
(2003-2006)\end{array}$ & $\begin{array}{l}\text { Neodesenvolvimentista } \\
\text { (a partir de 2007) }\end{array}$ \\
\hline $\begin{array}{l}\text { - Reorganização institucional do } \\
\text { - Inovações (descentralização) } \\
\text { (PAB/CPMF/EC 29) } \\
\text { - Atenção básica e ESF } \\
\text { - Medicamentos genéricos } \\
\text { - Mutirões } \\
\text { - DST/Aids } \\
\text { - Agências reguladoras (Anvisa } \\
\text { - ANS) } \\
\text { - Organizações sociais de saúde }\end{array}$ & $\begin{array}{l}\text { - Expansão da ESF(Proesf) } \\
\text { - Saúde bucal (Brasil Sorridente) } \\
\text { - Humanização na saúde } \\
\text { - Nova forma de acesso a } \\
\text { medicamentos (Farmácia } \\
\text { Popular) } \\
\text { - Urgência e emergência: Samu/ } \\
\text { Centrais de Regulação } \\
\text { - Gestão do trabalho e da } \\
\text { educação em saúde } \\
\text { - Pacto pela Saúde }\end{array}$ & $\begin{array}{l}\text { - Complexo econômico-industrial } \\
\text { da saúde } \\
\text { - Gestão de tecnologias em saúde } \\
\text { - Fomento a pesquisas (editais } \\
\text { nacionais, PPSUS etc.) } \\
\text { - Hospitais filantrópicos de } \\
\text { excelência (Proadi-SUS) } \\
\text { - Nova proposta de regionalização } \\
\text { - Redes de atenção à saúde e } \\
\text { - linhas de cuidado } \\
\text { - MPA } 24 \text { horas } \\
\text { Mais Médicos }\end{array}$ \\
\hline
\end{tabular}

PAB, piso da atenção básica; CPMF, Contribuição Provisória sobre Movimentação Financeira; EC, emenda constitucional; Anvisa, Agência Nacional de Vigilância Sanitária; ANS, Agência Nacional de Saúde Suplementar; Proesf, Projeto de Expansão e Consolidação da Saúde da Família; Samu, Serviço de Atendimento Móvel de Urgência; PPSUS, Programa Pesquisa para o Sistema Único de Saúde; Proadi-SUS, Programa de Apoio ao Desenvolvimento Institucional do Sistema Único de Saúde; UPA, Unidade de Pronto Atendimento.

Fonte: adaptado de Viana e Silva (2012). 


\section{Análise Descritiva dos Segmentos Institucionais de Gestão em Saúde no Brasil (2005-2013)}

Considerada a diversidade de modalidades institucionais de gestão e prestação de serviços no setor Saúde no Brasil, é complexa a tarefa de definir ordenações e classificações que permitam tanto análises distintivas, como de agregados com características afins. No Brasil, o CNES estabelece uma tipologia com o detalhamento de 13 modalidades institucionais para o setor (definidas como "natureza da organização"), para as quais disponibiliza dados que podem ser processados por configurações e ordenações sistêmicas (níveis de hierarquia, esferas administrativas, tipos de estabelecimentos, personalidades jurídicas etc.), tipos de formalizações normativas (contratos, convênios, habilitações etc.), características de estruturas físicas (leitos hospitalares, equipamentos etc.) e quantitativos da produção de serviços (atendimentos prestados etc.) e da força de trabalho (notadamente ocupações profissionais). ${ }^{12}$

Os dados do CNES sobre os estabelecimentos de saúde estão disponíveis em série histórica de períodos mensais, iniciada em agosto de 2005, período ainda curto para análises de tendências retrospectivas que possam subsidiar projeções e análises prospectivas mais consistentes. Além disso, tal fonte secundária ainda apresenta indícios de subnotificações, que podem gerar vieses analíticos. Mesmo assim, trata-se da fonte disponível de maior confiabilidade, uma vez que a maior parte dos dados anteriores acessíveis provém de levantamentos amostrais periódicos (Pesquisa de Assistência Médico-Sanitária) realizados pelo IBGE.

Embora a classificação de estabelecimentos de saúde por naturezas administrativas adotada pelo CNES permita um maior detalhamento de tipos específicos, para análises mais abrangentes existem algumas classificações imprecisas (por exemplo, a classificação de organizações sociais como “administração indireta”). Considerando análises que levem em conta outras características, além da "natureza administrativa", há o requerimento de critérios de agregação, classificação e síntese.

Com o propósito específico de realizar análise descritiva e tendencial, simplificada e subsidiária para projeção de cenários futuros, optou-se por um escopo com agregação segmentar e classificação mais abrangente, com três setores primordiais de institucionalidades (pública estatal, pública não estatal e privada). Por meio dessa classificação inicial, considerados também os critérios de égide formal de direito administrativo (público ou privado) e relação com o SUS (serviços próprios, complementares ou suplementares), estabeleceu-se a derivação de nove segmentos institucionais, descritos a seguir (Quadro 3) e esquematizados na Figura 1.

\footnotetext{
${ }^{12}$ As modalidades de natureza organizativa estabelecidas pelo CNES são: administração direta da saúde (Ministério da Saúde, secretarias estaduais e Municipais de Saúde); administração direta de outros órgãos (Ministério da Educação, Forças Armadas etc.); administração indireta via autarquias; administração indireta via fundações públicas; administração indireta via empresas públicas; administração indireta via organizações sociais públicas; empresas privadas; fundações privadas; cooperativas; serviços sociais autônomos; entidades beneficentes sem fins lucrativos; sociedades de economia mista; e sindicatos.
} 
Quadro 3 - Tipos de esferas, setores e segmentos institucionais utilizados para a análise de tendências e cenários futuros

A) Esfera pública, setor estatal.

A1) Segmento de administração direta, égide de direito público, serviços próprios do SUS: serviços próprios do Ministério da Saúde, secretarias estaduais e municipais de Saúde.

A2) Segmento de administração direta, outros órgãos estatais (exceto do setor Saúde), égide de direito público, serviços complementares ao SUS e suplementares: serviços de outros ministérios, como o Ministério da Educação (por exemplo, alguns hospitais universitários), serviços de Forças Armadas etc.

A3) Segmento de administração indireta, égide de direito público, serviços próprios do SUS: serviços de autarquias (federais, estaduais e municipais), autarquias em regime especial, fundações públicas, consórcios interfederativos etc.

A4) Segmento de administração indireta, égide de direito privado, serviços próprios do SUS: serviços de empresas públicas de saúde (alguns hospitais universitários, serviços estaduais, municipais etc.), fundações estatais, autarquias em regime especial, sociedades de economia mista, parcerias públicoprivadas.

A5) Segmento de previdência complementar de servidores de estatais, sob administração indireta, égide de direito privado, serviços suplementares ao SUS: serviços de entidades fechadas de previdência complementar (EFPC) de servidores públicos (federais, estaduais e municipais) e de servidores de empresas estatais etc. Alguns dos serviços de saúde de fundos de previdência de servidores de estatais estão cadastrados no CNES como fundações privadas sem fins lucrativos (Cassi, Petros etc.).

B) Esfera pública, setor não estatal: segmento de serviços públicos ofertados por associações civis sem fins lucrativos, égide de direito privado, com serviços complementares contratados pelo SUS e serviços suplementares: associações civis qualificadas como organizações sociais (OSs), organizações da sociedade civil de interesse público (Oscips) e congêneres.

Esfera privada, setor privado:

C) Segmento privado sem fins lucrativos, égide de direito privado, com serviços complementares conveniados ao SUS e serviços suplementares: entidades beneficentes, serviços sociais autônomos, associações sindicais, fundações privadas (incluídas algumas entidades fechadas de previdência complementar de servidores de estatais), cooperativas etc.

D) Segmento privado com fins lucrativos, égide de direito privado, com serviços complementares contratados pelo SUS e serviços suplementares: serviços de empresas privadas (várias modalidades).

E) Segmento misto e ambivalente (público-privado), égide de direito privado, com serviços complementares contratados pelo SUS e serviços suplementares: sociedades de economia mista, contratos de parcerias público-privadas e congêneres. 
Figura 1 - Representação esquemática de setores, segmentos e modalidades de serviços de saúde no Brasil

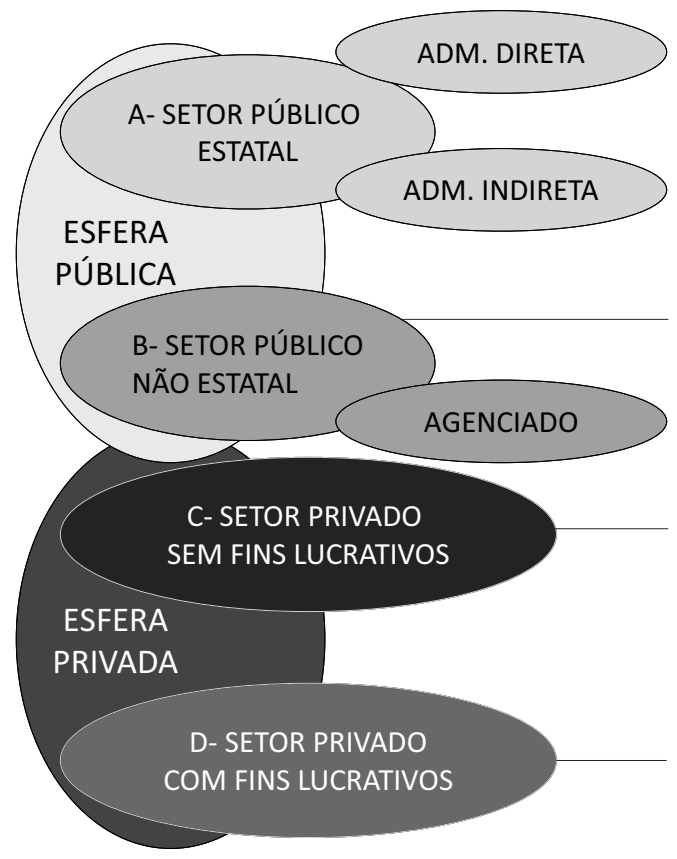

A1. Serviços governamentais próprios

A2. Serviços estatais de outros setores (exceto de Saúde)

A3. Autarquias típicas e sob regime especial de direito público

A4. Autarquias típicas e sob regime especial de direito privado

A5. Fundações privadas previdenciárias das Estatais

B. Organizações sociais e congêneres

C. Estabelecimentos fundacionais, sindicais, cooperativados, associativos filantrópicos etc.

\section{Empresas privadas}

E. Estabelecimentos mistos e ambivalente: economia mista

Essa classificação permite um melhor discernimento da ênfase em agregados com características afins, com pelo menos três setores (estatal, público-estatal e privado) e foco naqueles segmentos em que há disponibilidade de agregação de dados e melhor possibilidade para análises comparativas. Com base nessa classificação, buscou-se uma análise mais descritiva e sumária do atual cenário de institucionalidades de gestão em saúde, em termos de quantificação de proporcionalidades para estabelecimentos cadastrados (CNES) e agregados em segmentos institucionais. Em tal descrição, realçam-se aspectos relevantes da oferta e organização desses serviços (tipos, níveis de atenção, distribuição estadual, vínculos empregatícios de trabalhadores etc.).

A forma de agregação de dados do CNES para a conformação de segmentos institucionais está descrita no Quadro 4 a seguir: 
Quadro 4 - Forma de agregação de dados com base nas naturezas administrativas de estabelecimentos de saúde definidas no CNES para segmentos institucionais de gestão em saúde

\begin{tabular}{|c|c|}
\hline Natureza administrativa (CNES) & Segmentos institucionais de gestão em Saúde \\
\hline 1. Administração direta da Saúde & A1. Estatal, administração direta, setor Saúde \\
\hline 2. Administração direta de outros órgãos & A2. Estatal, administração direta, outros órgãos \\
\hline 3. Administração indireta, autarquias & \multirow{2}{*}{ A3. Estatal administração indireta, direito público } \\
\hline 4. Administração indireta, fundações públicas & \\
\hline 5. Administração indireta, empresas públicas & A4. Estatal administração indireta, direito privado \\
\hline $\begin{array}{l}\text { 6. Administração indireta, organizações sociais } \\
\text { públicas }\end{array}$ & $\begin{array}{l}\text { B. Associações civis sem fins lucrativos qualificadas } \\
\text { como organizações sociais de saúde }\end{array}$ \\
\hline 7. Empresas privadas & C. Privado com fins lucrativos \\
\hline 8. Fundações privadas & \multirow{5}{*}{ D. Privado sem fins lucrativos } \\
\hline 9. Cooperativas & \\
\hline 10. Serviços sociais autônomos & \\
\hline 11. Entidades beneficentes sem fins lucrativos & \\
\hline 12. Sindicatos & \\
\hline 13. Sociedades de economia mista & E. Misto \\
\hline
\end{tabular}

Em ambas as configurações (tipologia CNES e de segmentos institucionais) não foi possível a discriminação e agregação específica de estabelecimentos de saúde do segmento de "Previdência complementar de servidores de estatais (A5)", uma vez que estão cadastrados (CNES) de forma dispersa em várias modalidades de natureza administrativa.

Para a projeção parcial de tendência e cenário futuro, optou-se por uma análise retrospectiva de variações quantitativas de dados acerca de determinadas características dos estabelecimentos de saúde, ordenados em segmentos institucionais, tomando-se como referências temporais os meses de dezembro de 2005 e 2013. Portanto, não se trata propriamente de enfoque longitudinal, mas de enfoque em dois recortes transversais com intercurso de oito anos. Assim, com base na análise de algumas tendências retrospectivas, definidas por variações entre os dois períodos aludidos, busca-se a projeção de uma tendência inercial para o futuro, ou seja, aquela em que estariam mantidos os principais fatores determinantes e condicionantes do período considerado retrospectivamente. ${ }^{13}$

\footnotetext{
${ }^{13}$ Conforme referido anteriormente, uma análise retrospectiva entre séries históricas transversais de somente oito anos não permite projeções mais consistentes para longo prazo; todavia, é esse o período em que os dados estão disponíveis.
} 


\section{Descrição da Trajetória Tendencial dos Segmentos Institucionais de Gestão em Saúde no Período 2005-2013}

As informações descritas e ordenadas no Quadro 5 por modalidades de segmentos institucionais de gestão em saúde apresentam as variações proporcionais nos períodos referidos acerca dos seguintes aspectos: quantidade de estabelecimentos, proporção de estabelecimentos com vínculo de complementaridade com o SUS, principais tipos de estabelecimentos, disponibilidade de leitos hospitalares para o SUS, variações por níveis de complexidade assistencial, distribuição de taxas de oferta por estados brasileiros, disponibilização de atividades de ensino e caracterização de vínculos empregatícios de servidores (somente para 2013). 


\begin{tabular}{|c|c|c|c|c|c|c|c|c|}
\hline \multirow{2}{*}{ Item } & \multicolumn{4}{|c|}{ Público-estatal } & \multirow{2}{*}{$\begin{array}{c}\text { Associações } \\
\text { civis sem fins } \\
\text { lucrativos } \\
\text { B }\end{array}$} & \multicolumn{3}{|c|}{ Privado } \\
\hline & A1 & $\mathrm{A} 2$ & A3 & A4 & & $\mathrm{C}$ & D & $\mathrm{E}$ \\
\hline $\begin{array}{l}\text { Número de } \\
\text { estabelecimentos } \\
\text { e taxa média de } \\
\text { incremento }\end{array}$ & $\begin{array}{l}\text { De } 42,2 \% \text { do } \\
\text { total em } 2005 \\
\text { para } 27,1 \% \text { em } \\
2013 . \text { Aumento } \\
\text { de } 41,4 \% \text { no } \\
\text { período. }\end{array}$ & $\begin{array}{l}\text { De } 0,3 \% \text { do } \\
\text { total em } 2005 \\
\text { para } 0,2 \% \text { em } \\
2013 . \text { Aumento } \\
\text { de } 52 \% \text { no } \\
\text { período. }\end{array}$ & $\begin{array}{l}\text { De } 0,5 \% \text { do } \\
\text { total em } 2005 \\
\text { para } 0,3 \% \text { em } \\
2013 . \text { Aumento } \\
\text { de } 48,3 \% \text { no } \\
\text { período. }\end{array}$ & $\begin{array}{l}\text { De } 0,1 \% \text { do } \\
\text { total em } 2005 \\
\text { para } 0,2 \% \text { em } \\
2013 . \text { Aumento } \\
\text { de } 302 \% \text { no } \\
\text { período. }\end{array}$ & $\begin{array}{l}\text { Cerca de } 0,1 \% \\
\text { do total em } \\
2005 \text { e } 2013 \text {. } \\
\text { Aumento } \\
\text { de } 240 \% \text { no } \\
\text { período. }\end{array}$ & $\begin{array}{l}\text { De } 4,3 \% \text { do total } \\
\text { em } 2005 \text { para } \\
3,4 \% \text { em } 2013 \text {. } \\
\text { Aumento de } 75 \% \\
\text { no período. } \\
\text { Pessoa física: } 1 / 3 \\
\text { do total. }\end{array}$ & $\begin{array}{l}\text { De } 52,5 \% \text { do } \\
\text { total em } 2005 \\
\text { para } 68,6 \% \text { em } \\
2013 . \text { Aumento } \\
\text { de } 188 \% \text { no } \\
\text { período. } \\
\text { Pessoa física: } \\
\text { de } 47,7 \% \text { para } \\
52,7 \% \text {. }\end{array}$ & $\begin{array}{l}\text { - De } 0,05 \% \text { do } \\
\text { total em } 2005 \\
\text { para } 0,01 \% \text { em } \\
2013 . \text { Aumento } \\
\text { de } 2.144 \% \text { no } \\
\text { período. } \\
\text { - } 100 \% \text { pessoas } \\
\text { jurídicas (PJ) para } \\
2005 \text { e } 2013 \text {. }\end{array}$ \\
\hline $\begin{array}{l}\text { Proporção de } \\
\text { estabelecimentos } \\
\text { com vínculo de } \\
\text { complementaridade } \\
\text { com o SUS }\end{array}$ & $\begin{array}{l}\text { De } 99,4 \% \text { em } \\
2005 \text { para } \\
99,6 \% \text { em } \\
2013 .\end{array}$ & $\begin{array}{l}\text { De } 88,4 \% \text { em } \\
2005 \text { para } \\
85,9 \% \text { em } \\
2013 .\end{array}$ & $\begin{array}{l}\text { De } 97,7 \% \text { em } \\
2005 \text { para } \\
94,5 \% \text { em } \\
2013 .\end{array}$ & $\begin{array}{l}\text { De } 96,2 \% \text { em } \\
2005 \text { para } 97,7 \% \\
\text { em } 2013 \text {. }\end{array}$ & $\begin{array}{l}\text { De } 96,8 \% \text { em } \\
2005 \text { para } \\
94,4 \% \text { em } 2013 .\end{array}$ & $\begin{array}{l}\text { De } 60 \% \text { em } 2005 \\
\text { para } 40 \% \text { em } \\
2013 . \\
\text { Somente PJ: de } \\
99 \% \text { para } 71 \% .\end{array}$ & $\begin{array}{l}\text { De } 14,6 \% \text { em } \\
2005 \text { para } 6,5 \% \\
\text { em } 2013 . \\
\text { Somente PJ: } \\
\text { de } 86,7 \% \text { para } \\
47,1 \% \text {. }\end{array}$ & $\begin{array}{l}\text { - De } 44,4 \% \text { em } \\
2005 \text { para } 3,6 \% \\
\text { em } 2013 . \\
\text { - Somente PJ: de } \\
\text { 100\% para 50,8\%. }\end{array}$ \\
\hline $\begin{array}{l}\text { Principais tipos de } \\
\text { estabelecimentos }\end{array}$ & $\begin{array}{l}\text { Ambulatórios } \\
\text { de atenção } \\
\text { básica, } \\
\text { unidades de } \\
\text { vigilância em } \\
\text { saúde, hospitais } \\
\text { gerais, Centros } \\
\text { de Atenção } \\
\text { Psicossocial e } \\
\text { laboratórios } \\
\text { públicos. }\end{array}$ & $\begin{array}{l}\text { Centros } \\
\text { de saúde, } \\
\text { hospitais gerais } \\
\text { (notadamente } \\
\text { hospitais } \\
\text { universitários) } \\
\text { e consultórios } \\
\text { isolados. }\end{array}$ & $\begin{array}{l}\text { Centros } \\
\text { de saúde, } \\
\text { hospitais } \\
\text { gerais, } \\
\text { unidades } \\
\text { móveis de } \\
\text { atendimento } \\
\text { pré-hospitalar } \\
\text { de urgência } \\
\text { e centros de } \\
\text { especialidades } \\
\text { médicas. }\end{array}$ & $\begin{array}{l}\text { Centros de } \\
\text { saúde, unidades } \\
\text { móveis de } \\
\text { atendimento } \\
\text { pré-hospitalar de } \\
\text { urgência, centros } \\
\text { de especialidades } \\
\text { médicas e } \\
\text { serviços de apoio } \\
\text { diagnóstico e } \\
\text { terapêutico. }\end{array}$ & $\begin{array}{l}\text { Unidades de } \\
\text { urgência e } \\
\text { emergência } \\
\text { e centros } \\
\text { de atenção } \\
\text { hemoterápica. }\end{array}$ & $\begin{array}{l}\text { - Complementar: } \\
\text { hospitais gerais, } \\
\text { hospitais } \\
\text { especializados, } \\
\text { unidades mistas e } \\
\text { centros de parto } \\
\text { normal. } \\
\text { - Suplementar: } \\
\text { consultórios } \\
\text { isolados e } \\
\text { policlínicas }\end{array}$ & $\begin{array}{l}\text { - Complementar: } \\
\text { hospitais gerais, } \\
\text { hospitais } \\
\text { especializados } \\
\text { e unidades } \\
\text { de apoio em } \\
\text { diagnose e } \\
\text { terapia. } \\
\text { - Suplementar: } \\
\text { consultórios } \\
\text { isolados, centros } \\
\text { de especialidades } \\
\text { médicas, } \\
\text { policlínicas } \\
\text { e pronto } \\
\text { atendimento }\end{array}$ & \\
\hline $\begin{array}{l}\text { Serviços hospitalares: } \\
\text { disponibilidade de } \\
\text { leitos para o SUS }\end{array}$ & $\begin{array}{l}\text { 98\% dos leitos } \\
\text { disponíveis } \\
\text { ao SUS no } \\
\text { período. }\end{array}$ & $\begin{array}{l}\text { De } 83,5 \% \\
\text { dos leitos } \\
\text { disponíveis ao } \\
\text { SUS em } 2005 \\
\text { para } 61,5 \% \text { em } \\
2013 .\end{array}$ & $\begin{array}{l}\text { Cerca de } \\
95 \% \text { de leitos } \\
\text { disponíveis } \\
\text { ao SUS no } \\
\text { período. }\end{array}$ & $\begin{array}{l}\text { Cerca de } 92 \% \text { de } \\
\text { leitos disponíveis } \\
\text { ao SUS no } \\
\text { período. }\end{array}$ & $\begin{array}{l}\text { De } 99 \% \text { de leitos } \\
\text { disponíveis ao } \\
\text { SUS em } 2005 \\
\text { para } 96,5 \% \text { em } \\
2013 .\end{array}$ & $\begin{array}{l}\text { De } 75 \% \text { de leitos } \\
\text { disponíveis ao } \\
\text { SUS em } 2005 \text { para } \\
70 \% \text { em } 2013 \text {. }\end{array}$ & $\begin{array}{l}\text { De } 56,5 \% \text { de } \\
\text { leitos disponíveis } \\
\text { ao SUS em } 2005 \\
\text { para } 36 \% \text { em } \\
2013 .\end{array}$ & $\begin{array}{l}\text { De } 100 \% \text { em } 2005 \\
\text { para } 43 \% \text { em } \\
2013 .\end{array}$ \\
\hline
\end{tabular}


Quadro 5 - Caracterização dos segmentos institucionais de gestão em saúde com base em análise tendencial retrospectiva. Brasil 2005-2013 (cont.)

\begin{tabular}{|c|c|c|c|c|c|c|c|c|}
\hline \multirow{2}{*}{ Item } & \multicolumn{4}{|c|}{ Público-estatal } & \multirow{2}{*}{$\begin{array}{c}\text { Associações } \\
\text { civis sem fins } \\
\text { lucrativos } \\
\text { B }\end{array}$} & \multicolumn{3}{|c|}{ Privado } \\
\hline & A1 & A2 & A3 & A4 & & $\mathrm{C}$ & $\mathrm{D}$ & $\mathrm{E}$ \\
\hline $\begin{array}{l}\text { Proporção de } \\
\text { estabelecimentos que } \\
\text { mantêm vínculos com } \\
\text { o SUS sob gestão } \\
\text { municipal, estadual, } \\
\text { gestão dupla e outras } \\
\text { formas de gestão } \\
\text { (informados) }\end{array}$ & $\begin{array}{l}\text { Municipal: de } \\
71 \% \text { em } 2005 \\
\text { para } 89 \% \text { em } \\
2013 . \\
\text { Estadual: de } \\
3,5 \% \text { em } 2005 \\
\text { para 3,7\% em } \\
2013 . \\
\text { Dupla e outras } \\
\text { formas: de } \\
24,2 \% \text { em } 2005 \\
\text { para } 7,2 \% \text { em } \\
2013 .\end{array}$ & $\begin{array}{l}\text { Municipal: de } \\
67,3 \% \text { em } 2005 \\
\text { para } 72,2 \% \text { em } \\
2013 . \\
\text { Estadual: de } \\
\text { 12,2\% em } 2005 \\
\text { para 18,8\% em } \\
2013 . \\
\text { Dupla e outras } \\
\text { formas: de } \\
\text { 19,9\% em } 2005 \\
\text { para } 9 \% \text { em } \\
2013 .\end{array}$ & $\begin{array}{l}\text { Municipal: } \\
\text { de } 68,2 \% \text { em } \\
2003 \text { para } \\
75,2 \% \text { em } \\
2013 . \\
\text { Estadual: de } \\
\text { 11\% em } 2005 \\
\text { para 16,3\% em } \\
2013 . \\
\text { Dupla e outras } \\
\text { formas: de } \\
\text { 20,4\% em } \\
\text { 2005 para } \\
\text { 8,5\% em } 2013 .\end{array}$ & $\begin{array}{l}\text { Municipal: de } \\
69 \% \text { em } 2003 \\
\text { para } 79,4 \% \text { em } \\
2013 . \\
\text { Estadual: de } \\
\text { 10,4\% em } 2005 \\
\text { para } 12,2 \% \text { em } \\
2013 . \\
\text { Dupla e outras } \\
\text { formas: de } 19 \% \\
\text { em } 2005 \text { para } \\
8,4 \% \text { em } 2013 .\end{array}$ & $\begin{array}{l}\text { Municipal: de } \\
62 \% \text { em } 2003 \\
\text { para 54,4\% em } \\
2013 . \\
\text { Estadual: de } \\
6,3 \% \text { em } 2005 \\
\text { para 40,5\% em } \\
2013 . \\
\text { Dupla e outras } \\
\text { formas: de } \\
30,2 \% \text { em } 2005 \\
\text { para 5,1\% em } \\
2013\end{array}$ & $\begin{array}{l}\text { Municipal: de } 56 \% \\
\text { em } 2003 \text { para } \\
78,2 \% \text { em } 2013 . \\
\text { Estadual: de } \\
\text { 17,4\% em } 2005 \\
\text { para } 13,2 \% \text { em } \\
2013 . \\
\text { Dupla e outras } \\
\text { formas: de } 25 \% \\
\text { em } 2005 \text { para } \\
\text { 8,6\% em } 2013 \text {. }\end{array}$ & $\begin{array}{l}\text { Municipal: de } \\
\text { 44,4\% em } 2003 \\
\text { para } 91,8 \% \text { em } \\
2013 . \\
\text { Estadual: de } \\
\text { 44,4\% em } 2005 \\
\text { para 5,7\% em } \\
2013 . \\
\text { Dupla e outras } \\
\text { formas: de } 11,1 \% \\
\text { em } 2005 \text { para } \\
0,5 \% \text { em } 2013 .\end{array}$ & $\begin{array}{l}\text { Municipal: de } 73 \% \\
\text { em } 2003 \text { para } \\
90,4 \% \text { em } 2013 \text {. } \\
\text { Estadual: de } 10,6 \% \\
\text { em } 2005 \text { para } \\
6,2 \% \text { em } 2013 \text {. } \\
\text { Dupla e outras } \\
\text { formas: de } 14,8 \% \\
\text { em } 2005 \text { para } \\
3,3 \% \text { em } 2013 \text {. }\end{array}$ \\
\hline $\begin{array}{l}\text { Variações por níveis } \\
\text { de complexidade } \\
\text { assistencial } \\
\text { (informados) }\end{array}$ & $\begin{array}{l}\text { Atenção } \\
\text { básica: de } \\
\text { 51,3\% (2005) } \\
\text { para 42,8\% } \\
\text { (2013). } \\
\text { Média } \\
\text { complexidade } \\
\text { (MC): de } \\
\text { 44,3\% (2005) } \\
\text { para 43,4\% } \\
\text { (2013). } \\
\text { Alta } \\
\text { complexidade } \\
\text { (AC): de 4,3\% } \\
\text { (2005) para } \\
\text { 5,9\% (2013). }\end{array}$ & $\begin{array}{l}\text { A. básica: de } \\
\text { 46,4\% (2005) } \\
\text { para 43,2\% } \\
\text { (2013). } \\
\text { MC: de 40,8\% } \\
\text { (2005) para } \\
\text { 43,6\% (2013). } \\
\text { AC: de 12,8\% } \\
\text { (2005) para } \\
\text { 8,4\% (2013). }\end{array}$ & $\begin{array}{l}\text { A. básica: de } \\
14,6 \%(2005) \\
\text { para } 15,8 \% \\
(2013) . \\
\text { MC: de } \\
54,8 \%(2005) \\
\text { para } 55,2 \% \\
(2013) . \\
\text { AC: de } 30,5 \% \\
(2005) \\
\text { para } 26,4 \% \\
(2013) .\end{array}$ & $\begin{array}{l}\text { A. básica: de } \\
45,1 \%(2005) \\
\text { para } 22,7 \% \\
(2013) . \\
\text { MC: de 43,1\% } \\
\text { (2005) para } \\
58 \%(2013) . \\
\text { AC: de } 11,8 \% \\
\text { (2005) para } \\
8,6 \%(2013) .\end{array}$ & $\begin{array}{l}\text { A. Básica: de } \\
\text { 39,3\% (2005) } \\
\text { para 15,8\% } \\
\text { (2013). } \\
\text { MC: de 36,1\% } \\
\text { (2005) para } \\
\text { 59,1\% (2013). } \\
\text { AC: de 24,6\% } \\
\text { (2005) para } \\
21,2 \%(2013) .\end{array}$ & $\begin{array}{l}\text { A. Básica: de } \\
\text { 12,5\% (2005) } \\
\text { para 5\% (2013). } \\
\text { MC: de 61,8\% } \\
\text { (2005) para } \\
\text { 60,6\% (2013) } \\
\text { AC: de 24,2\% } \\
\text { (2005) para } \\
\text { 31,4\% (2013). }\end{array}$ & $\begin{array}{l}\text { A. Básica: de } \\
7,2 \%(2005) \\
\text { para } 2,9 \% \\
(2013) . \\
\text { MC: de } 67,2 \% \\
\text { (2005) para } \\
73,6 \%(2013) . \\
\text { AC: de } 25,6 \% \\
(2005) \text { para } \\
22,8 \%(2013) .\end{array}$ & $\begin{array}{l}\text { A. Básica: de } \\
\text { 0\% (2005) para } \\
\text { 14,4\% (2013). } \\
\text { MC: de } 50 \% \\
\text { (2005) para } \\
\text { 71,4\% (2013) } \\
\text { AC: de } 50 \% \\
\text { (2005) para } \\
\text { 14,3\% (2013). }\end{array}$ \\
\hline $\begin{array}{l}\text { Distribuição } \\
\text { geográfica das } \\
\text { taxas de oferta por } \\
10.000 \text { habitantes* }\end{array}$ & $\begin{array}{l}\text { Média } \\
\text { nacional: de } \\
2,8(2005) \\
\text { para } 3,6 \\
\text { (2013). } \\
\text { Maiores taxas } \\
\text { nos estados de } \\
\text { RR, PI e PB. }\end{array}$ & $\begin{array}{l}\text { Média } \\
\text { nacional: de } \\
\text { 1,7 (2005) } \\
\text { para 2,2 } \\
\text { (2013). } \\
\text { Maiores taxas } \\
\text { nos estados de } \\
\text { RR, AC, MA e } \\
\text { MG. }\end{array}$ & $\begin{array}{l}\text { Média } \\
\text { nacional: de } \\
3,0(2005) \\
\text { para 4,1 } \\
(2013) . \\
\text { Maiores taxas } \\
\text { nos estados } \\
\text { de PR, MG, PI } \\
\text { e SE. }\end{array}$ & $\begin{array}{l}\text { Média nacional: } \\
\text { de } 5,5 \text { (2005) } \\
\text { para } 21,1 \\
(2013) \text {. } \\
\text { Maiores taxas } \\
\text { nos estados de } \\
\text { RN, RR e MT. }\end{array}$ & $\begin{array}{l}\text { Média } \\
\text { nacional: de } \\
5,5(2005) \\
\text { para 10,2 } \\
(2013) . \\
\text { Maiores taxas } \\
\text { nos estados de } \\
\text { MS, MG, SC, } \\
\text { BA, MT, e RR. }\end{array}$ & $\begin{array}{l}\text { Média nacional: } \\
\text { de 2,8 (2005) } \\
\text { para 4,5 (2013). } \\
\text { Maiores taxas } \\
\text { nos estados de } \\
\text { SC, DF, MG, PR } \\
\text { e RS. }\end{array}$ & $\begin{array}{l}\text { Média nacional: } \\
\text { de 3,4 (2005) } \\
\text { para 9,1 (2013). } \\
\text { Maiores taxas } \\
\text { nos estados de } \\
\text { RS, SC, PR, DF, } \\
\text { SP, MG, ES, MS } \\
\text { e MT. }\end{array}$ & $\begin{array}{l}\text { Média nacional } \\
\text { de taxa de } \\
\text { cobertura de } \\
\text { planos de saúde: } \\
25 \% \text { em } 2013 . \\
\text { Maiores taxas nos } \\
\text { estados de SP, DF, } \\
\text { RJ, ES, MG, PR, } \\
\text { SC e RS. }\end{array}$ \\
\hline
\end{tabular}


Quadro 5 - Caracterização dos segmentos institucionais de gestão em saúde com base em análise tendencial retrospectiva. Brasil 2005-2013 (cont.)

\begin{tabular}{|c|c|c|c|c|c|c|c|c|}
\hline \multirow{2}{*}{ Item } & \multicolumn{4}{|c|}{ Público-estatal } & \multirow{2}{*}{$\begin{array}{l}\text { Associações } \\
\text { civis sem fins } \\
\text { lucrativos } \\
\text { B }\end{array}$} & \multicolumn{3}{|c|}{ Privado } \\
\hline & A1 & A2 & A3 & A4 & & C & D & $\mathrm{E}$ \\
\hline $\begin{array}{l}\text { Disponibilização de } \\
\text { atividades de ensino }\end{array}$ & $\begin{array}{l}\text { Cerca de } 2 \% \text { do } \\
\text { total em } 2005 \text { e } \\
2013 .\end{array}$ & $\begin{array}{l}\text { De } 17 \% \text { do } \\
\text { total em } 2005 \\
\text { para } 12 \% \text { em } \\
2013 .\end{array}$ & $\begin{array}{l}\text { De } 25 \% \text { do } \\
\text { total em } 2005 \\
\text { para } 20 \% \text { em } \\
2013 .\end{array}$ & $\begin{array}{l}\text { De } 9 \% \text { do total } \\
\text { em } 2005 \text { para } \\
3 \% \text { em } 2013 .\end{array}$ & $\begin{array}{l}\text { De } 11 \% \text { do total } \\
\text { em } 2005 \text { para } \\
6 \% \text { em } 2013 .\end{array}$ & $\begin{array}{l}\text { De } 11 \% \text { do total } \\
\text { em } 2005 \text { para } 6 \% \\
\text { em } 2013 .\end{array}$ & $\begin{array}{l}\text { Cerca de } 0,5 \% \text { do } \\
\text { total em } 2005 \text { e } \\
2013 .\end{array}$ & $\begin{array}{l}\text { De } 0 \% \text { em } 2005 \\
\text { para } 1 \% \text { em } 2013 .\end{array}$ \\
\hline $\begin{array}{l}\text { Caracterização } \\
\text { de vínculos } \\
\text { empregatícios dos } \\
\text { profissionais em } 2013\end{array}$ & $\begin{array}{l}\text { Estatutários: } \\
40,9 \% \\
\text { Temporários: } \\
25,5 \% \\
\text { CLT: } 13,7 \% \\
\text { Autônomos: } \\
\text { 10,4\% } \\
\text { Comissionados: } \\
\text { 1,2\% } \\
\text { Cooperativados: } \\
\text { 0,7\% } \\
\text { Contratos } \\
\text { verbais ou } \\
\text { informais: } 0,5 \% \\
\text { Outros } \\
\text { subtipos:1,1\% } \\
\text { S/I: } 6 \%\end{array}$ & $\begin{array}{l}\text { Estatutários: } \\
\text { 42,7\% } \\
\text { Temporários: } \\
8,6 \% \\
\text { CLT: 7,8\% } \\
\text { Autônomos: } \\
8,9 \% \\
\text { Comissionados: } \\
\text { 0,2\% } \\
\text { Cooperativados: } \\
\text { 0,4\% } \\
\text { Contratos } \\
\text { verbais ou } \\
\text { informais: } 0,8 \% \\
\text { Outros } \\
\text { subtipos:12,8\% } \\
\text { S/I: } 17,8 \%\end{array}$ & $\begin{array}{l}\text { Estatutários: } \\
35,7 \% \\
\text { Temporários: } \\
12 \% \\
\text { CLT: } 24,5 \% \\
\text { Autônomos: } \\
\text { 9,9\% } \\
\text { Comissiona- } \\
\text { dos: 0,7\% } \\
\text { Cooperativa- } \\
\text { dos: 0,4\% } \\
\text { Contratos } \\
\text { verbais ou } \\
\text { informais: } \\
\text { 0,5\% } \\
\text { Outros } \\
\text { subtipos: } \\
\text { 8,3\% } \\
\text { S/I: 8\% }\end{array}$ & $\begin{array}{l}\text { Estatutários: } \\
18 \% \\
\text { Temporários: } \\
\text { 18,7\% } \\
\text { CLT: } 26,5 \% \\
\text { Autônomos: } 7 \% \\
\text { Comissionados: } \\
\text { 0,9\% } \\
\text { Cooperativados: } \\
\text { 0,5\% } \\
\text { Contratos verbais } \\
\text { ou informais: } \\
\text { 0,6\% } \\
\text { Outros } \\
\text { subtipos:3,2\% } \\
\text { S/I: } 18,3 \%\end{array}$ & $\begin{array}{l}\text { Estatutários: } 0 \% \\
\text { Temporários: } \\
\text { 50,1\% } \\
\text { CLT: } 11,2 \% \\
\text { Autônomos: } \\
30 \% \\
\text { Comissionados: } \\
0 \% \\
\text { Cooperativados: } \\
\text { 0,3\% } \\
\text { Contratos } \\
\text { verbais ou } \\
\text { informais: } 0,1 \% \\
\text { Outros } \\
\text { subtipos: } 2,2 \% \\
\text { S/I: } 5 \%\end{array}$ & $\begin{array}{l}\text { Estatutários: 0\% } \\
\text { Temporários: } \\
\text { 5,2\% } \\
\text { CLT: 42,2\% } \\
\text { Autônomos: 36\% } \\
\text { Comissionados: } \\
0 \% \\
\text { Cooperativados: } \\
\text { 5,7\% } \\
\text { Contratos verbais } \\
\text { ou informais: } \\
\text { 1,3\% } \\
\text { Outros } \\
\text { subtipos: } 2,6 \% \\
\text { S/I: } 7 \%\end{array}$ & $\begin{array}{l}\text { Estatutários: 0\% } \\
\text { Temporários: } \\
6,4 \% \\
\text { CLT: } 22 \% \\
\text { Autônomos: 49\% } \\
\text { Comissionados: } \\
\text { 0\% } \\
\text { Cooperativados: } \\
\text { 0,6\% } \\
\text { Contratos verbais } \\
\text { ou informais: } \\
\text { 1,7\% } \\
\text { Outros } \\
\text { subtipos:11,2\% } \\
\text { S/I: 9,1\% }\end{array}$ & $\begin{array}{l}\text { Estatutários: } 0 \% \\
\text { Temporários: } 10 \% \\
\text { CLT: } 34 \% \\
\text { Autônomos: 36\% } \\
\text { Comissionados: 0\% } \\
\text { Cooperativados: } \\
\text { 0,6\% } \\
\text { Contratos verbais } \\
\text { ou informais: } 2,2 \% \\
\text { Outros } \\
\text { subtipos:12,5\% } \\
\text { S/I: 4,7\% }\end{array}$ \\
\hline
\end{tabular}

Fonte: Elaboração própria, com base em dados do DataSUS e CNES, 2013.

(*) Mapas em anexo

Legenda:

A1 - estatal, administração direta, setor governamental de Saúde

A2 - estatal, administração direta, outros órgãos

B - associações civis sem fins lucrativos

A3 - estatal, administração indireta, direito público

$\mathrm{C}$ - privado sem fins lucrativos

A4 - estatal, administração indireta, direito privado

D - privado com fins lucrativos

E - privado misto 
Por meio das informações do Quadro 5, é possível constatar que:

- Os tipos de estabelecimentos de saúde que predominam em cada segmento são diferentes. Na esfera pública estatal há predomínio de ambulatórios de atenção básica, unidades de vigilância em saúde, centros de atenção psicossocial, laboratórios públicos, hospitais gerais, centros de saúde, unidades móveis pré-hospitalares e centros de especialidades médicas. Na esfera privada o destaque é para os serviços de atenção hospitalar geral e especializada (complementar ao SUS) e para os consultórios isolados, policlínicas e centros de especialidades (na saúde suplementar).

- Houve aumento absoluto no número de estabelecimentos cadastrados no CNES em todos os segmentos, mas esse aumento foi bastante desigual. Como resultado, a proporção de estabelecimentos públicos em relação ao total caiu, principalmente os serviços de saúde da administração direta. De modo inverso, a proporção de estabelecimentos do setor privado aumentou no período, com destaque para aqueles com fins lucrativos (incluindo pessoa física).

- Houve redução na proporção de estabelecimentos com vínculos de complementaridade com o SUS (venda de serviços) em todos os segmentos, especialmente os privados com fins lucrativos e privados mistos.

- A grande maioria dos leitos hospitalares da esfera pública (estatal e não estatal) e dos estabelecimentos privados sem fins lucrativos está disponível para o SUS, mas com redução entre os estabelecimentos dos outros órgãos da administração direta, do segmento de associações civis sem fins lucrativos e do privado filantrópico. Por outro lado, os estabelecimentos privados lucrativos reduziram bastante a proporção de leitos disponíveis para o SUS no período (de $56 \%$ para $36 \%$ ).

- Houve aumento da proporção de estabelecimentos que mantêm vínculos com o SUS sob gestão municipal em todos os segmentos, com exceção dos estabelecimentos da esfera pública não estatal, que inclui as organizações sociais de saúde. Nesse último caso, o que ocorreu foi o aumento dos estabelecimentos sob gestão estadual.

- Serviços de atenção básica estão mais presentes no segmento público estatal, embora seja interessante notar que houve aumento na proporção desse tipo de serviço entre os estabelecimentos privados mistos e redução proporcional na esfera pública.

- Serviços de média complexidade são predominantes em todos os segmentos institucionais, com destaque para os estabelecimentos privados com fins lucrativos e privados mistos; pouco mais de 70\% dos seus estabelecimentos estão concentrados nesse nível de complexidade assistencial. Além disso, o segmento de associações civis sem fins lucrativos apresentou grande variação positiva nesse tipo de serviço no período (de 36\% para 51\%).

- Serviços de alta complexidade representam uma proporção importante dos estabelecimentos da esfera privada, especialmente os filantrópicos (31\%) e lucrativos (23\%). Também são importantes nos estabelecimentos do segmento A3 - serviços do SUS pertencentes à administração indireta e que se submetem às regras do direito público (26\%) e no segmento de associações civis sem fins lucrativos $(21,2 \%)$.

- As taxas de oferta de serviços no território nacional possibilitam fazer duas constatações. A primeira é que houve aumento da oferta em todos os segmentos institucionais, com destaque 
para os seguintes segmentos: A4 - serviços do SUS pertencentes à administração indireta e que se submetem às regras do direito privado (de 5,5 para 21,1 por 10.000 habitantes); associações civis sem fins lucrativos (de 5,5 para 10,2); e privado lucrativo (de 3,4 para 9,1). O segundo aspecto é que existe uma oferta maior de serviços públicos estatais em estados das regiões Norte e Nordeste, ao passo que a oferta de serviços privados está mais concentrada nos estados das regiões Sul, Sudeste e Centro-Oeste. Já os serviços públicos não estatais apresentam taxas mais elevadas em estados de todas as regiões do país - MS, MG, SC, MT, BA e RR.

Os vínculos empregatícios dos profissionais que atuam nos diferentes segmentos institucionais tendem a ser mais fortes e estáveis nos estabelecimentos da esfera pública estatal, com predomínio de vínculos estatuários (administração direta) e contratos CLT (administração indireta, direito privado), e mais frágeis nos demais estabelecimentos. Embora na esfera privada o percentual de profissionais com contrato CLT seja importante, variando de $22 \%$ a $42 \%$, a prestação de serviços (terceirização) é o vínculo predominante nos estabelecimentos privados lucrativos (49\%) e privados mistos (36\%). Os vínculos são ainda mais frágeis nos estabelecimentos da esfera pública não estatal, nos quais os contratos temporários representam 50\% e os profissionais autônomos 30\%.

Considerados os estabelecimentos em seu conjunto, observa-se que houve um incremento de 120,5\% dos estabelecimentos de saúde cadastrados no país entre 2005 e 2013 (Figura 2). Tal aumento foi mais proeminente no setor privado $(179,4 \%)$ que no setor público $(42,3 \%)$, o que, em parte, pode ser explicado por um maior número de cadastramentos de estabelecimentos privados de pessoas físicas (com fins lucrativos). Em termos proporcionais, aproximadamente $72 \%$ dos estabelecimentos cadastrados no CNES em 2013 eram do setor privado.

No setor público há realce no incremento de cadastros de estabelecimentos nos segmentos "A4estatal de administração indireta sob a égide de direito privado" (301,2\%) e "B- associações civis sem fins lucrativos sob a égide de direito privado" (240,2\%). Tal incremento é significativamente maior do que os ocorridos nos demais segmentos do setor público (média de 42\%). Embora a proporção de estabelecimentos cadastrados nesses dois segmentos ainda seja pequena em relação ao total, respectivamente $0,16 \%$ (A4) e 0,09\% (B), observa-se uma maior inflexão tendencial de incremento no período considerado.

Do ponto de vista da divisão dos estabelecimentos nos dois ramos do direito, observa-se que o incremento de cadastramentos para estabelecimentos sob a égide do direito público foi de 40,6\% no período, ao passo que dentre aqueles cadastrados sob a égide do direito privado o crescimento foi de $180 \%$. 
Figura 2 - Incremento proporcional do número de estabelecimentos de saúde cadastrados, de acordo com os setores e segmentos institucionais. Brasil -2005-2013

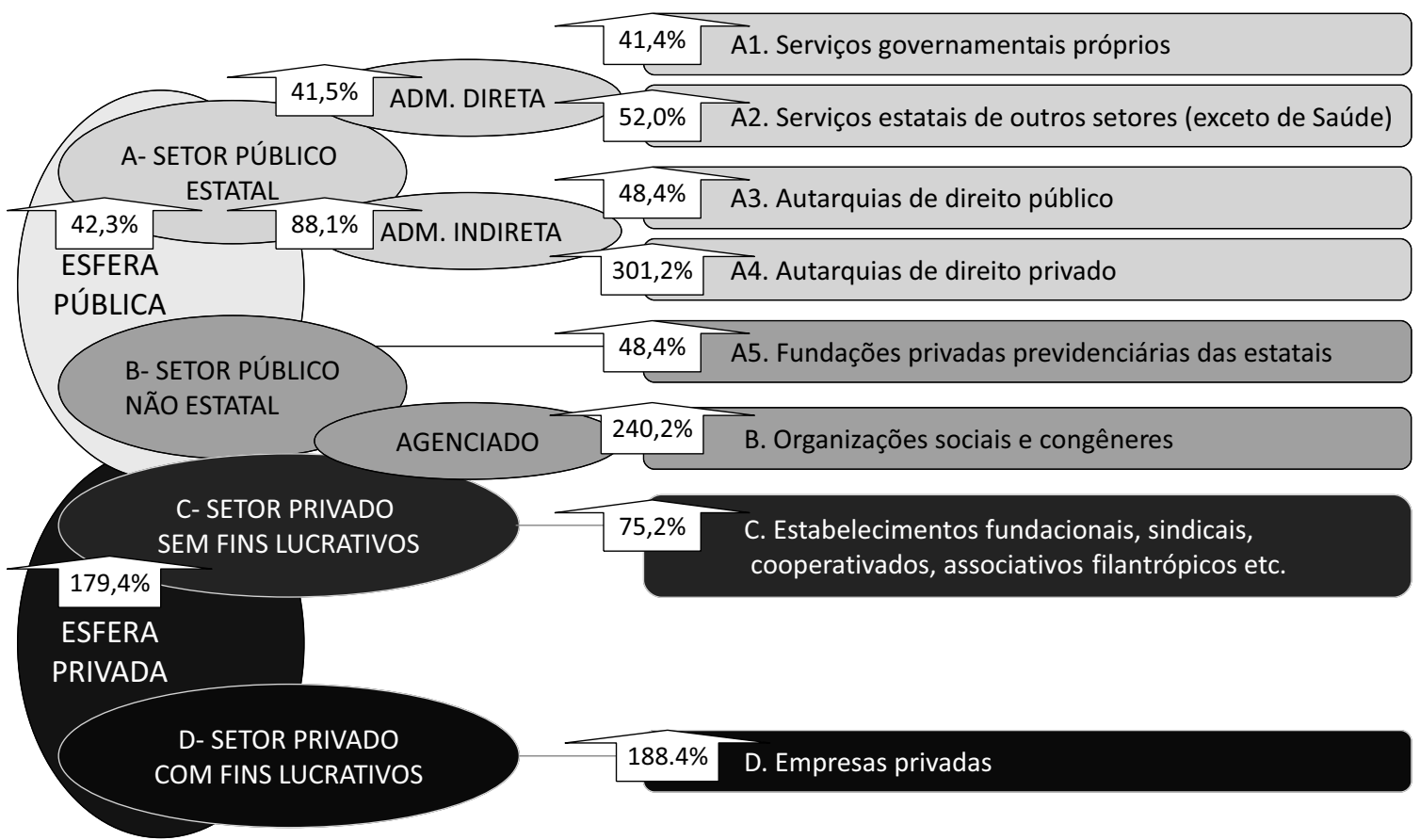

Fonte: Elaboração própria, com base em dados do DataSUS e CNES, 2013.

Com base nas variações observadas, é possível calcular a taxa média de crescimento anual para cada segmento institucional. Essas taxas podem ser visualizadas no Gráfico 1, de acordo com o qual a taxa de crescimento para o conjunto dos estabelecimentos de saúde no período foi de $10,6 \%$. A taxa também é positiva para cada um dos segmentos separadamente, embora o incremento não tenha sido o mesmo para todos os tipos de estabelecimentos. Quatro segmentos apresentaram taxas médias de incremento anual superior à média total: A4 (19\%,1); B (17,2\%); A3 (16,6\%); e D (14,9\%). Por outro lado, apresentaram crescimento abaixo da média os segmentos A1 (4,5\%), A2 (5,4\%) e C (7,4\%). 
Gráfico 1 - Taxas médias de incremento anual de estabelecimentos de saúde cadastrados (CNES), de acordo com segmentos institucionais. Brasil - 2005-2013

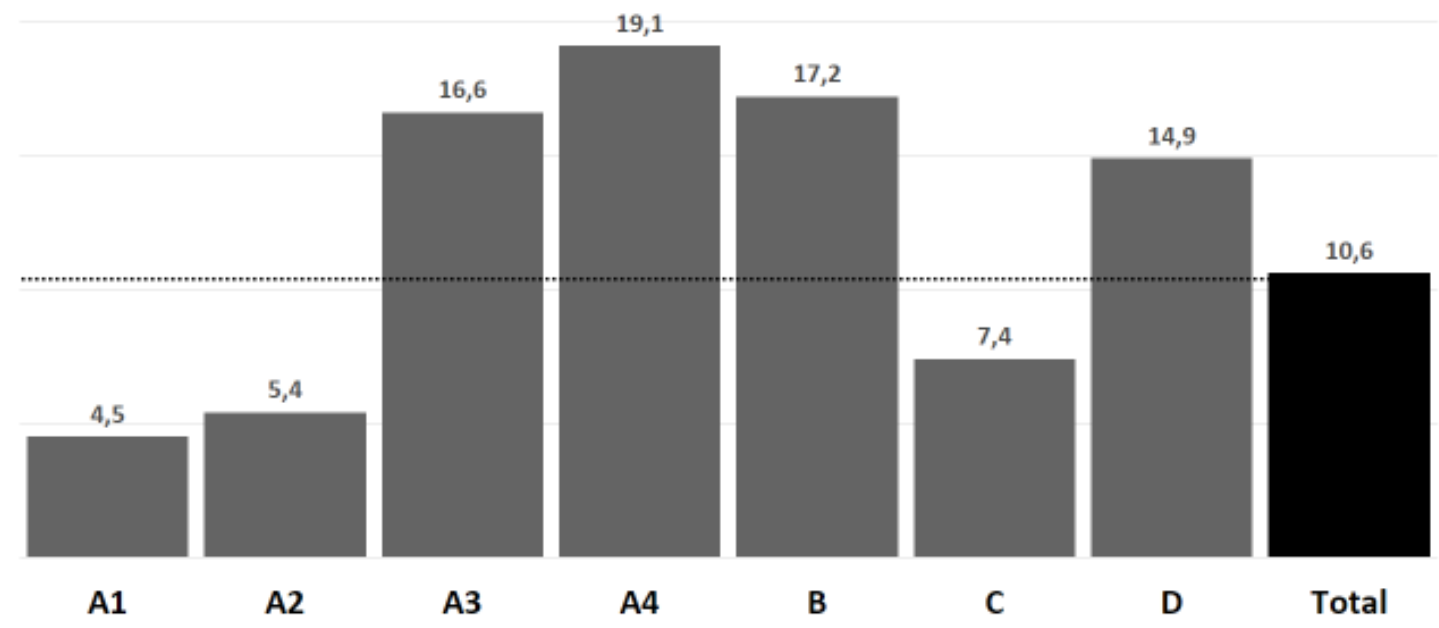

Fonte: Elaboração própria, com base em dados do DataSUS e CNES, 2013.

Considerando os aspectos tendenciais descritos retrospectivamente, denota-se, de modo mais enfático, a diminuição do peso proporcional de segmentos institucionais de gestão em saúde sob a égide administrativa do direito público, com a contrapartida de crescimento daqueles sob a égide do direito privado que já eram predominantes no conjunto. Tal tendência também se expressa para tais setores e segmentos sob a égide do direito público ou privado quando considerados especificamente os estabelecimentos com vínculo de complementaridade com o SUS.

No setor estatal, evidencia-se particularmente a tendência para o incremento de estabelecimentos sob a égide do direito privado (como empresas públicas e fundações estatais), o que, hipoteticamente, pode ser associado a alguns fatores que têm produzido constrangimentos para a expansão de serviços estatais de saúde sob a égide do direito público, tais como: subfinanciamento do setor estatal da administração direta; preponderância de transferências de recursos financeiros federais vinculados a determinadas estratégias programáticas; e limite proporcional de gastos com pessoal estabelecido pela Lei de Responsabilidade Fiscal.

Conforma-se gradualmente uma instância híbrida, a partir de segmentos públicos sob a égide do direito privado, pela confluência de serviços estatais da administração indireta (principalmente empresas públicas, fundações estatais) e serviços públicos não estatais (organizações sociais, Oscips etc.), fenômeno já identificado internacionalmente, cujas instâncias congêneres são denominadas como de "quase-mercados" (Grand, 1991; Feiok, 1998). Atualmente ainda é pequena a quantidade de serviços sob gestão pública e égide do direito privado (estatais e não estatais), mas convém realçar que os segmentos com tal característica são aqueles com maiores taxas de incremento anual e tendência 
de distribuição mais abrangente nos estados brasileiros (sem associação específica com governos de determinados partidos políticos ou outras características e conotações de natureza político-partidária).

Convém também realçar a expansão de estabelecimentos privados com fins lucrativos (D), notadamente de pessoas físicas, segmento atualmente preponderante e tendendo a um aumento proporcional ainda mais significativo nos próximos anos. Como esse segmento é o de menor vinculação complementar com o SUS (em 2013, somente 6,4\% de seus estabelecimentos), o que se projeta é a expansão de serviços suplementares, especialmente aqueles vinculados às operadoras de planos de saúde.

No caso do segmento privado sem fins lucrativos (C), o tipo de estabelecimento com tendência mais proeminente para incremento são aqueles cooperativados, principalmente as cooperativas de especialidade médicas que oferecem planos de saúde, tipo de organização que mais cresceu no período.

Acerca da distribuição de estabelecimentos de saúde de acordo com os níveis de complexidade assistencial, observa-se outra forma de segmentação, com predominância de serviços de atenção básica e de alta complexidade no setor público, estando o setor privado com a predominância de serviços de média complexidade (notadamente ambulatórios de especialidades médicas e serviços de apoio diagnóstico e terapêutico). Tal característica se torna ainda mais evidente quando se trata especificamente do conjunto de estabelecimentos vinculados ao SUS. Há uma significativa concentração de serviços de média complexidade vinculados complementarmente ao SUS nas regiões Sul e Sudeste.

Uma característica proeminente na atual configuração organizacional e logística dos setores público e privado de saúde e de seus segmentos institucionais é a ausência de integralidade da atenção. Há prescrição normativa e constitucional de integração de respostas sistêmicas e reticulares, com componentes institucionais (políticas, estratégias, ações etc.) de promoção, proteção e recuperação (assistência e reabilitação) da saúde para lidar com determinantes múltiplos, imbricados e complexos; situações e condições desiguais de risco e vulnerabilidade; decorrências e eventos também complexos etc. Do modo como os setores e segmentos institucionais de saúde estão organizados existe grande ênfase no componente médico-assistencial e correspondente defasagem estrutural nos componentes de proteção e, principalmente, de promoção da saúde. No modo de organização da institucionalidade privada essa desintegração da atenção se torna ainda mais evidente.

A setorização (pública, privada, pública-privada) e a segmentação de instituições prestadoras de serviços de saúde estão previstas constitucionalmente, assim como a pluralidade de instâncias de gestão institucional. Entretanto, trata-se de condição normativamente subordinada ao controle do poder público, com base em suas prerrogativas singulares de regulamentação, fiscalização e controle (artigo 197 da Constituição Federal - Brasil, 1988). Desse modo, a perspectiva constitucional versa sobre um pluralismo integrado sob a égide do poder público, o que põe em evidência a capacidade instituinte e regulatória do Estado brasileiro na ordenação, integração e coordenação dos diversos setores e segmentos institucionais.

Essa configuração tendencial retrospectiva acerca do tamanho e abrangência dos segmentos institucionais de gestão em saúde, quando projetada ao futuro em dinâmica inercial, ou seja, na perspectiva de que seus principais fatores determinantes e condicionantes não sejam significativamente alterados nos próximos anos, permite a projeção de um cenário mais provável em um horizonte de 
médio prazo. Se alguns dos hipotéticos fatores determinantes e condicionantes forem significativamente alterados nos próximos anos, também é possível a prospecção de configurações tendenciais distintas e cenários futuros alternativos. Algumas prospecções sumárias sobre aspectos do cenário decorrente da tendência inercial e sobre aspectos correspondentes a pelo menos dois cenários alternativos estão sumariamente descritas a seguir.

\section{Prospecção Sumária acerca de Cenários Futuros para os Segmentos Institucionais de Gestão em Saúde em Horizonte de Médio Prazo}

Em todas as tendências e cenários projetados para um horizonte de médio prazo, como até 2030, há convicção sobre a permanência de pluralismo segmentar na gestão institucional em saúde. A questão primordial que se apresenta se refere a uma caracterização sobre os prováveis tipos de pluralismo segmentar, levando-se em conta principalmente as razões, os meios e os modos implicados:

- a arquitetura segmentar, com os pesos, alcances e arranjos relativos de cada segmento institucional em função de seu provável tamanho e abrangência;

- a modelagem sistêmica e funcional de atenção à saúde, consideradas principalmente as diretrizes organizativas de hierarquização e regionalização;

- a preponderância normativa e administrativa de direito público ou privado;

- as vinculações e/ou interações com o SUS;

- o financiamento público direto e indireto;

- as vinculações empregatícias e características da força de trabalho;

- a competência e a capacidade de regulação estatal, intrínseca e extrínseca, e de controle público/social;

- os tipos preponderantes de governança sistêmica múltipla; e

- fatores diferenciais em âmbito setorial, ou seja, determinantes e condicionantes significativos intrínsecos ao setor Saúde que, uma vez mantidos ou modificados, podem consolidar ou alterar o curso de tendências e cenários futuros.

Em relação ao perfil e prioridades de problemas, necessidades e demandas de saúde para os próximos anos, optou-se por uma configuração tendencial comum para os três cenários projetados: o gradual aumento da expectativa de vida da população para outros patamares (transição demográfica) e a conjugação de eventos de causas variadas (tripla carga de doenças: agudas, crônicas e de causas externas) com proeminência de condições crônicas de evolução. Na perspectiva de tal tendência nos próximos anos os (sub)sistemas de saúde poderão estar estruturados e aptos a produzir respostas institucionais (bens, serviços etc.) compatíveis e coerentes com o perfil e as prioridades de demandas, com ênfase em reabilitação (recuperação) e medidas de apoio ao autocuidado (proteção) e de promoção da saúde, mas, também, com redes assistenciais regionalizadas. Como o referencial de tendência para demandas futuras é o mesmo para os três cenários projetados, o que se busca evidenciar são as possibilidades de reformas estruturantes para a conformação de um modelo de atenção integral compatível com a proposta do SUS. 
Além da abrangência institucional e setorial, existem múltiplos determinantes e condicionantes que podem alterar o intercurso da tendência assinalada para o perfil ou prioridades em termos de problemas, necessidades e demandas de serviços de saúde. Para o propósito específico dessa projeção de cenários, importa realçar que a tendência e cenário apontados como preponderantes para as demandas de serviços requerem inovações institucionais para aprimorar os meios, os modos e as capacidades de integração sistêmica e institucional para a produção de respostas compatíveis e impactantes que resultem na melhora das condições de saúde de indivíduos e populações. ${ }^{14}$

Um esquema sintético acerca de três prováveis cenários futuros pode ser visualizado na Figura 3: o pluralismo do empresariado sob a égide do direito privado (tendência inercial de agenciamento contratual com regulação produtiva); o pluralismo integrado sob a égide do direito público (tendência de inovação institucional focada na universalidade integral e equidade redistributiva); e o pluralismo mercantil sob a égide do direito privado (tendência de privatização subvencionada pelo poder público e regulação agenciada).

Figura 3 - Representação esquemática de três tendências e cenários possíveis para a configuração de institucionalidades de gestão em saúde no Brasil, horizonte de 2030

\section{EMPRESARIAMENTO MERCANTIL SUBVENCIONADO PELO ESTADO}

- Privatização com oligopólios mercantis, regulação contratual agenciada e ênfase na compra, oferta e consumo de tecnologias e serviços biomédicos assistenciais. Incremento de subvenções fiscais e em outras modalidades.

- Regulação "branda" e agenciada.

- Proeminência de capital estrangeiro. Preponderância na Atenção Especializada de serviços privados com fins lucrativos e suplementares ao SUS. Serviços públicos acessórios (transferência de custos) e complementares.

- Fragmentação com ênfase em assistência biomédica, sob governança operativa e contratuação procedimental.

\begin{tabular}{|c|c|}
\hline & $\begin{array}{c}\text { AGENCIAMENTO ESTATAL SOB A ÉGIDE } \\
\text { DO DIREITO PRIVADO }\end{array}$ \\
\hline $\begin{array}{l}\text { Tendência inercial } \\
\text { e cenário provável }\end{array}$ & $\begin{array}{l}\text { - Incremento de serviços qualificados como } \\
\text { públicos sob a égide do direito privado por meio }\end{array}$ \\
\hline $\begin{array}{l}\text { SUS COM “UNIVERSALISMO BÁSICO” E } \\
\text { "COMPLEMENTAR" AO SETOR PRIVADO }\end{array}$ & $\begin{array}{l}\text { interesse social e em parcerias público- } \\
\text { privadas. }\end{array}$ \\
\hline $\begin{array}{l}\text { - Provimento estatal para grupos de procedimentos de baixo } \\
\text { custo orçamentário e alta densidade populacional. Definição de } \\
\text { "pacotes básicos" de acesso universal e de "padrões de } \\
\text { integralidade" assistencial. Com a consolidação de "duplas filas" } \\
\text { e "duplas portas" de acessibilidade, constituem-se também vias }\end{array}$ & $\begin{array}{l}\text { - Oferta de "universalidade básica" e "padrões } \\
\text { de integralidade" em redes assistenciais } \\
\text { temáticas, segmentação com ênfase em } \\
\text { assistência biomédica, sob contratuação } \\
\text { procedimental e governança operativa. }\end{array}$ \\
\hline de transferências de custos do setor privado para o SUS. & - Provimento estatal com agenciamento de \\
\hline $\begin{array}{l}\text { - Subordinação aos modos de governança sistêmica e } \\
\text { procedimental, regulada pela política de diminuição de } \\
\text { "déficit primário". }\end{array}$ & $\begin{array}{l}\text { prerrogativas de gestão e autoridade sanitária, } \\
\text { regulação contratual com ênfase procedimental } \\
\text { na oferta e consumo de tecnologias e serviços } \\
\text { biomédicos assistenciais. }\end{array}$ \\
\hline
\end{tabular}

\footnotetext{
${ }^{14}$ Convém realçar que uma projeção de cenários com abrangência nacional configura contextualizações genéricas, pois pode haver concomitância ou confluência de mais de um cenário em distintas regiões e locais do país.
} 
O pluralismo do empresariado, de institucionalidade híbrida, sob a égide do direito privado (cenário I) está relacionado com uma dinâmica inercial de manutenção de vetores determinantes e condicionantes da institucionalidade da gestão em saúde. Essa tendência deve projetar um cenário futuro de consolidação da predominância quantitativa do segmento institucional privado com fins lucrativos, suplementar ao SUS e sob regulação estatal agenciada (ANS). Os tipos de estabelecimentos que mais devem crescer, em termos proporcionais e de abrangência de cobertura territorial e populacional, são: empresas públicas, fundações estatais e congêneres (segmento público estatal de administração indireta, sob a égide do direito privado) e organizações sociais, Oscips e congêneres (segmento de associações civis sem fins lucrativos). Para fins de prestação de serviços públicos, tais segmentos poderão conformar uma instância de quase-mercado regulada por relações contratuais (contratos de gestão, termos de parceria etc.) focadas na produção de procedimentos assistenciais. Denominamos esse tipo de vinculação contratual como "empresariamento" público, pois privilegia a gestão empresarial agenciada contratualmente e regulada em foco procedimental e produtivo.

O pluralismo integrado, de institucionalidade estatal, sob a égide do direito público (cenário II) depende da alteração substancial de fatores diferenciais em âmbito setorial, mas, sobremaneira, de fatores mais abrangentes, como reformas institucionais do Estado brasileiro (tributária, política etc.). Em âmbito setorial, requer inovações e reformas incrementais do setor público estatal, com ênfase e prioridade na institucionalidade sob a égide do direito público. Requer, ainda, maior provimento e melhor aporte de recursos financeiros, além de reforço na capacidade regulatória estatal e controle público/social. A arquitetura plural e segmentar estaria focada não somente em integração sistêmica como também social. Ocorreria substituição da hierarquização em níveis de complexidade assistencial por arranjos de poliarquia reticular de atenção integral, com ênfase redistributiva, visando produzir maior equidade. Universalidade integral com redes regionais de serviços, sob governança constitutiva e direcional, coordenação federativa, regulação forte e maior controle público/social. Em tal perspectiva, a capacidade regulatória estatal não estaria pautada somente em normatividade prescritiva e contratual (regulação agenciada e contratualizada), mas se daria principalmente pelo controle direto da maior parte dos serviços de saúde e da produção de insumos. Não se trataria de um processo de estatização, propriamente dito, mas de inovação na institucionalidade estatal, com maior provimento e melhor aporte de recursos financeiros para esse setor, além de reordenamento de processos de trabalho e maior integração de cargos e carreiras profissionais do SUS.

O pluralismo mercantil, de institucionalidade privada lucrativa (cenário III) apresenta como tendência projetada a privatização preponderante para o conjunto do sistema de saúde, com subvenções estatais para oligopólios mercantis de operadoras de planos de saúde, com regulação agenciada. O setor privado, filantrópico e lucrativo, além de manter a maior quantidade de estabelecimentos e serviços de saúde, obteria maior incremento proporcional, notadamente nas regiões metropolitanas do país. A característica mais significativa nesse cenário seria a inversão do sentido de complementaridade do setor privado ao setor público, ou seja, em tal perspectiva os segmentos institucionais públicos serviriam de suporte e complemento aos privados. A focalização dos serviços públicos em estratos populacionais de maiores riscos e vulnerabilidades seria outra característica marcante desse cenário. O Quadro 6 a seguir caracteriza os cenários segundo os itens considerados para sua projeção. 
Quadro 6 - Caracterização dos cenários para a configuração de institucionalidades de gestão em saúde no Brasil, horizonte de 2030

\begin{tabular}{|c|c|c|c|}
\hline Item & $\begin{array}{c}\text { Cenário I - Pluralismo do } \\
\text { empresariado, institucionalidade } \\
\text { híbrida e direito privado }\end{array}$ & $\begin{array}{c}\text { Cenário II - Pluralismo integrado, } \\
\text { institucionalidade estatal e direito } \\
\text { público }\end{array}$ & $\begin{array}{l}\text { Cenário III - Pluralismo mercantil, } \\
\text { institucionalidade e direito privados }\end{array}$ \\
\hline Arquitetura segmentar & $\begin{array}{l}\text { - Predominância do segmento institu- } \\
\text { cional privado com fins lucrativos. } \\
\text { - Incremento e consolidação de um } \\
\text { setor híbrido de quase mercado (por } \\
\text { meio da conjugação do segmento } \\
\text { estatal de administração indireta sob } \\
\text { égide do direito privado + segmento } \\
\text { de associações civis sem fins lucrati- } \\
\text { vos). } \\
\text { - Redução do segmento estatal de } \\
\text { administração direta (A1) em termos } \\
\text { proporcionais e de abrangência. }\end{array}$ & $\begin{array}{l}\text { - Ampliação proporcional dos segmentos } \\
\text { estatais da administração direta e nota- } \\
\text { damente da administração indireta sob } \\
\text { a égide de direito público (A4). } \\
\text { - Consolidação de nichos do setor priva- } \\
\text { do (filantrópico e lucrativo) com ênfase } \\
\text { em sua vinculação complementar ao } \\
\text { SUS. } \\
\text { - Maior ampliação do segmento estatal } \\
\text { de administração indireta sob a égide } \\
\text { do direito privado (A4) e segmento de } \\
\text { associações civis sem fins lucrativos na } \\
\text { produção de insumos. }\end{array}$ & $\begin{array}{l}\text { - Consolidação da predominância do } \\
\text { segmento institucional privado com } \\
\text { fins lucrativos. } \\
\text { - Incremento e consolidação de um } \\
\text { setor híbrido de quase mercado (por } \\
\text { meio da conjugação do segmento } \\
\text { estatal de administração indireta sob } \\
\text { égide do direito privado + segmento } \\
\text { de associações civis sem fins lucrati- } \\
\text { vos). Redução do segmento estatal de } \\
\text { administração direta (A1) em termos } \\
\text { proporcionais e de abrangência. } \\
\text { - Ampliação do segmento misto (E), } \\
\text { com ênfase no tipo específico de } \\
\text { parcerias público-privadas para inves- } \\
\text { timentos em serviços hospitalares e } \\
\text { ambulatoriais especializados. }\end{array}$ \\
\hline $\begin{array}{l}\text { Modelo de atenção à } \\
\text { saúde }\end{array}$ & $\begin{array}{l}\text { - Segmentação dos níveis de complexi- } \\
\text { dade assistencial, com padronização } \\
\text { da oferta de serviços e procedimentos } \\
\text { de acessibilidade universal, de acordo } \\
\text { com a disponibilidade de recursos } \\
\text { públicos e critérios de eficiência } \\
\text { (universalismo básico). } .^{15} \\
\text { - Integralidade em xeque em virtude } \\
\text { das diversas formas de segmentação } \\
\text { sistêmica e da fragmentação das } \\
\text { instâncias de gestão (notadamente } \\
\text { aquelas sob contratos públicos). } \\
\text { - Ênfase em arranjos público-privados, } \\
\text { híbridos ou combinados. }\end{array}$ & $\begin{array}{l}\text { - Ênfase na estruturação da atenção } \\
\text { básica como instância de coordenação } \\
\text { de redes de atenção integral à saúde. } \\
\text { - Inovações e criação de políticas, estraté- } \\
\text { gias, serviços e ações intersetoriais para } \\
\text { a promoção e proteção da saúde, para } \\
\text { além dos serviços de vigilância. } \\
\text { - Serviços de assistências organizados em } \\
\text { redes integradas, a partir de itinerários } \\
\text { de cuidado considerados prioritários em } \\
\text { distintas e diversas regiões. } \\
\text { - Universalidade no acesso aos serviços } \\
\text { de atenção integral à saúde em âmbito } \\
\text { regional, com ênfase em equidade } \\
\text { redistributiva. }\end{array}$ & $\begin{array}{l}\text { - Segmentação dos níveis de complexi- } \\
\text { dade assistencial. } \\
\text { - Acessibilidade universal contemplando } \\
\text { procedimentos de menor lucratividade } \\
\text { para o mercado, além de algumas } \\
\text { estratégias e ações programáticas de } \\
\text { baixo custo orçamentário estatal. } \\
\text { - Planos de saúde subvencionados pelo } \\
\text { Estado e focados em procedimentos } \\
\text { ambulatoriais médicos especializados, } \\
\text { mas com baixa densidade tecnológica. } \\
\text { - Regionalização focada em serviços de } \\
\text { média complexidade, dependentes de } \\
\text { mercado e quase mercado. }\end{array}$ \\
\hline
\end{tabular}

${ }^{15}$ Filgueira e colaboradores (2006). 


\begin{tabular}{|c|c|c|c|}
\hline Item & $\begin{array}{l}\text { Cenário I - Pluralismo do } \\
\text { empresariado, institucionalidade } \\
\text { híbrida e direito privado }\end{array}$ & $\begin{array}{c}\text { Cenário II - Pluralismo integrado, } \\
\text { institucionalidade estatal e direito } \\
\text { público }\end{array}$ & $\begin{array}{l}\text { Cenário III - Pluralismo mercantil, } \\
\text { institucionalidade e direito privados }\end{array}$ \\
\hline $\begin{array}{l}\text { Preponderância } \\
\text { administrativa e jurídica }\end{array}$ & $\begin{array}{l}\text { Predomínio dos serviços gerenciados } \\
\text { sob a égide do direito privado, com } \\
\text { ênfase na garantia de oferta, acessibi- } \\
\text { lidade e consumo de procedimentos } \\
\text { assistenciais padronizados. }\end{array}$ & $\begin{array}{l}\text { - Predomínio de serviços sob a égide do } \\
\text { direito público, tanto da administração } \\
\text { direta (nos municípios) como indireta } \\
\text { (nas regiões de saúde). } \\
\text { - Estabelecimentos privados filantrópicos } \\
\text { e lucrativos permanecem sob a égide do } \\
\text { direito privado. }\end{array}$ & $\begin{array}{l}\text { - Preponderância de serviços sob a } \\
\text { égide do direito privado e dinâmicas } \\
\text { de mercado. }\end{array}$ \\
\hline Relação com o SUS & $\begin{array}{l}\text { Preponderância de serviços suple- } \\
\text { mentares ao SUS, porém de menor } \\
\text { abrangência territorial e com foco em } \\
\text { assistência ambulatorial especializada } \\
\text { e serviços de apoio diagnóstico e } \\
\text { terapêutico. } \\
\text { - Os serviços próprios do SUS poderão } \\
\text { ser complementares ao setor privado, } \\
\text { ao invés do que está estabelecido } \\
\text { constitucionalmente. }\end{array}$ & $\begin{array}{l}\text { - Preponderância quantitativa de serviços } \\
\text { próprios do SUS, com distribuição } \\
\text { abrangente. } \\
\text { - Os serviços privados do segmento de } \\
\text { associaçes civis sem fins lucrativos } \\
\text { com vínculo complementar ao SUS } \\
\text { estariam focados em procedimentos } \\
\text { de média complexidade hospitalar e } \\
\text { ambulatorial. }\end{array}$ & $\begin{array}{l}\text { - Preponderância de serviços suple- } \\
\text { mentares ao SUS, porém de menor } \\
\text { abrangência territorial e com foco em } \\
\text { assistência ambulatorial especializada } \\
\text { e serviços de apoio diagnóstico e } \\
\text { terapêutico. } \\
\text { - Os serviços próprios do SUS poderão } \\
\text { estar disponibilizados para atender } \\
\text { procedimentos básicos ou com } \\
\text { enfoque específico (determinadas } \\
\text { condições de risco e vulnerabilidade). }\end{array}$ \\
\hline Financiamento público & $\begin{array}{l}\text { - Financiamento público direto insufi- } \\
\text { ciente para as demandas de investi- } \\
\text { mentos necessários para a ampliação } \\
\text { de serviços e focado no custeio de } \\
\text { ofertas padronizadas. } \\
\text { - Manutenção de subvenções e } \\
\text { subsídios indiretos estatais para } \\
\text { os serviços suplementares ao SUS, } \\
\text { principalmente por meio de renúncias } \\
\text { fiscais e isenções para pessoas físicas } \\
\text { e jurídicas. }\end{array}$ & $\begin{array}{l}\text { - Financiamento público direto gra- } \\
\text { dualmente incrementado até atingir } \\
\text { o patamar (em relação ao PIB) do } \\
\text { gasto público em países com sistemas } \\
\text { universais de saúde de menor porte } \\
\text { populacional. } \\
\text { - Diminuição de subvenções e subsídios } \\
\text { indiretos estatais para os serviços suple- } \\
\text { mentares ao SUS (planos de saúde). }\end{array}$ & $\begin{array}{l}\text { - Financiamento público direto insufi- } \\
\text { ciente para as demandas de investi- } \\
\text { mentos necessários para a ampliação } \\
\text { de serviços e focado no custeio de } \\
\text { ofertas padronizadas. } \\
\text { - Ampliações de subvenções, subsídios } \\
\text { (diretos e indiretos) e isenções tribu- } \\
\text { tárias para o setor privado. } \\
\text { - Maior aporte de recursos estatais para } \\
\text { o segmento Associações Civis sem fins } \\
\text { lucrativos (B). }\end{array}$ \\
\hline
\end{tabular}




\begin{tabular}{|c|c|c|c|}
\hline Item & $\begin{array}{l}\text { Cenário I - Pluralismo do } \\
\text { empresariado, institucionalidade } \\
\text { híbrida e direito privado }\end{array}$ & $\begin{array}{c}\text { Cenário II - Pluralismo integrado, } \\
\text { institucionalidade estatal e direito } \\
\text { público }\end{array}$ & $\begin{array}{l}\text { Cenário III - Pluralismo mercantil, } \\
\text { institucionalidade e direito privados }\end{array}$ \\
\hline $\begin{array}{l}\text { Vínculos empregatícios } \\
\text { e características da força } \\
\text { de trabalho }\end{array}$ & $\begin{array}{l}\text { - Redução de servidores públicos sob } \\
\text { regime estatutário, incremento pro- } \\
\text { porcional de servidores públicos sob } \\
\text { regime CLT. } \\
\text { - Aumento de vínculos de trabalhado- } \\
\text { res autônomos (notadamente no setor } \\
\text { privado) e com contratos temporários } \\
\text { (setor privado e segmento de associa- } \\
\text { ções civis sem fins lucrativos). } \\
\text { - Os serviços com atividades de ensino } \\
\text { poderão estar concentrados no segmen- } \\
\text { to estatal de administração indireta sob } \\
\text { égide do direto privado (A4). }\end{array}$ & $\begin{array}{l}\text { - Prevalência de vínculos de emprego } \\
\text { público sob regime celetista, com } \\
\text { diminuição de contratos temporários e } \\
\text { informais. } \\
\text { - Os vínculos estatutários poderão dimi- } \\
\text { nuir gradualmente, mas permanecerão } \\
\text { significativos principalmente em muni- } \\
\text { cípios de pequeno porte populacional. } \\
\text { - No setor privado também prevaleceriam } \\
\text { vínculos de CLT. }\end{array}$ & $\begin{array}{l}\text { - Predominância de empregados autô- } \\
\text { nomos e terceirizados. } \\
\text { - Redução significativa de servidores } \\
\text { públicos sob regime estatutário, } \\
\text { incremento proporcional de servidores } \\
\text { públicos sob regime CLT. }\end{array}$ \\
\hline $\begin{array}{l}\text { Capacidade de regulação } \\
\text { estatal e controle } \\
\text { público/social }\end{array}$ & $\begin{array}{l}\text { - Para o setor privado e suplementar } \\
\text { ao SUS poderá persistir o modelo de } \\
\text { regulação agenciada, com ênfase na } \\
\text { garantia de consumo de procedimen- } \\
\text { tos de baixo e médio custos. } \\
\text { - Para os segmentos que compõem } \\
\text { o setor de quase-mercado poderá } \\
\text { prevalecer a regulação pautada em } \\
\text { contratos com ênfase em eficiência } \\
\text { procedimental e produtiva. } \\
\text { - Dificuldade para manter e ampliar } \\
\text { os espaços de controle público/social } \\
\text { (para além das instâncias de defesa } \\
\text { de consumidores). }\end{array}$ & $\begin{array}{l}\text { - A regulação estatal do conjunto de } \\
\text { segmentos institucionais de saúde } \\
\text { ocorreria tanto por prerrogativa e via } \\
\text { normativa, como em função de maior } \\
\text { controle estatal sobre a oferta de servi- } \\
\text { ços próprios. } \\
\text { - Os contratos organizativos entre entes } \\
\text { públicos e estatais tenderiam a regular } \\
\text { a articulação interfederativa em âmbito } \\
\text { regional, pautados em propósitos de } \\
\text { integralidade e metas de curto, médio e } \\
\text { longo prazos. } \\
\text { - A regulação dos segmentos não esta- } \\
\text { tais ocorreria por meio de contratos } \\
\text { ampliados e pautados em garantias de } \\
\text { princípios e diretrizes constitucionais, } \\
\text { com controle público/social e ênfase em } \\
\text { metas regionais. } \\
\text { - A regulação agenciada dos segmentos } \\
\text { privados seria mais restrita e específica, } \\
\text { com ênfase na garantia de atenção } \\
\text { integral à saúde dos beneficiários. }\end{array}$ & $\begin{array}{l}\text { - Ênfase em regulação agenciada com } \\
\text { foco em garantia de acessibilidade de } \\
\text { beneficiários de serviços privados a } \\
\text { procedimentos padronizados. } \\
\text { - } \text { Regulação contratual com o segmento } \\
\text { estatal da administração indireta sob } \\
\text { a égide do direito privado (A4) e com } \\
\text { o segmento associações civis sem fins } \\
\text { lucrativos (B). } \\
\text { - Ausência de controle público/social } \\
\text { dos serviços de mercado e quase } \\
\text { mercado, com restrição ao segmento } \\
\text { estatal de administração direta da } \\
\text { saúde (A1). }\end{array}$ \\
\hline
\end{tabular}




\begin{tabular}{|c|c|c|c|}
\hline Item & $\begin{array}{l}\text { Cenário I - Pluralismo do } \\
\text { empresariado, institucionalidade } \\
\text { híbrida e direito privado }\end{array}$ & $\begin{array}{c}\text { Cenário II - Pluralismo integrado, } \\
\text { institucionalidade estatal e direito } \\
\text { público }\end{array}$ & $\begin{array}{l}\text { Cenário III - Pluralismo mercantil, } \\
\text { institucionalidade e direito privados }\end{array}$ \\
\hline $\begin{array}{l}\text { Tipos preponderantes de } \\
\text { governança sistêmica }\end{array}$ & $\begin{array}{l}\text { - Predomínio de modos de governança } \\
\text { mais operativa e procedimental. } \\
\text { - Em termos organizacionais, modos de } \\
\text { governança mais administrativa; em } \\
\text { termos individuais, modos de gover- } \\
\text { nança de contatos administrativos. } \\
\text { - Os modos de governança constitutiva } \\
\text { e diretiva poderão ser fracos e insu- } \\
\text { ficientes para alterar o intercurso de } \\
\text { tendência inercial. }\end{array}$ & $\begin{array}{l}\text { - Ocorrência simultânea de modos de } \\
\text { governança constitutiva, diretiva e } \\
\text { operativa para o setor público, estatal e } \\
\text { não estatal. } \\
\text { - Comissões intergestoras do SUS como } \\
\text { instâncias proeminentes de processos } \\
\text { decisórios federativos para os modos } \\
\text { de governança diretiva, em articulação } \\
\text { com instâncias de controle público/ } \\
\text { social. } \\
\text { - Em termos organizacionais, coexistên- } \\
\text { cia de modos de governança de relações } \\
\text { contextuais, de suporte e relações } \\
\text { administrativas. Em termos individuais, } \\
\text { modos de governança de normas profis- } \\
\text { sionais, fronteiras individuais e contatos } \\
\text { administrativos. }\end{array}$ & $\begin{array}{l}\text { Predomínio de modos de governança } \\
\text { mais operativa e procedimental, } \\
\text { com foco em mediações de caráter } \\
\text { mercantil (acomodação de interesses } \\
\text { corporativos e de oligopólios). } \\
\text { - Em termos organizacionais, um modo } \\
\text { de governança mais administrativa de } \\
\text { mercado; em termos individuais, um } \\
\text { modo de governaça mais focada em } \\
\text { contratos administrativos. }\end{array}$ \\
\hline
\end{tabular}




\section{Referências}

ABRUCIO, F. L. Trajetória recente da gestão pública brasileira: um balanço crítico e a renovação da agenda de reformas. Revista de Administração Pública, 41(número especial): 67-86, 2007. Disponível em: <http://dx.doi. org/10.1590/S0034-76122007000700005 > . Acesso em: 10 jun. 2014.

BRASIL. Constituição da República Federativa do Brasil de 1988. Brasília, Diário Oficial da União, 1988. Disponível em: <www.planalto.gov.br/ccivil_03/constituicao/constituicao.htm>. Acesso em: 10 jun. 2014.

CASTLES, F. G. The Future of the Welfare State: Crisis Myths and Crisis Realities. Oxford: Oxford University Press, 2004.

DAIN, S. Do Direito Social à Mercadoria, 2000. Tese de Concurso para Professor Titular, Rio de Janeiro: Instituto de Medicina Social, Universidade do Estado do Rio de Janeiro.

DEPARTAMENTO DE INFORMÁTICA DO SUS (DATASUS) \& CADASTRO NACIONAL DE ESTABELECIMENTOS DE SAÚDE (CNES). CNES Estabelecimentos, 2013. Disponível em: < http://www2.datasus.gov.br/DATASUS/ index.php? area $=0204 \& i d=6906>$. Acesso em: março 2016.

DRAIBE, S. \& HENRIQUE, W. "Welfarestate", crise e gestão da crise: um balanço da literatura internacional. Revista Brasileira de Ciências Sociais, 3(6): 53-78, 1988.

FEIOCK, R. C. A Quasi-Market Theory of Local Development Competition. Florida: Florida State University, 1998. Disponível em: <http://localgov.fsu.edu/papers/archive/Feiock_001.pdf>. Acesso em: 10 jun. 2014.

FERLIE, E. et al. A Nova Administração Pública em Ação. Brasília: Editora da Universidade de Brasília, 1999.

FILGUEIRA, F. et al. Universalismo básico: Una nueva política social para América Latina. In: INTER-AMERICAN DEVELOPMENT BANK AND PLANETA, 2006, Washington. (Working paper series)

GRAND, J. L. Quasi-Markets and Social Policy. The Economic Journal, 101(408): 1.256-1.267, 1991.

HAM, C. Health Care Reform: learning from international experience. Philadelphia: Open University Press, 1997.

HUPE, P. L. \& HIIL, M. J. The three action levels of governance: reframing the policy process beyond the stages model. In: PETERS, B. G. \& PIERRE, J. Handbook of Public Policy. London: Sage, 2006.

LEVI, M. L. \& SCATENA, J. H. G. Evolução recente do financiamento do SUS e considerações sobre o processo de regionalização. In: VIANA, A. L. D. \& LIMA, L. D. (Orgs.). Regionalização e Relações Federativas na Política de Saúde do Brasil. Rio de Janeiro: Contracapa, 2011.

MAJONE, G. Do Estado Positivo ao Estado Regulador: causas e consequências de mudança no modo de governança. Revista do Serviço Público, 50(1): 5-36, 1999.

MATTOS, R. A. As agências internacionais e as políticas de saúde nos anos 90: um panorama geral da oferta de ideias. Ciência \& Saúde Coletiva, 6(2): 377-389, 2001.

MÉDICI, A. C. Aspectos teóricos e conceituais do financiamento das políticas de saúde. In: PIOLA, S. F. \& VIANNA, S. M. (Orgs.). Economia da Saúde: conceitos e contribuição para a gestão da saúde. Brasília: Ipea, 1995.

MÉRRIEN, F. X. L' État Providence. Paris: Puf, 1994. (Collection Que Sais Je?)

MILWARD, H. B. \& PROVAN, K. G. How networks are governed. In: CAROLYN, H. \& LYNN, L. E. (Eds.). Governance and Performance: new perspectives. Washington: Georgetown University Press, 2000.

NÚCLEO DE ESTUDOS DE POLÍTICAS PÚBLICAS (NEPP). Levantamentos Preliminares dos Serviços de Saúde Públicos e Privados na América Latina e Caribe. Campinas: NEPP, 2003.

OSBORNE, D. \& GAEBLER, T. Reinventando o Governo: como o espírito empreendedor está transformando o setor público. Brasília: Mh Comunicação, 1994. 
OSBORNE, S. P. The New Public Governance? Emerging perspectives on the theory and practice of public governance. New York: Routledge, 2010.

PAHIM, M. L. L. Organizações Sociais de Saúde do Estado de São Paulo: inserção privada no SUS e gestão financeira do modelo pela Secretaria de Estado da Saúde, 2009. Tese de Doutorado, São Paulo: Faculdade de Medicina, Universidade de São Paulo. Disponível em: <www.teses.usp.br/teses/disponiveis/5/5137/tde-08122009185716/pt-br.php>. Acesso em: 12 jun. 2014.

PEREIRA, L. C. B. A Reforma do Estado dos anos 90: lógica e mecanismos de controle. Brasília: Ministério da Administração Federal e Reforma do Estado, 1997. (Cadernos Mare, 1)

PIERSON, C. Beyond the Welfare State? The new political economy of welfare. Texas: Penn State University Press, 1998.

PIERSON, P. Dismantling the Welfare State? Reagan, Thatcher and the politics of retrenchment. Cambridge: Cambridge University Press, 1994.

REZENDE, F. C. Tendências da gestão pública nos países da OCDE. In: LEVY, E. \& DRAGO, P. A. Gestão Pública no Brasil Contemporâneo. São Paulo: Fundap, 2005.

RICHARDS, D. \& SMITH, M. Governance and Public Policy in the UK. Oxford: Oxford University Press, 2002.

SILVA, P. L. B. Serviços de Saúde: o dilema do SUS na nova década. São Paulo em Perspectiva, 17(1): 69-85, 2003.

SMITH, A. Governança de múltiplos níveis: o que é e como pode ser estudada. In: PETERS, B. G. \& PIERRE, J. (Orgs.). Administração Pública: coletânea. São Paulo: Editora Unesp, 2010.

TENÓRIO, F. G. \& SARAVIA, E. J. Esforços sobre gestão pública e gestão social: as recentes reformas do Estado. In: MARTINS, P. E. M. \& PIERANTI, O. P. Estado e Gestão Pública: visões do Brasil contemporâneo. 2. ed. Rio de Janeiro: FGV, 2006.

VIANA, A. L. \& SILVA, H. P. Desenvolvimento e institucionalidade da política social no Brasil. In: MACHADO, C. V.; BAPTISTA, T. W. F. \& LIMA, L. D. (Orgs.). Políticas de Saúde no Brasil: continuidades e mudanças. Rio de Janeiro: Editora Fiocruz, 2012.

VIANA, A. L. et al. Pesquisa Política, planejamento e gestão das regiões e redes de Saúde. Cnpq/MS, Banco de Indicadores, 2013. Disponível em: <www.resbr.net.br>. Acesso em: 17 jun. 2014. 


\section{ANEXO}

Nos mapas apresentados a seguir estão georreferenciados estratos de taxas de oferta populacional para estabelecimentos de saúde nos estados brasileiros, considerados os períodos de julho de 2005 e 2013 e de acordo com as principais modalidades administrativas tratadas no capítulo. Para o cálculo de denominadores populacionais foram utilizadas diversas escalas (10.000 habitantes, 1.000.000 habitantes, 10.000.00 habitantes) em razão de distintas magnitudes de oferta e do propósito específico de realçar os estados brasileiros com maiores incrementos de taxas de oferta das distintas modalidades administrativas.

Figura 1 - Segmento de Administração Direta, égide de direito público, serviços governamentais próprios do Sistema Único de Saúde (A1)

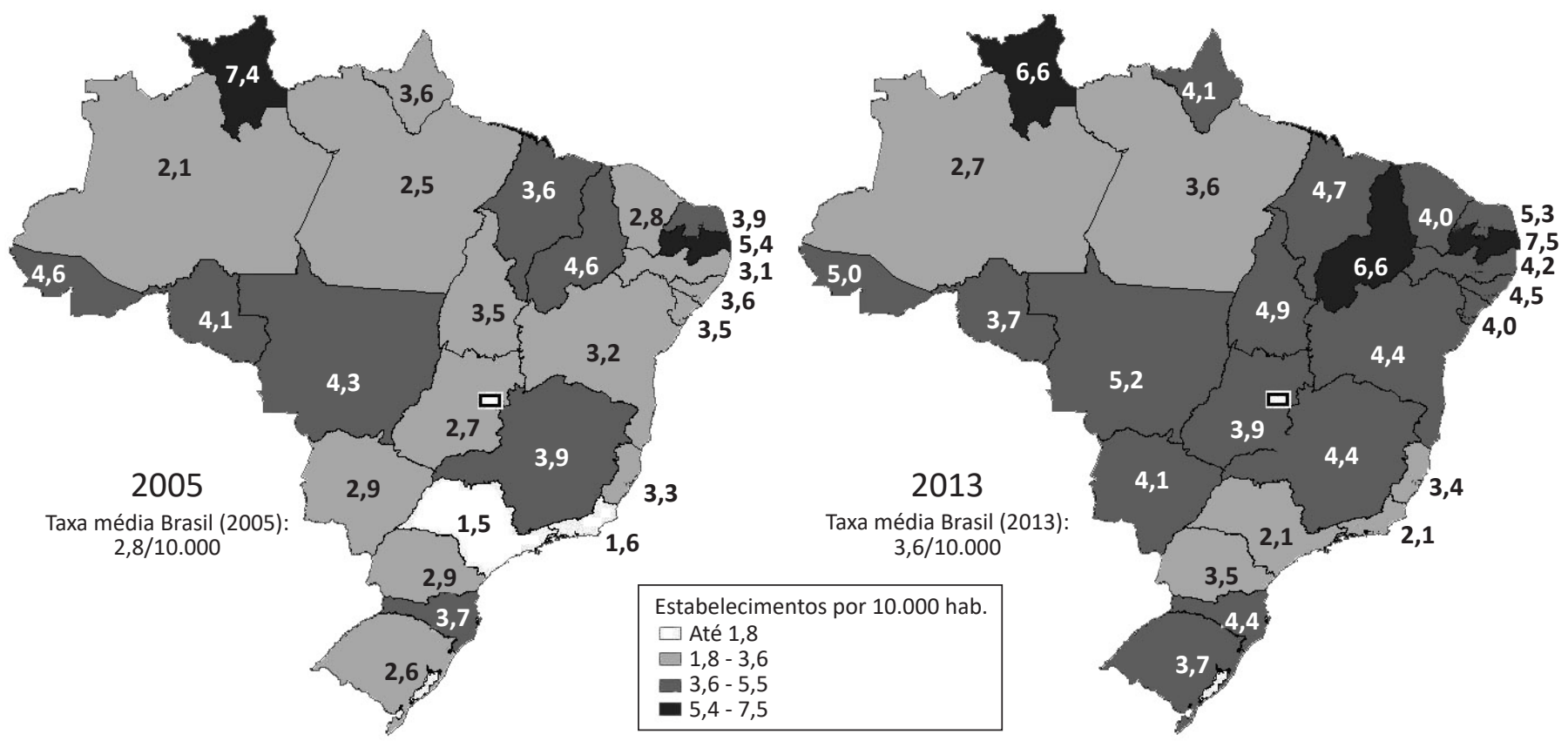

Fonte: DataSUS \& CNES, 2013. 
Figura 2 - Segmento de administração direta, outros órgãos estatais (exceto órgãos governamentais de Saúde), égide do direito público, serviços complementares ao SUS e suplementares (A2)

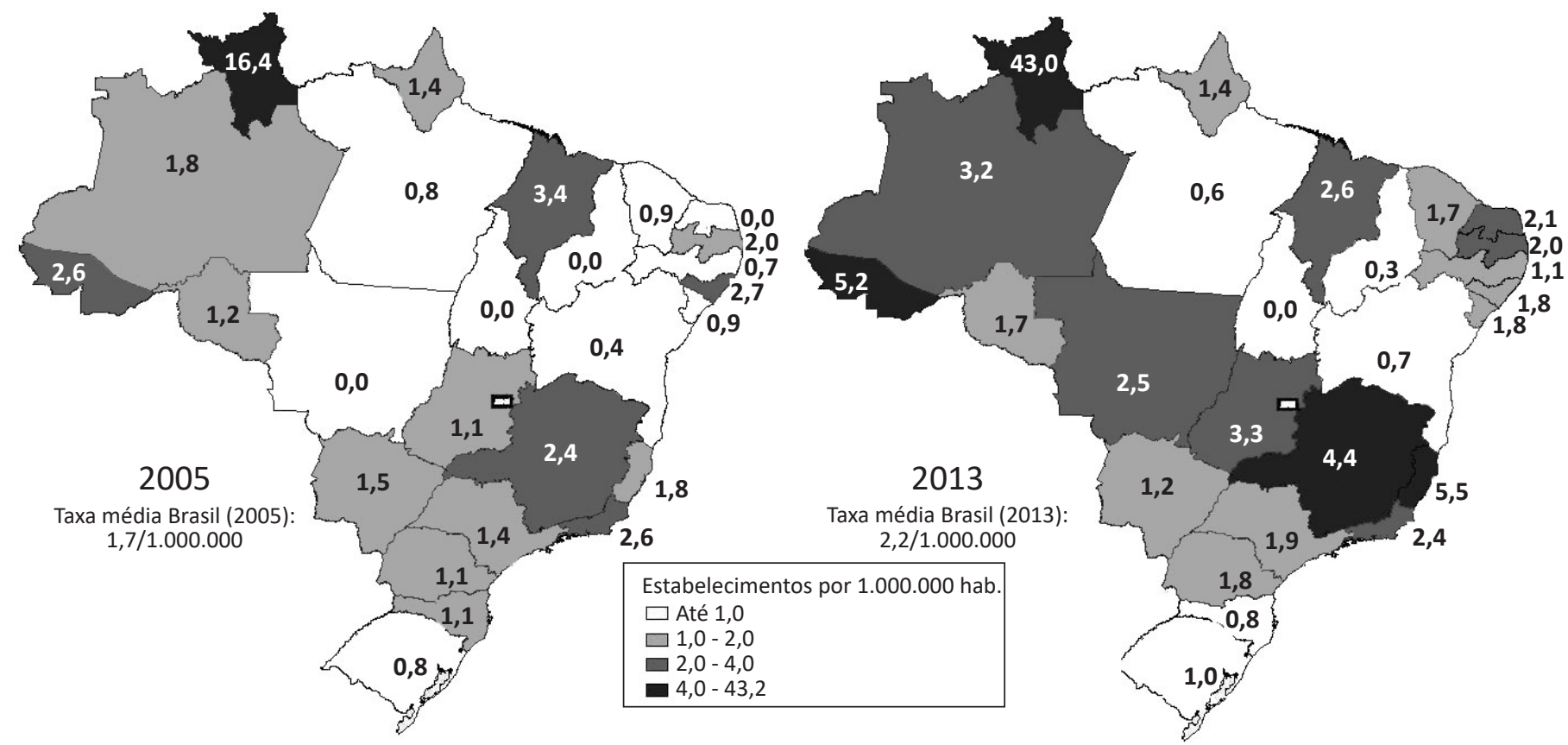

Fonte: DataSUS \& CNES, 2013.

Figura 3 - Segmento de administração indireta, égide do direito público, serviços próprios do SUS (A3)

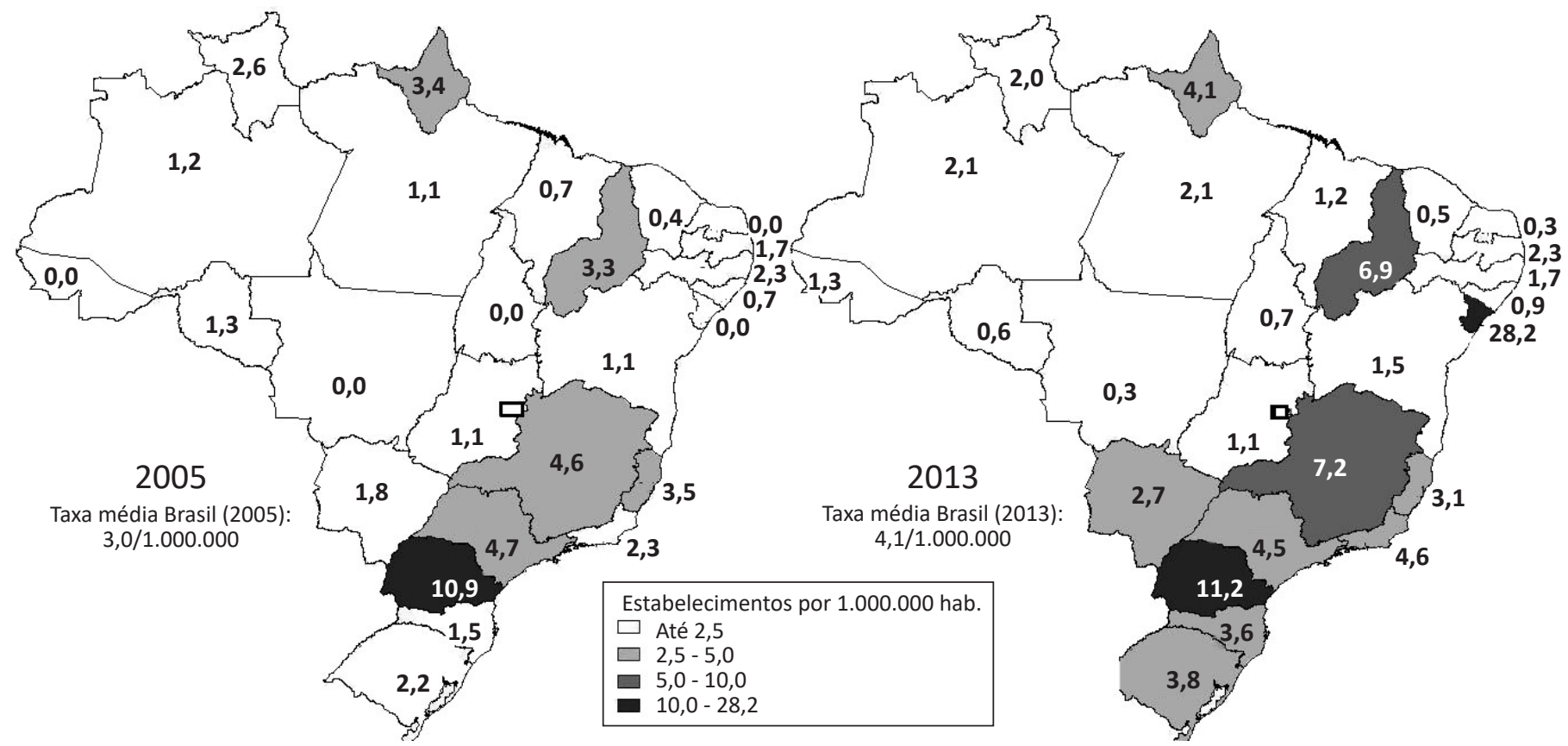

Fonte: DataSUS \& CNES, 2013. 
Figura 4 - Segmento de administração indireta, égide do direito privado, serviços próprios do SUS (A4)

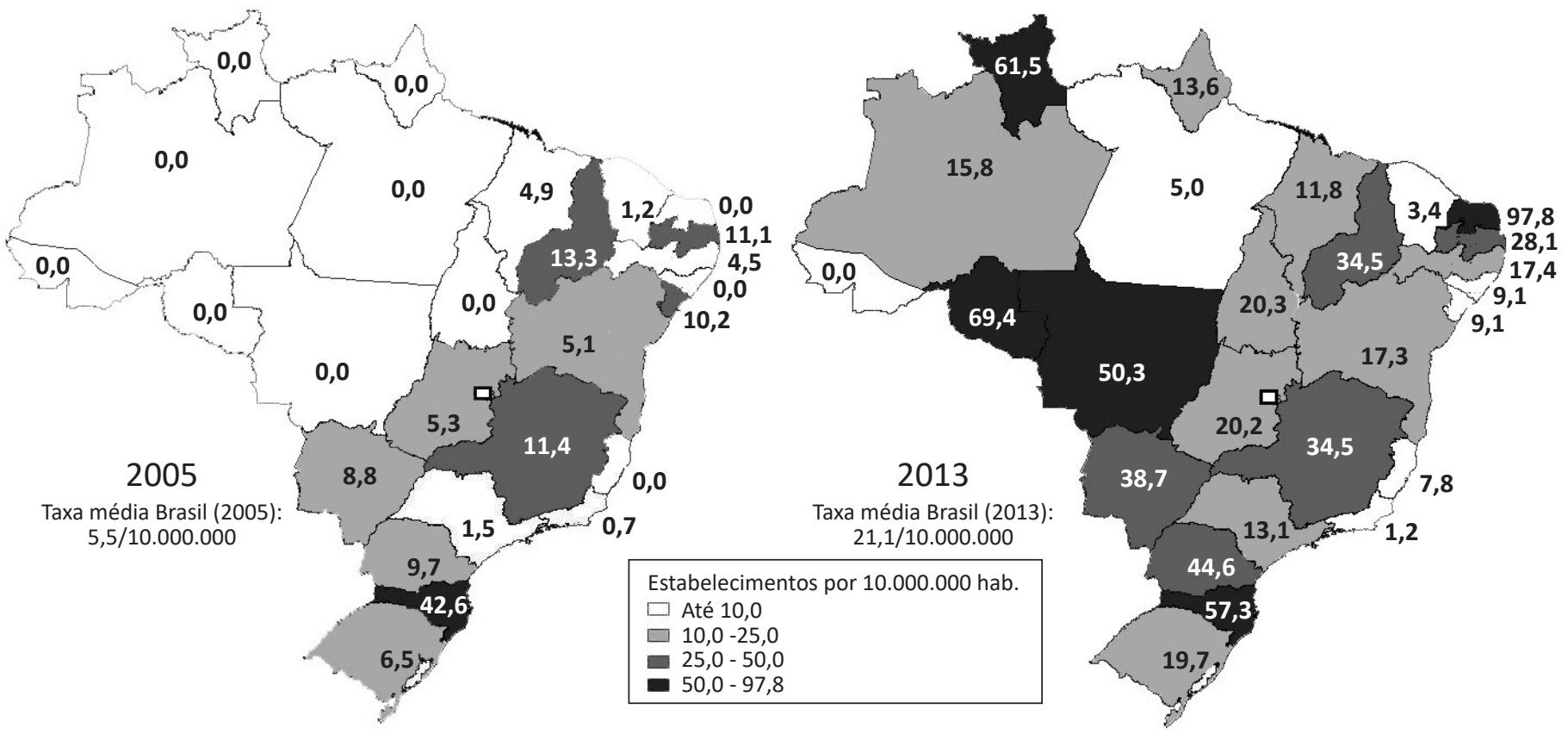

Fonte: DataSUS \& CNES, 2013.

Figura 5 - Segmento de serviços públicos não estatais, égide do direito privado, com serviços complementares contratados pelo SUS e serviços suplementares (B)

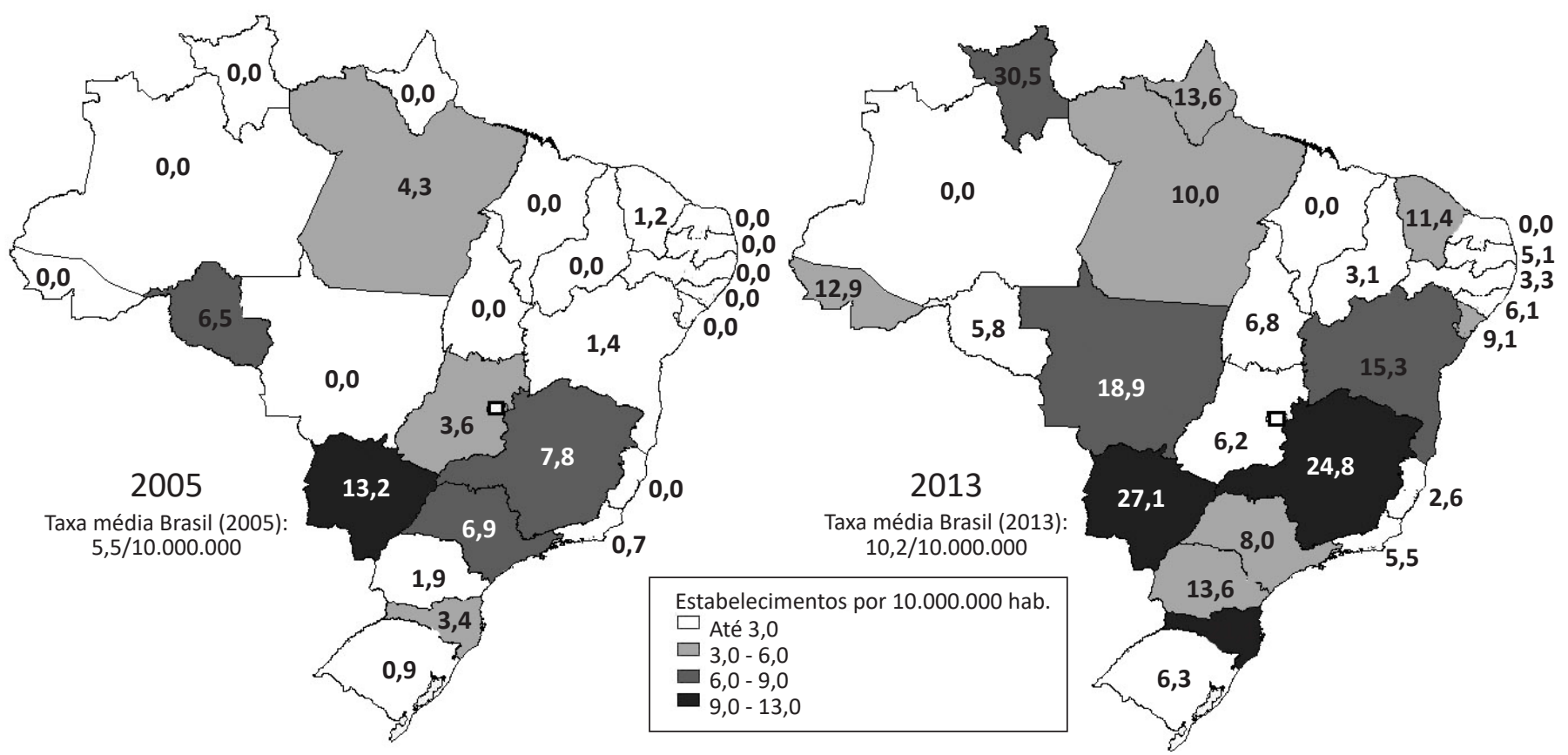

Fonte: DataSUS \& CNES, 2013. 
Figura 6 - Segmento privado sem fins lucrativos, com serviços complementares conveniados ao SUS e serviços suplementares (C)

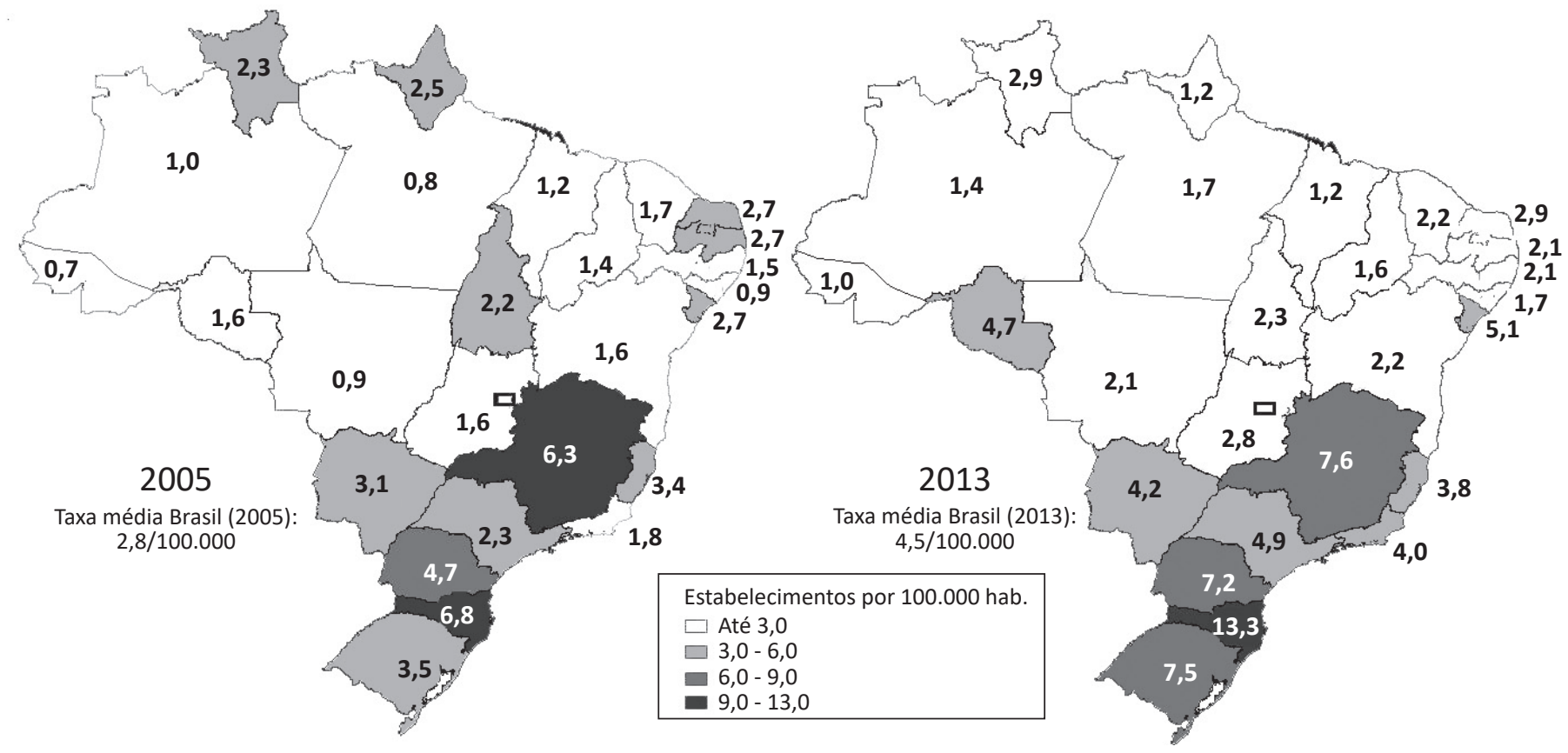

Fonte: DataSUS \& CNES, 2013.

Figura 7 - Segmento privado com fins lucrativos, com serviços complementares contratados pelo SUS e serviços suplementares (D)

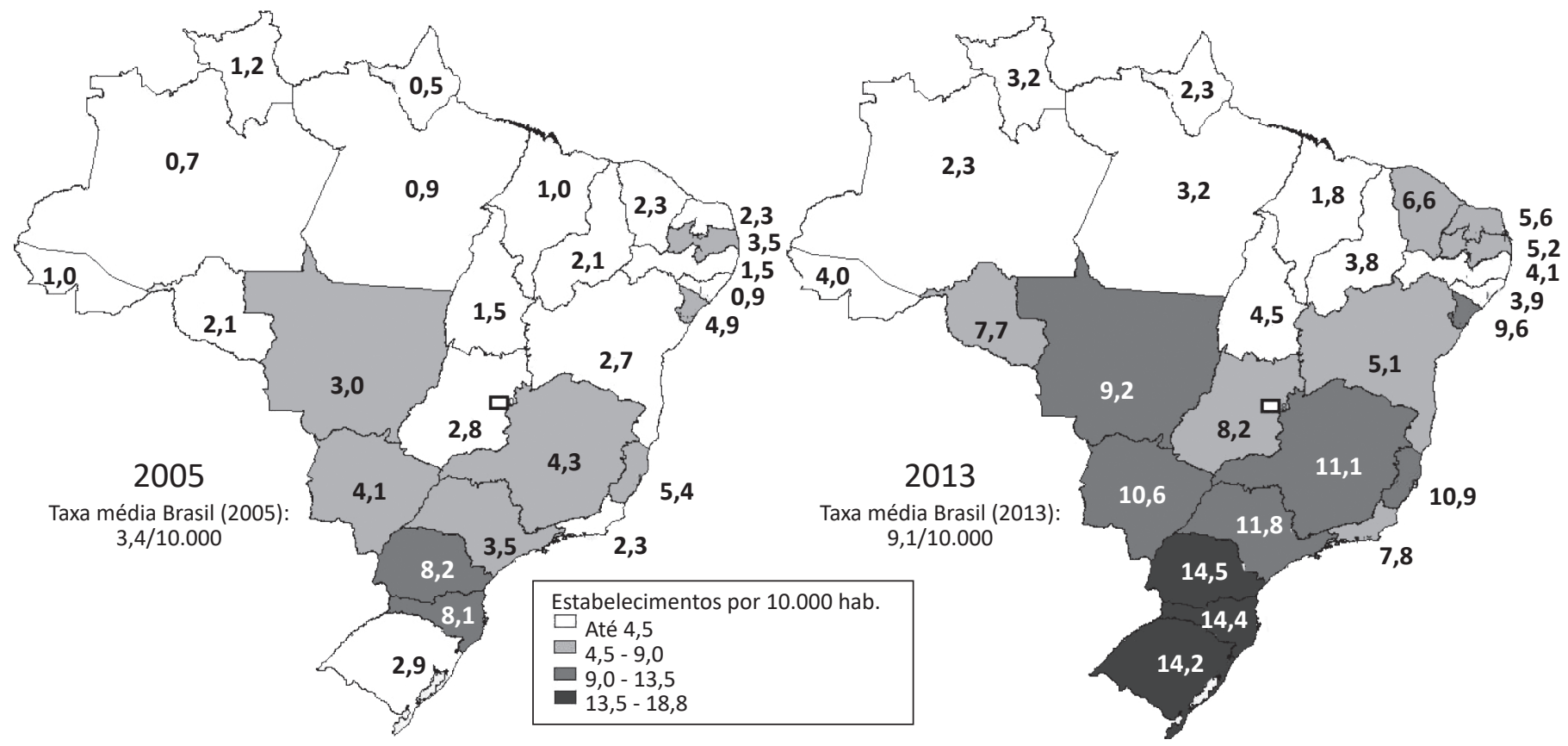

Fonte: DataSUS \& CNES, 2013. 


\title{
ESTRUTURA ATUAL E ESTIMATIVAS FUTURAS DA FORÇA DE TRABALHO EM MEDICINA, ENFERMAGEM E ODONTOLOGIA NO BRASIL - 2000 A 2030
}

\author{
Sabado Nicolau Girardi \\ Lucas Wan Der Maas \\ Cristiana Leite Carvalho \\ Celia Regina Pierantoni
}

Nas duas últimas décadas no Brasil e, sobretudo, na segunda metade da primeira década de 2000, assistiu-se a um importante crescimento da economia e da força de trabalho nacional. Após duas décadas de crise nos mercados de trabalho, informalização da economia e precarização das relações de trabalho, verifica-se a partir dos anos 2000 uma importante recuperação do emprego formal e dos salários. Nesse contexto, as atividades da saúde ampliaram os números da sua força de trabalho em proporções muito superiores ao total da economia. Entre 2000 e 2010, a força de trabalho ocupada em atividades de saúde cresceu a 5,5\% ao ano diante do incremento de 2,8\% ao ano do total de outras atividades. Em termos absolutos, o volume da ocupação no macrossetor quase dobrou, de 3,5 para 6,0 milhões de pessoas, passando de 5,4\% para mais de 7\% do total da economia (Tabela 1).

De fato, o mercado de trabalho em saúde no Brasil se desenvolveu nesse período em um contexto demográfico, econômico, social, político e cultural de crescentes demandas por serviços de saúde. Demograficamente, podem-se destacar o crescimento e o envelhecimento da população no país como explicativos dessa demanda (Carvalho \& Garcia, 2003). Do ponto de vista socioeconômico, a já citada recuperação do mercado de trabalho e a ascensão social de parte significativa da população estimularam o consumo dos planos de assistência médica e geraram fortes pressões para produção de bens, serviços e tecnologias de saúde mais diversos e de qualidade (Dal Poz, Pierantoni \& Girardi, 2012). Politicamente, a própria implantação e consolidação do Sistema Único de Saúde (SUS) e o avanço das políticas públicas da área, a exemplo da Estratégia Saúde da Família (ESF) - principal responsável por descentralizar o acesso à assistência básica em saúde -, resultaram na demanda substancial por recursos humanos (Girardi et al., 2010).

Entre as profissões e ocupações da saúde, o aumento da força de trabalho ocupada, de 8,2\%, foi ainda maior em relação ao setor Saúde como um todo. Em 2010, a força de trabalho ocupada no macrossetor Saúde ${ }^{1}$ correspondia a 7\% do total de ocupados no Brasil (ante 5,4\% em 2000), tota-

\footnotetext{
${ }^{1}$ O conceito de macrossetor Saúde guarda similaridade ao de complexo produtivo da saúde, englobando além dos serviços de saúde propriamente ditos, as atividades de produção e distribuição de fármacos, vacinas e medicamentos para uso humano; a produção de insumos e equipamentos para o setor; as atividades de ensino, pesquisa e desenvolvimento; as atividades de financiamento e planos de saúde; as atividades de saneamento e a gestão governamental dos serviços de saúde. Para maiores detalhes sobre o conceito e estimativas ver Zaeyen e colaboradores (1995).
} 
lizando 6,049 milhões de pessoas (Tabela 1). Desses, 4,493 milhões estavam ocupados em serviços de saúde propriamente ditos - o núcleo do setor - sendo 2,451 milhões em ocupações de saúde (ou seja, médicos, enfermeiros, cirurgiões-dentistas, farmacêuticos, técnicos de enfermagem, técnicos em radiologia, agentes comunitários de saúde etc.) e 1,257 milhão em ocupações não saúde (funções administrativas, serviços gerais, limpeza e conservação etc.). Além disso, 784 mil pessoas estavam em ocupações de saúde nas atividades industriais, de ensino, comércio, entre outras ligadas diretamente à área.

Os médicos e cirurgiões-dentistas experimentaram crescimento inferior à média do total de ocupações de saúde e bem próximo do observado para o total da economia, respectivamente, 3\% e $2,9 \%$ ao ano (Tabela 1). Já entre os enfermeiros o crescimento foi explosivo, de 14,9\%. Em todos os casos, o incremento da força de trabalho em saúde acompanhou a enorme expansão do ensino superior verificada no período.

Tabela 1 - Distribuição do número de ocupados em saúde* discriminados por ocupações de saúde e não saúde. Brasil - 2000 e 2010

\begin{tabular}{|c|c|c|c|c|c|}
\hline & \multicolumn{2}{|c|}{2000} & \multicolumn{2}{|c|}{2010} & \multirow{2}{*}{$\begin{array}{l}\text { Incremento } \\
\text { geométrico }\end{array}$} \\
\hline & $\mathrm{N}$ & $\%$ & $\mathrm{~N}$ & $\%$ & \\
\hline Pop. ocupada no macrossetor Saúde & 3.536 .862 & 100 & 6.049 .479 & 100 & 5,5 \\
\hline Ocupações da Saúde & 1.476 .226 & 41,7 & 3.236 .060 & 53,5 & 8,2 \\
\hline Médicos** & 243.830 & 6,9 & 328.006 & 5,4 & 3,0 \\
\hline Enfermeiros** & 76.961 & 2,2 & 308.429 & 5,1 & 14,9 \\
\hline Cirurgiões-dentistas*** & 161.896 & 4,6 & 214.909 & 3,6 & 2,9 \\
\hline Ocupações Não Saúde & 2.060 .637 & 58,3 & 2.813 .419 & 46,5 & 3,2 \\
\hline Núcleo do setor & 2.443 .632 & 69,1 & 3.708 .704 & 61,3 & 4,3 \\
\hline Pop. ocupada no total da economia & \multicolumn{2}{|c|}{65.629 .892} & \multicolumn{2}{|c|}{86.353 .839} & 2,8 \\
\hline $\begin{array}{l}\% \text { do macrossetor no total da } \\
\text { economia }\end{array}$ & \multicolumn{2}{|c|}{5,4} & \multicolumn{2}{|c|}{7,0} & \\
\hline
\end{tabular}

* No trabalho principal da semana de referência.

**Ocupados na própria profissão ou em outra função.

Fonte: elaboração própria, com base em dados do IBGE (2002, 2012). 


\section{Estrutura Atual da Força de Trabalho}

\section{Perfil ocupacional}

No censo demográfico do Instituto Brasileiro de Geografia e Estatística (IBGE) de 2010, informava-se a existência de 355.583 médicos residentes no país, valor próximo ao de profissionais com registro ativo no Conselho Federal de Medicina no mesmo ano, que era de 364.757 (Tabela 2). Dos recenseados, 328.006 médicos ( $92 \%$ do total) estavam economicamente ativos na semana de referência do inquérito, e 286.399 (80,5\%) exerciam a função de médicos como trabalho principal da semana de referência, 39.734 (11,2\%) se ocupavam em outras funções e 1.873 (0,5\%) estavam desocupados. Como o IBGE coleta informações apenas sobre o trabalho principal, supõe-se que parte dos ocupados em outras funções também exercia a medicina nos trabalhos secundários, totalizando algo em torno de 300 mil pessoas. À mesma época, 190.503 detinham vínculos formais de emprego, como celetistas, estatutários e demais vínculos assalariados regulares (Brasil, 2011). Considerando que os médicos se vinculam ao mercado de trabalho e a serviços de saúde de distintas formas, como autônomos - tradicionais ou em rede -, cooperados, pessoas jurídicas, além de se empregarem em atividades de outras áreas (ensino, administração etc.), esse volume de emprego corrobora a tese da existência de plena ocupação dos médicos na economia brasileira.

O número total de enfermeiros contabilizados no censo foi de 355.383, número próximo ao registrado no Conselho Federal de Enfermagem (Cofen, 2013), de 346.968 em 2013. Acredita-se que essa diferença, no entanto, não representa inflexão no número de registrados, mas um hiato entre formados na profissão e portadores de registro. Ao contrário do que foi observado entre os médicos, menos da metade dos enfermeiros $(46,7 \%)$ tinha como trabalho principal as atividades típicas da profissão, ainda que 308.429 (86,8\%) estivessem economicamente ativos. Ressalta-se que parte dos enfermeiros ocupados em outras funções estava na própria área de enfermagem, como técnicos e auxiliares de enfermagem e "cuidadores pessoais" (cerca de 50 mil pessoas). Ao mesmo tempo, por meio dos números da Relação Anual de Informações Sociais (Rais) constatava-se que 168.662 mil enfermeiros detinham empregos regulares na economia formal, o que sugere uma forte formalização da categoria, quando ocupada na profissão.

Para cirurgiões-dentistas o número encontrado no censo de 2010 foi de 241.622 profissionais, sendo 214.909 (88,9\%) ativos, 187.172 (77,5\%) ocupados na profissão e 2.122 (0,9\%) desocupados, proporções muito próximas às encontradas entre médicos. Os registros de ativos em 2013, segundo o Conselho Federal de Odontologia (CFO, 2013), totalizavam 251.587 pessoas. Quanto aos empregados no mercado formal, verifica-se aqui importante diferença entre os cirurgiões-dentistas e outras profissões em análise. Trata-se de uma força de trabalho com baixa proporção de vínculos empregatícios formais em relação aos ocupados na economia (56.310 profissionais com emprego formal em 2010 ou 23\% do total). Em parte, isso pode ser explicado pela predominância das formas de trabalho autônomas, tanto a de autônomos tradicionais estabelecidos em consultórios privados quanto empregados informalmente em clínicas onde predominam as relações de pagamento por porcentagem. 
Tabela 2 - Número de médicos, enfermeiros e cirurgiões-dentistas residentes no país em 2010, por condição de atividade, registrados nos conselhos profissionais em 2013 e ocupados na economia formal em 2010

\begin{tabular}{|c|r|r|r|}
\hline \multicolumn{1}{|c|}{ Indicador } & \multicolumn{1}{|c|}{ Médicos } & Enfermeiros & Cirurgiões-dentistas \\
\hline $\begin{array}{l}\text { 1. Profissionais residentes no país } \\
\text { 1.1. Economicamente ativos }\end{array}$ & 355.583 & 355.383 & 241.622 \\
\hline $\begin{array}{l}\text { Ocupados na profissão } \\
\text { Ocupados em outra função }\end{array}$ & $286.399(80,5 \%)$ & $165.797(46,7 \%)$ & $187.172(77,5 \%)$ \\
\hline $\begin{array}{l}\text { Desocupados } \\
\text { 1.2. Não economicamente ativos }\end{array}$ & $1.873(0,5 \%)$ & $19.011(5,4 \%)$ & $2.122(0,9 \%)$ \\
\hline $\begin{array}{l}\text { 2. Profissionais em atividade em } \\
\text { 2013(CFM, Cofen e CFO) }\end{array}$ & $27.577(7,8 \%)$ & $46.955(13,2 \%)$ & $26.713(11,1 \%)$ \\
\hline $\begin{array}{l}\text { 3. Número de profissionais empregados } \\
\text { na economia formal (Rais 2010) }\end{array}$ & 373.991 & $123.621(34,8 \%)$ & $25.615(10,6 \%)$ \\
\hline
\end{tabular}

Fonte: elaboração própria, com base em dados do IBGE $(2002,2012)$.

\section{Composição demográfica}

Quanto à composição por sexo e idade das populações em questão, as pirâmides etárias a seguir (Gráficos 1 a 3) permitem identificar, para a população economicamente ativa, a transição ocorrida entre os anos 2000 e 2010 no que diz respeito a essa composição. Nos três casos, observou-se rejuvenescimento da força de trabalho, isto é, aumento de pessoas na base da pirâmide. Tal crescimento se explica basicamente por abertura de vagas no ensino superior ao longo das duas últimas décadas. Identificou-se ainda que esse crescimento ocorreu principalmente entre mulheres.

No topo das pirâmides de médicos e cirurgiões-dentistas, nota-se um envelhecimento, principalmente entre os homens, o que reflete a característica de uma força de trabalho na qual a aposentadoria em um vínculo de emprego formal, seja do tipo estatutário ou celetista, não implica necessariamente abandono da atividade laboral. Essa continuidade do exercício laboral se explica fundamentalmente pela importância da prática autônoma convencional e das formas de trabalho autônomas consorciadas em cooperativas e do trabalho organizado na forma de pessoa jurídica. As pirâmides de médicos e cirurgiões-dentistas, no entanto, apresentam uma diferença no centro da pirâmide, já que nas faixas etárias entre 40 e 60 anos o volume de médicos é mais estreito em relação à base, o que é explicado por uma oferta de egressos do ensino superior mais restritiva entre as décadas de 1970 e 1980, comparativamente às décadas posteriores. No caso específico da odontologia, o crescimento do número vagas e egressos no ensino superior tem se mostrado estável, o que explicaria o formato quase triangular da pirâmide.

O envelhecimento e a feminização observados durante a década de 2000, em medicina e odontologia, indicam pelo menos duas tendências para os próximos anos. Em primeiro lugar, o volume de saídas da força de trabalho, por morte ou aposentadoria definitiva, será maior do que no passado, o que deverá ocorrer não só em termos absolutos, mas também relativos. Note que a proporção de 
médicos não economicamente ativos em relação ao total, em 2010, era de 7,8\% (Tabela 2), mesmo com o aumento no número de médicos com mais de 60 anos desde o início da década, o que provavelmente não será sustentado. Em segundo lugar, o crescimento da participação feminina expõe uma redução da carga horária média de dedicação ao trabalho, bem como do tempo médio de permanência no mercado ao longo da vida. Esses dois fatores certamente impulsionarão o crescimento da demanda por novos profissionais nos próximos anos.

A enfermagem apresentou comportamento diferente nessa transição entre os anos censitários. O que se deve destacar, de fato, é o substancial incremento do número de pessoas (alargamento da base da pirâmide) e a permanência de uma maioria feminina. Além disso, ao contrário do que se demonstrou para as outras duas profissões, o topo da pirâmide não se alterou, do ponto de vista da composição, já que, nesse caso, a saída do mercado de trabalho ocorre no início da terceira idade, sobretudo como resultado da aposentadoria e da predominância das relações de trabalho heterônomas - tanto entre os ocupados na profissão quanto em outras funções. Como destacado, a enfermagem é uma categoria altamente formalizada e, portanto, dependente de uma trajetória típica de atuação no mercado de trabalho ao longo da vida. As altas proporções de mulheres sugerem ainda que as saídas do mercado ocorrem em menor tempo se comparadas a profissões com maior proporção de homens. Nenhuma evidência aponta que tais tendências se alterarão em longo prazo e que a demanda por enfermeiros está mais condicionada à capacidade de acomodação do mercado como se verá adiante, afinal mais da metade dos graduados não exerce a profissão de enfermeiro.

Gráfico 1 - Composição etária e de sexo da população economicamente ativa de médicos. Brasil 2000 e 2010

2000

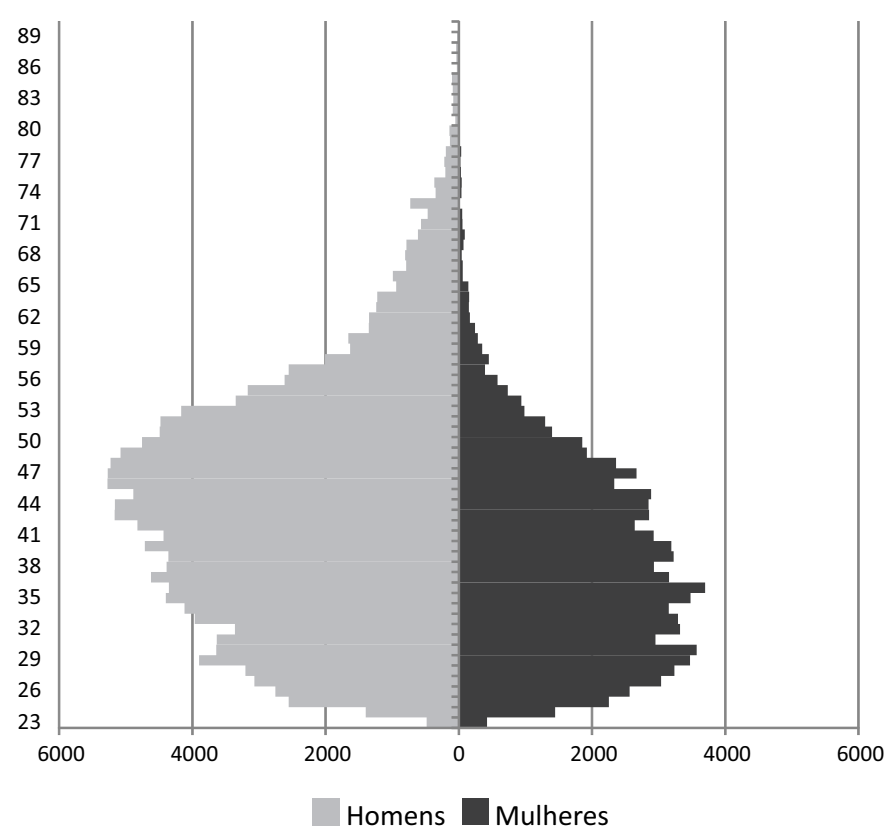

2010

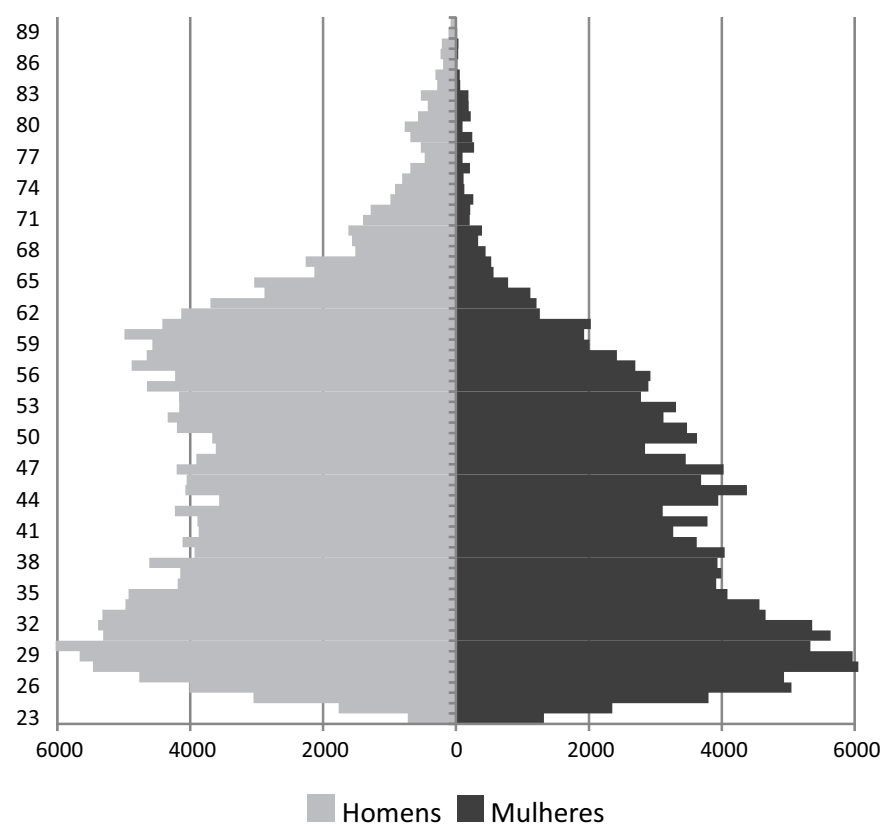

Fonte: elaboração própria, com base em dados do IBGE $(2002,2012)$. 
Gráfico 2 - Composição etária e de sexo da população economicamente ativa de enfermeiros. Brasil -2000 e 2010
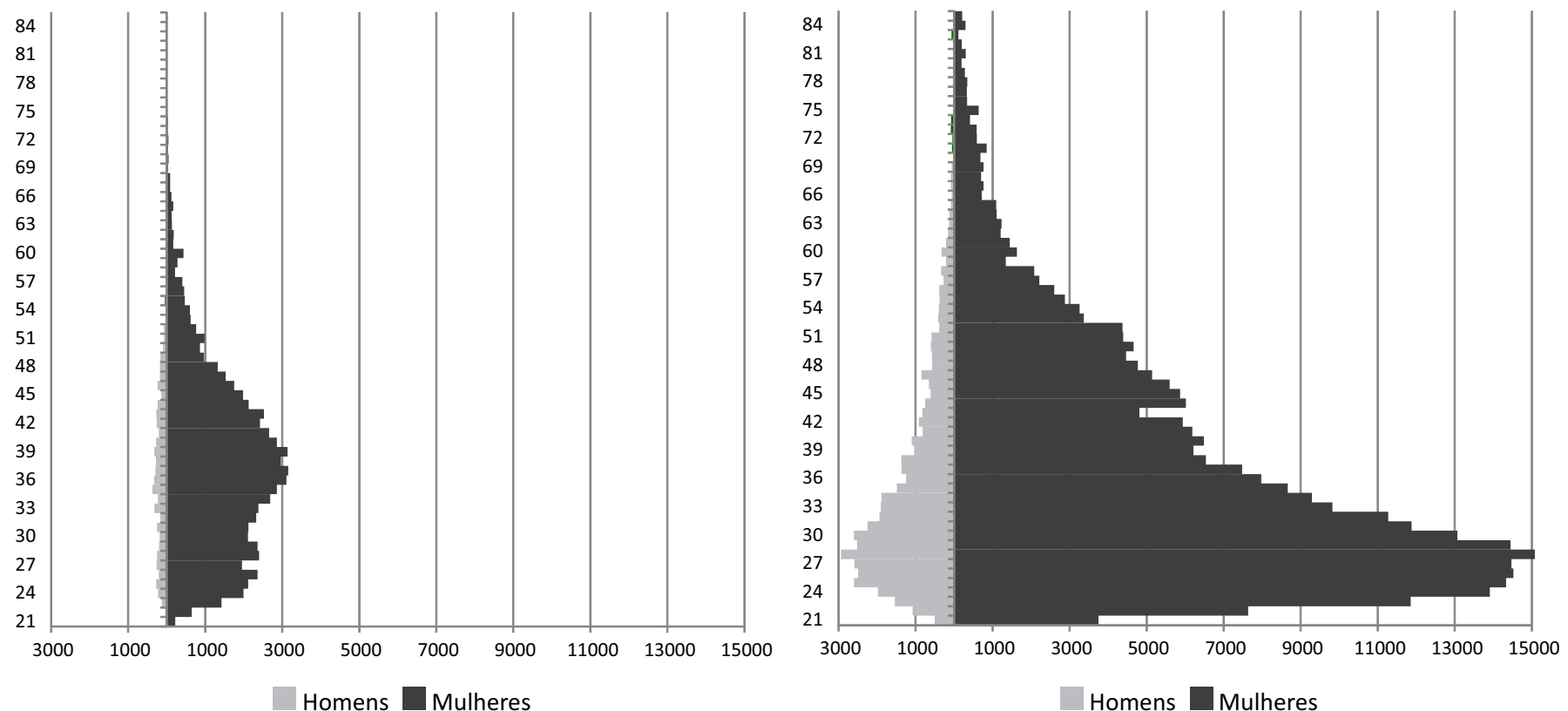

Fonte: elaboração própria, com base em dados do IBGE (2002, 2012).

Gráfico 3 - Composição etária e de sexo da população economicamente ativa de cirurgiões-dentistas. Brasil - 2000 e 2010

2000

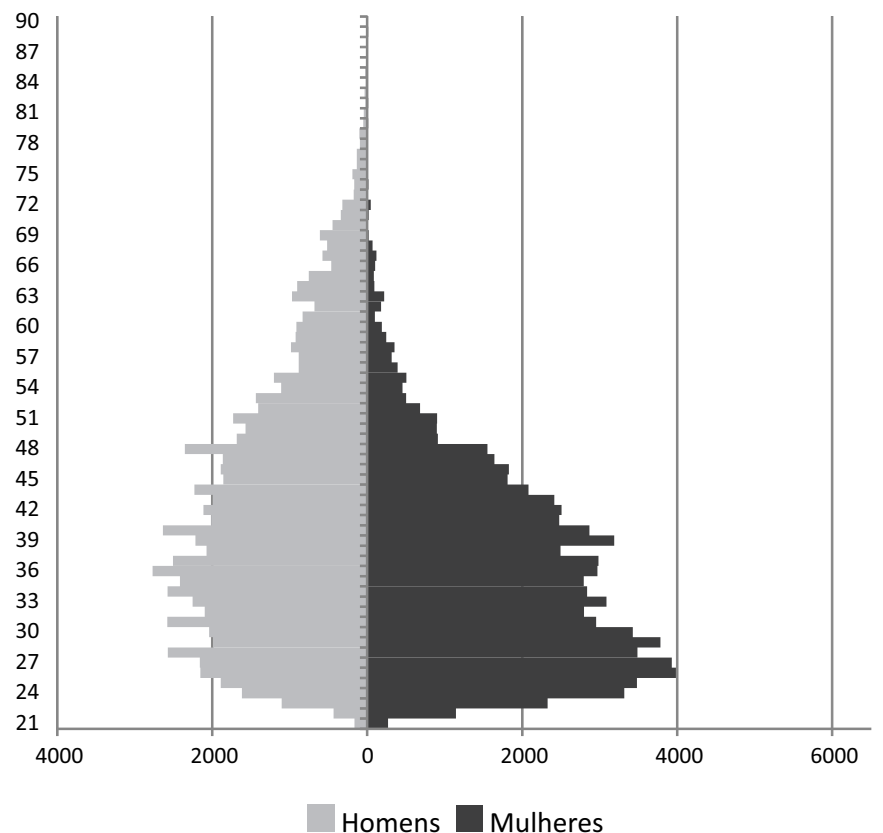

2010

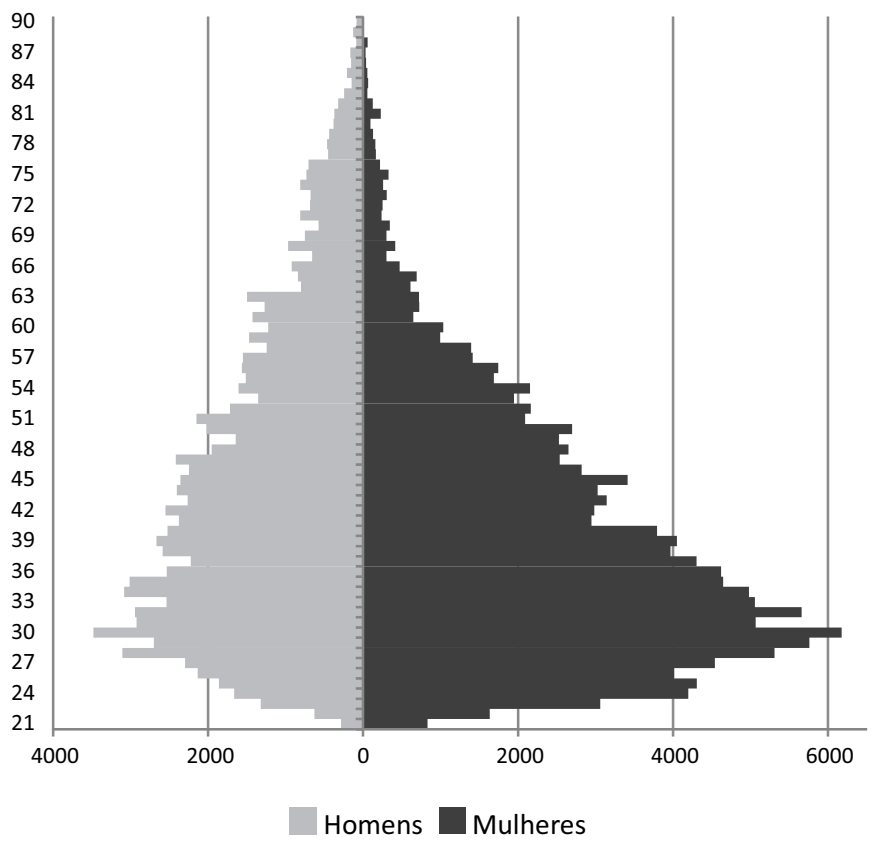

Fonte: elaboração própria, com base em dados do IBGE $(2002,2012)$. 


\section{Perfil da oferta segundo fluxos de formação}

Nos Gráficos de 4 a 6 está representada a evolução do número de vagas, ingressos e percentual de não preenchimento de vagas dos cursos de medicina, enfermagem e odontologia no Brasil, durante o período 1991 a 2012, segundo dados do Censo da Educação Superior do Instituto Nacional de Estudos e Pesquisas Educacionais Anísio Teixeira (Inep, 2013). ${ }^{2}$ No cômputo geral, no primeiro ano da série, as três áreas apresentaram ofertas de vagas em patamares muito próximos e com crescimento lento. A partir dos anos 2000, no entanto, o ritmo de crescimento acelerou, e na área da enfermagem observou-se um aumento significativo no número de vagas, distanciando-se da medicina e odontologia, que cresceram em ritmo semelhante, ainda que a odontologia um pouco acima. Durante todo o período foram criadas 10.145 vagas em medicina no país, o que representou um incremento bruto de 229,3\% (em números absolutos, aumento de 7.786 para 17.931 vagas). Em enfermagem criaram-se 125.783 vagas até o ano de 2010, $1.487,71 \%$ de aumento (de 7.460 para 133.243), mas nos anos seguintes, 2011 e 2012, foram fechadas 13.063 vagas. Em odontologia, por sua vez, a oferta cresceu 284,2\% até 2011, ou 13.546 novas vagas (de 7.315 para 20.861), tendo fechado 272 postos em 2012.

Esse salto trouxe consequências do ponto de vista do aproveitamento de vagas. Ao passo que em medicina o preenchimento de vagas se manteve constante, em enfermagem praticamente a metade das vagas foram desperdiçadas nos últimos anos da série, chegando ao ápice de 46,5\% em 2010 (133.243 vagas para 71.244 ingressos). É importante destacar que até 2003 o percentual de não preenchimento das vagas em enfermagem permaneceu constante e muito baixo. Com a expansão significativa no número de vagas a partir de 2000, no entanto, não se observou um acompanhamento do número de ingressos. Nos dois últimos anos da série, com o fechamento de vagas, o percentual de não preenchimento diminuiu, mas ainda continuou em níveis elevados. Em medicina a dinâmica é diferente, já que ao longo de todo o período assistiu-se à correspondência entre o número de ingressos e a oferta de novas vagas. Em odontologia também se observou um distanciamento entre as curvas de ingressos e de vagas, como visto em enfermagem, ainda que em números relativos e absolutos menores. Além disso, tal tendência se iniciou já no final da década de 1990 e alcançou seu pico em 2009, com 30,1\% de não preenchimento. Houve um recuo nos anos seguintes.

Em suma, os dados de formação apontam desperdício de vagas em enfermagem e odontologia, ainda que a procura pelos cursos tenha aumentado no período. Em outras palavras, a oferta de vagas nessas áreas foi superior à procura, mesmo em um período de crescimento da oferta geral de cursos superiores no Brasil e fundamentalmente de expansão do setor Saúde. Em medicina, ao contrário, o aumento da oferta esteve sempre acompanhado pela demanda correspondente, não havendo desperdício.

\footnotetext{
${ }^{2}$ Os dados detalhados podem ser consultados nas Tabelas 2, 3 e 4, no Apêndice.
} 
Gráfico 4 - Evolução do número de vagas e ingressos e percentual de não preenchimento de vagas de medicina. Brasil - 1991-2012

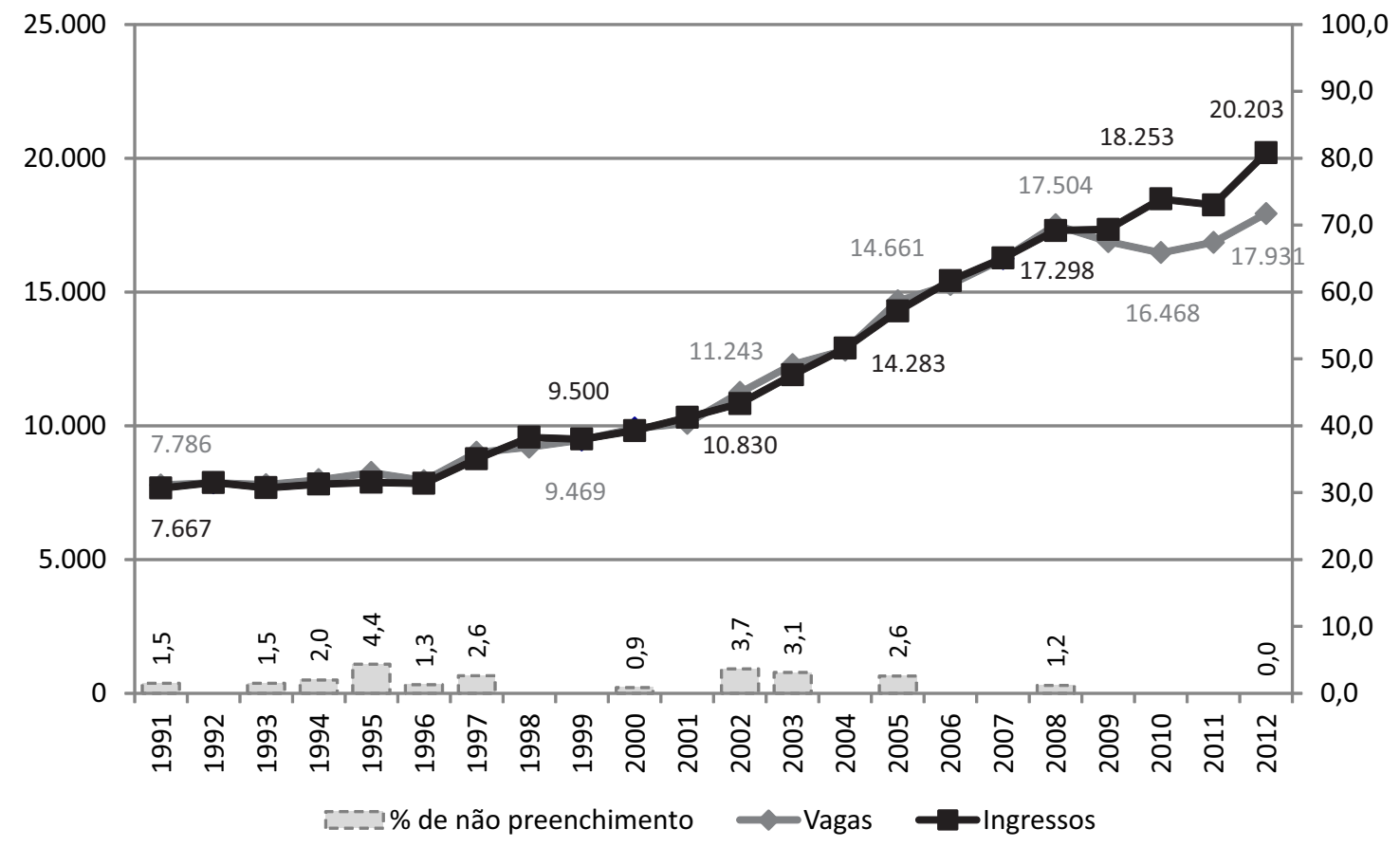

Fonte: elaboração própria, com base em dados do Inep (2013).

Gráfico 5 - Evolução do número de vagas e ingressos e percentual de não preenchimento de vagas de enfermagem. Brasil - 1991-2012

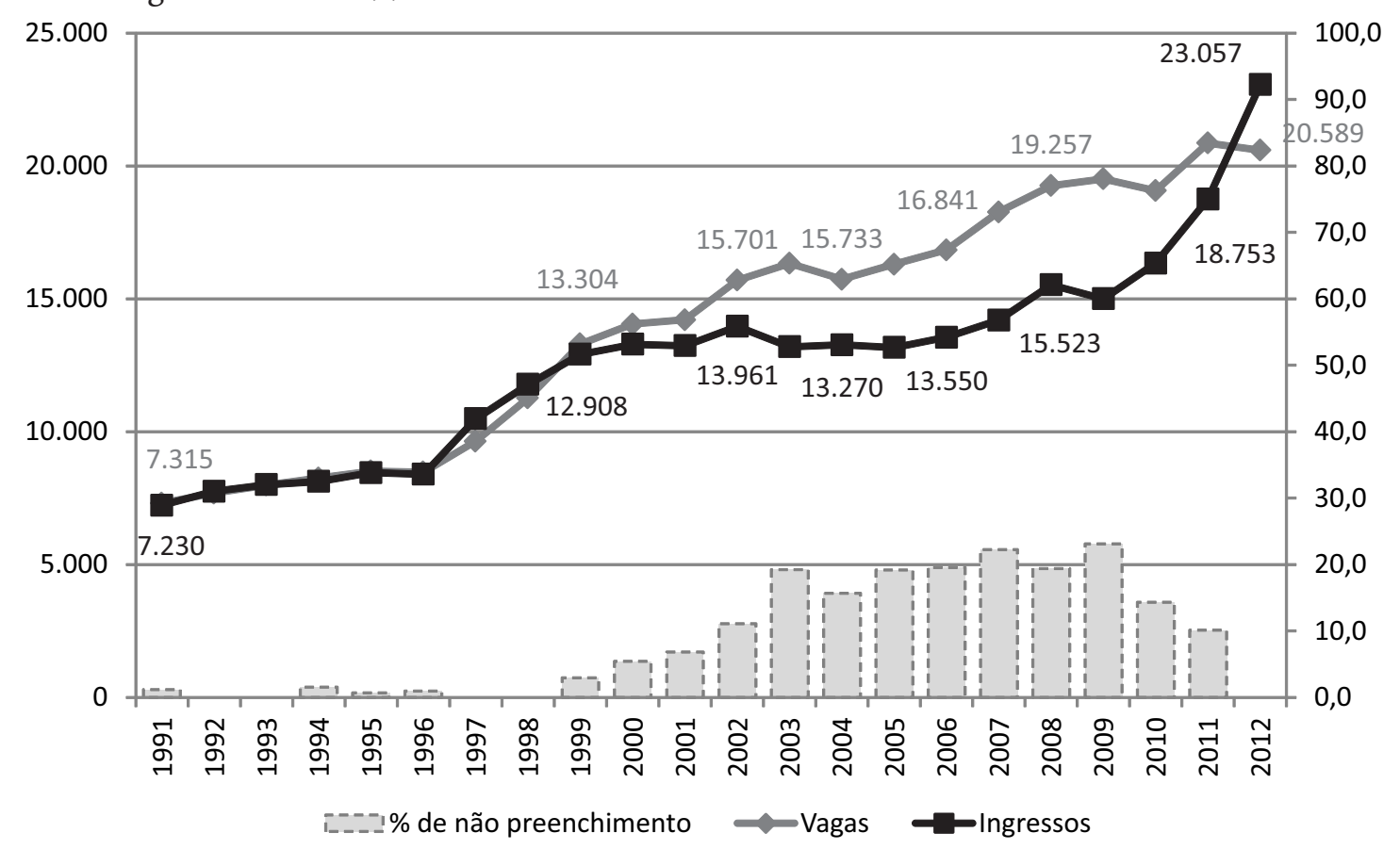

Fonte: elaboração própria, com base em dados do Inep (2013). 
Gráfico 6 - Evolução do número de vagas e ingressos e percentual de não preenchimento de vagas de odontologia. Brasil - 1991-2012

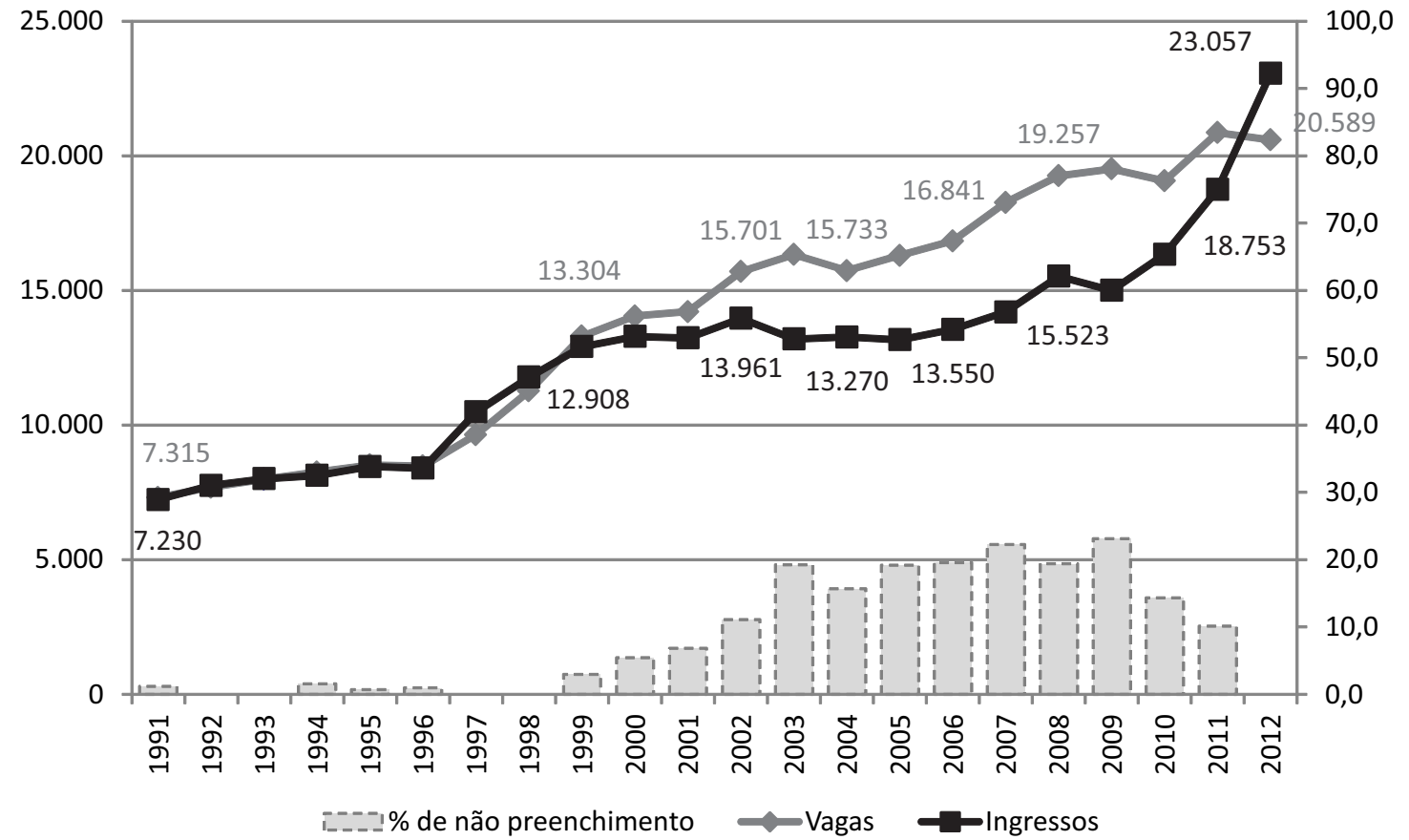

Fonte: elaboração própria, com base em dados do Inep (2013).

Nos Gráficos de 7 a 9, por sua vez, demonstra-se a evolução do número de ingressos, egressos e o percentual de não concluídos (taxa de eficiência terminal), durante o período de 1991 a 2012. Em medicina, os números de ingressos no ano $i$ e egressos no ano $i+6$ são bem próximos, indicando que a maioria dos estudantes que ingressam no curso conclui no tempo previsto. A variável percentual de não concluídos é pouco significativa ao longo do período, ainda que tenha aumentado a partir de 2007 em relação ao ano inicial de 2002, atingindo os maiores patamares entre 2008 e 2010. Nesse sentido, pode-se dizer que as escolas médicas, além de registrarem um bom aproveitamento entre a oferta e a demanda de vagas, também são "boas formadoras", pois há uma correspondência direta entre alunos que entram nos cursos e se tornam efetivos profissionais da área.

Assim como no quesito de aproveitamento de vagas, os cursos de enfermagem e odontologia têm comportamento semelhante quando se observa um hiato entre os ingressos no ano $i$ e os egressos no ano $i+5$. Entretanto, na odontologia esse hiato é observado desde os egressos de 2001, na enfermagem, a partir de 2006. No período em análise, o maior percentual (41,2\%) de não concluídos nos cursos de enfermagem ocorreu em 2010; nos cursos de odontologia, 38,9\% em 2006. Para esses cursos, portanto, vemos sinais de desperdício também ao longo do período previsto de formação, isto é, não só há um grande hiato entre oferta de vagas e procura pelo curso, como significativa desistência de graduandos. 
Gráfico 7 - Evolução de ingressos e egressos de medicina e taxa de eficiência terminal dos cursos. Brasil - 1991-1996 e 2007-2012

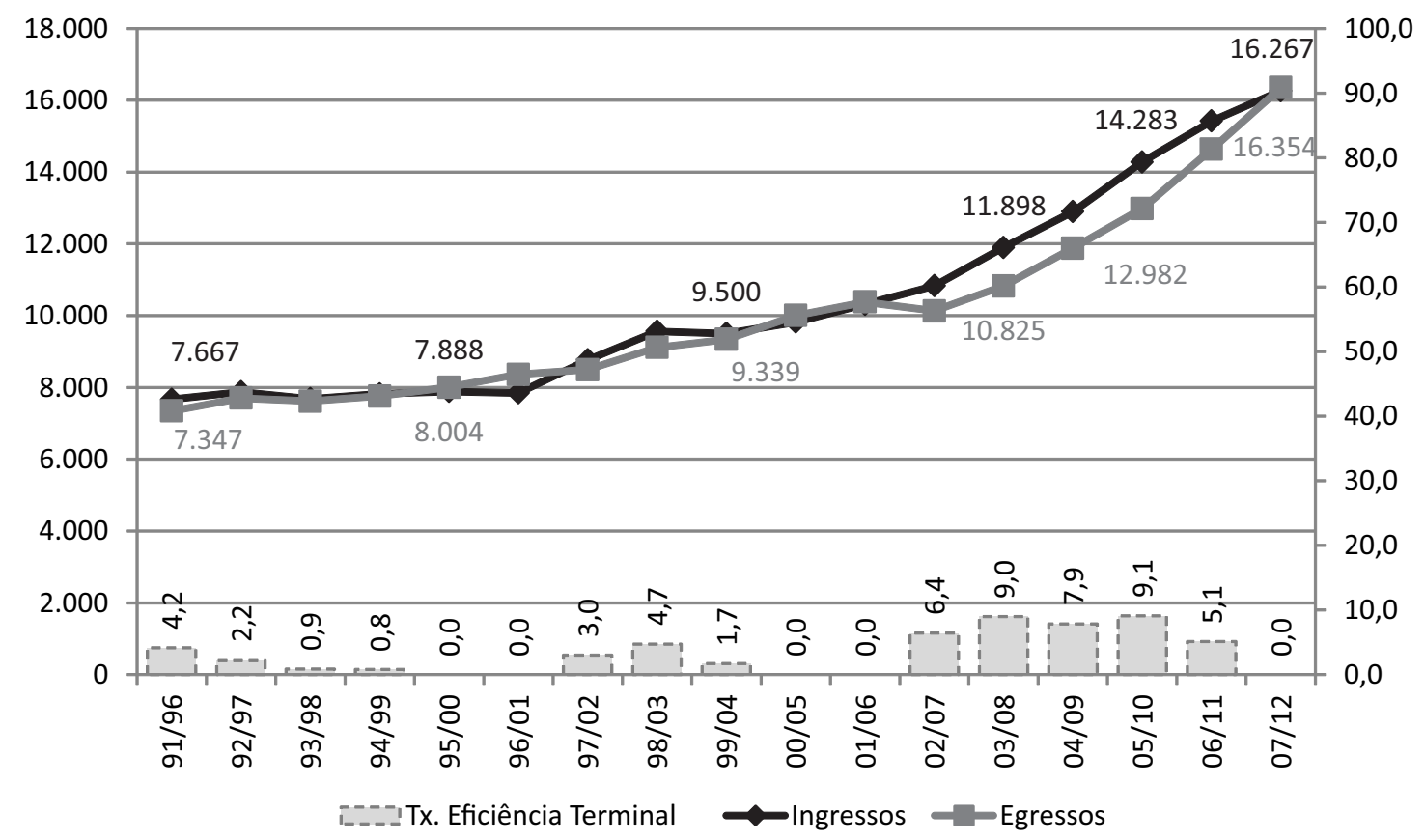

Fonte: elaboração própria, com base em dados do Inep (2013).

Gráfico 8 - Evolução de ingressos e egressos de enfermagem e taxa de eficiência terminal dos cursos. Brasil - 1991-1995 e 2008-2012

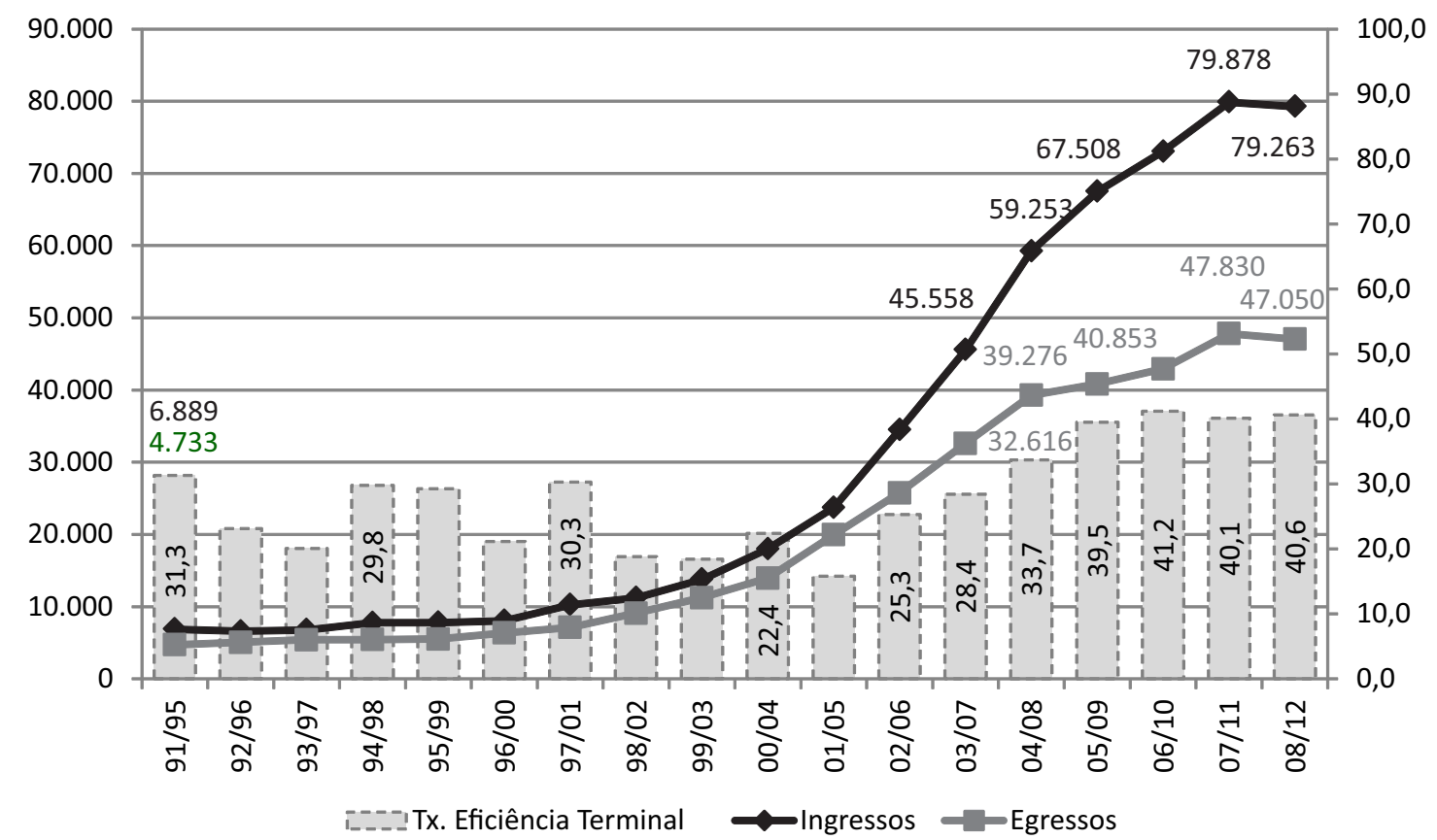

Fonte: elaboração própria, com base em dados do Inep (2013). 
Gráfico 9 - Evolução de ingressos e egressos de odontologia e taxa de eficiência terminal dos cursos. Brasil - 1991-1995 e 2008-2012

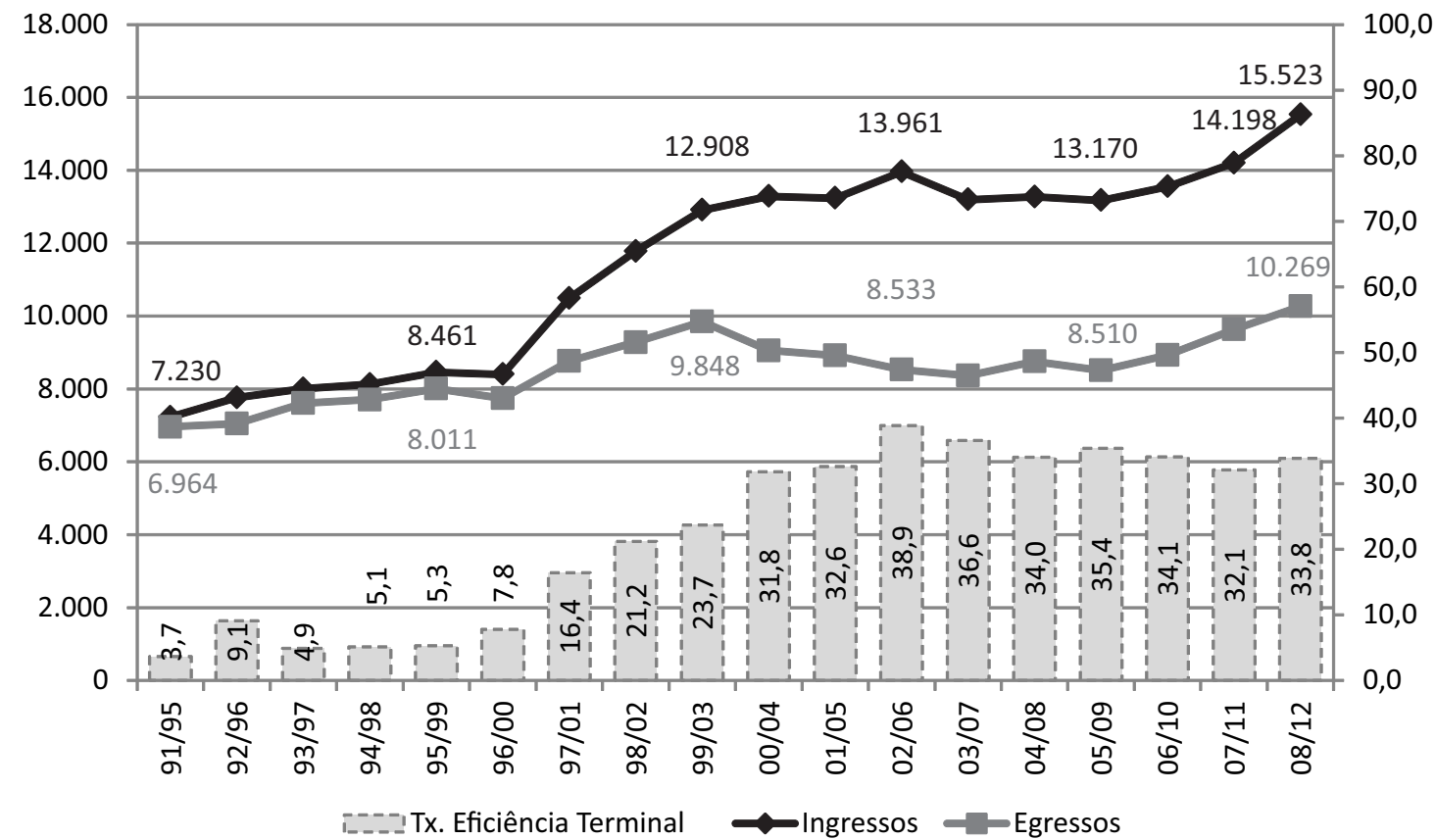

Fonte: elaboração própria, com base em dados do Inep (2013).

\section{Estimativas Futuras da Força de Trabalho}

\section{Sobre as técnicas e métodos}

Metodologias para a realização de previsões sobre a força de trabalho qualificada em saúde são relativamente escassas nos países em desenvolvimento, como afirma Rodrigues (2008), podendo citar para o caso de médicos, autores como Medina (1988) e Goic (1994, 1999), que desenvolveram uma metodologia de projeção baseada nas possibilidades de entrada e saída do profissional médico no mercado de trabalho. Existe também a metodologia proposta por Bevilacqua e Sampaio (2002) baseada em um modelo estatístico para a projeção de médicos segundo especialidades no Brasil. Um dos estudos mais recentes para vários países latino-americanos, entre eles o Brasil, é o de Barber Pérez, González López-Valcárcel e Suárez Vega (2011). No presente estudo, o cenário quantitativo do estoque de médicos, enfermeiros e cirurgiões-dentistas foi definido utilizando uma adequação da metodologia de projeções de população conhecida como "método das componentes demográficas", 3 anteriormente aplicada por Girardi e colaboradores (2012) apenas para médicos. Tal metodologia se baseia no conceito da equação compensatória e seus componentes que, de forma esquemática, ilustra-se na Figura 1.

\footnotetext{
${ }^{3}$ Para maiores detalhes sobre o Método das Componentes Demográficas, ver, por exemplo: Shryock e Siegel (1976), Celade (1984), Cedeplar (1999).
} 
Figura 1 - Equação compensatória para estimativas de recursos humanos

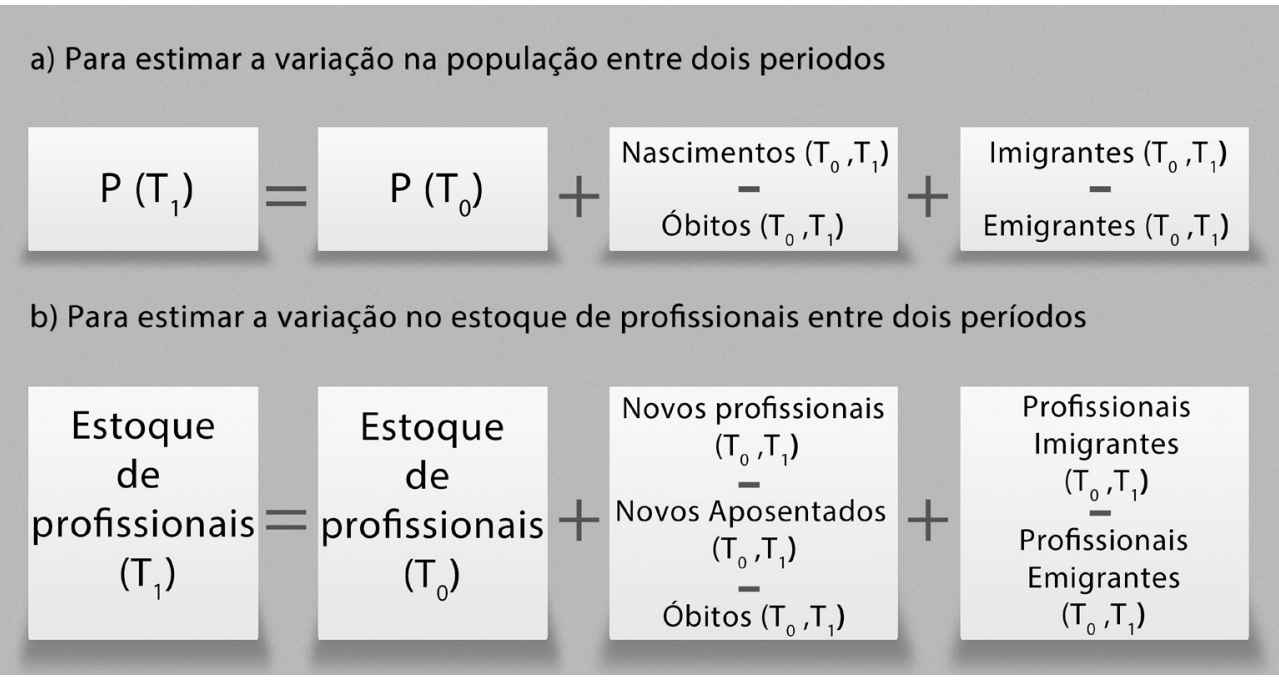

Fonte: Rodrigues, 2008.

O item a da Figura 1 explicita o processo de estimativa da população a partir de um período inicial $\left(\mathrm{T}_{0}\right)$ para um período seguinte $\left(\mathrm{T}_{1}\right)$, ao qual se adiciona uma nova população (no caso, nascimentos) e os demais eventos demográficos inerentes a uma coorte ou geração que se modifica aumentando ou diminuindo ao longo do tempo, seja por mortalidade (óbitos) e/ou fluxos migratórios. A adequação para estimar estoques de médicos é ilustrada no item b. Uma aplicação dessa adequação foi feita inicialmente por Rodrigues (2008) para Minas Gerais, na qual se empregaram também as estimativas de outros segmentos de força de trabalho qualificada (Pereira, Nascimento \& Araújo, 2013). Ressalta-se ainda que, seguindo o método das componentes demográficas, o esquema foi aplicado aos dados por sexo e idade. ${ }^{4}$

É importante esclarecer sobre a equação compensatória que, do ponto de vista conceitual, alguns aspectos mais complexos ficam de fora, como: a demanda e a necessidade de serviços de saúde, o impacto do desenvolvimento de novas tecnologias, a expansão da medicalização etc. Um elemento bastante determinante é a regulação profissional, podendo alterar (ampliar/diminuir) os escopos de prática de cada uma das profissões (Girardi et al., 2009). Apesar disso, exploram-se neste capítulo alguns cenários nos quais os estoques futuros de profissionais são adequados de acordo com alterações nos escopos de prática.

Para estimar a força de trabalho futura de médicos, enfermeiros e cirurgiões-dentistas seguindo a lógica da equação compensadora do método das componentes demográficas foi necessário estimar por profissão, sexo e idade: o número atual de profissionais economicamente ativos, isto é, a disponibilidade inicial, em 2010, de força de trabalho; o número de novos profissionais que se juntarão aos estoques iniciais e que derivam do sistema formativo das respectivas profissões, em outras palavras,

\footnotetext{
${ }^{4}$ Detalhes sobre a aplicação do método podem ser vistos em Rodrigues (2008).
} 
trata-se do número de nascimentos determinado pela quantidade e preenchimento das vagas em cursos de graduação e pelos níveis de conclusão dos cursos (comparação entre egressos e ingressos); o número de óbitos e as saídas por aposentadoria; e as entradas e saídas em razão da migração.

\section{Sobre os dados}

O primeiro componente da estimativa futura de profissionais é a definição do seu estoque inicial. O cálculo do número de profissionais da saúde é frequentemente feito a partir de um conjunto de bases de dados, buscando minimizar as dificuldades de contar aqueles que estão efetivamente disponíveis para o trabalho na assistência à saúde ou em atividades a ela relacionadas. O censo demográfico do IBGE se destaca, a priori, como a fonte que fornece o total de médicos, enfermeiros e cirurgiões-dentistas, estejam eles ocupados, desocupados ou não economicamente ativos, como se viu no tópico anterior. Neste caso, contam-se as pessoas que declararam ter graduação na área ou que estavam ocupadas no trabalho principal da semana de referência na profissão, sendo as duas condições não excludentes. ${ }^{5}$ Dessa forma, os valores podem ser superiores aos dos registros dos conselhos profissionais, em virtude da contagem de graduados na profissão que não possuem registro. Neste estudo utilizou-se o censo como referência para o cálculo do tamanho da população economicamente ativa das três profissões e sua composição por sexo e idade.

O segundo componente, isto é, o número de novos profissionais foi derivado dos dados de evolução da oferta, preenchimento de vagas (relação entre vagas e ingressos) e dos níveis de conclusão dos cursos de medicina, enfermagem e odontologia do Brasil, os quais provêm do Censo da Educação Superior do Inep. Utilizaram-se dois indicadores. De um lado, a razão entre número de inscritos por vaga - um importante indicador, pois o aumento da procura pelo curso, mesmo com o crescimento do número de vagas, destaca que a profissão é bem vista na percepção dos pretendentes à profissão, do ponto de vista vocacional e também econômico. Por outro lado, a chamada taxa de eficiência terminal da graduação. Essa taxa é medida pela relação entre o número de ingressos no ano $i$ e de egressos no ano $i+n$, sendo $n$ o número de anos de duração do curso, menos 1 . Expressa através de percentual, tal proporção não pode ser confundida com a verificação do número de alunos que não se formaram dentre aqueles que ingressaram. A proporção expressa a não conclusão no período provável de formação em relação ao volume de ingressantes e concluintes nos dois períodos em análise, seja por atraso ou desistência.

Os números de óbitos foram obtidos indiretamente considerando como evidência os dados da Rais de 2010 (Brasil, 2011), aplicando-se ao estoque atual as probabilidades de morte decorrentes de tabelas de sobrevivência. Não existe claro consenso sobre diferenciais de mortalidade adulta segundo composição profissional, embora um bom número de estudos coincida em indicar níveis de mortalidade menores para grupos como médicos e cirurgiões-dentistas. Presume-se que essas categorias

\footnotetext{
${ }^{5}$ Contam-se graduados e ocupados na profissão; graduados na profissão, mas ocupados em outra função; e os ocupados na profissão, sem informação de graduação na área (Destacando que o registro de curso de graduação no censo ocorre para a última graduação concluída pelo entrevistado e desde que o maior nível de formação seja o de graduação. Dessa forma não é possível saber a graduação dos pós-graduados). Os dados foram consistidos, tendo sido desconsiderados os casos de entrevistados identificados nas três profissões que não tivessem nível superior completo ou idade mínima de 22 anos, no caso de médicos; e de 21 anos, no caso de enfermeiros e cirurgiões-dentistas.
} 
profissionais, por terem educação superior e acesso mais facilitado a bens de consumo, apresentam menores níveis de mortalidade que os definidos para a média do cidadão brasileiro, o que pode ocorrer de forma diferente para enfermeiros. Assim, calculou-se o diferencial dos riscos de morte por sexo e idade entre os indivíduos classificados como médicos, enfermeiros e cirurgiões-dentistas e o restante dos trabalhadores, cada um em seu momento, por meio da Rais. O mesmo diferencial foi aplicado à tábua de mortalidade do total do país para aquele ano, assumindo que essa é representativa dos profissionais em questão e de um sistema de tábuas-modelo. ${ }^{6}$

A população total do Brasil estimada para os períodos considerados, salvo especificação contrária, foi a definida pelo Centro de Desenvolvimento e Planejamento Regional da UFMG (Cedeplar, 2012).

\section{Sobre os pressupostos adotados para as projeções}

No exercício de estimativa para os anos de 2010 a 2030, assumiu-se como população inicial o número de residentes no país em 2010 aptos ao exercício da profissão, para o qual se estabeleceu um corte de acordo com a condição de atividade. Dessa forma, incluíram-se todos os economicamente ativos (ocupados e desocupados), independentemente da idade. Em razão das diferenças demográficas e de oferta e demanda de cada profissão, procedeu-se a um modelo para cada caso com pressupostos e cenários distintos, os quais são apresentados a seguir:

- O número de novos profissionais que se juntarão aos estoques existentes está estreitamente associado a uma cadeia de eventos que historicamente mostram associação e regularidade. Tal cadeia começa com o planejamento e posterior pedido de vagas para admissão de novos alunos às escolas. Uma vez que se autoriza a abertura de vagas, estas se cristalizam em matrículas que após o período regular de duração do curso refletem um número de egressos. No caso da medicina, após seis anos o número de egressos foi praticamente constante em relação ao número original de vagas, no período de 1991-1996 a 2007-2012, apresentando uma taxa de eficiência terminal média de 90\%. Já para enfermagem e odontologia, com cinco anos se observa uma distância maior entre egressos e vagas correspondentes, no período de 1991-1995 a 2008-2012, o que reflete um alto abandono do curso, principalmente na segunda metade da década de 2000. Em média, as taxas foram de $72 \%$ e $77 \%$, respectivamente.

- O volume de profissionais no Brasil entre 2010 e 2015 está praticamente definido principalmente pela formação dos estudantes de medicina que se matricularam entre 20032004 a 2009-2010 e pelos estudantes de enfermagem e odontologia que se matricularam entre 2004-2005 a 2009-2010. Esse volume variará ligeiramente em razão do percurso da migração e da mortalidade, esta última, afetando minimamente a variação do estoque. Para os anos posteriores a 2015, o volume poderá divergir caso venha a se registrar variação do número de vagas que as universidades oferecerão para os anos posteriores a 2010, o que foi definido por meio de cenários hipotéticos abordados adiante.

\footnotetext{
${ }^{6}$ A tabela de mortalidade para o país é aquela definida pelo IBGE (IBGE, 2009). O sistema de tábuas-modelo de mortalidade utilizado foi o de Coale e Demeny (Modelo Oeste), que é o que com mais frequência costuma se ajustar melhor à experiência de mortalidade dos países em desenvolvimento (Coale \& Demeny, 1983).
} 
- Definiu-se que, se a média dos trabalhadores apresenta uma esperança de vida similar à correspondente ao total do país para 2010, os médicos e cirurgiões-dentistas, respeitando os diferenciais encontrados na Rais, teriam uma esperança de vida superior em aproximadamente quatro anos (Tabela 1 do Apêndice), com ligeira vantagem para o sexo feminino; e os enfermeiros teriam uma esperança de vida similar, também respeitando a análise realizada pela Rais. Ressalte-se que essa decisão, embora subjetiva e suscetível a melhoras, pouco afeta o resultado final, uma vez que na população economicamente ativa o número de óbitos esperados variará muito pouco, qualquer que seja o nível de mortalidade definido.

- As saídas por aposentadoria, quando significam saída definitiva do mercado de trabalho, não foram consideradas uma vez que o modelo admite apenas a população economicamente ativa.

- Quanto às entradas e saídas em consequência da migração, presume-se que o estoque de profissionais alterar-se-á em virtude da migração da mesma forma em que o Brasil é afetado. As evidências disponíveis sugerem que o saldo migratório internacional de profissionais da saúde tem sido tradicionalmente irrelevante, daí que, neste exercício, se considere que o volume total da força de trabalho das profissões em questão seja desprezível. A validade dessa decisão será revisada, evidentemente, à luz dos próximos censos demográficos.

\section{Cenários e resultados}

\section{Médicos}

Na construção dos componentes que constituem o estoque de profissionais explicitado no item anterior, o volume de médicos economicamente ativos no Brasil para o período entre 2010 e 2015 foi definido, principalmente, com base na formação dos estudantes de medicina que se matricularam entre 2003-2004 a 2009-2010. Esse volume varia ligeiramente em função do comportamento da migração e da mortalidade, esta última, afetando minimamente a variação do estoque. Para os anos posteriores a 2015, o volume poderá divergir caso seja registrada variação de monta no número de vagas efetivamente ofertadas nos anos posteriores a 2012, como é o caso do que se desenha a partir do Programa Mais Médicos do Governo Federal (Brasil, 2013). Assim, há possibilidade de se vislumbrar alguns cenários que podem determinar a futura variação desse estoque:

- Cenário tendencial: com base no comportamento que as escolas de medicina do país apresentaram no período entre 1991 e 2012, em relação ao número anual de vagas, assumese que o crescimento de 3,4\%, não será sustentado. De fato, no último quadriênio, entre 2009 e 2012, as vagas cresceram em um patamar menor, de 2,4\% ao ano. Assume-se, nesse cenário, que as vagas manterão um ritmo menor de crescimento e passarão de 17.931, em 2012, para 24.161, em 2024. O volume de novos médicos até 2030, portanto, aumentará a partir dessa tendência. Além disso, em média, a taxa de eficiência terminal do curso será de $84 \%$, e a razão de ingresso por vaga será de 1,0, valores que também foram observados para o último quadriênio.

- Cenário Mais Médicos: o segundo cenário é baseado na oferta de novas vagas previstas no Programa Mais Médicos num total de 12.761 entre 2013 e 2017 (sendo 1.762 em 2013, 
2.912 em 2014, 4.242 em 2015, 3.619 em 2016 e 226 em 2017). ${ }^{7}$ A partir de 2018, prevê-se que o número total de vagas resultante, que passará de 17.931 para 30.692, permanecerá constante sem a intervenção do Programa. As tendências quanto ao preenchimento das vagas e à conclusão do curso no tempo previsto serão aquelas observadas entre 2003 e 2012, isto é, taxa de eficiência terminal de $87 \%$ e razão de ingresso por vaga de 1,0 .

- Cenário sem crescimento: como comparação, um terceiro cenário implicará manter o número de vagas anuais entre 2010-2015 constante até 2030, isto é, sem alteração. Além disso, a eficiência terminal e o preenchimento de vagas permanecerão como observados no último quadriênio.

Esses cenários resultam, para 2030, em estoques oscilando entre 552,9 e 668,7 mil profissionais médicos para Brasil (Tabela 3). No caso do cenário tendencial, esperar-se-ia que a atual RMH, de 1,72 médico por cada mil habitantes em 2010, passasse para 2,57 em 2030. A razão ficaria em 2,46 no cenário de crescimento zero do número de vagas e em 2,98 no cenário do Programa Mais Médicos. A composição por idade obtida no cenário tendencial indica que a diferença por sexo tenderá a cair, visto que o número de vestibulandos e estudantes segundo sexo tende a ser igual, com ligeira tendência ao maior aumento entre as mulheres.

Tabela 3 - Brasil 2010-2030: número de médicos, incremento médio anual e razão por mil habitantes

\begin{tabular}{|c|c|c|c|c|c|}
\hline Cenários & 2010 & 2015 & 2020 & 2025 & 2030 \\
\hline \multicolumn{6}{|c|}{ a) Médicos } \\
\hline Cenário 1 (tendencial) & 328.006 & 383.652 & 440.021 & 505.897 & 577.707 \\
\hline Cenário 2 (Mais Médicos) & 328.006 & 384.681 & 444.477 & 553.692 & 668.767 \\
\hline Cenário 3 (sem crescimento) & 328.006 & 385.922 & 443.850 & 501.287 & 552.983 \\
\hline \multicolumn{6}{|c|}{ b) Incremento médio anual do n. de novos profissionais } \\
\hline Cenário 1 (tendencial) & & 11.129 & 11.274 & 13.175 & 14.362 \\
\hline Cenário 2 (Mais Médicos) & & 11.335 & 11.959 & 21.843 & 23.015 \\
\hline Cenário 3 (sem crescimento) & & 11.583 & 11.586 & 11.487 & 10.339 \\
\hline \multicolumn{6}{|c|}{ c) N. de profissionais por mil habitantes } \\
\hline Cenário 1 (tendencial) & 1,72 & 1,88 & 2,07 & 2,30 & 2,57 \\
\hline Cenário 2 (Mais Médicos) & 1,72 & 1,89 & 2,09 & 2,52 & 2,98 \\
\hline Cenário 3 (sem crescimento) & 1,72 & 1,89 & 2,09 & 2,28 & 2,46 \\
\hline
\end{tabular}

Fonte: elaboração própria, com base em metodologia específica.

\section{Enfermeiros}

Os cenários desenhados para enfermeiros são os seguintes:

- Cenário tendencial: com base no comportamento que as escolas de Enfermagem do país apresentaram no período entre 1991 e 2012, em relação ao número anual de vagas, assume-

\footnotetext{
7 Dados do cadastro do Programa Mais Médicos de fevereiro de 2016 obtidos por solicitação especial ao Departamento de Gestão da Educação em Saúde da Secretaria de Gestão do Trabalho e da Educação em Saúde do Ministério da Saúde.
} 
se que o crescimento de $13,7 \%$ ao ano não será sustentado. De fato, no último quadriênio, entre 2009 a 2012, as vagas decresceram a 2,1\% ao ano. Assume-se que as vagas manterão esse ritmo de fechamento e passarão de 120.180, em 2012, para 83.962, em 2025. O número de novos enfermeiros, portanto, acompanhará tal tendência sofrendo desaceleração em seu crescimento até 2030. Além disso, em média, a taxa de eficiência terminal será de 64\% e a razão de ingresso por vaga de 0,63 , valores que também foram observados para o último quadriênio.

- Cenário regulatório: é baseado na reversão do quadro atual de fechamento de vagas nos cursos de enfermagem, buscando estabelecer volumes de profissionais que no futuro possam cobrir um escopo de prática ampliado da profissão (por exemplo, em anestesia, obstetrícia e geriatria), bem como a expansão das atividades da ESF, a qual passaria a exigir a presença de dois enfermeiros por equipe. Ainda que os mais de $50 \%$ da força de trabalho graduada em enfermagem não ativa na profissão passem a sê-lo, supõe-se que ainda assim não será suficiente para atender o novo cenário regulatório suposto. Assim, prevê-se a mesma tendência observada entre 2003 e 2012, isto é, crescimento de vagas de 9,1\% ao ano até 2017 (passando de 120.180 para 171.559), eficiência terminal de $86 \%$ e razão de ingressos por vaga de 0,75 .

- Cenário sem crescimento: como comparação, um terceiro cenário implicará manter o número de vagas anuais observado em 2012 constante até 2030, isto é, sem incremento. A eficiência terminal e o preenchimento de vagas permaneceriam como no último quadriênio.

Tais cenários resultam, para 2030, em estoques oscilando de 1,073 a 1,970 milhão de enfermeiros para Brasil (Tabela 4). No caso do cenário tendencial, esperar-se-ia que a razão de 1,59 enfermeiro por cada mil habitantes em 2010, passasse para 4,78 em 2030. A razão ficaria em torno de 5,61 no cenário de crescimento zero do número de vagas e 8,77 no cenário regulatório.

Tabela 4 - Brasil 2010-2030: número de enfermeiros, incremento médio anual e razão por mil habitantes

\begin{tabular}{|c|c|c|c|c|c|}
\hline Cenários & 2010 & 2015 & 2020 & 2025 & 2030 \\
\hline \multicolumn{6}{|c|}{ a) Enfermeiros } \\
\hline Cenário 1 (tendencial) & 308.429 & 492.630 & 713.892 & 907.186 & 1.073 .915 \\
\hline Cenário 2 (regulatório) & 308.429 & 588.531 & 954.632 & 1.440 .372 & 1.970 .500 \\
\hline Cenário 3 (sem crescimento) & 308.429 & 557.773 & 843.510 & 1.054 .183 & 1.258 .893 \\
\hline \multicolumn{6}{|c|}{ b) Incremento médio anual do n. de novos profissionais } \\
\hline Cenário 1 (tendencial) & & 36.840 & 44.252 & 38.659 & 33.346 \\
\hline Cenário 2 (regulatório) & & 56.021 & 73.220 & 97.148 & 106.026 \\
\hline Cenário 3 (sem crescimento) & & 49.869 & 57.147 & 42.135 & 40.942 \\
\hline \multicolumn{6}{|c|}{ c) N. de profissionais por mil habitantes } \\
\hline Cenário 1 (tendencial) & 1,59 & 2,42 & 3,36 & 4,13 & 4,78 \\
\hline Cenário 2 (regulatório) & 1,59 & 2,89 & 4,49 & 6,56 & 8,77 \\
\hline Cenário 3 (sem crescimento) & 1,59 & 2,74 & 3,97 & 4,80 & 5,61 \\
\hline
\end{tabular}

Fonte: elaboração própria, com base em metodologia específica. 


\section{Cirurgiões-dentistas}

Os cenários desenhados para cirurgiões-dentistas são os seguintes:

- Cenário tendencial: com base no comportamento que os cursos de odontologia do país apresentaram entre 1991 e 2012, em relação ao número anual de vagas, assume-se que o crescimento de 5,1\% ao ano não se sustentará. De fato, no último quadriênio, entre 2009 a 2012, as vagas cresceram a 2,0\% ao ano. Assume-se que as vagas manterão esse ritmo menor de crescimento e passarão de 20.589, em 2012, para 26.500, em 2025. O número de novos cirurgiões-dentistas acompanhará tal tendência. A taxa de eficiência terminal será de 69\% e a razão de ingresso por vaga de 0,91, valores que também foram observados para o último quadriênio.

- Cenário regulatório: é baseado na reversão do quadro atual de desaceleração do crescimento de vagas com o objetivo de estabelecer volumes de profissionais que no futuro possam cobrir uma demanda reprimida na área, neste caso, prevendo a universalização dos serviços de saúde bucal no SUS, sem que se alterem substancialmente os serviços privados. Prevê-se a mesma tendência observada entre 1991 e 2012, isto é, crescimento de vagas de 5,1\% ao ano (passando de 20.589, em 2012, para 39.237, em 2025). Além da ampliação no número de vagas, este cenário inclui intervenções nos níveis de aproveitamento de vagas e conclusão do curso, considerando uma razão de ingresso por vaga de 0,9 e taxa de eficiência terminal de 90\%.

- Cenário sem crescimento: como comparação, um terceiro cenário implicará manter o número de vagas anuais observado em 2012 constante até 2030, com eficiência terminal e preenchimento das vagas similar ao último quadriênio.

Esses cenários resultam, para 2030, em estoques oscilando de 439 a 562,4 mil cirurgiões-dentistas para o Brasil (Tabela 5). No caso do cenário tendencial, esperar-se-ia que a razão de 1,11 cirurgiãodentista por cada mil habitantes em 2010, passasse para 1,96 em 2030. A razão ficaria em torno de 1,99 no cenário de crescimento zero do número de vagas e 2,50 no cenário regulatório.

Tabela 5 - Brasil 2010-2030: número de cirurgiões-dentistas, incremento médio anual e razão por mil habitantes

\begin{tabular}{|c|c|c|c|c|c|}
\hline Cenários & 2010 & 2015 & 2020 & 2025 & 2030 \\
\hline \multicolumn{6}{|c|}{ a) Cirurgiões-dentistas } \\
\hline Cenário 1 (tendencial) & 214.909 & 263.299 & 317.203 & 376.449 & 439.098 \\
\hline Cenário 2 (regulatório) & 214.909 & 279.653 & 353.195 & 445.291 & 562.423 \\
\hline Cenário 3 (sem crescimento) & 214.909 & 273.723 & 342.546 & 396.449 & 446.641 \\
\hline \multicolumn{6}{|c|}{ b) Incremento médio anual do $\mathrm{n}$. de novos profissionais } \\
\hline Cenário 1 (tendencial) & & 9.678 & 10.781 & 11.849 & 12.530 \\
\hline Cenário 2 (regulatório) & & 12.949 & 14.708 & 18.419 & 23.426 \\
\hline Cenário 3 (sem crescimento) & & 11.763 & 13.765 & 10.781 & 10.038 \\
\hline \multicolumn{6}{|c|}{ c) N. de profissionais por mil habitantes } \\
\hline Cenário 1 (tendencial) & 1,11 & 1,29 & 1,49 & 1,71 & 1,96 \\
\hline Cenário 2 (regulatório) & 1,11 & 1,37 & 1,66 & 2,03 & 2,50 \\
\hline Cenário 3 (sem crescimento) & 1,11 & 1,34 & 1,61 & 1,81 & 1,99 \\
\hline
\end{tabular}

Fonte: elaboração própria, com base em metodologia específica. 


\section{Considerações Finais}

O presente capítulo teve por objetivo apresentar as estruturas e as estimativas dos quantitativos de médicos, enfermeiros e cirurgiões-dentistas no Brasil entre 2010 e 2030 . A metodologia utilizada, quando aplicada às populações de profissionais de nível superior, tem dado resultados consistentes. A qualidade e oportunidade dos censos de população e do ensino superior, comparativamente à relativa precariedade de outros sistemas estatísticos, justificam o uso da metodologia demográfica aqui adaptada. Além disso, a flexibilidade de se desenharem cenários hipotéticos permite considerar aspectos relativos à demanda futura por recursos humanos da saúde, elemento que não é explorado diretamente em outros modelos.

Em relação à medicina, a análise dos dados sugere uma tendência pregressa a 2010 de crescimento contido da oferta de vagas na graduação, resultando em uma razão de 1,72 médico por mil habitantes naquele ano. Do ponto de vista demográfico, assistiu-se a um aparente paradoxo, constituído pela concomitância entre um forte rejuvenescimento da força de trabalho ao lado de seu envelhecimento em razão do elevado tempo médio de permanência dos profissionais no exercício da profissão e do prolongado período de relativa estagnação do número de vagas nos anos 1980 e primeira metade dos anos 1990. Observou-se ainda ampliação da participação feminina, embora insuficiente para que os homens deixassem de ser a maioria. A grande oferta de oportunidades de trabalho e serviços médicos, o crescimento do emprego formal e dos salários e o pleno aproveitamento das vagas oferecidas pelos cursos de medicina nos anos recentes corroboram os diagnósticos de escassez e justificam a adoção de políticas de ampliação da oferta de médicos, a exemplo do Mais Médicos. Os resultados das projeções, em quaisquer dos cenários analisados, indicam escassez de médicos no futuro. Nem mesmo no cenário de maior expansão e adequação da distribuição regional da oferta de vagas e cursos (Mais Médicos), a questão da escassez seria afastada, ainda mais se considerarmos o crescimento das demandas decorrentes do envelhecimento populacional e das mudanças epidemiológicas, tecnológicas e organizacionais em curso em nosso país.

A enfermagem representou uma situação oposta à da medicina, na medida em ampliou expressivamente a oferta de vagas nos cursos de graduação e a população de diplomados nos anos 2000 . O fato de ter uma composição majoritariamente feminina, associado ao expressivo rejuvenescimento ocorrido naquela década e a dependência de uma trajetória assalariada típica no mercado de trabalho acarretaram uma exposição minoritária de enfermeiros diplomados ao exercício efetivo da profissão. A taxa de 1,59 enfermeiro por mil habitantes em 2010, portanto, deve ser reduzida a menos da metade para que se considere a disponibilidade real de profissionais para os serviços de saúde. Embora as vagas nos cursos de enfermagem tenham começado a declinar a partir de 2011, o cenário tendencial assinala uma taxa de 4,78 enfermeiros por mil habitantes em 2030, mesmo com a manutenção de baixas taxas de aproveitamento de vagas e de eficiência terminal dos cursos. Tal razão, no entanto, só se mostrará relevante caso aumente a proporção de pessoas ocupadas na profissão. Note-se que um cenário ainda mais expansivo poderia ser considerado, com uma razão de 8,77 profissionais por mil habitantes em uma conjuntura de ampliação de escopos de práticas em áreas como obstetrícia, anestesiologia, geriatria e saúde da família. 
A odontologia, por sua vez, apresentou uma situação próxima à da medicina, com o crescimento mais contido das vagas de graduação e processos concomitantes de rejuvenescimento, envelhecimento e feminilização da população economicamente ativa. Entretanto, a odontologia apresentou um quantitativo menor de profissionais, com um aproveitamento bem menor das vagas existentes e baixa participação no mercado de trabalho formal, além de uma maioria feminina, em que pese a existência de enorme demanda pelos serviços de saúde bucal do SUS. Assim, contra uma razão de 1,1 profissional por mil habitantes em 2010, prevê-se um cenário regulatório com uma razão de 2,5 em 2030, o qual se esperaria atender às atuais demandas de acesso universal e integral aos serviços de saúde bucal, sem que se alterasse substancialmente a disponibilidade de profissionais no mercado privado.

\section{Referências}

BARBER PÉREZ, P.; GONZÁLEZ LÓPEZ-VALCÁRCEL, B. \& SUÁREZ VEGA, R. Oferta, Demanda y Necesidad de Médicos Especialistas en Brasil: proyecciones a 2020. Las Palmas: Universidad de Las Palmas de Gran Canaria, 2011.

BEVILACQUA, R. G. \& SAMPAIO, S. A. P. As especializações: histórico e projeções. In: NEGRI, B.; FARIA, R. \& VIANA, A. L. D. (Orgs.). Recursos Humanos em Saúde: política, desenvolvimento e mercado de trabalho. Campinas: Editora Unicamp, 2002.

BRASIL. Ministério do Trabalho e Emprego. Relação Anual de Informações Sociais: competência 2010. Brasília: MTE, SPPE, DES, CGET, 2011. CD-ROM.

BRASIL. Lei 12.871, 22 de out. 2013. Institui o Programa Mais Médicos, altera as Leis n. 8.745, de 9 de dezembro de 1993, e n. 6.932, de 7 de julho de 1981, e dá outras providências. Diário Oficial da União, Brasília, 2013.

CARVALHO, J. A. M. \& GARCIA, R. A. O envelhecimento da população brasileira: um enfoque demográfico. Cadernos de Saúde Pública, 19(3): 725-733, 2003.

CENTRO DE DESENVOLVIMENTO E PLANEJAMENTO REGIONAL (CEDEPLAR). Projeção Populacional das Unidades da Federação, Brasil, por Sexo e Grupos Quinquenais de Idades, 1990-2020. Belo Horizonte: Cedeplar, Universidade Federal de Minas Gerais, 1999. (Mimeo.)

CENTRO DE DESENVOLVIMENTO E PLANEJAMENTO REGIONAL (CEDEPLAR). Estimativas de população: revisões preliminares incorporando informação do Censo Demográfico de 2010. Relatório de pesquisa. Belo Horizonte: Cedeplar, 2012.

CENTRO LATINOAMERICANO DE DEMOGRAFÍA (CELADE). Métodos para Proyecciones Demográficas. Santiago: Celade, 1984.

COALE, A. \& DEMENY, P. Regional Model Life Tables and Stable Populations. 2. ed. New York: Academic Press, 1983.

CONSELHO FEDERAL DE ENFERMAGEM (COFEN). Análise de Dados dos Profissionais de Enfermagem Existentes nos Conselhos Regionais. Brasília: COFEN, 2011. Disponível em: <http://www.cofen.gov.br/wp-content/ uploads/2012/03/pesquisaprofissionais.pdf>. Acesso em: 22 maio 2017.

CONSELHO FEDERAL DE ENFERMAGEM (COFEN). Enfermagem em Números. Brasília: COFEN, 2013. Disponível em: <http://www.cofen.gov.br/enfermagem-em-numeros>. Acesso em: jun. 2013.

CONSELHO FEDERAL DE MEDICINA (CFM). Portal Médico. Estatística. Disponível em: < http://portal.cfm.org. br/index.php?option=com_estatistica $>$. Acesso em: jun. 2013.

CONSELHO FEDERAL DE ODONTOLOGIA (CFO). Dados Estatísticos. Disponível em: < http://cfo.org.br/ servicos-e-consultas/Dados-estatisticos>. Acesso em: jun. 2013. 
DAL POZ, M. R.; PIERANTONI, C. R. \& GIRARDI, S. Formação, mercado de trabalho e regulação da força de trabalho em saúde no Brasil. In: GADELHA, P.; CARVALHO, J. N. \& PEREIRA, T. R. A Saúde no Brasil em 2030: diretrizes para a prospeç̧ão estratégica do sistema de saúde brasileiro. Rio de Janeiro: Fiocruz, Ipea, Ministério da Saúde, Secretaria de Assuntos Estratégicos da Presidência da República, 2013.

DEPARTAMENTO DE PLANEJAMENTO E REGULAÇÃO DA PROVISÃO DE PROFISSIONAIS DE SAÚDE (DEPREPS). Cadastro do Programa Mais Médicos. Brasília: DEPREPS/SGTES/MS, 2016.

GIRARDI, S. N. et. al. Avaliação nacional da demanda de médicos especialistas percebida pelos gestores de saúde. Relatório de Pesquisa. Belo Horizonte: Estação de Pesquisa de Sinais de Mercado, EPSM/NESCON/FM/ UFMG, 2009. Disponível em: < http://epsm.nescon.medicina.ufmg.br/epsm/>. Acesso em: 01 jul. 2014.

GIRARDI, S. et al. O trabalho precário em saúde: tendências e perspectivas na estratégia da saúde da família. Divulgação em Saúde Para Debate, 45: 11-23, 2010.

GIRARDI, S. N. et al. Monitoramento da demanda por especialidades e residências médicas no Brasil. Relatório de pesquisa. Belo Horizonte: Estação de Pesquisa de Sinais de Mercado, EPSM/NESCON/FM/UFMG, 2012. Disponível em: < http://epsm.nescon.medicina.ufmg.br/epsm/> . Acesso em: 01 jul. 2014.

GOIC, A. Disponibilidad de médicos en Chile y su proyección a mediano plazo. Revista Médica de Chile, 122: 141-153, 1994.

GOIC, A. Disponibilidad de médicos en Chile y su proyección a mediano plazo: cinco años después. Revista Médica de Chile, 127: 1.183-1.188, 1999.

INSTITUTO BRASILEIRO DE GEOGRAFIA E ESTATÍSTICA (IBGE). Microdados do Censo Demográfico: amostra de uso público. Rio de Janeiro: IBGE, 2002. CD-ROM.

INSTITUTO BRASILEIRO DE GEOGRAFIA E ESTATÍSTICA (IBGE). Brasil: tábua completa de mortalidade, 2009. Disponível em: <www.ibge.gov.br/home/estatistica/populacao/tabuadevida/2009/defaulttab.shtm>. Acesso em: 01 jul. 2014.

INSTITUTO BRASILEIRO DE GEOGRAFIA E ESTATÍSTICA (IBGE). Microdados da Amostra do Censo Demográfico 2010. Rio de Janeiro: IBGE, 2012. Disponível em: <http://ftp.ibge.gov.br/Censos/Censo_Demografico_2010/ Resultados_Gerais_da_AmosAmo/Microdados/>. Acesso em: 27 abr. 2012.

INSTITUTO NACIONAL DE ESTUDOS E PESQUISAS EDUCACIONAIS ANÍSIO TEIXEIRA (INEP). Dados Estatísticos dos Cursos de Graduação Presenciais, segundo as Instituições de Ensino e o Curso: Censo de 1991 a 2012. Brasília: Inep, 2013.

MEDINA, E. Necessidades de médicos em Chile. Revista Médica de Chile, 116: 389-394, 1988.

PEREIRA, R. H. M.; NASCIMENTO, P. M. \& ARAÚJO, C. T. Projeções de mão de obra qualificada no Brasil: cenários para a disponibilidade de engenheiros até 2020. Revista Brasileira de Estudos de População, 30(2): 519-548, 2013.

RODRIGUES, F. G. Médicos em Minas Gerais: projeções para o período 2010-2020, 2008. Dissertação de Mestrado, Belo Horizonte: Universidade Federal de Minas Gerais.

SHRYOCK, H. S.; SIEGEL, J. S. \& STOCKWELL, E. G. The Methods and Materials of Demography. New York: Academic Press, 1976.

ZAEYEN, A. et al. Economia política da saúde: uma perspectiva quantitativa. Texto para Discussão $n^{\circ} 370$, Rio de Janeiro: Instituto de Pesquisa Econômica Aplicada, 1995. 


\section{APÊNDICE}

Tabela 1 - Estimativas de esperança de vida ao nascer para a população total e para os profissionais médicos, enfermeiros e cirurgiões-dentistas. Brasil - 2010

\begin{tabular}{|l|c|c|}
\hline & Homens & Mulheres \\
\hline 1. População Total do Brasil (*) & 69.4 & 77.0 \\
\hline 2. Médicos e Cirurgiões-dentistas (**) & 73.1 & 81,3 \\
\hline 3. Enfermeiros (**) & 69.4 & 77.0 \\
\hline Diferença entre (1) e (2) & 3.7 & 4.3 \\
\hline Diferença entre (1) e (3) & 0.0 & 0.0 \\
\hline
\end{tabular}

* Tábua de Mortalidade de 2009 do IBGE

** Estimativa realizada segundo o sistema de tábuas-modelo de Coale e Demeny (1983), com base nos dados do MTE (Brasil, 2011)

Tabela 2 - Evolução do número de cursos de medicina, vagas, inscritos no vestibular, ingressos, matriculados e egressos. Brasil - 1991-2012

\begin{tabular}{|c|c|c|c|c|c|c|c|}
\hline Ano & Cursos & Vagas & Inscritos vestibular & Ingressos & Matriculados & Egressos & Acumulado 10 anos \\
\hline 1991 & 80 & 7.786 & 170.151 & 7.667 & 46.881 & 7.315 & - \\
\hline 1992 & 80 & 7.864 & 174.128 & 7.875 & 47.753 & 7.074 & - \\
\hline 1993 & 80 & 7.800 & 198.657 & 7.683 & 47.386 & 7.228 & - \\
\hline 1994 & 81 & 7.979 & 201.218 & 7.820 & 47.919 & 7.622 & - \\
\hline 1995 & 85 & 8.247 & 241.503 & 7.888 & 47.934 & 7.194 & - \\
\hline 1996 & 86 & 7.946 & 250.944 & 7.845 & 48.667 & 7.347 & - \\
\hline 1997 & 88 & 9.001 & 261.620 & 8.764 & 48.601 & 7.705 & - \\
\hline 1999 & 92 & 9.202 & 263.384 & 9.566 & 50.879 & 7.616 & - \\
\hline 2000 & 100 & 9.469 & 288.571 & 9.500 & 52.304 & 7.758 & - \\
\hline 2001 & 106 & 10.089 & 282.065 & 10.313 & 57.930 & 8.363 & 76.152 \\
\hline 2002 & 115 & 11.243 & 326.482 & 10.830 & 59.755 & 8.498 & 77.335 \\
\hline 2003 & 126 & 12.281 & 321.532 & 11.898 & 60.912 & 9.113 & 79.220 \\
\hline 2004 & 136 & 12.824 & 334.431 & 12.894 & 64.965 & 9.339 & 80.937 \\
\hline 2006 & 149 & 14.661 & 313.683 & 14.283 & 68.834 & 10.004 & 83.747 \\
\hline 2007 & 160 & 15.278 & 303.076 & 15.424 & 74.034 & 10.381 & 86.781 \\
\hline 2008 & 177 & 16.241 & 364.108 & 16.267 & 79.246 & 10.133 & 89.209 \\
\hline 2009 & 185 & 16.876 & 390.774 & 17.339 & 97.994 & 11.881 & 96.541 \\
\hline 2010 & 181 & 16.468 & 542.007 & 18.473 & 103.312 & 12.982 & 101.519 \\
\hline 2011 & 188 & 16.852 & 695.964 & 18.253 & 108.142 & 14.634 & 107.790 \\
\hline 2012 & 206 & 17.931 & 850.674 & 20.203 & 111.530 & 16.354 & 132.507 \\
\hline
\end{tabular}

Fonte: elaboração própria, com base nos dados do Inep (2013). 
Tabela 3 - Evolução do número de cursos de enfermagem, vagas, inscritos no vestibular, ingressos, matriculados e egressos. Brasil - 1991-2012

\begin{tabular}{|c|c|c|c|c|c|c|c|}
\hline Ano & Cursos & Vagas & Inscritos vestibular & Ingressos & Matriculados & Egressos & Acumulado 10 anos \\
\hline 1991 & 108 & 7.460 & 28.995 & 6.889 & 22.237 & 3.434 & - \\
\hline 1992 & 110 & 7.311 & 27.517 & 6.588 & 22.873 & 3.340 & - \\
\hline 1993 & 107 & 7.334 & 32.789 & 6.769 & 24.470 & 3.795 & - \\
\hline 1994 & 108 & 8.252 & 35.722 & 7.759 & 26.040 & 4.373 & - \\
\hline 1995 & 108 & 8.068 & 43.800 & 7.806 & 27.477 & 4.733 & - \\
\hline 1996 & 111 & 8.283 & 43.990 & 8.059 & 29.414 & 5.065 & - \\
\hline 1997 & 123 & 9.905 & 53.287 & 10.238 & 31.873 & 5.411 & - \\
\hline 1998 & 140 & 11.376 & 59.728 & 11.215 & 33.543 & 5.447 & - \\
\hline 1999 & 153 & 13.781 & 76.951 & 13.789 & 37.179 & 5.522 & - \\
\hline 2000 & 183 & 20.417 & 102.974 & 17.996 & 45.342 & 6.355 & 47.475 \\
\hline 2001 & 215 & 24.646 & 122.337 & 23.723 & 53.179 & 7.139 & 51.180 \\
\hline 2002 & 285 & 37.061 & 186.823 & 34.475 & 71.475 & 9.102 & 56.942 \\
\hline 2004 & 332 & 47.347 & 201.621 & 45.558 & 92.134 & 11.252 & 64.399 \\
\hline 2005 & 474 & 70.400 & 230.680 & 59.253 & 120.851 & 13.965 & 73.991 \\
\hline 2006 & 564 & 95.367 & 223.497 & 67.508 & 153.359 & 19.968 & 89.226 \\
\hline 2007 & 636 & 108.629 & 242.386 & 73.036 & 186.955 & 25.755 & 109.916 \\
\hline 2008 & 690 & 117.340 & 234.738 & 79.263 & 224.742 & 39.276 & 170.950 \\
\hline 2009 & 765 & 119.966 & 259.042 & 74.699 & 235.281 & 40.853 & 206.281 \\
\hline 2010 & 805 & 133.243 & 258.337 & 71.244 & 245.462 & 42.940 & 242.866 \\
\hline 2011 & 847 & 121.051 & 298.188 & 70.903 & 246.876 & 47.830 & 283.557 \\
\hline 2012 & 871 & 120.180 & 341.761 & 76.891 & 236.713 & 47.050 & 321.505 \\
\hline & & & & & \\
\hline
\end{tabular}

Fonte: elaboração própria, com base nos dados do Inep (2013). 
Tabela 4 - Evolução do número de cursos de odontologia, vagas, inscritos no vestibular, ingressos, matriculados e egressos. Brasil - 1991-2012

\begin{tabular}{|l|l|l|l|l|l|l|l|}
\hline Ano & Cursos & Vagas & Inscritos vestibular & Ingressos & Matriculados & Egressos & Acumulado 10 anos \\
\hline 1991 & 83 & 7.315 & 118.162 & 7.230 & 30.702 & 6.089 & - \\
\hline 1992 & 85 & 7.691 & 116.191 & 7.758 & 31.950 & 6.203 & - \\
\hline 1993 & 86 & 7.996 & 107.738 & 8.006 & 33.388 & 6.355 & - \\
\hline 1994 & 89 & 8.253 & 116.476 & 8.126 & 35.101 & 6.773 & - \\
\hline 1995 & 91 & 8.521 & 136.927 & 8.461 & 35.999 & 6.964 & - \\
\hline 1996 & 93 & 8.476 & 141.556 & 8.396 & 37.303 & 7.050 & - \\
\hline 1997 & 101 & 9.643 & 132.918 & 10.488 & 38.631 & 7.613 & - \\
\hline 1998 & 117 & 11.267 & 116.243 & 11.777 & 41.093 & 7.710 & - \\
\hline 2000 & 131 & 13.304 & 108.820 & 12.908 & 43.815 & 8.011 & - \\
\hline 2001 & 153 & 14.051 & 97.533 & 13.285 & 46.324 & 7.742 & 70.510 \\
\hline 2002 & 159 & 15.701 & 84.617 & 13.961 & 47.753 & 9.281 & 73.186 \\
\hline 2003 & 171 & 16.333 & 71.455 & 13.195 & 46.915 & 9.848 & 79.757 \\
\hline 2004 & 174 & 15.733 & 69.517 & 13.270 & 46.039 & 9.056 & 82.040 \\
\hline 2005 & 179 & 16.301 & 66.919 & 13.170 & 46.731 & 8.919 & 83.995 \\
\hline 2007 & 185 & 16.841 & 64.007 & 13.550 & 46.693 & 8.533 & 85.478 \\
\hline 2008 & 193 & 18.266 & 63.621 & 14.198 & 46.723 & 8.366 & 86.231 \\
\hline 2009 & 196 & 19.257 & 67.258 & 15.523 & 48.752 & 8.754 & 87.275 \\
\hline 2010 & 201 & 19.069 & 81.893 & 16.338 & 57.603 & 8.930 & 88.962 \\
\hline 2011 & 209 & 20.861 & 102.963 & 18.753 & 63.590 & 9.637 & 89.834 \\
\hline 2012 & 215 & 20.589 & 134.670 & 23.057 & 70.293 & 10.269 & 90.822 \\
\hline
\end{tabular}

Fonte: elaboração própria, com base nos dados do Inep (2013). 


\title{
PROJEÇÃO DAS CAPACIDADES DE FORMAÇÃO DE PROFISSIONAIS DA SAÚDE
}

\author{
Mario Roberto Dal Poz \\ Thereza Christina Varella \\ Maria Ruth dos Santos
}

A análise dos principais aspectos históricos e conceituais das mudanças e necessidades de qualificação técnica, conhecimento especializado e oferta de formação das profissões da saúde de nível superior tem por objetivo delinear os condicionantes, a situação atual e os cenários possíveis e prováveis das categorias de médicos, enfermeiros, farmacêuticos, dentistas e fisioterapeutas para os próximos vinte anos.

A projeção de situações prospectivas implica a adequação de um conjunto de variáveis sendo, portanto, um trabalho eivado de incertezas. Segundo Boudon (1981), cenários são imagens de futuro, ou jogos coerentes de hipóteses nos quais há um conjunto formado pela descrição de uma situação de origem e dos acontecimentos que conduzem a uma determinada posição futura no contexto de uma narrativa lógica e coerente. Os cenários têm destaque entre os instrumentos utilizados pelos estudos prospectivos, com a vantagem de que se opõem às concepções determinísticas ou fatalistas do futuro, assumindo como pressuposto que os processos de mudanças são incertos e indeterminados e que os atores sociais têm diante de si, a cada instante, alternativas múltiplas e diversas.

A ação dos homens tem potencial para influir na história e pode assumir percursos diversos de acordo com as conjunturas políticas e os condicionamentos estruturais e que, por mais racionalidade que se imponha às prospecções, ainda assim há que se levar em conta os fatos inesperados e os constrangimentos, já que é impossível ter domínio sobre todas as variáveis. Dessa forma, é necessário dispor de lucidez para compreender que nenhum cenário será exatamente como aquele apontado, uma vez que a história evolui incorporando traços de diversas possibilidades e trazendo ainda para o contexto situações inusitadas (Porto \& Régnier, 2003).

Um determinado conjunto de cenários prospectivos pode transformar-se em um quadro de referência com incertezas reduzidas para a tomada de decisões estratégicas e para a formulação de políticas, podendo ser incorporado no processo de planejamento público da força de trabalho, tendo em vista o aperfeiçoamento do exercício das ocupações e profissões na área da saúde no Brasil e o desenvolvimento de sistemas de saúde (Vianna et al., 2013).

É consenso que as profissões, em geral, sofreram profundas transformações ao longo do século $\mathrm{XX}$ influenciadas por importantes processos de mudanças na estrutura profissional das sociedades e que as profissões da saúde, em particular, não ficaram imunes a essas mudanças. Na perspectiva da 
saúde, algumas profissões surgem, outras reduzem seu âmbito de atuação, bem como outras ainda se fortalecem abrindo novas áreas funcionais na divisão do trabalho ou se adaptam às mudanças no ambiente social e político.

Do ponto de vista da organização da rede de serviços, pode-se estabelecer, seguindo critérios socioculturais, um grupo de profissões nucleares (médicos, enfermeiros, dentistas e farmacêuticos) que sustentam grande parte das atribuições do sistema de atenção e contam com representação no imaginário social. Outras que estão em processo de consolidação de seu campo de atribuições e, mesmo que regulamentadas, tanto pelo setor educacional quanto pelos órgãos disciplinares do trabalho, ainda disputam o controle de nichos de atuação (fisioterapeuta e fisiatra, psicólogo e psiquiatra/ psicanalista, nutricionista e médicos/nutrólogos, a título de exemplo). Observa-se ainda com atenção, e de forma preliminar, profissões emergentes como obstetra, sanitarista, quiroprático, optometrista, entre outros, já com graduações em curso.

No panorama da educação superior no Brasil se destaca o crescimento expressivo do ensino universitário a partir da última década do século XX, em sintonia com as mudanças introduzidas pelas Diretrizes Curriculares Nacionais (DCNs). Na sequência, é traçado um paralelo entre a formação superior em saúde e a organização e funcionamento do sistema de saúde no país com a apresentação da situação e da evolução da formação das profissões da saúde, ressaltando-se as principais tendências quantitativas observadas desde 2000. De igual forma, analisa-se a formação das profissões da saúde com base na visão de especialistas das respectivas áreas e da revisão da literatura sobre o tema. Por fim, consideram-se os possíveis cenários e tendências para as próximas décadas.

\section{Panorama da Educação Superior no Brasil}

No campo da educação, a aprovação da Lei de Diretrizes e Bases da Educação Nacional e as DCNs para os cursos de graduação da área da saúde pelo Conselho Nacional de Educação foram movimentos importantes do setor que sinalizaram a necessidade de articulação entre o processo de formação e os princípios e diretrizes do Sistema Único de Saúde (SUS) (Brasil, 1996, 2001).

As DCNs destacam a reestruturação dos cursos de graduação com a extinção dos currículos mínimos e a adoção de diretrizes curriculares específicas para cada curso. Elencam ainda responsabilidades para as instituições de ensino em relação à autonomia didático-científica, à autonomia para criar cursos e fixar os currículos e programas, recomendando que cada curso adote aquelas que melhor atendam ao perfil epidemiológico e social da comunidade.

No plano internacional, em relação às possibilidades de desenvolvimento do ensino superior, observa-se uma tendência de expansão do acesso ao ensino superior ao longo das últimas décadas. Segundo a Unesco, a segunda metade do século XX passa para a história da educação superior como o período de sua expansão mais espetacular: o número de matrículas de estudantes em escala mundial se multiplicou mais de seis vezes, de 13 milhões em 1960 a 82 milhões em 1995 (Unesco, 1998).

Para Porto e Régnier (2003), os motivos que justificam esse fenômeno são múltiplos e de distintas naturezas: crescimento no número de formandos do ensino secundário (o percentual da população mundial com mais de 25 anos que concluiu o ensino médio ou secundário passou dos 15\% em 1965 
para 26\% em 1990) (World Bank, 2000); a necessidade de aquisição de competências essenciais para enfrentar um mercado de trabalho variante e cada vez mais seletivo e excludente; as transformações no conteúdo das ocupações e nas profissões, trazendo de volta para os bancos escolares uma população adulta; as facilidades que o desenvolvimento das tecnologias de informação e comunicação apresentam para o campo do ensino em termos de aumento da capacidade de atendimento das instituições, estimulando as experiências com ensino a distância; e, finalmente, o anseio da sociedade por ascensão social mediante o acesso ao ensino superior.

No Brasil, associado à qualidade de vida e à equidade social, o acesso a níveis mais altos de ensino se coloca como um elemento estratégico para que o país possa entrar competitivamente na sociedade da informação e da inovação tecnológica. O país alcançou, em 2010, 6,3 milhões de matrículas em 29,5 mil cursos oferecidos por 2.377 instituições. Considerando toda a última década, de 2001 a 2010, o crescimento no número de matrículas foi de 110\%, como pode ser visto na Tabela 1 a seguir. "Talvez tenha sido a melhor década de acesso à educação superior, tanto em termos relativos como em absolutos - mas, sobretudo, em absolutos", disse o então ministro da Educação e, segundo o ministério, um dos fatores que explica esse crescimento é o do aumento da oferta de cursos a distância e tecnológicos, dentre outros, sendo que esse forte crescimento vem se verificando nas matrículas dos cursos noturnos. No período 2011-2012, as matrículas continuaram a crescer, atingindo o número de 7.037.688 de matrículas no ensino superior brasileiro em 2012.

Tabela 1 - Número de matrículas em cursos de graduação. Brasil - 2001-2010

\begin{tabular}{|c|c|c|c|c|c|c|c|c|c|c|c|}
\hline \multirow[t]{2}{*}{ Ano } & \multirow[t]{2}{*}{ Total } & \multicolumn{8}{|c|}{ Públicas } & \multirow[t]{2}{*}{ Privadas } & \multirow[t]{2}{*}{$\%$} \\
\hline & & Total & $\%$ & Federal & $\%$ & Estadual & $\%$ & Municipal & $\%$ & & \\
\hline 2001 & 3.036 .113 & 944.584 & 31,1 & 504.797 & 16,6 & 360.537 & 11,9 & 79.250 & 2,6 & 2.091 .529 & 68,9 \\
\hline 2002 & 3.520 .627 & 1.085 .977 & 30,8 & 543.598 & 15,4 & 437.927 & 12,4 & 104.452 & 3 & 2.434 .650 & 69,2 \\
\hline 2003 & 3.936 .933 & 1.176 .174 & 29,9 & 583.633 & 14,8 & 465.978 & 11,8 & 126.563 & 3,2 & 2.760 .759 & 70,1 \\
\hline 2004 & 4.223 .344 & 1.214 .317 & 28,8 & 592.705 & 14 & 489.529 & 11,6 & 132.083 & 3,1 & 3.009 .027 & 71,2 \\
\hline 2005 & 4.567 .798 & 1.246 .704 & 27,3 & 595.327 & 13 & 514.726 & 11,3 & 136.651 & 3 & 3.321 .094 & 72,7 \\
\hline 2006 & 4.883 .852 & 1.251 .365 & 25,6 & 607.180 & 12,4 & 502.826 & 10,3 & 141.359 & 2,9 & 3.632 .487 & 74,4 \\
\hline 2007 & 5.250 .147 & 1.335 .177 & 25,4 & 641.094 & 12,2 & 550.089 & 10,5 & 143.994 & 2,7 & 3.914 .970 & 74,6 \\
\hline 2008 & 5.808 .017 & 1.552 .953 & 26,7 & 698.319 & 12 & 710.175 & 12,2 & 144.459 & 2,5 & 4.255 .064 & 73,3 \\
\hline 2009 & 5.954 .021 & 1.523 .864 & 25,6 & 839.397 & 14,1 & 566.204 & 9,5 & 118.263 & 2 & 4.430 .157 & 74,4 \\
\hline 2010 & 6.379 .299 & 1.643 .298 & 25,8 & 938.656 & 14,7 & 601.112 & 9,4 & 103.530 & 1,6 & 4.736 .001 & 74,2 \\
\hline
\end{tabular}

Fonte: Censo da Educação Superior 2010, do Instituto Nacional de Estudos e Pesquisas Educacionais Anísio Teixeira (Inep, 2012).

Essa ampliação do número de matriculados, fortemente apoiada na expansão do setor privado de ensino, vem sendo acompanhada por um conjunto de consequências, tais como: aumento no número de vagas ociosas, especialmente entre as instituições privadas, e a persistente evasão; altas taxas de inadimplência nas instituições privadas e redução da relação candidatos/vaga nos vestibulares para 
o segmento privado e aumento dessa relação para o segmento público, dentre outras. No entanto, persistem dificuldades e estrangulamentos no âmbito do sistema brasileiro do ensino superior - como as questões da qualidade do ensino ministrado, da contínua crise nas instituições públicas e de ineficiência e/ou descontinuidades dos esquemas de financiamento. Além da expansão acelerada da graduação, outras tendências se agregam na transformação do setor do ensino superior brasileiro, tais como: interiorização do ensino; consolidação da pós-graduação; melhoria na qualificação do corpo docente e aumento da produtividade do sistema, evidenciados pelos dados dos censos do Inep vinculados ao Ministério da Educação (MEC) (Porto \& Régnier, 2003: 65-68).

\section{A Formação e o Sistema de Saúde no Brasil}

O processo de institucionalização do SUS tem sido caracterizado por intensos debates que refletem a presença de interesses contrários em relação a sua materialização, tanto como política pública alicerçada na universalidade, equidade, integralidade, participação da população e dever do Estado quanto em relação à redução dos direitos constitucionais no que concerne a seu alcance e magnitude, incidindo em sua própria legitimidade.

Alguns autores indicam os riscos para a garantia de direitos universais ao avaliarem o panorama atual do SUS, explicitando ameaças presentes no cotejo entre o projeto privatista de cuidados de saúde e o projeto da Reforma Sanitária (Viana et al., 2002; Buss \& Labra, 1995; Bahia, 2014; Ocké-Reis, 2014).

Mendes e colaboradores (2011) registram ainda a desigualdade de acesso da população aos serviços de saúde, o desafio de construção de práticas baseadas na integralidade, os dilemas para alcançar a equidade no financiamento do setor, os avanços e recuos nas experiências de controle social e a falta de articulação entre os movimentos sociais dentre algumas das muitas dificuldades a serem superadas para a manutenção do SUS.

No campo específico da força de trabalho em saúde, as desigualdades têm aumentado ao longo do tempo, como demonstrado por Sousa, Dal Poz e Carvalho (2012). Os médicos e os profissionais de enfermagem são as categorias de trabalhadores da saúde com distribuição mais heterogênea entre as áreas mínimas comparáveis (AMC). ${ }^{1}$ Segundo esse estudo, os estados mais pobres experimentam a maior escassez de profissionais da saúde (abaixo da média nacional) e apresentaram as maiores disparidades na distribuição dos médicos e pessoal de enfermagem (acima da média nacional). Nas áreas pobres, a maioria do pessoal da saúde tem menor qualificação, e a maior parte dessa desigualdade acontece em razão da diferença dentro de cada estado de quintis de pobreza e do estrato rural urbano. Eliminar as disparidades no mercado de trabalho da saúde exige políticas e intervenções em nível estadual com foco em áreas pobres e rurais.

Nesse contexto em que se encontram as políticas públicas de saúde e de educação, investir na formação dos profissionais da saúde se afigura como uma das estratégias centrais para consolidar e

\footnotetext{
${ }^{1}$ Áreas mínimas comparáveis é a ferramenta mais utilizada no intuito de driblar os problemas oriundos do processo de ampliação do número de municípios e das transformações territoriais associadas ao município originário e consiste em agrupar os dados dos novos municípios aos daqueles que os originaram.
} 
defender os interesses da sociedade que realmente atendam às necessidades de saúde colocadas pela população usuária do SUS. Além disso, aumentam as exigências para que as instituições de ensino superior rompam com o modelo de ensino fragmentado, medicalizado, individualizado e com ênfase tecnicista, e se orientem para projetos de ensino voltados para a satisfação das necessidades sociais de saúde do país. Esse conjunto de transformações mapeadas, relativas tanto à perspectiva internacional quanto ao contexto específico de desenvolvimento da formação superior em saúde no país, desdobra-se em uma série de condicionantes. A natureza da evolução dessas condições irá definir o desenho que os possíveis cenários poderão adquirir nos próximos anos.

Segundo Porto e Régnier (2003) tais condicionantes se dividem entre os que têm maior ou menor incerteza quanto a sua consolidação e as trajetórias possíveis. Os de menor incerteza, também chamados de tendências consolidadas ou invariantes, dificilmente sofrerão profundas alterações a ponto de terem seu curso afetado, embora possam assumir compassos de evolução diferenciados, segundo o cenário ou contexto. Os de maior incerteza, como as mudanças em andamento, indicam que algumas dessas mudanças podem ou não vir a se concretizar e ocupar espaço proeminente na organização e funcionamento do setor, configurando as tendências para o futuro.

Dessa forma, ao analisarmos as mudanças e necessidades de qualificação técnica, conhecimento especializado e oferta de formação das profissões da saúde de nível superior, emergem como principais tendências consolidadas ou invariantes: a demografia brasileira com base no crescimento e perfil populacional e sua distribuição no país; a incorporação tecnológica reorganizando o processo de produção em saúde; e a carga das doenças e as consequências sobre as demandas profissionais.

Segundo o documento "Indicadores sociodemográficos: prospectivos para o Brasil 1991-2030" (Unfpa \& IBGE, 2006: 111-112), a julgar pelas hipóteses implícitas nas projeções dos números representativos das variáveis demográficas, pode-se deduzir que o perfil demográfico da população ainda passará por uma longa jornada de transformações, com mudança da pirâmide etária brasileira. Ao longo do período analisado, o país experimentou ganhos significativos sobre a mortalidade e, assim, continuará transpondo barreiras para assegurar aumentos na esperança de vida ao nascer e reduções na mortalidade de crianças.

Em paralelo, e levando-se em conta o continuado declínio da fecundidade e o aumento da longevidade de sua população, o Brasil caminhará rapidamente rumo a um padrão etário cada vez mais envelhecido, com reflexos imediatos no consumo de serviços de saúde. Essas mudanças, seguramente, provocarão a necessidade de avaliações permanentes das políticas sociais voltadas para o atendimento das demandas de um contingente de adultos e idosos que crescerá de maneira veloz. Por exemplo, o contingente de 65 anos ou mais demanda até quatro vezes mais internações que a média da população (WHO, 2000).

Com o envelhecimento da população brasileira, a demanda por determinadas categorias profissionais e especialidades médicas, como geriatria, tende a aumentar. Associada ao déficit, a distribuição também é irregular, uma vez que a maior parte dos profissionais está nas regiões Sul e Sudeste do país. O Norte é onde há maior carência, seguida pelo Nordeste e Centro-Oeste. No entanto, em 2030, serão 40 milhões de idosos, o que torna crítico adotar políticas e programas específicos para 
mudar o quadro atual. Além disso, com a mudança do perfil epidemiológico e com o desenvolvimento tecnológico, o Brasil vai precisar capacitar também outros profissionais tais como fisioterapeutas, enfermeiros geriátricos, odontogeriatras, dentre outros (Dal Poz, Pierantoni \& Girardi, 2013).

Vecina Neto e Malik (2007) registram em estudo sobre assistência hospitalar que, desde o início do século XX, notadamente após a sua segunda metade, houve uma busca contínua por novas drogas, equipamentos e soluções em saúde e lembram que, na saúde, a existência da inovação não implica a substituição da tecnologia anterior. ${ }^{2}$

Nas sociedades contemporâneas, num contexto de complexidade do objeto saúde-doença-cuidado e de aceleração da produção e de produtos (resultado da disseminação de novas tecnologias como microeletrônica e informática, biotecnologia, novos materiais, química fina e novas fontes energéticas e de mudança nos padrões de competitividade dos países decorrentes dos rearranjos no sistema capitalista de produção), surgem desafios relacionados às necessidades de integração das diversas profissões no que se refere à incorporação de novas tecnologias no processo de trabalho e a reorientações na formação e nas qualificações profissionais.

A crescente disponibilidade de novas tecnologias provoca redefinição do conteúdo do trabalho, das condições de empregabilidade e reorganização do processo de produção, o que por sua vez repercute na estrutura do mercado de trabalho, com o desaparecimento de um conjunto de ocupações e o surgimento de outras, e com o consequente redimensionamento do espaço de cada uma na atenção em saúde.

Para Vecina Neto e Malik (2007) o perfil epidemiológico se constitui em um elemento presente em todos os cenários. Desde o fim do século XX, observa-se a redução da mortalidade por moléstias infectocontagiosas (a velha agenda), o aumento da mortalidade ocasionada pelas doenças crônicodegenerativas e causas externas (a nova agenda, formada pelas chamadas doenças e agravos não transmissíveis - Dant), o reaparecimento de enfermidades que faziam parte da agenda antiga (como a dengue, a tuberculose e o cólera, denominadas reemergentes) e o surgimento da "novíssima agenda", representada por enfermidades infectocontagiosas emergentes (Aids, hantaviroses, doença espongiforme humana, além de bactérias ultrarresistentes a antibióticos).

Na visão de Schmidt e colaboradores (2011), as doenças crônicas não transmissíveis (DCNT) se tornaram prioridade na área da saúde no Brasil posto que $72 \%$ das mortes ocorridas em 2007 foram atribuídas a elas. As DCNT são a principal fonte da carga de doença, e os transtornos neuropsiquiátricos detêm a maior parcela de contribuição.

Esse novo perfil de doenças, associado à potencialização de outros elementos, tende a um aumento na demanda de utilização de ações e serviços de saúde cada vez mais complexos. Os portadores de enfermidades crônico-degenerativas têm necessidade de cuidados por período mais longo que aqueles com doenças infectocontagiosas. As complicações das doenças crônico-degenerativas associadas ao aumento na faixa etária se traduzem em necessidade mais intensa de recursos tecnológicos (Vecina Neto \& Malik, 2007: 826).

${ }^{2}$ Em relação à incorporação de tecnologias, a medicina baseada em evidências e a avaliação de tecnologia têm sido propostas, mas pouco utilizadas. Há centros que fazem avaliação tecnológica, mas seus resultados, mesmo considerados acertados, nem sempre são seguidos, segundo Vecina Neto e Malik (2007: 827). 
Além das invariantes que provavelmente devem estar presentes em qualquer configuração de contexto ou cenário, o desenho para o setor irá depender da evolução de um conjunto de condicionantes. Tais reservas se referem tanto ao fortalecimento/enfraquecimento do setor com o aporte de financiamento influenciando a conformação de modelos de atenção e o estabelecimento de prioridades quanto às transformações nos marcos regulatórios profissionais e o embate em arenas políticas conformando novos arranjos no mercado de trabalho. Por exemplo, mudanças nos marcos legais passam pelo Congresso, envolvem órgãos de controle (Ministério Público e Tribunal de Contas) e o Judiciário, entre outros. Esse tipo de ação, em geral, ultrapassa os tempos dos mandatos do Executivo.

Nesse caso, o que irá definir a configuração futura do ensino superior em saúde no país serão as escolhas que os diversos agentes que partilham essa área vierem a adotar em relação às constrições externas e da sua disposição de levar adiante projetos próprios, no jogo de forças entre os atores e suas disputas de poder e conquista de espaço. Esse processo pode resultar no surgimento de novos serviços, formas de atuação etc. com transformações nos ambientes político, econômico, social, tecnológico, cultural, dentre outros. Apesar das dificuldades de previsão sobre as políticas, e elas valem inclusive para as projeções, particularmente no que diz respeito às possíveis mudanças no que queremos para 2030, a implementação dessa agenda exige o planejamento de longo prazo. O estabelecimento de projeções para mais duas décadas deverá levar em consideração as variáveis apresentadas.

\section{Situação Atual da Formação das Profissões da Saúde}

O Brasil vem atravessando nas últimas décadas um processo conjugado de modernização econômica e abertura externa com estabilidade econômica. Dentre os estrangulamentos estruturais que comprometem a competitividade sistêmica do Brasil no contexto internacional de acelerada mudança estão os baixos níveis de escolaridade e de qualificação da mão de obra e, interligado a isso, as limitações do sistema de inovação e desenvolvimento tecnológico.

Em relatório sobre educação divulgado pela Organização para a Cooperação e Desenvolvimento Econômico (OCDE) em setembro de 2012 (OECD, 2012), o Brasil está na 38ª colocação entre 40 nações quando o assunto é educação superior. Somente $11 \%$ da população entre 25 e 64 anos de idade atingiram esse patamar educacional, quando o recomendável é, ao menos, 31\%. Somando-se a isso, apenas 18\% da população brasileira entre 18 e 24 anos (IBGE, 2011) estão matriculados no ensino superior, índice inferior a Bolívia (22\%), Colômbia (23\%) e Chile (24\%).

Apesar desses índices, houve no país uma forte expansão do ensino superior a partir da década de 1990, atrelada especialmente ao setor privado e marcada por um processo de desregulação denominado por alguns autores de revolução silenciosa (Schwartzman, 2001).

Os cursos de formação das profissões na área da saúde também tiveram um incremento expressivo do número de vagas abertas, como observado na Tabela 2, determinado principalmente pelo setor privado de ensino, não obstante tenha havido expansão também nas instituições públicas (Pierantoni et al., 2012). 
Tabela 2 - Taxa de crescimento dos cursos da saúde. Brasil - 2000-2012

\begin{tabular}{|l|r|r|r|}
\hline \multicolumn{1}{|c|}{ Cursos } & 2000 & 2012 & \multicolumn{1}{c|}{$\Delta \%$} \\
\hline Biomedicina & 7 & 229 & $3171 \%$ \\
\hline Ciências biológicas & 332 & 1002 & $201 \%$ \\
\hline Educação física & 267 & 1076 & $302 \%$ \\
\hline Enfermagem & 183 & 867 & $373 \%$ \\
\hline Farmácia & 143 & 456 & $218 \%$ \\
\hline Fisioterapia & 178 & 520 & $192 \%$ \\
\hline Fonoaudiologia & 76 & 89 & $17 \%$ \\
\hline Medicina veterinária & 90 & 185 & $106 \%$ \\
\hline Medicina & 100 & 206 & $106 \%$ \\
\hline Nutrição & 99 & 366 & $269 \%$ \\
\hline Odontologia & 142 & 215 & $51 \%$ \\
\hline Psicologia & 192 & 546 & $184 \%$ \\
\hline Serviço social & 95 & 376 & $295 \%$ \\
\hline Terapia ocupacional & 37 & 59 & $59 \%$ \\
\hline
\end{tabular}

Fonte: Censo da Educação Superior 2010, do Instituto Nacional de Estudos e Pesquisas Educacionais Anísio Teixeira (Inep, 2012).

Observa-se na Tabela 3, com exceção das ciências biológicas, em todas as graduações há predomínio de cursos nas instituições privadas de ensino superior. No curso de medicina, nota-se um comportamento diferenciado nesse aspecto, pois havia em 2000 um número maior de cursos em instituições de ensino superior (IESs) públicas, quadro que se inverte em 2012. O percentual de cursos privados de psicologia decresce em 2012 em razão de um expressivo crescimento de cursos em IESs públicas. Já no curso de terapia ocupacional, o qual também registra esse decréscimo, há uma conjugação entre o crescimento de oferta pública e a diminuição de cursos em IESs privadas para explicar o fenômeno. 
Tabela 3 - Curso da área da saúde, segundo natureza jurídica. Brasil - 2000-2012

\begin{tabular}{|l|c|c|c|c|}
\hline \multicolumn{1}{|c|}{ Cursos } & \multicolumn{2}{|c|}{2000} & \multicolumn{2}{c|}{2012} \\
\hline Biomedicina & Público $\%$ & Privado\% & Público \% & Privado\% \\
\hline Ciências biológicas & 28,6 & 71,4 & 12,7 & 87,3 \\
\hline Educação física & 53,0 & 47,0 & 50,8 & 49,2 \\
\hline Enfermagem & 41,2 & 58,8 & 28,1 & 71,9 \\
\hline Farmácia & 41,0 & 59,0 & 21,3 & 78,7 \\
\hline Fisioterapia & 28,0 & 72,0 & 25,4 & 74,6 \\
\hline Fonoaudiologia & 15,2 & 84,8 & 13,7 & 86,3 \\
\hline Medicina veterinária & 14,5 & 85,5 & 25,8 & 74,2 \\
\hline Medicina & 38,9 & 61,1 & 35,7 & 64,3 \\
\hline Nutrição & 52,0 & 48,0 & 45,1 & 54,9 \\
\hline Odontologia & 28,3 & 71,7 & 21,9 & 78,1 \\
\hline Psicologia & 35,9 & 64,1 & 30,7 & 69,3 \\
\hline Serviço social & 21,9 & 78,1 & 23,3 & 76,7 \\
\hline Terapia ocupacional & 32,6 & 67,4 & 19,1 & 80,9 \\
\hline
\end{tabular}

Fonte: Censo da Educação Superior 2010, do Instituto Nacional de Estudos e Pesquisas Educacionais Anísio Teixeira (Inep, 2012).

A tendência de crescimento dos cursos é acompanhada por um expressivo aumento na oferta de vagas principalmente no setor privado. Tal quadro se reflete, por exemplo, na oferta de cursos de graduação em ciências biológicas: ainda que a rede pública disponha de um grande número de vagas e tenha observado crescimento significativo, a esfera privada ultrapassa o dobro dessa oferta. Dessa forma o percentual de crescimento das vagas é muito maior que o dos cursos em todas as graduações, com importante participação das IESs do setor privado. Entretanto, quando analisamos a taxa de ocupação dessas vagas (relação entre vagas e ingressantes), observa-se uma tendência decrescente no período de 2000 a 2012. A graduação em medicina se configura como uma excepcionalidade. Na série histórica considerada e apresentada na Tabela 4, verificou-se que o número de ingressantes supera o de vagas. Tal fato, além de ser explicado pela grande procura do curso (a relação candidato-vaga para o curso de medicina vem se mantendo no primeiro lugar no ranking de disputa por vagas na universidade), pode ser também atribuído a mandados judiciais e transferências obrigatórias, dentre outros. A fonoaudiologia e a terapia ocupacional apresentam as mais baixas taxas de ocupação de vagas. 
Tabela 4 - Taxa de ocupação de vagas das graduações da saúde. Brasil - 2000-2012

\begin{tabular}{|c|c|c|c|c|c|c|c|c|c|c|c|c|c|}
\hline \multirow[t]{2}{*}{ Cursos } & \multicolumn{13}{|c|}{ Taxa de ocupação das vagas } \\
\hline & 2000 & 2001 & 2002 & 2003 & 2004 & 2005 & 2006 & 2007 & 2008 & 2009 & 2010 & 2011 & 2012 \\
\hline Biomedicina & 95,1 & 88,5 & 90,8 & 81,1 & 73,4 & 75,5 & 58,3 & 53,4 & 51,5 & 51,4 & 47,5 & 51,3 & 59,7 \\
\hline $\begin{array}{l}\text { Ciências } \\
\text { Biológicas }\end{array}$ & 85,7 & 93,8 & 90,3 & 90,1 & 86,4 & 82,1 & 74,4 & 70,5 & 67,4 & 55,2 & 52,4 & 49,6 & 50,3 \\
\hline Educação física & 89,2 & 95,2 & 89,3 & 90,4 & 88,9 & 81,5 & 73,5 & 70,8 & 62,4 & 52,1 & 52,5 & 53,4 & 60,6 \\
\hline Enfermagem & 88,1 & 96,3 & 93,0 & 96,2 & 84,2 & 81,0 & 76,8 & 73,6 & 67,9 & 62,3 & 61,1 & 59,9 & 68,3 \\
\hline Farmácia & 94,4 & 92,7 & 92,2 & 96,2 & 90,4 & 82,8 & 80,8 & 67,9 & 62,2 & 56,9 & 59,0 & 56,6 & 64,8 \\
\hline Fisioterapia & 94,1 & 89,1 & 84,2 & 79,5 & 64,9 & 61,3 & 57,4 & 51,6 & 45,9 & 39,6 & 43,0 & 47,4 & 60,7 \\
\hline Fonoaudiologia & 61 & 66,4 & 58,7 & 5 & 45,8 & 3 & 45 & $4:$ & 33,7 & 30,9 & 26,1 & 38,0 & 50,1 \\
\hline $\begin{array}{l}\text { Medicina } \\
\text { veterinária }\end{array}$ & 88,5 & 95,8 & 89,0 & 89,6 & 85,8 & 86,6 & 90,0 & 77,2 & 69,0 & 68,9 & 74,8 & 73,6 & 94,6 \\
\hline Medicina & 109,1 & 95,9 & 108,0 & 112,0 & 104,0 & 107,8 & 116,2 & 111,7 & 112,3 & 111,7 & 112,2 & 108,4 & 112,7 \\
\hline Nutrição & 80,1 & 79,1 & 77,6 & 78,3 & 67,3 & 64,9 & 61,3 & 56,8 & 49,8 & 48,8 & 51,8 & 53,2 & 63,5 \\
\hline Odontologia & 94,5 & 93,2 & 88,9 & 80,8 & 84,3 & 80,8 & 80,5 & 77,7 & 80,6 & 76,9 & 85,7 & 89,9 & 112,0 \\
\hline Psicologia & 89,9 & 91,6 & 84,8 & 84,3 & 72,0 & 66,3 & 65,3 & 63,8 & 58,0 & 50,1 & 61,7 & 65,2 & 80,3 \\
\hline Serviço social & 90,4 & 94,0 & 90,8 & 87,9 & 83,8 & 82,5 & 79,4 & 68,3 & 59,7 & 52,7 & 58,6 & 60,4 & 61,5 \\
\hline $\begin{array}{l}\text { Terapia } \\
\text { ocupacional }\end{array}$ & 77,3 & 77,9 & 72,9 & 66,8 & 64,6 & 53,8 & 49,7 & 46,4 & 29,4 & 41,9 & 54,5 & 45,9 & 48,6 \\
\hline
\end{tabular}

Fonte: Censo da Educação Superior 2010, do Instituto Nacional de Estudos e Pesquisas Educacionais Anísio Teixeira (Inep, 2012).

Outro indicador usado na educação superior é a taxa de eficiência terminal calculada pela relação entre concluintes e ingressantes em $n$ anos de duração dos cursos. No caso da saúde utilizamos as resoluções do $\mathrm{MEC}^{3}$ que disciplinam a duração dos cursos da saúde para esse cálculo. Considerando esse indicador, a maioria das graduações da saúde apresenta baixas taxas de eficiência, com decréscimo no período de 2000 a 2012. Para essa análise consideraremos grupamentos de graduações.

As profissões tradicionais como medicina, enfermagem, odontologia e farmácia, cujas origens remontam ao Brasil Colônia, mesmo que com configurações diferenciadas das atuais, e a medicina veterinária, ligada às ações de agricultura e pecuária, organizam-se também no fim do século XIX e início do século XX. As modernas, que surgem com o processo de desenvolvimento na década de 1930, totalmente desvinculadas da saúde, como a educação física (atrelada às ações do Exército) e o serviço social, consolidam os projetos assistencialistas da época.

\footnotetext{
${ }^{3}$ Resolução n. 2, de 18 de junho de 2007 que dispõe sobre carga horária mínima e procedimentos relativos à integralização e duração dos cursos de graduação, bacharelados, na modalidade presencial e a n. 4, de 6 de abril de 2009, que dispõe sobre carga horária mínima e procedimentos relativos à integralização e duração dos cursos de graduação em biomedicina, ciências biológicas, educação física, enfermagem, farmácia, fisioterapia, fonoaudiologia, nutrição e terapia ocupacional; e bacharelados, na modalidade presencial.
} 
E há um terceiro grupo, as áreas contemporâneas, que se organizam entre as décadas de 1960 e 1970, em sua maioria regulamentadas durante o regime militar, como a psicologia, a fisioterapia, a fonoaudiologia, a terapia ocupacional, a biologia e a biomedicina.

Dentre as profissões tradicionais, o curso de medicina tem a melhor eficiência terminal: entre $92 \%$ e $96 \%$ no período analisado. A graduação em farmácia, em 2002, ostentava uma taxa de 98\%, chegando a 2012 com 53\%. O curso de enfermagem também demonstra uma tendência decrescente no período com taxas de 89\% (2002), 95\% (2007) e 59\% (2012); o de odontologia exibe comportamento semelhante com uma pequena recuperação em 2012 (72\%); educação física mantém uma taxa em torno de $60 \%$ com leve tendência decrescente; e serviço social apresentou o indicador acima de $100 \%$ em 2008, chegando a 72\% em 2012. O grupo das áreas contemporâneas revela taxas decrescentes com índices em torno de 60\% em 2012.

\section{Os Cursos Selecionados e o Enade}

Passaremos a analisar neste item o desempenho dos cursos selecionados (enfermagem, farmácia, fisioterapia, medicina e odontologia) levando em consideração o desempenho no Enade (Exame Nacional de Desempenho dos Estudantes), instituído em 2004 pela lei n 10.861 de 14 de abril deste mesmo ano como componente do Sistema Nacional de Avaliação da Educação Superior (Sinaes).

O Enade tem como objetivo aferir o desempenho dos estudantes em relação aos conteúdos programáticos previstos nas diretrizes curriculares da respectiva área de graduação, suas habilidades para ajustamento às exigências decorrentes da evolução do conhecimento e suas competências para compreender temas exteriores ao âmbito específico de sua profissão ligados à realidade brasileira e mundial e a outras áreas do conhecimento (Inep, 2012).

O desempenho dos estudantes de cada curso participante do Enade é avaliado e expresso por meio de conceitos, com base em uma escala ordenada em cinco níveis, considerando os padrões mínimos estabelecidos por especialistas das diferentes áreas do conhecimento. A seguir, na Tabela 5, expõem-se os valores escalonados.

A avaliação é realizada a cada três anos, e tomaremos como base aquelas realizadas em 2007 e 2010.

Tabela 5 - Distribuição dos conceitos

\begin{tabular}{|c|r|}
\hline Conceito & Notas finais \\
\hline 1 & 0,0 a 0,94 \\
\hline 2 & 0,95 a 1,94 \\
\hline 3 & 1,95 a 2,94 \\
\hline 4 & 2,95 a 3,94 \\
\hline 5 & 3,95 a 5,0 \\
\hline
\end{tabular}

Fonte: Enade 2010 (Inep, 2010). 


\section{Enfermagem}

Em 2010, avaliaram-se estudantes de 691 cursos, desses, 80,0\% de instituições privadas de ensino. Já em 2007 foram 540, mantendo-se, entretanto, a mesma proporcionalidade entre instituições públicas e privadas, como pode ser observado na Tabela 6.

Tabela 6 - Número de cursos de enfermagem participantes no Brasil por categoria administrativa, segundo conceitos no Enade. 2007 e 2010

\begin{tabular}{|l|r|r|r|r|r|r|r|r|r|r|r|r|r|}
\hline \multicolumn{1}{|c|}{ Conceito } & \multicolumn{2}{|c|}{1} & \multicolumn{2}{|c|}{2} & \multicolumn{2}{|c|}{3} & \multicolumn{2}{|c|}{4} & \multicolumn{3}{|c|}{5} \\
\hline Ano & 2007 & 2010 & 2007 & 2010 & 2007 & 2010 & 2007 & 2010 & 2007 & 2010 & 2007 & 2010 \\
\hline Público & 1 & 6 & 11 & 11 & 19 & 20 & 31 & 53 & 12 & 22 & 33 & 26 \\
\hline Privado & 14 & 16 & 133 & 195 & 109 & 176 & 8 & 24 & 0 & 6 & 169 & 136 \\
\hline
\end{tabular}

Fonte: Enade 2010 (Inep, 2010).

Observa-se que nos conceitos 4 e 5, que indicam uma melhor avaliação de desempenho, predominam os cursos do setor público, 40,2\% em 2007 e 54,3\% em 2010. Chama atenção que apenas $1,8 \%$ (2007) e 5,4\% (2010) dos cursos do setor privado tenham alcançado esse patamar. A maioria dos cursos do setor privado apresenta conceitos 2 e 3 (55,9\% e 67,1\%) nos anos analisados.

\section{Medicina}

No Enade, em 2007, avaliaram-se estudantes de 153 cursos. A participação de cursos do setor privado representou 58,8\% desse contingente. Em 2010 foram avaliados estudantes de 177 cursos, quando se verificou uma pequena diminuição na participação de cursos do setor privado (56,5\%), como observado na Tabela 7.

Tabela 7 - Número de cursos de medicina participantes no Brasil por categoria administrativa, segundo as Grandes Regiões e conceitos no Enade. 2007 e 2010

\begin{tabular}{|l|c|c|c|c|c|c|c|c|c|c|c|c|}
\hline Conceito & \multicolumn{2}{|c|}{1} & \multicolumn{2}{|c|}{2} & \multicolumn{2}{|c|}{3} & \multicolumn{2}{|c|}{4} & \multicolumn{3}{|c|}{5} & \multicolumn{2}{c|}{ SC } \\
\hline Ano & 2007 & 2010 & 2007 & 2010 & 2007 & 2010 & 2007 & 2010 & 2007 & 2010 & 2007 & 2010 \\
\hline Público & 4 & 1 & 10 & 1 & 12 & 11 & 17 & 31 & 8 & 24 & 10 & 9 \\
\hline Privado & 4 & 6 & 19 & 19 & 17 & 28 & 12 & 19 & 0 & 4 & 12 & 24 \\
\hline
\end{tabular}

Fonte: Enade 2010 (Inep, 2010).

Evidencia-se também na medicina uma melhor avaliação do desempenho de IES do setor público, que avançou de 2007 para 2010. Em 2007, 41\% dos cursos de instituições públicas obtiveram conceitos 4 e 5 no Enade contra 18,8\% dos cursos privados. Em 2010 o panorama melhorou: 71,4\% dos cursos públicos foram avaliados nos conceitos 4 e 5 , estando neste mesmo patamar 23\% das instituições privadas que ainda mantiveram conceitos 2 e 3 em 47\% dos cursos em 2010. 


\section{Farmácia}

Em 2010, o Enade contou com a participação de estudantes de 340 cursos, com a predominância das instituições privadas de ensino (82,1\%). No ano de 2007 avaliaram-se estudantes de 271 cursos, sendo $82,3 \%$ desse contingente representado pelo setor privado, como demonstrado na Tabela 8 .

Tabela 8 - Número de cursos de farmácia participantes no Brasil por categoria administrativa, segundo conceitos no Enade. Brasil - 2007 e 2010

\begin{tabular}{|l|r|r|r|r|r|r|r|r|r|r|r|r|r|}
\hline \multicolumn{1}{|c|}{ Conceito } & \multicolumn{2}{|c|}{1} & \multicolumn{2}{|c|}{2} & \multicolumn{2}{|c|}{3} & \multicolumn{2}{|c|}{4} & \multicolumn{2}{|c|}{ SC } \\
\hline Ano & 2007 & 2010 & 2007 & 2010 & 2007 & 2010 & 2007 & 2010 & 2007 & 2010 & 2007 & 2010 \\
\hline Público & 2 & 0 & 7 & 4 & 7 & 12 & 13 & 14 & 12 & 19 & 7 & 12 \\
\hline Privado & 24 & 5 & 84 & 43 & 38 & 120 & 2 & 43 & 1 & 4 & 74 & 64 \\
\hline
\end{tabular}

Fonte: Enade 2010 (Inep, 2010).

Como nos cursos anteriores, o desempenho dos alunos do setor público é bastante superior aos dos estudantes do setor privado. Analisando o grupamento de cursos que obteve conceitos 4 e 5 , verificamos que mais de 50\% dos estudantes de cursos do setor público tanto em 2007 quanto em 2010 estavam nesse grupamento. Apenas 1,3\% em 2007 e 16,8\% dos estudantes dos cursos do setor privado alcançaram esse patamar e mais de 50\% em 2007 e 2010 tiveram avaliação nos conceitos 2 e 3.

\section{Fisioterapia}

O Enade de fisioterapia em 2007 contou com a participação de estudantes de 399 cursos. Levandose em consideração a categoria administrativa da IES, destaca-se a predominância das instituições privadas de ensino, que concentraram quase 90\% dos cursos avaliados. Em 2010 avaliaram-se estudantes de 448 cursos, dos quais $87,3 \%$ do setor privado, como apresentado na Tabela 9.

Tabela 9 - Número de cursos de fisioterapia participantes no Brasil por categoria administrativa, segundo conceitos no Enade. Brasil - 2007 e 2010

\begin{tabular}{|l|c|c|c|c|c|c|c|c|c|c|c|c|}
\hline \multicolumn{1}{|c|}{ Conceito } & \multicolumn{2}{|c|}{1} & \multicolumn{2}{|c|}{2} & \multicolumn{2}{c|}{3} & \multicolumn{2}{c|}{4} & \multicolumn{2}{c|}{5} & \multicolumn{2}{c|}{ SC } \\
\hline Ano & 2007 & 2010 & 2007 & 2010 & 2007 & 2010 & 2007 & 2010 & 2007 & 2010 & 2007 & 2010 \\
\hline Público & 1 & 1 & 3 & 7 & 7 & 8 & 8 & 12 & 11 & 13 & 13 & 16 \\
\hline Privado & 1 & 23 & 42 & 125 & 155 & 140 & 45 & 40 & 1 & 3 & 112 & 60 \\
\hline
\end{tabular}

Fonte: Enade 2010 (Inep, 2010).

Confirma-se também nos cursos de fisioterapia uma superioridade na avaliação dos cursos de instituições públicas, dos quais 44\% obtiveram conceitos entre 4 e 5 nos dois anos analisados. Já no setor privado apenas cerca de $11 \%$ alcançou esse patamar. A maioria dos cursos deste setor obteve avaliação entre 2 e 3. 


\section{Odontologia}

Em 2007 o Enade de odontologia contou com a participação de estudantes de 173 cursos, dentre os quais 71,7\% eram de instituições privadas. Esse mesmo percentual se mantém em 2010, dos 189 cursos avaliados, como pode-se observar na Tabela 10.

Tabela 10 - Número de cursos de odontologia participantes no Brasil por categoria administrativa, segundo as Grandes Regiões e conceitos no Enade. Brasil - 2007 e 2010

\begin{tabular}{|l|c|c|c|c|c|c|c|c|c|c|c|c|}
\hline \multicolumn{1}{|c|}{ Conceito } & \multicolumn{2}{|c|}{1} & \multicolumn{2}{c|}{2} & \multicolumn{2}{c|}{3} & \multicolumn{3}{c|}{4} & \multicolumn{3}{c|}{5} \\
\hline Ano & 2007 & 2010 & 2007 & 2010 & 2007 & 2010 & 2007 & 2010 & 2007 & 2010 & 2007 & 2010 \\
\hline Público & 0 & 1 & 1 & 2 & 4 & 12 & 24 & 32 & 16 & 5 & 4 & 2 \\
\hline Privado & 5 & 4 & 31 & 36 & 56 & 58 & 11 & 14 & 1 & 4 & 20 & 19 \\
\hline
\end{tabular}

Fonte: Enade 2010 (Inep, 2010).

O desempenho superior dos estudantes avaliados nos cursos do setor púbico também é evidente na odontologia. Chama a atenção que os cursos decaíram tanto no setor público como no privado, de 2007 para 2010. Observa-se em 2007 que 81,6\% dos cursos do setor público tiveram conceitos entre 4 e 5 e 32,3\% do setor privado estiveram nesse patamar. O cenário se modifica em 2010, quando 68,5\% dos cursos do setor público obtiveram 4 e 5 e 13,3\% do setor privado alcançaram esses conceitos.

\section{As Tendências da Formação das Profissões da Saúde}

Para analisar as tendências da formação das profissões da saúde, conjugamos aspectos da conformação e estrutura da educação superior com dados secundários das graduações da saúde, refinando a análise para as categorias profissionais de médicos, enfermeiros, dentistas, farmacêuticos e fisioterapeutas. Para o alcance desse objetivo realizamos revisão sistemática da literatura sobre o tema, ouvimos e processamos opiniões de especialistas e representantes de entidades profissionais e/ou educacionais, e analisamos os dados do censo da educação superior estimando projeções da oferta educacional de profissionais para as duas décadas subsequentes.

No estabelecimento de projeções para mais duas décadas, consideraram-se as seguintes variáveis:

- A demografia brasileira com base no crescimento e perfil populacional e sua distribuição no país.

- A incorporação tecnológica criando demandas profissionais e reorganizando o processo de produção em saúde.

- A carga das doenças e as consequências sobre as demandas profissionais.

No Brasil, nas últimas décadas, a atuação dos profissionais da saúde vem passando por distintos movimentos de transição caracterizados por processos centrados na doença e na especialização, nos quais as competências profissionais convergem para a atuação na assistência à enfermidade, à lesão ou à disfunção já estabelecidas. Verifica-se também uma inflexão para o desenvolvimento de competências de caráter preventivista e promocional, voltadas para a determinação de condicionantes da qualidade de vida e saúde de indivíduos e coletividades e para sua manutenção. 
O processo de mudança de atuação dos profissionais implica revisão de competências, de saberes e habilidades, de métodos de ensino e dos múltiplos papéis que serão requeridos para desempenho de práticas ampliadas e complexas em que o cuidado e o contexto se tornam cada vez mais indissociáveis. São muitos os desafios em curso:

- desenvolver capacidades para atuar sobre os determinantes sociais da saúde na complexidade das inter-relações entre os condicionantes sociais, econômicos, ambientais, biológicos, psicológicos, subjetivos e culturais do processo saúde-doença;

- articular medidas de prevenção dos múltiplos e contínuos riscos que podem provocar agravos à saúde;

- contribuir para o desenvolvimento da governança no intuito de agir sobre os determinantes sociais da saúde com a participação na definição de responsabilidades dos atores e setores envolvidos;

- desenvolver ferramentas para as ações de promoção da saúde, de vigilância de práticas de risco e o monitoramento da situação de saúde;

- atuar em diferentes ambientes e cenários e nos diversos níveis de complexidade e de estruturação do sistema de saúde; dentre outras.

Considerando a literatura e a visão dos especialistas das áreas, foi possível identificar ao menos quatro variáveis que se articulam em diferentes aspectos apresentados na Figura 1, que influenciam na formação profissional:

Figura 1 - Variáveis e influências na formação profissional em saúde

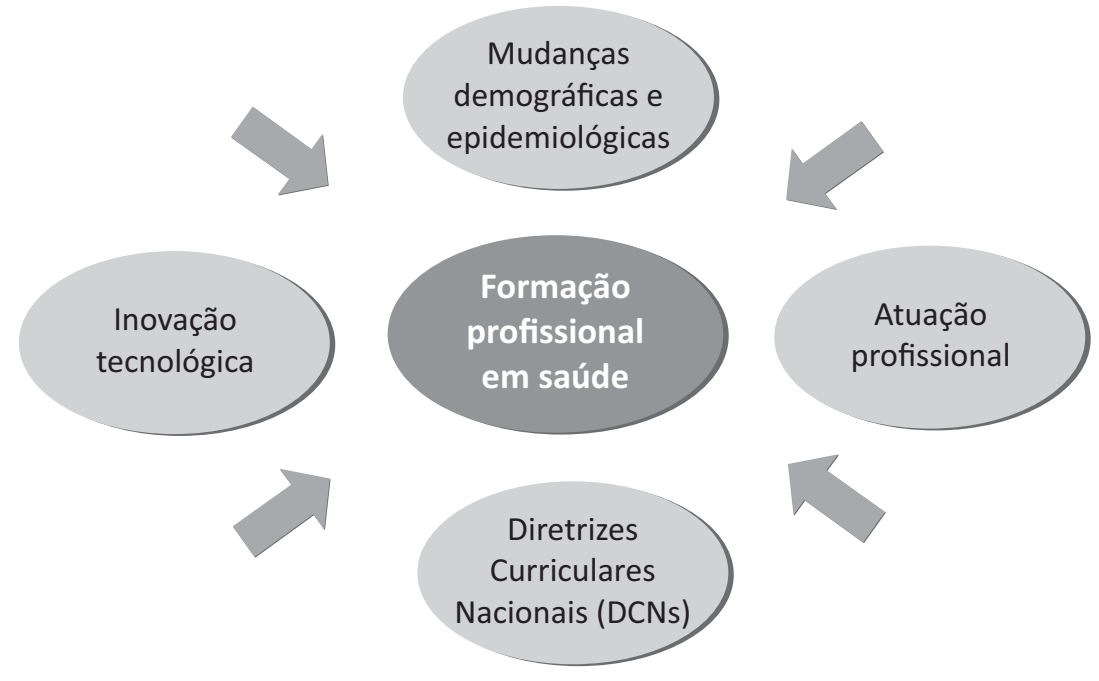

Considerando a visão dos especialistas das áreas em relação à influência das variáveis na formação profissional, observamos as tendências detalhadas a seguir:

- Atuação profissional:

» Práticas de trabalho em equipes multiprofissionais, ao passo que a formação tende a continuar segmentada. 
» Particularmente na medicina, prevalece nos espaços de formação certo desprezo pelas especialidades clínicas, traduzido pela tendência de escolha de especialidades de alta densidade tecnológica e caráter procedimental, vistas como mais bem remuneradas e de maior prestígio.

»O objeto de trabalho da fisioterapia continuará sendo o movimento humano. A responsabilidade profissional, no entanto, não se restringirá ao nível terciário da reabilitação, mas deverá se ampliar para os níveis primário e secundário.

» A fisioterapia cresce a partir da década de 1990, ampliando as suas especializações, o seu campo de atuação e redefinindo o seu status profissional. Atualmente conta com 13 especialidades regulamentadas, algumas inclusive com demandas próprias de regulamentação, como a quiropraxia.

» Em relação ao farmacêutico é necessário reafirmar que o perfil e as características desse profissional vêm sofrendo transformações substanciais neste início de século, com o resgate de suas funções básicas e originárias pertinentes aos medicamentos, com foco nos usuários desses insumos terapêuticos e uma atuação mais clínica. Para tanto, fazse necessário que os estudantes recebam uma boa formação nas disciplinas básicas de patologia, fisiologia e farmacologia.

- Inovação tecnológica:

»A semiologia vem sendo progressivamente substituída na prática clínica pelos exames de imagem e de laboratório, com imagens em três dimensões em tempo real, e repercussões claras sobre a relação custo-efetividade. Procedimentos diagnósticos de imagem e de laboratório vêm ganhando maior espaço como especialidade médica de prestígio.

»O alto turnover de conhecimentos exige movimentos de recertificação profissional, que hoje fica a cargo das sociedades de especialistas.

» As inovações tecnológicas impactam fortemente a assistência e o ensino da enfermagem, particularmente as chamadas tecnologias duras.

»Grande parte do artesanato odontológico secular necessário para os procedimentos clínicos mais corriqueiros certamente será substituído pela tecnologia digital das próximas décadas. No mínimo a dentística, a prótese e a ortodontia serão completamente reconfiguradas.

»Há uma enorme demanda por inovações na área farmacêutica, tanto no desenvolvimento e produção de medicamentos quanto nos serviços farmacêuticos diretamente dirigidos ao cuidado em saúde, demanda que impactaria tremendamente na autonomia, na soberania e na economia nacionais, mas que ainda é pouco explorada na formação profissional.

» A constante introdução de novos recursos farmacológicos e a sua diversidade abrem espaço para a atuação clínica do farmacêutico na gestão do uso de medicamentos. Nesse sentido, percebe-se um movimento nacional buscando equacionar a formação clínica farmacêutica. 
- Mudanças demográficas e epidemiológicas:

» As questões mais importantes dizem respeito à mudança de paradigma da cura para a promoção e prevenção em um contexto de envelhecimento populacional, alta prevalência de doenças crônico-degenerativas, câncer etc.

» O foco no cuidado e não na cura é claramente um produto dessas mudanças.

»Parece haver grandes diferenças na abordagem ou na forma como as escolas médicas têm priorizado ou incorporado essas mudanças. Não são disponíveis estudos suficientes.

» Há indicações de reconfiguração de currículos da enfermagem tanto para contemplar a formação de enfermeiros-obstetras que atuem na mudança do modelo de atenção à saúde da mulher e neonato, quanto para aprimorar o cuidado ao idoso, possivelmente em razão do aumento de demanda.

»O envelhecimento populacional tem como consequência para a clínica odontológica no mercado de serviços um aumento na demanda em periodontia, dentística estética, implantodontia e prótese sobre implantes.

»Para as próximas gerações, mais saudáveis (porque impactadas pelas mudanças epidemiológicas decorrentes de políticas públicas de fluoretação) e longevas, nesse mesmo mercado, apenas a demanda de periodontia deve ser mantida e aumentada. A ortodontia e a dentística estética provavelmente manterão a tendência de demanda crescente.

»O novo perfil epidemiológico, caracterizado por enfermidades relacionadas ao fazer e viver das pessoas, requer uma intervenção complexa e integral por parte do fisioterapeuta, mais voltada para uma saúde promotora do autocuidado e de ações que incorporem no cotidiano da assistência outros princípios de caráter social, formativo e educativo.

» A expansão das atividades clínicas do farmacêutico ocorreu, em parte, como resposta ao fenômeno da transição demográfica e epidemiológica observado na sociedade. A crescente morbimortalidade relativa às doenças e aos agravos não transmissíveis e à farmacoterapia repercutiu nos sistemas de saúde e exigiu um novo perfil do farmacêutico.

- Diretrizes Curriculares Nacionais (DCNs):

»Há um reconhecimento de que foram realizadas mudanças positivas para flexibilizar os desenhos curriculares conforme as realidades locais e estruturas física e pedagógica institucionais.

» Em várias áreas, como a enfermagem, incorporaram-se os conceitos de competências profissionais, regulamentaram-se os estágios e a inserção da pesquisa e produção de conhecimento como um componente importante da graduação, especialmente por meio da obrigatoriedade do trabalho de conclusão de curso.

» Entretanto, também se observam mudanças negativas, como a uniformização dos desenhos curriculares e projetos pedagógicos que, em muitos casos, passaram a ser transcrições das DCNs sem uma operacionalização cotidiana em conformidade com o proposto.

» A maior parte das orientações contidas nas diretrizes amplia conteúdos relativos a uma formação mais próxima das disciplinas da saúde coletiva, reorientando a formação do dentista, de caráter essencialmente tecnicista. 
» A fisioterapia precisa redimensionar seu objeto de intervenção, que deve aproximar-se do campo da promoção da saúde e do movimento da saúde coletiva sem abandonar suas competências concernentes à reabilitação.

»Conforme instituído nas DCNs, os cursos de fisioterapia devem estruturar-se com base nos princípios do SUS e adequar a formação dos profissionais ao perfil epidemiológico da população.

» Nesse contexto de transformações, surge o farmacêutico generalista com formação humanista, crítica e reflexiva, para atuar em todos os níveis de atenção à saúde, com base no rigor científico e intelectual, resgatando a atenção farmacêutica como atividade específica desse profissional.

» A falta de um consenso ou, minimamente, um projeto nacional para a formação/profissão farmacêutica, a tradição na formação tecnicista e biologista, as diferentes interpretações das DCNs, por vezes excessivamente simplistas e tão abrangentes que se tornam impossíveis de operacionalizar, bem como o grande crescimento do número de cursos de farmácia no setor privado, não necessariamente vinculados às necessidades sociais, ainda fazem do ensino um dos grandes desafios para a profissão farmacêutica no Brasil no atual século.

- Sensibilidade das profissões para absorver e se adaptar às mudanças:

» Parece haver certo consenso de que a escola médica ancorada na estrutura departamental disciplinar tem muita dificuldade de se mover e revisitar continuamente seus conteúdos e práticas em ritmo minimamente compatível com as mudanças.

» A farmácia apresenta uma grande capacidade de adaptação às mudanças da sociedade ou, minimamente, ao mercado de trabalho, ainda que isso possa lhe descaracterizar como profissão. Contudo, em relação ao desenvolvimento tecnológico específico da área, a questão não pode passar pelo prisma único da capacidade de adequação da profissão. Na condição de país tecnologicamente dependente e sem um projeto nacional de desenvolvimento forte, ao menos no que diz respeito à área farmacêutica, a pressão externa ao setor tem determinado a subordinação das ações em saúde - e a consequente produção de respostas em razão das necessidades de saúde de nossa população -, à lógica da potente concorrência e pressão comercial.

Observou-se na situação da formação superior das profissões da saúde no período de 2000 a 2012 algumas tendências gerais que permearam a maioria dos cursos da saúde (Inep, 2012). Em primeiro lugar tem-se uma concentração regional no Sudeste de todos os cursos da área e um expressivo crescimento fortemente pautado pela presença de instituições privadas que detêm em média $72 \%$ do total desta oferta. Essa mesma tendência é observada para o número de vagas, ingressantes e concluintes. Verifica-se também ao longo da década uma diminuição na taxa de ocupação das vagas, em especial no setor privado, a partir dos anos 2004 e 2005, exceção para o curso de medicina. A taxa de eficiência terminal dos cursos é baixa e vem decrescendo no período, o que pode ser atribuído ao aumento da evasão. Os dados utilizados para construção dos modelos de projeção para 2030 têm como fonte a série histórica de concluintes entre 1991 e 2012 para os cursos selecionados, segundo a natureza jurídica do estabelecimento de ensino, divididos em públicos e privados. 
Considerando que a adoção de hipóteses e modelos simples são mais eficientes e confiáveis, nesta análise utilizou-se um modelo de crescimento aplicando-se aos concluintes observados em 2012 uma taxa média geométrica de crescimento anual da população residente no Brasil de 1,67\% ao ano, estimada pelo IBGE (Ripsa, 2008). Na análise e aceitação dos modelos, levou-se em conta ainda que o crescimento linear das vagas e graduações só ocorreria se o mercado fosse elástico e infinito, o que não é o caso. O mercado educacional e o mercado de trabalho são relativamente inelásticos, cujo crescimento depende de algumas variáveis sociais e econômicas, como o tamanho do mercado de trabalho (empregos ou prática privada), a capacidade das famílias e/ou Estado de financiar a educação e a saúde, a existência de infraestrutura - escolas e corpo docente - e a capacidade regulatória do Estado e das próprias profissões.

Como já analisado, no período de 2003 a 2013 o número de cursos de medicina no setor privado praticamente dobrou, passando de 60 para 113. Esse crescimento bastante rápido produziu uma quantidade de egressos que sobrepujou o setor público em 2009, continuando a crescer. A proporção de concluintes em medicina no setor privado já representa praticamente $60 \%$ do total de egressos dos cursos.

Em decorrência da lei n. 12.871 de 2013 (Brasil, 2013) que institui o programa Mais Médicos, está prevista a abertura de 11.447 novas vagas de graduação em medicina até 2017. Das vagas previstas, 3,6 mil deverão ser criadas em instituições públicas e outras 7,8 mil em escolas privadas. A expectativa é a de que o número de concluintes aumente progressivamente, como mostrado no Gráfico 1.

Gráfico 1 - Concluintes do curso de medicina por natureza jurídica: projeções com modelo de crescimento linear de $1,67 \%$ anual a partir de 2012 até 2030

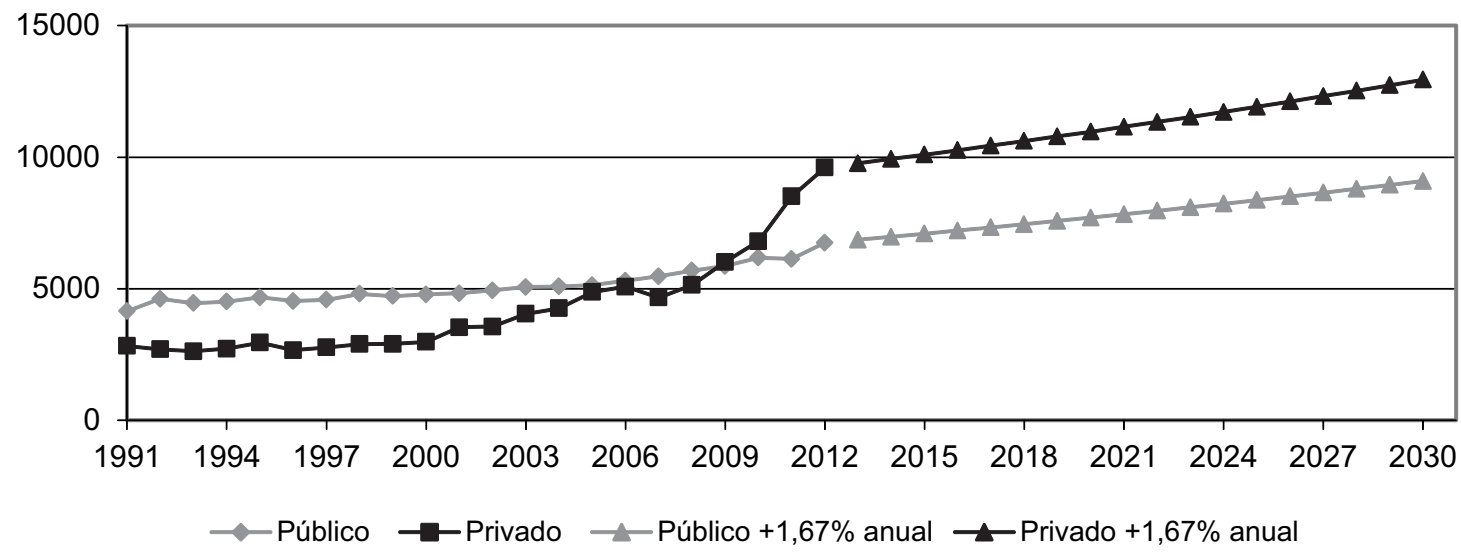

Fonte: Censo da Educação Superior 2010, do Instituto Nacional de Estudos e Pesquisas Educacionais Anísio Teixeira (Inep, 2012).

No caso da enfermagem, a taxa de ocupação das vagas vem caindo na última década, bem como se reduzindo a eficiência terminal dos cursos (ex. taxa de abandono). Assim, apesar de o número de concluintes no último ano ter sido muito alto em virtude do crescimento histórico, paralelamente há uma tendência à redução do número de vagas no setor privado, o que leva à hipótese mais provável de tendência à estabilidade no curto e médio prazo, num patamar abaixo dos quarenta mil recentes, mas provavelmente acima dos trinta mil, que se manteve estável por alguns anos. Por isso, no caso 
de concluintes de enfermagem em estabelecimentos privados, em vez de uma taxa de crescimento de 1,67\% ao ano, o cenário mais provável é de redução do número de concluintes de pelo menos $1 \%$ ao ano na projeção para 2030, como observado no Gráfico 2.

Gráfico 2 - Concluintes do curso de enfermagem por natureza jurídica: projeções com modelo de crescimento de 1,67\% anual para estabelecimentos públicos e redução de 1\% anual para estabelecimentos privados a partir de 2012 até 2030

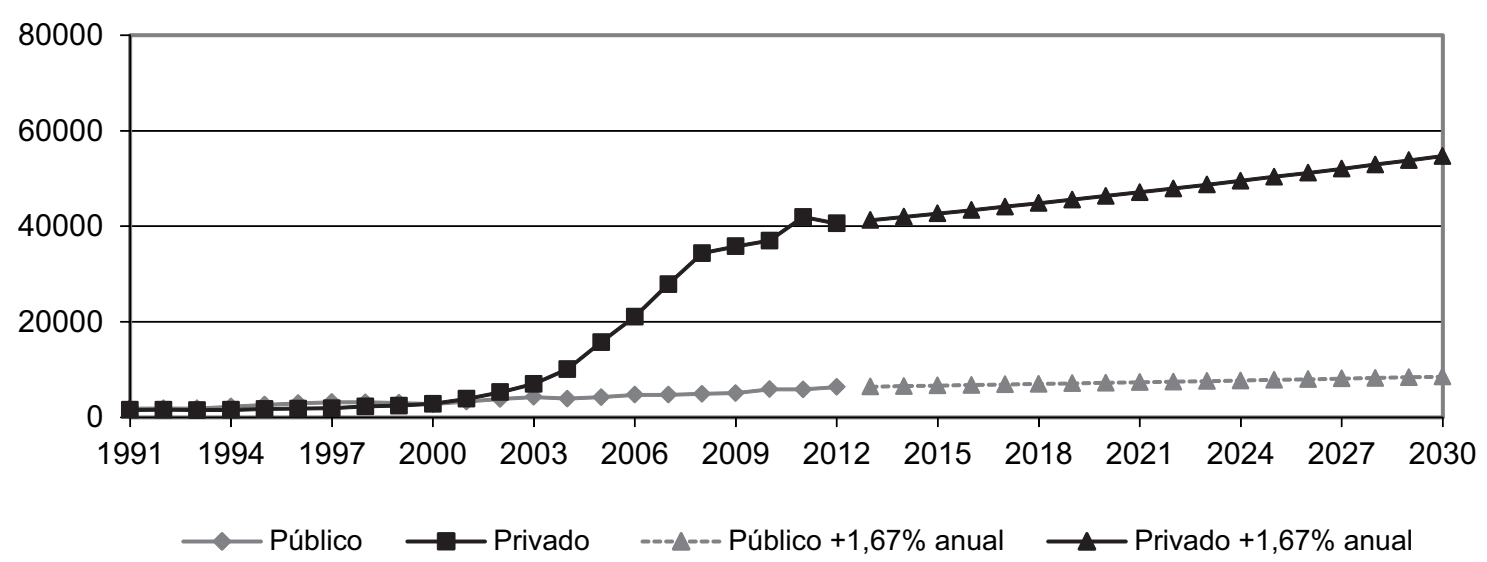

Fonte: Censo da Educação Superior 2010, do Instituto Nacional de Estudos e Pesquisas Educacionais Anísio Teixeira (Inep, 2012).

O número de concluintes de cursos de graduação em odontologia tem crescido quase que linearmente, exceto por uma aceleração entre os anos 2000 a 2003, retornando ao padrão anterior já em 2006 e se mantendo nesse padrão nos anos seguintes. Considerando o conjunto de fatores já analisados para a área de odontologia, espera-se que esse crescimento continue no mesmo padrão, que parece seguir o do crescimento demográfico, no qual o segmento privado responde por $60 \%$ dos concluintes, como pode ser observado no Gráfico 3 a seguir.

Gráfico 3 - Concluintes do curso de odontologia por natureza jurídica: projeções com modelo de crescimento linear de $1,67 \%$ anual a partir de 2012 até 2030

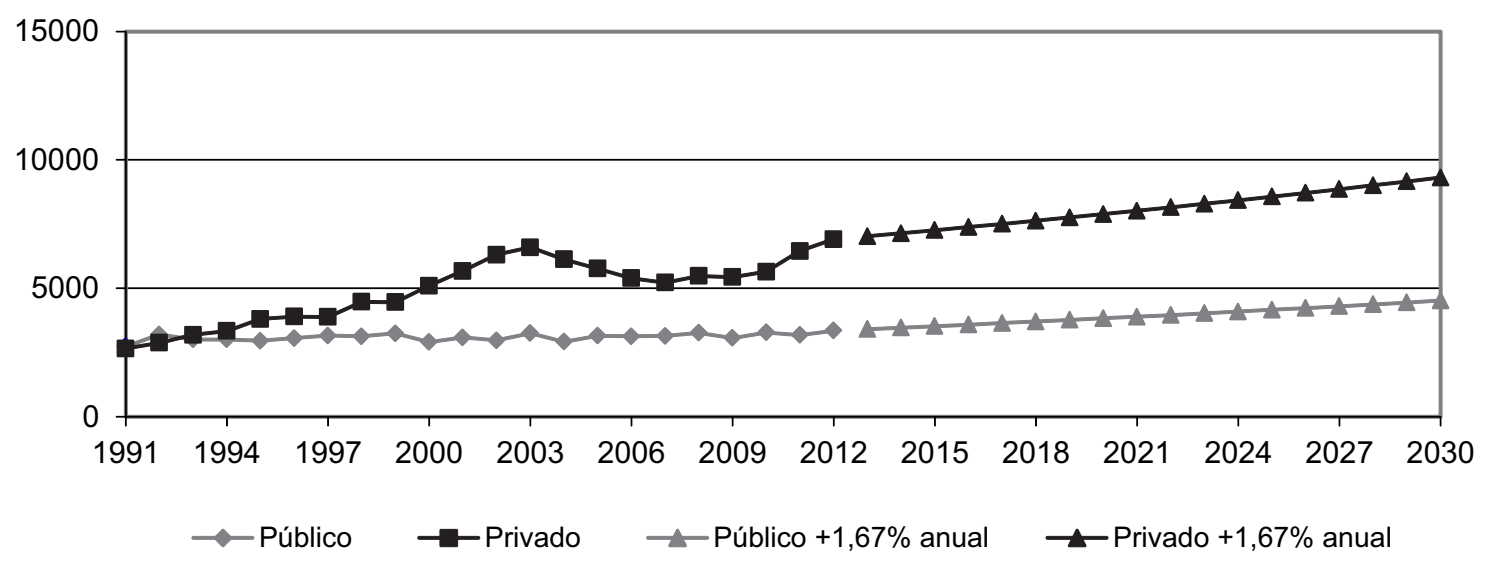

Fonte: Censo da Educação Superior 2010, do Instituto Nacional de Estudos e Pesquisas Educacionais Anísio Teixeira (Inep, 2012). 
A abertura de novos cursos de graduação em farmácia e o número de concluintes no setor privado se expandiu exponencialmente a partir do ano 2000, provavelmente respondendo à expansão acelerada do mercado de trabalho, ao passo que o setor público praticamente ficou estabilizado em torno dos 3.000 egressos por ano, tendência que deve manter-se inalterada ainda nas próximas década e meia, como apresentado no Gráfico 4.

Gráfico 4 - Concluintes do curso de farmácia por natureza jurídica: projeções com modelo de crescimento linear de $1,67 \%$ anual a partir de 2012 até 2030

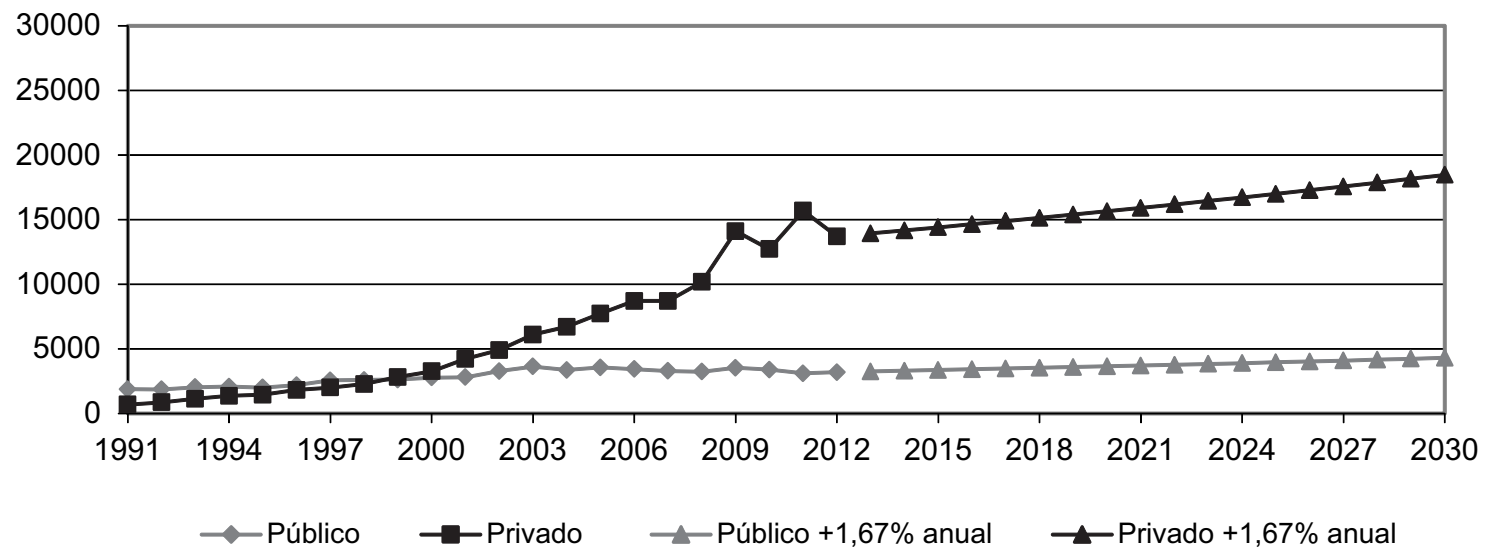

Fonte: Censo da Educação Superior 2010, do Instituto Nacional de Estudos e Pesquisas Educacionais Anísio Teixeira (Inep, 2012).

Apesar de o setor público ter dobrado sua capacidade de produção, a expansão no número de egressos dos cursos de fisioterapia ocorreu majoritariamente no segmento privado, no período de 2000 a 2010. Mesmo com uma redução em 2012, em razão da queda no número de ingressos alguns anos antes, esse quadro já se reverteu e a tendência é de retomada do crescimento, no mínimo associado ao crescimento demográfico, como visto no Gráfico 5.

Gráfico 5 - Concluintes do curso de fisioterapia, por natureza jurídica: projeções com modelo de crescimento de $1,67 \%$ anual a partir de 2012 até 2030

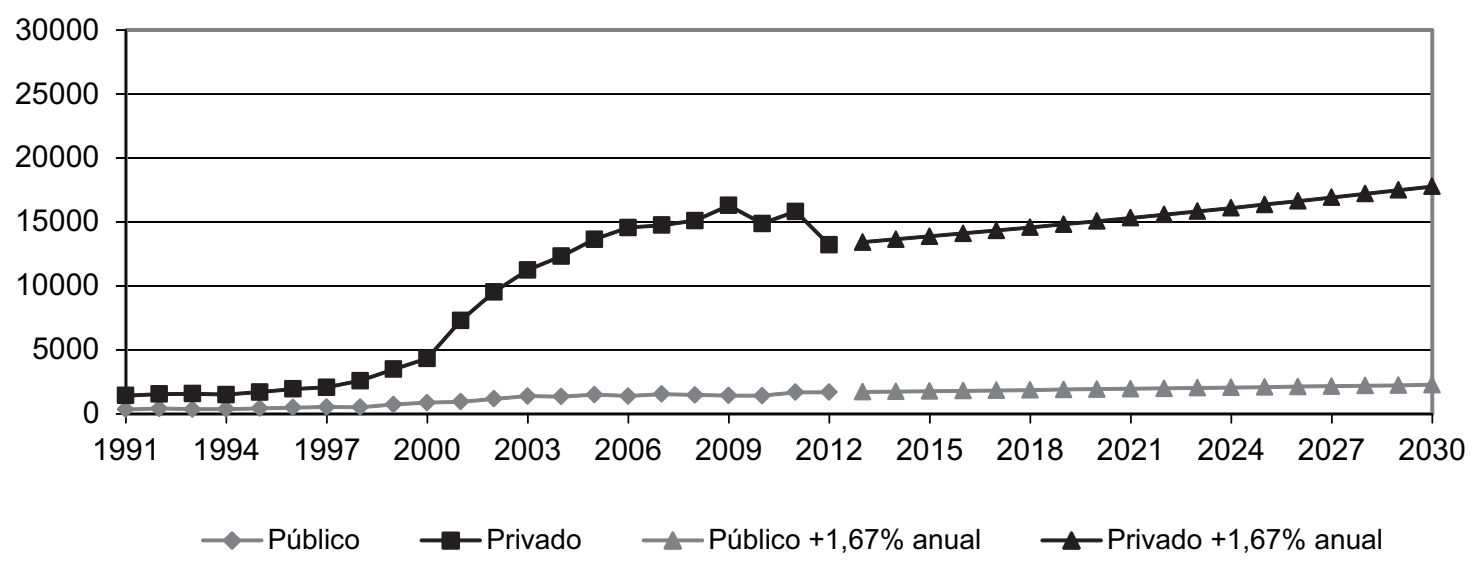

Fonte: Censo da Educação Superior 2010, do Instituto Nacional de Estudos e Pesquisas Educacionais Anísio Teixeira (Inep, 2012). 


\section{Considerações Finais}

No Brasil vivenciou-se uma forte expansão da educação superior, que se inicia em meados dos anos 1990 e toma maior impulso a partir de 2000. Tal expansão foi conformada pelas instituições de ensino superior de natureza privada e com concentração regional.

Parte da explicação desse fenômeno pode ser atribuída à flexibilização dos cursos a partir da edição das DCNs, das políticas governamentais como Fies (Fundo de Financiamento Estudantil), Prouni (Programa Universidade para Todos - programa de concessão de bolsas a instituições privadas) e à perspectiva de ascensão social via educação superior pressionando o mercado sem o respectivo incremento do ensino público.

Esse quadro se reproduziu na formação das profissões da saúde, entretanto, observa-se um esgotamento dessa tendência ascendente para quase todos os cursos, exceção da graduação em medicina que mantém uma ocupação plena de todas as vagas oferecidas e tendência de crescimento pelas políticas de fomento a expansão de cursos.

Outro aspecto a ser destacado é a superioridade da qualidade dos cursos públicos indicada pelo Enade desde sua implantação, em 2004. O percentual de cursos públicos com avaliações 4 e 5 é bem maior do que o dos cursos privados que, inversamente, mantêm um maior percentual nas avaliações de graus 2 e 3 . Esse fato poderá acarretar o fechamento de maior número de graduações e vagas do setor privado, caso o quadro não se reverta.

Em razão dos diversos fatores analisados, incluindo a lei n. 12.871 de 2013, que institui o Programa Mais Médicos, a expectativa é a de que o número de concluintes em medicina aumente progressivamente nas próximas duas décadas.

No caso da enfermagem, há uma tendência à redução do número de vagas no setor privado, o que nos conduz à hipótese mais provável de tendência à estabilidade, no curto e médio prazo, e a uma redução do número de concluintes de pelo menos 1\% ao ano na projeção para 2030.

Considerando o conjunto de fatores já analisados, a área de odontologia parece manter o mesmo ritmo de desenvolvimento do crescimento demográfico.

A tendência de crescimento em resposta à expansão acelerada do mercado de trabalho da área de farmácia deve manter-se inalterada ainda na próxima década e meia. No entanto, o número de concluintes em fisioterapia deve retomar o aumento, provavelmente associado ao crescimento demográfico.

No plano pedagógico, as DCNs cumpriram papel de fomentar mudanças na organização dos projetos político-pedagógicos com tendências às ações de cuidados que promovam a saúde das pessoas e de coletividades restringindo a focalização meramente curativa. Por outro lado, as inovações tecnológicas parecem reconfigurar áreas clássicas da clínica e semiologia por meio da adoção de diagnósticos e tratamentos cada vez mais dependentes de aparato sofisticado de tecnologias.

O discurso recorrente do trabalho em equipe e multiprofissional não foi capaz de se traduzir em práticas de ensino integradas entre as diferentes profissões da saúde, pelo contrário, mantém-se na formação o insulamento e a segmentação. 
Por fim, no plano do macrocontexto, considerando o projeto político e econômico de orientação liberal, configura-se, a médio e longo prazo, um sistema do ensino superior em saúde cada vez mais pautado pelas mudanças no próprio mercado. A tendência é de uma acentuada divisão entre poucas instituições de excelência acadêmica e tecnológica, situadas nos centros urbanos dos eixos Sul e Sudeste e um grande número de instituições com dificuldade para atender aos padrões mínimos de exigência de qualificação para o ensino e incapazes de realizar pesquisa e extensão. Em tal cenário, se forem levados a termo os processos regulatórios baseados nos mecanismos avaliativos das instituições de ensino superior, o resultado poderá ser uma reconfiguração da área, com fechamento de instituições ou novos arranjos institucionais por conglomerados e consórcios para atender às pressões do mercado.

\section{Referências}

BAHIA, L. O SUS e a agenda por resgatar, 2014. Disponível em: <http://cebes.com.br/2014/01/o-sus-e-aagenda-por-resgatar/>. Acesso em: 1 mar. 2014.

BOUDON, R. Desigualdades das Oportunidades. Brasília: Editora Universidade de Brasília, 1981. (Coleção Sociedade Moderna)

BRASIL. Senado Federal. Lei n. 9.394, de 20 dez. 1996. Estabelece as diretrizes e bases da educação nacional. Brasília, Diário Oficial da União, 1996.

BRASIL. Conselho Nacional de Saúde. Resolução n. 287/98, de 8 out. 1998. Disponível em: <www.conselho. saude.gov.br/resoluções/1998/Reso287.doc>. Acesso em: 1 mar. 2014.

BRASIL. Conselho Nacional de Educação. Câmara de Educação Superior. Resolução CNE/CES n. 3, de 7 nov. 2001. Diretrizes Curriculares Nacionais do curso de graduação em Enfermagem. Brasília, Diário Oficial da União, 2001.

BRASIL. Senado Federal. Lei n. 10.861, de 14 abr. 2004. Brasília, Diário Oficial da União, 2004. Disponível em: <www.planalto.gov.br/ccivil_03/_ato2004-2006/2004/lei/110.861.htm>. Acesso em: 1 mar. 2014.

BRASIL. Conselho Nacional de Educação. Câmara de Educação Superior. Resolução n. 2, de 18 jun. 2007. Dispõe sobre carga horária mínima e procedimentos relativos à integralização e duração dos cursos de graduação, bacharelados, na modalidade presencial. Brasília, Diário Oficial da União, n. 116, p. 6, 19 jun. 2007. Seção 1.

BRASIL. Conselho Nacional de Educação. Câmara de Educação Superior. Resolução n. 4, de 6 abr. 2009. Dispõe sobre carga horária mínima e procedimentos relativos à integralização e duração dos cursos de graduação em Biomedicina, Ciências Biológicas, Educação Física, Enfermagem, Farmácia, Fisioterapia, Fonoaudiologia, Nutrição e Terapia Ocupacional, bacharelados, na modalidade presencial. Brasília, Diário Oficial da União, n. 66, p. 27, 7 abr. 2009.

BRASIL. Senado Federal. Lei n. 12.871, de 22 out. 2013. Brasília, Diário Oficial da União, 2013. Disponível em: <www.planalto.gov.br/ccivil_03/_ato2011-2014/2013/Lei/L12871.htm>. Acesso em: 01 mar. 2014.

BUSS, P. M. \& LABRA, M. E. (Orgs.). Sistemas de Saúde Continuidades e Mudanças: Argentina, Brasil, Chile, Espanha, Estados Unidos, México e Quebec. Rio de Janeiro: Editora Fiocruz, 1995.

DAL POZ, M. R.; PIERANTONI, C. R. \& GIRARDI, S. Formação, mercado de trabalho e regulação da força de trabalho em saúde no Brasil. In: GADELHA, P.; CARVALHO, J. N. \& PEREIRA, T. R. A Saúde no Brasil em 2030: diretrizes para a prospecção estratégica do sistema de saúde brasileiro. Rio de Janeiro: Fiocruz, Ipea, Ministério da Saúde, Secretaria de Assuntos Estratégicos da Presidência da República, 2013.

FUNDO DE POPULAÇÃO DAS NAÇÕES UNIDAS (UNFPA) \& INSTITUTO BRASILEIRO DE GEOGRAFIA E ESTATISTICA (IBGE). Indicadores Sociodemográficos: prospectivos para o Brasil 1991-2030. São Paulo: ArbeitFactor, 2006. Disponível em: <www.ibge.gov.br/home/estatistica/populacao/projecao_da_populacao/publicacao_UNFPA. pdf $>$. Acesso em: 13 jan. 2014. 
INSTITUTO BRASILEIRO DE GEOGRAFIA E ESTATISTICA (IBGE). Pesquisa nacional por amostra de domicílios (Pnad). Rio de Janeiro, v. 31, p.1-135, 2011. ISSN 0101-6822. Disponível em: < http://biblioteca.ibge.gov.br/ visualizacao/periodicos/59/pnad_2013_v33_br.pdf> Acesso em: 13 jan. 2014.

INSTITUTO NACIONAL DE ESTUDOS E PESQUISAS EDUCACIONAIS ANÍSIO TEIXEIRA (INEP). Exame Nacional de Desempenho de Estudantes (Enade), 2010. Disponível em: < http://enadeies.inep.gov.br/enadeles/ enadeResultado >. Acesso em: 1 mar. 2014.

INSTITUTO NACIONAL DE ESTUDOS E PESQUISAS EDUCACIONAIS ANÍSIO TEIXEIRA (INEP). Censo da Educação Superior 2010, 2012. Disponível em: <http://portal.inep.gov.br/superior-censosuperior>. Acesso em: 12 jan. 2014.

MENDES, J. M. R. et al. Gestão na saúde: da Reforma Sanitária às ameaças de desmonte do SUS. Textos \& Contextos, 10(2): 331-344, 2011.

OCKÉ-REIS, C. O. Ciclo Eleitoral e Financiamento da Saúde: o caso dos subsídios. Rio de Janeiro: Cebes, 2014. Disponível em: < http://cebes.com.br/2014/02/ciclo-eleitoral-e-financiamento-da-saude-o-caso-dos-subsidios/> . Acesso em: 22 maio 2004.

ORGANISATION FOR ECONOMIC CO-OPERATION AND DEVELOPMENT (OECD). Education at a Glance 2012: highlights, OECD publishing, 2012. Disponível em: <http://dx.doi.org/10.1787/eag_highlights-2012-en> . Acesso em: 13 jan. 2014.

ORGANIZAÇÃO DAS NAÇÕES UNIDAS PARA A EDUCAÇÃO, A CIÊNCIA E A CULTURA (UNESCO). Declaração Mundial sobre o Ensino Superior no Século XXI: visão e ações. Paris, 1998. Disponível em: < www.direitoshumanos.usp.br/index.php/Direito-aEduca\%C3\%A7\%C3\%A3o/declaracao-mundial-sobre-educacao-superior-noseculo-xxi-visao-e-acao.html> Acesso em: 12 jan. 2014.

PIERANTONI, C. R. et al. Graduações em Saúde no Brasil: 2000 - 2010. v. 1. 1. ed. Rio de Janeiro: Cepesc, 2012.

PORTO, C. \& RÉGNIER, K. O Ensino Superior no Mundo e no Brasil - Condicionantes, Tendências e Cenários para o Horizonte 2003-2025: uma abordagem exploratória. Brasília: MEC, 2003. Disponível em: <http://portal.mec.gov. $\mathrm{br} / \mathrm{sesu} /$ arquivos/pdf/ensinosuperiormundobrasiltendenciascenarios2003-2025.pdf $>$. Acesso em: 22 maio 2014.

REDE INTERAGENCIAL DE INFORMAÇÃO PARA A SAÚDE (RIPSA). Indicadores Básicos para a Saúde no Brasil: conceitos e aplicações. 2. ed. Brasília: Organização Pan-Americana da Saúde, 2008. Disponível em: <http:// tabnet.datasus.gov.br/tabdata/livroidb/2ed/CapituloA.pdf>. Acesso em: 18 maio 2014.

SCHMIDT, M. I. et al. Doenças crônicas não transmissíveis no Brasil: carga e desafios atuais. The Lancet, 377(9.781): 1.949-1.961, 2011. (Série Saúde no Brasil, 4)

SCHWAZTZMAN, S. A Revolução Silenciosa do Ensino Superior. In: DURHAM, E. \& SAMPAIO, H. (Orgs.). O Ensino Superior em Transformação. São Paulo: Núcleo de Pesquisas sobre Ensino Superior/USP, 2001.

SOUSA, A.; DAL POZ, M. R. \& CARVALHO, C. L. Monitoring inequalities in the health workforce: the case study of Brazil 1991-2005. PlosOne, 7(3): 1-7, 2012.

VECINA NETO, G. \& MALIK, A. M. Tendências na assistência hospitalar. Ciência \& Saúde Coletiva, 12(4): 825-839, 2007.

VIANA, A. L. et al. Mudanças Significativas no processo de descentralização do sistema de saúde no Brasil. Cadernos de Saúde Pública, 18: 139-150, 2002.

VIANNA, C. M. M. et al. Modelos econométricos de estimativa da força de trabalho: uma revisão integrativa da literatura. Physis, 23: 925-950, 2013.

WORLD BANK. Higher Education in Developing Countries: peril and promise. Washington: The Task Force on Higher Education Society, 2000.

WORLD HEALTH ORGANIZATION (WHO). The World Report 2000. Health systems: improving performance. Geneva: WHO, 2000. 


Formato: $21 \times 26 \mathrm{~cm}$

Tipologia: Candara e Charter

Papel: Print Max 90g/m² (miolo)

Cartão supremo $250 \mathrm{~g} / \mathrm{m}^{2}$ (capa)

CTP, Impressão e acabamento: Imos Gráfica e Editora Ltda.

Rio de Janeiro, outubro de 2017

Não encontrando nossos títulos em livrarias, contactar a EDITORA Fiocruz:

Av. Brasil, 4036, térreo, sala 112 - Manguinhos

21040-361 - Rio de Janeiro, RJ

Tel.: (21) 3882-9039 e 3882-9041 - Telefax: (21) 3882-9006

www.fiocruz.br/editora

editora@fiocruz.br 

Neste livro, seus autores apostam na racionalidade do planejamento e da epidemiologia para fundamentar a formulação de políticas de saúde. Sem negligenciarem os determinantes econômicos e políticos, analisam a situação atual e prospectam o futuro, produzindo informações relevantes para a ação.

O desenho de cenários e a indicação de tendências disponíveis na iniciativa Brasil Saúde Amanhã podem contribuir para a práxis de sujeitos comprometidos com a defesa do Sistema Único de Saúde e da Reforma Sanitária brasileira.

Jairnilson Silva Paim

Professor titular de política de saúde do Instituto de Saúde Coletiva da Universidade Federal da Bahia

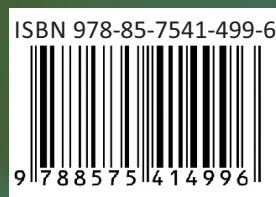

